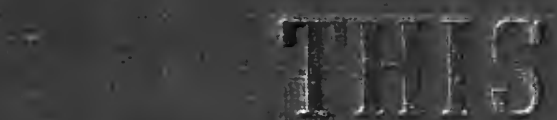

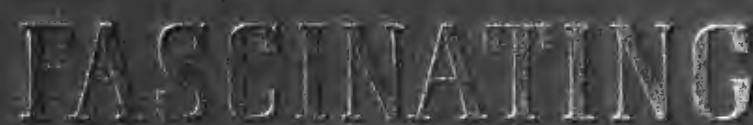

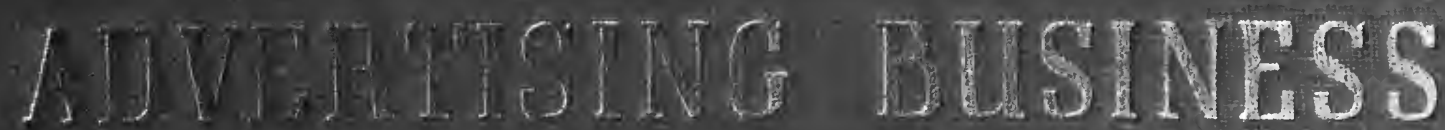
WAMN WHUIS BHDD 
From the collection of the

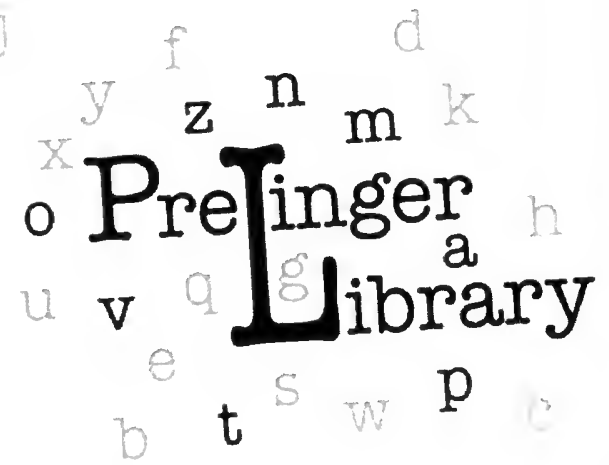

San Francisco, California 2006 
To Jerny Kuderna - a real atist with a pencil, and with a smile! Hamy Brid

Dei. 5,1947 



\section{THIS FASCINATING ADVERTISING BUSINESS}




\title{
This Fascinating
}

Advertising Business

\author{
BY \\ HARRY LEWIS BIRD
}

THE BOBBS-MERRILL COMPANY

PUBLISHERS

INDIANAPOLIS - NEW YORK 
COPYRIGHT, I 947 , BY THE BOBBS-MERRILI COMPANY PRINTED IN THE UNITED STATES OF AMERICA

First Edition 


\section{TO SOOSEY}

$$
\text { ... of course }
$$





\section{GRACIAS!}

THIs book is far from being the one-man enterprise that its title page would indicate. Dozens of people have helped generously. The author wishes in particular to thank Captain Paul Sawyer of the Gordon Best Company for his co-operation in preparing the glossary and reading the manuscript, as well as his colleagues, Frank Morr, Willard Stevens, Edwin Trizil and William C. Mottershead, for their suggestions.

The various advertising associations have been uniformly helpful. In particular, acknowledgment is due to Frederic Gamble and Richard Scheidker of the American Association of Advertising Agencies; Elon G. Borton, Advertising Federation of America; W. L. Witt, National Industrial Advertisers Association; Jane Bell, Direct Mail Advertising Association; Jean Flinner and Mrs. "Duffy" Schwartz of the Advertising Council; Frank Pellegrin, National Association of Broadcasters; A. E. Haase, Association of National Advertisers; A. W. Lehman, Advertising Research Foundation; Preston Reed, Financial Advertisers Association; the staffs of the Brand Names Foundation, Outdoor Advertising Association of America, Magazine Advertising Bureau, Audit Bureau of Circulations, Bureau of Advertising of American Newspaper Publishers Association, Associated Business Papers, Agricultural Publishers Association, Premium Advertising Association and the National Retail Dry Goods Association.

In the publication field, H. W. Marks and Joel Lewis of Printers' Ink, Reg Clough of Tide, Robert Murray of Advertising Age, and F. C. Kendall of Advertising and Selling rendered invaluable assistance. Individually, thanks are due also to Robert T. Kesner and E. F. Schmidt of American Home Foods, Inc.; James W. Young, Anson Lowitz and Kenneth Ward of J. Walter Thompson Company; to M. O. Lokensgard, Norman Heffron, Lawrence Valenstein, Vincent Clauson, Hal Makelim, Mary Koehler, Rosemary York, Howard Davidson, H. C. Persons and Will Cuppy.

Robert J. Landry, author of This Fascinating Radio Business, gave liberally of his time. All four major radio networks, as well as innum- 
erable other media, supplied essential data. Professor George Burton Hotchkiss offered counsel that was indispensable.

None of these authorities is cited in an attempt to disclaim responsibility for the views expressed in this book. Every effort has been made to verify all statements of fact; their interpretation must be considered the author's own unless specific sources are quoted. 


\section{SOME DEFINITIONS}

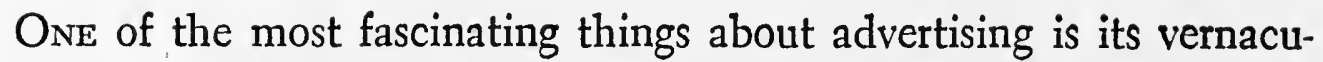
lar-vivid, picturesque, but often unintelligible to the layman. In this book every effort has been made to avoid terms that are not selfexplanatory. Understanding of a few key words, however, is essential to the reader. The following list is for the benefit of those unfamiliar with the basic processes of advertising. For a more complete view of advertising patois, a Glossary will be found in the back of the book.

ADVERTISER-any firm, institution or organization which seeks to stimulate the sale or use of its goods or services through advertising; usually known to its agency as "the Client."

Advertising Account - the total advertising program of an advertiser, generally used in connection with its agency relationship. Thus, "The ABC Company has appointed the XYZ Agency to handle its account."

ADVERTISING AGENCY-an organization of specialists engaged in planning, preparing, placing and checking the accounts of a number of advertisers. Most agency compensation is in the form of a 15 percent discount or "commission" allowed by media in which the advertising is placed.

ART - any illustrative or decorative material used in advertising; includes hand-lettered display lines, photographs and borders as well as drawings or paintings.

CAMPAIGN - a series of advertisements in various media, all related to the promotion of a specific product or service for a definite period of time.

Circulation-total number of copies of a publication (per issue); in radio, estimated number of radio families listening to a station or network at a definite time. Also known as "coverage."

$\mathrm{COPY}$ - the headline and text of an advertisement; from the timehonored printer's term denoting the manuscript to be "copied" in setting type.

Cur - a printing plate.

INSERTION-each separate appearance of an advertisement.

LAYOUT-sketch showing the arrangement of elements in a proposed advertisement. 
LiNe (or "Agate Line") - a measurement of advertising size: 1/14 of an inch in depth, one column in width.

Medium (plural, "Media") - any advertising vehicle; also the combined units in any particular branch of advertising. Thus magazines collectively may be considered a medium; any individual magazine is also spoken of as a medium.

NETWORK-a group of radio stations joined by wire connections to broadcast programs simultaneously. Those supplying this service on a coast-to-coast basis include: National (NBC); Columbia (CBS); Mutual (MBS) and American (ABC).

SchEDULE-list of media with specific date and time for each element in an advertising campaign. 


\section{CONTENTS}

\section{Book I \\ THE "WHY" OF ADVERTISING}

CHAPTER

PAGE

I Where's the Fascination? . . . . . . . . 17

II How It All Started . . . . . . . 25

III Advertising's Covered Wagon Days . . . . . 34

IV Advertising-The Road Bumder . . . . . . 51

V Who's Right About Advertising? . . . . . 63

VI The Story of the Brands . . . . . . 73

\section{Book II}

\section{THE "WHO" OF ADVERTISING}

VII The Consumer-Goods Advertiser . . . . . 85

VIII The Advertising Agenct . . . . . . . . 103

IX The Retall Advertiser . . . . . . . . 128

X The Industrial AdVertiser . . . . . . . 144

XI The Advertiser of Intangibles . . . . . . 153

XII Some People of Advertising . . . . . . . 163

Book III

THE "WHERE" OF ADVERTISING

XIII Consumer Magazines . . . . . . . . . 181

XIV NewsPapers-And Newspaper Advertising . . . 197 


\section{CONTENTS-continued}

CHAPTER

XV “We're on the Atr!" . . . . . . . . . . . 212

XVI Signs of the Times . . . . . . . . . . . 240

XVII It's IN the MAmbaG

XVIII Other Media-Large and Small . . . . . 265

\section{Book IV}

\section{THE "WHAT" OF ADVERTISING}

XIX Good Products and Good Pacrages . . . . . . 287

XX They Call It "Copy" . . . . . . . . . . . 295

XXI The Idea Takes Shape . . . . . . . . . . 308

XXII Producing and Reproducing the Ads . . . . . 321

XXIII To Market! To Market! . . . . . . . . . 328

XXIV Getring In and Getring On . . . . . . . . 336

XXV When Ao Fellows Get Together . . . . . . 346

XXVI Advertising in the Atomic Age . . . . . . . 355 


\section{IST OF ILLUSTRATIONS}

Modern Advertising Rolls On . . . . . . . Frontispiece

FACING

PAGE

Newspaper Advertisements of 100 Years Ago . . . . . . 30

Magazine Promotion in Mid-Victorian Days . . . . . . 31

How Advertising Overcomes Prejudice . . . . . . . . . 46

Advertisers Tie in with Brand Prestige . . . . . . . . . 47

A Notable Pair of Mood-Creating Advertisements . . . . . 64

How National Magazine Advertising Is "Merchandised" to Re-

tailers . . . . . . . . . . . . . . . . 65

Agency Media Directors Know Their Markets . . . . . . 96

One of a Famous Series . . . . . . . . . . . . . 97

How Department Store Ads Are Born . . . . . . . . 100

Up from the "Cracker Barrel" Days . . . . . . . . . . 101

Association Advertising Sells an Idea . . . . . . . . 124

Crusading Copy That Jolted Readers into Action . . . . . 125

How Advertisers "Merchandise" a Radio Program . . . . . 160

Examples of Radio Station Promotion . . . . . . . . . 161

"Minute Movies" Are Shown in Thousands of Theaters . . . 192

A Classic Example of Institutional Advertising . . . . . . 193

The Best Three Posters of 1946 . . . . . . . . . . . 196

"3-Sheet" Posters Give Point-of-Purchase Identification . . . 197

Car Card Copy Can Be Longer Than Outdoor Posters, but

Must Tell a Simple, Direct Story . . . . . . . . 220

Telephone Directory Advertising-Before and After . . . . 221

Following Through on a Sampling Campaign . . . . . . 224

How Swift \& Co. Sampled Its New Household Cleanser . . 225

Before and After in Package Redesigning . . . . . . . . 256

Solving Various Packaging Problems . . . . . . . . . 257

Four Varied Illustrative Techniques in Modern Advertising . 288

Three Stages in Ad-Making . . . . . . . . . . 289

Wartime Advertising-I and II . . . . . . . . . 320

A Current Example of Advertising in Public Service . . . . 321 



\section{BOOK I}

\section{THE "WHY" OF ADVERTISING}





\section{Chapter I}

\section{WHERE'S THE FASCINATION?}

DVERTISING has a triple hold on the public imagination: as an occupation, as a continuous and kaleidoscopic show, as an integrated part of the American free enterprise system.

Everybody has opinions about it. Everybody, at one time or another, has used it-and been used by it. And nearly everybody has given some thought, serious or otherwise, to adopting it as a career.

Like the people of the theater, the movies or the daily press, the folks who work in advertising sometimes seem to the laity to move in a world apart. A spate of recent best sellers has helped intensify this illusion. The young advertising man or woman is after a milliondollar account. He gets a sensational idea. Through ruses and strategems he sells it to the grouchy old client. Boom! Success! What matter that in the book this triumph is spurned at the moment of realization? The author has underscored the popular belief that advertising is a mysterious wonderland full of March Hares and Mad Hatters, where gold galore waits at the note of a singing jingle.

Actually the people who plan, create and produce advertising are no more glamorous than your next door neighbor. To them advertising is a living-sometimes exciting, frequently hectic, but in the net a breakfast-to-supper job and not a role in a Clark Gable film.

Why, then, this notion that admen and women are in the same class as movie stars or jazz musicians, newspaper reporters or airline pilots, as candidates for the title of "dream-job" holders? Why should the doing of advertising work seem more thrilling than that of storekeeping or punch pressing or insurance selling?

The explanation is simple. It is the business of advertising to fascinate people, in the literal sense of "to allure and hold intent, especially by qualities that charm: to interest or captivate by an irresistible influence." Thus Mr. Webster's New International defines the verb. With reservations, this explanation of the way to fascinate can be accepted as an accurate statement of what advertising is supposed to 
accomplish. The better the ad, the more it allures and holds the attention, whether by qualities that charm or those that startle. Certainly every creator or sponsor of an advertising message hopes that it will prove irresistible.

Some ads do this better than others. But whatever an ad's objectives, the worst thing that can happen to it is to be ignored. Since it voluntarily seeks the spotlight, the advertising business as conducted by its practitioners can have no complaint if it is subject to the normal amount of envy, distrust, abuse, misconstruing of motives and other typical human reactions to public characters. Nor should the fraternity feel too surprised because everybody (to borrow Jimmy Durante's phrase) wants to get into the act.

Indeed, with the efficiency and thoroughness of today's advertising, one must be conscious of it continually. How can any American avoid being aware of it? He is engulfed by advertising from the moment he turns on the radio for the morning time signals and opens the breakfast paper until he drops off to sleep reading an ad-crowded magazine. Meanwhile he has received circulars via the postman, seen posters en route to his bus, subway or commuter's train, looked at car cards on his way to work, passed innumerable window displays. Should he seek recreation at the theater he is apt to find ads in the program; at the cinema, "minute movies" extolling the virtues of various products; at the ball park, more ads on his score card. He looks up and sees a skywriter reminding him of Pepsi-Cola or Phillips 66. The signboards he overlooked during the day are illuminated after dark to trap his unwary eye. The advertising men are right: America is "blanketed" with advertising.

Yet by and large the country does not resent this unending intrusion of selling words, pictures, sounds. It is very generally understood that advertising pays the bills for a large part of our national entertainment and increasingly accepted that advertising has had much to do with present standards of health, economic security, comfort and convenience.

This does not mean that everybody likes all advertising. Certain forms of oral and printed salesmanship have come in for sharp criticism. Copy that is deliberately misleading, illustrations that are offensive to public decency and good taste are approved by no one. Advertising men themselves, as will be explained in subsequent chapters, were the first to challenge deceptive and objectionable uses of 
their craft. But one may dislike some kind of food and still be very much in favor of eating!

That in itself is one of the fascinations of advertising: the fact that antipathy toward a particular technique or theme does not necessarily make it ineffective. On numerous occasions studies have shown that large sections of the populace were outwardly opposed to some specific advertising appeal-yet the products promoted by that appeal were leaders in sales. For years a certain female radio announcer led every voice on the air in unpopularity polls. For the same period her sponsor's business showed consistent gains year after year. And conversely, many programs and periodical campaigns which have been widely admired and praised have proved to be box-office poison and brought in no orders. Advertisements that exhaust every superlative in describing an article seldom arouse more than a yawn of disbelief. But let some merchant frankly announce that he has a bunch of "cats and dogs" that no sane person would possibly want and his store will be packed with buyers.

These are extreme examples, of course. The great bulk of successful advertising is friendly and informative and sells by persuasion, not by bullying, and definitely not by antagonizing the reader or listener. The procedure can never quite be standardized, however, so long as human nature retains its element of unpredictability.

Advertising has other fascinations-for the person who plans to make a career in it and for the objective observer as well. The professional ad man or woman finds satisfaction in its creative aspects. There is tangible evidence of creation-an advertisement seen in a newspaper, a poster along the boulevard, a voice coming over the air-things in which he has had a part; and there is also the knowledge of having influenced people constructively when the advertised product or service is one that makes a positive contribution to society. And today, with the world still disorganized from the effects of war, with the welfare of so many millions abroad dependent on America's maintaining full employment, he may feel that stimulating the flow of business is a far from insignificant contribution.

The pages to come will explain how the technique of mass influence, developed in America far more professionally and scientifcally than in any other land, was dedicated to the task of winning the war, and how it is now being devoted to many broad problems of individual and community betterment. Before this happened, adver- 
tising had provided the impetus for virtually all the material progress of this country over the 75 years between the end of the Civil War and the beginning of World War II.

It was an age of invention and technological growth. Advertising took new things from obscurity to universal acceptance. Drudgery, back-bending toil, was largely eliminated from the home, the store, the factory and the farm. Again advertising had a significant part. Decade by decade the nation's health, life expectancy, literacy, housing, means of transportation improved steadily. Work hours were shortened, wages increased, educational and cultural opportunities opened to millions who might never have known such benefits without the influence of advertising.

Some may argue that none of these gains can be traced directly to advertising, since its sole purpose during the era was as a salesbuilder, a profit-maker. This is true. There can be no advertising without an advertiser. And except in rare cases no advertiser will spend his money in promoting a product unless he sees better than an even chance of getting that money back with interest. Since the earliest times advertising has been used with a frankly selfish purpose: Buy $m y$ goods or services instead of the other fellow's. This candid pursuit of profit led, and still leads, to many abuses. It is the chief target of those who would make advertising, trade-marks and brand names the whipping boys for any and all shortcomings in our economic system.

Granted, then, that America's social gains were mere by-products of advertising, the fact remains that they were made. Further, the rate of progress, the breadth and depth of penetration of these better things were far greater in this country where advertising had become so much a part of business activity than anywhere else. In the European mind the "American Way of Life" became synonymous largely with the free enterprise system-and free enterprise cannot exist without competitive selling.

Advertising has substantially underwritten the editorial and printing costs of our national magazines, the world's finest in physical appearance, in service to readers, in coverage of world events and domestic trends, in interpretation of modern life. It eliminated the need of subsidies. It gave the editors freedom to speak up. To the newspapers of America advertising has brought equal freedom, a chance to perfect all manner of mechanical improvements, including color print- 
ing, halftone illustrations, amazing speed, as well as an endless variety of features.

Commercial sponsorship of radio has made it possible for $37,000,000$ American families to hear the latest news virtually as it happens. Companies with goods to sell found radio a powerful aid, and the means was furnished to bring into 96 out of every 100 homes the finest symphony concerts, the great operas, the actual voices of leaders in education, religion, government and the arts. It has played host at thousands of historic events. Throughout the war it helped to finance the world-wide entertainment of our armed forces.

Mass transportation owes much of its stature to advertising. Without it the automobile undoubtedly would have remained a millionaire's monopoly. Without auto license fees and gasoline taxes we should never have had the thousands of miles of paved roads that link the states into an ever closer community. Travel by rail, bus, steamship and air has been popularized through constant advertising-not only by the carriers but by hotels, resorts, cities and states seeking to woo the tourist. From this continual flow of people has come a firm feeling of kinship between the regions of our country, helping to integrate our nation in times of crisis.

Never before in history have so many people bought so many books as in America during the past 25 years. Book publishers are consistent advertisers.

Few American publications carry no advertising. Among them is Reader's Digest, said to have a circulation of over $8,000,000$. But the Digest is a consistent advertiser, using direct mail and other media to solicit subscriptions. And its international editions all have a sizable advertising revenue. Many of the articles featured in the Digest are reprinted from periodicals owing their existence largely to advertisements.

In the field of health, advertising popularized soap and bathtubs, clean teeth and properly fitted glasses. Today's youngsters are taller, huskier, will live longer than their parents on an average-at least in part because of consistent merchandising of milk, orange juice, fresh and canned fruits, refrigeration and other aids to better balanced diet.

When the American fleet was bombed at Pearl Harbor and the nation found itself fighting against enemies who had been preparing for years, advertising was ready to help speed the mobilization of the 125,- 
000,000 who stayed at home. Totalitarian countries kept their civilians in line by edicts or fear propaganda. Americans demanded and got the truth. Then they buckled down and did the job in the democratic way, voluntarily. The victory was that of a free, informed citizenry, guided in its co-operation by that familiar voice of free enterprise, advertising.

Fascinating? The more one learns about the workings of this vital human agency we call advertising, the more fascinating it becomes.

One point should be clarified. This book is not designed as a "defense" of advertising. As well talk about defending electricity. Advertising is a force, and its results depend on how it is used. It has always existed and in one form or another will continue to exist. Herman Wouk expressed the views of many advertising men in his popular 1947 novel, Aurora Dawn, through the words of his remarkable character, Father Standfield:

They is some wild-eyed folks likes to holler, "Abolish advertisin'." Shucks tryin' to stop advertisin' in this land is like tryin' to stop freckles with a rubber eraser. Maybe in these here countries where the gov'ment makes everythin' and hands out everythin' and runs everythin' they don't have no such problem, but as long as you got different fellers makin' and sellin' the same thing and tryin' to beat each other at it yer gonna have 'em hangin' out signs. That's all advertisin' is, in radio, magazines, it don't matter none where, it's all the same thing-hangin' out signs.*

\section{Is There an "Advertising Business"?}

While the title of this book seems fully justified as far as the word "fascinating" is concerned, it might be considered a misnomer in conveying the impression that advertising is a separate business. Some $\$ 3,000,000,000$ was invested in various forms of advertising in 1946. Yet this total is small by comparison with the money spent on personal selling and dwarfed by the outlay for raw materials, labor and machinery. Still, one seldom hears references to "the sales business" or "the production business." Why then talk of "the advertising business" as if it were a separate trade or industry? In reality advertising is not a business, but an inseparable part of all business.

If advertising is not a business, what is it? Enthusiasts have called

* Herman Wouk, Aurora Dawn (Simon \& Schuster, 1947). Quoted by permission of the author. 
it a science, an art, a profession. Cynics have dubbed it a racket, a game, a parasitical growth. Every description has been true-and false.

Many advertising men today are fully as professional in their approach to the job as the doctor, lawyer or educator. Year by year the practice of advertising has become increasingly scientific. And from an artistic point of view tremendous progress has been made. But advertising, because of its integration with trade and commerce, can never be wholly professional; because it deals with so many unpredictable factors it cannot be reduced to an exact science; and even its "artiest" devotees recognize the need of far greater compromise with expediency than is necessary in the field of fine arts.

What about the negative side?

The phrase, "the advertising game," isn't heard so much as it used to be, but it still crops up occasionally in the conversation of laymen-or of dilettantes looking for an easy road to riches. However, anything in which hard-headed business men invest billions each year can scarcely be called a "game." Few advertising men get very far unless they take their work seriously and study it constantly. Advertising may look easy; in reality it is one of the most complex and demanding vocations of the day.

There are racketeers in advertising, unfortunately, just as in every other legitimate occupation. This does not mean that all advertisingor even any considerable portion of it-is a racket. Legitimate advertisers were the first to recognize the need for cleaning house. As far back as 1905 the ad men of America had resolved to "expose fraudulent schemes and their perpetrators." The Printers' Ink model statute, first promulgated in 1911, has been made into law in virtually every state; it is an all-inclusive safeguard against untrue, deceptive or misleading advertising. And it was originated and carried through largely by advertising men.

Almost every city has its Better Business Bureau to protect the consumer against racketeers in retail trade. More often than not, local admen will be found serving as officers or directors-without pay-as their part in helping to keep advertising clean.

$\mathrm{No}$, it is as unfair to call all advertising a racket because of occasional illegal or unethical usage as to call all medicine quackery on account of a few charlatans.

The question of whether advertising is or is not a "parasitical growth" will be discussed in Chapter V. It is necessary here only to note that not even the most extreme opponents of advertising favor 
its abolition in all forms. So once again the general condemnation is unjust.

Perhaps having gone the full round, the best single word to describe advertising is the one with which we started. Recognizing its inaccuracy and its limitations, "the advertising business" comes closer to embracing our subject than any other term we might select.

\section{The Purpose of This Book}

It has already been stated that this volume, one of a series covering broad fields of American industry and commerce", is not a "defense" of advertising. If the author errs on that score, charge it to his zest for an occupation which-after 25 years-still impresses him as the most fascinating.

Neither is this an instruction manual or a streamlined course on how to become a success in advertising.

Rather, it is proposed to take the reader behind the scenes in advertising - to give something of its history, growth and present status, to introduce some of its colorful personalities, to discuss its place in our economy and to explain briefly how modern advertising is planned, produced, distributed and checked.

In 400-odd pages it is impossible to cover all of the fascinating and significant facts of advertising or to mention the innumerable people who have contributed to its astonishing development. But from this peek backstage it is hoped that even the reader least familiar with the field will get a clearer understanding of the why, who, how, what and where of advertising.

Instead of calling this a behind-the-scenes view, we might say the book provides a look under the hood of a big motor truck, representing American business, of which advertising is the electrical system. Certainly advertising supplies the spark that makes the whole machine run. Often it is also the self-starter. Advertising provides the lights that enable folks to see the machine, as well as helping those inside to steer a straight course. In its ability to retain the good will of present customers and to add new ones, advertising is both the storage battery and the generator of business.

And who can deny that it is the horn?

* This Fascinating Railroad Business, by Robert Selph Henry; This Fascinating Lumber Business, by Stanley F. Horn; This Fascinating Oil Business, by Max W. Ball; This Fascinating Radio Business, by Robert J. Landry. 


\section{Chapter II}

\section{HOW IT ALL STARTED}

7 HOUSANDS of years ago men who had something to trade or sell had discovered the power of advertising to attract possible

1 customers. Ancient shopkeepers used symbolic signs to indicate what kind of goods they were offering, for few people could read. So what we know today as point-of-sale advertising was undoubtedly the first form of trade promotion. Nor has the employment of such symbols entirely died out. Some of us still recall the colorful statues of Indians without which no cigar store was once considered to be in business. The classic examples of symbolic signs are, of course, the red-and-white barber pole and the pawnbroker's three gilded balls.

Thanks to the wonders of neon tubing, we are seeing a revival of symbolic store identification. The jeweler hangs out a giant illuminated watch or diamond ring. The optician displays a pair of spectacles. The bowling alley proprietor goes even farther and has an animated sign in which a neon bowler swings a ball, sends it twinkling on its way and scores a perfect strike every time.

Those ancient tradesmen soon learned, however, that a sign over the door was not enough; it merely interested the passers-by who were already in need of the particular article it displayed. Moreover, there was no assurance that the prospect might not happen to see a competitor's sign first. So the practice of having "barkers" outside the shop was a natural development. A goodly number of such gentry still ply their ancient art at Coney Island, on the Atlantic City boardwalk, at sideshows and even along Forty-second Street in New York City. The radio store or movie theater that has a loudspeaker above the entrance merely applies modern electronics to one of the oldest business-getting devices known to man.

Probably the next stage in the evolution of advertising was the sending out of "criers." A merchant who had just received a fresh caravan of fancy items might hire somebody to wander through the city broadcasting the fact to the populace. In Greece the public crier was a figure of importance, impressive in appearance and suavely persuasive in speech. He often announced a forthcoming auction. 
Not only is the radio announcer of today the direct descendant of this ancient spellbinder, but there is even a closer parallel-the old Greek criers were frequently accompanied by musicians. To make the comparison still more pat, in early Egypt the crier sang or chanted his sales messages. Who said "singing commercials" are something new?

Shop signs, barkers and criers continued to form the chief means of sales promotion during Roman and medieval times. Another medium gradually came into use, the public notice which was called a "si quis" because it customarily began with the Latin phrase "Si quis," meaning "If anyone." In the case of a lost article the handbill would start, "If anyone knows"; when goods were being offered, the heading would read, "If anyone desires." The term si quis was used for centuries in England long before the appearance of the word "advertisement" in its present meaning of commercial announcement. Elizabethan dramatists wrote about the si quis, but to them an "advertisement" was either a piece of news or a warning. Perhaps they weren't so far wrong, even in the modern sense!

\section{Enter-the Printing Press}

With the invention of printing from movable types, reputedly by one Johannes Gutenberg just about 500 years ago, advertising as we know it today really had its start. Printing led to widespread literacy, helped break down the barriers of ignorance and fear, played an important role in virtually every phase of modern civilization-including, of course, the newspaper and magazine.

The first printed advertisement in English is presumed to have been a small handbill from the press of William Caxton, issued in 1480 on behalf of a religious book, The Pyes of Salisbury-"pyes" being a set of rules for conducting Easter services. Newspapers came more slowly. Not until 1612 did the first one appear: Le Journal Général d' Affiches, in Paris. It is believed to have consisted chiefly of classified advertisements, legal and public notices, although no copies are in existence. Nevertheless, it continued to be issued and over 300 years later, under the title of Les Petites Affiches ("Little Announcements"), it was still flourishing.

In England newspapers began to make their appearance about the time the Pilgrims landed on Plymouth Rock. These periodicals were 
known often as "mercuries." What is said to be the first newspaper advertisement in England appeared on the back page of one of these crude journals in 1625 and, like the Caxton handbill, offered a book for sale. This volume dealt with the marriage of Prince Charles, soon to be King Charles I, and Princess Henrietta Maria of France, and the advertisement concluded with the punch line that the book contained a "liuely (sic) Picture of the Prince and the Lady cut in Brasse."

Books continued to be the chief advertised product for some time although the vendors of cures and nostrums soon discovered the new medium. The first advertisement for coffee is found in a $1652 \mathrm{Mer}$ cury. In 1666, the year of the great London fire, the Gazette of that city announced that it was so pressed for space regarding announcements of "books, medicines and other things not properly the business of a paper of intelligence," that henceforth all advertisements would appear in a separate supplement.

Use of the word "advertisement" to identify paid items in the newspapers had become common by 1650 . For utilitarian reasons, presentday advertising men who have to struggle with this cumbersome thirteen-letter word heartily regret its choice. It is far too long for our streamlined speech, and almost impossible to fit into a headline. Besides which, there is confusion as to its pronunciation. Webster gives adver'tisement as the preferred method, but hedges by including advertize'ment as an option, adding the comment: "especially in U. S." It is one of those ee-ther or eye-ther words!

For all practical purposes the single syllable "ad" is quite acceptable, though scowled upon by purists. Whenever possible one dodges the issue by talking about "advertising," which is shorter and a lot easier to say. But how often ad men wish that those pioneers back in 1650 had picked out some nice little, simple term comparable to "radio"!

With the restoration of Charles II in 1660, newspapers and advertising gained new impetus. Merchants recognized the value of paid space for certain types of selling. However it was not until the time of John Houghton, "the father of publication advertising," that much attention was paid to making advertisements anything more than mere announcements.

Houghton was the publisher of a weekly trade sheet and price list, started in 1692, A Collection for the Improvement of Husbandry and Trade. Not content with merely accepting such ads as came to him 
(as modern space-selling parlance has it) "over the transom," he began to insert little items suggesting that various products might be effectively promoted through his columns. For example, he wrote: "Whether advertisements of schools or houses and lodgings about London may be useful, I submit to those concerned." Evidently the appeal succeeded, for soon he was printing enough of such messages to declare: "I now find advertisements of schools, houses and lodgings in and about London are thought useful."

He had a conversational style of writing that seemed to take the reader into his confidence and impart news of special importance rather than bluntly trying to sell something. We can see a modern counterpart of this technique in the "shoppers' columns" currently popular. One of these, "Buy-Lines by Nancy Sasser," now appears in some 75 newspapers with over $12,000,000$ circulation and has numbered among its blue-chip clients such important national advertisers as Frigidaire, General Mills, Hormel, Swift, Heinz, Schlitz, Cream of Wheat and Carey's Salt.

The comparatively recent concept that the periodical publisher should stand back of his advertisements with his personal guarantee of satisfaction was foreshadowed 250 years ago by Houghton in advertising copy like this:

I have met with a curious (i.e., expert) gardener that will furnish anybody that sends to me for fruit trees, and floreal shrubs, and garden seeds. I have made him promise with all solemnity that whatever he sends shall be purely good, and I verily believe he may be depended on.

Here in primitive form is the same type of appeal seen today in the use of a publisher's endorsement of a product. Good Housekeeping, for instance, after tests in its own laboratories, permits approved advertisers to insert in their copy and on their labels an oval seal bearing the words: "Replacement or refund of money guaranteed by Good Housekeeping if defective or not as advertised therein."

Unfortunately, few advertisers or publishers felt this sense of public responsibility. In 1710, The Tatler was moved to complain:

Advertisements are used to inform the World where they may be furnished with almost everything that is necessary for Life. If a Man has Pains in his head, Cholic in his Bowels, or spots in his Cloathes, he may here meet with proper Cures and Remedies. If a Man would re- 
cover a Wife or a Horse that is stolen or strayed; if he wants new Sermons, Electuaries [medicines], Asses' milk or anything else, either for his Body or his Mind, this is the place to look for them in.

The same writer also declared that advertisements were being used by men of small achievements in order to have their names printed alongside the names of kings and statesmen. Could that be why so many ads of the Victorian era, before the days of big corporations, featured a picture of the company's full-bearded founder-like the Smith brothers of coughdrop fame?

Fifty years after The Tatler, in 1760, Dr. Samuel Johnson spoke his mind about advertising of that day with caustic words that still stand as a challenge to every copy writer and account executive:

Whatever is common is despised. Advertisements are now so numerous that they are very negligently perused, and it is therefore become necessary to gain attention by magnificence of promises, and by eloquence sometimes sublime and sometimes pathetick. Promise, large promise, is the soul of an advertisement.

But, he adds, "there are some [advertisers] that know the prejudice of mankind in favour of modest sincerity." And right there the learned doctor uttered what the brash 1920's used to call "a mouthful." More than one modern advertiser has refused to be deluded by the idea that it is necessary to gain attention "by magnificence of promise," and has built an enduring business on public confidence as a result.

\section{Early Advertising in America}

Neither Captain John Smith, in his expedition to Virginia in 1607, nor the Mayflower, which reached Plymouth in 1620, carried a printing press, though Mexico and Peru, Spanish colonies, both had presses in the sixteenth century. It was not until 1638 that Britain saw fit to ship one to Massachusetts as a gift to Harvard University. For the next half century the only printing permitted was religious in character. Then in 1690 the first newspaper appeared. Entitled Publick Occurences both Foreign and Domestick, it was promptly suppressed after one issue. Not until 1704 did another appear. The Boston News 
Letter, a dull and stodgy sheet by all accounts, consisted mostly of articles lifted from London papers of many months back. But its issue of May 1-8 contained, according to Frank Presbrey," the first paid advertisements published in America. One offered a reward for the capture of a thief and the return of clothing; another for the return of two anvils which had been "taken up" from a wharf; the third advertised the sale of a mill, houses and farm at Oyster Bay, Long Island.

In 1721 James Franklin, older brother of Benjamin, started the New England Courant and soon landed in jail for his outspoken views. Ben ran the paper while his brother was incarcerated and got enough experience so that, after he moved to Philadelphia, he helped start The Universal Instructor in All the Arts and Sciences and Pennsylvania Gazette in 1728. Soon Benjamin took over, shortened the name to Pennsylvania Gazette and thereby earned the right to have his picture printed every week on the editorial masthead of The Saturday Evening Post, which traces its source back to Ben's original sheet.

Franklin believed in the use of white space, display headlines and illustrations, in contrast with other American papers of that era, in which all matter, both news and advertising, was set solid and without any breathing space. $\mathrm{He}$ is credited with the introduction of "stock cuts," standard illustrations of certain common situations, which Cobb Shinn and other firms of today still find in demand by advertisers who do not wish to go to the expense of special art and engraving.

The Pennsylvania Gazette carried, among other things, advertisements of the stove Benjamin Franklin had invented as well as ads for runaway slaves, lottery tickets and several patent medicines such as "Seneka Rattlesnake Root," none of which would be acceptable nowadays. Franklin also pioneered in enlarging his paper from the standard two columns to a three-column sheet. He showed an independence of tradition and a willingness to experiment with new, untried forms that fully justified his fame, in later years, as one of the creative thinkers of all time.

Daily newspapers had already appeared in England when the first American daily, the Pennsylvania Packet and Daily Advertiser, made

* Frank Presbrey, The History and Development of Advertising (DoubledayDoran, 1929), p. 126. Quoted by permission of Mrs. Frank Presbrey. 


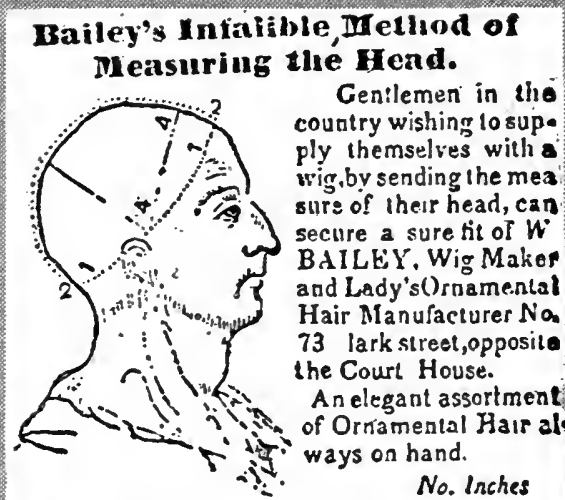

Fig, 1, round the head,

Fig. 2, froun the foretead to the nape of the neck,

Fig 3 , across the crown of the head to the fronl of the ear.

Fig. 4, across the top of the head from the tip of one ear to the other,

N. B.-Gentlemen wishing their hair cut or Iressed to look perfect, will do well to try. IV. BAILEY'S Mathematical System of Cutling tho hair.

Aligust18-8, 1 i48
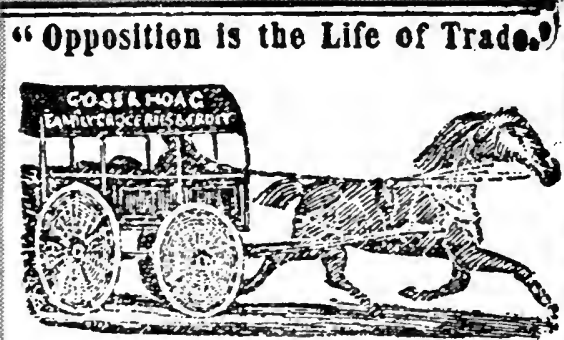

GOSS 8 HOAG would inform their Cuse T toners, and the Citizens of Chicago genera!Iv, that they have established an "Express" top the purpose of forwarding. free of charge, firne cerics, and Provisinus purchased of thern. 10 ally part of the City. 'I'hey will kcep on hand, at all times, a full and desirable Stock of Family Gro. ceries and Provisions, and all articles bought of them, are warranted to please.

Orders and niemorandums may be given to the Driver and will be promplly atleided to.

Jou't forget the number, No. 11 Clark St.

July 27, 1848.

\section{SLOAN'S COLUMN,}

IT All the Medicines advertised by W. B. Sing are sold by Merchants, Druggists, Acc.in nearly, evers town in all the Western States.

\section{Notice to the Sick.}

Persons wanting any kind of Popular Family Me dicenes are advised to go to W. B. Sloan's Medical Bepot No. 40 Lake street, and they will find them PURE and (iENUINE, at the very lowest prices. The fame o virs establishment has extended far and wide, and $m s$ to he exirnding in popularity every day. Fim 8, Merchauts, Druggists and dealers in medicines are thronging it from every part of the coulutry, and obtaining supplies

03 See advertisenents ln our eolumns. 20

\section{Libcral Offer.}

ANY person that furnishes me, before the ist day of next August, the ficts in reference to the most Extraordinary Cure, cfiected by the use of my Ointmellt, shall receive a premium of Ten Dollars and for tbe serond most extraordinary cure, Five Dollars; third. Twó Dollars; fourth, Onc Doller, and Gfil, a 50c. box of the Ointunent. Address, part-poid

Feh. 1,1849 IV. B. SLOAN Chicago, Illisois.

GREAT' CHANCE.-100 enterprising young men

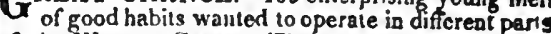
of the Western States. 'The best assurance will be given that each one can with a casb capital of from $\$ 5 \mathrm{~N}$ to $\$ 200$, make in ove year from $\$ 250$ to $\$ 1.000$ clear profit.

We don't want you to take our word for it, but cal and see for yourselves.

In order to obtain a full description of the busmeas and mode of operation, personal application is neces sary. 18 W.B.SLOAN

oct 18 N. 40, Lake St. Chieago

Dr. Beach' Book and ifedicinos. McAliater' All-Healing Oimtmeat and Mair uil.

SOLD Wholesale and Ketail at the proprietor' Lorocst Prices by W. B. SLOAN, General A rent No. 40, Lake street, Chicago oct 18

\section{Dr. J. A. KeNNICOTT, Dental Surgeon,}

Would respectfully inform tho citizens of Chicago and viciuity, that he has Incated at 96 Lako street, opposite the Stage Ottice, whoro ho will at ALL nours attend to business in the line of his profes. sion. Teeth filled with gold, and zoarranied for life, and alt other operations in Dental Surgery porformed in a judicious and satisfactory manner. For recommendatious tho subscriber would sefer to specimens of his skill in the dental art at his office. je3

\section{NEWSPAPER ADVERTISEMENTS OF 100 YEARS AGO}

eprinted from the Centennial Edition of The Chicago Tribune, June 10, 947. All advertising was restricted to a single column width and small body pe. 


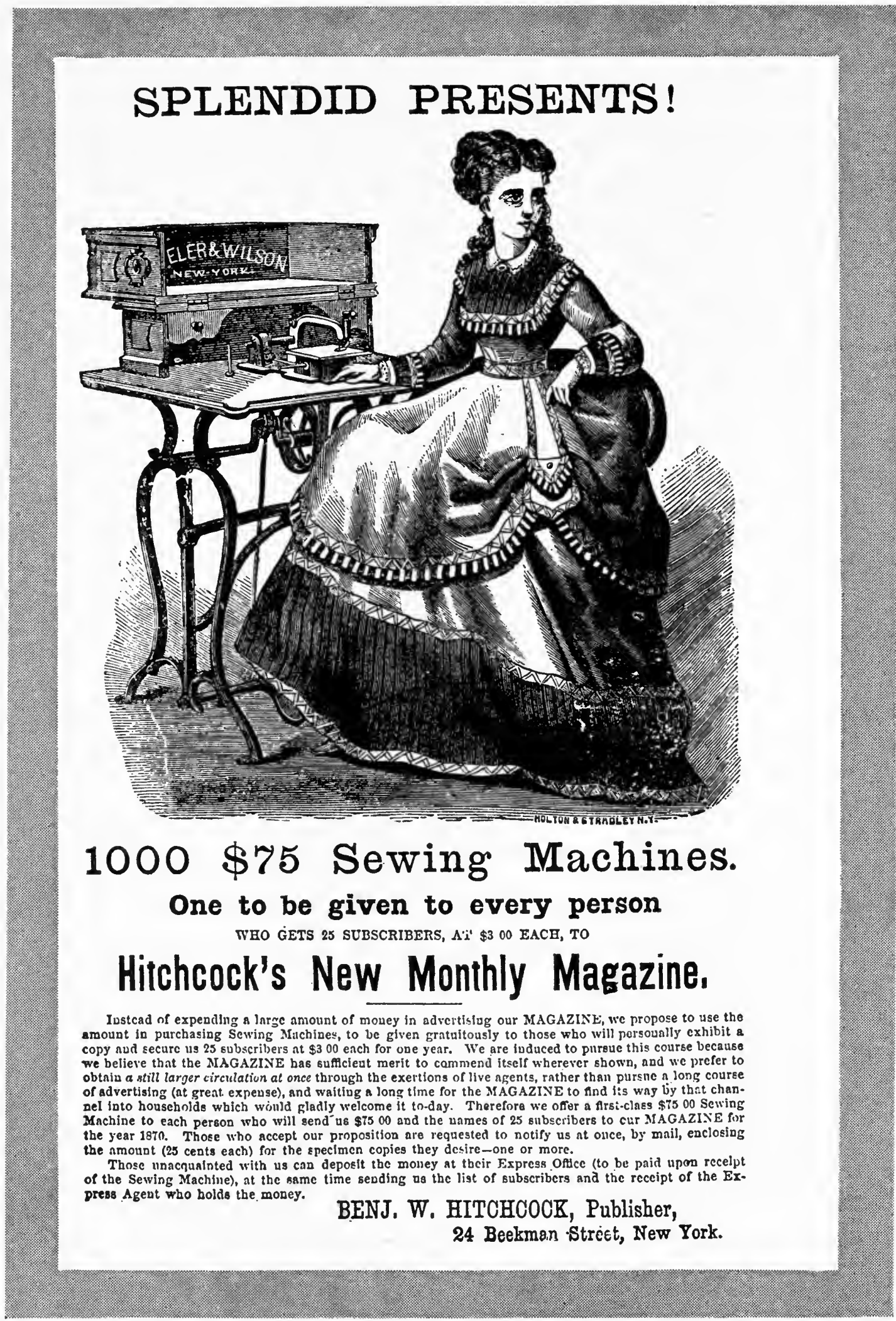

Courtesy Willard E. Stevens, owner of Harper's Weekly

\section{MAGAZINE PROMOTION IN MID-VICTORIAN DAYS}

This early scheme for building circulation is interesting because of its typographic style, quaint woodcut illustration and stilted phraseology. With complete inconsistency, the publisher announces that he is offering the premiums "instead of expending a large amount of money in advertising." 
its debut in 1784. Of its 16 columns, ten were devoted to advertising including the entire front page. The New York Advertiser started a year later, with a rate of three shillings per advertisement. This latter paper had the distinction, in 1789, of inciting an order for a suit from President Washington in response to an advertisement. Also significant in this newspaper was an advertisement from one J. Jacob Astor, offering for sale an assortment of "Piano Fortes made by the best makers in London," as well as stating, "He gives Cash for all kinds of Furs." The founder of one of America's greatest fortunes was an advertiser in the first year of the republic.

By 1810 there were over 350 newspapers and magazines in the United States, but their circulation was small. Advertising was still a very haphazard matter. A common practice was to charge the advertiser a fixed sum, such as $\$ 40$ per year, which included his subscription and an ad in every issue. A newspaper with a circulation of 2,000 copies was unusual. As against this, however, the advertiser could feel sure that those who received the paper would go through it column by column, not missing a single item. Readership ratings on those sheets of a century ago were undoubtedly very high!

Inventions played an important part in the growth of American industry, and its handmaiden, advertising. Whitney's cotton gin in 1794 led to the development of a native textile industry. Fulton's steamboat in 1807 provided a new, swift means of transporting manufactured goods-and also newspapers. The invention of the Fourdrinier paper-making machine in 1803, making possible the largescale production of paper, led directly to the cheap newspaper. From an average of six cents per copy, the price suddenly dropped as the New York Sun brought out a daily edition in 1833 for one cent. The success of this low price was instantaneous. In one year the Sun's circulation rose to 10,000 copies daily; in two years it had passed the 20,000 mark, comfortably ahead of any other paper in the world, including the London Times, which had 17,000 circulation. The steamoperated printing press provided rapid production, and soon the steam locomotive was to supply the means of carrying newspapers far and wide.

Across the years, advertising media have been quick to adopt new methods. When faster, better methods of reproduction are developed, the ad men take them up. For instance, when Ben Day, son of the founder of the New York Sun, devised a mechanical shading process 
for printing plates, its earliest acceptance was by advertisers. This process is still very widely used. Similarly, the linotype and other machines for setting up type matter owe much of their present popularity to a ready acceptance by the advertising fraternity.

\section{The Industrial Age-and Barnum}

Thus far the only advertising we have considered has been retail in nature, because no other kind was being done. The modern strategy of creating consumer preference for a particular brand of merchandise and thereby getting dealers to handle it was still unknown. National media were nonexistent. What few manufacturers America had in 1800 disposed of their products direct to users or through near-by dealers. The Yankee chapman or peddler, with a pack on his back or a wagon loaded with goods, was the forerunner of our present-day system of national distribution-but he depended on his glib tongue rather than on any previously inspired acceptance of his wares through the printed word.

American industry received its first great impetus during the Napoleonic Wars. In 1808 Jefferson put an embargo on British and French imports, forcing the native manufacture of such things as textiles. By the end of the War of 1812 many new industries were flourishing, and protective tariffs were enacted in their behalf. The value of American-made goods trebled in the 25 years following the first embargo decree, and the age of homecrafts was over.

While the foundation for the industrial era was being laid, a new type of advertising was blossoming in a totally different field-that of showmanship. It was to have a profound effect on the attitude of businessmen toward advertising for many years; in fact; its influence is far from dead today. This was the gaudy, flamboyantly sensational style of promotion whose proud parent became the master showman of the age: Phineas T. Barnum.

Beginning with lurid handbills to help sell lottery tickets, Barnum found his true sphere in 1835 when he first exhibited Joice Heth, a Negress alleged to be 160 years old and the former slave of George Washington's father. Barnum's ballyhoo methods, using posters, circulars, newspaper ads and publicity, attracted swarms of the cynical as well as the credulous. Joice Heth cost him $\$ 1,000$ and at the height 
of his campaign the weekly "take" was well over that figure. When she died after a year or so, a post-mortem showed her to be not over 80 , and Barnum's fortunes declined. At one point he was reduced to writing ads for a Bowery theater at $\$ 4.00$ a week. Even there he tossed extravagant adjectives around in a style hitherto reserved for patentmedicine advertisers.

Like a true promoter, Barnum bounced back from his lean years and in 1842 got control of the American Museum in New York. He gave it a "grand opening" equal to any Hollywood première of the present day, with lights blazing from the roof, a band playing, brilliantly colored paintings covering the façade, banners strung across the street, sandwich men, and a virtual barrage of press-agent stunts. Inside of a year he had paid off the purchase price.

"I knew when I started," Barnum wrote afterward, "that every dollar spent in advertising would bring back ten."

It was such statements, coupled with his extraordinary success as a showman, that caused even the most conservative and tight-fisted businessmen to loosen their purse strings and spend money on all sorts of wild promotional ideas. The sponsors of these ideas lacked Barnum's uncanny ability to sense popular tastes and reactions as well as his genius for timing. As a result, when these harebrained schemes failed, the whole advertising field caught the blame. In reality most of what Barnum called "advertising" was something entirely different-either sublimated press-agentry or some novel form of attracting attention that had no possible application in the business world.

Barnum's greatest triumphs were the presentation of a midget whom he named "General Tom Thumb" and the concert tour of the Swedish Nightingale, Jenny Lind. He also introduced the Siamese Twins, the Dog-faced Man and hundreds of other freaks. He called his circus "The Greatest Show on Earth," a slogan which persists to this day. Other echoes of the Barnumesque method are heard in such modern slogans as that of the Chicago Tribune, which unblushingly calls itself "The World's Greatest Newspaper," and Goodyear, presenting its claim for preference on the grounds that it is "The Greatest Name in Rubber."

Undoubtedly, old P. T. did much to sell advertising to industry in the half century between 1842 and his death in 1891, when he was the shining example of success. But he also gave the modern advertising man a lot to live down! 


\section{Chapter III}

\section{ADVERTISING'S COVERED WAGON DAYS}

T CENTURY ago gold was discovered in California—and the great A rush was on. About the same time, American business began to 1 stake out its claim over the rich mother lode of advertising. According to the Encyclopædia Britannica, "The Modern Period [in advertising] may be dated from about 1850 . The reason for putting the dividing point between the early and modern periods at 1850 is the rapid appearance of newspapers and magazines, which made possible the development of modern advertising on a large scale."*

Transportation and communication have been indispensable allies of modern advertising. Between 1830, when the first experimental rail line was laid, and the outbreak of the Civil War, more than 30,000 miles of railroads were built. By 1869 we had our first transcontinental line. Wherever the iron horse went, there went the latest periodicals, linking the nation ever more firmly in bonds of paper and printers' ink, ties that were to prove stronger than all the edicts of dictators.

Newspapers carried the news of Sutter's Mill throughout the East, caused over 200,000 men to head for the gold fields and thus developed the Pacific Coast more rapidly in ten years than the Spanish dons had done in three centuries. In 1850 America boasted some 200 dailies, with a total circulation of $1,000,000$ copies per day, 2,300 weeklies, and 500 magazines, chiefly religious and agricultural. Advertising soared in volume, though most of it was pretty dull stuff. Few illustrations were used, and since most papers restricted their advertisers to single-column width and agate type (the size found today in newspaper "want ad" sections) there was little chance for dramatic appeals.

American ingenuity manifested itself, however, in many novel ways. One of the pioneers was Robert Bonner, who in 1851 took over a small weekly paper and built it into a family journal, the New York Ledger, with a circulation of 400,000 copies. Bonner advertised widely in other papers, and when they refused to set his ads any larger than

* The Encyclopcedia Britannica, XIV Ed., I, 200. Quoted by permission of the Encyclopædia Britannica. 
fourteen lines to the inch, he conceived the plan of repeating the same message over and over again. One of his early efforts was a two-line announcement of a forthcoming story in the Ledger, repeated 93 times to fill a complete column in the Herald. Then he went to a double column and finally an entire page, all consisting of a single sentence endlessly reiterated. He later ran as much as four pages in one issue of the local papers.

Other advertisers strove for attention by breaking up each sentence into several phrases, each of which would be repeated three, four or more times before going on to the next. Still another device was to form the agate type into odd shapes, much after the fashion of the modern stuntist who makes silhouettes on a typewriter. Frank Presbrey* reproduces one interesting example of this, an advertisement of Brady's Photographic Gallery, located at 359 Broadway. The text is set in the shape of the numerals 3,5 and 9, strung out down the column. This appeared in 1856, several years before Brady won fame as the Civil War cameraman.

The decade that marked the dawn of the modern period in advertising was notable for its exuberance. In the 1850's America was on the march. Manufacturing had passed the $\$ 1,000,000,000$ total sales per annum. Immigrants were pouring in. Europe was beginning to respect us as a great power.

Advertising reflected this dynamic spirit. The cities were flooded with weird and wonderful appeals for attention. Placards, posters and painted signs bloomed on every wall and building. The horsecars had sheaves of handbills on spikes waiting for the riders to pull them off and read. Wagons and buggies bedecked with signs moved up and down the streets, just like the poster-plastered express trucks of today. Parades of sandwich men crowded the sidewalks. Urchins constantly thrust handbills or "fliers" at the pedestrians. At night, blazing gaslights illuminated the advertising signs on the rooftops. And every newspaper was laden with ads; the New York Tribune ran as high as 22 columns in a 48-column, eight-page issue.

\section{The Birth of the Advertising Agency}

The middle years of the nineteenth century witnessed another event that was to have a permanent influence on advertising. That was the birth of the advertising agency.

*Op. cit., p. 233. 
Prior to that time a few individuals had specialized in advertising, chiefly as free-lance writers. But there were no firms concentrating in the field. The creating and placing of advertisements, generally speaking, were side-line jobs to most advertisers. Sometimes the work would be done by the store proprietor, or by the manager of a factory selling goods direct to consumers. Space solicitors for the newspapers and magazines of the day might, on occasion, help out with suggestions. The modern concept of an independent organization rendering impartial, professional counsel on advertising, however, was still in the future.

It is not surprising then that most advertising was dull, uninviting, haphazard. Only when somebody like Barnum gave advertising first place in his attention did the real possibilities of this strange, littleunderstood force reveal itself.

The coming of the advertising agency changed all this. The agency system produced a group of firms in which men spent all their time thinking about advertising, devising ways to make it more productive, broadening its services. In such circumstances it was only natural that advertising should forge rapidly ahead. Market analysis, scientific space buying, copy testing, art in advertising, long-range planningthese are just a few of the many advertising developments either originated or aggressively sponsored by agencies. Even advertisers who do not use agencies-such as many department stores-owe much to agency-pioneered techniques and methods.

The first advertising agents, in the sense of men or firms actively engaged in placing advertisements in more than one medium, are believed to have been Volney B. Palmer and John L. Hooper. Palmer had offices in New York, Boston and Philadelphia, and as early as 1841 solicited business on the basis that he could place advertising in the leading papers of the United States and Canada. Hooper, a former solicitor for the New York Tribune, became a free-lance agent in the 1840's and his agency maintained a continuous existence until absorbed by George P. Rowell, the founder of Printers' Ink, in the 1870's. A little later, S. M. Pettengill \& Co. entered the agency field, calling themselves "Advertising Agents, authorized to accept advertisements for the most widely circulated newspapers in the United States and the British Colonies."

These early agencies made no attempt to plan or prepare advertising campaigns. They were solely space brokers. They accepted 
advertisements for insertion at the publishers' announced rates and then bargained with the publishers to get lower prices. In his book, Forty Years an Advertising Agent, George Rowell describes how he took a billing of $\$ 2,000$ for his first month and was able to place it with the specified newspapers for $\$ 600$.

It was not uncommon for an advertiser to submit his proposed schedule to several agencies and place his order with the one that gave the lowest bid. The bargaining abilities of the agencies played an important part in their obtaining the business.

One of the first national campaigns placed through an agency was that of the Federal War Loan in the Civil War, handled by Peaslee \& Co. War bond advertisements appeared in between 4,000 and 5,000 papers. Since the ads were placed at the publisher's "card rates"-his asking price-and since all agencies prided themselves on their bargaining powers, it may be assumed that this was a very profitable contract. The Civil War bond campaign is generally considered the first real national advertising campaign in America. It established a record in total number of newspapers used. Unlike the war-bond advertising in World War II, it was paid for by the national government.

In the early days of advertising agencies, the chief appeal was convenience. An advertiser wishing to reach a large number of markets could turn his copy over to an agency and be relieved of all the detail necessary in getting in touch with each publisher separately. Early agencies capitalized on the advertiser's inertia by offering "lists" of newspapers at flat rates. Rowell issued a circular listing 100 papers in which he would place a one-inch ad for a month for $\$ 100$. Since he already had contracts with many papers to take a whole column for $\$ 100$ a year, from which he deducted his 25 percent commission plus a cash discount, it can be seen that the offer was very profitable to the agency. At the same time it worked no hardship on the advertiser, who would have had to pay $\$ 1.00$ or more per paper if ordered separately.

This was one of several phases in the evolution of the agency system to its present form. Ralph Hower in his history of N. W. Ayer \& Son describes four stages of metamorphosis:

Newspaper stage: the agent directly represented the publisher. Space-jobbing stage: the agent became a broker, selling space to 
advertisers and then buying it from the publishers to fill his orders.

Space-wholesaling stage: the agent contracted for large amounts of space in advance and sold it on a piecemeal basis; in those days many publishers welcomed such arrangements because of high credit losses from firms advertising direct.

Advertising concession stage: the agent secured a monopoly of all advertising in a publication by paying a fixed sum; then he set up his own rates, selling to advertisers and other agencies.*

Each of these larval forms was alike in that most of the revenue, if not all, came from commissions paid by the publishers. That practice has continued in the present agency setup, which might be called the Complete advertising service stage. The percentage of commission allowed the agency fluctuated for many years but now has been generally standardized at 15 percent plus a 2 percent cash discount.

Still another kind of organization contributed to the agency structure of today. This was the "non-placing agency" of the 1890's and 1900 's. As the name suggests, it placed no ads but confined its services to preparing plans, writing copy and making designs or layouts. Among the leaders were Charles Austin Bates, the George Ethridge Co. (later an art studio) and Calkins \& Holden, who became a general agency. They did work for straight-line agencies as well as advertisers.

Critics of the commission system argue that it is illogical and unsound. They point out, for example, that often as much work is required to prepare a $\$ 100$ ad in a business paper as a $\$ 25,000$ spread in a national weekly. The pros and cons of this controversy will be aired more fully in a subsequent chapter.**

Whether the commission method is sound and proper, or an inequitable makeshift, it has worked reasonably well for over a century.

The incentive of quick, substantial profits has attracted men with a high degree of initiative and imagination to the agency business. The advertiser has been able without cost to himself-thanks to the commission method of payment-to "hire" the thinking of such men for his selling problems.

Kenneth Goode put the case very pointedly when he wrote:

Advertising is hailed as a benefactor to civilization. It is. And has

* Reprinted by permission of the publishers from Ralph M. Hower, The History of an Advertising Agency: N. W. Ayer \& Son at Work, 1869-1939, Cambridge, Mass.: Harvard University Press, 1939.

** Chapter VIII. 
been. But .... the real benefactor so far as advertising is concerned is not so much the "force" of publicity as the enterprise and ingenuity of the men whose brains have been utilizing that force. Thinking in terms of finances and factories, taking for granted the human element-the only element of any vital importance-American business leaders might have been utterly lost without the stimulating guidance of the type of mind the advertising industry has so notably developed.

For sixty years, while others have been absorbed in profits and processes, the advertising-minded man has hustled with his eye turned outward toward humanity. He has been the constructive imagination of American business. He has made merchandising. His packaging has made the chain store. His competition to render new services, his designing for attractiveness and convenience, his eternal search on behalf of the public, has in truth made the advertising man the real accelerator of civilization.*

Not all such men as Mr. Goode describes are to be found in advertising agencies by any means. Many are advertising directors of manufacturers or retailers; others may be sales managers or presidents. Their titles are not nearly so important as their vision.

\section{Mid-Victorian Handicaps}

Advertisers at the dawn of the "modern era"-the 1850's, '60's and '70's-had to do without most of the modern conveniences that ad men now accept as a matter of course.

There were, for instance, no published directories of periodicals until some years after the Civil War. When George Rowell received an order from a Hartford publisher for an advertisement to be placed in newspapers in New Brunswick, Nova Scotia and Prince Edward Island, no information on papers in these areas was available. He was fortunate in having a solicitor named Fox who came from Nova Scotia. Fox told him that the Boston printers nearly all had one or more Canadians working for them. Rowell sent Fox out to call on these Bluenoses and ask them to recall all the names of provincial papers within their knowledge--whether issued daily, weekly or semiweekly, and the approximate population of the town. From the size of the town, Rowell estimated the newspaper rate by comparison with rates for similar sized New England town journals. He submitted his

* Kenneth M. Goode, Advertising (Greenberg Publisher, Inc., 1932). Quoted by permission of the publisher. 
estimate to the book publisher for something over $\$ 200$ in space, got it approved and then started writing the Canadian papers on his list compiled from the memories of Boston printers.*

In 1869 Rowell brought out the first edition of his American Newspaper Directory, giving not only the name and address of each paper on which any data could be obtained but also an estimate of its circulation. This latter feature was revolutionary, since newspapers then and for many years afterward were very chary about supplying circulation data.

Today advertisers have available the four volumes issued monthly of Standard Rate \& Data Service, not only listing all periodicals but also giving their rates, circulations, page and column dimensions, mechanical requirements and other essential information. Separate books embrace newspapers; magazines, farm papers and transportation advertising; business papers; and radio. Circulation figures in the vast majority of cases are carefully audited. Rates are uniform and not subject to bargaining. But the would-be advertiser 80 years ago enjoyed none of these benefits.

He bought, for the most part, on blind faith. More often than not, he had no way of telling whether the advertising received the circulation for which he had paid. It was not until advertising media banded together to assure honest records and ethical methods of promotion that the buyer of space knew for sure what he was getting for his money.

Obtaining the facts about circulation was only one of the advertiser's problems. For many years American newspapers refused to "break" their columns-the dividing lines between columns had to remain inviolate. So, although a firm might buy several columns or even a full page of space, the regulations did not permit using display headlines or illustrations of more than a single-column width.

Advertisers abroad had been allowed to use bold type as large as 72-point (one inch in height) across as many columns as they wished to pay for. Naturally American concerns seeing these foreign examples began to demand the same privileges. In the late 1860's the rules against large type and multicolumn displays were relaxed. Lord \& Taylor and R. H. Macy, New York department stores, were pioneers in bringing this about. Apparently the results were satisfactory, for

* Forty Years An Advertising Agent (Printers' Ink, 1926). By permission of Printers' Ink. 
the department stores took larger and larger units of space. The first full-page ad appeared in the '70's. Double pages, then three or more pages, became not uncommon. In recent years department stores have used entire sections of Sunday newspapers, sometimes running eight, twelve or sixteen pages in a single issue.

Illustrations presented another obstacle to the mid-Victorian advertiser. It seems incredible, but as late as 1873 certain of the leading metropolitan newspapers refused to permit pictures of any kind in their advertising columns. Such restrictions had disappeared by the end of the decade and pictures became more and more popular. However, the illustrations of those days were far removed from what we see today. The halftone process was not invented until 1878 and did not receive wide usage until the 1890's. The standard type of illustration was the "woodcut," painstakingly carved line by line from a block of wood. Craftsmen in this field often became amazingly proficient in reproducing the likeness of a product or an individualso much so that in the early days of the halftone the woodcut was considered superior. Only in comparatively recent years have the mail-order catalogue houses abandoned woodcuts for most of their illustrations, and even now an expertly made woodcut is sometimes preferred, particularly for a small picture on a poor grade of paper.

Alexander Drake, as "art manager" of Scribner's Monthly (later The Century), believed that there was a better way of utilizing photographs than the painstaking woodcut or steel engraving method. $\mathrm{He}$ is recognized as the first to use a new invention whereby a photographic impression could be transferred to a wood block. This resulted in an immediate improvement of the magazine's illustrations and was the acme of pictorial technique until the halftone was perfected.

To this day, the age of the woodcut is still reflected in advertising slang. Printing plates are called "cuts"-or in England, "blocks"-a carry-over from the time when all pictures were actually cut by hand from a block of hardwood.

One of the most serious handicaps that confronted the advertiser in the years immediately following the Civil War was the lack of marketing information.

Market analysis and advertising research are comparatively recent developments. The firm investing in a campaign even up to World War I had little if any opportunity of knowing whether or not it was 
aiming its copy at the right markets, or of checking the correctness of the copy appeal and the effectiveness of the program-all matters which modern research covers as a matter of course.

The Department of Commerce through its Census Bureau, Patent Office, Bureau of Foreign and Domestic Commerce and Bureau of Standards now makes available a wealth of information constantly utilized by advertisers, media and agencies. The Federal Trade Commission, Interstate Commerce Commission, Federal Communications Commission and Department of Agriculture are other governmental agencies supplying information about products, raw materials and markets. Virtually none of these sources existed 50 years ago, even had advertising people wanted to use them or known how to use them.

Nowadays every city has its research and survey specialists whose primary function is to eliminate guesswork and waste in advertising. Advertising agencies have their own research staffs. Many firms that advertise employ a full-time market analyst with perhaps several assistants. None of this scientific background was obtainable in the nineteenth century, nor was it demanded. The Curtis Publishing Company was a leader in the field of market analysis. Crowell-Collier, McCall's, and Macfadden publications have rendered excellent service in the magazine industry. Among newspapers, the Milwaukee Journal, the Cleveland Press and the New York World-Telegram have been leaders.

Trade associations such as the Advertising Research Foundationsponsored by the Advertising Federation of America, the Association of National Advertisers and the American Association of Advertising Agencies-have done remarkable work. The outdoor media through Traffic Audit Bureau, the business press through the Associated Business Papers and, of course, the radio industry have all contributed to the fund of marketing and advertising knowledge now at the command of the advertiser.

Getting back to mechanical processes, electricity was used in making electrotypes-printing plates which reproduced the original adlong before Edison discovered the incandescent light. Presbrey says "copy of electrotype form" was commonly featured by pioneer advertising agents as a sales point."* By this process the original ad could be duplicated any number of times and facsimiles shipped far and wide. Newspaper publishers liked "electros" because of their convenience.

* Op. cit., p. 269. 
The stereotype and "mat" (matrix)-another method of duplicating printing plates or type-came into general use in the 1880's. Its application was largely in connection with newspaper advertising, since the stereotype was not suitable for the more detailed needs of magazine work. In its orbit the mat is still in constant use. Many advertisers today call any newspaper ad or illustration a "mat."

The rotary press, adopted first for magazine use in 1884, marked a signal advance. In 1886 Ottmar Mergenthaler invented the Linotype, a machine for setting type mechanically instead of by hand. It was nearly twenty years before his device was widely used but today it is seen in thousands of newspaper composing rooms and job printing plants. With its kindred developments-the Monotype, Intertype and Ludlow - the Linotype revolutionized printing. While it is true that many ads are still hand-set from "foundry" type a letter at a time, Mergenthaler's invention of a practical method of machine composition greatly speeded the production of periodicals and thereby had a real influence on advertising development. Virtually all catalogues, books, magazines and newspapers are set by mechanical means.

The advertiser in the early days of the modern era had no opportunity to use color. Some attempts were made to reproduce color illustrations by lithography or hand tinting but it was not until 1890 that the New York World brought out an issue containing two-color printing. This was purely a stunt, although it inspired other papers to experiment. In 1893 the Kansas City Journal said it was ready to accept four-color ads. ${ }^{*}$ Not until several decades later, as we shall see, did newspaper color advertising gain any notable degree of acceptance.

Magazines had been much more progressive in employing color. The famous Godey's Lady's Book contained steel engravings in color showing the latest Paris fashions. Between 1827 and 1877 it was the Vogue or Harper's Bazaar of its day. No commercial producers, however, seem to have sensed the value of color.

One of the first examples of color advertising appeared on the back cover of Youth's Companion in 1893. It was a full-color lithograph of The Awakening of Cupid by the French artist Perrault and advertised Mellin's Food. The cost of the ad was very high $-\$ 14,000$ for 650,000 circulation-but it created such a sensation that the sponsor unquestionably got his money's worth.

Procter \& Gamble, makers of Ivory Soap, in 1896 prepared a color

* Printers' Ink, 50th Anniversary Edition, July 28, 1938, p. 196. 
insert which they printed and shipped to the magazines to be bound into an issue. The same year, Cosmopolitan ran a lithographed cover in colors which greatly increased newsstand sales. But it took years longer for publishers to accept color as a standard advertising device.

As an indication of the present popularity of color in consumer advertising, the May 1947 Ladies' Home Journal carried 123 full-page and half-page ads in four colors, and one two-page spread in four colors; 25 two-color ads; and 74 black-and-white ads of a half page or larger. Color advertising is permissible only in half-page or full-page units. Thus among the sizes of ads where color could be used, 149 out of 223 advertisers used it-a two-to-one ratio.

The mail-order houses, keeping accurate records of the sales-making power of each catalogue page, were pioneers in proving that for certain types of merchandise, color would outpull black and white several times over.

Still another handicap confronting the legitimate advertiser of the '60's and '70's was the prevalence of freakish, exaggerated or downright dishonest advertising. From the former practice of merchants merely announcing what goods they had for sale, competition had become so intense that claims had grown out of all reason. In this atmosphere reputable business firms were reluctant to make any statements about their products. They confined themselves to a mere announcement of their trade name, which obviously limited the results from advertising. This "business card" type of advertising still survives in the austere displays of a few swank firms like Tiffany \& Company.

The man who is credited with leading the way to honesty in advertising was John E. Powers. He stated as his fundamental principle: "Say the right things to the right people in an acceptable way." For a period of thirty or more years from 1860 on, Powers stuck to his guns. He wrote no copy about a product unless he was convinced of its merits. Then he stated the advantages in simple, conversational, utterly convincing terms. Powers reached the height of fame as advertising counsel for John Wanamaker between 1880 and 1886. When Mr. Wanamaker hired him, the Philadelphia merchant is supposed to have said, "Mr. Powers, tell me something new to do in advertising," to which Powers answered, "Be honest-it has never been tried before."*

* By permission from Principles of Advertising, by Daniel A. Starch. Copyrighted 1923, by McGraw-Hill Book Co., Inc., p. 458 . 
Powers has been called "the father of modern advertising." $\mathrm{He}$ developed a method of approach that is still the envy of copy writers. Here, for example, is one of his most famous ads, written some 50 years ago for Macbeth, makers of lamp chimneys:

One of the minor troubles of house-keeping is the breaking of lamp-chimneys. Chimneys cost but little apiece, and break but one at a time. You class these little surprises among 'mysterious providences', and bear them, meekly resigned.

All wrong! the chimneys are wrong: the glass was ready to pop the minute it cooled.

The maker saved two cents on a chimney, and put this loss and annoyance on you.

Pearl top chimneys do not break in use.

This style of advertising became known as "reason-why," in contrast to copy based on sweeping claims, emotional or fear appeals. Later exponents like Charles Austin Bates, Nathaniel C. Fowler and Claude Hopkins followed much the same pattern; they exerted a tremendous influence in wooing business away from the Barnumesque or "buncombe" school of copy.

\section{Other Mid-Victorian Influences}

The period following 1850 was marked by a strong religious revival, and this led to a remarkable growth in the number and popularity of religious papers. By 1870 some 400 weeklies of this type were being published, with an estimated combined circulation of 5,000,000 copies. This compared with $10,000,000$ circulation for over 4,000 secular weeklies indicates that the average religious paper had a circulation five times greater than that of the average general publication.

Advertisers flocked to use the religious press, since it was assumed that this medium reached the more stable, home-loving classes. Carlton \& Smith, an advertising agency which later became the J. Walter Thompson Company, specialized in soliciting space in such periodicals. F. Wayland Ayer, who founded the Philadelphia agency of $\mathrm{N}$. W. Ayer \& Son, broke into advertising by selling ads for the $\mathrm{Na}$ tional Baptist; in less than a year he had earned $\$ 1,200$ in commissions and with his savings started his business in 1869 . In 1871 he paid the National Baptist $\$ 6,400$ for the exclusive use of its advertising columns 
and made a profit of $\$ 1,758.98$ on the deal.* In 1882 Ayer separated his space-jobbing activities from the agency by forming the Religious Press Association, and thereafter the agency dealt with such periodicals on the same basis as any other media.

The Philadelphia Centennial of 1876 was an event of tremendous significance to the industrial growth of the nation. It introduced many strange and wonderful things to the public. The telephone had just been invented; the electric generator had come into practical use only a few years before. The hundreds of thousands who flocked to the Exposition were inspired with new pride in America's industrial achievements. Thereafter they greeted the news of fresh advances in science-particularly any new electrical discovery-with considerably less skepticism. Edison met plenty of opposition in popularizing the incandescent light, which he invented in 1879, but the stimulus of the Centennial had helped prepare the public for it.

Manufacturers put their best foot forward in exhibiting products at Philadelphia. But in many fields their quality compared unfavorably with that of European exhibits. As a result, says Presbrey, there was "a general and successful effort by American manufacturers to improve quality."**

Actually, what the Centennial did, in putting manufactured goods in the spotlight and thereby stimulating the maker to turn out better articles, is no different from the effect of any advertising campaign. Advertising lifts the cloak of anonymity. "Once bitten twice shy" is a relentless buying maxim. Shoddy products may continue to sell if unidentified by a trade-mark or brand name; as soon as they are labeled and advertised, the public has an easy guide for avoiding a second purchase.

By awarding medals for excellence, the exposition authorities also pushed American industry into devoting more attention to quality. A firm which won a gold medal at Philadelphia lost no time in telling the world about it. Packages broke out in a rash of medallions; advertising space was freely used to announce the coveted awards. And what manufacturer, having received kudos for product quality, would knowingly risk this prestige by debasing his output?

\footnotetext{
* Reprinted by permission of the publishers from Ralph M. Hower, The History of an Advertising Agency: N.W. Ayer \& Son at Work, 1869-1939, Cambridge, Mass.: Harvard University Press, 1939.

** Frank Presbrey, The History and Development of Advertising (DoubledayDoran, 1929). Quoted by permission of Mrs. Frank Presbrey.
} 


\section{o products made by}

\section{Standard Brands}

RECEIVE AWARDS

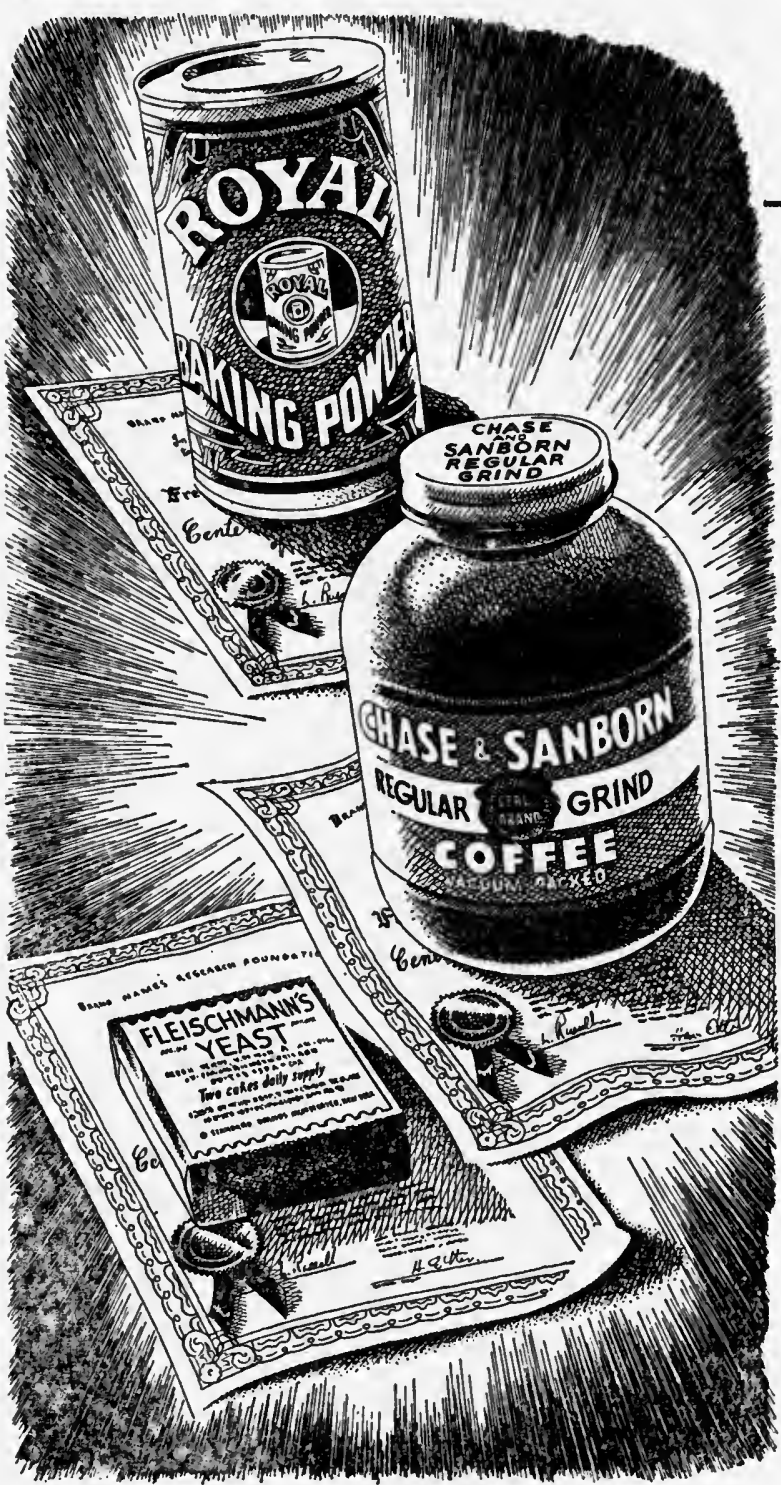

FOR 75 YEARS

OF SERVICE

\section{ROYAL BAKING POWDER}

Introduced in 1866. Because of its marvelous leavening action, as well as its purity and wholesomeness, Royal Baking Powder has become a household standard throughout the world.

\section{CHASE \& SANBORN COFFEE}

Introduced in 1864. More people have been using Chase \& Sanborn Coffee in the past year than ever before. "Shade-grown" flavor is bringing the biggest success in Chase \& Sanborn's 82 years.

\section{FLEISCHMANN'S YEAST}

Introduced in 1870. Fleischmann made the first compressed yeast and pioneered the methods of yeast manufacture which made possible the uniformity, potency, dependable quality of virtually all yeasts ever since.

On February 5th, 1946, the Brand Names Research Foundation awarded its Certificate of Public Service to THREE brand names of products made by Standard Brands Incorporated. This important distinction honors Royal Baking Powder, Chase \& Sanborn Coffee and Fleischmann's Yeast for their records in maintaining the highest public confidence for more than 75 years.

These quality products are backed by advertising-year-in, year-out. Feature and display these fast-moving brands. 
The 1870's also witnessed the beginnings on a national scale of the giant mail-order industry. Selling goods by mail, either direct to the user or through agents secured by advertising, was nothing new. But now it began to assume impressive proportions. In Chicago A. Montgomery Ward and George R. Thorne started Montgomery Ward \& Company and issued their first mail-order catalogue-a pocket-size price list of 100 pages. The year was 1872. In Boston, Butler Brothers were building a thriving business in selling by mail to the thousands of small retailers who were seldom visited by traveling salesmen. What grew to be the largest mail-order firm of all-Sears, Roebuck \& Company-had its beginnings in 1884 when Richard W. Sears began selling watches by mail. Sears built his annual sales from nothing to $\$ 50,000,000$ in 17 years.

Augusta, Maine, became a center of the mail-order business through the energy and genius of E. C. Allen, who as a boy had sold berries to the Civil War camps around his home town. Later, answering various "Agents Wanted" ads, he had made a fair living as a sales agent until he decided it was more profitable to be a principal and let others sell for him. He devised a recipe for making a washing compound from inexpensive ingredients that could be bought at any drugstore, and started advertising for agents. The recipes, printed on slips the size of a post card, cost him $\$ 1.00$ for 1,000; he sold them to agents at five for $\$ 2.00,25$ for $\$ 5.00,100$ for $\$ 10$ or 1,000 for $\$ 25$. The agent was supposed to get $\$ 1.00$ for the recipe. Of course whoever bought the recipe could print unlimited quantities himself, but Allen exacted from each agent a solemn promise not to divulge the formula "and to exact the same promise from every one to whom you sell the valuable secret." Apparently purchasers took this promise seriously, for in 1870 he contracted with George Rowell for $\$ 11,000$ worth of advertising space in all the leading papers of the country. Rowell cagily asked for $\$ 5,000$ down and $\$ 500$ cash a week on the balance. It was paid promptly. Some months later the young man came in and asked how much it would cost to run an 18-line ad for three months in every paper in America. The price was $\$ 30,000$, which Allen paid on the spot.*

Shortly thereafter, Allen started his own magazine, which he sent out free or for a nominal price to names obtained from mailing lists. Ostensibly it was a conventional periodical but its real purpose was to

* Forty Y'ears An Advertising Agent. 
obtain inquiries for agents. From this start developed a whole class of "mail-order journals" such as Grit, published at Williamsport, Pennsylvania, Comfort and the Vickery-Hill list at Augusta, and the Chicago Blade and Ledger. Allen died a millionaire while still under forty.

Yet another development of the middle nineteenth century which affected advertising was the innovation of "boiler plate" or "patent insides" for small newspapers that could not afford to buy special stories or features.

"Boiler plate" got its odd name from the fact that the feature material would be made up in full-page electrotypes which resembled the metal used in making boilers. The weekly release might contain such features as an installment of a serial, a short story, a digest of world news, farming counsel, recipes, jokes and ads. The country editor would use the plates as pages 2 and 3 of his four-page paper, printing local news on the front and back. Or if he had a larger volume of local advertising, he might use four pages of "boiler plate" and four of his own.

One of the first such services was launched during the Civil War by the Milwaukee Evening Wisconsin for near-by county weeklies whose printers had gone into the army. The metropolitan paper excerpted enough material from its columns to fill two inside pages and sent them to the small towns, leaving it up to the local editors to cover the outside with community news and advertisements. Before long the publisher of the Wisconsin sensed the value of these "patent insides" as an advertising medium and began to sell space. At the height of its popularity, around the turn of the century, the "boiler plate" system offered circulation in some 10,000 country papers. As of March 1947 the Western Newspaper Union had on its list 2,366 such papers with a combined circulation of $1,772,771$ divided into 30 territories; the largest being Minneapolis, with 183 papers, Milwaukee, 157, St. Louis, 158 and Sioux City, 125.

The use of jingles and slogans in advertising reached the proportions of an epidemic in the last half of the century. Not that it was anything new. One school of advertisers has always advocated the "clever" turn of phrase whether in rhyme, catchpenny expression or parody. In the early 1800's Warren's Shoe Blacking jingles had achieved such universal popularity in England as even to receive a mention in Pickwick Papers. Mrs. Warren is said to have remarked, when asked 
about her advertising, "We keeps a poet." Rumor had it that he was none other than the great Byron."

Such modern advertising pioneers as the makers of Ivory Soap, Castoria, Campbell's Soup, Herpicide, De Long Hook \& Eye and Pear's Soap all went overboard for doggerel. Here is a choice ad that appeared some 50 years ago for a clothing manufacturer:
A pant hunter pantless
Goes panting for pants,
And pants for the best pants
That the pant market grants.
He panteth unpanted
Until he implants
Himself to a pair of
Plymouth Rock Pants! *

The craze hit the jackpot in the advertising of Sapolio with its "Spotless Town" jingles by J. K. Fraser. This mythical town with its quaint characters caught the country's fancy; people began to look forward to each new Sapolio ad, much as present-day fans eagerly await the next Bob Hope show for Pepsodent.

The trade character "Phoebe Snow" poetically described how clean her gown stayed when she took a trip on the Lackawanna Railroad"the Road of Anthracite." Retail stores, public utilities, hotels and steamship lines climbed on the band wagon until the advertising columns seethed with verse.

In the field of slogans, many were born but few were spoken. Some of the more pointed ones, however, have remained. "The Beer that made Milwaukee Famous," "Ivory Soap-It Floats" and "99 44/100 percent pure," "Burpee's Seeds Grow," "All the News that's Fit to Print" (N.Y. Times) and "The Prudential has the strength of Gibraltar," are all more than 50 years old. In the first days of the Eastman Kodak, people hesitated to buy because they had no facilities for finishing the negatives; the company offered to do all the developing and printing if the purchaser would merely send the camera to the factory. From this plan came the famous slogan, "You press the button-we do the rest," which was quickly adopted into everyday lingo.

* G. B. Hotchkiss, An Outline of Advertising (MacMillan, 1940). Cited by permission of the author.

** Presbrey, op. cit. 


\section{THIS FASCINATING ADVERTISING BUSINESS}

Thus advertising, despite its lack of adequate information, its technical limitations, its abusers and detractors, displayed amazing virility and ingenuity in those pioneering years of the modern era. Crude, blatant, haphazard it might be, but it got results. Many a forward step in trade and industry was taken with its adolescent guidance; many of the creature comforts and conveniences we accept now as a matter of course were sold to the public originally through those same crude methods. Advertising men of today may wonder how the oldtimers did it without the aid of scientific research, audited circulations, copy testing, four-color printing, radio networks and all the other accessories. But the fact remains that they did! 


\section{Chapter IV}

\section{ADVERTISING-THE ROAD BUILDER}

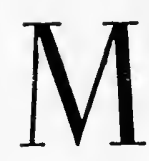

ORE than one after-dinner speaker has eloquently described advertising as a "trail blazer," the idea being that advertising has marked the route of progress for civilization to follow. The comparison is picturesque but misleading.

Few great inventions have been actually pioneered by advertising. Whitney, Fulton, Stephenson, Morse, Marconi, De Forest-to name some of the men whose devices have revolutionized modern lifemade little if any use of advertising to announce their discoveries. Edison, in his later years, became a sporadic advertiser but his expenditures in this field did not compare in size with those of General Electric, Westinghouse, Victor or other manufacturers utilizing his inventions. Alexander Graham Bell relied on personal demonstrations to popularize the telephone. While the automobile industry undoubtedly owes much of its universal acceptance to advertising, one of its outstanding figures, Henry Ford, was an in-and-outer during the years of greatest expansion; not until the 1920's did Ford become a consistent advertiser.

Inventors as a rule come from the ranks of scientists, mechanics, dreamers. They work with metals and chemicals rather than with people. Rarely have they had selling experience. They have a tendency to cling to the oft disproved statement generally accredited to Emerson (himself no salesman!) - "If a man will make a better mousetrap than his neighbor, even though he live in the depths of a wood, the world will beat a path to his door."

Fortunately for the world, if not always for the inventor, some promotional-minded individual becomes interested in every successful invention. The "better mousetrap" theory is ignored; a practical method of distribution is devised; advertising starts to function. Edison, for example, patented his phonograph in 1878 but did not put his own machine on the market for years. Meanwhile, Columbia and Victor had started operations on an aggressive scale. The Victor people with their appealing trade-mark of the dog listening to a phono- 
graph and the slogan, "His Master's Voice," took the leadership in the field.

By itself, advertising cannot do all of the missionary work on a new invention. There must be a period of trying out, of feeling the popular pulse, of determining the market, of establishing distribution. The finest advertisement in the world will be wasted if the prospective customer can't find a place to buy the product. The technical "bugs" must be removed from the product itself as well as from its manufacturing process.

This does not mean that advertising is unimportant in helping to introduce a new product. But its role is that of a road builder, not a trail blazer. The man with the hatchet, notching a tree now and then as he winds his way through virgin forest, may leave a trail that expert woodsmen can follow. Ordinary folks, however, won't bother to look for it. They prefer to stay on the well-traveled highway of their habitual buying habits.

What advertising must do in the case of a new product, or an improvement on an old product, is to build another highway that is even more attractive and easier to follow than the familiar one. There may be barriers of prejudice, indifference or custom blocking the way; advertising may be regarded as a sort of bulldozer capable of uprooting these objections. In an actual road-building job one such machine does the work of innumerable hand-wielded shovels. So, too, advertising performs its job on a mass scale, riding over or through handicaps that would defeat the best efforts of lone trail blazers.

\section{The Case of the Razor}

King C. Gillette invented a safety razor. There had been other safety razors before he put his product on the market. But Gillette made it easy for men to ask for his razor and his blades. This is an example of his early copy:

If you are still depending upon the barber or old-fashioned razor, you are in the same category as the man who climbs ten flights of stairs when there is an elevator in the building.... With the Gillette, the most inexperienced man can remove, without cut or scratch, in three to five minutes, any beard that ever grew. 
Today the Gillette people no longer have to sell men on using a safety razor in preference to a straight razor or a trip to the barber. Their competition is coming from the makers of other razors and blades. So we find them stressing, on the air and in the magazines, a highly competitive theme: "Look sharp, feel sharp, be sharp! Use Gillette Blue Blades, with the sharpest edges ever honed."

About 1930 another type of product stepped into the whiskerremoving field-the machine shaver. Electric shaving as represented by Schick, Remington, Sunbeam and others is still in the pioneering era to the extent that the basic idea remains to be sold to a large part of the market; at the same time it is a hotly contested field in itself. The dual selling job of electric shavers is evident in this text from a 1941 Schick ad:

Get ready, gentlemen, to change your shaving habits for the better! For whether you use a blade razor or an electric shaver, here's the whisker-whipping whizzer you're going to come to sooner or later-so why delay?

Made by Schick--which tells a lot in itself, since Schick started the whole electric shaver business.

Made for you-with the sure-fire, quick-and-easy, slick-and-nickless workability you've waited for in an electric shaver.

Above all-made to give close shaves-30 percent quicker, easier, better because of Schick's new exclusive Hollow-Ground 2-M Head.

Then follows a description of the new features, an urge to try the new shaver, and a money-back offer, "if you're not getting the best shaves ever" after a 30-day trial.

Remington Rand, on the other hand, has employed advertising aimed primarily at the man already converted to electric shaving, by featuring a "multiple-head" electric shaver. A 1946 Saturday Evening Post page declared: "Years ago Remington Rand stopped making single-head shavers-just as automobile manufacturers gave up the single-cylinder car." The only direct reference to razor shaving is a small caption at the bottom of the ad: "Shave Dry-No Lather-No Blades."

More recently, new shavers have come on the market with still another principle, a mechanically operated shaving head. The makers of this type of shaver are starting a pioneering job all their own.

What is the result of this continual pioneering of new products, 
their popularization, the rise of competing products and methods, the apparently endless war of claims and counterclaims, the emphasis on "revolutionary," "sensational," "history-making" improvements? Critics of advertising declare that such competitive cycles are wasteful, leading to overexpansion of production facilities, overspending on promotional efforts, overbuying by the public. But none can deny that such competition has stimulated manufacturers to make frequent improvements in their products or that, broadly speaking, articles of the latest design cost the consumer no more. In fact previous to World War II the price trend was steadily downward.

To the inventor, the advantages of his brain child seem so obvious that he can't understand why everybody does not immediately rush out and buy it. The manufacturer or merchandiser likewise is filled with enthusiasm for the new product. He talks, eats, sleeps, dreams of nothing else. Mr. and Mrs. Smithers, on the other hand, have been doing very nicely all these years without it: why should they suddenly change? A factual, unemotional news item about the new product may arouse momentary interest but it alone has no power to upset deeply grooved buying habits.

At this writing, such varied items as electric blankets, home air conditioners, private airplanes, anhydrous foods and television receivers are struggling for a wider share of the consumer's income. All of them have ceased to be "hot" enough to command newspaper headlines. They have their devotees; they are also confronted by millions of potential buyers who view them, if not with skepticism, then with indifference.

Virtually every manufactured article in universal use today stood at that same point once upon a time.

For most of them, advertising built the road over which buyers now travel so naturally, so habitually, that it is hard to realize they ever did anything else.

The first big job of advertising, then, corresponds to that of the bulldozer-and it is a job that must be done by the first company in the field. So while the inventor or pioneer firm enjoys a certain initial momentum, all is not peaches and cream. The educational work costs money, particularly in view of the fact that so much of it has to be concentrated on selling the general merits of a type of article rather than a specific brand. Later arrivals get a "free ride" on the missionary work of the pioneer; they enter a market already partly converted 
to that kind of product and can devote their energies to competitive selling. It is up to the pioneer to intrench himself so firmly before imitators appear and to keep steadily improving his product and maintaining his public leadership to such an extent that the Johnnycome-latelies will never be able to catch up.

Hence the advertising bulldozer cannot be retired after the road has been built. There will be competitive landslides across the road; "dips" will develop in the demand as the easy-to-sell customers are used up; weeds and saplings of public indifference will grow up through the cracks of neglected markets. Advertising must be kept ever at work if the road to the product is to remain smooth, clear, more inviting than that of a competitor's.

The history of advertising yields many examples of firms that won quick success through pioneering methods and then allowed their advertising bulldozer to rust while other, more attractive roads were being built. And on the positive side, every industrial pioneer who retains his position today has done so because of continued progress both in his products and in his merchandising methods.

\section{Breakfast Table Autocrats}

One of America's greatest industries got its start when Dr. J. $\mathrm{H}$. Kellogg became superintendent of the Battle Creek Sanitarium in 1876. As a young intern he had seen a doctor toast rye bread and grind it into crumbs for patients on a cereal diet. At Battle Creek Dr. Kellogg experimented with precooked cereals. With his brother W. K. Kellogg, he brought toasted corn flakes onto the market. Aggressively advertised, they established themselves on millions of breakfast tables. To this day Kellogg is one of the leading national advertisers.

A traveling salesman, Charles W. Post, went to Battle Creek to be treated in 1895. Impressed with Dr. Kellogg's methods, he remained there, developing ready-prepared cereals of his own-Grape-Nuts, made from wheat and malted barley, and a kind of corn flakes whose odd brand name reflected his deeply religious leanings, "Elijah's Manna." Later this was changed to Post Toasties. Post also produced Postum, a cereal drink to replace coffee, of which he disapproved. By 1899 , Post was spending $\$ 400,000$ a year for advertising. 
The Post products are now a part of General Foods, but there has been no interruption in their advertising for half a century.*

Shredded Wheat, the invention of Henry D. Perkey, a lawyer, appeared about the same time. Starting with house-to-house peddling and demonstrations in stores, it grew to have what was said to be the widest distribution of any breakfast food in the world when the company was acquired by National Biscuit in 1930.

General Mills, formerly the Washburn-Crosby Company of Minneapolis, was a late entrant in the cereal derby but by spectacular advertising, with radio programs for children as the pacemaker, has put its Wheaties, Cheerios and Kix among the leaders. Quaker Puffed Wheat and Puffed Rice, and Shredded Ralston are other cold cereals that have employed hot radio serials to send their sales curves upward.

By 1903, when the breakfast-food industry was far from its present size, Paul Latzke was able to write in The Saturday Evening Post:

Practically the entire country has felt the stimulus which had its origin here [in breakfast-food advertising]. The farmers throughout the grain-growing belt have enormously benefited, and naturally, for where one person used a breakfast food a few years ago there are now a hundred. Such an era of grain-eating has never been seen in the world. ... The railroads have benefited and the paper-making industry has fairly jumped. ... From cereals it [advertising] has spread to every other line of foodstuffs.

And this has been done without increasing the cost to the consumer or reducing the profits of the manufacturer. On the contrary, it has been the general experience that the retail prices of standard goods have been decreased on the whole, [and] that the quality has been elevated.**

More recently George Sokolsky, in an article in Liberty Magazine reprinted in his book, The American Way of Life, had this to say on the subject:

Those who dislike advertising and cereals say that it is unfair to make a cereal popular by making such a character as Sunny Jim or Jack Armstrong popular. What these people never understand is that

* George E. Sokolsky, The American Way of Life (Farrar \& Rinehart, 1938). Cited by permission of the author.

** Quoted from The Saturday Evening Post by George Sokọlsky in The American Way of Life. 
we like to be told facts pleasantly. It is more interesting to us to learn to use wheat flakes through Sunny Jim than because some unimaginative government bureau says that children will drink more milk if they eat more cereals and that the two in combination are splendid for them. When I was a child, Sunny Jim caught my eye; my boy swears by Dick Tracy-and eats his breakfast!*

The cereal companies are also credited by Printers' Ink** with having given the chief impetus to the general adoption of packaged merchandise. In the '70's the box, barrel and bin were the common grocery-store containers. Then Kellogg, Post and other breakfastfood makers began to vie with each other in putting out attractive packages. By 1900 packaged brands were seen in such varied lines as molasses, flour, cheese, baking soda and dozens of other items formerly sold only in bulk. Even staples such as salt and sugar started appearing in printed cloth bags.

The National Biscuit Company with its "In-er-seal" package for Uneeda Biscuits helped the cause along. As dispensed from the oldtime cracker barrel, soda crackers were anything but the crisp, tasty, sanitary food of today. Uneeda had an inner wax-paper wrap, a cardboard box and an outer wrap to protect the contents, with a distinctive color scheme. Incidentally, one stunt that speeded the wide acceptance of the Uneeda package was advertising it as a handy box in which the schoolchild's lunch could be carried!

Modern self-service merchandising, which led to the rise of the supermarkets and is now the vogue in a large majority of food stores, is the direct result of the trend toward clean, attractive, selling packages launched by breakfast food.

\section{“Them Newfangled Things"}

Most articles now in common use had some sort of acceptance before the modern era of advertising. The automobile has been associated with advertising since its very birth.

The story of the automobile outdazzles anything in pure fiction. It was a crackpot's dream in 1895, when in all America there were just four cars. Two years later, the number of registrations had risen

* Op. cit.

** Printers' Ink, 50th Anniversary Edition, July 28, 1938. Cited by permission of Printers' Ink. 
to 900 , virtually all on cars of foreign make. The year 1900 saw ownership reach 8,000 , with an annual output of 5,000. A decade afterward, the industry was turning out 181,000 cars a year; that was doubled in 1912 , and nearly doubled again by 1914. Increase followed increase until by 1929 passenger-car production reached $4,794,898$. The depression of the '30's slowed production down, but the industry was over the 5,000,000 mark just before World War II.

In terms of capital invested, employment and payrolls, the automobile industry is a major factor in our national economy. Its effect reaches into every other field, for it is a main consumer of steel, glass, paint, rubber, machine tools, and electrical parts, not to mention oil. Max Ball* is authority for the statement that automotive vehicles in 1940 used 89 percent of all the gasoline consumed in the United States; of this, one-fourth went into trucks and busses, three-fourths into passenger cars. At that time there were 377,000 gasoline retailers, including 197,000 filling stations. Buckley-Dement's most recent mailing-list catalogue reports 137,013 garages, auto dealers, accessory and repair shops. Factories producing tires, batteries and other parts constitute another big element in the business picture. The automobile is almost solely responsible for the 2,200,000 miles of surfaced roads in this country. It has revolutionized real-estate values, retail merchandising, rural education. It was even, some fashion authorities say, the chief cause of the short skirt!

Advertising was by no means the only reason for the overpowering success of the automobile; brilliant, daring engineering advances, miraculous feats of production, sales programs that functioned with military precision, the unlimited backing of investors which permitted this breathless expansion—all had a part. But advertising was equally important. The first sale of an American-built car is said to have been made by Winton in 1898 as the result of a one-inch ad in Scientific American.

In that year the bicycle craze had reached its peak. There were over 100 bicycle manufacturers, and some 200,000 machines, each costing $\$ 100$ to $\$ 150$, were sold in 1898 . Thirteen magazines were devoted entirely to cycling. A special issue of the American Wheelman ran to 308 pages, one of the largest magazines ever issued up to that time. Advertising was liberal, even lavish. In 1899 the "bicycle trust"

* Max W. Ball, This Fascinating Oil Business (The Bobbs-Merrill Company, 1940). Cited by permission of the publisher. 
was formed, one of its objects being to "consolidate the advertising interests of its members." This it did by abandoning advertising almost wholly. By 1900 the fad for cycling had faded even more swiftly than it had risen and two years thence the American Bicycle Company had gone broke.

Meanwhile, the bicycle makers had proved the value of large advertising appropriations and the unwisdom of depending only on free publicity. At the height of the craze, newspapers had devoted many news columns to cycling but when the public lost interest so did the press. The automotive industry has never fallen into this trap. Despite the huge quantities of free space it has received, the industry continues to tell its own story through advertising.

Bicycle plants by the score were converted to making autos. Winton, Olds, and Pope led the parade. In 1900 there were 57 automobile factories; this number had increased to 136 in 1905. Most of these companies made only a few cars and then died, but the names of some of the "orphans" still bring back nostalgic memories to oldtimers-names like Locomobile, Aerocar, Winton, Haynes, Franklin.

Pioneer automobile advertising was designed to inspire confidence, and for that reason much emphasis was laid on performance. Famous drivers like Barney Oldfield were hired to put cars through severe tests to supply ad copy. As cars became more reliable, emphasis was switched to utility. About this time, car manufacturers took up the plan that had worked so well in the bicycle field ten years before and started bringing out "yearly models" with a great fanfare at the Auto Shows, heavily supported by advertising. Millions of people paid their way into these shows and fought for the privilege of being first to own a new model.

Failures as well as successes have marked the history of automobile advertising during the half century. Of the 3,000 and more makes of cars that have passed into limbo, many were strongly advertised: Hupmobile, Auburn, Durant, Pierce-Arrow, Chandler are names that occur offhand. But the saddest of all to advertising men in general and copy writers in particular was Jordan.

By many people, Edward S. Jordan is ranked among the all-time masters of advertising copy. Even today the pieces he wrote for his ill-fated car fairly seem to sing. In an article in Advertising Fortnightly for September 26, 1923, he gave what he considered the essentials of successful copy. First, he wrote, it must promise satisfaction of the 
universal longing for companionship; then it must appeal to the reader's interest in the other sex; finally, it must have rhythm or swing, with dramatic phrases to linger in the memory. Whether his formula is adaptable to all products is highly questionable, but it certainly worked for Jordan Motor Car ads, making them much read and long remembered. His most famous advertisement for the Jordan Playboy ripples and sparkles like a mountain brook, from the lilting headline, "Somewhere West of Laramie," to the pay-off sentence, "The truth is-the Playboy was built for her."

If advertising alone could have done it, Jordan would still be making autos.

On the credit side of the ledger, automotive advertising has many accomplishments. The distinctive prestige-building copy of Theodore F. MacManus for Cadillac made it a leader in the fine-car field during the second decade of the century, a position it has never relinquished; one of his advertisements in particular, "The Penalty of Leadership," remains in the copy writers' hall of fame.

When Walter P. Chrysler stepped in as head of what had formerly been the Maxwell-Chalmers companies, his advent was staged with a gigantic teaser campaign that had the public agog. Engineering-wise, the new Chrysler fully measured up to its advance billing, dynamically affecting the whole industry. Then in the early 1930's at the depth of the depression he challenged Ford and General Motors in the lowpriced field. Again advertising supplied the spark. Sterling Getchell, an authentic genius among admen, came up with the audacious and irresistible theme: "Look at All Three!"

For sheer restraint, nothing has quite topped the old Dodge Brothers campaign on the billboards and in the magazines, created by George Harrison Phelps back in 1921. An ad or a poster would consist of a single word or phrase, centered in a sea of white space, or on a poster, white against a blue background, with the name Dodge Brothers in the corner. One time it would be "Dependable," another time "A Good Name," another "Low Operating Cost." That series is still recalled when others far more pretentious and eloquent have been forgotten.

"Body by Fisher" was another advertising tour de force of the twenties. The advertisements were remarkable in that they never showed an automobile, merely a painting of a beautiful girl by McClelland Barclay, with brief copy and the Fisher Body trade-mark. 
In recent years Fisher has concentrated on contests among highschool students, with awards of college scholarships for the best replicas of the medieval coach in the trade-mark.

At the start of this chapter mention was made of Henry Ford's spasmodic use of advertising. During the period of his company's greatest growth very little national advertising was put behind the Ford, although its dealers invested important amounts locally. Ford's refusal to modernize in line with the times gave Chevrolet its opportunity to capture first place after World War I. In 1927 rumors of a new Ford gathered headway. Newspapers sent reporters to Detroit, but no advance details were given out. At the Ayer agency in Philadelphia, where ads were being prepared, and at the Donnelley printing plant in Chicago, where literature was in work, the utmost secrecy prevailed. Then in late summer the campaign broke. Within five days, $\$ 1,500,000$ had been spent in newspaper advertising by Henry Ford, the man who "didn't believe in advertising." Inside of a few months, over 800,000 of the new cars had been bought and Ford was back in the thick of the fight.

Postwar automotive plans are thus far only beginning to be put in action. Studebaker got the jump with a wide-vision car whose rear end looked enough like its front end to inspire endless radio wisecracks. Kaiser and Frazer are making a valiant effort to capture public fancy. A new car with some radical features-the Tucker-has been announced. To date the other companies have offered only slight changes from their prewar models, but one may be sure that exciting new developments will appear when the present backlog of demand has slackened. For that has been the unvarying policy of the industry since its diaper days.

Which comes first-the development of something new and different by the research engineers, or the call for something new by the sales and advertising end of a business? It doesn't especially matter. The result, year after year, has been a steady stream of improvements: electric lights, self-starter, cord tires, four-wheel brakes, high-compression engine, safety glass, sealed-beam headlights, and the automatic gear shift. Today's $\$ 1,200$ car is miles ahead of the $\$ 5,000$ car of 25 years ago in every respect.

Lest the engineers and production men get too cocky, however, what Alfred P. Sloan, Jr., chairman of General Motors, said 20 years ago may be remembered: "Advertising has reduced the cost of many 


\section{THIS FASCINATING ADVERTISING BUSINESS}

articles, such as automobiles, as no other business force could." And it is the reduced cost of these articles that has been the basis of their sustained and increasing popularity.

Advertising has built broad highways of buying habit over which the public travels straight to the products-better products than Grandpa ever dreamed of, for less money than we should have to pay if advertising were not on the job. 


\section{Chapter V}

\section{WHO'S RIGHT ABOUT ADVERTISING?}

MAN bought a fine, handsome, shiny new hammer at a hardware
store. He took it home and started to drive a nail into the wall
to hang up a picture. The hammer slipped off the nailhead and smashed his thumb.

"Yeow! Blink th' blankety-blank censored hammer!" howled the man. "Ditto for the guy who sold it to me and the manufacturer who made the blank-of-a-blank contraption! Yee-ow!"

His wife came in, fresh from a club meeting where a very learned professor had delivered a lecture on the evils of advertising.

"Oh, Flotsam, your poor thumb!" She picked up the hammer, saw the trade-mark of a well-known manufacturer and snorted. "Hmph! Just as I thought! It's all the fault of advertising!"

No phase of human activity is above criticism. Americans take pride in exercising their constitutional right to dislike or disparage anything they please. Advertising offers a broad target. By its very nature and of necessity, it is the most conspicuous object on the landscape. And it is extremely vulnerable to attack, both for its past sinswhich were enormous-and for its present errors of omission and commission. But to condemn all advertising and demand its complete abolition or rigid federal control because of its abuses, its misuses and its shortcomings is like denouncing the whole system of education or the institution of the family because neither has produced ideal results.

Supersensitive advertising men resent any criticism of their craft. But the more fair-minded realize that honest criticism, whether justified or not, is an antidote to smugness, a stimulant to frank self-examination, a spur to progress.

Assaults on advertising are nothing new. They were common 200 years ago and astonishingly similar in tone to those of today. Advertising, said Dr. Samuel Johnson, forces or seduces men into buying things they do not need; promises results it does not deliver; need- 
lessly raises the cost of goods; seeks to influence the press in its favor. In short, though the old master of invective probably never heard the phrase, he clearly believed that advertising is "an economic parasite."

Turning to the present, Fulton Oursler, former editor of Liberty and now a senior editor of Reader's Digest, tells the following story:

My little daughter had come home from the village school and after her first helping of dessert turned to me with great big eyes and she said, "Daddy, why do you have advertisements in Liberty? The things they say are not true. I don't believe a word of any one of them. They say what isn't so and try to make you buy what they want to sell, and if we didn't have any advertising things would be better and cheaper."

I looked at April as if she were some other family's child, but there she was, my own eleven-year-old daughter placidly peeling her orange and not seeming to be aware of the sensation she had created. I waited a few moments before I ventured to try my voice. I said, "Did you come to this all by yourself?"

"No, daddy, I learned it at school today. The teacher taught us that advertising was not truthful."*

Unfortunately for advertising, many school teachers hold similar views and have no hesitation about passing them along to their pupils, making little or no effort to learn the facts. Until recently business men have paid scant attention to what was being taught in the public schools with regard to the American free enterprise system; its detractors have all too often had a free hand in spreading their adverse propaganda.

As a result, we have the paradoxical condition of various groups in America attacking one of the foundation stones of the system from which they derive their living and from which they hope to obtain ever greater advantages. Teachers in one breath demand more payto which, this writer feels, they are fully entitled-and in the next breath utter sweeping condemnations of the entire business order which alone can make such increases possible. Labor unions and farmers, among the chief beneficiaries of our mass-production economy, have, with the school teachers, been among the leaders in backing co-operative buying organizations which aim at undermining the structure upon which national prosperity is based.

* George E. Sokolsky, The American Way of Life (Farrar and Rinehart, 1938). Quoted by permission of the author. 


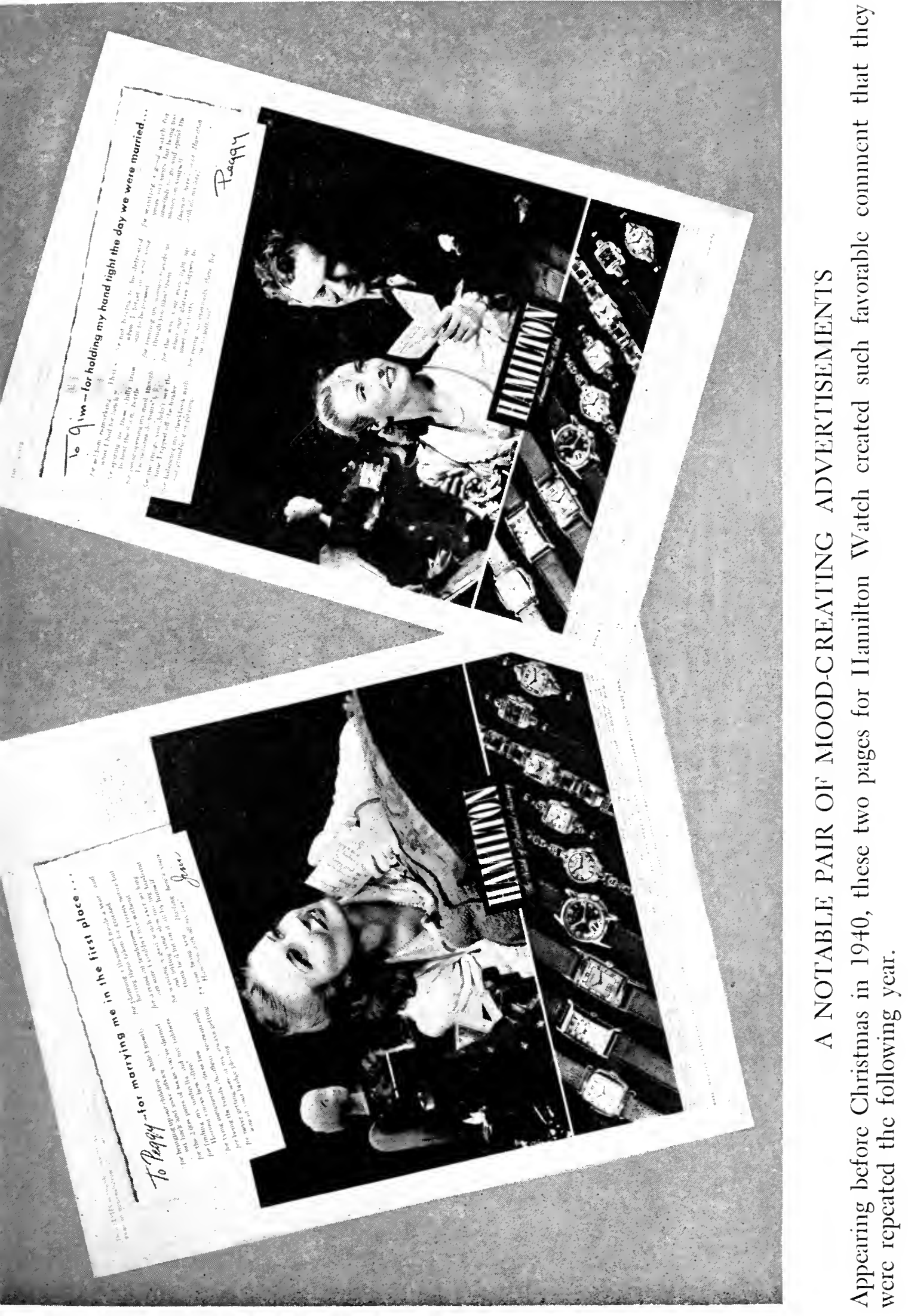


Are all businessmen crooks, cheats, money-grubbers whose word is not to be trusted? That is what is implied by the school teacher who says advertising is not truthful. How about it?

\section{Advertising Fights for the Truth}

Long ago, advertisers started to recognize that their greatest single hurdle was dishonest advertising. Whether called misleading, deceptive or downright lying, the ad that does not live up to its promises hurts each individual advertisement and advertising in general.

The members of the advertising fraternity have said far harsher things about the misuse and abuse of their means of livelihood than any public reformer. Over the past 100 years there has been a neverending struggle to clean up advertising - to make it impossible for the phonies, the sharpshooters, the twisters, the get-rich-quick artists, to defraud people.

As far back as 1860 Orange Judd, publisher of the American Agriculturist, announced that he would accept advertisements "only from parties who have a business character to sustain" and that false or misleading copy. would be excluded. In 1880 Farm Journal declared that it would guarantee the reliability of its advertisers. Cyrus H. K. Curtis was one of the first publishers in the women's field to ban objectionable advertising from his magazine, the Ladies' Home Journal.

In 1906 Good Housekeeping established an "institute" for investigating the dependability of its advertised products. Dr. Harvey W. Wiley, chief chemist of the U.S. Department of Agriculture and father of the potent Pure Food and Drugs Act, left federal service to head the Good Housekeeping Institute. Forty years later advertisers are still proud to display "The Good Housekeeping Seal of Approval" on their products and in their advertising.

Responsibility of the publisher for the truth of advertisements he accepts is not today always enforceable by law, but no reputable medium now seeks to pass the buck. Any reader, or radio listener, who feels that he has been defrauded has only to notify the periodical or radio station and the fireworks will start immediately.

This same acceptance of obligation extends to advertising agencies, to all national advertisers and to all local advertisers who are members of clubs affiliated with the Advertising Federation of America.

It has not been an easy victory, and the war is by no means over. 
Human nature is so constituted that a certain percentage will always seek the easy way to profits. But the fight goes on. Through the National Better Business Bureaus and the local chapters in each large city-through all legitimate associations of advertising peoplethrough the advertising offices of every honestly conducted mediuma constant battle is being fought against those who try to use advertising for dishonest or misleading purposes.

Not so very long ago a firm could advertise "a complete sewing machine for 25 cents" and send a needle and thread, or "a steel en. graving of George Washington for \$1.00" and send a one-cent stamp. Just within the current year, sharpers managed to slip classified advertisements past the eagle eyes of several papers with the wording: "Hurry! Last chance to send one dollar to Box___," and got thousands of dollar bills from the gullible folks who never stopped to ask why they should mail a dollar to that address!

One cannot condemn all advertising for a few such isolated instances. Nonetheless, all advertising suffers. This fact has led to ever louder demands for action. At the 1911 convention of the Associated Advertising Clubs of the World, now the Advertising Federation of America, under the leadership of Samuel C. Dobbs, the admen voluntarily adopted "Truth" as their slogan.

The same year Printers' Ink, the advertising weekly founded 23 years before by George R. Rowell and then headed by John Irving Romer, engaged a New York attorney to investigate the existing laws on fraudulent representations and to draw up a model state law punishing all misleading advertising. This "Printers' Ink Model Statute" is now in effect in one form or another in virtually every state, and 25 states have adopted it verbatim. It is worth repeating here:

Any person, firm, corporation or association who, with intent to sell or in any wise dispose of merchandise, securities, service, or anything offered by such person, firm, corporation or association, directly or indirectly, to the public for sale or distribution, or with intent to increase the consumption thereof, or to induce the public in any manner to enter into any obligation relating thereto, or to acquire title thereto, or an interest therein, makes, publishes, disseminates, circulates or places before the public, or causes, directly or indirectly, to be made, published, disseminated, circulated, or placed before the public, in this state, in a newspaper or other publication, or in the form of a book, notice, handbill, poster, bill, circular, pamphlet, or letter, or in 
any other way, an advertisement of any sort regarding merchandise, securities, service, or anything so offered to the public, which advertisement contains any assertion, representation or statement of fact which is untrue, deceptive or misleading, shall be guilty of a misdemeanor.

In 1911 New York and Massachusetts were the only states with laws against fake advertising. These laws were inadequate. This "model statute" was bombproof. Note that though radio was not even a gleam in Philco's eye at that time, the medium is covered like a tent-as are sky-writing, television, neon signs and other post-1911 media.

The whole absorbing story of how this statute was coaxed and bullied through state legislatures-of the great work of William $\mathrm{H}$. Ingersoll of "dollar watch" fame, Herbert S. Houston, Merle Sidener, O. C. Harn, Phil Thomson, Harry Robbins, Mac Martin, C. P. Barnum (no kin) and many others-is told in H. J. Kenner's absorbing book, The Fight for Truth in Advertising, published in 1936, silver anniversary of the real Bunker Hill in the war against bunk.

Due acknowledgment should be given to Samuel Hopkins Adams for his forthright articles in magazines exposing frauds, quackeries and "dubious traffic," and to Joseph H. Appel, Philadelphia merchant carrying on the great traditions of John Wanamaker. Possibly the tribute paid to Merle Sidener of Indianapolis, who headed the "vigilance committee" for several years, is typical of these and numerous other admen who fought the chiselers and crooks of their day:

A straight-speaking, true-thinking, incorruptible fighter ... he is bent on destroying the "graft" of the last [sic] of the easy-money men. Also he desires to educate honest merchants and manufacturers who are too enthusiastic, who are afflicted with over-statement in advertising. *

The remainder of Mr. Kenner's book, unfortunately now out of print but still available at public libraries, is devoted to such revealing subjects as "Blocking the Blue-Sky Promoters," "Fighting Fraud by Education," "Protecting the Merchandise Consumer" and "Correct-

* H. J. Kenner, The Fight for Truth in Advertising. Reprinted by permission of Elbert Hubbard. Quoted by H. J. Kenner of the Better Business Bureau of New York. 
ing Unfair Price Advertising," all of which indicate but sketchily the very real and difficult problems that confronted-and still confrontadvertising's vigilantes.

Governmental regulation is not a cure. The Federal Trade Commission, even armed with punitive powers, can act only against advertising that has already appeared, and its docket is so loaded that several months may elapse before it can review the evidence and issue a cease and desist order. Meanwhile the damage may have been done. Self-policing by legitimate business, of the very kind that started in 1911, is the most effective means of safeguarding the buyer and thereby preserving advertising's good name. It is a thankless task. Mr. and Mrs. John J. Everyman will never appreciate the efforts made in their behalf. But it is the only way to protect advertising's good name.

Here is a quotation taken from a college textbook on economics. It presents the viewpoint of a detached observer:

Business organizations and government agencies make some effort to protect the consumer (and honest business enterprises) against dishonest trade practices. The Better Business Bureaus, which are supported by private firms, and the Federal Trade Commission, do the most important work in supervising the selling methods of business.*

Business-honest business-is the front line of defense against fraud, trickery, tongue-in-cheek advertising. Thirty years ago Elbert Hubbard wrote about destroying the "graft of the last of the easymoney men." We know that was merely wishful thinking. There will always be easy-money men to attempt to pervert the sharp-edged tool of advertising to their own sly uses. Legitimate advertisers, representatives of media, all to whom advertising means honest work and honest results, can never go to sleep. The price of public confidence in advertising is constant wakefulness on the part of the advertising man.

\section{Does Advertising Raise Prices?}

Professor Neil H. Borden of the Graduate School of Business Administration at Harvard has made one of the most comprehensive

* Clifford L. James, Outlines of the Principles of Economics (Barnes \& Noble, 1941). Quoted by permission of the publisher. 
studies of the relation between advertising and prices. His findings are published in a very large book, The Economic Effects of Advertising. For the average reader there is a condensed version called Advertising in Our Economy.

After pointing out that prices are affected by many factors, Professor Borden declares that "it is difficult to decide when advertising costs for differentiated merchandise or the net profits taken by sellers, both of which enter into price, shall be considered unduly large."*

He then presents two basic considerations to be kept in mind in judging whether or not prices are too high:

First, the consumer should have a freedom of choice throughout a wide range of merchandise. . . .

Second, there should be adequate checks in the economic system to prevent advertising and aggressive selling costs from becoming unduly large. . . . It is desirable socially that consumers have among their choices adequate opportunity to buy merchandise on a price basis, without cost of product differentiation (such as special features), services, and other nonprice competitive forms adding substantially to what they must pay.**

Various products were studied by Professor Borden. In each case he found that while prices of advertised lines were sometimes higher than nonadvertised items in the same field, competition has operated to keep this spread from becoming excessive. And the more advertisers there are in a field, the less price advantage will any one firm have, as in the case of mechanical refrigerators.

In drugs and cosmetics he found "some of the most extreme effects of advertising in increasing prices."** The explanation lies in the fact that the individual seeking satisfaction is willing to pay considerably more for a product that gives "even slight promise of greater efficacy," he decided.

Among dentifrices, an investigation in 1941 reported by Professor Borden revealed prices ranging from 3.6 cents per ounce for CraigMartin tooth paste, to 18.5 cents per ounce for Kolynos, with the leading brands commonly selling at 11 cents per ounce or above. Private brands were offered by chain drugstores, variety chains and

* Neil H. Borden, Advertising in Our Economy (Richard D. Irwin, Inc., 1945), p. 174. Quoted by permission of the publisher.

** Ibid., p. 175.

*** Ibid., p. 180 . 
department stores at prices from 4 to 10 cents less per tube than leading manufacturers' brands. In some cases the private-label tooth paste was outselling the nationally advertised brand by a wide margin; in others, the reverse was true."*

Across the country it is interesting to note that advertised tooth pastes maintain relatively the same leadership. For example, here are figures from recent consumer preference analyses issued by three newspapers for their respective cities.

\begin{tabular}{|c|c|c|c|c|c|}
\hline Colgate's & & $\begin{array}{c}\text { Average } \\
\text { of } 3 \text { Cities } \\
27.8 \%\end{array}$ & $\begin{array}{c}\text { Milwaukee } \\
\text { Journal } \\
29.2 \%\end{array}$ & $\begin{array}{c}\text { Indianapoli } \\
\text { Star } \\
23.5 \%\end{array}$ & $\begin{array}{c}\text { is Omaha } \\
\text { World-Herald } \\
30.7 \%\end{array}$ \\
\hline epsodent & & 27.7 & 25.4 & 29.3 & 28.5 \\
\hline & & 17.7 & 13.8 & 23.5 & 15.8 \\
\hline Listerine . & & 6.4 & 7.4 & 3.8 & 8.1 \\
\hline Kolynos . & & 3.1 & 3.7 & 1.7 & 4.0 \\
\hline bb's . & & 3.0 & 3.3 & 2. & 3 \\
\hline 'hillips' . & & 2.5 & 4.0 & 2.0 & 1.6 \\
\hline han's & & 2.4 & 2. & 3. & 1 . \\
\hline & & 1.8 & 1.7 & 2.2 & 1.5 \\
\hline raig-Martin & & 1.7 & 3.4 & 1.2 & (Under $1 \%$ ) \\
\hline
\end{tabular}

These figures are based only on families buying some kind of tooth paste. In Milwaukee this took in 69.3 percent of the families surveyed; in Omaha, 76.3 percent; in Indianapolis, 76.9 percent. No private-label brand appears among these ten leaders, although Avon, a brand sold house to house; had a 1.9 percent preference in Omaha and 1.6 percent in Indianapolis. However, the nonmention of unadvertised tooth paste may be due to the fact that those answering the surveys, which included all income brackets, may not have been able to remember the names, or because of a possible desire to avoid appearance of cheapness. Generally speaking these figures must be considered an accurate cross section of consumer buying habits. They bear out the theory that people are willing to pay more where considerations of health or good looks are involved, though the extra benefit of the higher-priced article is not provable.

Price reductions are sometimes used by manufacturers of nationally advertised articles, as was done by the cigarette makers in the depression when 10-cent brands began cutting seriously into the sale of

*Tbid., pp. 207-9. 
standard 15-cent leaders. Camel, Lucky Strike, Chesterfield and other popular brands were reduced until they sold for as little as 9 to 11 cents, with two packs for 25 cents the general price. The period of rising costs for labor and materials at the end of World War II sent cigarette prices up to as much as 21 cents per pack or more. Neither the decrease nor the increase was the result of advertising.

"Fair trading" of advertised items is permissible in states having a fair-trade law. The manufacturer stipulates the retail prices of his goods and the dealer enters into an agreement to abide by these prices. The purpose is to prevent using nationally known items as "loss leaders" - that is, goods sold at a loss in order to attract trade. Fair trading is a protection to the small independent store owner in his struggle for existence. It may result in some consumers having to pay more for a fair-traded brand than they might have, if the line did not use this device. But they are spared the necessity of "shopping around" because the price is the same wherever the brand is sold. The customer who does not wish to pay the established price always has the privilege of switching to a lower-priced commodity; when an appreciable number of people do this the manufacturer must perforce adjust his prices downward or go out of business.

Some advertising men feel that their part of the sales function has been overemphasized in considering prices. It used to be generally accepted that advertising made mass production possible, thereby lowering manufacturing costs and hence the price to the consumer. Then critics of advertising came along with the theory that the money spent in promotional efforts raised, rather than lowered, prices, since it had to be added to the cost.

A sensible middle-of-the-road view may be the answer. Whether mass production exists because of advertising or vice versa, the two generally work together to bring about lower prices-or better products for the same prices. In some instances high-pressure selling and advertising enable the manufacturer and dealer to get more for products than the consumer needs to pay to obtain equivalent goods. The promotional background may add a prestige or psychological value which causes the purchaser to feel he is getting his money's worth. On the other hand, the advertiser may be guilty of taking advantage of public ignorance, superstition or credulity to put a fictitious value on his goods or services. Such a condition renders the overpricing producer vulnerable to competition from honestly priced, honestly 
advertised articles; advertising, which may have helped the first business to overcharge, is even more effective as an aid in remedying this inequity.

The whole question of the effect of advertising on prices became academic with the universal and alarming rise in living costs following World War II. Not even the harshest critic of advertising could say that it was to blame for these higher prices!

\section{The Immunity of Industrial Advertising}

Nearly all attacks on advertising, it is-interesting to note, have been aimed at that branch having to do with the promotion of consumer goods; more specifically, the advertising in general magazines, newspapers and radio programs.

Seldom is adverse comment directed toward one of the essential parts of any national campaign-the dealer element. Yet without adequate distribution and retail support few consumer campaigns could succeed.

Nor do the critics mention the equally important advertising devoted to industrial and technical products, raw and processed materials used in manufacturing. It may lack some of the glamour of cosmetic or hosiery copy, but it represents an annual investment running into hundreds of millions. No one has seriously questioned its efficiency and value. And if advertising is good for the manufacturer of machine tools or industrial chemicals, why shouldn't it be good for the maker of furniture or radios or baby foods?

To sum up, sweeping condemnation of all advertising because of some instances of its misuse or abuse is as unsound as blanket praise. Advertising has a long way to go to reach perfection, but it has come a long way. It has earned the right of recognition as a significant force for better living. 


\section{Chapter VI \\ THE STORY OF THE BRANDS}

${ }^{\mathrm{T}} \mathrm{THE}$ very core of national consumer advertising is the brand name. With the exception of a few campaigns designed to sell a whole industry-for example, the American Meat Institute or the Air Transport Association-and those developed by the Advertising Council for social-service projects, nearly all general magazine, network radio, outdoor, and manufacturers' newspaper advertising is devoted to brands.

What is a "brand"? Originally it was a mark with a hot iron on a barrel to identify the maker. Out West it denotes ownership of an animal. In the days of the guilds, each shop was required to place on its products an identifying mark so that the maker could be held responsible in case of faulty workmanship.

Many brand names widely recognized today originated decades ago. Through consistently maintained quality they have become an integral part of our daily existence. Sometimes the brand is the name of an individual-Stetson, Kuppenheimer, Clapp, Campbell, Swift; sometimes it is a coined word-Pepsodent, Spam, Pyrex, Perma-Lift; sometimes it is descriptive-Eversharp, Ivory, Arch-Aid, Swansdown; sometimes, imaginative-Big Ben, Palm Beach, Mum, Sunkist. The origin is not nearly so important as the connotation in the public mind.

Innumerable statements have been written about brand names. One of the most widely quoted was first published in the form of an advertisement by Gair's, a men's apparel store in Redlands, California, in the Redlands Daily Facts of April 24, 1935, and since reprinted many times:

\section{"WHO MADE IT?"}

\section{You Have a Right to Ask This Question}

Would you buy a car if the maker was ashamed to put his name on it? The answer, if we know the American public, is NO! 
Whether it is an automobile or a suit of clothes, you have the right to ask this question before buying: "WHO MADE IT?" Just as an artist who has pictured his inspiration on canvas is proud to put his name on his work, so too do standard quality manufacturers, having pride in their product, always insist that their names are on their merchandise. If you are shown merchandise on which the maker has very carefuly concealed his identity, you may be sure there is a reason for it-THE QUALITY AND THE WAGES HAVE BEEN CUT TO "GET THE PRICES DOWN."

With the conviction that no institution can be more permanent than the kind of merchandise it sells, it has always been our policy to select our stocks from those makers whose principles are our principles. Thinking citizens in ever-increasing numbers are now rightly insisting-for their own protection-on knowing "WHO MADE IT?" when purchasing merchandise of any kind.

Civic-minded citizens can do their part to maintain national buying power by demanding standard merchandise of every kind in any standard quality store, made by makers proud enough of their products to insist their names are on it-manufacturers who have never paid their employees an un-American wage scale to "get the prices down" under those of competitors. By having always paid their employees-American citizens, all-a just wage scale, the standard quality manufacturers in the face of anti-social competition have nobly maintained their social contribution to America.

Then followed a list of branded merchandise handled by the store. In similar vein Mandel Brothers, Chicago department store, ran a series of newspaper advertisements on the theme of "America's Favorite Labels." The opening page reproduced a large number of brand names with this copy:

We have always believed that whatever best serves our customers also serves us best. Listed on this page are names of America's leading manufacturers . . . names you know well . . . labels you trust. Many of the names have been part and parcel of our business for generations, because they have given to you, our customers, the quality merchandise you want. Some are newer than others ... . but all are today Mandel's partners in serving the public. All are famous for their unswerving faithfulness in bringing you the best . . . good times or bad. When you buy at Mandel's, you buy the best products of America's leading manufacturers. 
Both these messages to the public are part of a concerted effort by national advertisers, agencies and media to present the favorable aspects of branded and trade-marked products. This activity is centered in the Brand Names Foundation, an organization sponsored by these different phases of advertising, all of which have a stake in preserving the popular confidence in brands.

One method used in obtaining general publicity on brand names has been the awarding of certificates for products which have been continuously merchandised under a certain name for $50,75,100$ years or more. It is truly remarkable to find how many of the articles we use today had their origin several generations back. At a presentation dinner in New York on February 5, 1946, 200 companies whose brands were established prior to 1897 received such awards. The oldest brands thus honored were all varieties of English china: Royal Worcester, 1751; Wedgwood, 1759; and Spode, 1770. One of the betterknown brands in silver plate, 1847 Rogers Bros., has the year of its adoption built right into it. Oddly, the company began featuring that date very early in its history-in the 1850 's - to distinguish its products from those of a competitor with the same name.

The figure of the chocolate girl, "La Belle Chocolatiere," appearing on packages and in advertising for Baker's chocolate and cocoa, dates back to 1780 . It is one of the earliest uses of a trade character. The plan of identifying some sort of picture with the product has grown immensely in popularity over the past 50 or 60 years, until today there is hardly a product made for consumers that doesn't have a pictorial device.

Among the most successful from the standpoint of general recognition value are the "Green Giant" of Minnesota Valley Canning Co.; "Elsie the Cow" of Borden products; the Dutch girl of Old Dutch Cleanser; the Spearmint men of Wrigley's Gum; "Aunt Jemima" of pancake fame; "Pepsi" and "Pete," the Pepsi-Cola cops; "Leo the Lion" of Metro-Goldwyn-Mayer pictures; "Johnny," the page boy for Philip Morris cigarettes, and the Jantzen bathing girl.

Some products have become identified with radio personalities, either real or fictitious. For example, Fibber McGee and Molly have been sponsored by Johnson's Wax for so many years that the team and the product are synonymous. The tobacco auctioneer is a Lucky Strike institution. Bob Hope means Pepsodent to millions.

Another type of trade character which helps to humanize a com- 
pany and its products is exemplified by "Betty Crocker," featured in General Mills advertising. To large numbers of people she is an actual person. Her mail is voluminous; she is said even to have had marriage proposals. General Mills' object in selecting a fictitious name rather than using the name of the real head of their home economics department is to protect their advertising investment; a human being may die, change jobs or, after a build-up, get an inflated idea of personal importance and salary, but the mythical "Betty Crocker" can go on forever.

In addition to the brand name and the trade character or device, the advertiser often makes use of a distinctive style of lettering to differentiate his product or service from competition. This may be accompanied by a shield, silhouette, or some geometrical figure such as a circle, square, triangle or pyramid.

This characteristic method of displaying the brand name is usually found at the bottom of the advertisement, and is known in the trade as a "logotype."

Formerly the logotype was considered sacrosanct. Anyone who dared to suggest revising it would have been guilty of lese majesty, bolshevism and blasphemy. But styles change. The rococo designs of the 1880's and 1890's began to seem more and more incongruous when applied to modern streamlined products. A few daring advertisers brought their logotypes up-to-date, and to everyone's surprise business kept right on coming in as usual. Nowadays it is considered quite proper to modernize the lettering of a trade-mark for the sake of greater readibility and appropriateness.

The year 1870 was significant in the history of advertised brands. The United States Patent Office inaugurated the modern system of trade-mark registration. During the first year only 121 trade-marks were registered. Year by year the number grew until in 1906 more than 10,000 new ones were added. By May 1947 total registrations had reached 429,000 .

Just how much value companies attach to their trade-mark protection is seen in the reports of many lawsuits to halt infringements. Over 400 attempts were made to imitate the name "Uneeda," the property of National Biscuit Company, during its first fifteen years. While most trade-marks are carried on a company's books along with goodwill at a cash value of $\$ 1.00$, the real worth of these symbols often amounts to a sizable proportion of all assets. As far back as 1919 it was reported that American Tobacco Company trade-marks 
were valued at $\$ 45,000,000$ out of total assets of $\$ 227,000,000$ and about the same time Liggett \& Myers put a cash appraisal of over $\$ 40,000,000$ on their trade names and good will.*

\section{The Beautyrest Record}

There is romance galore in the promotion of every popular branded product. It would be absorbing to trace the history of any one of a thousand universally known brands from its inception; to watch the struggles, the setbacks, the crises when the future of the business hung on the courage and vision of one man or a small group. Almost without exception, such a study would reveal a pattern like the following:

1. A period of slow growth with little or no advertising, during which the company "finds itself," both as to the kind of product or service at which it excells and as to the all-important personnel needed for large-scale, quality performance.

2. A period of decision. One item, group of items, or type of service, is selected because it appears to fill a definite public need. The company resolves to concentrate on that particular line. Advertising is one of the weapons chosen for the project.

3. A period of pioneering. Rarely does a new product, or a reshaping of a familiar product, win instant acceptance. Dealers are skeptical, indifferent, hostile. Consumers show little inclination to abandon long-established buying habits.

4. A period of growth and recognition. The new brand takes hold. The company was right-it does fill a need. More and more people buy. Word-of-mouth advertising reinforces the paid advertising. Dealers get calls for the brand. Production leaps. Profits roll in.

5. A period of competition. Attracted by the company's success, other firms jump into the field, start making "something just as good" for less money. Strong pressure is put on the company by dealers, salesmen, even some factory executives, to meet these price threats. Wiser counsel prevails. Instead of debasing the product, it is made better. Price reductions are made only as the result of operational savings. Merchandising efforts are increased; dealers and clerks are shown why this brand is worth the extra cost. Advertising is intensified to do the same educational job with the consumer.

* Printers' Ink, Nov. 11, 1920, p. 109. 
The story goes on, but there are no more periods. No successful business ever gets beyond the period of competition. The more successful it is, the more intense competition becomes.

Of greatest concern to the consumer are the two key decisions in this story: one, when the manufacturer decided to concentrate on a specific product for which he felt a need existed and which he believed he could make better than his competitors; two, when he refused to be turned from his course by price pressure but plowed back profits in the form of product and service improvements.

This pattern, repeated over and over like the endless addition of coral polyps, has built the island of consumer confidence which constitutes the brand-names system in America.

Let's take a typical case: the Simmons Company, makers of furniture and bedding. In 1946, their seventy-fifth anniversary year, they had net sales of $\$ 92,924,877$, based on net working capital of $\$ 25,233$,826 , with land, buildings and machinery valued at $\$ 14,698,916$. On net earnings of $\$ 5.08$ per share, stockholders were paid $\$ 2.00$ in dividends, $\$ 3.08$ being retained in the business.

How did Simmons reach this point? Very largely through the development of brand names that represent dependable value in the minds of prospective buyers, plus profit opportunities to their retail dealers.

In 1916, Zalmon G. Simmons of Kenosha, Wisconsin, took a much maligned product - the metal bed, regarded as suitable only for boardinghouses, hospitals and maids' rooms-and made it respectable. Stylists were retained to create smart designs. Beautiful color pages in magazines gave an atmosphere of refinement and luxury to the steel bed. Dealers began to show Simmons Beds in their own advertising. Then other bedroom furniture, all made of steel, was added to the line, enabling the furniture store to offer harmonious ensembles.

Late in 1924 Mr. Simmons introduced the famous "Beautyrest" mattress. Until that time, mattresses had been purely utility items. He gave them a plus value. He established research fellowships on sleeping habits and sleep comfort at the Mellon Institute, and used their findings as the basis of dramatic advertising campaigns. "We discovered," he said, "that we weren't in the spring and mattress business. We were in the business of selling sleep-sound, restful, health-building sleep!"

Sales of the Beautyrest doubled in 1926, the second full year; 
doubled again in 1927, and again in 1928. The following year sales again soared. After a dip during the depression, Beautyrest production again started to climb, until in 1941 the peak year of 1929 was surpassed.

Engaged largely in war production until 1945, the company devoted its advertising chiefly to war projects with an occasional product theme such as "How to relax in wartime," and "Make that shut-eye count." With the return of peace, it had to apologize for the shortages of its products and tell consumers that the Beautyrest and other Simmons products were worth waiting for.

Then came the Simmons Electronic Blanket, developed in the firm's own research laboratories and introduced with a spectacular full-color campaign. National advertising, linked with an educational program to dealers and floor salesmen, made it a highly salable gift item for Christmas in 1946.

Postwar plans include a continuing campaign on the Electronic Blanket, increased advertising on the Beautyrest mattress and an institutional series which features Simmons products "to help furnish your dream home"-such as metal furniture, lounges, sofa beds, porch and garden furniture.

What part has advertising played in the success of Simmons? In 1916 , the first campaign cost $\$ 98,000$. Since then the company has appropriated between $\$ 20,000,000$ and $\$ 25,000,000$ for national advertising. Besides this, advertising service is rendered to dealers in the form of mats, literature and radio spot announcements. From $10,000,000$ to $15,000,000$ lines of newspaper advertising are the annual average devoted to Simmons products by local dealers.

The company's salesmen are trained to give every assistance to retailers and their floormen in learning the features of Simmons products. Store executives are taken to the factories to become more familiar with construction details. At the semiannual furniture markets Simmons has set up model displays to help retailers in improving their own displays. In March 1946 the company issued a manual, "Ideas for Bedding Department Modernization," for which over 1,000 requests were brought in by a single ad in Retailing Home Furnishings.

Summing up the reasons for their sales progress in the seventy-fifth anniversary report, Simmons officials made this statement:

What is the secret of Simmons' sales success? It is product integrity. It is alertness. It is the manufacturer putting himself in the 
shoes of the dealer and trying to help him solve his selling problems. It is the realization that his dealer's success is basic to the company's own success.

It is industry responsibility, the challenge of leadership that Simmons has attained in the bedding industry.

It is public responsibility, the deep sense of obligation that Simmons has always felt and exercised to contribute its utmost to better living throughout the world.

From sales of $\$ 72,088$ in 1885 , to $\$ 1,089,865$ in 1899 and $\$ 6,683,303$ in 1915, the Simmons Company has forged steadily ahead on this platform. It has made epochal contributions to home comfort. But far from resting on its laurels, it is projecting new products, improvements on its present products, new ways to expand. In the words of its president, Grant Simmons, "A business cannot remain static at any point in its career, not even at a grandfatherly seventy-five. It must either regress or progress."

\section{Brands Must Stay Made}

Like the reputation of an individual, the brand of a manufactured product or the name of an institution is not something that, once established, remains fixed for all time. A brand must not only be made-it must stay made. It must continue to satisfy the public in the face of competition. It must perforce use laboratory and consumer research to hold its leadership.

Free competition, the American system of private enterprise, is responsible for the brand-names system. It is far from perfect. But thus far, in the opinion of many thoughtful students of business, no better way has been devised to assure the average purchaser of a fair return for his money under a wide variety of circumstances while at the same time stimulating a constant advancement in goods offered for sale.

Under the existing system, the maker of a branded item has a definite sense of responsibility to the buyer. His prior investment in that brand, his hope for future profit from it, both combine to guarantee to the purchaser a return comparable with any offered by competition. With our present mass-production system, a manufacturer must have some assurance of patronage before risking the expenditures necessary to make a large quantity of goods; the established preference for his brand gives him such assurance. 
The rise of national brands, it has been pointed out by the Brand Names Foundation, is an aid to "buymanship." In primitive societies the shopper can afford to examine each article and haggle over the price; in our busy existence few people have the time or patience to do this. Modern bargaining is done by buying, or refusing to buy, certain merchandise. That which does not sell must either go up in value or come down in price.

Freedom of choice, implicit in our democracy, is involved in the brand-names system, as well as freedom of opportunity for new products. Indirectly, freedom of speech depends to a certain extent upon retaining this system, for revenue from the advertising of national brands helps to keep newspapers, magazines and radio independent of the need for governmental subsidies or support by political factions that exists in many other countries.

Finally, brands contribute to progress. Competing producers are stimulated to make things better or to make new things. Consumers are stimulated toward a higher living standard, which leads to full employment and a dynamic society. It is ironic that many who disparage the modern economic system for overstandardizing American culture are the same individuals most anxious to eliminate the brandnames system and establish grade labeling, which would remove virtually all incentive for developing distinctive features and qualities in products.

Corresponding to the brand name on a product is the name of an established retail store or service institution such as a bank, a power laundry, a moving van company, an appliance repair shop. Each of these types of business must depend upon public good will and confidence. Local advertising designed to keep the firm name before present and potential customers is an important factor in their prosperity. Some retailers, particularly department stores, by consistently truthful, prestige-building advertising backed up by good merchandise and courteous service, have given their store labels a standing as great as the average nationally advertised brands or greater. But they too must be constantly alert to hold their advantage against competition-which means better advertising and better service to the consuming public. 



\section{BOOK II}

\section{THE "WHO" OF ADVERTISING}




\section{,}




\section{Chapter VII}

\section{THE CONSUMER-GOODS ADVERTISER}

NOAP, drugs, foods, automobiles, home appliances, cigarettes, beverages, cosmetics, fountain pens-that's the roll call of products offered for sale by the top 25 advertisers of 1946. Every one comes under the general heading of consumer goods.

The manufacturer of articles in virtually universal use outranks all other types of business in advertising expenditures. He is far and away the biggest client of the advertising agency. Although the term "national advertiser," strictly speaking, covers any firm using national media-including the business and industrial magazines, for example-it is generally applied only to producers of consumer goods. Some national advertisers sell services rather than tangible merchandise. Represented in this category are such names as American Telephone and Telegraph, Pennsylvania Railroad, American Airlines, Prudential Insurance, Statler Hotels, Metro-Goldwyn-Mayer; but they are a small minority among national advertisers.

National advertising leadership can be narrowed still farther. Of the producers of consumer goods, those making low-cost items that are quickly used up and frequently purchased-in other words, packaged merchandise-make up the great majority of multimillion-dollar advertisers. Here is the list of the top 25 companies with combined 1946 expenditures of $\$ 1,000,000$ or more in magazines, network radio and national farm magazines (these figures do not include newspaper, outdoor or other media):

Rank Advertiser

Total 3 Media

1 Procter \& Gamble . . . . . . . . . . $\$ 22,456,427$

2 Sterling Drug . . . . . . . . . . . 11,606,604

3 General Foods . . . . . . . . . . . 10,933,037

4 Lever Brothers Company . . . . . . 9,530,518

5 American Home Products . . . . . . . 8,582,714

6 General Mills . . . . . . . . . . . 8,579,171

7 General Motors . . . . . . . . . 8,176,766

8 Colgate-Palmolive-Peet . . . . . . . . 7,824,710 
Rank Advertiser

Total 3 Media

9 Bristol-Myers

$6,342,203$

10 Miles Laboratories

11 General Electric Co.

12 Ford Motor Co.

13 Swift \& Co.

14 R. J. Reynolds Tobacco Co. .

15 Schenley Distillers .

16 Liggett \& Myers

17 Distillers Corp.-Seagram

18 Campbell Soup Company

19 Standard Brands

20 Borden Company

21 National Dairy Products Co.

22 Philip Morris \& Co.

23 Eversharp, Inc.

24 Kellogg Company

25 American Tobacco Co.

All but three of these-General Motors, Ford and General Electric-are in the packaged-goods field. The remaining 22 sell a good part if not all of their output through groceries or drugstores.

A large proportion of the national advertising in newspapers, as well as posters and car cards, also originates from manufacturers of consumer goods. And so does nearly all printed or lithographed display material for store windows, counters and walls. Much of the local advertising in newspapers is devoted to "tying in" with national consumer campaigns. Advertising aimed at dealers who handle consumer goods is an important factor in the field of business publications. Of other branches of advertising, too-direct mail, commercial films, mail order, television, sky-writing, premiums-the consumer-goods manufacturer is one of the heaviest users.

It is no wonder that to the average person national advertising is most closely identified with small packages!

The development and operation of a program of national consumer advertising is a highly specialized procedure.

Glancing through a magazine, or listening to a series of radio shows, one might be forgiven for thinking otherwise. What's so diffcult in writing a few hundred words about a product, getting an 
artist to draw a pretty picture and then inserting the finished ad in a magazine or newspaper? Or, for a network show, merely whipping up a few commercials?

The answer is that these are only the visible or audible parts of a campaign. In themselves they demand extreme care, skill and flairthe very simplicity which makes them look so easy is achieved only by endless effort and experience-they are like the one-eighth of an iceberg showing above water; there is far more below the surface.

Virtually all national advertising is produced by a team consisting of executives representing the manufacturer and people from the advertising agency handling the account. The relation between the two groups is an intimate one. On it depends much of the productiveness of the campaign. So the headmen of business are giving more and more attention to the selection of their own advertising executives and to the selection of their advertising agencies.

It was not always thus. In the early years few companies boasted an advertising department, or even an advertising manager. Then as appropriations increased it became necessary to have somebody to check the bills, to see that the ads were placed, to write circulars and sales letters. Sometimes a bookkeeper who was handy with words would be promoted to handle the advertising; this was how Claude Hopkins got his first foothold in the field. Or the sales manager, conscious of the close tie-up between personal and printed selling, might call in one of his bright young salesmen from the road to take over the job. Too often the advertising manager occupied a purely clerical role, the basic decisions being made by higher-ups.

Gradually, however, the position has assumed greater importance. In some companies today it carries with it the title of vice-president. The advertising manager may become a member of the board of directors and in more than one instance has gone on to become president of his company. If the company is one of the larger advertisers, as will be explained later in this chapter, he will have under him various writers, production assistants, research men, home economists and other departmental employees according to the nature of the advertising problem.

But establishing a strong, efficient advertising staff is only half of the team-building process. The other half is selecting the right agency to service the account. 


\section{Picking the Advertising Agency}

The national advertiser trying to decide between several agencies feels like a pretty girl besieged by suitors, each ardently pleading his own case and pledging lifelong happiness. How to choose the right one?

Sometimes it's love at first sight-with about the same chance of permanence as in marriage. Sometimes it's a matter of propinquity; the agency is near by and able to give the account constant attention. Sometimes family relationships or personal friendships tip the scale.

Nowadays few advertisers make their selection, however, without having been exposed to a number of agency solicitations. Word that an account is "open" gets around via the grapevine with incredible speed. Rumors of an impending change or of a new product about to enter the advertising arena often get started on the slightest provocation. Agency "bird dogs"-new-business men-descend upon the advertiser in troops and let fly with their heaviest artillery. By the time a company's executives have listened to half a dozen presentations they are completely confused. With each agency claiming to be the ideal one for the account, the advertiser often feels like flipping a coin for his choice.

Current practice among large advertisers favors the "guided solicitation" method. The advertiser picks out a few agencies which seem about right in size, background and quality of work. This is not difficult, because the accounts of all recognized agencies are published regularly in Standard Advertising Register and also in McKittrick's Directory of Advertisers. Knowing what accounts an agency handles, he can look at their ads for various clients and listen to the programs they produce on the air. It is generally considered desirable to have an agency with experience in the advertiser's field-foods, cosmetics, automotive products or men's wear, for instance-but not an agency handling the advertising of a direct competitor.

The advertiser then calls in his candidate agencies, explains his needs and gives each solicitor a questionnaire to be returned by mail. One such questionnaire, mentioned in a series of Printers' Ink articles on agency solicitations, was described by the advertiser who used it, as follows: 
We were interested in the length of time they [the agencies] had been in business; their principal personnel; their principal accounts and length of service; their accounts recently acquired; their annual billing in magazines, radio, newspapers; previous experience with our type of product; their previous experience with other packaged goods; their previous experience with men's products; their personnel available and previous experience; their facilities for market research, copy, art, radio and media; their competitive business directly and indirectly.

On this questionnaire were the factors we considered in calling in agencies. We then selected the agency on the basis of the answers to these questions. We asked for no campaigns-no ideas. We went about selecting an agency as we would a sales manager.

All six agencies came back after the questionnaires had been mailed in and studied by us. Sitting in on the meetings were the advertising manager, the sales manager and myself [vice-president]. From then on we asked only a few leading questions. But from the questionnaire the agencies had a means of catching on to our thinking, so they knew how to talk to us."

The questionnaire method is not infallible. Bruce Barton tells about a big advertiser who prepared a list of 50 questions for the dozen agencies soliciting his business. ${ }^{*}$ He asked for every conceivable detail of their organization, personnel, accounts and methods of planning campaigns, as well as a complete file of one year's campaign for one of their accounts. The answers of all 12 agencies were so thoroughly satisfactory that he still couldn't make up his mind. So he finally selected an agency by asking the clients of each for their opinions and judging by the enthusiasm of the responses.

Usually the company's top management will make the final decision, but the advertising manager will have a voice in the selection since he is the one who will have to work most closely with the agency from then on.

Some advertisers retain the same agency for many years. Others make frequent changes. Among the 123 companies who spent $\$ 1,000,000$ or more each in magazines, network radio and newspaper

* Edward J. Dever, Jr., "How Some Advertisers Guide Agency Solicitations," Printers' Ink, Nov. 29, 1946, p. 36. Used by permission of Printers' Ink.

** Bruce Barton and Bernard Lichtenberg, Advertising Campaigns, pp. 77-80. Used by permission of the Alexander Hamilton Institute. 
advertising in 1945, there were 72 agency changes in the previous five years. Where possible, companies with the most consistently successful advertising records avoid changing agencies. Each time a new agency comes in, there is a period of studying the product and problem during which the promotional effort more or less marks time. After an agency has served a client for several years it should acquire a mass of market data, a familiarity with the advertising and sales personnel and a knowledge of competition, all of which help increase its efficiency on the account. Against this advantage is the argument that a new agency will bring a fresh viewpoint and original ideas into play. It sometimes happens also that after an agency handles an account for a considerable time it acquires a series of inhibitions; "they"-meaning the client-are presumed to dislike certain types of headlines, illustrations and text. Clinging to these taboos, the advertising becomes sterile. The new agency, ignoring these hypothetical don'ts, prepares ads which win an enthusiastic okay. Whereupon the staff of the former agency screams, "But they wouldn't let us do that!"

Large advertisers frequently divide their advertising among two or more agencies. This is the conventional procedure with a company having a great variety of products, some of which compete directly with one another. For example, Procter \& Gamble make Ivory Flakes, Duz and Dreft, all used for the same purposes. Each of them is advertised through a different agency. The 123 advertisers mentioned above in the $\$ 1,000,000$-and-up bracket employed a total of 289 agencies in 1946.

But whether the consumer-goods advertiser uses one agency or several, whether he changes agencies as often as some Hollywood stars change mates or stays with the same one year after year, his agency affiliations must work as a unit with his own advertising managerthe quarterback of the advertising team!

\section{Duties of the Advertising Manager}

Only in exceptional cases can it be said that the president of a company is "his own advertising manager." The late George Washington Hill took a keen interest in Lucky Strike advertising and was credited with having originated many of its most outstanding campaigns. Rob- 
ert R. Young of the Chesapeake \& Ohio has written a number of arresting ads for his railroad system.

Normally, however, high officials approve the annual budget, discuss the over-all plan and then leave it to the advertising manager to work out the detailed campaign with the agency. Supervising the company's advertising in national media is only one of his duties, although naturally the most important one. The agency will always look to him as its chief source of information about the company, the company's policies, the product or products and the new developments in the line. Ideas which may be radically different from previous advertising may be submitted to him for approval and it is up to him to say yes or no. In some cases-fortunately few-the agency will strive to "please" him rather than to produce copy that will get the most results from the appropriation. He may be the first to decide that the present agency is not performing so well as some other agency might.

Besides serving as the main liaison with the agency and principal spark plug in supplying suggestions for campaign themes, he must frequently supervise the work of a large department. He is expected to speak with authority on public relations, sometimes on employee relations, except where the company has a separate public relations and/or employee relations director; work with the sales department to effect the maximum use of all advertising, and to insure its proper prorating among various markets; keep a finger on printing and lithography ordered for various advertising purposes; and perform innumerable other duties varying from one business to another.

The Association of National Advertisers in 1946 retained McKinsey \& Company, management consultants, to analyze the workings of member advertising departments. A summary of their findings was published in a book entitled Organization of the Advertising Function. Twenty-one companies were studied in detail and 202 summarized. Besides supervision of product advertising, no less than 33 other activities were noted as being performed wholly or in part by the department.

Included in this list were such jobs as: preparing exhibits for conventions; preparing catalogues and house organs; holding consumer meetings or schools; preparing posters for building employee morale; handling community fund drives in the company; preparing the annual report; advertising for new employees; handling pre-testing of 
products; arranging employee parties; getting up material for use in dealing with the government; preparing motion pictures or slides for the sales deparment, and writing speeches!

From all of this, it will be seen that "managing the advertising" for a big company is no one-man sinecure. Quite the reverse. The advertising department may have anywhere from two to 200 employees, possibly more, and it is the job of the advertising manager to keep them all functioning smoothly.

\section{The General Mills Setup}

General Mills, Inc., of Minneapolis, was one of the companies participating in the McKinsey survey. According to Standard Advertising Register for July 1946, S. C. Gale occupied the position of Vice-President and Director of Advertising and Public Relations. The expenditures of the company for advertising, according to the same source, amounted in 1945 to $\$ 8,260,217$ for farm papers, national magazines and radio. It should be noted that this figure does not include newspapers, dealer displays, consumer literature or supplementary media.

Lion's share of the giant appropriation went to radio with $\$ 6,407$,342 , of which $\$ 1,765,757$ was for Cheerioats (the name of this product has since been changed to Cheerios), $\$ 468,483$ for Cheerioats and Kix combined, $\$ 1,540,355$ for Wheaties, $\$ 580,062$ for Betty Crocker Soups, $\$ 504,966$ for Bisquick, $\$ 408,112$ for Softasilk Cake Flour. In the magazine field Wheaties, Gold Medal Flour and an all-over institutional campaign received the biggest chunks of the $\$ 1,407,760$ budget. The farm-paper appropriation of nearly half a million had a \$155,141 slice for Larrowe Feeds.

Now let's see how these budgets were administered. The company retained four advertising agencies: Dancer-Fitzgerald-Sample, Inc., on Gold Medal, Kix, Softasilk and Cheerioats; Knox Reeves Advertising, Inc., on Wheaties, Bisquick and Betty Crocker Soups; Batten, Barton, Durstine \& Osborne, Inc., on public relations and household appliances; and Zimmer-Keller, Inc., on the Larrowe Division.

Mr. Gale reported to the company president, Harry A. Bullis, himself a very advertising-minded executive, while the following offcials reported to Mr. Gale: Grocery Products Advertising Manager, Radio Program Manager, Flour and Feed Advertising Manager, Adver- 
tising Comptroller, Mechanical Division Advertising Manager, Director of the Home Service Department, Assistant Director of the Department of Public Services (public relations), and the Director of Market Analysis. Each of these is an important executive in his own right.

The Director of Home Service, for example, has charge of kitchen operations, including the model kitchens which attract visitors from all sections of the country; it is here that the Betty Crocker recipes are developed and tested. This department also handles mail requesting recipes and assistance on homemaking subjects and directs the radio and movie contacts.

The Vice-President in charge of Advertising is also a member of the company's Executive Council, serves on the top-management Operating Board, is a member of the Current and Future Planning Committee, co-chairman of the Market, Merchandising and Advertising Committee, member of the Personnel Committee and member of the Nutrition Committee.

Budgets for the coming year are worked out by each division, which estimates the number of units it expects to sell, establishes an advertising rate per unit, and multiplies. The annual budget must be approved by the President and the Executive Committee of the Board of Directors. Then it is turned over to the advertising managers and "they are the doctors from there on."

Each advertising program is subject to approval by a policy committee which is headed by the Vice-President in charge of Advertising and includes the head of the Legal Department, the head of Products Control, the Chief Economic Adviser, the Chief Nutritionist, the head of Research and the Assistant Director of Public Service. This committee passes on general policies, specifies claims for each product, testimonials and the like.

"In appraising results," Mr. Gale states, "General Mills employs various research groups, and in addition the advertising program is related to actual sales results by each product for each wholesale trading area. The results attained by this comprehensive approach to advertising are best reflected by the company's outstanding growth in volume and profits."

General Mills has a normal staff of 129 in the department, including 50 in advertising, 35 in home service, 19 in public service (public relations) and 25 in market analysis. 


\section{Other Advertisers}

International Harvester Company operates many related activities in its Consumer Relations Department. It maintains extensive advertising schedules for its various divisions which include Farm Tractors and Equipment, Motor Trucks, Industrial Power, and Refrigeration. The department's magazine section regularly prints, in its own Harvester Press, 30 publications directed to the general public, special customer fields, its dealers, and to the 80,000 employees in its 26 manufacturing plants. Its chief public relations medium is the Harvester World. The department issues numerous catalogues and instruction manuals, conducts farm practice research, assists dealers in merchandising, supervises exhibits at state fairs, plans and distributes motion picture and slide films, maintains a speakers bureau and heads various other activities. The International Harvester Consumer Relations Department employs 269 people.

By way of contrast, the Hoover Company, to quote the report, "has found that its specific needs are met best with a small advertising department consisting of the advertising manager and his assistant. These executives-together with the Vice-President in charge of Advertising, Engineering and Patents-are responsible for the over-all planning and direction of advertising. The agency is 'the rest of the advertising department." "* For many years this account has been directed by a Chicago agency, Leo Burnett Company, Inc. Records of Publishers' Information Bureau show that Hoover spent $\$ 257,273$ in magazine advertising in 1945.

Standard Oil Company of Indiana is one of the growing number of companies with a separate Public Relations Department; the director of this department is, however, a member of the Advertising Committee, which considers advertising policies, expenditures and programs, and either passes on them directly or recommends them to the Board of Directors. This awareness of the importance of sound public relations as influenced by advertising is shown in the statement of the Company's principal advertising objectives:

1. To help keep the Company's name favorably before the public.

2. To aid in selling the Company's products.

* McKinsey \& Company, Study on the Organization of the Advertising Function (Association of National Advertisers, Inc.) 1946, p. 55. Quoted by permission of the ANA. 
3. To assist in introducing new products.

4. To expand distribution by helping to secure and hold new dealers.

5. To help in building the morale of the Company personnel.*

\section{The Advertising Appropriation}

National advertising requires money. Before embarking on a campaign, the advertiser must decide in a general way how much he wishes to spend to reach his objectives. Customarily this is done once a year. The annual advertising appropriation or budget serves as the basic control in planning the company's program and while subject to change to meet unforeseen conditions it largely sets the pattern for that length of time.

Appropriations are determined in many ways. The simplest is to take a fixed percentage of the previous year's sales, or a certain amount of money per unit sold. This method is often used in industry-wide co-operative campaigns, where each firm supporting the campaign allots so much per case or per pound of goods sold in one year, the sum to be used for the next year's advertising. The percentage may be that commonly employed in industry, or it may be based on what the advertiser has found necessary to do an adequate promotional job. With a new product, or a company invading new markets, the tendency is to take a higher percentage than with long-established products which have already done their "missionary work."

Another method is to forecast the coming year's sales and apply the percentage. If the advertiser feels optimistic he may decide that business will increase and set up a larger budget on the basis of the expected rise. If the outlook does not appear favorable, he may retrench by applying the fixed percentage or he may feel that there is need for greater advertising effort to combat a decline and appropriate a higher percentage of anticipated sales.

In larger companies having divisional or district offices, the practice is to break down the forecast geographically. Some parts of the country may be on the upswing, others static or showing a downward trend. The percentage method is applied to the over-all estimate and also to these geographical estimates, resulting in greater or less amounts being allocated to the various regions.

Besides the appropriation based on a percentage of past or antici-

*Ibid., pp. 85-87. 
pated sales the advertiser may also use the "task method." He may be planning to add to his line a product which will require several years of aggressive selling to build into a position of leadership. Normal advertising percentages do not apply, because of lack of precedent and also because competitors may be in possession of the field. So after a study of market possibilities for the period when he expects his new product to become established, he may set up an appropriation based on what would be a reasonable volume at that later date. Or by analyzing how much advertising is now being done on similar products he may arrive at a sum necessary to do a dominating job. Even though this amount may take all the profits on the new number for some time, it may still be a sound investment if the campaign succeeds. Just as a manufacturer will not charge the entire cost of his production machinery, for example, against the first year's sales, so he may prorate part of the introductory advertising expense over a longer stretch.

Then, too, the new article may use up some scrap material or take up the slack in production. It may have a low sales cost because it can be carried by the regular salesmen without impairing their effciency on the main lines. It may round out the line, enabling the men to sell a dealer his entire needs in a particular field and thus help close the door to competitors. Any of these situations will justify a firm in stepping up the advertising budget at least until the specific task is accomplished.

The task plan is also used where an advertiser wishes to dominate a certain market or to improve a spotty sales condition. In either case he may deliberately overspend-in trade parlance, "hypo" that market. On products where shipping cost is important, a larger percentage of the appropriation may be assigned to the region around the plant. A good many advertisers spend extra money right in their home town, as a matter of pride, to win community good will and to foster employee loyalty and make it easier to get good workmen.

To some companies, it is a matter of prestige to be the leading seller in certain cities-New York and Hollywood, for example. Dealers and consumers in other places presumably are impressed by such pre-eminence. Perhaps this is one reason for the "greatness" of the Great White Way!

Cities identified in the public mind with specific products may become obiects of special advertising interest to manufacturers of those 


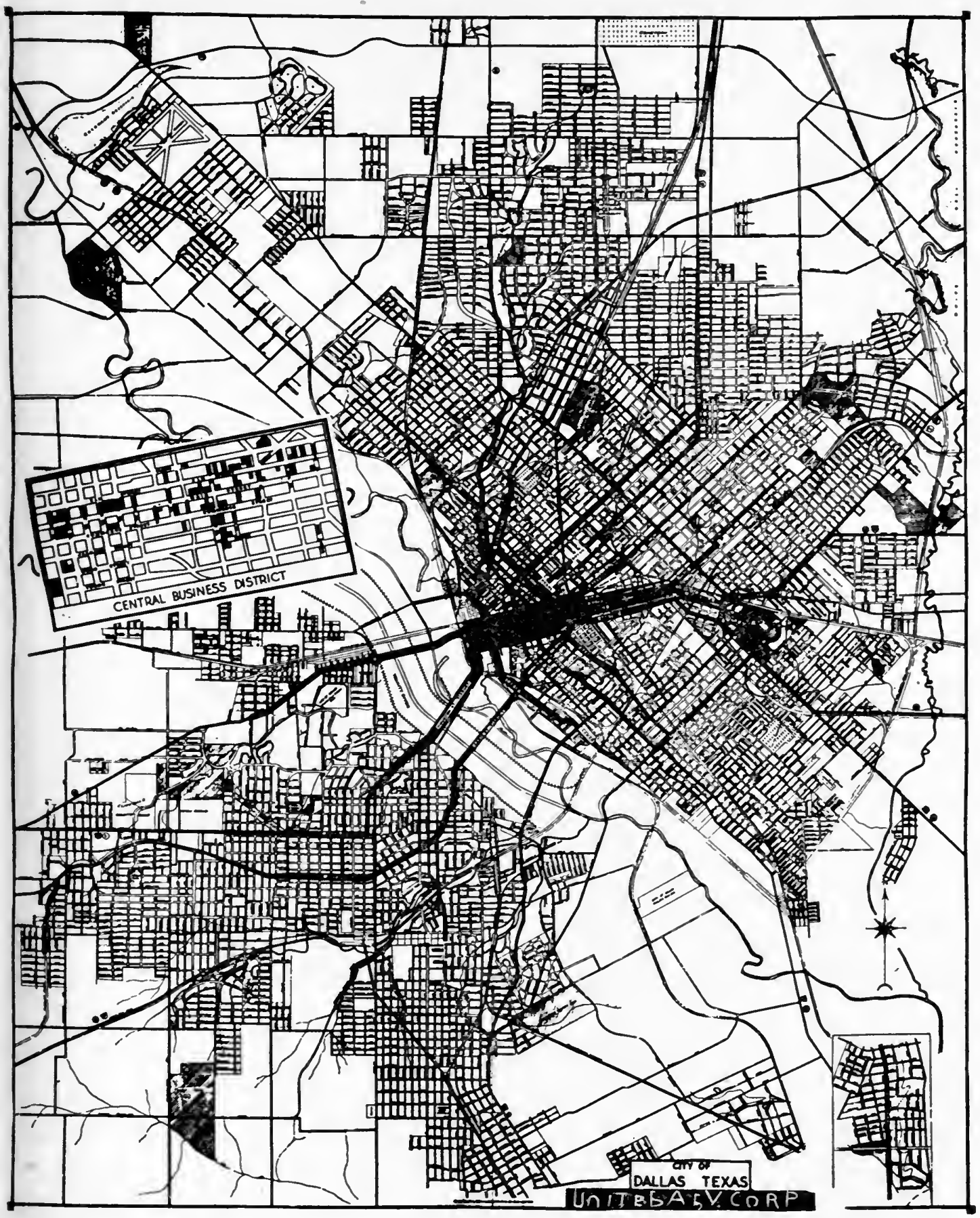

AGENCY MEDIA DIRECTORS KNOW THEIR MARKETS

This "Traffic Flow Map" of Dallas, Texas, is typical of data provided for using advertising with precision. Thickness of lines indicates density of traffic for location of outdoor posters. A No. 100 Showing gives adequate poster coverage of such a market. 


\section{Never Underestimate the Power of a Woman!}
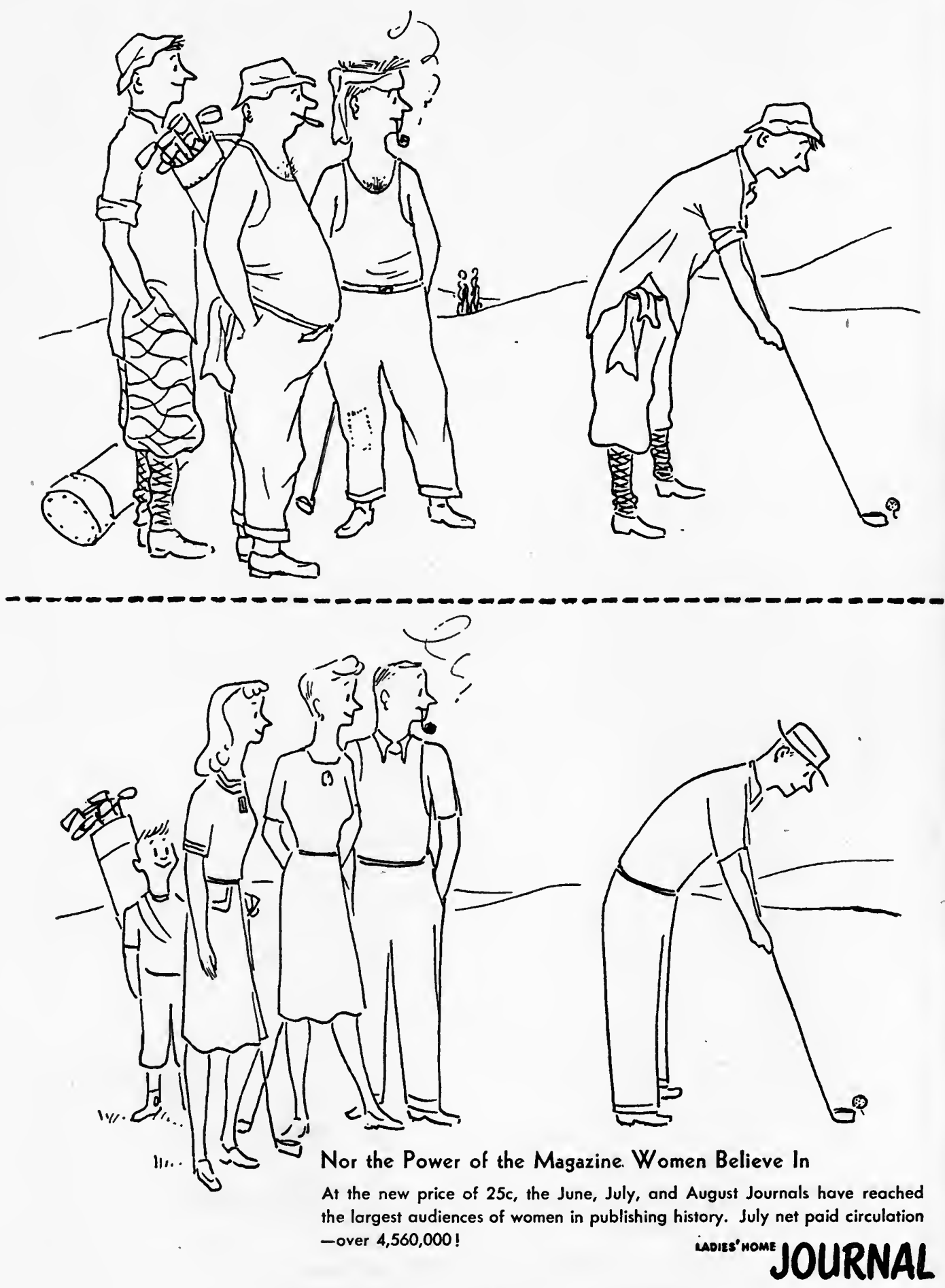

\section{ONE OF A FAMOUS SERIES}

There's a chuckle and a selling message in each of these Ladies' Home Journal ads. "Bj" Kidd, noted woman copywriter, sparked the basic idea and created many of the earlier pieces. 
products. To be able to say that one makes the largest-selling beer in Milwaukee, or the most popular beans in Boston, or the most soughtafter bathing suits in Miami Beach, is quite a feather in the favorite's cap.

Special appropriations may also be made for many kinds of tests. A national advertiser enjoying moderate acceptance may wish to find out if intensified effort will increase his business enough to pay for the extra cost. Instead of stepping up his entire budget, he will be wiser to test the new plan in one or more local markets first. Or tests may be made on new advertising appeals, sampling, small versus large ads, price changes, new packages, method of distribution and so on. Because of uncertainty as to the outcome it is not generally considered good business to weaken the regular campaign by reducing it to pay for the test.

Firms selling by mail tend to keep their advertising budgets flexible. Ads or mailing pieces carry a key number such as "Department 56L" or "Studio B-6" to serve as a check on the source of the inquiry or order. New pieces of copy are being tried out regularly, and when one is found that produces exceptional results the advertiser may decide to put extra money behind it. The profits from the first mailing or advertisement help to pay for the expanded program.

With this plan it is possible to run a shoestring into a fortune, if the tested copy continues to produce according to form. However, as Professor Hotchkiss points out,* the law of diminishing returns is very likely to set in. There are only certain particular magazines, newspapers and radio stations that are consistent mail-pullers; even these may inexplicably fail to produce, and the advertising man is left with a red face. Direct mail may work on a small list but peter out on a large one.

Once the advertising appropriation for a period, or for a specific task, has been determined, the next problem is how to divide it. A fixed amount must be set aside for the advertising department overhead. The remainder, less a reserve for emergencies, is then split among the different media-magazines, newspapers, radio, outdoor, trade papers, direct mail, display materials and other channels. Each of these in turn must be subdivided; if radio is to be used a certain amount will go for purchase of time, another part for talent, another, in the case of transcriptions, for recording and frequently another for

*Op. cit., p. 426. 
promoting and publicizing the show. Publication advertising, besides the cost of the space, also takes money for art work, typesetting and plates; this production expense may vary from 5 or 10 percent of the space charges to as much as the cost of the ad itself.

Companies operating by sales districts also allocate the budget territorially. If a group of national magazines is used in the campaign, for instance, they may compute what percentage of the total circulation goes into each area and charge that proportion of the cost against the districts. A district which gets less than its rightful share of the appropriation as shown by the circulation breakdown may be given additional advertising in local media to even things up.

When the choice of media has been made, the real headaches begin. There's never enough money to use all available elements in a particular field. The advertiser and his agency must leave somebody off the list. Advertising solicitors are notably persistent and ingenious in presenting the merits of their particular newspaper, magazine, network or other medium. The decision must be made on the basis of which media will bring the advertising to the right type and quality of customers in specific areas and will do it best in relation to advertising cost. Indirect benefits must be considered; one magazine aimed at the consumer may have a strong influence with dealers, while another, though small in circulation, may reach the notable type of user who sets the styles for the masses.

The question of what should be charged to advertising also has to be decided. Obviously direct media and production costs belong in the budget, but what about such pesky items as ads in charity bazaar programs, painting the company name on delivery trucks and on the factory, distributing samples of the product to plant visitors, entertaining customers or prospects, or sponsoring an athletic team for the sake of free publicity?

Some years ago Printers' Ink published a chart for allocating the advertising appropriation. It had three classifications: the "white list"-all charges that belong in the advertising account; the "black list"-those that do not, although too frequently put there; and the "gray list"-border-line charges which might or might not come out of the ad budget. *

The old rule, "When in doubt, charge it to advertising," has di-

* "How to Determine the Advertising Appropriation," Printers' Ink, 1946, p. 16. Quoted by permission of Printers' Ink. 
verted huge amounts of money from legitimate advertising objectives, weakened innumerable campaigns to the point of futility. "The cornerstone of any sound appropriation policy," says the Printers' Ink report, "is that the advertising budget, once set up, will not be subjected to unjustified charges that will dissipate its efficiency."*

\section{The Advertising Plan}

Since every advertising campaign must be tailor-made to fit the product or service being advertised, no two are exactly alike. Experience has taught national advertisers and agencies, however, that to succeed, any campaign must encompass the following fundamentals:

1. A good product or service, one for which there is an existing or latent need.

2. A market for that product or service which can be reached with reasonable thoroughness within the allowable expenditure.

3. A basic advertising theme, idea or keynote for the campaign which will appeal to the self-interest of the proposed buyers and which can be simply and dramatically expressed.

4. Adequate provision for making the product or service available through local outlets-stores, showrooms, sales offices, canvassers or by mail.

5. Thorough co-ordination of the advertising with the company's own salesmen and with these local outlets.

6. Proper timing of the campaign as to season, popular trends in taste and customs, financial status of buyers.

7. Continuity-telling the prospects often enough and over a long enough period to win acceptance for the basic theme.

In each of these "musts," the company's advertising executives and the agency should work hand in glove with the sales and production departments. If the product is not right-as to quality, quantity, appearance or price-the faulty condition has to be corrected before the campaign starts or the whole effort will be handicapped.

Advertising a poor product may hurt a company more than not advertising at all, by creating additional dissatisfied customers who will be difficult if not impossible to sell in the future.

*Ibid., p. 18. 
Market analysis may be either a sales or advertising department function. In any event, those planning the campaign must know where and who the present and potential customers are. This will be discussed in a later chapter.

The basic theme of the campaign is the cause of more conferences and arguments and misconceptions than everything else put together. Given a certain thing to sell, what dominating or arresting idea will best pave the way to its acceptance by the public? Shall it be a slogan, a new pictorial twist, a singing jingle? Should some new product or service feature be played up, some new angle of design, construction, ingredients? Perhaps a new package or container will do the job; or focusing on some new use or combination of uses.

Sometimes an old familiar feature that has not been stressed can be given a dramatic treatment, as when Milton Feasley began writing those unforgettable ads about halitosis for Listerine. Sometimes it's a fresh, imaginative way of describing flavor, as when Schlitz Beer came out with the theme, "Just the kiss of the hops-none of the bitterness." Sometimes it's inherent in the name of the product, like Pennzoil's "Sound your Z."

Distribution of the product is, naturally, a sales rather than an advertising job. But the campaign planners must give the most careful consideration to every part of this process. The once prevalent concept of using advertising to develop "consumer demand"-in other words, selling prospects so thoroughly that they would go to the store and insist on having a particular item and no other, thereby forcing the dealer to order it-has given place to the more logical and reasonable objective of creating "consumer acceptance," putting the prospect in a receptive state toward the product or service. But this favorable state is of no value to the advertiser unless the thing advertised is available.

"Advertising," said the late Ray Lillibridge, a New York agency head, "starts the consumer toward the product. Selling starts the product toward the consumer. They meet at the point of sale." That is-they meet if all parts of the advertising and sales program mesh properly!

So the campaign must take into consideration the length of time required to inform the dealers or local representatives about the advertising, fill their orders, and have the merchandise in their hands when the program starts. "Jumping the gun" with ads that appear 


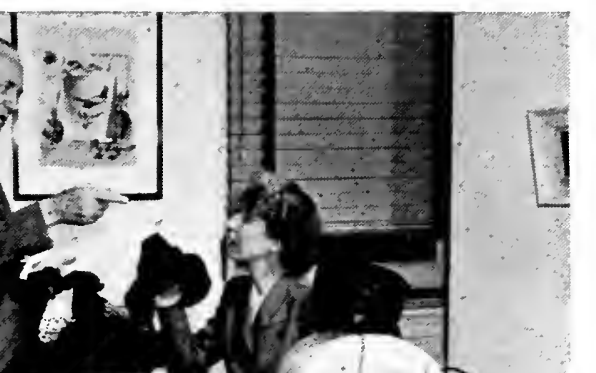

First step in getting an ad prepared at Marshall Field \& Company is deciding what to advertise. Here Matt Hyland, buyer of French Room Millinery, points out features of a new number to Kay Rickman, Divisional Advertising Co-ordinator of Apparel and Millinery, corresponding roughly to "account executive" in an agency.

Daily morning meeting of Ficld's advertising staff to criticize prospective ads with Margaret Egan, advertising manager, presiding.
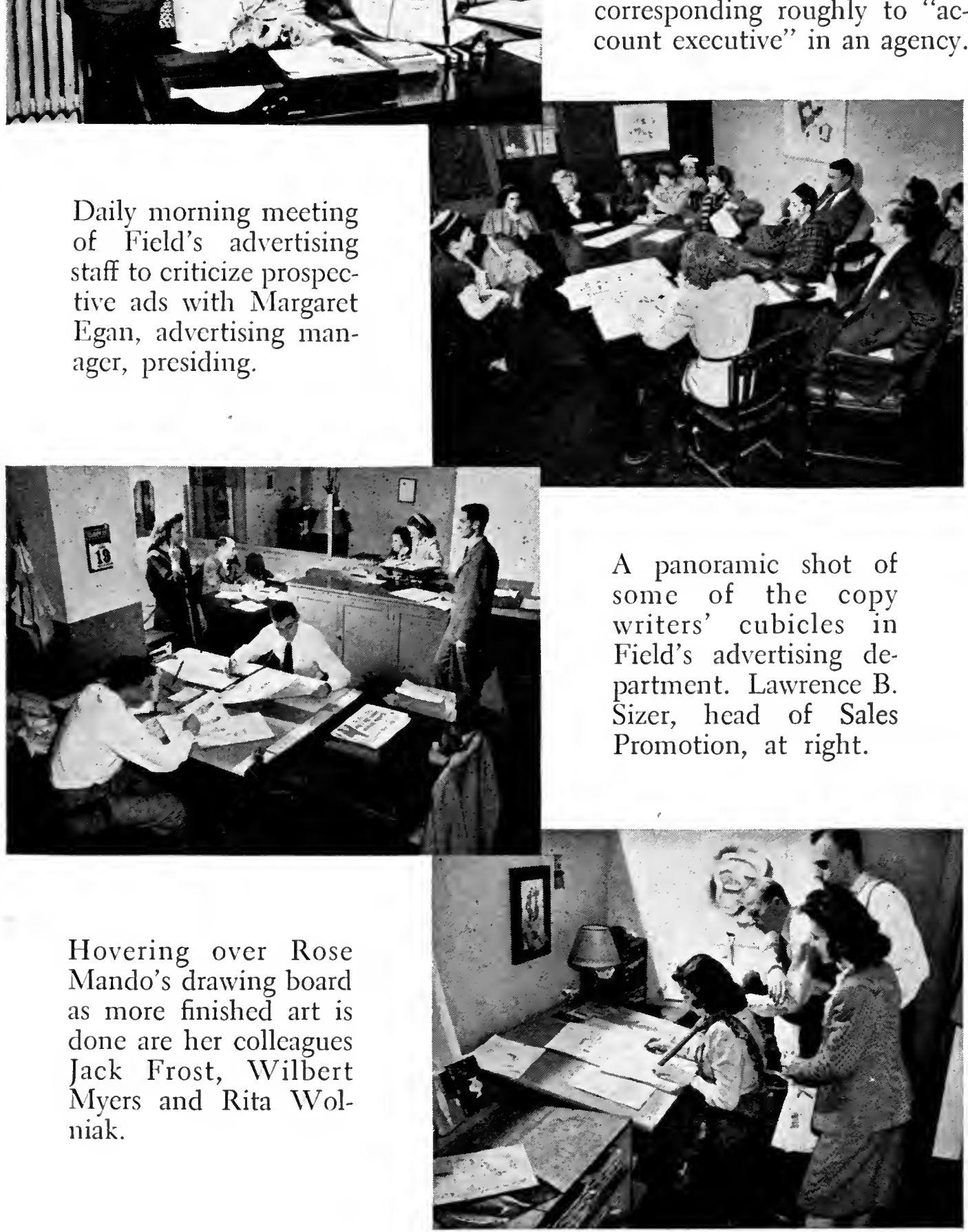

Photos courtesy Marshall Field \& Company 

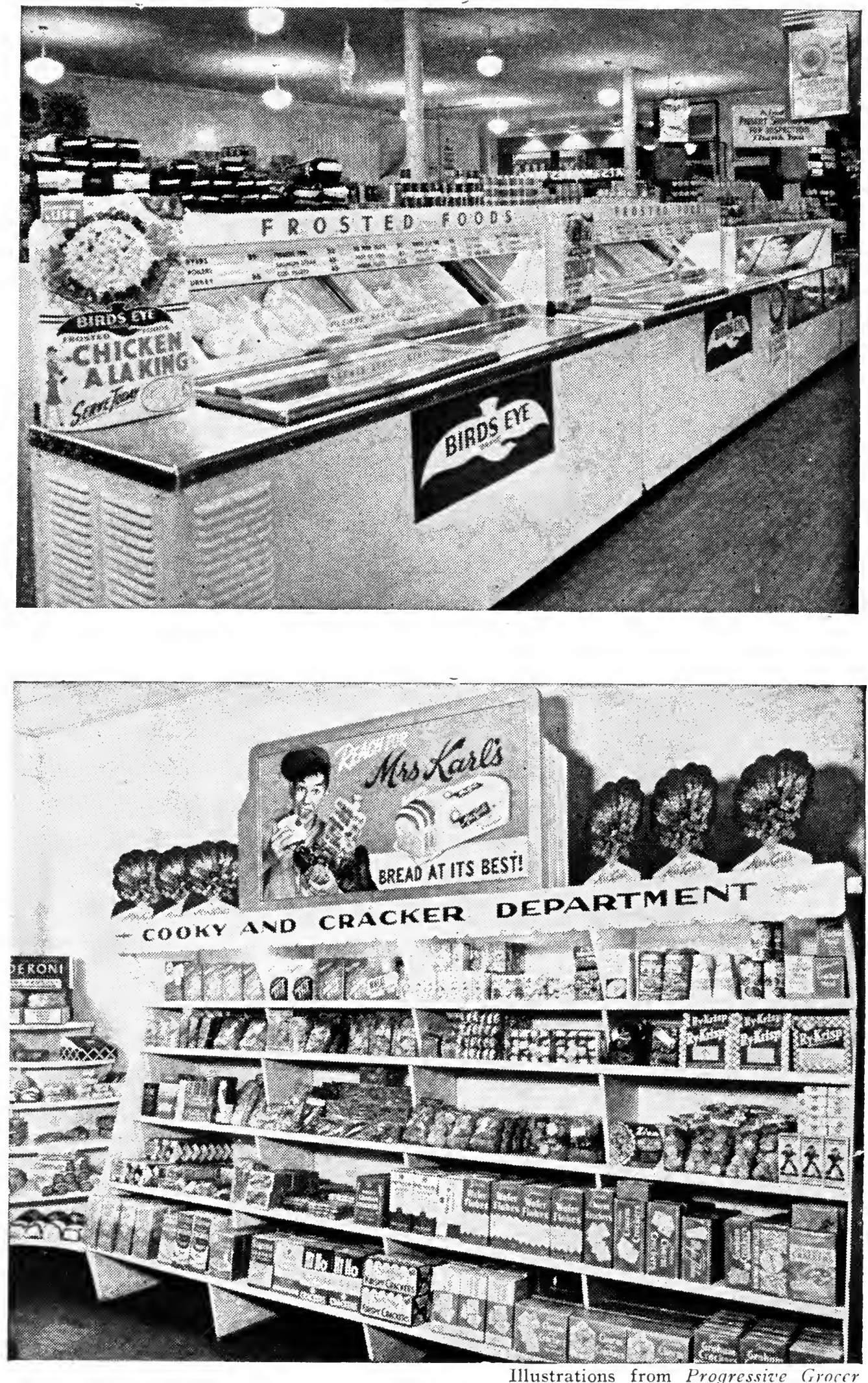

\section{UP FROM THE "CRACKER BARREL" DAYS}

Two views in modern food stores, demonstrating how self-service-a dircet outgrowth of advertising-has revolutionized modern merchandising. 
before the product is adequately stocked is a serious source of waste in the advertising of many new items or new models.

It is the responsibility of the advertising department and agency to make sure that the company's own salesmen know about the campaign and use it as a selling tool. For instance, very meager results may be expected from a series of advertisements or radio programs stressing a product's beauty, convenience or quality if the salesmen put their main emphasis on price. On the other hand, when the salesmen are enthusiastic about their company's advertising and can transmit that enthusiasm to wholesalers and dealers, even a modest or uninspired campaign has a far better chance of succeeding.

Elaborate methods are sometimes used to present the campaign, just for that reason. Before World War II, the annual sales conventions of certain large advertisers rivaled Broadway theatrical productions in showmanship. Full-scale shows were often prepared, traveling from city to city and performing in the leading local theater for the benefit of the distributor and dealer organization. To the accompaniment of tap dancers, orchestras, floodlights, velvet curtains and pretty girls in tights, the new models would be unveiled and the forthcoming advertising program introduced. If a network radio show was to spearhead the campaign, its star might attend the convention. "Blowing up" or enlarging the new ads to giant proportions was a common practice. Then the whole story would be retold in a lavish portfolio or sales manual given to each man as his year's "ammunition."

Wartime restrictions and easy selling have outmoded such saturnalia, but we may expect to see them or their equivalent return when competition gets rugged. The use of portfolios containing proofs of new advertisements, information as to media, circulation, dealer helps and other data is, however, a recognized adjunct of any national campaign. These are given to each company salesman in the hope that they will be shown to the wholesalers, chain buyers and dealers. Sometimes they are, but the wise advertising manager takes no chances. If the salesman neglects to show his advertising portfolio to the trade, mailing pieces and business paper ads will at least partially inform the trade about the campaign.

A substantial proportion of all linage in the drug, grocery, hardware, department store and beverage publications is devoted to describing and explaining the consumer advertising of manufacturers. 


\section{THIS FASCINATING ADVERTISING BUSINESS}

Many campaigns include "tie-in" materials such as window displays, counter cards, wire hangers, decalcomanias, leaflets, booklets and specially prepared ads in the local newspaper with space at the bottom for the dealer to insert his name. Having more of such material offered to him from advertisers than he can possibly use, the dealer must be sold on the value of "tying in" with that particular campaign. The task of persuading him that this one series of ads or radio shows or posters represents a rare and unusual profit opportunity-making it worth while for him to stock, display and push the advertiser's product-is known as "merchandising the advertising." In expenditure it may represent only a fraction of the cost of the consumer campaign, perhaps 5 to 10 percent, but it is one of the most vital steps in the entire plan. 


\section{Chapter VIII}

\section{THE ADVERTISING AGENCY}

$\mathrm{P}$ REVIOUS chapters of this book have described the evolution of the advertising agency from its origin before the Civil War as a strictly space-selling organization on through the many stages by which it grew into the present form-a highly ethical institution rendering creative and mechanical services to advertisers on a professional basis. The last chapter discussed the selection of an agency by the manufacturer of consumer goods, and the broad aspects of client-agency relationship.

But thus far there have been no direct answers to the questions: What, exactly, does an advertising agency do to earn its commissions? Why have the various media found it advisable to establish and maintain the present agency structure?

According to present standards the advertising agency is an independent firm, free from control either by media or by advertisers, which offers a complete advertising service to its clients. Early in advertising history it was found that the manufacturer of a product was not the best person to tell other people about it. He was too inclined to be biased by his own enthusiasm. Far better to have a third party, reflecting the consumer attitude, do the selling. This individual would approach a product from an objective viewpoint and his comments would be much more likely to interest the ultimate purchaser than those of the original sponsor. To this day the successful advertising agency is one that retains its "consumer viewpoint"-planning ads from the angle of the man in the street or the woman in the kitchen rather than the man behind the product.

In this respect the agency is similar to a legal firm counseling a number of corporations, or an accounting firm supplying audits and statistical information.

To provide unbiased counsel-with no outside influence, direct or indirect-the agency must be a separate entity. The minute a publisher, radio station owner or other individual financially interested in 
promoting some specific medium enters the picture, the agency loses its freedom of judgment.

Assume, for example, that an agency has been named to direct a $\$ 100,000$ account. Its gross revenue is 15 percent of $\$ 15,000$. It will receive that amount regardless of the media it recommends. But unless the program developed by the agency produces results satisfactory to the client, some other agency is likely to be named next year. Therefore it behooves the present agency to recommend impartially those media which, in its best judgment, will do an effective job this year. Only in this way can it hope to hold its accounts for subsequent campaigns.

Once this basic fact has been grasped, many details become clear. The agency takes a long-range attitude: its concern is not merely with current billing but with what may happen in the future. The desires and wishes of an individual advertiser are important, granted. If, however, what that advertiser wants does not agree with the agency's own experience as to what constitutes productive advertising, the agency people are quite apt to veto his wishes. The advertiser may get what he wants, with another agency. But if his program fails, he is more likely than not to come back to the agency that gave him its frank opinion in the first place.

\section{Advertising Media and the Agency}

Over a long period of time, media such as national magazines, newspapers, outdoor and transit advertising have come to consider the agency as their chief source of productive advertising. All they have to sell is white space in a publication or "dead air" on the radio. They cannot do a complete job of filling this space or air time. Dealing with 100 or more individual advertisers, this would be impossible. Sometimes media will assist prospective advertisers to prepare suitable copy; radio stations and networks often develop sustaining (nonsponsored) programs with the idea of selling them to a client, while a few business publications and other media may have creative departments to work with smaller accounts. These are, however, the exception. Virtually all national advertising today is agency-created.

But the agency is not merely interested in filling orders for space or time. It must make advertising work. To do this it constantly strives for fresh, new, ever more attractive methods of telling the client's 
story in competition with other advertising. It devises methods of coordinating the ad program with the sales and production end of the business, thus increasing effectiveness and encouraging the advertiser to continue using its services.

The active agency is always on the lookout for new business-firms that have never before advertised, or that have not realized their full opportunities for advertising, or that have stopped advertising. Media solicitors also seek to develop new advertisers, but since their sale must be supplemented by a creative service it is the agency men who do most of the pioneering.

From a financial angle, media owners appreciate the agency because it simplifies their credit operations and carries the risk of losses. Sixty, or seventy years ago publishers regularly expected 25 percent of their advertisers to default on payment of bills. Today, thanks to the soundness of the agency structure, media credit losses are infinitesimal. This has come about through the system known as "recognition."

The 15 percent commission granted by media cannot be claimed by any organization until certain requirements have been met. To be "recognized," an agency must satisfy the individual media owners or association on these points:

1. It must be a bona fide agency, free of financial control by an advertiser or by a medium owner.

2. It must keep all commissions (not rebate any to an advertiser).

3. It must possess personnel of experience and ability adequate to serve general advertisers.

4. It must have the financial responsibility to meet the obligations it incurs in ordering space or time. Some types of recognition require a certain minimum of liquid capital in the agency's possession.

In order to simplify the recognition problem, certain groups of media have joined to give over-all approval to an agency. These include the American Newspaper Publishers' Association (ANPA) for most newspapers; Periodical Publishers' Association (PPA) for many of the general magazines; Associated Business Papers (ABP) for some 200 or more trade and technical publications and the Agricultural Publishers' Association (APA) for farm papers. The ANPA and PPA have each at the present time about 600 agencies on their recognized list. The National Association of Broadcasters (NAB) adopted recognition standards at its 1935 convention but no blanket method of 
screening the various agencies was set up. Agencies placing network business are recognized at the discretion of the network, and the same holds true for individual stations. Outdoor advertising is placed by many agencies through the National Outdoor Advertising Bureau: nonmember agencies may establish their credit responsibiilty with the Outdoor Advertising Association of America, an organization of poster-plant owners.

An agency desiring to use only a few magazines or newspapers will not necessarily require recognition by a national association. As the list of clients grows, however, and new media are added, this becomes a matter of importance. Over 200 agencies have recognition from all the national organizations. Recognition once granted may be withdrawn if the agency fails to maintain the required standards.

The agency regularly passes on to its clients any cash discounts allowed by the media, on condition that the client pays the agency's bill by the discount date. The client is entitled to the exact amount of the cash discount allowed to the agency by the publisher. For example, with a magazine whose published rate is $\$ 100$ the agency commission of 15 percent would be $\$ 15$, and the total amount due by the agency to the medium, $\$ 85$. If the magazine allows a 2 percent cash discount, this would be computed on the net amount; 2 percent of $\$ 85$, or $\$ 1.70$. The agency would thus pay the publisher $\$ 85$ less $\$ 1.70$, or $\$ 83.30$ and passing this cash discount to the client would receive $\$ 100$ less $\$ 1.70$ or 98.30 , retaining $\$ 15$.

To establish uniform relations between various media and the agencies, the $4 \mathrm{~A}$ 's developed three standard agency-media contracts, one for publications, one for spot broadcasting and one for transportation advertising, which are now used voluntarily by the great majority of agencies.

\section{The Agency Setup}

Advertising agencies differ so enormously in size, kinds of business and individual operations that it is impossible to describe a typical one. Broadly speaking, however, they perform most or all of the following functions:

1. Contact with clients.

2. Fact-finding (research).

3. Campaign planning. 

4. Writing advertisements.
5. Planning and supervising radio programs.
6. Selecting and ordering media.
7. Making layouts, ordering and supervising art work.
8. Mechanical production.
9. Merchandising (sales promotion).
10. Checking and billing.
11. Publicity and public relations.
12. Soliciting new business.

These services may, and frequently do, overlap. In highly departmentalized agencies some of them may be subdivided. For example, the buying of radio time may be separate from the placing of advertisements in publications or on posters. The writing of radio commercials may be segregated from other forms of copy. Fact-finding may include product or market research, polls of the reading and listening public, copy-testing, consumer panels.

In addition the agency may offer specialized services, such as producing radio shows or commercial films, preparing house organs or catalogues, conducting contests, management engineering, operating a model kitchen. More than one agency has even owned and operated a retail store or an automobile dealership to provide a practical laboratory for its advertising plans.

1. Contact with clients-Liaison between the advertiser and his agency may take many forms. In the conferences where basic advertising policies and programs are determined the contact is often made by an officer of the agency, particularly in dealing with the client's top management. Of course, the wise agency will attempt to make sure that the president, board of directors, treasurer, general manager and sales manager of each client company are all familiar with the advertising program and enthusiastic about it.

Chief agency representative in the workaday contacts with the client is the account executive. Actually he is far more than a gobetween. He should have a trigger-quick mind, a reservoir of facts about markets and media, intimate grasp of the advertiser's selling problems and the ability to transmit and interpret information to his creative staff.

As a rule the account man has a finger on-though not necessarily in-each of the agency functions where his client is involved. His is the job of securing the "okay" on plans, copy, art, finished advertise- 
ments and bills. Hence his need for knowing what goes on within the agency so he can discuss any phase of the campaign intelligently with the advertiser.

Would you like to be an account executive? Here is what Dr. Donald $\mathrm{E}$. Laird says are characteristic traits of such gentry:

He generally likes to make speeches, meet and direct people, interview sales prospects and look at antique furniture. If he could earn as much money, and have other things pretty much his own way, he would like to be a cartoonist, novelist, orchestra conductor or sales manager. Among occupations he is apt to dislike are auto repairman, bank teller, florist, inventor, life insurance salesman, and physician.*

Among his likes, summarizing Dr. Laird's findings, are golf, detective stories, Life and poker. Among dislikes-hunting, stamp collecting, picnics, driving an automobile, observing birds, and roughhouse initiations.

A study by Advertising Age entitled "Advertising Agency Functions and Compensation" gives as the Number 1 agency function, "counseling on distribution, sales, merchandising and advertising." In a survey of 155 agencies the majority stated that besides advising clients on basic advertising policies and programs they also counseled with them on distribution policies, sales and merchandising policies and plans, catalogues, sales aids, house organs; assisted in planning sales contests and sales conventions and advised on sales quotas.* Such counsel, if and when given, would be largely in the hands of the account executive. It is obvious that he must be a well-grounded individual.

If the account is small or not too demanding, the account executive may handle other business. In fact, most account executives have several clients. They divide their time among these firms according to the demands of the various campaigns. As a rule advertising accounts have their peaks and valleys. When a series of advertisements is being prepared to cover a period of several months or a year, the A. E. may be swamped in work on a certain product: after the series

* By permission from What Makes People Buy, by Donald E. Laird, copyrighted 1935, by McGraw-Hill Book Co., Inc.

** "Advertising Agency Functions and Compensation," Advertising Age, August 12, 1946, Section two, p. 6. Cited by permission of Advertising Age. 
is okayed and running he may have a breather, permitting him to ration more of his time to other accounts.

On larger accounts the executive may have an assistant account executive and/or several junior contact men training to reach the enviable position of account executive themselves.

These "outside" men are not the only members of the agency seen by the client. It is sound practice to have the creative men or women assigned to an account visit the factory or general office, sit in on conferences with the advertising manager, browse around the research laboratories, talk with the production people and even go out on the road with salesmen. This not only results in better copy but also helps bind the account more closely to the agency as a whole rather than merely to one man. There is always the danger where an account is serviced largely by one individual that he will walk out with the business and transfer it to another agency or start one of his own. A great many agencies, in fact, have been launched precisely that way!

2. Fact finding or research-The broad subject of market analysis will be considered in some detail later. ${ }^{*}$ It is important to note here, however, that fact-finding yields precedence to no phase of advertising as an agency "must." Without adequate knowledge of markets and distribution, product use and acceptance, competitive activity, prechecking and postchecking of the campaign, the agency would be working in the dark. The client may have what he feels is a thorough understanding of his field; nevertheless, the agency must satisfy itself as to market facts to do a sound job of planning and executing the campaign.

In a booklet issued by the American Association of Advertising Agencies to explain the structure of the agency business, effective agency service is defined as "interpreting to the public, or to that part of it which it is desired to reach, the advantages of a product or service." This interpretation, say the 4 A's, should be based upon (1) a study of the client's product or service; (2) an analysis of the present and potential market for which it is adapted; (3) a knowledge of the factors of distribution and sales and their methods of operation; and (4) a knowledge of all available media and means which can be profitably used to carry the interpretation to the consumer, wholesaler, dealer, contractor or other factor.**

* Chapter XXIII

** The Structure of the Advertising Agency Business (the American Association of Advertising Agencies, New York, 1946). Cited by permission of the American Association of Advertising Agencies. 
Each of these steps clearly calls for research.

Opinions and practices vary widely as to the extent, nature and methods used in agency fact-finding. The agency may have its own research director, operating either alone or with a staff of assistants. The account executive may supervise research activities, calling on independent research organizations when the occasion demands. The creative personnel may engage in individual research to develop advertising ideas-actually "ringing doorbells" or calling on retailers, or riding a sales route with a truck distributor. Larger agencies usually have a librarian to classify the mountains of data constantly piling up on every conceivable phase of advertising and marketing: books, reports, business-paper articles, media studies, and so on. Mail questionnaires or the personal interview method may be used. In recent years "panels" or permanent groups of consumers who can be quickly polled by mail have been established by some agencies.

The cost of such research, when essential to proper servicing of the account, is usually borne by the agency. Where the information obtained serves the client, a fee is often charged for the work.

3. Campaign planning-Development of the advertising plan within the agency may take one of several channels. A popular arrangement is the "plan board" method. This may be headed by the agency president, with executives in charge of copy, art, media, research and other departments as members. Or the planning chairmen may concentrate all of his efforts on this work. The plan board, with the account executive, formulates all general plans on the account and the work then funnels into the appropriate departments.

Another method is the "group plan." Each account executive will have one or more copy writers, an art director, a man to direct mechanical production, and such specialists as are needed-for example a radio producer if the account uses considerable radio advertising. This group is responsible for the creative work on the account. If there is not sufficient work to keep a man busy in this group he may also be assigned to another group, but on that particular account the members operate as a team. The advantage of this system is that it enables certain people to become thoroughly familiar with the special problems and policies of a client. If the group shows signs of going stale, new blood can be added.

* Otto Kleppner, Advertising Procedure (Prentice-Hall, Inc., New York, 1941), pp. 545-6. Used by permission of Prentice-Hall, Inc. 
With smaller agencies, the entire staff may constitute the "group" on every account in the shop, although even with as few as two copy writers the tendency is to have each writer specialize.

For important planning there is usually considerable give and take among the various partners, account executives, writers and other workers.

One large agency which has won many awards for its outdoor posters, has a policy of calling on everybody in the organization to submit ideas when a new campaign is being considered. It is said that for a particular poster series that attracted national acclaim, over 3,000 suggestions, out of which eight were selected, were offered by employees from the chairman of the board down to the errand boy.

Regardless of the method used for preparing the advertising plan, it must represent the best thinking of the agency, for its success or failure will reflect upon the entire organization. Clients are very conscious of the advertising done by their own agency for other accounts; prospective clients study the published work of the agencies seeking their business. So no plan for a campaign goes out of the agency without being studied by its top executives, at least in the broad aspects of basic strategy and underlying theme.

4. Writing advertisements-Once the main theme has been determined, preparation of copy comes next. Words take charge. In cubbyholes down the hall, men and women writers grapple with headlines, lead paragraphs, persuasive text, action-winning closes. Phrases are jotted down, hashed over, rejected or welded into finished copy. The writer may use a thick black pencil and yellow paper or a Parker 51 fountain pen; he may start right in on the typewriter or do his first draft in longhand and then type it out or have it typed for him; he may use a dictating machine or a stenographer. No matter what the medium there is no easy way to create effective copy-it is hard work.

Nonetheless, copy writing is regarded by most nonwriting employees of the agency as an easy job. They can't understand why a whole day should be spent on a single 120-word commercial, a week on one Ladies' Home Journal page for which the copy may fill a single typewritten page. In the course of 25 years as a copy writer the author has encountered few laymen who didn't either state openly or imply that they could write better ads than any in the magazines.

Why, then, should advertising agencies be constantly on the lookout for copy writers-and cheerfully pay their stars salaries ranging 
into the top income brackets? Perhaps copy isn't as easy as it looks! Perhaps it does take a peculiar combination of talents, of which the ability to string words together is only one.

Seasoned advertisers recognize the crucial significance of good copy. In a recent Printers' Ink survey among national advertisers the question was asked: "Rank in order of importance the agency's various services to your company: copy, merchandising ideas, research, space buying, direct mail, art and layout, new products, planning, other services." * Forty-three percent placed copy first, another 29 percent second. Hence copy ranked one-two with nearly three-fourths of the responders.

The late Claude Hopkins, considered by many as the greatest copy writer of them all, was almost a fanatic on the importance of copy. He cared little for fancy art work, or for fancy writing. But he had untold faith in the power of copy, particularly headlines. On more than one occasion, he declared, he had seen the results from a piece of copy increased eight to tenfold by a change in headline. He summed up his philosophy in such categorical statements as the following:

We cannot expect people to read our ads again and again. Our subject attracts them, and they give us brief attention. It is up to us, then, to convince them or forever lose their interest. They will not read another ad of ours if we fail to present in an enticing way something they desire.**

As previously mentioned, under the "group" system, the copy writer assigned to a particular account functions in close harmony with the account executive in planning the campaign. With the plan board method, the agency's copy department manager-sometimes called the copy chief-sits in on the basic creative work and then assigns the writing to one of his staff. Or, with a smaller agency, he may do some of the actual copy himself. If the agency is still smaller, the account executive may take care of the creative work between calls on his clients.

Agency copy writers have a variety of backgrounds. They may get their start as newspaper reporters, as department-store clerks, house-

* E. J. Dever, Jr., "Services Advertisers Expect from Agencies," Printers" Ink, January 10, 1947. Used by permission of Printers' Ink.

** Claude C. Hopkins, My Life in Advertising (Harper and Brothers, New York, 1927), p. 183. Quoted by permission of Harper and Brothers. 
to-house solicitors, factory hands, bundle wrappers or short-order cooks. A very fine copy man in a leading Chicago agency started his career as a silk weaver. Another had worked in a museum. Among his duties was that of tinting photographic post cards to be sold to visitors. When he was discharged for some minor cause, the only work he could get was painting slides for a firm that sold them to advertisers in movie houses. He began to suggest phrases and then to create entire slides. His work attracted the attention of an agency president who offered him a job.

Though no two are alike in antecedents, experience, education or working methods, all agency writers have one thing in common, a keen, fresh, alert interest in people. By choice they ride the subway or the bus, in order to rub elbows with their public. They brazenly eavesdrop in grocery stores or department stores, give their friends the third degree about their buying habits, prowl around factories or laboratories asking all manner of silly questions in quest of human reactions and thoughts. By nature they may be introverts, but the necessities of their job force them to be sociable.

The popular conception of an advertising writer as an aloof, "arty," temperamental, unbusinesslike creature cooped up in his ivory tower and dashing off reams of clever prose has led many copy aspirants astray. The copy stars of today are salesmen, either by instinct or training. They write not to awe the reader or listener with their cleverness but to persuade him to buy. If the persuasion calls for gay, fanciful lines they can produce them; if the formula is simplicity and directness they will come up with text as clean, as free from detours as the Gettysburg Address. They know how to make every word count, whether the copy pattern specifies a single brief paragraph or a full-dress parade of the product's many advantages.

While on the job, the copy writer who wants to get ahead must forego any tendency toward Bohemianism in dress or habits. One never knows when a client may drop in, or a rush call come through requiring a visit to the client's offices. The serious-minded young copy man or woman will welcome such contacts. If properly handled they are steps leading upward in one's value to the agency and in earning power.

Courage is a priceless trait for a copy writer: courage to say what he thinks in conferences; to defend what he has written when he knows it is good; to protest against emasculating changes in his copy and 
against asinine suggestions on what to write. Of course back of such courage must be discrimination, the capacity for self-criticism, the generosity to admit that the other fellow has a good idea now and then.

Above all, the copy writer in an agency must, without losing his flair, his imaginative power, learn teamwork. It's a large order. But no phase of advertising holds greater satisfaction or offers more opportunities.

5. Planning and supervising radio programs-With the exception of agencies concentrating on industrial or direct-mail advertising, virtually every United States agency has one or more clients using radio. Among the larger firms this is an important part of the billing and a special radio department is set up to handle this medium. The vicepresident and radio director of a big agency occupies a key position. Among the best known are Arthur Pryor, Jr., son of the famous band leader, who has this title with Batten, Barton, Durstine \& Osborn; Thomas H. A. Lewis, married to the film star Loretta Young, long in charge of radio at Young (no kin) \& Rubicam, now with Kenyon \& Eckhardt; Tom Luckenbill of William Esty \& Company, and John Bates of J. M. Mathes, Inc.

Sometimes the agency radio department will create a program from the ground up. More often it will take over an already existing show which may be a network sustainer, a local production, or a "package" program complete with author, cast, music and producer. A notable example of the latter is "Information Please," the brain child of Dan Golenpaul; in its ten years or so on the air it has been sponsored by such advertisers as Canada Dry, Heinz, Lucky Strike and Parker Pen, each having a different agency, yet the format has remained the same.

The large radio department may include program directors or producers, casting directors, musical directors, script and commercial writers. In the smaller agency, most of these roles are filled by outside talent working under the over-all supervision of the agency. One job is never farmed out: that of writing the commercials. An agency may lack the facilities for writing and staging a program, but it yields to no one its prerogative of creating the selling messages for its clients.

6. Buying space and time-Fountainhead of information on media, the agency "space" and/or "time" buyer occupies a most strategic position. The best planned and best written campaign may fizzle unless media are properly chosen. So the individual in charge of this department has much to worry about. 
$\mathrm{He}$ is the man whom the representatives of different publications and radio networks ask to see. If he wished, he could eat on some space seller's expense account every noon and many evenings. Yet the ironic truth is that he consistently selects the names for a client's schedule solely on the basis of which ones will deliver the best results.

The media director of an agency is primarily concerned with where the advertising is to appear after it has been created and approved. Generally he has little to say about the theme or context, being kept well occupied with "placing." $H$ is is the pioneer function of the agency, long before the days when such features as market analysis, radio production, commercial films and consumer panels were added.

He can state offhand which paper is the best buy for a particular audience in Topeka or Seattle; why one should buy two or more papers to "cover" Boston; which Sunday newspapers give the most co-operation in installing window displays in grocery stores.

Some agencies have separate departments for publication and radio purchasing. Occasionally there may be another space buyer for outdoor and transit ads. In many agencies the space buyer handles all media, with or without a corps of assistants. His gray hairs are the result: 1 , of clients suddenly deciding to cancel a whole series of noncancellable media contracts; 2 , of account executives rolling in just before quitting time to request a specific schedule of publications involving a certain amount of money-same to be ready at 9:30 A.M. the following day.

7. Making layouts, ordering and supervising art work-The Art Department of an advertising agency may range in size from less than one man to a hundred or more.

In the minute agency a free-lance artist may occupy office space without rent, devoting a few hours per week to the firm's layout and art needs by way of payment. The average small agency has a fulltime art director who designs the ads and supervises purchases of "art work," drawings, photographs, hand lettering, retouching, from outside sources. As the business grows, he may acquire several assistants. In the plan board type of agency the art director usually sits in on discussions of basic campaign plans for all accounts; he may bring along a pad of layout paper and sketch the rough ideas as they are presented by the account executive, agency principals and copy people. With the group method an agency may have several art directors each assigned to one or more accounts.

The design for the advertisement generally passes through several 
stages: the "rough rough" or preliminary phase when ideas are groping for expression; the "rough" or "tissue rough" when the basic idea is starting to crystallize; and the "comp," short for "comprehensive layout," which is executed almost as carefully as the finished advertisement, the illustrations often being sketched by the same artists who will do the actual drawings. If the ad is to be in color, the comp will faithfully reproduce those colors. Sometimes the text matter is set in type and stamped in on the comp, or a proof of the type pasted in.

Comprehensives are used chiefly in presenting a campaign to the board of directors or other high officials of the company not familiar with advertising technique and hence unable to picture in their own minds, merely from seeing roughs, how the ads will look. The veteran advertising manager, on the other hand, much prefers to have ideas presented in rough form, being perfectly able to visualize the final job from such a blueprint. As a matter of fact he is apt to be doubly critical of material that is submitted in too elaborate a fashion, rightly feeling that if the fundamental idea is good it needs no fancy frills to sell itself to him.

Knowledge of available art sources is an essential part of the art director's equipment. He must keep in touch with the commercial artists of his city, both free lance and those in studios, as well as the photographers and photo-retouchers. If the talent in his community is limited he may make trips to New York, Chicago or elsewhere to obtain the desired quality of work.

Some agencies find it practical to have finished artists on their pay roll, particularly where there is a steady flow of some special kind of art work. In most cases, however, illustrations, lettering and photography are purchased outside.

The almost universal practice in billing art work is to charge the client cost plus an agency service charge of 15 percent. A growing practice is to add 17.64 percent, which yields a revenue of 15 percent on the gross amount.

Besides his chief duties as designer of ads and supervisor of art purchases, the art director functions as consultant on many problems of an artistic nature.

Although most art directors remain in their own orbit, occasionally one steps out, either into the ranks of general agency executives or into the select group of magazine illustrators. Rene Clark, art director of 
Calkins \& Holden, became its president for a time. Lester Loh is not only art director, but a vice president and director of J. M. Mathes, Inc., as is Arthur Surin at Geyer, Newell \& Ganger. James Yates went from art direction for William Esty, handling Camel Cigarettes, to Curtis Publishing Company where he did a notable re-styling job on The Saturday Evening Post; later he reverted to the agency field but then became art director of the Curtis monthly, Holiday. A few art directors who combine copy-writing ability with design skill have been put in charge of all creative work for their agencies, as was Sid Wells in the Chicago office of McCann-Erickson, Incorporated.

The most successful art directors are not necessarily those with great ability in producing finished art. They must possess imagination, versatility, a catholic taste, appreciation of all forms of pictorial expression, grasp of typography, engraving and printing processes and a strongly developed merchandising instinct. After all, the ad has a selling job to do, and it must sell in format and illustration as well as in words.

8. Mechanical Production- "In a medium-sized agency there are in process, at times, upward of two thousand separate production jobs," according to a standard book on agency practice.* "How can any one individual or group of individuals hope properly to keep in touch with that number of production jobs without the use of some system?"

These particular writers advocated the use of a production-control board for this purpose. With this method a large sheet is ruled off for each account and various colored thumbtacks used to denote the progress of the different jobs through copy, layout, art, client okay, engraving, typesetting, electrotyping and printing operations. The board shows at a glance which jobs are making satisfactory headway, which are being delayed and who is to blame.

Whether a control board or some other method is employed, responsibility for getting the work done on time usually devolves upon the production staff. Some agencies have a separate "traffic division" charged with following orders through from their point of origin to completion. The "group" method makes provision for the assignment of a "detail man," or girl, who pesters the life out of anybody unfortunate enough to be bottle-necking a particular job.

All media have "closing dates," the fixed time after which no ad

* Floyd Y. Keeler and Albert E. Haase, The Advertising Agency (Harper and Brothers, New York), p. 94. Quoted by permission of Harper and Brothers. 
can be inserted. With a national magazine this may be two or three months in advance of publication; with a daily paper, only a few hours before it hits the street. The production and traffic people must know the closing date for every publication and control the ad preparation accordingly. The customary procedure is to set up a schedule by working back, allowing an adequate amount of time for each operation; this determines how far in advance preparation for the ad should be started.

For example, assume that a four-color advertisement is to appear in the February issue of Good Housekeeping. The closing date is "15th of third preceding month," November 15. The engraver estimates that he will need a minimum of twenty working days to turn out his plates; five days are added as a "cushion." Five more days are required if duplicate plates are to be sent. Another five days must be allowed for obtaining the client's okay. Shipping of plates will take five days more.

This gives 40 days so far; with the five-day work week that means plates should be started September 20. Natural-color photography is to be used for the main illustration; three weeks are set aside for this, with another week for client's approval. Before the photo can be taken, copy must be written, layout made and both okayed. The copy has to be set and fitted into the layout, but that can be done while the color photograph is in work.

The amount of time to be allowed for creative work varies considerably. If a new copy theme is being developed preliminary discussions may start several months in advance. Where the "pattern" has already been set, many agencies make a practice of notifying the copy department or writer four to six weeks in advance of the date when that particular ad should go into the art department for layout. The hypothetical traffic schedule for the February Good Housekeeping ad, therefore, might look like this:

June 28: Notify copy dept.

July 26: Copy due.

Aug. 16: Layout completed.

Aug. 23: Client OK on copy and layout. Start art and typesetting.

Sept. 13: Complete art and typesetting.

Sept. 20: Client OK on art and type. Start color plates. 
Oct. 18: Plates due.

Nov. 1: Final OK on entire ad.

Order reproduction plates.

Nov. 8: Ship plates to publisher.

Nov. 15: Closing date.

This appears like an ideal arrangement with ample time for each step. There is only one thing wrong with the picture: it is now not June 28, but October 12 !

Instead of three weeks, the color photography has to be done in a maximum of one week and it had better be right-there's no time to re-photograph! Instead of 25 working days for the engraver, he must be cajoled or bludgeoned into getting the plates out in 15. Instead of four weeks for copy and three for layout, they must be done overnight; but then, late hours are no novelty to creative folks in advertising agencies. At the last minute, if the closing date has arrived and the ad is still uncompleted, publishers may grant an extension; though of late years they have become less and less co-operative on that score.

Somehow, by dint of feverish effort, the production man "catches the issue." He relaxes. Never again! From now on, ads must be started far enough ahead to-

The phone rings. It's another account executive. "Look, Bill! I just got back from Glockenspiel and Krood's. They wanna run a series in Time, starting with the first January issue. Yes, I know it closes in two weeks, but__

And that's mechanical production in an agency!*

9. Merchandising and Sales Promotion-Close behind the creation of effective copy and attention-compelling layouts, among services that agency clients value most, is the development of merchandising plans and ideas.

Nearly thirty years ago the American Association of Advertising Agencies, in adopting their standards of practice, set up as the final point: "Co-operation with the client's sales work, to secure the greatest effect from advertising."

And in its survey of agency operations in August 1946, Advertising Age found:

Advertising's greatest advances [since 1918] have been in advertising research, copy testing, audience and research measurement, mer-

* For information on the technical aspects of production, see Chapter XXII. 
chandising and sales promotion-both to dealers and to consumers at the point of sale. Although the quality of creative work ... still plays an all-important role in the sale of advertising [agency] service, emphasis has shifted to those services designed to increase the effectiveness of advertising.*

Named among the ways in which agencies assist clients in improving results are the following. The percentage figures indicate the ratio of agencies (reached by the Advertising Age survey) performing each of these services.

1. Send principals, account executives or creative personnel on occasional field trips with client's salesman. (85\%)

2. Prepare point-of-sale display material. (96\%)

3. Prepare presentations and sales aids to help advertiser's salesmen merchandise campaign to trade. (94\%)

4. Present advertising program to trade meetings, conventions, shows. $(89 \%)$

5. Prepare direct-mail broadsides, folders and letters to merchandise campaign to trade. (95\%)

6. Prepare dealer tie-in advertisements or radio announcements. $(86 \%)$

7. Write letters or broadsides requesting merchandising activity by newspapers or radio stations. $(78 \%)^{* *}$

Not infrequently the merchandising work of an agency may include direct sales assistance. The survey disclosed that 54 percent of the agencies reporting make calls on key distributors, jobbers and chainstore buyers, not only to secure data useful in preparing the campaign or to check on its reception, but with the avowed purpose of getting orders.

Merchandising activity may be centered in a special department of the agency or spread among the "groups." It is a primary concern of every account executive. Collaboration among account representatives will often produce a valuable interchange of merchandising information and support. The man handling Account $\mathrm{X}$ on a field trip to Texas for his client, involving calls on grocery jobbers in several cities, may find time to visit drug jobbers in those same towns on be-

* Advertising Age, August, 1946, p. 15. Quoted by permission of Advertising Age.

** Ibid., pp. 16-17. 
half of the executive handling Account Y. Mention has already been made of similar back-scratching activities by agencies having a number of offices and by agencies affiliated with a national group.

Indicative of the modernity of this agency function is the fact that Keeler and Haase's The Advertising Agency, published only 20 years ago, lists neither merchandising nor sales promotion in its index. Reference is made to a "Marketing or Research Department," but the authors state plainly: "Market investigation ... as a primary function of the agency, comprehends only such endeavor as is necessary for the formulation of sound advertising plans." Today few if any agencies consider that they have fulfilled their obligations to the client until they have followed through to see that the campaign actually works and have done everything possible to make it work.

Payment for merchandising service is a matter of individual arrangement between agency and client. The time spent by agency people in the field, except on special investigations requested by the advertiser, is seldom billed, though traveling expenses may be. Preparation of displays, sales aids, dealer mailings may be done gratis if the agency handles the printing or lithographing, in which case the usual 15 percent commission is generally added; where the client does the buying, a special "service fee" may be charged. Accounts requiring considerable merchandising work in proportion to the amount of commissionable media may operate on a monthly or annual fee against which commissions are credited.

Under the present agency-commission system, it is essential that compensation for work done be kept as uniform as possible regardless of the plan selected, lest the agency be influenced in its recommendations by those media which offer it the greatest profit. Certainly no agency gets rich from fees on merchandising service; at the same time, if such activity pays dividends to the client, its cost justifiably should be borne by the client. But there is another large "IF" to be considered. If effective merchandising and sales promotion help the agency to hold an account against competition, it can be regarded as a form of business insurance for the agency. And where the premium is not excessive or out of line with the revenues from that account, the agency may absorb it as a necessary part of operating expense.

10. Checking and Billing-The agency's responsibility for the appearance of an advertisement does not end with shipping the engrav-

*Op. cit., p. 75. 
ings or art work to the publication, the commercials to the network or local station, the posters to the posting company, the car cards to the transit office. Each insertion or appearance must be checked.

This is relatively easy for magazines. A clerk in the agency's checking department merely goes through the periodical and notes that the ad has appeared. Usually this routine is supplemented by the account executive, who wants to make sure that his ad has been given a good "position," i.e., next to reading matter, in a part of the "book" where it will be seen by the maximum number of readers and by preference on a right-hand page (although research has shown little if any difference in pulling power between a right-hand and left-hand page.) The production manager and art director will look at the ad to see if it has been properly reproduced. Where the advertisement contains a key number, or other special information to be inserted by the publication, this must also be verified for accuracy.

With posters, the space department may send somebody to "ride the showing," traveling about the city to make sure that posters have good locations from the standpoint of visibility, closeness to dealers, density of traffic and quality of neighborhood.

With the possible exception of spot radio, newspaper advertising is the most difficult to check, especially when a long list of papers has been ordered. If mats are supplied, these have a tendency to shrink the size of the ad, so that a 100-line insertion may occupy only 96 lines of space. Rulers are used by the checkers to make sure that the client has received the linage ordered. The checking department must also be on guard against poor position, an ad "buried" or surrounded by other advertising, as well as faulty reproduction. Certain clients insist that their ads must not be placed on the same page with a competing product, and this is another checking department responsibility.

Billing, both for media and for mechanical expense, is handled in a variety of ways. In the small agency, a bookkeeper may make out the invoices, based on orders received from the space and production departments. With larger agencies, the procedure is much more complex. Any expenditure for which the agency expects the client to pay must be preceded by a signed estimate. If the cost exceeds the estimate, the additional charge must be cleared with the advertiser by the account executive. More accounts are lost by agencies because of disputes over art and mechanical charges than any other reason except possibly the lure of new ideas. 
Since most agencies operate on a relatively limited cash reserve, promptness in billing is vital. Publication insertions are sometimes invoiced to the client in advance of the appearance of the ad and always as soon thereafter as possible.

Proper invoicing of production expenditures calls for constant alertness. A single advertisement may represent outlays for art from two or three sources, typography from another, engraving from another, electrotyping from still another. The accepted method is to collate all costs in a "job ticket" containing the estimates and purchase orders on that particular piece, and then to round up the bills from suppliers in order that invoices may go to clients without delay. An artist who has done an illustration for an ad will be hounded just as grimly for his bill as he was for delivery of the art work.

The 4 A's recognize the need for quick billing in this statement:

The client is obligated to pay promptly the agency's bills for publication space and radio time. It is a fundamental principle that the client must pay the agency in time for the agency to pay the media by their due dates.

It is not a function of agencies to finance the advertising of their clients. (Media strongly object to agency financing of clients since the large amount of capital required would shut out of the agency business men with high talent but modest funds-men whose creative work might do much to increase the volume of advertising.) *

11. Publicity and public relations-Back in the Barnum days, advertising space was often openly a bribe to the publisher for free publicity in the editorial columns. Advertising agencies inherited this press-agentry function. It became accepted procedure for an agency placing space in a newspaper or magazine to request the insertion of articles promoting the advertiser.

As the great metropolitan newspapers and national magazines developed, their publishers saw the fallacy in such requests. The periodical is of value as an advertising medium only if it enjoys the confidence of its readers. A newspaper or magazine filled with obvious bouquets for its advertisers quickly loses its hold. Hence more and more publishers have adopted a policy of printing items about business firms only when such items are of genuine reader interest.

Among its "practices to be avoided in newspaper relations," the

* Structure of the Advertising Agency Business, the American Association of Advertising Agencies. 
American Association of Advertising Agencies includes the following on free publicity:

(a) Obtaining for advertisers that indiscriminate type of free publicity which has no legitimate news, educational or editorial value.

(b) Inducing or influencing any publisher to print news or editorial items by any promise of advertising, or threat to withhold it, expressed or implied. (In this connection, it seems undesirable to forward such items to the publisher accompanied by orders to insert advertising.)

Such practices tend to weaken the editorial influence of the press, thus impairing its value as an advertising medium. They also tend to add to the cost of general advertising and to the rates that all have to pay.*

For its own sake, therefore, the ethical agency makes no unreasonable publicity requests of any periodical or radio station. This does not deter it from taking advantage of all legitimate channels of publicity. Many agencies have a special publicity department headed by a former newspaper reporter or magazine editor familiar with the editors or staff writers of a large number of periodicals and skilled in devising "releases" (publicity stories) that will win acceptance in the news columns.

Some of these publicity stories have legitimate news value, as when Henry Ford II announced sweeping reductions in the prices for Ford automobiles in 1947, to offset the current inflationary trend. Or when Henry Kaiser and J. K. Frazer brought out their new models in the automotive field right after V-J Day in 1945.

Certain products lend themselves to pictorial publicity. Industrywide groups may crash the rotogravure section of newspapers coast to coast with a picture of a girl in a bathing suit who has been named "Miss (Name of Industry) for (Year)." The Frozen Foods Institute in selecting "Miss Frozen Foods of 1947" took the precaution to have her photographed sitting on a cake of ice. Another favorite fancy is to have the model wearing a costume, the briefer the better, made out of lettuce, tangerines, ice cream cones or whatever the product happens to be.

Makers of food items may wangle free space by means of recipes or photos of food preparation which appeal to cookery editors. Fur-

* Quoted by permission of the AAAA. 


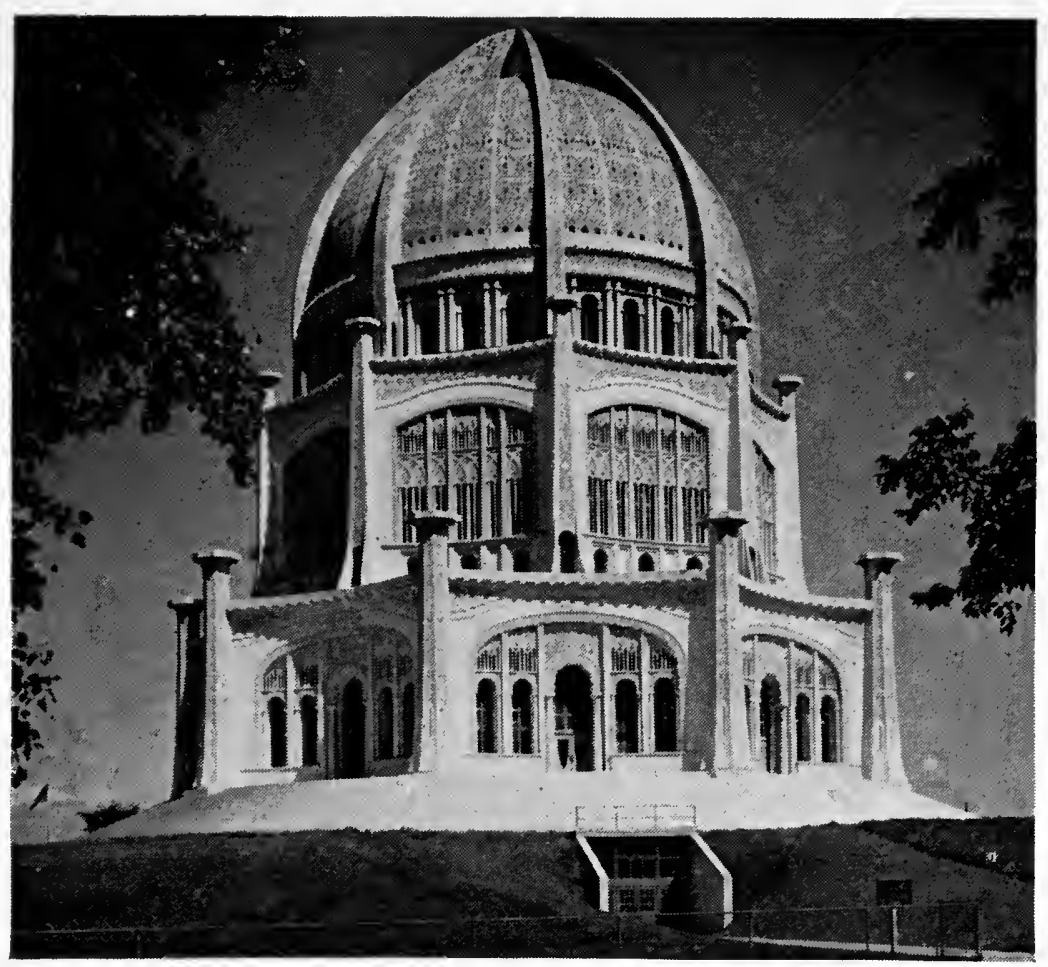

\section{Beauty to the Top of lts}

\section{Gleaming White Dome with CONCRETE}

TN the hands of skillful architects and trained engineers, concrete, $\mathbf{L}$ the versatile structural plastic, provides the beauty of a Bahá'i Temple, and the strength for towering dams and for highways which carry the nation's heaviest traffic.

\section{HUNDREDS OF USES}

Concrete has a hundred uses on farms and in cities. It builds firesafe, weather-resistant farm and industrial buildings, attractive homes, apartments, hospitals and schools.

\section{CONCRETE FOR LOW ANNUAL COST}

With all its advantages of beauty, firesafety, rugged strength and weather-resistance, concrete gives low annual cost-the true measure of economy in construction.

We will gladly cooperate with your architects or engineers in securing all the advantages of concrete for your future construction.

Bahái Temple, Wilmette, III., exemplifies the architectural beauty which can be oblained with concrefe. Concrete for exposed surfaces was precast from white crystalline quartz aggregate and whife portland cement. Louis J. Bourgeois was the architect.

\section{PORTLAND CEMENT ASSOCIATION}

Dept. 8e-12, 33 w. Grand Ave., Chicago 10, llinols

A national organization to improve and extend the uses of concrete ... through scientific research and engineering field work

\section{ASSOCIATION ADVERTISING SELLS AN IDEA}

The advantages of this material rather than a particular brand are emphasized in this campaign. 


\section{A Hog Can Cross the Country Without}

\section{Changing Trains-But YOU Can't!}

\section{The Chesapeake \& Ohio Railway and the Nickel Plate Road are again proposing to give human beings a break!}

It's hard to believe, but it'a true.

If you want to ahip a hog from coast to coast, he can make the entire trip without changing cars. You can't. It is impossible for you to pass through Chicago, St. Louis, or New Orleans without breaking your trip?

There is an invisible harrier down the mid. dle of the United States which you cannot cross without inconvenience, lost time, and trouhle.

\section{0,000 Victims in 1945 !}

If you want to board a sleeper on one coast and ride through to the other, you must make double Pullman reservations, pack and transfer your baggage, often change stations, and wait around for connections.

It's the aame sad story if you make a relatively short trip. You can't cross that mysterious line! To go from Fort Wayne to Milwaukee or from Cleveland to Des Moines, you must also atop and change trains.

Last year alone, more than 560,000 people were forced to make annoying, time-wasting stopovers at the phantom Chinese wall which splits America in half!

\section{End the Secrecy!}

Why shonld travel be iess convenient for pea ple than it is for pigs? Why should Amerieans be denled the beoefits of through train serviee? No one has yet been able to explain it.

Canada has this service... with a choica

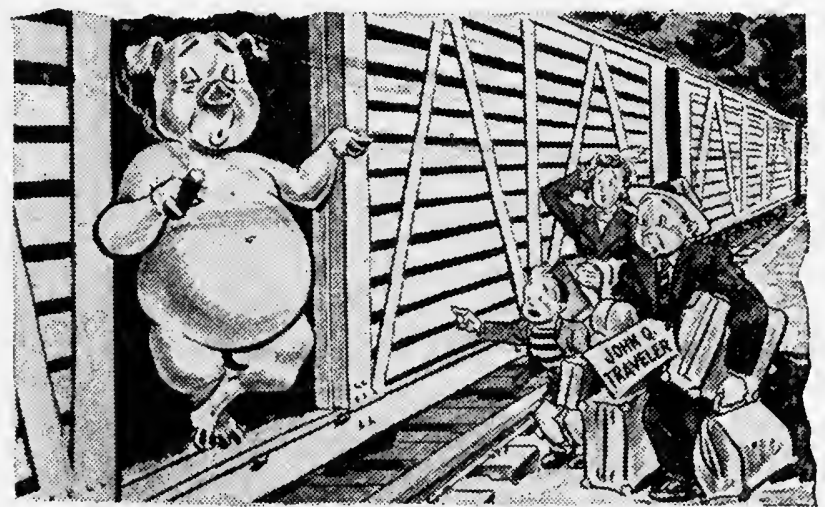

of two routes. Canada isn't split down the middle. Why ahould we be? No reasonable answer has yet been given. Passengers at ill have to stop off at Chicago, St. Louis, and New Orleans-although they can ride right through other important rail centers.

It's time to pry the lid off this mystery. li's time for action to end this inconvenience to the travelling public... NOW!

Many railroads could conperate to provide this needed through service. To date, the Chesapeake \& Ohio and the Nickel Plate ALONE have made a public offer to do so.

\section{How about it!}

Once more we would like to go on record with thia apecific proposal:
The Chesapeake \& Ohio, whose western passenger terminus is Cincinnati, stands reaciy now to join with any combination of oth $r$ railrnads to set up connecting transcontinentul and intermediate service thronga Chicago and St. Louis, on practical schedulcs aud roules.

The Nickef Plate Road, which runs to Clifcago and St. Louis, aiso stands realy now is join with any combination of roads to set up the same kind of connecling service throush these two cities.

Through railroad service can't be blocked forever. The public wants it. It'a bound to come. Again, we invite the aupport of the public, of railroad people and railroad investors-for this vitally needed improvement in rail transportationl

\section{Chesapeake \& Ohio Railway · Nickel Plate Road

\section{CRUSADING COPY THAT JOLTED READERS INTO ACTION}

Robert R. Young of the Chesapeake \& Ohio lines proved once again that peopl read long copy-when it has something to say. 
niture manufacturers and their agencies bear down on the home styling angle.

Publicity stories about new products, new packages, new models, changes in personnel, new factories and so on are acceptable in the trade papers and often in the business or financial section of newspapers. Sending out articles of this kind is a legitimate agency service, sometimes done gratis and sometimes charged for, but printing such material should never be made a condition of awarding advertising to a publication.

"Public relations" is to publicity what the oculist is to the optician. The latter makes and sells eyeglasses; the oculist, a full-fledged M.D., not only prescribes spectacles when needed but tackles the causes of eye trouble. So with the public relations expert. He studies the whole area of his client's contacts with consumers, with their communities, with suppliers and service companies and with competitors. Most agencies advise clients on these relations in a general way. Some corporations retain separate public relations counsel for this specialized field, some have it handled by the agency.

Detailed discussion of public relations has been purposely omitted from this book. Although many agencies render service in this field and many advertising departments are held accountable for the public relations of their firms, the author feels that it is a separate subject and should be treated as such.

12. Soliciting new Business-"So you want to be an advertising man? Okay, let's see you advertise yourself to me!" This is a standard challenge of the agency executive to the novice applying for a job. And it is too frequently the attitude taken by an advertiser about to choose a new agency. The personality of the solicitor may overshadow some serious shortcoming in the background, resources or suitability of the agency for that particular account. Elaborate presentations, even to completely prepared advertisements or radio transcriptions, may bowl over the prospective client, who appoints the new firm in a white heat of enthusiasm only to meet with disillusionment when his business fails to double the first year.

Today many agencies refuse to engage in "dogfights" for new business. Despite Hollywood, million-dollar accounts don't change hands because of a sensational idea thought up by some glib-talking stripling with only superficial knowledge of a manufacturer's production and distribution problems. 
Brilliant copy, art and merchandising talent may win a new client, but almost without exception it happens because such talent has been demonstrated on another account!

After the agency has been appointed, after it has had ample time to analyze the needs of the new account, it will create a sound, carefully developed campaign tailored to the product. The campaign will incorporate the best thinking of the agency and the client. And while it may not turn the entire industry topsy-turvy or swamp the plant with orders it will do a professional job. The agency can look forward to holding the business over a period of years and the advertiser is spared the wasted time and agony of changing agencies every year or so.

The practice of submitting speculative ideas has cost advertising agencies millions of dollars in bygone days. It interferes with service to present clients, who are entitled to first call on the best creative brains of the staff. It is definitely considered "unsound, uneconomic and unprofessional" by the $4 \mathrm{~A}$ 's.

Nevertheless, it takes a strong-willed agency president to say "No!" when a solicitor dashes in with the tidings that a luscious new account will fall into his lap "the minute we show 'em something!" Sometimes the temptation is irresistible; copy men and art directors beat their brains out; that terrific idea is produced; then, the day before it is to be presented to the palpitating prospect, the advertising papers announce that the account has been awarded to another agency. That's one time when fascinating is hardly the word for this business!

New accounts may be solicited either by men who devote all their time to it or by the same men who will later service the business. The former method is quite generally employed by the larger agencies. A new business department operates under the direction of a major officer, with solicitors making calls on prospects that have been selected as worthy candidates for the roster of clients. Sometimes these calls may continue for months and years, with or without result. The solicitors also call on advertisers who have indicated, either directly or through the always seething advertising grapevine, that they are dissatisfied with their present agency and might make a change.

In medium-sized agencies the account executives do their own soliciting. Instead of the new business being turned over to the house for handling, as is done with the previous method, the account man services it himself. This has several disadvantages from the agency stand- 
point. The more successful an account executive is the less time he has to develop new clients. After the agency reaches a certain stage of growth it can only expand farther by adding new account executives. The most serious objection is that sometimes the account executive, having secured the business originally and having been its chief contact ever since, may come to feel that he has the account "in his hip pocket" and attempt to transfer it to another agency for one reason or another. Such switching rarely occurs, however, if the creative and merchandising departments of the agency are doing a bang-up job for the client.

Compensation for obtaining new business may be by straight salary, salary plus bonus or a drawing account against a percentage of the gross billing. The percentage varies from as low as $2 \mathrm{I} / 2$ or 3 percent up to as high as 10 percent of the gross, with 5 percent being somewhere about average for the account executive who sells and handles the account himself. Working on an arrangement of this kind, a man adept at obtaining and holding clients can often earn more for himself and serve his accounts better than if he had his own agency, struggling with overhead, payrolls and administrative routine. More than one owner of a small agency has given up the dubious privilege of seeing his name on the front door to become an account executive in a larger firm, and thereby added years to his life.

No discussion of new business solicitation can overlook the chief source, increasing the advertising of present clients. Every campaign represents an opportunity. The advertiser who has stepped up his sales 25 percent by spending $\$ 50,000$ in one year may decide to appropriate $\$ 100,000$ the next year in the hope that this will produce a 50 percent gain. Frequently it is harder for the account representative to hold the client down to a conservative figure than to obtain an essential increase. But if the agency as a whole creates a sound plan and tops this with the other ingredients of modern advertising, the billings will grow on a solid basis.

Present-day agencies are established on a professional level. Standards of practice have risen year by year. Regardless of best sellers and the movies, the rank and file of agency people do a conscientious, workmanlike job. They have a very real pride of craftsmanship. The number who function with tongue in cheek, while vociferous, is minute compared with those who believe in simple honesty, and who spend the advertiser's money as if it were their own. 


\section{Chapter IX \\ THE RETAIL ADVERTISER}

TOR every national advertiser using magazines, network radio and H other far-reaching media to influence the sale of his goods or 1 services, there are at least 25 retailers or local service firms doing some sort of advertising in a limited area.

True, this advertising may be nothing more than an occasional handbill, or a $\$ 1.00$ ad in a county weekly, but it is just as important to that little business as a spread in Life is to Eversharp. From such humble beginnings have come the Macys and Marshall Fields, the Krogers and the Walgreens, the Woolworths and the Penneys-retail titans that outrank all but a few of the very largest manufacturers, public utilities, insurance companies and other great national advertisers.

Newspapers constitute the chief medium of local advertising, with department stores, grocery and drug chains as chief buyers of space. Furniture and floor coverings stores, women's apparel shops, men's clothiers, shoestores and movie theaters also are apt to be steady newspaper advertisers.

Other local media include radio stations, posters, classified advertising in newspapers and phone directories, direct mail, road signs, handbills, premiums or souvenirs, paper matches, booths and displays, street banners, sound trucks, streetcar and bus cards, suburban and country weeklies and sandwich men.

Naturally local advertising in New York City or Chicago has little in common with that done in Taylor, Wisconsin, or Olive Hill, Kentucky, as to cost or number of people reached; but virtually all local advertising seeks immediate as well as long-range results. The department store owner who runs an ad in the Friday night paper expects a crowd on Saturday morning. The supermarket operator with a fresh shipment of vegetables can't wait for customers to find out about it by word of mouth; he uses advertising in the form of window streamers, newspaper space, handbills, occasionally radio. There is, however, a growing tendency among retail advertisers to devote a portion of 
their advertising to building up the prestige of the store, institutional advertising. Professor Hotchkiss quotes the advertising manager of a leading store who declared that although only 6 percent of his advertising was institutional, it was the most productive 6 percent in his entire appropriation.* Attractive, informative local advertising, even though it talks only about specific merchandise, has a cumulative prestige or institutional value.

-How big is local advertising by comparison with national? Dr. Hans Zeisel, manager of research development for McCann-Erickson, Inc., estimated in Printers' Ink that total U. S. advertising volume for 1946 was $\$ 3,116,600,000$, of which 65.2 percent was national and 34.8 percent local. In newspapers he figured that local advertisers spent $\$ 671,000,000$, against $\$ 292,000,000$ by national firms; in radio, $\$ 131$,000,000 local, $\$ 358,000,000$ national; under miscellaneous, including advertising department costs, display materials, and other media, $\$ 223,000,000$ local, $\$ 430,000,000$ national. It adds up to over $\$ 1,000$,000,000 for local advertising in one year.***

That's a staggering total, but let us see what it helped to accomplish. During this same year of 1946, according to another P.I. study, ${ }^{* * *}$ the nation's retail sales reached almost $\$ 94,000,000,000$, an increase of 28 percent over the previous year. This means that only slightly more than 1.1 percent of the total retail sales went into advertising costs, a figure that not even the most rabid opponent of advertising could call exorbitant.

Now, take a look at some types. of retail advertising and see what makes them work.

\section{Department Store Advertising}

For sheer drama and continuous action, few branches of advertising can rival that of a modern department store. Every day presents a fresh challenge. The doors are open, the employees on duty, the merchandising waiting, but will the customers come? Much depends on the store's advertising. Or rather, to use department store language, its "publicity." (This includes not only advertising but also window

\footnotetext{
* George Hotchkiss, op. cit., p. 421.

** Dr. Hans Zeisel, "1946 Advertising Volume Greatest in U. S. History," Printers' Ink, March 27, 1947. 1947.

*** Walter P. Burn, "94 Billions in Retail Sales in 1946," Printers' Ink, April 4,
} 
and interior displays, public relations and comparison shopping in other stores.)

This constant pressure for business and the quickness with which results can be observed are not the only exciting things about a department store advertising career. New items keep coming in, new styles, patterns, models, colors. Special selling events are always either being planned or already under way. Unexpected purchases are forever being announced, each with its need for fresh copy.

Perhaps most interesting and stimulating of all is the never-ending contact with people: merchandise managers, department heads, buyers, salesclerks, and the general public. It's no job for a recluse! But for anyone who enjoys personal relationships, who has the knack of working with others and at the same time has the creative flair, the field is wide open.

Newcomers who want to break into advertising are often advised to try the department stores. There are far more jobs in proportion to the dollars spent than in an agency or a manufacturer's advertising staff. Because of the valuable training and experience obtained in such work, department store advertising people are sought after by agencies, leaving openings for ambitious youngsters. Even though there may be no immediate vacancy in the advertising section, the applicant can usually get a job behind a counter while waiting. This period of personal selling won't hurt at all when an ad job is available.

All successful department stores operate with a carefully workedout plan, corresponding to the campaign program of a national advertiser. As a rule, the plan covers a six-months period. The publicity director or advertising manager of the store, in co-operation with the merchandise manager and general manager, will decide what special selling appeals or "promotions" will be used during that time, estimating the probable amount of business and applying his publicity percentage to determine the approximate amount of the budget.

Many factors influence the percentage of total sales set aside for publicity. Curiously, as stores grow in size they tend to spend higher percentages since they must draw from an ever-widening area of customers. And there is another reason too, as Edwards and Howard point out:

The relatively higher percentage expenditure of the large store may be attributed to greater wisdom rather than necessity. As a rule, the 
larger store is likely to be more keenly aware of the benefits to be derived from advertising. More than likely it grew to be a large store because it advertised frequently and regularly. It therefore recognizes the wisdom of investing in aggressive, consistent advertising, and it commits itself to a policy of continued advertising effort in order to maintain its position of leadership in the community. ${ }^{*}$

Intensive advertising by competitors may also force a higher publicity percentage. A newly established store will of necessity have to spend more per dollar of sales than one with a steady clientele.

The biggest spread comes between the different types of stores. A conservative or "nonpromotional" type of store will always spend less than a store featuring special events and relying heavily on price advertising. Most of the better known department stores come about midway between the two types and can be called "semipromotional." Typical advertising percentages for these different classes of stores run something like this:

Nonpromotional stores (emphasizing leadership in style, wide choice of merchandise, usually above-average prices) -1.5 to 2.5 percent. Semipromotional stores (emphasis about equal between quality and price; has regularly scheduled sales events, but considerable volume of business not attributable to promotions) -3 to 4 percent.

Promotional stores (quick turnover, lower price, less service to customers, little regular trade but continual promotions with largespace ads) -5 to 6 percent or higher.**

Basement store advertising, being almost exclusively promotional in nature, will run into higher figures than the store-wide average.

The display section, which takes care of window trims, interior setups, advertising cards and bulletin boards, will average about 1 percent of sales regardless of the type of store, it appears from several studies.

Once the advertising budget has been determined, either for six months or a year, it is subdivided. From 10 to 15 percent will go for salaries and departmental overhead. Another 10 percent may be set aside for "institutional" use, ads featuring the store as a whole rather

* C. M. Edwards and W. H. Howard, Retail Advertising and Sales Promotion (Prentice-Hall, 1936, 1943), p. 99. Quoted by permission of Prentice-Hall.

** Ibid., pp. 158-159. 
than any one line. Still another 10 percent may be allocated for art work and plates. The remainder goes into media, with newspapers getting somewhere between 80 and 90 percent of the average "media budget."

The next problem is to assign funds by sections or departments, based on a study of the previous year's sales, publicity expense and profits. Certain lines which have a wider profit margin or are important in influencing the consumer's attitude toward the store will receive a higher percentage than the unspectacular staple lines.

Having divided the budget by departments it is now spread out over the period either seasonally or by months. Sometimes it is even split on a weekly basis. Or, instead of first dividing the budget by departments, the advertising manager may separate it by time periods and then make the departmental separations. In any event, the available money is assigned before the period starts, to prevent excessive spending at one time and not enough at others.

Special events or "promotions" are usually assigned at the beginning of the publicity period. These may be either to introduce newly received merchandise, the Spring Fashion Festival, Back-to-School, Winter Opening, etc., or chiefly to dramatize the store's value-giving resources. Almost anything can be used as a "peg" on which to hang a special sale. Among the traditional events are:

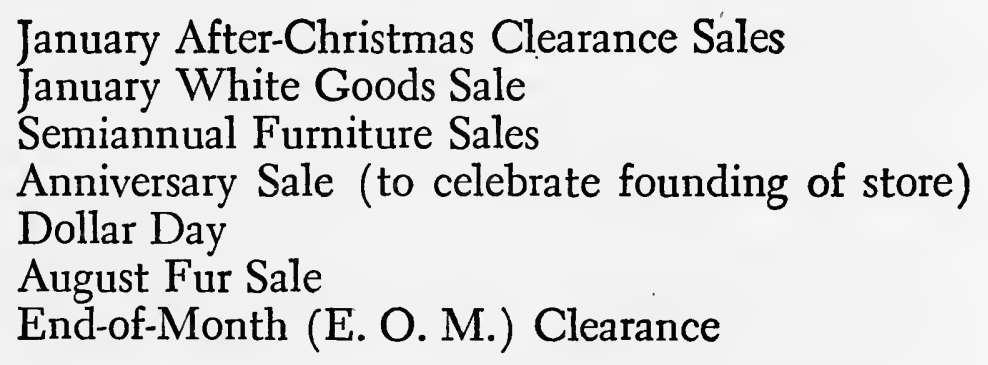

Some events are store-wide, others limited to departments. By way of variation, occasionally a single item such as hosiery or handkerchiefs will be given a store-wide push by having aisle tables scattered through the store. Holidays and occasions like Father's Day, Baby Week, spring vacation and graduation often serve as promotional springboards.

Conditions during and immediately after World War II caused many advertising managers to confine their six-months plan to generalities and do their detailed planning month by month. The 
monthly plan may be started from 30 to 60 days in advance. It has several advantages. With probable shortages in many lines, obviously there is little use in planning promotions until one knows what merchandise will be available. Competition, the business outlook and consumer trends are more difficult to predict now than before the war. In fact some stores, located close to markets where they can make quick selections and obtain prompt deliveries, work on a weekly plan, starting only seven days in advance of the actual week to develop their promotions. This hand-to-mouth method is not recommended for anyone suffering from cardiac ailments.

Weekly, monthly, semiannually or yearly, whichever the plan may be, it arrives sooner or later at the operational stage. The theme has been selected, the merchandise offerings set. In the advertising department even the ad sizes, newspapers (assuming that there is more than one in the city) and insertion dates have been determined. Now the advertising staff goes to work.

Depending on the size of the store, this staff may consist of from one to 100 or more people. Some of the larger stores have advertising departments which are in reality "agencies in everything but the 15 percent."

Under the advertising manager, who reports to the publicity director and has general supervision over the budget, the plan, and the character of the store's advertising, the larger stores will have an assistant manager, copy chief, copy writers, art director, layout and finish artists, photographer, production manager and staff, proofreaders, media managers (newspapers, direct mail, radio, signs), bookkeepers, file clerks, merchandise clerk (to check items in and out of the department when required by writers or artists) and various secretaries and stenographers. In addition one of the foregoing or another individual, sometimes even several, will occupy a position corresponding to that of research director in an agency. Department store research includes not only intensive study of market trends, consumer tastes and previous sales records in the store, but as much information as possible about what the competition is doing. Such knowledge is obtained by: (1) closely observing rivals' advertising and window displays: (2) sending "comparison shoppers" to the other stores posing as legitimate consumers to observe and report back all possible information regarding styles, prices and whatever else seems pertinent. 
The actual functioning of a department store advertising staff is most clearly shown in a sequence of pictures, "How Marshall Field Turns Out Ads," which appeared originally in Advertising Age, July 29, 1946.

Copy writers or divisional advertising co-ordinators interview the merchandising men or buyers to obtain facts about items to be featured. Photos or, where advisable, the actual merchandise is brought into the department. Headlines and text are written. Layouts are made. Artists or photographers supply the illustrations. The ad comes together and must then pass the critical eye of the buyer, for accuracy, and the advertising department brass hats, for smartness, buy-appeal, store "character." From there it goes into production, appearing a few hours or a few days later in the newspaper. Long before then, the man or woman who started it on its brief career will be working on other ads, other promotions.

To maintain poise and sanity under such conditions is difficult, but not impossible. Most department store advertising people do it by working furiously when the pressure is on, then relaxing completely. Those who escape the rapids and whirlpools to the calmer waters of agency or magazine work are prone to look back nostalgically.

Most essential duty of ad underlings is that of maintaining store "character." This elusive something comprises many ingredients: the phraseology of the copy, just gay and informal enough, but not too flippant; the price angle, played up or down; short or long text; emphasis on value or style. It also includes other elements beyond the copy writer's control, such as the store's treatment of customers, handling of window displays, interior arrangement.

Macy's in New York, for example, concentrates on thrift. Its copy stresses value, long wear, over-all economy. Bergdorf-Goodman and Altman's are pre-eminently purveyors of style merchandise. Stores like Field's in Chicago, Hudson in Detroit, Chapman in Milwaukee and Holmes in New Orleans lean toward the carriage trade but keep their feet on the ground with "value-giving" promotions. NeimanMarcus in Dallas and L. S. Ayres in Indianapolis are other stores that have successfully combined a style appeal with the economy note.

Recent years have seen a leveling off in department store policies in this respect. Even frankly promotional stores have added smartness to their advertising layouts while modernizing their windows and interiors. Although their business was built on a never-ending bargain 
appeal, their former customers, financed by wartime pay increases, began to drift to the stores whose packages and labels carried a certain snob appeal. Mrs. Factory-hand, having substantial money in her reticule, started shopping at the smarter stores. The promotional type of department store either had to get "classy" or take the consequences. At the same time, the high-hat stores whose white-collar patronage had been caught in the pinch of fixed incomes and rising prices veered toward the promotional type of treatment.

One way of establishing store character is by the number of individual items in an advertisement. Bargain-basement or special-event copy such as "dollar day" is noticeable for the quantity of merchandise crowded into a single ad. Upstairs or prestige copy, by contrast, will feature only a few items, often with lavish white space.

In this connection it is interesting to note the three typical forms into which most department store ads fall: the "one item" ad, used generally for ready-to-wear but occasionally for specialties; the "related items" ad, which may feature a dress or a man's suit, with all the necessary accessories to complete a harmonious ensemble; and the "omnibus" ad, made up of unrelated articles. Sometimes the store may use all three forms on a single page, by pyramiding a number of small ads around a large one.* The pyramid technique is frequently seen in the advertising of New York department stores, where it is regarded with great favor because it permits a number of repetitions of the store signature, has all the impact of "one item" ads, and at the same time gives the institutional effect of a full-page advertisement. Besides, it makes the individual buyers happy because they have separate ads!

The store's "signature" in advertisements gives an interesting clue to its general "character." Pick up any newspaper and notice how the name of the institution is displayed. A few years ago stilted, oldfashioned signatures-" "logotypes," to use the trade term-were universal. Then somebody discovered that the public wouldn't stop buying if the logotype were brought up-to-date; in fact, a looser, more informal signature greatly improved the appearance of the ad. Nowadays you will see many store logotypes that look as if some artist had dabbled them with a thick brush in an idle moment. This casual

\footnotetext{
* Edward Kaylin and Alan A. Wells, Simplified Sales Promotion for Retailers (National Retail Dry Goods Association, 1940), p. 49. Cited by permission of the publisher.
} 
note, started by Vogue and Harper's Bazaar, accompanied by more generous use of white space, sketchy rather than painstakingly accurate drawings, and a general breezy informality in the copy, is part of an intentional upgrading of the "character" of many a department store.

Besides newspapers, department stores use many other local media. Direct mail accounts for five to seven percent of the average publicity budget. It takes the form of envelope enclosures with monthly chargeaccount statements, special mailings to the same list and occasional mailings to general lists. A department store opening a branch in a suburb-a common occurrence in recent years-may circularize all the telephone subscribers in that area. Special lists of club members may be used for specific promotions. Catalogues and house magazines have been issued by many stores. In some instances booklets or folders supplied free by manufacturers and imprinted with the store name have worked out very well.

Radio advertising is generally used as a supplementary medium. A few stores have had traceable results from its use: Wieboldt's in Chicago, for example, sponsored a morning "Musical Clock" program during the breakfast hour, interspersing time and weather reports with phonograph records. Other stores have employed spot announcements. The customary plan for finding out whether radio pays or not is to offer some "special" over the air which is not featured in newspaper advertising or store displays and tabulate the calls for it. Not all department store executives have the patience to stay with a radio program until it develops a following.*

The same broad comment applies to other media-24-sheet posters (billboards), spectaculars (illuminated, hand-painted display boards), streetcar and bus cards and road signs. They may contribute to the general prestige of the store but they lack the flexibility of newspaper advertising.

National magazines have been used for advertising department stores in large cities. Publications like Mademoiselle, Vogue, Harper's Bazaar and Deb carry a substantial amount of "high-style" displays. Nearly always the advertisement consists of a full-page illustration of some smartly attired model wearing a gown or suit available at the store in question. In the Christmas season of 1946, however, tradi-

\footnotetext{
* But see the discussion in Chapter XV of Joske's and other retailers who use radio extensively.
} 
tion' was shattered by a series of full-color spreads run in Life by Marshall Field \& Company and prepared by Foote, Cone \& Belding. At a cost of $\$ 25,000$ or $\$ 30,000$ each it is dubious whether the spreads paid out directly, but they created a profound impression on the advertising fraternity.

\section{Chain-Store Advertising}

Comparatively new, but formidable in volume, is the use of local newspapers for price advertising by the chain stores.

Back in the dawn of modern advertising a grocer or druggist would occasionally invest a few dollars in newspaper space; mostly his advertising was confined to announcements painted on his windows or "fliers" (single-page circulars) distributed from door to door by boys.

De luxe grocers were able to use small space effectively but for the outlying store waste circulation made the cost of newspaper advertising prohibitive.

Then along came the chain stores and the picture changed. With stores in all parts of the city and suburbs, they could appeal to all readers of a newspaper-and did. Organizations like A \& P, Safeway, Kroger, Jewel, Gristede and Hill Stores blossomed forth in big newspaper space. The first ads were pretty crude. They consisted of type as black as newspaper headlines, relieved only by an occasional picture of a package.

Lately chain-store food advertising has become less blatant. A certain amount of space is being devoted to "editorial"-that is, illustrations and text regarding service, value or special events. Some semblance of style appears in the general arrangement and typography. The ad-planners evidently have heeded the words of the famous old ear-trumpet headline, "Don't shout-I can hear you perfectly."

It is estimated that food chains spend an average of two percent of sales in advertising. Assuming that chain stores did one-third of all retail food business in 1946, this would indicate an advertising expenditure in the neighborhood of $\$ 156,000,000$. The exact amount cannot be computed because a portion of chain-store newspaper linage is sometimes paid for by manufacturers whose brands are featured.

\footnotetext{
* Based on estimated food-store sales of $\$ 23.5$ billions for 1946, including groceries, combination grocery and meat stores, food sales in department and general stores, meat and sea-food markets, bakeries, fruit and vegetable stores, candy and confectionery stores and dairy stores.
} 
All chain stores carry nationally advertised merchandise. In fact, without national brands it is doubtful whether self-service stores could have reached their present position. Consumer acceptance of familiar products enables the chain to feature low prices on items of known quality, items for which the shopper has a standard of comparison. An advertisement offering three cans of Campbell's tomato soup for 29 cents is much more apt to attract the thrifty housewife than one pushing an anonymous soup at three cans for 27 cents.

At the same time, the chains do a large share of their volume on "private label" foods for which low price is the only claim. In some instances these unknown brands are of excellent quality; then the shopper gets a real bargain. However, without the incentive of developing permanent consumer prestige, the canner or packer will seldom go beyond minimum requirements as to quality, flavor, etc. Why should he, when the business has been given to him on a price basis and the next order may be awarded to a competitor who can turn it out a little cheaper?

To counteract this popular preference for branded items, some of the larger chains have developed their own nationally advertised brands. The best examples are those of the A \& P Stores: Bokar, Red Circle and Eight O'Clock coffee, "Ann Page" bakery and related lines. These are regularly featured in women's magazines and have become widely accepted. A \& $\mathrm{P}$, incidentally, publishes its own service magazine, Woman's Day, with an average monthly circulation of over 2,800,000 copies; it carries ads not only of A \& P brands but of many other well-known items.

Chain drugstores in many cities have been equally aggressive in using local advertising. Walgreen's, which had total sales of over $\$ 92,000,000$ in the first eight months of 1946, has gone in for fullpage newspaper space and even double pages, as well as radio, sponsored newscasts, play-by-play accounts of baseball games, and variety programs. The Stineway Drug Stores in Chicago have an evening "Symphonic Hour" that rates high with lovers of classical music. Other drug chains advertise consistently, using local newspapers as the leading medium. As with the food chains, some manufacturers pay a part of the advertising expense when their brands are featured. On some radio programs sponsored by drug chains the manufacturers may receive a certain number of commercial announcements for which they are charged at the spot rate, while the chain pays the 
quarter or half-hour rate. Similarly in newspapers, manufacturers have been known to pay the "national" line rate for space in omnibus ads for which the chains paid a much lower "local" rate.

Variety chains or "syndicate" stores seldom advertise on a scale comparable to the food and drug chains. Institutions like Woolworth, Kresge, Grant and Penney rely chiefly on locations in busy shopping areas, merchandise-packed window displays, and impulse buying. In smaller cities the Penney and Grant stores may advertise competitively in newspapers and by handbills. Many of these general merchandise stores operate on a semiautonomous basis, the local store manager being allowed to advertise or not at his discretion.

Chains of auto-supply and sporting-goods stores, such as Western Auto, and Davega in New York, as a rule will be found among the consistent advertisers. Those which do a volume of mail-order as well as retail business employ catalogues and direct mail to solicit outof-town patronage. The apparel chains like Bond Clothing, Richman Brothers, Lane Bryant, and Foreman \& Clark probably have an advertising cost comparable to that of the "promotional" type of department store.

In the footwear field a number of manufacturers-Florsheim, NunnBush, W. L. Douglas, Bostonian and others-have factory-owned stores in some cities, but they also sell through independent dealers. Advertising may be run at the local rate by virtue of the retail outlets, whereas it actually benefits all dealers in that area. Under such circumstances the manufacturer may charge part of his local promotion to national advertising. Manufacturers who sell exclusively through their own stores stress the "factory-to-you" angle with strong economy appeal, whereas those operating factory-owned stores and selling through independents as well are more apt to talk quality and style.

Remarkable in the past 20 years has been the entry of mail-order houses into the retail field. Sears, Roebuck \& Company established its first retail store in 1925, after selling exclusively by mail for the four previous decades. Today it is estimated that of over $\$ 1,000,000$,000 annual sales, Sears does about 70 percent over the counter, and only 30 percent by mail. Newspaper reports published in September 1946 revealed that Sears spent $\$ 14,155,000$ for advertising in 1945, of which 79 percent was invested in newspapers. The total included over $\$ 11,000,000$ for newspaper advertising, $\$ 1,600,000$ for circulars, $\$ 439$,000 for radio and $\$ 927,000$ for outdoor, direct mail, special promotions 
and other media. Some 938 dailies and weeklies carried Sears advertising.* Montgomery Ward, second largest mail-order house, whose labor difficulties drew nation-wide attention, since the settlement of its disputes has done a substantial amount of advertising in Chicago on the advantages of getting a job in its plant, in addition to ads on merchandise.

\section{What About the Independents?}

While the food and drug chains were making great inroads by increased use of advertising, what were the independent, or locally owned stores, doing?

At first-little or nothing. Then, as they began to feel the pinch, some of them set up a clamor for government protection. Some states passed anti-chain-store legislation involving heavy tax penalties. There was talk of action by the federal government.

But here and there, more wide-awake merchants realized that their best answer to chain-store competition was-competition. Magazines like Progressive Grocer, trade groups like the National Association of Retail Grocers, manufacturers with a stake in the independent field, all took a hand in the job of helping the little fellow fight fire with fire. Store modernization, better displays, better-trained clerks, the installation of self-service layouts, more featuring of nationally advertised brands and consistent advertising were the weapons advocated. They stemmed the tide. In 1941 chain stores did 37 percent of the food business; in 1945, only 32 percent. While all food retailing showed tremendous gains during the war era, the chains raised their volume less than 19 percent while the independents went ahead 56 percent.

At a disadvantage because the chains, with stores scattered all over a city, could economically use local newspaper advertising while the lone independent could not, the independents in many places overcame that handicap by banding together in "voluntary co-ops." They would select a single identifying name, put it on their respective store fronts, brighten up the store interiors and chip in a share toward the common fund. Then advertising would appear over the signature of the group. To Mrs. Consumer it had just as much eye-appeal and purse-appeal as that of the chains. But each retailer kept his own in-

* Advertising Age, Sept. 16, 1946, p. 48. 
dividuality, his own personal contacts in his neighborhood. Some of these groups were launched by wholesalers. In other instances the retailers took over the wholesale functions. Thus in Iowa we find the Briardale Food Stores, comprised of independent member stores throughout the state, purchasing through the Grocers' Wholesale Cooperative, Inc., in Des Moines. Briardale advertising appears regularly in the newspapers. When special promotions are featured each retailer gets the necessary window streamers and inside display materials to capitalize on it.

A survey made jointly by the National Association of Retail Grocers and The Saturday Evening Post reveals that 43 percent of stores covered belong to one or more buying co-ops. The highest percentage of members is among stores doing from $\$ 100,000$ to $\$ 300,000$ per year52.5 percent. Below and above this volume group, membership declines. Only 22.2 percent of stores with sales under $\$ 30,000$ a year are members. Geographically, the "co-op" movement has made greatest headway on the Pacific Coast, where 59.2 percent of the independent grocers surveyed are members and another 14.3 percent plan to join. It is weakest in the West South Central region, with only 14.3 percent of the grocers belonging.*

On the question of advertising, the same survey disclosed that two-thirds of the responding stores use one or more media. Most popular is the newspaper, favored by 68 percent of advertising grocers; next, printed circulars, 32 percent; mimeographed circulars, 9.4 percent; radio, 9 percent; letters, 8.7 percent; post cards, 4.8 percent, and billboards, 2.1 percent. It might be thought that big-city grocers would be the heaviest advertisers, but according to the survey, those in medium and small-sized cities are the leaders-no doubt because of the lower rates. The largest users of radio are in cities of 5,000 to 25,000 , where a one-minute announcement may be bought for as little as $\$ 1.00$ or $\$ 1.50$, and a daily newscast may be sponsored for perhaps $\$ 15$ or $\$ 20$ a week. (Naturally these figures do not apply to all radio stations within that population bracket!) Radio and countyweekly advertising appeal particularly to the retailer drawing trade from the surrounding rural area. Friday is considered the best day of the week for food advertising, to catch the heavy week-end buying,

* The Independent Grocer, Report No. 2 (The Curtis Publishing Co. and National Association of Retail Grocers, 1946). Quoted by permission of the National Association of Retail Grocers. 
with Thursday second and Saturday third. These three days account for 80 percent of all newspaper food advertising. *

Mimeographed circulars don't look very impressive compared with the full-color magazine ads of A \& $\mathrm{P}$ or the full-page newspaper ads of the giant chains, but they have proved worth while for many independents. Run off on one side of an $8 \mathrm{r} / 2 \mathrm{xll}$ or $8 \mathrm{r} / 2 \times 14$-inch sheet, they can be folded, sealed with a precancelled stamp and mailed for a total cost of less than two cents per name. "In many cases," says one authority, "the informal and personal touch that grocers are able to get into circulars produced in this manner gives their stores a character which does a great deal to build them wide followings. The drawings may be crude, but often this type of circular has greater readership than more formal advertising."**

Retailers can get plenty of help in preparing ads. Manufacturers supply illustrations and free cuts of their products automatically; in addition, many manufacturers and jobbers furnish stock headings such as "Hot-Weather Specials," "Thanksgiving Food Sale," "Lenten Ideas" and the like in various sizes, around which the merchant may build his own message.

Generally speaking, independent retailers are more conservative about spending money for advertising than are the chains. Progressive Grocer studied the operating expenses of 125 independent food stores ranging from California supermarkets doing an average of $\$ 478,313$ in annual sales down to service groceries in the $\$ 50,000$-a-year class, and found the percentage less than half that of chain-store ad budgets. The supermarkets spent most, around 1.3 or 1.4 percent for advertising. The grocer selling at the rate of $\$ 1,000$ a week was averaging about five dollars a week for advertising. This doesn't seem like much. But when one considers that the same group showed average salary paid to owner of only $\$ 35.60$ per week and net profits of $\$ 31.73$-out of which had to come any funds for modernization or expansionone can't be too critical.***

The account executive servicing a million-dollar campaign, or the radio representative seeking to sign up a sponsor for a network show with a time and talent cost of $\$ 15,000$ per week, may wonder what

*Ibid., pp. 21-26.

** Ralph F. Linder, ed., New Idea Book for Food Merchants (Butterick Co., publishers of The Progressive Grocer, 1941). Quoted by permission of the publisher. *** "Facts in Food and Grocery Distribution," Progressive Grocer, January, 1946. 
can be done with a yearly appropriation of $\$ 250$ for advertising. Yet that microscopic sum is significant. Wisely invested, it can help to increase the retailer's business, broaden his service to the community, make him a more substantial citizen, enhance his value as a purveyor of branded merchandise. Frittered away on unsound, hit-or-miss expenditures, it can turn him against all advertising and lead to a static condition where forward progress stops and rigor mortis sets in.

With this $\$ 250$ budget must go-if it is to be effective-a forwardlooking policy of customer service. Advertising men find it hard to face the grim fact that to the retail merchant an attractive store front, a well-lighted and conveniently arranged interior, adequate stocks of quality merchandise, courteous clerks and a friendly store "character" are far more important than a big consumer campaign. But here again it is a question of getting the product right before the advertising can deliver maximum results.

In a broader sense, any improvement in a retail store that increases its customer appeal may be considered as "advertising." And on that basis the retailers of America-not alone the grocers and druggists but the hardware, furniture, jewelry, book, shoe and home-appliance dealers as well-have all become better "advertisers" in the past 25 years. 


\section{Chapter X \\ THE INDUSTRIAL ADVERTISER}

WIDE gap stretches between advertising of consumer goods or services and that of industrial goods or services. Most advertising appeals to the emotions, senses, wants or instincts of the individual and the family. It is personal in tone. Attention-getting devices are widely used. Nearly always there is a definite invitation, an urge to buy.

On the other hand, industrial advertising is designed to help the sale of materials, products, equipment or services for the making of other products. The purchaser will seldom use the article personally. His interest lies in the benefits to be obtained through lowered costs, increased output, greater salability, more efficient or better satisfied employees. For that reason advertising aimed at industrial markets customarily emphasizes facts about construction and performance rather than glamour or entertainment.

At first glance this might seem to imply that industrial ads are dull and uninteresting. Perhaps so, as far as the general public is concerned. But to the man for whom they are intended they have great interest. Nothing gets more careful, thorough reading. The head of a firm of consulting engineers, for example, recently declared that he spends about 20 hours each month examining several thousand pages of technical advertising and taking notes on it. It is part of his work to keep track of new products and standard products entering into industrial designing. "In the ficld of manufacturing," he writes, "the most prolific and up-to-the-minute source of information is in the advertising pages of the technical and trade magazines."*

One has only to observe the eagerness with which men in the same business or profession will gather and talk shop at any social gathering to appreciate the fundamental appeal in industrial advertising. The more closely it approaches the "shop talk" ideal, the more effective it becomes.

* Harvey S. Pardee, "An Engineer Analyzes Industrial Advertising," Industrial Marketing, June 1946. 


\section{Who Uses Industrial Advertising?}

The National Industrial Advertisers Association classifies manufacturers of industrial and technical products under these eight headings:

MAjoR EquipMENT: Heavy machinery and construction equipment.

ACCEsSORY Equiṕment: Small tools, jigs, dies, time clocks, etc.

OpERATING SupPLIES: Oils, greases, brooms, paper work forms, etc.

Fabricating Parts: Metal and steel sheets and rods, textiles, lumber, etc.

Containers or Packaging Materials: Boxes, jars, bottles, cans, foil, etc.

Process Materials: Wood pulp, chemicals, acids, alkalis, etc.

Primary Materials: Raw cotton, crude petroleum, iron ore, hides, wheat, etc.

BuILDing Materials: Fabricated steel, lumber, bricks, roofing, etc.*

In addition there are numerous associations, consultation services, insurance companies, publishers and other types of firms who use industrial advertising. The lion's share of promotional effort in the industrial field, however, is done by the producers and processors of raw materials, equipment and supplies. Some industrial products are used in manufacturing, some in transportation or distribution, some in plant maintenance. Often a company's products may come under several headings. Paint, as an example, is bought in large quantities for finishing manufactured products; it is definitely a maintenance material; it can be classed also as "operating supplies" since it has been discovered that different colors of paint used on various machinery parts and as traffic flow lines in factories will aid operating effciency.

Many industrial advertisers rank among the best-known names in American commerce. In the field of heavy equipment are such great corporations as American Locomotive, Caterpillar Tractor, AllisChalmers, General Electric, Westinghouse. In building materials,

* "Industrial Advertising Budgets for 1946," (c) National Industrial Advertisers Association. Quoted by permission of NIAA. 
U. S. Steel, Weyerhaeuser Lumber, U. S. Gypsum, Johns-Manville. Among process materials, Monsanto Chemical, Shell Oil, Aluminum Company of America, Bakelite, Du Pont, Revere Copper \& Brass.

Some of the important advertisers make some products for consumer use and another group of products for industry. Armstrong Cork Company produces a large volume in linoleum flooring for homes but in the industrial field it is best known for its sound and shock-absorbing materials such as "Cushiontone," an acoustical ceiling material. It also manufactures asphalt tile for factories and offices. Crane Company has a leading place in home plumbing and heating equipment; its valves, pipes and fittings have many applications including cross-country pipe lines. "Yale" is synonymous with locks in the mind of the average consumer. The factory purchasing agent knows the Yale \& Towne Manufacturing Co. as a source of industrial scales, hand and electric hoists, hand-lift and electric trucks.

Where their products have utility for a wide variety of industries, larger concerns will often run ads in general magazines. Even though a high percentage of the circulation is wasted, such campaigns may pay off through giving the company's salesmen the "lift" of seeing their line advertised in a publication like The Saturday Evening Post, Life or Time. The last-named periodical is especially popular with industrial advertisers, presumably because its wide circulation among directors, stockholders and financiers reaches men who may have a voice in industrial purchases, yet may never see a technical publication.

For many years the Goodyear Tire \& Rubber Company has been using full pages and spreads in general weeklies featuring the "G. T. M."-Goodyear Technical Man. Each ad describes some dramatic adaptation of rubber hose, belting, molded goods, packing or tank lining to a materials-handling problem. Instead of talking in generalities the copy gives specific figures on performance, length of life and economy.

In a different vein but on similar products the B. F. Goodrich Company has employed consumer magazines to describe how its engineers solve knotty technical situations. On-the-job photographs combine with colorful headlines to make a very readable series. "Seven-ton concrete tunnels tied with rubber bands" was the heading of one Good. rich ad in a prize-winning campaign a few years ago; the text explained how rubber was used to seal huge sewer-pipe joints. Another ad, 
headed, "A lot of apple sauce but it's rubber's dish," told about rubber conveyor belts for quick packing of apples.

The rank and file of industrial advertisers do not use general media. Since most of them sell exclusively to other manufacturers and the consuming public is not a factor, their advertising is directed into channels that will create the maximum impact per dollar on their major prospects.

\section{Industrial Advertising Budgets}

As might be expected, the percentage of gross sales spent for advertising by industrial advertisers is smaller on an average than that spent for consumer-goods advertising. Here are figures from the previously mentioned NIAA study of industrial budgets:

\begin{tabular}{|c|c|c|c|}
\hline & $\begin{array}{l}1945- \\
\text { Actual }\end{array}$ & $\begin{array}{c}1946 \\
\text { Estimated }\end{array}$ & $\begin{array}{c}1947 \\
\text { Estimated }\end{array}$ \\
\hline Major Equipment & - $1.17 \%$ & $1.32 \%$ & $1.67 \%$ \\
\hline Accessory Equipment & - 2.66 & 3.16 & 3.26 \\
\hline Operating Supplies & - 1.42 & 1.75 & 2.51 \\
\hline Fabricating Parts. & .76 & .63 & .82 \\
\hline Process Materials . & . 5.19 & 5.19 & 4.21 \\
\hline Building Materials &.$\quad .78$ & 1.12 & 1.58 \\
\hline No Product Classif. & . 1.26 & 1.62 & $1.34 *$ \\
\hline
\end{tabular}

The average, weighted according to the number of replies under each heading, gives 2.1 as the estimated advertising percentage for 1947 among these industrial firms. By comparison, the same group estimated their average total selling expense for 1947 as 10.13 percent-or nearly five times the advertising percentage.

This appropriation went into a variety of items. By far the largest amount was assigned to display ads in publications reaching industrial markets, and production costs on these ads. On an average, space charges in business magazines accounted for an estimated 35 percent of the total budget in 1947, and production-art work, photos, typesetting, plates-another 10 percent. Following these the most popular items on the budget were catalogues, other direct mail, publishers' consolidated catalogues, conventions and exhibits, product literature,

*Op. cit. (Schedules 1, 2,3). 
house organs, motion pictures and still films, editorial publicity and advertising to the general public. (This last named was used by less than one-fourth of the companies in the survey.) Market research, traveling and educational literature were other items listed.

Advertising department overhead accounted for roughly 15 percent of the average industrial budget in 1947, the survey indicates. Another four or five percent would be set aside for contingencies, reserves or miscellaneous. Of the remaining items, catalogues received an average of 14.12 percent of the total budget; other direct mail, 10.46 percent; conventions and exhibits, 8.45 percent; product literature, 8.52 percent; publishers' consolidated catalogues, 4.49 percent.

These percentages did not apply where an industrial advertiser concentrated a large proportion of his appropriation in some particular medium. For example, one firm in the process-materials field spent one-third of its 1947 budget on conventions and exhibits; one manufacturer of operating supplies has spent from 10 to 14 percent of his total in radio. Companies issuing house organs-either "internal" magazines designed to improve employee relations, or "external," edited for customers and prospects-may devote a large part of their appropriation to this medium.

\section{Industrial Advertisers and Agencies}

The industrial field is served by many advertising agencies, some specializing in this type of marketing, others handling it along with consumer products. Extent of agency service is shown in the annual report of advertising placed by agencies in business publications, issued by Industrial Marketing. For 1946, according to this tabulation, 458,425 pages of advertising space were produced by agencies, a new record. ${ }^{*}$

Leading the field was Fuller \& Smith \& Ross, Inc., with 15,128 pages. This agency got its double-ampersand name through a merger of Fuller \& Smith, Cleveland, and F. J. Ross Company, New York, in 1930. All three men represented in the firm name retired long ago. The president for more than 20 years has been Allen L. Billingsley. He makes his headquarters in Cleveland, where the agency has over

* "Advertising Placed by Agencies in Business Papers, 1946," Industrial Marketing, April 1947. 
200 employees and is accepted as the largest producer of printed matter, displays and promotional material in the area. At New York F \& S \& R has 130 employees, and ten or so in Chicago where it recently opened a third office. Among its hundred accounts are such large users of business papers as Westinghouse, Hercules Powder, Libbey-Owens-Ford, Aluminum Company of America, Yale \& Towne, Ferro Enamel and Dayton Rubber. The agency has a film department equipped to produce motion pictures and slide films. It does a good many research studies, often working closely with industrial engineers.*

Close behind Fuller \& Smith \& Ross in business-paper space for 1946 were J. Walter Thompson Company and Batten, Barton, Durstine \& Osborn, both general agencies. In fourth position was G. M. Basford Co., specialists in industrial accounts. Others among the leaders were McCann-Erickson, the Buchen Company, GriswoldEshleman, MacManus, John \& Adams, Albert Frank-Guenther Law, and Evans Associates. These top ten agencies placed 90,711 pages of business-paper advertising during the year.***

\section{Associations and Publications}

Founded in 1922, the National Industrial Advertisers Association is devoted to "the advancement of industrial advertising and marketing technique and practice," its prospectus declares. Affiliated with it are 25 district groups such as the Industrial Advertisers Association in New York and the Chicago Industrial Advertisers Association. Among the important NIAA activities are: data sheets indexing all current published material covering advertising production, media and administration; reports from committees assigned to investigate specific phases of industrial advertising and marketing; and an annual convention at which significant topics are discussed.

Representing the periodicals in this field are two associations: the Associated Business Papers (ABP), with a membership of some 150 magazines; and the National Business Papers Association (NBP). The $A B P$ includes publications with paid subscriptions. It has done consistently constructive work in raising the standards of business-

* Advertising Age, Jan. 27, 1947, 45.

** "Advertising Placed by Agencies in Business Papers, 1946," Industrial Marketing, April 1947. 
magazine copy, art and research. One of its significant contributions was the still-discussed "Tell All" campaign before the war which stressed the importance of giving business men complete information about the product advertised. Another popular ABP release was a booklet, "Hit the Road," urging the business-paper advertiser to break away from his desk and get out into the field before planning his campaigns.

The NBP, a newer organization, includes publishers of controlleddistribution business papers. This type of publication is sent free to selected individuals and firms in a particular field. Among the NBP members are such papers as Industrial Equipment News, World Petroleum, Progressive Grocer and Electrical Equipment.

Business papers relying on subscriptions or single-copy sales for their distribution generally belong to the Audit Bureau of Circulations. This long established organization has been a notable force in raising distribution standards among all classes of periodicals. A valuable feature of A. B. C. reports in the business-paper field is the breakdown of circulation according to type of job. For example, Metal Finishing, a publication reaching the metal trade, reported a net paid circulation on December 31, 1946, of 6,340 copies, distributed as follows:

Manufacturers engaged in production of metal products (ferrous and non-ferrous, which are fabricated, cleaned, polished, plated and finished: subscriptions in firm name only, 2,026; presidents, vicepresidents, owners, secretaries and treasurers, 386; plant executives, works managers, production managers and superintendents, 509; foremen in departments mentioned above, 1,021; metalurgists, chemists, chemical engineers, 580. Libraries, colleges, government bureaus and trade associations, 206; consultants and testing laboratories, 59; equipment and supply houses, 174; advertisers, their salesmen, branch offices and distributors, 195; men in armed services formerly classified above, 18; miscellaneous, 274; unclassified, 224; foreign, 691.

A similar service is rendered to advertisers by "free controlled" distribution business papers through the Controlled Circulation Audit. Reports very similar to those of the A. B. C. are sent out regularly, giving details of the mailing list used, total circulation and occupational breakdown. Both A. B. C. and C. C. A. also supply data on geographical distribution of their member papers. An advertiser interested in particular territories can thus find out how intensively the different publications reach those markets. 
In addition to subscription and free papers there is a third important group in the industrial field: the association journals. These magazines go to members automatically, the cost being included in their dues. Typical is the S. A. E. Journal, official organ of the Society of Automotive Engineers, Inc. Its total net paid circulation (sworn) as of December 31, 1946, was 16,675, including 14,147 nondeductible association subscriptions. The Northern Automotive Journal, a regional publication, with a guaranteed circulation of 8,000 , is the official organ of nine associations including the Minnesota, Wisconsin, South Dakota, North Dakota, Iowa and Montana State Automobile Dealer Associations; the Northwest Automotive Wholesalers Association; the N. W. Automotive Electrical Association, and the Twin City Garage Association.

Among business-paper publishers McGraw-Hill looms large. This famous company dates back to 1874 and issues some of the largest, most influential periodicals in many lines. General publications include Business Week and Science Illustrated. In the manufacturing field Factory Management and Maintenance has a circulation of 48,000 paid subscribers. Other McGraw-Hill papers are American Machinist, Power, Engineering News-Record, Textile World, Electrical Merchandising and some 25 others including annual reference catalogues. In the export field a McGraw-Hill affiliate, Business Publishers International Corp., puts out nine magazines, several being in Spanish like El Automovil Americano.

Chilton Company, Philadelphia, publishes 12 business papers, among them Motor Age, Iron Age, Boot and Shoe Recorder and Department Store Economist. Haire Publishing Company has a string of nine business papers, most of them edited for the retail trade. Simmons-Boardman publishes four papers, specializing in the railway field. Penton Publishing Company, Thomas Publishing Company, Robbins Publishing Company and Ahrens Publications are other multiple-magazine producers. There are a number of others, some national, some regional. Among the latter is W. R. C. Smith of Atlanta with five papers covering the South in various industries.

\section{Industrial Research}

"The industrial advertiser's first task is to find out for which use his product is sold," says John Allen Murphy. "Market studies should 
usually precede advertising. It is better to tackle a few markets at a time and do a job in them before other fields are added to the campaign."*

Back of these few words is a long record of trial and error in the industrial marketing profession. Too many manufacturers of machinery and materials have been afflicted with a consumer advertising complex, failing to recognize the need of determining the limitations of their selling area. As a result "shotgun" advertising has been scattered far beyond the potential markets. Murphy suggests a "piloting" operation in which the industrial marketer can try out a new product on a restricted scale where buyer reactions, competition, distribution channels and sales methods can be carefully studied. This method has been successfully adopted by some of the leading companies selling to industry.

Nowadays market research is regarded as a "must" by industrial advertisers. And this is only one phase of research affecting the advertising of technical or commercial products. Fred Olsen, director of research, Western Cartridge Company, suggests four types of questions which research should answer:

1. Technology: Is the new process or product technologically sound?

2. Patents: Will the new product or process be free from infringement?

3. Markets: What is the extent of the market for the product?

4. Economics: What is the estimated profit from the sale of the new product in the market which has been revealed by the market research?*

It is just as essential, Olsen points out, to determine that a product can be made profitably and efficiently as to know where and how it can be sold. The advertising man in industry must take a broad view. He must concern himself not only with market research but with technical and accounting research as well. He has become an important factor in his company. His prewar job of getting out the company's catalogues and circulars and okaying an occasional business-paper ad has developed into the postwar responsibility of helping to decide production and distribution policies.

* By permission from Handbook of Advertising, by E. B. Weiss, F. C. Kendall and C. B. Larrabee, copyrighted 1938, by McGraw-Hill Book Co., Inc.

** Fred Olsen, "Evaluating Research Activities," Industrial Marketing, Feb. 1947. Quoted by permission of the publishers. 


\section{Chapter XI}

\section{THE ADVERTISER OF INTANGIBLES}

NE phrase crops up regularly in any advertising discussion: "Goods or services." The advertising of goods-actual merchandise, things to eat and wear and ride in and manufacture other articles with or from-is far from simple. But it at least starts with something that can be seen. The advertising of a service entails the picturing or dramatizing of an idea.

What are these "services" that figure so prominently in talks and textbooks? They are the intangibles such as life insurance, transportation, public utilities, hospitals, education, dry cleaning; in fact, any return for an expenditure which does not produce actual merchandise.

In some instances it is possible to illustrate the end result of a service, which will be not merchandise but a condition or state of mind. The advertiser of railroad or bus travel may show pictures of passengers riding in luxurious comfort, or viewing strange and thrilling scenes at the end of the trip; he is not selling the actual seat in his vehicle nor the particular strip of beach at Catalina which he features, but the opportunity to enjoy these delights.

Some services are so much a part of everyday life that they require no explaining or justifying. Others require clarifying. Lewis F. Gordon, a well-known Atlanta banker and former president of the Financial Advertisers Association, brought out this distinction in a speech before F. A. A. members at their annual convention some years ago:

A man goes to the station where a porter picks up his bags, carries them onto the train, and gets a quarter for the service. Another porter shines his shoes and receives a quarter. A third porter picks up the bags and carries them to a taxi. He also receives a quarter. Finally a bellboy carries the bags to a room in the hotel and gets the fourth quarter. The man has spent a dollar without batting an eyelash. Why? Because he saw the services performed right before his eyes.... Yet the same man will come into a bank and squawk like a stuck pig over a dollar service on his checking account. ... What is the difference? He knows all about the one-he knows little or nothing about 
the other. Is that his fault? Not at all. The fault is ours in failing to acquaint him with our service.

Such an admission from a banker-a class of individuals popularly considered devoid of human feelings and also concern about the public's feelings-is indicative of today's trend in business thinking.

Bank advertising has grown steadily more friendly, more readable, more helpful, as executives of financial institutions have come to realize the effect of public opinion on profit. The annual statements required by law to be inserted in local papers have been simplified and supplemented with explanatory text so that even the uninitiated can understand many of them. Display advertisements now often talk about savings deposits, checking accounts, trust funds and loans in laymen's terms. One reason for this "humanized" approach has been the desire of banks to enter the field of consumer credit, which includes so-called "character" loans without co-makers or endorsers, automobile loans, appliance loans and home improvement (FHA Title I) loans. An F. A. A. survey in 1945 showed that 79 percent of banks covered were seeking and handling this type of business and that over 11 percent of all bank advertising represented in the survey was devoted to promoting consumer credit. A similar survey in 1947 disclosed an even greater swing to consumer credit, 25 percent of current bank advertising featured small loans.

But the banks have done more than advertise "friendly service"they have made it a reality. In hundreds of cities they have heeded the challenge issued by Robert Lindquist, assistant vice-president, American National Bank and Trust Company of Chicago, in his study for the Graduate School of Banking conducted by the American Bankers Association at Rutgers University. After thoroughly describing methods of co-ordinating bank advertising with new business activities he wrote:

Still another "follow through" remains for a bank to make if it is to get the most out of its advertising program. This is the preparation of the bank's staff to back up the advertising with the kind of service the customer has a right to expect. Good training and good equipment are important, but not enough. Service must be more than automatic efficiency. It must be human, friendly, alert, enthusiastic, and based on a genuine interest in the customer's welfare.*

* "Planning and Budgeting a Bank's Advertising Program," Report of 30th Annual Convention, Financial Advertisers Association, 1945. 
What has been happening in banks has been happening also in many other types of service institutions. The American Institute of Laundering through its beloved May Laing Grady has consistently stressed the importance of sound customer relations to its 2800 power laundry members. Twenty years ago laundries were obsessed with the fear that rapidly increasing sales of home washers would put them out of business. A nation-wide consumer campaign was launched in 1928 with a fund of over $\$ 5,000,000$ to promote the advantages of laundry service. At first, copy talked in general terms about "enjoying a Monday vacation"- - "no more blue washdays"-and similar appeals stressing labor-saving advantages of laundry service. Then it became apparent that the chief obstacle to laundry sales was the belief of many homemakers that laundries were hard on clothes.

Laundries were being blamed for fabric failures due to shoddy materials and poor workmanship as well as those which were their own fault. The Institute through its textile research department under George H. Johnson, a graduate textile engineer, began to work with the mills to improve launderability. Shrinkage, "fugitive" or quick-fading colors and other problems were tackled. The American Institute of Laundering Seal of Approval was inaugurated as a method of certifying products which met required standards. Along with this, laundry routemen were trained to interpret complaints in terms of proper responsibility, accepting blame where the laundry was amiss and explaining matters where it was not guilty.

With a steady improvement in laundry efficiency, a decline in "trouble-making" fabrics and articles and a wider understanding of the industry's aims and problems, unquestionably the laundry industry is better fortified to meet competition now than before it started to advertise. The actual advertising done was not nearly so important as the by-products.

John J. Joseph, assistant vice-president of Ohio Bell Telephone Company, stressed this same point in a talk before the Financial Advertising Association. The Bell System, he declared, overlooks no opportunity to coach its operators, installers, tellers and others who greet the public, as to their proper approach. This involves such fundamentals as tone of voice, phrasing of response to complaints and acceptance of payments. The advertising that appears in national magazines or is heard over the air will have little benefit, he feels, unless the performance behind it is right. 
"Because of the ordinary human suspicion of size," said Mr. Joseph, "big business will have to be a better citizen than if it were smaller. It will have to win public confidence. It will have to put the same thought and effort on public relations that it has on research, production and selling."

\section{Postwar "Idea" Advertising}

Industry-wide advertising was a near-miracle of the 1920's. Fred Millis of Indianapolis was one of the first to dramatize the inescapable truth that Mr. and Mrs. Consumer had only so much money to spend and that they would spend it for the things they wanted most. Ergo, it was up to the various industries to sell the idea of putting some of the money into their particular industry rather than another. With this premise he developed impressive campaigns for the Society of American Florists ("Say It With Flowers"), the National Retail Furniture Association ("First Furnish Your Home-It Tells What You Are"), the Photographers Association of America ("Photographs Tell the Story"), the Laundryowners National Association ("Let the Laundry Do It"), the National Macaroni Manufacturers Association and numerous others. The soap people meanwhile had launched their "Cleanliness Institute" campaign to induce the public to wash oftener and the paint people were promoting the slogan, "Save the surface and you save all."

Trade-association advertising suffered a setback with the depression, but by the late 1930's it was again in full action. Among the most prominent was the campaign of the Association of American Railroads handled by Arthur Kudner, which had the dual objective of getting people to travel by train and also to win good will for the railroad companies. The American Meat Institute in 1940 began an educational campaign, alarmed by the fact that per capita consumption of meat had declined from a high of 162.6 pounds in 1908 to 132.9 pounds in 1939. A nation-wide survey directed by Elmo Roper revealed that the public was badly informed on facts regarding meat and that women desired more information on proper preparation and food value of meat. Through Leo Burnett Company, Chicago advertising agency, a campaign was launched by the packers and has been consistently carried out ever since. Copy stressed the B vitamins in meat, suggested ways to serve meat, pointed out its importance in the 
summer diet. In 1942 this campaign won the Advertising \& Selling medal as the best trade association campaign of the year.

Throughout the war, most co-operative advertising was given over to patriotic projects. With peace the industries swung into action. At the annual meeting of the American Trade Association Executives in October 1946 it was revealed that industry-wide promotion activities would reach or exceed $\$ 20,000,000$ that year, a new record.

In 1909, according to the ATAE report, only one association announced that it was using advertising. By 1919 the number had jumped to ten, and ten years later it had reached 29. It was 60 in 1939, and 92 postwar, with an additional 14 associations planning to advertise in the near future. A total of 51 had discontinued advertising because of lack of finances, product shortages, the depression or other reasons. Well over one-third of these, it was reported, had since renewed their campaigns or planned to do so.

Included in the ATAE report were industries in food, clothing, beverage, insurance, appliance and other consumer fields; technical groups such as metal, machinery, coal, supply, lumber and equipment; and restricted groups such as specialized containers and equipment. One hundred three of the 118 associations represented had already used advertising.

\section{The Utilities Program}

Much has been written about the power of advertising. Outstanding among current campaigns is one the purpose of which is the advertising of power.

The Electric Industries Advertising Program started in a modest way in the years just before World War II. An early ad told about the part being taken by the power industry in arming America, and was sponsored by "52 local electric companies-all producing power for America under American business management." A footnote announced that names of sponsors would be furnished "on request from this magazine," an ingenious way to avoid listing a large number of contributors to a group campaign.

From 52 sponsors in 1941, the number jumped to 74 in 1942, and then 94 later in the year; in 1943, the total reached 118 and the campaign included a radio news program, "Report to the Nation," over CBS. By 1944, 148 companies were in the campaign and Phil 
Spitalny's All-Girl Orchestra was being featured in "The Electric Hour." The next year 167 companies, "self-supporting, tax-paying businesses," to quote an ad in Life for June 4, 1945, were sponsoring the magazine campaign plus Nelson Eddy with Robert Armbruster's Orchestra in the 4:30 CBS slot Sunday afternoons. The 1946 ads announced 170 sponsoring companies.

A wide variety of attention-getting copy and art treatments has been used, but throughout the past seven years each ad has stressed the economy, efficiency, tax contributions and good citizenship of the utilities. An advertisement in Time for January 13, 1947, had the surprise heading: "Ever Been to Chaugogagogmanchaugagogchaubunagungamaug?" The text said that this 40-letter word is the Indian name for a lake at Webster, Massachusetts. Translated, it means, "You fish on your side, I fish on my side, nobody fish in middle." That is sound policy for American business and government, continued the copy: let government regulate and business operate the nation's business. Combined control of politics and business is the basic feature of Nazism, fascism, socialism and Communism, the advertisement declared, adding that when government goes into business it doesn't pay taxes. The message wound up, "As a citizen, as a consumer, you have an interest in seeing that government and business fish on their own sides of the lake. Then you won't get caught in the middle!"

\section{A Concrete Example}

Over a long stretch, the Portland Cement Association has ranked among the most systematic users of advertising to tell its story.

This trade association occupies its own building (made of Portlandcement concrete, naturally!) in Chicago and has 26 district offices all staffed by engineers competent to co-operate with architects and engineers representing governmental agencies, industrial plant owners, farmers and others; to give technical help to contractors and all who are interested in concrete construction. Three floors of the association's headquarters building are occupied by research and testing laboratories. In addition, field laboratories are maintained at Elmhurst and Naperville, Illinois, and at several other locations for large-scale testing. The association also maintains a staff of fellowship scientists at the national Bureau of Standards, Washington, D. C.

Frank T. Sheets, for 13 years chief engineer of the Illinois Depart- 
ment of Highways, has been the full-time president of the Association since 1937. It has some 400 employees on its pay roll.

Publications in the 1947 campaign include six consumer magazines -Time, Newsweek, The American Home, Business Week, Parents, Better Homes and Gardens - and a long list of business and industrial papers. A separate campaign is aimed at the agricultural market through national farm magazines. The account is handled by Roche, Williams and Cleary of Chicago.

Supplementing the national advertising, each of the association's district offices has a separate advertising budget for local advertising in newspapers and other media in its territory. The association began to use advertising in a limited way in 1906 and launched its first official publication the following year. Its volume of advertising has varied from year to year, but since the late 1930's has been kept at a consistently high level. In an average year the staff handles more than 300,000 requests for information on uses of concrete.

In addition to display advertising, the Portland Cement Association uses its own printed matter extensively. According to H. C. Persons, assistant advertising manager, its 1947 inventory included several million pieces on about 400 different subjects. These ranged in size from 200-page books down to single-page "Information Sheets." The information sheets are usually releases on new developments to be covered more fully in longer material as additional data become available.

Seven periodicals are issued by the association, some bimonthly, some quarterly, some semiannually. Edited by specialists, these are illustrated with many on-the-job photographs as well as diagrams. Stories of actual installations are featured. In the case of important jobs, one article may describe the construction stages of the job and a sequel the finished product. The names of these "external house organs" describe their respective editorial areas: Architectural Concrete, Highways, Concrete for Railways, Soil Cement News, Reinforced Concrete, The Concrete Builder and Safety Magazine.

Motion pictures and slide films have been used for specific assignments. Several movies of general interest have been produced, particularly those dealings with concrete highways. Visual advertising is chiefly used for "how-to-do-it" films to be shown to engineers, contractors, architects; or, in the rural field, to farmers through agricultural experiment stations or county agents.

The association does not use radio for advertising, although it has 
co-operated with networks and individual stations in putting on "public events" programs where the use of concrete is involved.

Chief advertising appeals are "low annual cost"-broken down into low first cost, low maintenance cost and long life-and elimination of fire hazard. In advertising concrete for streets and highways, copy stressed also freedom from glare, high visibility and skid resistance. "You can see far and stop short on concrete," declared a typical ad in Time, on December 16, 1946. Beauty of architectural effects is demonstrated by photographs of concrete buildings. Advertising to farmers emphasizes economy, as in Country Gentleman for February, 1947, where the association ad was headlined: "How 20 sacks of Cement can work on your farm!" Various ways-140 fence posts, a 10-can milk cooling tank, a three-foot sidewalk 85 feet long.

Railroads have always been heavy users of concrete and the association pays particular attention to the many applications in that fieldbridges, grade-crossing eliminations, stations and others. Airports and public buildings are other major opportunities for the industry.

A trade association such as this does not concern itself with the sale of materials. The activities of the Portland Cement Association, for example, are limited to scientific research, development of new or improved products and methods, technical service to users, promotional and educational efforts-including safety work. The association having done the scientific research and market-building promotion, sales are the function of the member companies, of which there are over 60 in the United States and Canada.

\section{The Case of the Railroads}

It was in connection with railroading, so tradition declares, that a nineteenth-century tycoon uttered his impatient blast: "What do we care about the public? The public be damned!" Ever since, railroad men have been denying this attitude both by word and deed. Railroad advertising-particularly since the inauguration of the co-operative campaign of the Association of American Railroads was launched some fifteen years ago-has been steadily more solicitous of public approval.

Wartime advertising of the carriers was highly conscious of its responsibility as an interpreter of popular sentiment. One of the most famous pieces of copy ever written was "The Kid in Upper 4," an 


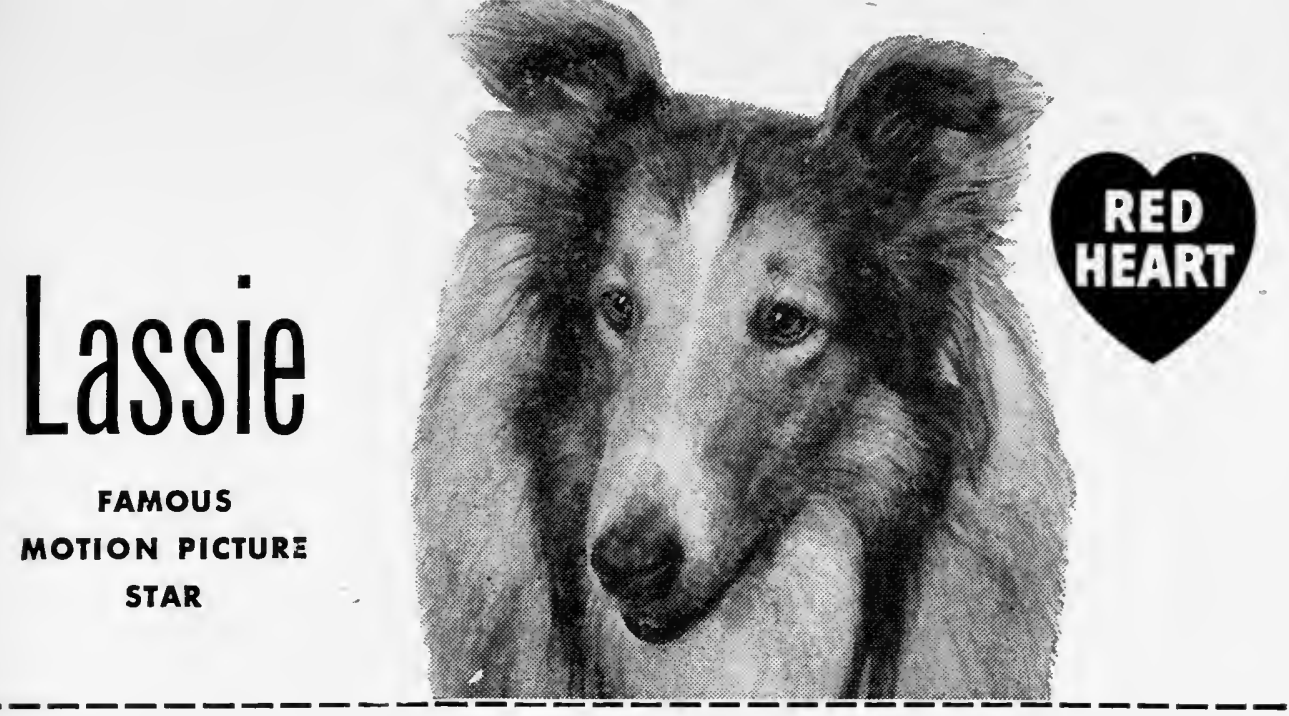

\section{Hear Lassie, America's Favorite Dog, In Person}

\section{ON "THE LASSIE SHOW"}

\section{SPONSORED BY RED HEART; AMERICA'S FAVORITE DOG FOOD}

New Coast-to-Coast Radio Show

Starts June 8

Listen Every Sunday to Your ABC Station at 3:00 P.M., E.D.S.T. 2:00 P.M., C.D.S.T. 1:00 P.M., M.S.T. • 12 NOON, P.S.T.

It's exciting! It's thrillingly different-with a sensational interest and product tie-up. For it stars Lassie, the most famous dog in the world today. The ABC Network will carry the show coast to coast each week on 162 stations.

Listen Sunday, June 8, and every Sunday afternoon, as Lassie - the appealing, talented dog of the screen-enters the homes of your customers, bringing them thrilling dog stories AND the Red Heart 2.Flavor story.

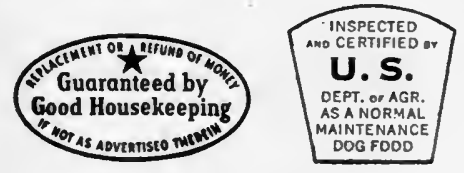

Lassie's barking about

all 3 Red Heart Flavors to give YOU 3 profits on 1 sale!

DISPLAY 'EM TOGETHER!

PRICE 'EM TOGETHER!

SELL 'EM TOGETHER!

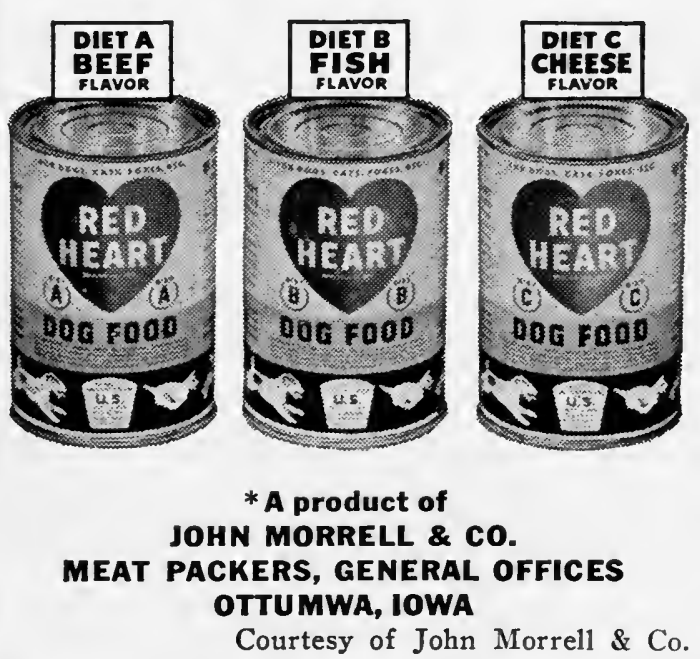




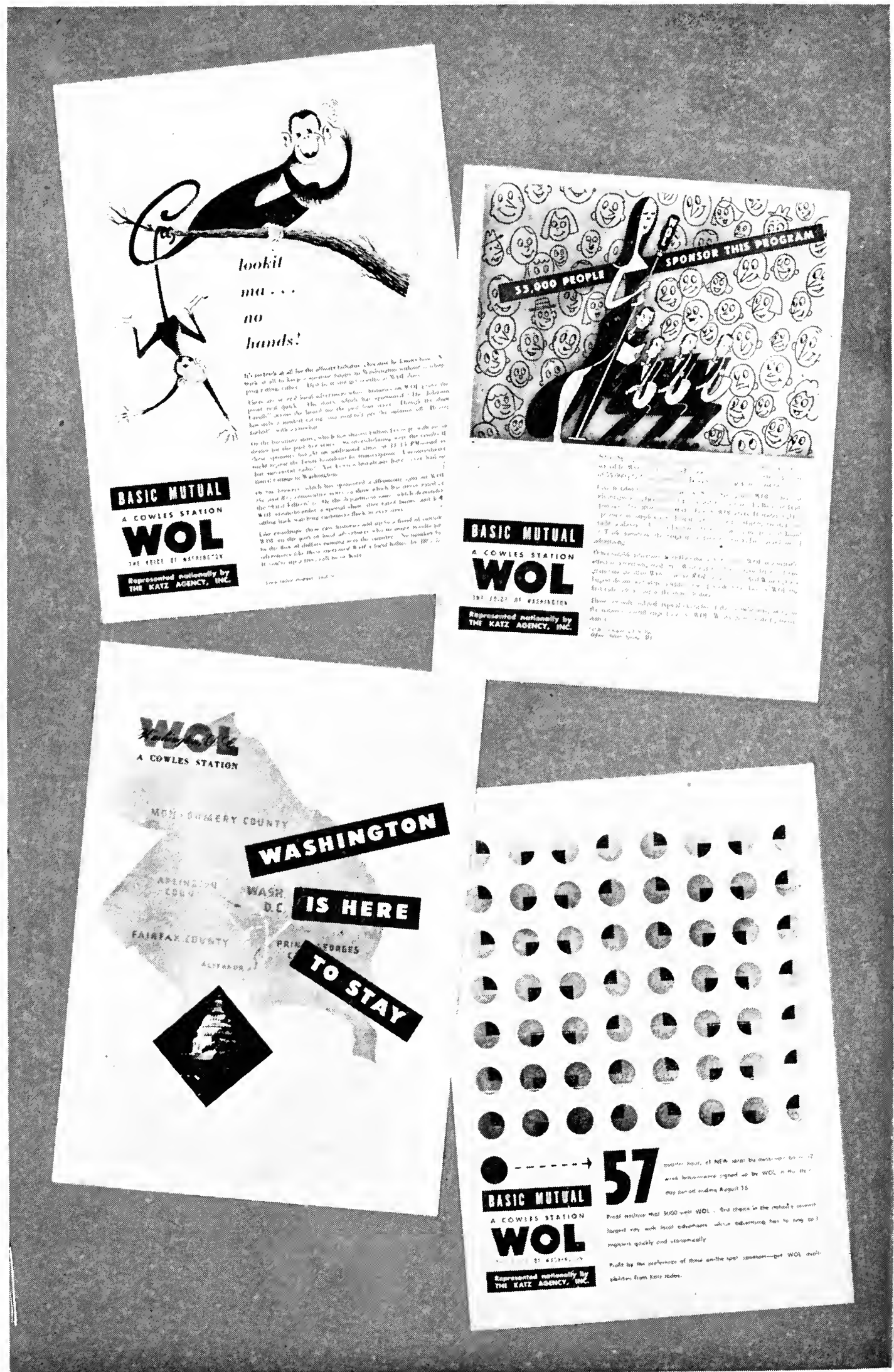

Courtesy Tom Means

EXAMPLES OF RADIO STATION PROMOTION

Direct mail and business paper advertising used by Station WOL, Washington, D. C. 
advertisement by the New York, New Haven \& Hartford Railroad. It was the work of a young copy man with the Wendell P. Colton Co. of Boston, the agency handling the account. Intended originally for regional use only, the simple, heart-warming message created such a tremendous impression that it was run in many newspapers and national magazines. Requests for reprints fairly swamped the New Haven offices. More than any one writing job of the early World War II years, it hit home.

Totally different in tone, theme and technique has been the recent series of advertisements by the Chesapeake \& Ohio Lines, inspired, if not actually written, by their dynamic chief executive, Robert R. Young. The most sensational appeared in the spring of 1946 with the heading: "A Hog Can Cross America Without Changing TrainsBut YOU Can't!" The copy dealt with the fact that transcontinental passengers were being forced to get off at Chicago, St. Louis or New Orleans and take a different train to their destination.

"Why should travel be less convenient for people than it is for pigs?" the ad challenged. It went on to state that the Chesapeake \& Ohio, whose western terminus is at Cincinnati, and the Nickel Plate, running to Chicago and St. Louis, stood ready to join with any combination of railroads for the purpose of setting up connecting schedules. Since then some 40 or more such connections have been provided. This ad succeeded despite the fact, as more than one exactitudinarian pointed out, that a hog crossing the country would be required to leave its car every day during the trip for rest and relaxation.

Other controversial advertisements by C. \& O. have enlivened the magazines in recent years. Tackling the matter of obsolete Pullmans, an advertisement in Time for August 12, 1946, demanded: "Why must sleeping car passengers put up with 'rolling tenements'? Nine out of every ten sleeping cars now in service belong in museums! What can be done about it?" Later in 1946 the line announced that it was working out a plan for "pay as you go" train travel, with credit cards-similar to the plan successfully used by the airlines before the war. In May 1947 another radical innovation was instituted-"No tipping of any C. \& O. employee."

Pullman advertising in the war years attracted much favorable comment, with its dramatic appeals for the elimination of needless travel. The New York Central, the Pennsylvania and the Santa $\mathrm{Fe}$ were lines using national magazines to win public recognition for the over- 
all job done by the railroads in moving war material-not merely for their own companies. A particularly memorable ad was one by the Pennsylvania in 1943 headed: "What it takes to move a division." The illustration showed an apparently endless number of freight and passenger trains stretching toward the horizon. Text explained that 75 trains were required to transport one armored division-about equal to the number of passenger trains running daily over the Pennsylvania between New York and Washington. "Multiply this one division by the many moving in this country and you can understand why you may have difficulty in getting a berth, or be obliged to stand in a coach, or arrive late at your destination," the ad stated.

Even before the war a number of railroads had adopted the policy of taking the public into their confidence with informative copy. Illinois Central for years has run newspaper advertising in newspapers all along the system, frankly discussing its policies and problems. "What happens to your dollar when you spend it via Illinois Central?" asked a $1947 \mathrm{ad}$. The answer: $52 \mathrm{x} / 2$ cents goes to pay the wages of some 40,000 I.C. employees, $283 / 4$ cents are assigned to materials and equipment, $10 \mathrm{~T} / 2$ cents go to taxes, $43 / 4$ cents to interest, and $3 \mathrm{~T} / 2$ cents to all other purposes.

"That's a h-l of a way to run a railroad!" was a Boston and Maine newspaper advertisement that won honorable mention in the 1942 Annual Advertising Awards. B \& $M$ found out the things patrons were complaining about and, taking the public behind the scenes, explained the reasons for delays. The disarming headline and candid text turned gripes into grins. "For the rest of the winter," said the award citation, "when trains were late commuters quoted "That's a hell of a way to run a railroad" but they smiled when they said it." 


\section{Chapter XII}

\section{SOME PEOPLE OF ADVERTISING}

TS is true in most fields of industry and trade, the big names in advertising are unknown to outsiders. Men have acquired towering prestige within the craft for their skill and daring; some have amassed fortunes; some have pioneered new techniques; many have contributed importantly to the high standards of integrity and professional practice that dominate advertising today. Yet except for a few thousand colleagues, nobody knows who they are. It is a queer quirk of fate that these masters of the art of putting brand names and slogans on everyone's lips should themselves remain anonymous.

Millions of people know that Bob Hope is the star of the Pepsodent Tooth Paste program, for example; only a few know that his boss is Charles Luckman, former general manager of Pepsodent and now head of titanic Lever Brothers Company, of which Pepsodent is a part. Mention "Luckman" to the man in the street, and if he sparks at all he'll undoubtedly identify the name as that of a star football player.

Radio fans from coast to coast associate "Fibber McGee and Molly" with the advertising of Johnson's Wax; again, only those behind the scenes know that the guiding spirit of this immensely popular show is Jack Louis of the Chicago agency of Needham, Louis \& Brorby, who built the old vaudeville team of Marian and Jim Jordan into the stars they are today.

Back of every trade-marked product is, or was, a living personality. In fact, the advertising business teems with personalities. Unknown though they may be to the general public, they have their own hall of fame. They value their recognition by fellow advertising men far more than any fleeting celebrity they might attain in the mass mind.

It is the purpose of this chapter to introduce a few of these menchosen almost at random. No attempt has been made to grade them in the order of their importance. Undoubtedly many significant figures are omitted. Those who appear here are not necessarily typical of the advertising profession; in fact, the writer seriously doubts 
whether there is such a thing as a "typical" advertising man. One thing they have in common-that elusive, indefinable flair of the master showman.

\section{The Man Who Made Luckies}

George Washington Hill, who died in September 1946, has been called the greatest advertising man ever to occupy the presidency of a major American company. He headed the American Tobacco Company for 21 years and throughout that period he kept up a constant personal interest in its advertising. The slogans he created or promoted became a part of the American language: "LS/MFT," "It's toasted," "Quality of product is essential to continuing success," "Nature in the raw is seldom mild," "Reach for a Lucky instead of a sweet," "Lucky Strike green has gone to war."

The son of Percival S. Hill, previous president of American Tobacco, he attended Williams College and at 19 entered the tobacco business. At first he sold Pall Malls, then a high-priced ultra-smart cigarette. He rose to the vice-presidency of American and in 1925 succeeded his father.

Popular-priced cigarettes got their first real impetus during World War I. Camel was the leading brand. Young George Hill began to promote Lucky Strike, using the theme "It's toasted." All cigarette tobacco, then as now, was heat-treated-but he pre-empted this claim for Luckies by powerful and consistent advertising. By 1929 he was spending $\$ 20,000,000$ a year in advertising, over $\$ 12,000,000$ for Luckies alone. This dropped considerably in the following years. American Tobacco's expenditures in radio, magazines and newspapers dipped from $\$ 8,120,000$ in 1934 to $\$ 5,290,000$ in 1943 . In 1945 the three-media figure was less than $\$ 3,000,000$, with probably a similar amount for talent and other costs. But while Hill's budgets were less, he was getting more sales for his advertising dollar. A study by the Curtis Publishing Company revealed that between 1934 and 1943 Lucky Strike sales increased from $34,000,000,000$ to $68,500,000,000$ units, whereas Camel rose from $32,000,000,000$ to $58,500,000,000$ and Chesterfield from 33,000,000,000 to 45,000,000,000. Both Camel and Chesterfield appropriations were larger than Lucky Strike throughout this period.

At the time of his death, Lucky Strikes were selling at the amazing 
rate of $85,000,000,000$ packages a year, and the company's net sales for 1945 had exceeded $\$ 557,000,000$. But Hill was not satisfied. He aimed at no less than $100,000,000,000$ units a year-more than a pack a week for every adult in America.

His greatest gains were registered in the feminine market. When he entered the tobacco business in 1904, few women smoked, and none except the most brazen dared to do so in public. The advertising themes he created had an important part in popularizing the cigarette with women and making its use socially acceptable. Frequently Hill's advertising ideas aroused irritation and controversy. In the 1920's he used testimonials from opera singers to plug the theme "Luckies are kind to the throat," and stirred up a hornet's nest. But this was nothing compared to what happened when he broke his campaign urging folks to "Reach for a Lucky instead of a sweet." He told a reporter that he got the idea from his mother, who had mentioned to him that when she was eating candy she didn't smoke, and vice versa. $\mathrm{He}$ started a drive to sell America on smoking cigarettes to avoid getting fat. The National Confectioners Association immediately protested; many of its members boycotted Luckies and tried to get consumers and dealers to do likewise. The Federal Trade Commission forced American Tobacco Company to eliminate "instead of a sweet" from the slogan. But the campaign meanwhile had captured the popular fancy. In New York City alone it boosted Lucky Strike sales 25 percent in two months. Later the offending slogan was changed to a variant, "Avoid that future shadow," which continued to ring up sales increases.

Although Hill had used and continued to use a wide variety of media-car cards, magazines, newspapers, outdoor signs, window displays-he is best remembered for his radio campaigns. He had unlimited faith in the power of repetition and radio gave him full scope. Over and over, on Lucky Strike commercials, the announcer would repeat, "LS/MFT_LS/MFT_Lucky Strike means fine tobaccoyes, Lucky Strike means fine tobacco!" He introduced the chant of the tobacco auctioneer as an overture, and the names of F. E. Boone and L. A. ("Speed") Riggs became familiar to millions who had never heard of George Washington Hill. The phrase "So round, so firm, so fully packed-so free and easy on the draw" was another of his dinnedin favorites.

Not all Lucky Strike ideas were devised by Hill, but he alone de- 
cided which ideas were to be used. William L. Day, who worked with him on a number of campaigns, said, "No man had to sell George Hill an advertising idea. When he saw what he wanted he got, I think, the same physical reaction a jive dancer gets to a good tune. He was physical-and so is the public in its reaction to cigarette copy. He was instinctive-and never lacking in the courage to back his decision with the full financial weight of his powerful appropriation." Elsewhere in his reminiscence Day uses the word "gutsy" - a favorite Hillism-to describe the quality that above all others pervaded Lucky Strike advertising.*

What manner of man was George Hill personally? Much was written and said about his striking resemblance to the soap tycoon Evan Llewellyn Evans, focal point of Frederic Wakeman's best seller, The Hucksters. But though Hill may have been eccentric in his mannerisms and ruthless in his pursuit of profits, he had a keen business mind and enormous ability as an organizer. Proof of his ability is seen in the fact that although he never had the controlling interest in American Tobacco, he dominated it completely. Over a 14-year stretch his annual income from salary and bonuses ranged from $\$ 400,000$ to well over a million. Stockholders might protest, but he had the figures to prove that he was worth it.

Lawrence Hughes caught some of the spirit and impact of the man in this paragraph from an article in Advertising Age ten days after Hill's death at the age of 61 :

Few advertising men may want to emulate his methods, but no one could question his success or his color. ... Those little white hats which he bought in France a dozen at a time and wore in the office ... The poem he wrote to the head of United Cigars when he cut him off as a direct buyer ... The time after he had blurted to me a fact which might have damaged relations with one of his biggest customers, and he asked me to hold up my right hand and swear never to divulge it . . . The cold blue eyes in the too-red face, above the black bow tie, the white shirt and the blue suit ... The dismal black-walled room at 111 Fifth Ave., which somehow reminded one of an undertaker on the make ... The nervous, ruthless energy with which the man drove himself and others ... "Nature in the raw is seldom mild."**

* William L. Day, "George Washington Hill as I Knew Him" (Advertising and Selling, October 1946). By permission of Advertising and Selling.

** Lawrence M. Hughes, "How Hill Lifted Lucky Sales" (Advertising Age, September 23, 1496). By permission of Advertising Age. 


\section{"Just an Admaker"}

He would walk into an advertising agency on fire with an idea. He had been leafing through magazines and newspapers studying the ads until he came to one that made him sneer. Then, working at top speed he would develop a new theme-headlines, copy, layouts-and set forth to sell the result. He always found a buyer.

Oversimplified, that describes the early career of one of the most meteoric individuals to flash across the advertising world in the late 1920's and early 1930's, J. Stirling Getchell. Long before he died at 41 on December 17, 1940, he had already gained legendary qualities. In his younger days he jumped from one advertising agency to another, staying from three months to a year. He made the circuit from Chicago to Detroit to New York and back again. In three years he worked twice each for Lord \& Thomas, J. Walter Thompson, and Batten, Barton, Durstine \& Osborn at a salary range of $\$ 6,000$ to $\$ 22,000$ a year. Though his earnings fluctuated wildly, he found himself at the age of 30, and with Lennen \& Mitchell he worked his way into the $\$ 50,000$ bracket. But here, as with previous agency jobs, he grew impatient of what he considered the backwardness and conventionality of those around him. He became known as a Simon Legree. Finally to keep peace in the shop the agency paid off his contract with $\$ 25,000$ in cash.

With this stake, "Getch" opened his own agency, J. Stirling Getchell, Inc. Economic conditions were far from propitious. But that didn't bother him. He set out after big accounts. His first was the De Soto Division of Chrysler. Using what was then a radical technique consisting of large illustrations with bold, newspaper-style headlines, De Soto advertising attracted universal attention. It proved so successful that shortly afterward the Getchell agency was awarded Chrysler's biggest division, Plymouth. The famous "Look at All Three" campaign resulted. For Plymouth, Getchell went even farther in the direction of news-style layouts; he took over the Gothic headings, boxes, and liberal pictorial treatment of the tabloids.

For Socony-Vacuum, Kelly-Springfield Tires and Allis-Chalmers, Getchell created hard-hitting magazine and newspaper advertising in which big headlines and photos predominated. Seldom did his ads go in for long copy; he preferred to tell the story with display lines, pictures and captions. 
Photographs were an obsession with him. Preparing for a campaign he would order not merely a dozen, but several hundred photos at a time. Groping for the picturization of a half-formed idea he would pore over these prints until he found exactly the ones he wanted. He drove photographers and art directors crazy by his perfectionism, but many agency men feel that he did more than any other one man to raise the standards of advertising photography.

"Getch" drove himself and his staff at a killing pace. His favorite time to start work on a new campaign was 5 P.M. By midnight he would be going strong. After wrestling with headlines and pictures until the milkman hour, his co-workers might be cheered by the feeling that at last he was satisfied with what had been done-only to have him tear the whole thing up and start over again the next day. There are tales of ads which Getchell sent back to typesetters for as many as 15 or 20 revisions.

The scientific aspects of advertising-market research, copy testing, readership studies, consumer psychology-had little interest for Getchell. "Somebody else can worry about that stuff," he would say. "I'm just an admaker." Admirers of his work agree that he was, indeed, just an admaker. But in this area he rates consideration as one of the authentic geniuses of the advertising craft.*

\section{Young Man in a Young Business}

"In many ways, advertising might be called the youngest part of business. Vital in its youth, reckless in its statements at times, yet generally picturing a better and brighter future. It wakens each morning to tell you and me and all America what is new in our world; what is new in the shops, in the stores and what is coming from the laboratories and great plants of the nation. It has been laughed at by its critics and abused by its friends, but it has lived and grown steadily.... It is you. It is I and millions of others. It is our hopes and desires spread into pictures and words. It is what we want for ourselves and ours." **

The man who spoke those words was at the time (May 1947) one of the top men of U. S. advertising: chairman of the board of the

* Summarized from articles in Advertising \& Selling for December 1940 and February 1941 by permission of the publisher.

** Thomas H. Young, "A Real Concept of Advertising," Chicago Federated Adv. Chub News, May 1947. 
Association of National Advertisers. He had been engaged in sales promotion and advertising work for more than 30 years, all of it with the same company. But he still had a young viewpoint and felt that he was in a young business. His name: Thomas $\mathrm{H}$. Young, director of advertising, United States Rubber Company.

Starting as a stock boy in a Boston shoestore, Tom Young was successively a salesman for bakeries and a printer before joining U. S. Rubber in 1916 as manager of the trade record department. He became sales promotion manager of the tire division in 1917, then enlisted as a private when America entered World War I, eventually rising to shavetail in the Army Air Corps overseas. Returning to the company in 1918 he worked at sales promotion until made president and general manager of the Goodyear India Rubber Company, a subsidiary, in 1921 when he was 28 years old. In 1926 he returned to advertising and sales promotion in the parent company. He was put in charge of sales development for the footwear and clothing division in 1936, and in 1939 became advertising director.

While directing a $\$ 4,000,000$ annual advertising budget, Young has retained the down-to-earth touch. His responsibilities cover the promotion of a tremendous range of products, including not only tires but also golf balls, tennis shoes, rubber tubing for industrial uses, rubber bathing suits, synthetic fabrics and many others. This is what he thinks about advertising and its relation to people:

Facts are necessary for advertising, but just because we are told that people want to know more facts about our products, this should not lead us too far astray. Just facts rarely sell goods-it is usually some more human impulse. Let's use facts, but let's not use facts to destroy the most important thing that has made advertising such a power: its humanness.

Those who know Young say that he has consistently emphasized the human values in his company's advertising.

\section{Frank and Earnest}

The good old days, or the "golden age" of advertising, most ad men will admit, ended with the stock market crash of 1929. Since then competition for the consumer's dollar has grown intense. Copy has become realistic. Research and testing have entered the picture. The 
day when a half-million dollar campaign would stampede the trade has passed.

Yet the influence of some of the greats of times past is still felt, and will be as long as advertising continues. Prominent among them stands Earnest Elmo Calkins. Born in 1868, he was nearing 60 when in 1925 he won the first Harvard Award as "the individual who has done the most to raise the standards of advertising."

Like many another advertising titan, Calkins hailed from the Middle West. He was a printer and newspaper man in Illinois after graduating from Knox College, the original of Clyde Fitch's "good old Siwash." Demonstrating his ad-writing ability as advertising manager of Schipper \& Black, Peoria, he went East to wind up at the turn of the century as chief copy writer for Charles Austin Bates. Soon after, he and Ralph Holden organized their firm Calkins \& Holden advertising agency. Afflicted with deafness, Calkins left more of the contact work to Holden until his partner's death in 1926. Calkins carried on for five years more before retiring.

Among the many accounts on which he wrote advertisements were the H. J. Heinz Company, Ingersoll Watch, Beech-Nut, Dobbs Hats, Saturday Evening Post, McCall's, Woman's Home Companion and American Magazine. He particularly enjoyed promotional work for publications, having never quite got the printers' ink out of his system. He was a contributor to Atlantic and many other magazines and wrote several books, including Louder, Please!, Business the Civilizer, The Business of Advertising and And Hearing Not: the Annals of an Adman.

Calkins' autobiographies abound with anecdotes about advertising. During his lean years in New York he once answered an ad for a writer who could produce copy in "the Gillam-Wanamaker style"alluding to the fresh individuality Manly Gillam was giving to the newspaper advertisements of the Wanamaker store in Philadelphia. "I submitted my attempts to out-Gillam Gillam," he writes, "and evidently succeeded, for while-as I learned later-Gillam himself had entered the contest, I got the job. Probably our respective demands in the way of remuneration had something to do with the result. ... There was no regular situation involved, merely the chance to write two or three pieces of copy a week at two or three dollars apiece, and in a few months this likewise flickered out."*

\footnotetext{
* Earnest Elmo Calkins, Louder, Pleasel (Atlantic Monthly Press, 1924), p. 131. Quoted by permission of the author.
} 
A pioneer in marrying art and advertising, Mr. Calkins helped establish one of the first art departments in an agency while with Charles Austin Bates, under the direction of George Ethridge, afterward head of a noted New York advertising art studio. His first big account in his own agency, that of Force Breakfast Food, was secured with the aid of eye-catching silhouettes and woodcuts from the pen of Walter Fawcett.

How a deaf man could become so eminently successful in advertising must remain one of the miracles of the profession. Modestly Calkins attributes it partly to good luck, partly to his small-town, Middle Western upbringing. But he adds this significant comment:

Advertising work was different when I began from what it has become. It was simpler, easier. It could to some extent be evolved from the inner consciousness. Today it is complex, highly competitive, and particularly is it the product of an infinite number of contacts with human beings. Above all things must the latter-day advertising man know his fellow man with the kind of knowledge that comes only from unlimited intercourse.*

With his integrity, forthrightness and simplicity of character, Earnest Elmo Calkins filled an important post during the years when advertising was emerging as a profession. He brought to it dignity and culture. He leaned backward in maintaining the highest ethical standards. Advertising is better today because for 40 years he was a part of it.

\section{Red All Over}

The field of magazine advertising solicitors has produced more than its share of advertising leaders. From this field came J. Walter Thompson, F. Wayland Ayer and many a top-notch agency man. Old-timers will recall such giants as Thomas Balmer, William Boyd and Charles Stoddard. Among those of the modern era, few can compare in eloquence, enthusiasm and vision with the red-headed dynamo, Arthur H. Motley-or as he prefers to be known-"Red" Motley.

A Midwesterner like so many successful advertising men, Red has been a salesman all his life. In his teens he tried to sell brushes in Minneapolis. After his army service in World War I, the only job

*Ibid., p. 209. 
he could get was working in an iron mine, but he soon left that to sell zithers and pay his way into the University of Minnesota. In 1928 he went to work for Crowell-Collier as an advertising solicitor. A couple of years later he was in charge of their Detroit office. He shot up through the organization with breath-taking speed until he landed one of the top jobs, publisher of American Magazine.

In this fine old family magazine, Motley instituted radical changes. He had never liked to be interrupted at a crucial point in a story by the parenthetical statement: "To be continued next month." Presently, American dropped serials and began publishing all stories complete in one issue. He liked detective yarns. So, too, he decided, did a lot of other people. Forthwith each issue of American contained a full-length mystery novel. He instituted other changes to "hypo" his "book" into new leadership in the general monthly field.

When he resigned to become president of Parade, the weekly Sunday supplement in some fifteen newspapers, friends of Red Motley shook their heads. He was venturing into a new, untried field, fiercely competitive. They needn't have worried. Within little more than a year, Parade added six newspapers, increased its circulation from slightly over 2,000,000 to more than 4,000,000, increased its line rate from $\$ 5.60$ to $\$ 10.60$ (including the Philadelphia Inquirer).

Like many an advertising man, Motley has had to defend his vocation against skeptics within his gates. His dander was raised when he heard his wife tell the next-door neighbors as she pointed to a back cover of the magazine he was representing, "My husband sells thosefor $\$ 10,000$ apiece!" Her attitude, and that of the guests, made Motley a super-bandit who "had the James boys looking like pikers." He started checking. Among other things, he learned that with the help of advertising, General Electric and Frigidaire had been able to market a better refrigerator at $\$ 175$ apiece than they had formerly put out at $\$ 500$.

As a result of his research, he said to himself, "You're not selling a piece of white paper with a little four-color ink (sic) on it for $\$ 10,000$. You are part of something that has made it possible for millions of Americans to take another forward step toward comfortable, efficient and healthful living." He told this to his wife, and her reply was, "Yeah, but what happened to the iceman?" Again he investigated, to discover that the ice industry, spurred by electric-refrigerator competition, had designed an icebox as beautiful and well insulated as the 
mechanical marvels, and had sold 600,000 more boxes that year than in any previous year for the last 30 years. Competition had forced an improvement which made the old-line companies bestir themselves and do "some original high-class thinking in order to survive."

Summing up his observations over a 20-year period, Motley has a direct challenge to the advertising field:

You, as want-creators, expert advertising men, have a terribly important role to play. That is the justification for the fact that in this profession of ours there is profit for many, opportunity for all who are willing to learn how to do their particular job well; who have enough confidence and belief in it to practise it honestly and proudly, giving it full sway. Want-creation-that's the "why" of advertising."

\section{Advertising's "Teen Age"}

Is advertising a young man's (or young woman's) business? Much evidence supports this view. Ayer started his agency at 21, Henry Ewald his at 26, Benton and Bowles were not ten years out of Yale when they launched their famous venture.** The boundless energy, self-assurance and imagery of youth are made to order for advertising. Never has this been brought home more forcibly than in a recent reminiscence dealing with the Cincinnati office of the J. Walter Thompson Company in 1912.

Stanley Resor, the agency's president for many years, had just left, leaving James Webb Young as copy chief, to become manager a year later. Needing another copy writer he wrote to the International Correspondence Schools asking them to recommend somebody. At that time, says Norman Lewis, it was about the only way to learn advertising "and a very good way." Their suggestion was James Davis Woolf, formerly a post-office clerk and at that time an examiner of papers for ICS. He was hired-eventually to become vice-president and director at Chicago and the author of several fine books on advertising. Young, who hired him, was with the agency for many years,

* From a speech before the Chicago Federated Advertising Club's course of advertising, March 3, 1947.

** William Benton and Chester Bowles launched their own agency, Benton \& Bowles, in 1929. Benton retired in comfortable circumstances in 1936, to become a vice-president of the University of Chicago and later Assistant Secretary of State. Mr. Bowles headed the Office of Price Administration during World War II. The firm, under Atherton W. Hobler and Clarence Goshorn, continues as one of the leading advertising agencies of the country. 
taught advertising at the University of Chicago, developed an amazing business in hand-woven wool neckties with his son, Webb Young, occupied a key role in the War Advertising Council and is now senior consultant of Thompson.

The staff of the Cincinnati office in 1912 handled such well-known national accounts as Woodbury's Soap, Gruen Watches, Brenlin Window Shades, Red Cross Shoes and Superior Underwear. And Young, the "old man" or boss, was 26; Harvey Manss, an account executive, was 27; Ed Stapleford, office manager, was 23, as was Jim Woolf. The art director was Albert Ross, a mature individual of 17!

Since then Manss has become vice-president of Sterling Drug, Inc., guiding the destinies of the Bayer Aspirin account; Stapleford went into the farm-paper field, and Ross won laurels as art director for Lord \& Thomas, later working with the writer in New York at Geyer, Cornell \& Newell. Norman Lewis, a 20-year-old copy man in 1912, after leaving Thompson was vice-president of the Chappelow agency for 15 years and in 1933 became president of the Ridgway Company, St. Louis agency. He has written How to Become an Advertising Man and Samples, Demonstrations and Packaging.*

\section{Heir Apparent}

Automotive advertising was the bellwether of the field for many years, until wartime restrictions intervened. The period from 1905 to 1940 witnessed the flowering of new-car promotion. Such great names as MacManus, Ewald, Nort Brotherton, and W. A. P. John in Detroit, Homer McKee in Indianapolis, Ward Canaday in Toledo and J. M. Cleary in Chicago created one dramatic campaign after another. But consistently over the years Theodore F. MacManus remained at or near the top. On various occasions he had handled nearly all the Detroit automotive accounts.

In the middle 1930's he was ready to take it easy. The old firm of MacManus Incorporated underwent a significant change in name; it became MacManus, John \& Adams. Mr. John, whose initials, W. A. P., had produced the inevitable nickname of "Wap," was universally known. But not many admen recognized the Adams part of the firm. This situation was soon remedied. Over the last

* Norman Lewis, "The 1912 Quiz Kids," Printers' Ink, March 28, 1947. 
twelve years or so, James R. Adams has been accepted not only as the rightful successor to "Mac" but as a great advertising man in his own right.

While the automobile business was just starting to feel growing pains, young Adams was riding a spavined field horse to school in southern Indiana. He grew up, went to Indiana and Notre Dame, taught school for three years and then enlisted in the army in World War I. From officers' training camp he went into newspaper work on the South Bend Tribune. In the same city was Studebaker, where presently he began editing the employee house organ. From this it was just a step to a position as advertising and sales-promotion manager of the Straube Piano Company. After three years there he moved to Critchfield \& Company, Chicago agency, writing Ford and Lincoln ads. Two years later he went to Detroit to write Chevrolet for Campbell-Ewald, doing such fine work that he was made head of the copy department and eventually was placed in charge of the Cadillac account. He also supervised both Pontiac and Oldsmobile at different times. In 1934 he joined in the founding of McManus, John \& Adams, of which he is today president and treasurer. MacManus died in 1940, and Mr. John became chairman of the board.

Sketchily, that is the Adams career. It skips many salient details: for example, his ability to pack hours of solid thinking into a sentence or a headline; his capacity for hard work without losing his geniality; his writing skill. He has authored one of the better advertising "howto-do-it" books, More Power to Advertising. Among other accounts his agency handles the Cadillac and Pontiac divisions of General Motors, Dow Chemical, Champion Spark Plug, Bendix Aviation and Bendix Radio; Jacobs Launderall. It occupies two floors in Detroit's Fisher Building as well as an office in Baltimore.

Adams came up through the copy department and has personally written more than $\$ 100,000,000$ worth of advertising. He prides himself on the fact that every line of it has been the truth. "An advertising lie is one of the worst lies on earth," he said recently. "When a man trifles with the truth in his own personal life, he pays his own penalty and that is all there is to it. But when he lies about himself (or a product) on an advertising page, he casts discredit on all business." *

* From Advertising Age, July 6, 1946. 


\section{"Just Like a Woman!"}

It may seem strange that while a top-heavy proportion of consumer advertising is aimed at women, so little mention should have been made thus far of women in advertising. This is not due to any feeling of sex superiority on the author's part. Rather, to quote Jimmie Durante, "Them is the conditions that prevail." Women, until recent years, have exerted incredibly little influence on the creation of advertising considering their importance as its target.

Here and there exceptions have occurred. The late Mrs. Erma Perham Proetz of St. Louis was a vice-president of Gardner Advertising Company and one of the few multiple winners of Harvard Advertising Awards for her campaigns on Pet Milk. In Chicago, Josephine Snapp directed public utility advertising and her memory is perpetuated in an annual award by the Chicago Women's Advertising Club to the outstanding adwoman of the year. Fleur Fenton headed her own agency in New York for many years.

Particularly in two advertising fields-department stores and cosmetics-have female advertising managers come into prominence. Miss Bernice Fitzgibbon is famous as Gimbel's sales promotion manager; Margaret Egan occupies a post of similar responsibility with Marshall Field, under Vice-President Lawrence Sizer. At Lord \& Taylor, President Dorothy Shaver keeps her interest in the store's sparkling displays and newspaper ads, directed by Mrs. Elieda Van Wesup, vice-president in charge of advertising, display and publicity. Speaking of Dorothys, farther up on Fifth Avenue Dorothy Cocks is advertising director of Dorothy Gray, Ltd. It may be unfair to remind her that she has been a successful advertiser of cosmetics for over 20 years, but it was nearly that long ago that the author featured one of her charming little direct-mail campaigns in Printed Salesmanship.

Women writers in agencies are no longer the novelty they once were. The wartime man-power shortage forced open many doors that had been tightly closed. Even some agencies specializing in industrial accounts had women writing copy-on oil-well equipment and concrete mixers! The feminine slant is, of course, a necessity with agencies handling food and beauty accounts. Such competent craftswomen as Barbara Collyer, a copy chief at Grey Advertising Agency, Hazel Reed at Gordon Best Company, Leslie Munro at Geyer, Newell \& 
Ganger, to name just a trio, consistently turn out advertising that sells-without losing the feminine touch.

A large part of copy addressed to women, however, is still being written by men. One member of her sex has dared to reverse this traditional procedure-writing copy to men, about women! She originated the lively series of ads for Ladies' Home Journal appearing in trade publications read by advertising men, built around the theme, "Never underestimate the power of a woman!" She is Mrs. "Bj" Kidd, formerly an associate copy director of N. W. Ayer \& Son, now an executive with Lewis \& Gilman, another Philadelphia agency, and a personality as sprightly and frank as her copy.

Not satisfied with telling men about the girls in her Journal ads, Mrs. Kidd wrote a book, Just Like a Woman! in which she mercilessly but amusingly proceeded to inform admen what was wrong with their approach to feminine psychology. Her chapter on the trials of an advertising man's wife is priceless. For example:

Being a One Man Laboratory of the Eternal Feminine is certainly the thorniest rose the advertising man's wife has no bed of, and several of them have confided to me that they wish they'd known what was coming sooner. Theirs are the tables upon which the experimental breakfast foods (one-third soy shreds) appear, the pots out of which comes only clients' coffee. Theirs the windows at which the test curtains made of skim milk flutter, the skins that quiver beneath the unknown hormones lurking in new beauty creams, the feet that anticipate instant immolation upon the first electrically heated rugs.

But it is not enough, they tell me privately, that feeling of keeping house at the World's Fair! What really gets them is having a man use your mind as if it were something he'd invented and kept in a glass jar. It is being waked up in the night to say whether you'd like a sedan or a convertible car after the war and why, or what makes you've noticed advertised recently. It is being cross-questioned at breakfast about why you buy that particular kind of scouring powder and "what it does for you." It is the uneasy necessity for always having a reason for everything, because you can't let the dear man down, when the normal feminine response to such inquiries would be a frank: "I don't know; I just do!"*

* Bj. Kidd, Just Like a Woman! (D. Appleton-Century, 1945), pp. 150, 151. Quoted by permission of the author. 


\section{THIS FASCINATING ADVERTISING BUSINESS}

Mrs. Kidd, whose real name is Elizabeth, attended the University of Chicago and the Art Institute. Married to Harry Kidd, famous modern painter, she lived in England, France and Spain, doing freelance journalism at the same time. Before going into agency work she was fashion director for a department store and editor of a house organ.

This chapter on advertising personalities could go on indefinitely. Hundreds of individuals have done things for and in the profession which should be told. But since a halt has to be called somewhere, it is only fitting to let the ladies have the last word. In this case, it's "Bj"- whatever that means! 


\section{BOOK III}

\section{THE "WHERE" OF ADVERTISING}




\section{Chapter XIII}

\section{CONSUMER MAGAZINES}

TIGHT MILLION magazines, every day of the year! That's the "consumption" of monthly, semimonthly and weekly periodicals by the American public as of the current year, 1947. It is a fantastic total-more than 20 magazines a year for every man, woman and child in this country; over a magazine every four days to each U.S. family!

Of this colossal amount, more than half is distributed in the form of single-copy sales over the counters of the nation's 90,000 newsstands; that is, voluntary circulation without benefit of subscription discounts, canvassers or premiums.

The present popularity of magazines assumes even greater significance in view of the many factors, competing for public attention. Motion pictures, radio, the automobile, outdoor sports, all have shown tremendous increases in public favor in recent years. Yet magazine sales continue to climb.

Somewhere between 6,500 and 7,000 "titles"-that is, individual magazines-are being published at the present time. The official 1939 Census of Manufacturers conductd by the Department of Commerce listed 4,985 titles, and since then many have been added. The paper shortage which developed in World War II kept down the number of new publications and restricted the normal growth of many established magazines. But despite this, a number of the leaders reached new heights. Over all, magazines increased 113 percent between 1933 and 1945, a rate far exceeding any other index of national living standards such as motion-picture attendance, telephones in service, and homes equipped with radio sets.

In the 1939 government survey the nearly 5,000 periodicals had an average per issue circulation of $239,000,000$ copies. Seven years later a conservative estimate placed the figure at over $350,000,000$, based on known circulation increases. This included not only general magazines but also the fraternal and religious periodicals, state farm pa- 
pers, labor publications, scientific, medical and legal journals and the business papers.

Narrowing this down, only 239 consumer magazines were listed in the May 1946 issue of Standard Rate G. Data Service as being members of the Audit Bureau of Circulations. These 239 accounted for a per-copy distribution of over $154,000,000$, an average of 650,000 per magazine.

For many publications, growth has accelerated since the end of the war; hence their popularity cannot be ascribed to wartime conditions. Here are a few of the figures showing six-months' average circulations of a number of leading magazines as of January 1,1945 , and January 1, 1947:

\begin{tabular}{|c|c|c|}
\hline & \multicolumn{2}{|c|}{6 months ending: } \\
\hline & $\begin{array}{c}\text { December } \\
31,1944\end{array}$ & $\begin{array}{c}\text { December } \\
31,1946\end{array}$ \\
\hline 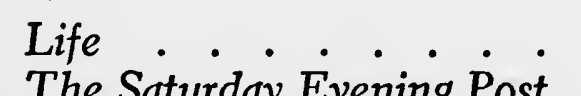 & $3,914,853$ & $5,144,181$ \\
\hline $\begin{array}{l}\text { The Saturday Evening Post } \\
\text { Better Homes and Gardens }\end{array}$ & $3,366,161$ & $3,848,031$ \\
\hline $\begin{array}{l}\text { Better Homes and Gardens } \\
\text { Good Housekeeping . }\end{array}$ & $\begin{array}{l}2,384,329 \\
7,543384\end{array}$ & $\begin{array}{l}2,770,787 \\
3046643\end{array}$ \\
\hline Ladies' Home Journal . & $4,238,568$ & $4,682,191$ \\
\hline MacFadden Women's Gro & $2,700,530$ & $3,208,653$ \\
\hline Time. . . . . . . & $1,161,575$ & $1,559,579$ \\
\hline Parents' Magazine & 692,026 & 945,164 \\
\hline pular Mechanics & 660,972 & 952,793 \\
\hline
\end{tabular}

Between 1914, when the Audit Bureau of Circulations was established, and 1945, popular magazines increased their sales eight-fold. This was all the more notable in view of the fact that the percentage of single-copy or newsstand sales had also steadily risen. In 1925 two out of every three magazines were bought on a subscription basis. By 1946 the ratio was almost exactly reversed; 62.3 percent of all circulation was on a single-copy basis.

To the advertiser this trend has great significance. Magazine subscriptions generally are secured by means of a discount from the single copy rate. Thus Life retails at 15 cents per copy, costs but $\$ 5.50$ per year by subscription-a saving of $\$ 2.30$. The price is even lower on a two or three-year basis. Some magazines depend almost entirely on subscriptions, for example, the farm papers. Others, like the so-called "true" and movie magazines and the "pulps," chiefly all-fiction mag- 
azines in the detective, western or romance field, are almost exclusively single-copy distribution. The Popular Fiction Group, for instance, has only 15,913 subscribers out of $2,709,151$ circulation-less than one half of one percent. The majority of general magazines have about a 50-50 distribution between newsstand and subscriptions.

Which type of circulation is best for the advertiser? In the past, many subscriptions were obtained by premiums, "club" rates and other devices which tended to depreciate the prestige of the magazine in the eyes of the subscriber. There can be no denying the fact that the individual who pays the single-copy price for a magazine at a drug or candy store, newsstand or railroad depot actually intends to read that particular issue. As against this must be balanced the point that the subscription copy is generally delivered to the home where in the normal course of events, if the magazine is well edited, it will be looked at by not only the subscriber but one or more other members of the family.

\section{Types of Consumer Magazines}

Aside from the "digest" magazines and a few others that do not carry advertising, the consumer periodicals of the country fall into a number of classifications based on their editorial content. Kleppner segregates them into four major groups: general, women's service, women's romance and class magazines-the last named being those aimed at a specific class of readers with a special hobby, viewpoint, problem or pursuit.*

This breakdown is perhaps oversimplified in view of the wide variety of consumer magazines now being published. Standard Rate G Data Service gives 31 different classifications and, even so, has to include one as "miscellaneous."

The following arrangement, while not orthodox, represents the way many advertising-space buyers consider their periodicals.

1. General weeklies and biweeklies-Included among the weeklies are such publications as Life, The Saturday Evening Post, Collier's, Time, Newsweek, United States News, World Report and The New Yorker; and Look, Liberty, Pathfinder are among the fortnightlies. With the numerous other publications in this field, this group prob-

* Kleppner, Advertising Procedure, pp. 291-294. 
ably has a combined circulation of around $18,000,000$ to $20,000,000$ copies per issue.

Because of their frequency of appearance and nation-wide coverage, these magazines are very important advertising media. They have extensive readership in the retail trade; many buyers in the food, home furnishing, drug and cosmetic fields make it a point to read each issue of the leading general weeklies to keep informed regarding new products and established products being promoted nationally. The publishers aggressively "merchandise" their "books" by means of promotional programs, reprints of ads on easel cards for display in the stores and other devices to make advertising more productive. Life and The Saturday Evening Post have been particularly successful in getting dealers to co-ordinate local ads and displays with their various magazine campaigns.

A notable example was the promotion by the Kroger Company, with 2,600 grocery stores in 18 states, of products "Advertised in Life." Giant banners, mammoth displays, window streamers, shelf markers and supporting ads in over 1,100 newspapers carried the theme for the two weeks between April 21 and May 3, 1947. Reporting on the event President Joseph B. Hall of Kroger declared: "Not only did the promotion produce the largest two-week sales period in our history, but, even more important, the foundation was successfully established for continued excellent sales movement of these leading national brands." *

One of the most unusual applications of magazine advertising was that of the Lionel Corporation in Liberty for November 23, 1946. Sixteen full pages in color were used to show the complete line of Lionel toy trains, transformers, accessories, track and miniature chemical laboratories. Broadsides and telegrams told the trade about the ad. A complete program of store displays, posters and newspaper ad mats was used to stimulate dealer activity for Christmas sales. Actually the 16-page ad was a consumer catalogue, distributed to $1,300,000$ families at a cost of less than six cents each. There was an added dividend in the fact that Lionel was able to obtain over half a million reprints for point-of-sale distribution at minimum cost.

This is by no means the first multiple-page ad in a weekly magazine. In 1912 Studebaker used five pages in one issue of The Saturday Eve-

* From an advertisement in Food Topics, June 2, 1947. 
ning Post. In 1940 Philco ran a "gate-fold"* advertisement for its new electric refrigerator in Collier's. Numerous other advertisers have used from three to eight pages in national weeklies, but it is believed that the Lionel advertisement was the largest of them all. At the time it appeared, Liberty was a weekly; since then it has become a monthly.

Several of the weeklies specializing in news summaries, such as Time, U.S. News and Newsweek, have a strong following among business executives and carry a considerable amount of what might ordinarily be thought of as industrial advertising.

Unique in the weekly field is The New Yorker, which despite its name has more readers outside Manhattan than in its home town. Of its nearly 300,000 circulation only 72,000 goes into New York City. California accounts for 29,913 copies; the smallest state is North Dakota with 188. Advertisers may buy either the whole circulation at a cost of $\$ 1,800$ a page or the New York edition for $\$ 700$. Most of them, even the local shops, take the national edition because of the likelihood that readers in the other 48 states will get to New York sooner or later!

2. General monthlies-This field, formerly the largest and most influential in the whole magazine industry, has narrowed down to only a few publications with large circulation. These are The American Magazine, Cosmopolitan and Redbook. In addition there are some general monthlies with limited distribution, including such old familiar names as Atlantic and Harper's.

In a class by itself is National Geographic, with almost $1,500,000$ subscribers (all members of the National Geographic Society) - one of the predominant quality media. Its format has been virtually unchanged since 'way back when. Another distinctive monthly is Esquire, which after a modest start during the depression has preempted the men's fashion field in addition to supplying excellent fiction and titillating cartoons at fifty cents per copy; its present circulation is around 606,000. Pic, a magazine for men, is a Street \& Smith publication which sells half a million copies per month. Coronet, pocket-size magazine sponsored by Esquire, for some years accepted no advertising, in March 1948, was again to become an advertising medium, with a guaranteed circulation of $2,000,000$ copies per month. True, a men's magazine published by Fawcett, is nearing the 1,000,000 mark.

* A gate-fold is an advertisement in which one page, usually the right-hand one, is wider than normal and folded into the magazine, opening out like a gate. 
3. Women's service magazines-The "services" rendered by this group are all concerned with home-making; recipes, menus, table-setting, interior decoration, child care, and beauty subjects including fashions and personal grooming. That makes them the logical advertising medium for grocery products, cosmetics and similar lines.

Leading magazines edited for home managers are Ladies' Home Journal, Good Housekeeping, McCall's, Woman's Home Companion, and Household. This last-named publication, little known in the big cities, has a circulation of over 2,000,000 copies a month. It is edited by Nelson Antrim Crawford and issued monthly by Capper Publications, Topeka, Kansas; a subscription costs 50 cents per year. Average distribution of women's magazines in cities of 100,000 and over is around 35 percent. The circulation of Household in these areas is about 3 percent.

Among the more familiar women's service magazines, Good Housekeeping has a niche all its own. It is the only one of the leaders that clings to the "flat" size- $8 \mathrm{t} / 2 \times 11 \mathrm{~T} / 2$ inches. It issues its own "seal of approval" to products tested and found satisfactory by the Good Houskeeping Institute.

McCall's, edited by Otis Weise, is possibly the most "dressmakingminded" of the service magazines. Its publishers have a large pattern business and publish quarterly and semiannual needlework and sewing books. Woman's Home Companion under Publisher Edward Anthony and Editor William Birnie has not only maintained its service function but has introduced a crusading note into its articles on juvenile delinquency, world co-operation and other subjects that women's magazines once wouldn't touch with a 100-foot pole.

Under its famed husband-and-wife combination, Bruce and Beatrice Gould, the old Journal has had an amazing rejuvenation. Its circulation today is 45 percent above 1939 and its advertising revenue 85 percent greater. Today with more than $4,600,000$ copies per issue the Ladies' Home Journal is a far bigger, more colorful, more widely read magazine than in the days of its famed long-time mentor, Edward W. Bok.

Today's Woman, specifically edited for younger homemakers, has soared to a guaranteed circulation of 700,000 in eight years. Woman's Day, Everywoman's, The Woman, Western Family and Family Circle are other women's service magazines of large circulation.

4. Women's groups. A notable thing of the last 25 years has been 
the rise of the "women's groups"- a collection of some two dozen magazines whose chief appeal is either the "true" or pseudo-autobiographical type of fiction (generally told in the first person and illustrated by photographs) or the movie-star-tells-all article. These periodicals have become a major advertising medium through their popularity with the "wage-earner" market and through smart promotion.

The field originated with True Story, a creation of Bernarr Macfadden in the early 1920's. Its instant success attracted imitators, including several magazines launched by the founder himself. At first these periodicals were inclined toward a preponderance of stories about unwed mothers, border-line flirtations and similar subjects, invariably with a moralistic ending. As time went on, editorial content was sanitized and endorsements secured from members of the clergy. Advertising, which had leaned toward such products as mail-order jewelry, bust developers, weight reducers, correspondence schools and the like, began to veer in the direction of nationally known brands of cosmetics, drug products, and even foods. Several of the magazines have instituted cooking and homemaking departments in their editorial structure, and all have recently exercised a much more rigid censorship over both copy and product in their advertising pages.

True Story, the pioneer, continues to lead in circulation and advertising patronage as an individual publication, but the other magazines in the field have challenged its leadership by merging into "groups," i. e., several periodicals sold as a unit to the advertiser. Thus the Macfadden Women's Group embraces Photoplay, Radio Mirror, True Romances, True Experiences and True Love and Romance, with a net sale for the November 1946 issues totalling 3,470,777 and a combined page rate of $\$ 4,950$. Other prominent groups are: Fawcett Women's Group, comprising True Confessions, Movie Story and Motion Picture, with slightly under 3,000,000 copies; Dell Modern Group, including Modern Romances, Modern Screen and Screen Romances, having a net sale in September 1946 of 3,140,665; Ideal Women's Group, four publications adding up to nearly 2,000,000 per issue; Hillman Women's Group, including Screen Guide, a bit under $1,500,000$, and the Hunter Screenland Unit, near that same figure.

Macfadden Publications have blazed the trail in this wage-earner market with radio, magazine and newspaper promotion. A forum of typical Macfadden readers has been established under Everett $R$. Smith, director of research, to give a cross-section of views on subjects 
of interest to the advertiser. Typical question: "Do you think advertisements help give you better products for your money?" Answer: "Yes" by 74 percent of husbands, 77.4 percent of wives. Another: "Would you be satisfied to see all advertising removed from magazines?" The reply: "No" by 90.9 percent of husbands, 91.8 percent of wives.

To the extent that they reach a market with spendable income, often unduplicated by general or service magazines, the "true and movie groups" have a definite spot in advertising. This market is not wage earners in general but chiefly the younger element. A study of Macfadden Women's Group readers in 1945 showed 77.2 percent under 36 years of age. This contrasts with most of the general magazines, the majority of whose readers are above that age. The study established the median age of Macfadden's regular readers as 22.9 years. Other characteristics of these readers: 70 percent of the copies go into homes where married women read them regularly; half of the homes have children under 18; Macfadden Women's Group families are 26.5 percent larger than the national average; 50.6 percent have incomes of over $\$ 3,000$ as against the national figure of 29.2 percent.

From an advertising angle it is desirable to reach the younger buyers whose brand preferences are not so firmly established. Particularly in such fields as food, cosmetics, candy, tooth paste, clothing and entertainment these younger families spend proportionately more of their income on advertised items than do the older, more settled families.

One may wonder why a publisher will issue two, three or more magazines, all very similar in character and theoretically competing with one another, rather than concentrating on a single title. The reason is simple. Newsstand sales depend to a large extent on display. Manufacturers of consumer goods know that the more of their merchandise they can induce the retailer to put on display in his store the more will be sold. Similarly, a "group" publisher with three to five titles will tend to get three to five times as much newsstand display as any one of his magazines would receive alone.

5. Newspaper supplements-When is a magazine not a magazine? When it's a newspaper! Some of the bulkiest circulations listed among consumer magazines are those of Sunday (and Saturday) newspaper inserts. Distributed along with the week-end paper, these 
publications occupy an anomalous position, half flesh and half fowl. But no advertising man can deny their impact or influence.

First and foremost comes American Weekly, a Hearst production with some 9,000,000 copies per week in 20 metropolitan newspapers. A "cycle" of full-color pages every fourth week as of May 1947 was priced at $\$ 221,520$, which included a 4 percent discount. The onetime full-color rate was $\$ 17,750$ per page. Developed by dynamic Mortimer Berkowitz, American Weekly has produced remarkable results for many advertisers, particularly in the mail-order field. Grocery, drug and automotive advertising has also been extensively carried over the past 25 years.

This Week, a slick-paper supplement of the New York Herald Tribune, Chicago News and some 22 other big newspapers, reported a circulation in 1946 of $8,473,057$ per week. The full-color page rate was $\$ 21,250$, with quantity discounts. A similar venture was Parade, with 4,200,000 copies a week and an $\$ 8,500$ full-color page rate. Pictorial Review, a serio-comic feature section duplicating much of the American Weekly circulation, was available either on a coast-to-coast basis or by individual papers. A full-color page for the whole group, $6,200,000$ copies, was priced at $\$ 14,500$. Puck, the comic section of some 15 Hearst newspapers, carried a $\$ 12,600$ tag for one-half page in colors, reaching 7,600,000 copies in March 1947.

Largest of the newspaper supplement groups as of May, 1947, were Metropolitan Group Gravure-14,776,267 circulation including puissant New York News, Chicago Tribune, Philadelphia Inquirer, Los Angeles Times - with some 26 papers, and the Metro Group Comics, offering a maximum of 48 papers in 42 cities with 18,775,722 circulation. Actually these are not magazines in any sense of the word, even though listed in the magazine section of Standard Rate 6 Data Service. But because they make color available and generally offer a better ad reproduction than straight newspaper reproduction they are sometimes considered in the magazine field.

All of these supplements offer merchandising co-operation with the advertiser and have been effectively used by many of the "blue-chip" firms as well as by smaller companies on a more localized basis.

6. The shelter group-Rapidly growing interest in home ownership made it inevitable that there should spring up a number of magazines dedicated to this field. The two leaders are both relatively new. Better Homes and Gardens, published by Meredith at Des Moines, Iowa, 
was known 25 years ago as Fruit, Garden and Home. In 1947 its circulation passed the 3,000,000-mark and issues of over 200 pages were the rule. A full-color page was priced at $\$ 11,600$ and the $\$ 2.50$ a year subscription price was a far cry from the old three years for $\$ 1.00$ rate. But by the same token the new Better Homes was a better buy both for consumer and advertiser.

American Home, second largest in the field, reported a 1947 circulation of 2,500,000 equitably divided between subscriptions and newsstand sales. Both these magazines, while carrying important linage among building and decorating advertisers, also had a substantial volume of food advertising. In fact, American Home declared that it had handled the third largest amount of editorial food linage over a nine-year period among all home, women's service, general and weekly magazines. This emphasizes the close relation between editorial and advertising content in periodicals. The advertiser naturally wishes to place his message in a medium that will be receptive and hence chooses those that provide an appropriate editorial background.

Other publications in the home-planning field include House Beautiful, House $\sigma$ Garden and a number of quarterly and semiannual publications as well as monthlies in the horticultural field.

7. Comics and pulps-Another spectacular development in the magazine field in recent years has been the sensational growth of the "comic books." These are the gaily-colored little publications which now besprinkle every newsstand. Their popularity, particularly with the younger generation, has been almost incredible. Some 25 different groups of comic magazines were listed in 1947, with as many as two dozen titles being included in a single group. Total circulation is difficult to estimate but it is probably in excess of 40,000,000 copies per issue.

Considering the tremendous "pass-on" readership of these comic periodicals there is justification for the assertion of the National Comics Group that "in 90 percent of the 14,000,000 homes with children from eight to twenty, the comics magazines are standard equipment, are also read by 40 percent of the adults in such homes, have more all-family readership and more readers per copy than any other periodical."*

The National Comics Group includes several characters who have figured prominently in the current vogue for this type of printing:

* From an advertisement in Advertising Age, June 9, 1947. 
Superman, Bat Man and Wonder Woman. Nine of the books are published monthly and 17 are bimonthly, for a combined circulation for the complete group of $8,000,000$. Among the titles are Boy Commandos, All American Comics, All Flash Comics, Detective Comics, Funny Stuff, Mutt and Jeff, Star Spangled Comics and Comic Cavalcade.

Harvey Comics, launched in 1940 by three brothers the oldest of whom was only 32, hit the 4,000,000 mark in 1947. Among their stellar attractions: Joe Palooka, Terry and the Pirates, Steve Canyon, the Green Hornet, Li'l Abner. At this writing they are publishing seven books, all bimonthly except Joe Palooka, a monthly. Surveys made by the brothers show that their readers are predominantly in the 8 to 16 year bracket, with a ratio of two boys for each girl.

From the standpoint of a major advertising medium the comic books have yet to entrench themselves. Certain types of advertisers, such as novelty manufacturers, have made them pay out. Their chief value would seem to be, aside from direct returns to coupon offers, in the field of secondary influence, i. e., getting the young readers to talk their parents into various purchases.

The comic technique of a sequence of pictures with the dialogue carried in "balloons" has been successfully employed by many advertisers and is the logical format for campaigns in this medium.

The criticism of comic books as being oversensational has caused several of the groups to retain child psychologists and educators to supervise their contents. Parents' Magazine publishes a number of periodicals for the younger set, including True Comics, established in 1941 for boys and girls from eight to sixteen, which deals largely with exciting episodes in the lives of American patriots. Its other juvenile publications like Polly Pigtails and Calling All Kids also contain com. ics designed to promote good citizenship.

"Pulps" is a term applied to magazines printed on paper made from pulpwood, similar to newsprint. They specialize in fast-moving fiction, generally stylized in the detective, western or romance pattern. Popular Publications has a group of some 23 such books with a total circulation of 2,725,000, including old-timers like Black Mask and Adventure. Thrilling Fiction Group has about the same total among some 29 titles.

Mention should also be made of the various men's groups, chiefly patterned along the True Detective lines. While they cannot be classed 
as pulps, they are of interest to advertisers chiefly as an additional medium to reach the wage-earner market.

8. Hobby magazines-Apparently there is nowadays no hobby, from photography and gardening to stamp collecting and model railroading, that does not have its magazine. One of the most widely pursued is that of home craftsmanship. In this field are such publications as Popular Mechanics, with nearly a million circulation; Popular Science, Mechanix Illustrated and Science and Mechanics. All contain instructions and diagrams on how to make various articles in the home workshop. Popular Mechanics after surveying its readers announced that 90 percent live in houses, 73.2 percent own their homes, 72.3 percent have home workshops, 66.3 percent are family heads and 56.6 percent have "power-driven tools." Naturally such publications offer an enticing market to the makers of home lathes, files and tools. But it is not so easy to see why these magazines are the most prolific producers of coupons for trade schools and technical books; nevertheless that is the case. Popular Mechanics and Popular Science are first on the schedules of virtually all leading residence and home-study courses in the technical field.

Another important hobby field is that of fishing and hunting. The leading periodicals in circulation are Sports Afield, Outdoor Life and Field and Stream, all with circulations between 475,000 and 750,000 each. Not far behind are Hunting and Fishing, Outdoorsman and Outdoors. These publications carry advertising not only of fishing tackle and shotguns but also of general products.

Other magazines in the field of hobbies or special interests include those devoted to dogs and pets, music, travel, games, military and naval affairs, arts and antiques, needlework and babies. The publication Congratulations, for example, is distributed to mothers of newborn babies in 485 hospitals and has a quarterly circulation of 500,000 . Advertising orders are accepted only on an annual basis, at a rate of $\$ 6,000$ per page.

9. Religious and fraternal magazines-Seventy-five years ago, religious publications were among the most important of all advertising media. Today they must be considered as only supplementary. The leadership in molding public opinion has passed to other hands. A few magazines like Extension, a Catholic monthly, and the Christian Herald, a Protestant magazine, have retained some semblance of advertising importance. In the daily field Christian Science Monitor has 


\section{THE}

\section{PEN
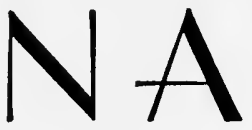 \\ LT T

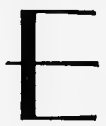

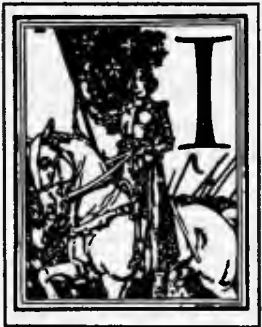

N EVERY field of human endeavor, he that is first must perpetually live in the white light of publicity. Whether the leadership be vested in a man or in a manufactured product, emulation and envy are ever at work. CIn art, in literature, in music, in industry, the reward and the punishment are always the same. CThe reward is widespread recognition; the punishment, fierce denial and detraction. C When a man's work becomes a standard for the whole world, it also becomes a target for the shafts of the envious few. If his work be merely mediocre, he will be left severely alone - if he achieve a masterpiece, it will set a million tongues a-wagging. C Jealousy does not protrude its forked tongue at the artist who produces a commonplace painting. CWhatsoever you write, or paint, or play, or sing, or build, no one will strive to surpass or to slander you, unless your work be stamped with the seal of genius. C Long, long after a great work or a good work has been done, those who are disappointed or envious continue to cry out that it cannot be done. C Spiteful little voices in the domain of art were raised against our own Whistler as a mountebank, long after the big world had acclaimed him its greatest artistic genius. CMultitudes flocked to Bayreuth to worship at the musical shrine of Wagner, while the little group of those whom he had dethroned and displaced argued angrily that he was no musician at all. C The little world continued to protest that Fulton could never build a steamboat, while the big world flocked to the river banks to see his boat steam by. C The leader is assailed because he is a leader, and the effort to equal him is merely added proof of that leadership. C Failing to equal or to excel, the follower seeks to depreciate and to destroy - but only confirms once more the superiority of that which he strives to supplant. CThere is nothing new in this. It is asold as the world and as old as the human passions-envy, fear, greed, ambition, and the desire to surpass. C And it all avails nothing. CIf the leader truly leads, he remains-the leader. C Master-poet, master-painter, masterworkman, each in his turn is assailed, andeach holds his laurels through the ages. C That which is good or great makes itself known, no matter how loud the clamor of denial. C That which deserves to live-lives.

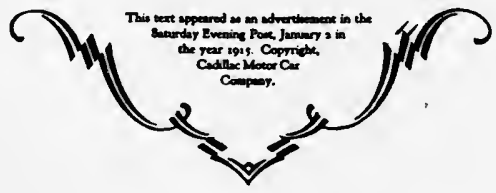

\section{A CLASSIC EXAMPLE OF INSTITUTIONAL ADVERTISING}

Written in 1914 by the late Theodore F. MacManus, this impelling messag sold Cadillac prestige and quality without once mentioning the name of th product. The only identification was in the company's signature in small typ at the bottom of the ad. 
also held its own as a medium of interest to the advertising-space buyer.

The lodges and fraternal organizations have been more successful in retaining their value as media. American Legion Magazine guaranteed 3,000,000 circulation as of July 1947, "with apologies to the 2,000,000 women readers Daniel Starch says we have." Over a million Eagles received their magazine every month while the Elks and Moose were not far behind. Among civic-club magazines The Rotarian had a distribution of 240,000 . It carried weight because its hand-picked members were often the leaders in local business and professional circles.

10. Class magazines-Since the days of Godey's Ladies' Book American women have had their fashion magazines. At present the two high-style periodicals in this field are Vogue and Harper's Bazaar, each with somewhere around a quarter of a million circulation and many times that many readers. Buyers of women's ready-to-wear are believed to be extremely susceptible to fashion comments in these magazines. They are also said to have a wide reading among patronesses of beauty parlors (the author may be forgiven for a lack of knowledge on this point).

In recent years a new type of magazine has appeared, appealing to the style-conscious teen-ager. Most successful in this field has been Seventeen, which in mid-1947 reported a circulation of some 850,000, Mademoiselle, a Street \& Smith publication with 426,000, and Junior Bazaar, over 100,000.

There are also numerous club and union magazines, including the Kellogg Group of Railroad Employee Publications and Koch's List of Railroad Magazines. There are service magazines like The Leatherneck and Our Army and Our Navy. There is Yachting. Old-timers look in vain for such ritzy magazines as The Spur and The Sportsman. They have disappeared into limbo.

\section{Success, Nothing Succeeds Like}

Nineteen hundred forty-six found the national magazines riding high, wide and very handsome. Space was still at a premium. Leading publications could virtually pick and choose their patrons. The result was a record-smashing total of cash business.

Topping all periodicals was Life, which reached a total of $\$ 56,000$,- 
000 in advertising revenue for 1946, figured on the one-time rate. With quantity discounts deducted, it is believed that this still compared favorably with the previous record of $\$ 53,000,000$ for The Saturday Evening Post in 1927.

For 1946, the Post was in second place with $\$ 47,000,000$ and Collier's third with $\$ 22,000,000$. Next in in order, according to Leading National Advertisers, were Ladies' Home Journal, Time and American Weekly. These, with Good Housekeeping and McCall's, accounted for more than half of the total of all 109 leading national magazines for the year, with practically $\$ 200,000,000$ in advertising.

Other magazines and supplements figured importantly in the totals, but these were the leaders. They won their positions through aggressive action and held them with more of the same tactics.

America's biggest advertising money-maker, Life, was far from a gold mine in its early years. Back in 1932 Time, Inc., began to experiment with a picture magazine and issued a dummy called Newsreel; later this was abandoned and a real newsreel, "The March of Time," was started instead. In 1936 another trial dummy, Rehearsal, was distributed to advertising men. Today it is a collector's item. After considering and discarding various names, including Parade, See, Look and Picture, all of which were later adopted by other publishers, the firm bought the name of Life, a once popular humor magazine, for $\$ 92,000$.

The original advertising rates were based on 250,000 circulation and the new Life appeared in November 1936. The first week's run of 400,000 was sold by noon of the first day. Print orders were stepped up week by week till 1,000,000 was reached, with advertisers getting a free ride of 750,000 copies. As a result, Life went into the red $\$ 5,000,000$ in its first 18 months. Then rates were adjusted and the magazine began to make a little money in 1938, by which time circulation had passed the 2,000,000 mark. In 1940 it had reached 2,900,000 to the Post's 3,162,000. Throughout this period Life continued to be a sellout at many newsstands. Saturation tests, i. e., supplying various cities with all the copies they could absorb, convinced the publishers that they had a potential 5,000,000 weekly medium. This confidence was justified when with some relief from the paper scarcity after the war, the issue of November 4, 1946, hit 5,398,508 sales.

A single-page ad in Life in 1947 cost $\$ 15,225$, a four-color page $\$ 22,000$ and a back cover $\$ 28,500$, based on a guarantee of $5,200,000$. 
These rates were up over 50 percent from 1945 when the guarantee was 3,600,000. Despite these thumping increases, Life still had to limit the number of insertions by advertisers and refused to accept nonconsumer ads.

Look, the second magazine in the pictorial field, grew out of the work done by Gardner and John Cowles on the rotogravure section of the Des Moines Register and Tribune, in which they used related pictures telling a story rather than the old roto technique of a jumble of miscellaneous photos. The first issue appeared in January 1937, and it quickly reached 1,500,000. A biweekly, Look has stepped up its circulation more slowly than Life, now guarantees (as of spring, 1947) $2,310,000$ per issue for a one-time page-ad rate of $\$ 6,330$. Its 1946 advertising revenue was over $\$ 6,000,000$-less than Vogue but more than Esquire.

The influence of the picture magazines has been felt throughout the magazine field. At one time there were a dozen imitators of Life and Look on the stands, including Picture, started with high hopes by the late J. Stirling Getchell and stopped after a few issues because clients said it took too much of his time. Virtually all general and women's magazines have borrowed some of the "picture-book" technique, using photo spreads and full-page photos. And a glance at the advertising pages will reveal many an ad whose layout stems directly from the editorial pages of Life.*

\section{Magazine Advertising in Generaı}

As compared with other media, magazines have certain advantages and certain disadvantages. On the positive side they offer relatively long life, excellent reproduction, particularly of color effects, prestige of an established number of readers, public confidence and selectivity of audience. From a negative angle they lack the flexibility of some other media because ads must be planned weeks or months ahead, and in the case of a manufacturer with spotty distribution they may involve a considerable amount of waste circulation.

To the advertiser one highly significant feature of magazines is that they are designed to be read at leisure. Most periodical advertising recognizes this fact by the use of entertainment or service appeal

* "Picture Magazines: 10 Years," Tide, December 20, 1946, pp. 17-19. By permission of Tide. 
rather than the greater emphasis on eye-catching devices found in newspapers. There are, of course, plenty of examples of long-copy and magazine-style ads in the newspapers, particularly the Sunday supplements, but generally it can be said that magazine advertising is less urgent, more subtle in its approach to the prospect.

In total volume, magazines must be considered the largest national advertising medium. The 1946 estimate of Dr. Hans Zeisel gives magazines some $\$ 430,000,000$, as against $\$ 358,000,000$ for national radio and $\$ 292,000,000$ for national newspaper advertising revenues. Both radio and newspapers have a large volume of local advertising. Over two-thirds of the total newspaper ad dollars come from retail sources, Dr. Zeisel estimates, while with radio about one-fourth of the over-all income is said to be from local sponsors.*

Advertising cannot claim the entire credit for the present stature of America's magazines. In recent years almost every publisher has found it necessary to raise his subscription and single-copy rates to meet increased costs. Five-cent weeklies went to 10 cents; women's service magazines from 10 to 15 and then 25 cents-in most cases with no appreciable loss in patronage. Magazines need this circulation revenue. But they also need the financial backing of advertisers, The Reader's Digest notwithstanding.

By underwriting editorial and production costs on an ever larger scale over the past 100 years, advertising has indeed made the modern magazine a proud institution in American life.

* Printers' Ink, March 28, 1947. By permission of Printers' Ink. 

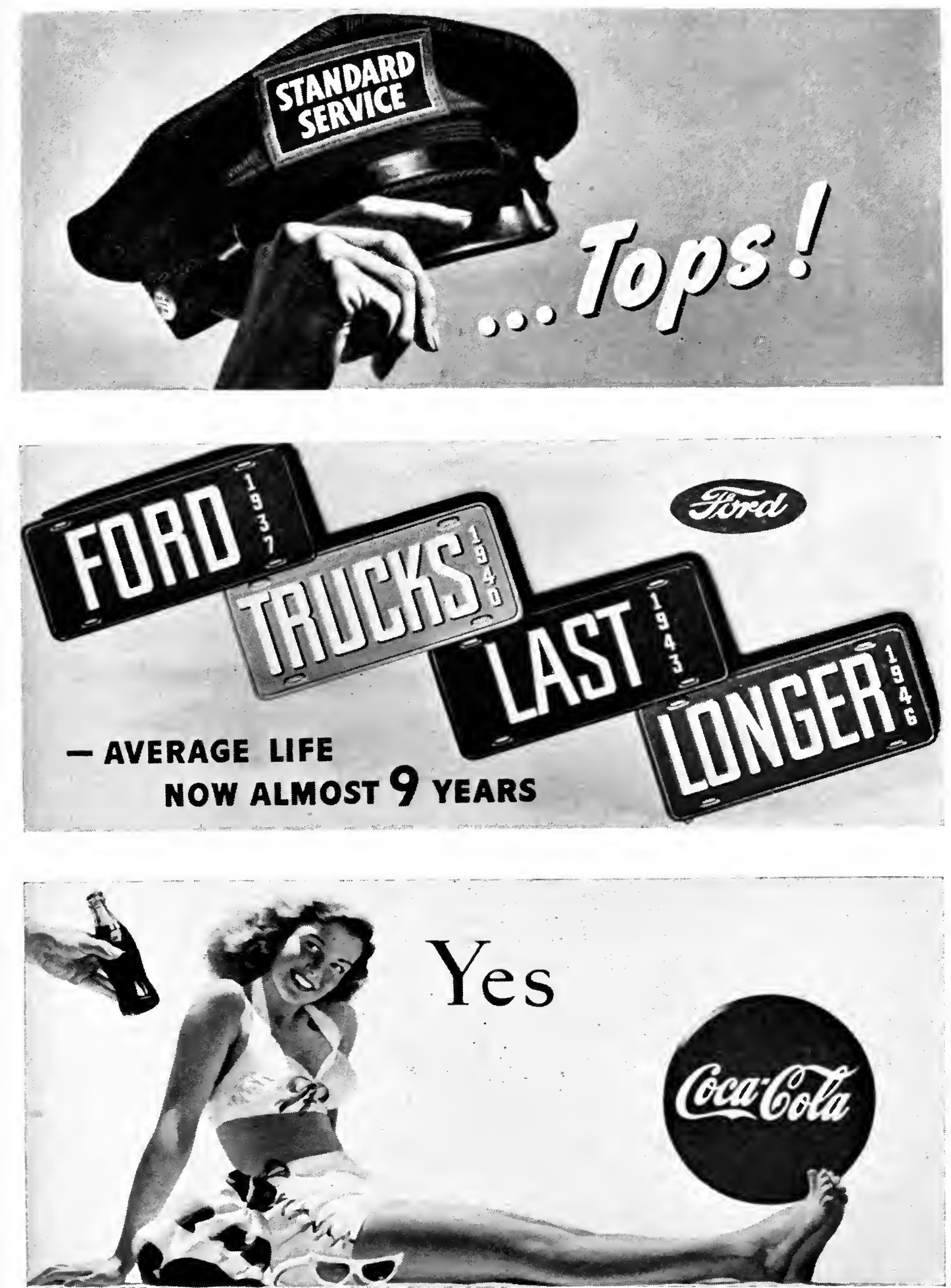

THE BEST THREE POSTERS OF 1946 

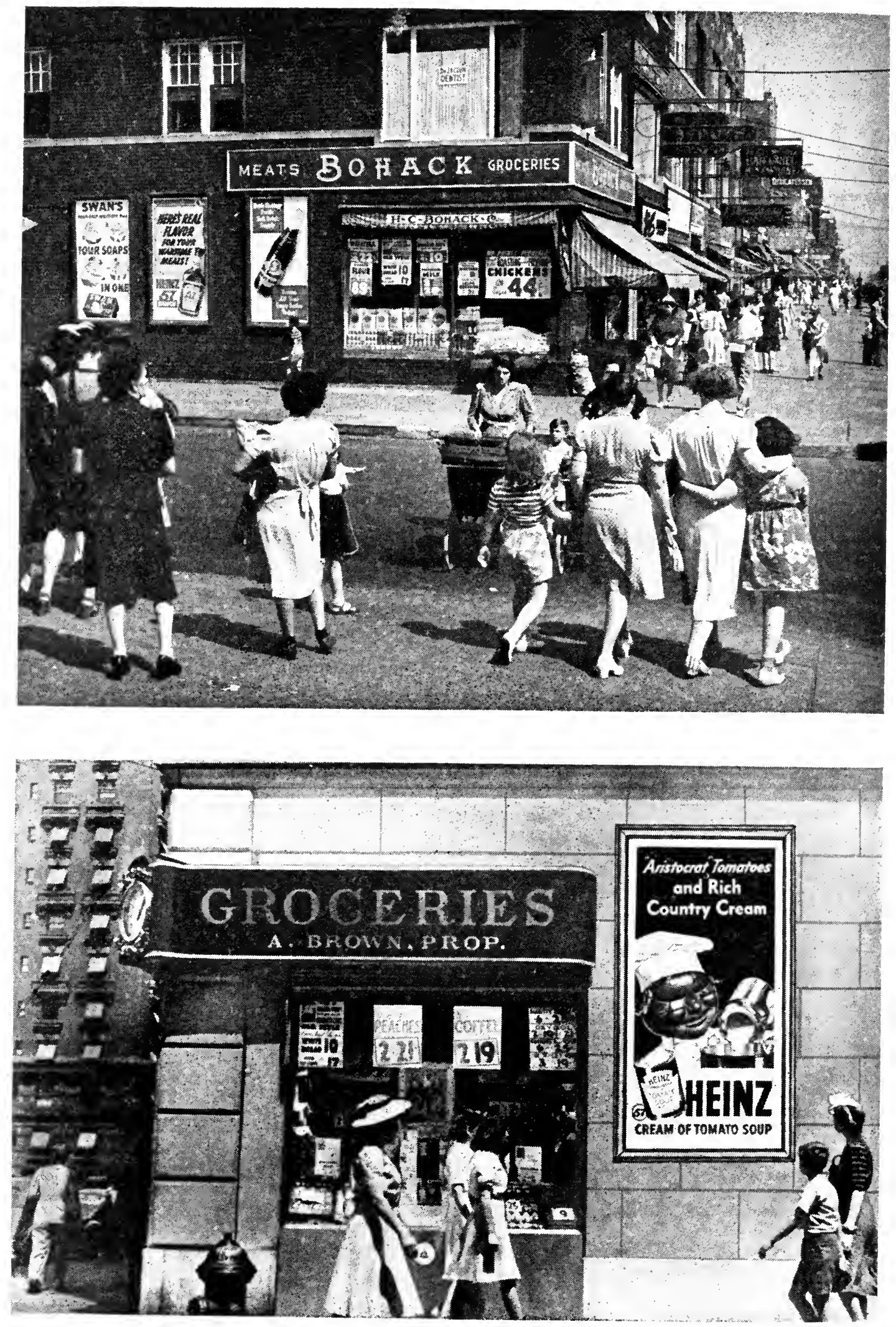

"3-SHEET" POSTERS GIVE POINT-OF-PURCHASE IDENTIFICATION

Notice consistent use of thic package, to give the store-bound shoppers a final reminder of ads previously seen in other media. 


\section{Chapter XIV}

\section{NEWSPAPERS-AND NEWSPAPER ADVERTISING}

TN TOTAL volume of business, newspapers far outstrip any other advertising medium. Estimates vary as to the exact amount of newspaper advertising in dollars and cents, but all agree that when local and national linage figures are combined, newspapers are well ahead of radio, magazines, outdoor or direct mail. Dr. Hans Zeisel, in fact, sets newspaper ad revenue for 1946 at a figure $(\$ 963,800,000)$ greater than radio $(\$ 489,400,000)$ and magazines $(\$ 430,400,000)$ combined."*

Summaries by the American Newspaper Publishers Association are more conservative, fixing the 1946 total at $\$ 898,000,000$ of which $\$ 270,000,000$ came from the national advertisers. This amount exceeds by over $\$ 50,000,000$ the previous high-water mark, reached in 1929.

Newspapers have come a long way since the Civil War days. Mechanically, the modern daily or Sunday paper is a production miracle. Stories can be set in type, dropped into page forms, made into curved stereos to fit the high-speed rotary presses and be "on the street" in the form of completely printed editions within a matter of minutes. Many a modern invention is used to rush news and pictures from their source: radio, radiophotography, telephotography, not to mention the prosaic shipment of negatives by transoceanic clipper. Electronic devices are being used to control the giant presses. Postwar developments now being considered include a photoelectric engraving machine which makes halftones of a plastic material, as well as numerous devices for improving and speeding up newspaper color printing.

Circulation has gone up year after year. In 1920, according to Alfred Stanford of the A. N. P. A. Bureau of Advertising, daily newspapers in the United States and Canada had a combined circulation of 29,500,-

* Printers' Ink, op. cit. 
000 . In 1947 , the figure stood at $51,000,000$, a gain of nearly 75 percent. Nor was this popularity confined to the cities. The American Press Association in 1947 reported a total of 8,312 weekly newspapers in country and suburban towns, with an over-all circulation of 12,513 ,483 per issue.

Advertisers pay close attention to the local popularity of the various newspapers in a city. When schedules are being made up, calling for a certain number of ads and a certain amount of linage in a particular market, the position of each paper will be carefully checked. How many readers does it have? Is its circulation primarily home-delivered or newsstand? Who are its regular readers? Are they white collar or wage earner, Park Avenue or lower East Side? Is it the leading vehicle for the department stores of that city? For the food chains and supermarkets? The drug chains? Will its selection carry the maximum amount of dealer prestige? These are all questions to be weighed in picking one newspaper over another. It is amazing to hear how often a space buyer in an agency can recite from memory the "best" paper in a town, the "best food paper," the best choice for a high-hat or a shirt-sleeves campaign.

\section{Do Advertisers "Influence" Newspapers?}

The responsibility for producing a newspaper that is an efficient advertising medium rests almost solely with the publisher and his editorial and circulation staff. Occasionally a campaign will be secured because of special favors granted to the advertiser, such as free publicity, but the great majority of newspapers maintain vigorous and even insolent independence of any effort to dictate their editorial policies.

A classic example of this occurred some years ago with the Chicago Tribune. Little Orphan Annie, a comic-strip heroine, was taking a cross-country bus trip. In several issues she encountered discomforts not at all flattering to motor-coach travel. The advertising manager of one of the bus companies, or perhaps one of the top executives, evidently took umbrage, and needled his advertising agency into writing a letter of protest. Unwisely the agency man mentioned that his concern advertised heavily in the Tribune, the innuendo being that if Annie didn't quit knocking bus travel, the ads might be placed elsewhere. The Tribune printed the letter in its "Voice of the People" 
department. On the same page appeared an editorial calling attention to the letter and announcing that the publisher had no intention of changing a single blurb in any comic strip to placate an advertiser. The Tribune, the editorial pointed out, was edited for its readers, and if they liked the paper it would automatically become a good advertising medium. So as far as Mr. Blank was concerned, concluded the diatribe, he could take his business elsewhere if he so chose. Meanwhile let him confine himself to handling the advertising for the PDQ Bus Company, and "we shall confine ourselves to editing the Chicago Tribune."

Not all requests from advertisers are treated so cavalierly, however. Untoward incidents occurring in department stores-an elevator accident, the arrest of a shoplifter, a near-panic caused by a small blazeare often reported as happening in "a downtown department store" without specific identification. The debut or wedding of the daughter of an important local merchant or banker may receive undue prominence. But as far as national advertisers are concerned they seldom get consideration in the news columns; when they do, it is because of some newsworthy happening or the ingenious creation of some synthetic publicity story that took the editor's fancy. And this can happen to a nonadvertiser. A case in point is that of Franklin Reynolds, the ball-point pen manufacturer, who bought an army plane and hired a veteran pilot to fly him around the world. Reynolds got a million dollars' worth of newspaper publicity on himself and his plane, the Reynolds Rocket, and promptly brought out a new pen named the Rocket to cash in. He advertised the pen extensively in newspapers, after the flight. Obviously his advertising had nothing to do with the columns of news items and photographs he obtained.

Are newspapers "friendly" to advertisers in their editorial policies and treatment of news? Only, in the writer's opinion, to the extent that they are advocates of the capitalistic system and its American manifestations: free enterprise, free speech, a minimum of government regulation, the right to make a profit. A majority of American newspapers opposed President Franklin D. Roosevelt, not at the dictates of their advertisers but because they felt that their own privileges and opportunities were in jeopardy. Most newspapers have taken a stand against unrestricted use of force and intimidation by labor unions for the same reason.

The "right to advertise" is a corollary of the right of free speech. 
So while newspapers reserve the right to censor advertising on the grounds of fraudulent or misleading copy, few will reject an advertisement because it expresses views contrary to its own policies. During the agitation over the Taft-Hartley Labor Bill advertising by the unions appeared frequently in many papers. And often the same issues would carry editorials and columnists' dissertations voicing the opposite position.

\section{Selling Newspaper Advertising}

The advertising columns of a newspaper are a commodity. They must be sold, like any merchandise. Moreover, they are a highly perishable commodity. Orice an issue has gone to press, it is literally, from the viewpoint of selling ads in it, a dead issue.

During World War II publishers had no difficulty in obtaining all the ads they could handle. In fact, the leading papers had to decline millions of dollars' worth of proffered space because they didn't have the paper on which to carry it.

Normally conditions are different. Competition for a place on "the list," as the national advertiser's schedule is known in the business, may lead newspapers to extraordinary efforts.

All the recognized channels of sales promotion are used by the publishers. Business-paper ads, direct mail and personal solicitation lead in popularity. However, not a few papers have used national magazines, posters, movies, premiums and other methods. One of the most interesting magazine campaigns of the 1920's was Phil Lennen's "Little Dramas in the Life of a Great Newspaper System," for Scripps-Howard newspapers. The series built up the alertness, resources and courage of the group of papers under the Scripps-Howard banner, not so much to enhance their prestige among the rank and file of magazine readers as to impress national advertisers with the advantage of using those journals.

Slogans are popular. The Atlanta Journal has one of the best: "The Journal covers Dixie like the dew!" In Philadelphia, advertisers are told "Nearly everybody reads The Bulletin." In Chicago advertisers can take their choice among "Chicago's HOME Newspaper" (The Daily News), "Chicago's PICTURE Newspaper" (The Times) or "The World's Greatest Newspaper" (The Tribune). In California the three McClatchy Newspapers at Sacramento, Modesto, and Fresno, 
all called The Bee, are jointly advertised with copy extolling the buying power of "the Billion Dollar Valley of the Bees." In St. Louis, the Globe-Democrat dramatized its coverage in the city and 88 surrounding counties in eastern Missouri and southern Illinois by referring to this area as "the 49th State."

The New York News, winning quick popularity among subway riders during the early 1920 's, came to be regarded by many advertisers as strictly a mass-market medium, not suitable for advertising highquality products. Surveys showed that the aggressive tabloid was reaching perhaps as many homes in the upper strata as those newspapers consciously edited for that market. Leo McGivena wrote a brilliant series of ads built around the theme, "the Stuyvesants and the Sweeneys," both of whom, he pointed out, were News readers.

Locally, newspaper space is sold by solicitors working out of the main office. Certain men are assigned to call on department stores and specialty shops; others may cover banks, real-estate offices, amusements, home-town factories. To obtain "foreign" advertising, space emanating from national advertisers, some of the larger dailies maintain their own sales offices in other cities. Most newspapers however, appoint one or more of the numerous firms of "general representatives" to get in touch with agencies and advertisers of the country. These "reps" may handle just a single paper, or as many as 150. They have a staff of salesmen armed with facts and figures about the papers they represent, and are supposed to know when important campaigns are being placed, in order to get as many of their periodicals as possible included on the advertiser's schedule. Occasionally one of these reps will do some educational selling on the merits of a newspaper he handles and thereby influence its selection, but as a rule the choice is predetermined by the agency and advertiser with the representative merely acting in the capacity of middleman.

The general representative is actually a survival of the original form of advertising agency. As has been told, in the last years of the nineteenth century agencies veered away from selling space to any and all advertisers and began to devote their efforts to serving a limited number of advertisers. Gradually copy, art, research and other facilities were added until the present agency structure emerged. Some agencies resisted this trend and became "special agents" or "specials." A few such firms still retain the word "agency" in their names, for example, the Katz Agency, which represents the Honolulu Advertiser, 
the Oklahoma City Oklahoman and Times and 18 other dailies, and the Julius Mathews Special Agency, handling some 75 papers, chiefly in the East. Most of the firms are identified by names of individuals as is the practice among advertising agencies. A few of the wellknown publishers' representatives are Moloney, Regan \& Schmitt; O'Mara \& Ormsbee; Osborn, Scolaro \& Meeker; West-Holliday Company; George A. McDevitt Company, and John B. Woodward, Inc. The standard basis of compensation for special representatives is 10 percent of the gross amount of the order, which with the agency's 15 percent commission gives the publisher a net of 75 percent of his space rate. This explains why local advertising, carrying neither agency nor representatives' commission, is generally lower priced than national space.

Besides direct mail and business paper advertising, newspapers indulge in a variety of activities to attract national advertisers. The most popular is known as "merchandising." In 1947 Deutsch \& Shea, New York agency, after a survey reported that 88 percent of all dailies in cities of 50,000 or over render some form of merchandising cooperation. Among the services offered to advertisers are: letters from the newspaper mailed to local wholesalers and retailers telling about an approaching campaign; supplying advertisers with "route lists". of grocery or drugstores for the use of the manufacturer's salesmen in calling on the trade; personal calls by the newspaper's "merchandising men" to inform dealers of the new campaign and urge that the advertised product be liberally stocked and displayed; surveys of retailers and consumers to show the relative acceptance of the product; exhibits of advertised products in downtown windows; miniature newspapers distributed regularly to retailers in the city, with news of current and future campaigns. Occasionally an alert publisher will even assign men to set up displays and banners in retail stores for important advertisers.

"Pantry surveys" are a popular method for newspapers to enhance their standing with national advertisers. These are reports based on analysis of a segment of the local families, showing brand preference in each of the important food products and sometimes including drugs and drug sundries. The Milwaukee Journal, Cleveland Press, Omaha World-Herald and Chicago Times are among the papers that have done notable work in this field. The usual method is to prepare an elaborate consumer questionnaire, covering shopping habits, car ownership and choice of brands in a wide variety of products, some to be 
answered by the wife and some by the husband. The questionnaires may either be filled in by interviewers calling at homes or by applicants coming to the newspaper office. As a reward for her trouble in answering the questions, the housewife customarily receives a basket of groceries, many of which are samples donated by the different advertisers.

These surveys are of great value to agencies and advertisers since they show relative sales positions of their products. For example, in the Milwaukee Journal 1947 Consumer Analysis, responses were subdivided under foods, soaps, toiletries, beverages, homes and equipment and general buying habits. Under "beverages," the survey showed that 89.7 percent drank beer; Schlitz was the favorite brand of 30.2 percent, Pabst of 21.1 percent, Blatz of 16.4 percent and Miller of 11.5 percent. Among cola drinks, Coca-Cola led with 38.3 percent, Pepsi-Cola was second with 14.1 percent and Graf's (a local bottler) was third with 12.6 percent. By comparison with 1946, Coca-Cola and Pepsi-Cola had shown a decline from 50.2 percent and 19.0 percent respectively while Graf's had increased from 8.0 percent to 12.6 percent, a significant gain. Such comparative figures enable an advertiser to tell whether his product is going up, down or holding its own in a particular market.

One remarkable feature of these "pantry polls" is that they reflect the national trend quite accurately even though only a small "sample" of the market is taken. In Milwaukee the report was based on 7,000 calls out of some 854,000 population in the county, representing approximately 230,000 families. The trick is to select a ratio of families in each economic group corresponding to the proportion of that group to the total. Over a series of interviews the responses start to level out, and beyond that point there seems to be very little change in the percentages. The survey must also be distributed equitably on a geographical basis to give a true cross-section of the city.

Like the women's group magazines, various newspapers have banded together in groups to offer the advertiser a convenient "package." An example is Interstate United Newspapers, Inc., which places advertising in some 135 newspapers with a circulation of $1,774,116$ and a combined line rate of $\$ 11.49$, all in the Negro market. In the same field, Associated Publishers, Inc., represents some 23 Negro papers including the "Afro-American" group along the eastern seaboard, which can be bought as a unit.

Several thousand small-town weeklies, under the banner of the 
American Press Association, are available by state groups or individually. The United States total is 3,966 and the combined advertising rate $\$ 1,709.92$ per inch per week for a circulation of $5,612,229$. This is a high unit price when compared with metropolitan papers, such as the New York News rate of $\$ 4.70$ a line ( $\$ 65.80$ per inch) for a Sunday circulation of over 4,500,000. Against this must be weighed the greater visibility of a small ad in the country newspaper, the wider penetration per copy and the greater thoroughness of reading. Mention has already been made of the Western Newspaper Union list, offering a similar service for 2,366 country town papers; its rate is $\$ 283.92$ per inch for $1,772,771$ circulation, subject to quantity discounts. There are several other groups in this field.

Advertisers interested in the high school market may purchase space in some 429 separate student papers as a unit. Their 714,322 circulation per issue cost $\$ 385.45$ a column inch as of June 1947, through the Richmond Advertising Service of Brooklyn. Another entry in the high school field is Scholastic Roto, a pictorial supplement edited by the National Scholastic Press. Association under the direction of Fred Kildow at the University of Minnesota, and distributed gratis with high school papers to over 1,000,000 students, eight monthly issues a year. The one-time rate of $\$ 4.17$ per line compares favorably with national magazines.

\section{Newspaper Groups}

College newspaper advertising can be bought as a package in some 600 papers having over a million circulation. Collegiate Digest, a roto supplement in over 300 college papers, is another medium. The College Comic Magazine Group also reaches this field through studentedited humor magazines.

Two prominent groups in the metropolitan field are the ScrippsHoward newspapers and, of course, the Hearst papers. Scripps-Howard papers are leaders in Cleveland, Knoxville and Pittsburgh, have a monopoly in Memphis, Evansville and El Paso, and trail from a circulation standpoint in New York, Indianapolis, Columbus, Denver, Fort Worth, Houston and Washington, D. C. They are consistently well edited and attractive typographically, making them desirable advertising media even where they do not sell the most copies. The 
Scripps-Howard lighthouse appearing on the masthead of some 21 papers is an emblem respected throughout the advertising fraternity.

The Hearst newspapers, except for their color supplements, American Weekly, Pictorial Review, Puck (the Comic Weekly) and Saturday Home Magazine, do not represent a cohesive advertising force. Hearst Advertising Service represents only ten of the papers, not including the top circulation medium, the New York Mirror. In their particular markets, however, they do an aggressive sales job. A recent project has been the publication of giant books containing community maps and market data on each of the ten cities represented by Hearst Advertising Service papers. It is interesting to note that while most newspaper reps confine their offices to such major advertising centers as New York, Boston, Philadelphia, Chicago, Detroit, Atlanta, Cleveland, Cincinnati, Seattle, San Francisco and Los Angeles, the Hearst Service also has one in the Maxwell Arcade Building in-Fort Lauderdale, Florida!

Strictly for promotional purposes, and not because of any similarity in editorial policy, the Sunday editions of the New York News, Philadelphia Inquirer and Chicago Tribune have banded together as the "First Three Markets Group." Other noncompeting newspapers have formed sales alliances.

By far the most ambitious effort along these lines is the American Newspaper Advertising Network, organized in 1946, with some 41 dailies having a combined 12,400,000 circulation and 37 Sunday papers with 15,600,000 as the nucleus. Many of the country's leading journals were founders, including the New York Times and News, Des Moines Register and Tribune, Boston Herald-Traveler and Globe, Philadelphia Bulletin and Inquirer, and Los Angeles Times. The A.N.A.N. contemplated a coast-to-coast "network" of newspapers paralleling those already existing in radio. Like radio, the newspaper network proposed to make it handy for national advertisers to place a campaign through one channel, fanning out nation-wide by means of local media, in this case the member newspapers. Also borrowing from radio, the A.N.A.N. sponsors offered discounts based not only on amount of space used, but on frequency. Thus an advertiser who used 1,200 lines per week for 13 weeks would receive a 4 percent discount, whereas if he continued for 52 weeks he would earn a 16 percent discount. This cumulative reduction in cost has been a strong factor in keeping advertisers on the air over a period long enough to 
give the advertising a chance to work, and it is surprising that the newspapers haven't adopted it sooner.

Chief argument in favor of using such a network of newspapers is that it gives concentrated coverage of the most productive sales areas. A.N.A.N. states that of the 3,072 United States counties, 318 produce 72 percent of the retail sales and it is in these counties that member papers deliver 79 percent of their circulation. To keep the arrangement flexible an advertiser is required to use only 80 percent of the basic markets in any one area. "Supplementary" newspapers were to be provided for additional coverage of the smaller cities not reached by the "basic" papers. The new network also contemplated "penetration" studies to show who reads newspapers, by age, sex and income, how much time is spent in newspaper reading, how many readers per copy; consumer "panels" in selected markets to determine "who is buying what, how much, how often and why"; and investigations to find the extent to which visual or audible advertising influences the purchasing of goods.

Thus far, neither Scripps-Howard nor Hearst has joined the newspaper network, each group figuring, apparently, that it has a "network" of its own. There are other important gaps in the structure. But for national advertisers it has much to offer in the streamlining of country-wide campaigns.

\section{Color Advertising in Newspapers}

One advantage enjoyed by magazines over newspapers has been in the matter of color. From the first timid experiments in the nineteenth century, color has grown into a recognized advertising tool of foremost importance. In many magazines, over half of the advertisements today are in two or more colors. Outdoor posters, car cards and direct mail all recognize the greater pulling power of color in advertising. Aside from Sunday supplements, however, the average newspaper has clung to black and white-just as it did 50 or 100 years ago.

Here and there a few papers have pioneered in what is known as "run-of-paper" color advertising: that is, color ads appearing in the regular news sections. The Indianapolis Times, a Scripps-Howard paper, started using color in 1934 and since then has run several thousand ads in two or more colors. In 1946 it carried over 480,000 lines of color advertising (about 200 pages), which was 4.05 percent 
of its total linage for the year and more than that of any other daily paper. As far back as 1929 the Chicago Tribune ran an ad in color. The Milwaukee Journal has successfully reproduced Kodachrome advertisements in full color for a local department store, the Boston Store. In New York the Journal-American alone among Manhattan dailies was equipped (March 1947) to handle color ads in its regular editions.

One of the largest newspaper campaigns in color was that of Schenley Distributors, with four 1,000-line ads appearing in 67 newspapers. Despite the wide variations in shades of ink and poor printing, Schenley said that the impact of the campaign was "terrific" and well worth the added cost. The Newspaper Advertising Executives Association studied 5,000,000 inquiries from 3,500 advertisements and discovered that color insertions brought 5.3 percent greater direct returns than black and white. One advertiser reported to the Indianapolis Times a 35 percent greater return from color ads. The additional cost of color, in those newspapers that make it available, runs from 20 to 40 percent.*

Newspapers want to adopt color as quickly as possible. They know that it adds interest to an issue and helps them compete more favorably with other media. With the present improvements in color printing equipment it seems only a question of time until all papers will be supplying color regularly.

\section{Local and Classified}

One of the oldest and most profitable sources of newspaper advertising revenue seldom receives attention in textbooks, the want ads. But in the aggregate, these neglected cousins of the advertising family comprise a significant part of the total space for many newspapers. On Sunday, September 8, 1946, the Chicago Tribune published a total of 12,163 individual want ads with a total line count of 83,143 , about 30 full pages. Classified advertising in the Tribune runs nine columns to the page; the Sunday rate ranges from $\$ 1.00$ a line for situations wanted to $\$ 1.50$ for help wanted, yielding close to $\$ 100,000$ for the want ads in this one issue. Since very little classified advertising pays a commission (only that placed by agencies with no office within 40 miles of Chicago and then only if the advertiser has no office within Tide.

* "Color Advertising in Newspapers," Tide, March 21, 1947. By permission of 
that area) and since it runs one more column to the page than general advertising, it is obviously a very desirable type of business.

Department store and other retail advertising constitutes the "bread and butter" of the majority of metropolitan newspapers. Although generally sold on annual contracts at quantity rates well below the national rate, the big local advertisers use space in such lavish amounts that they easily rank as the top spenders. The bigger stores have newspaper budgets running as high as a million dollars or more annually. Food and drug chains have also become increasingly important users of newspaper space.

Aside from the direct income, local retail advertising is a significant yardstick for national advertisers in gauging the standing of a newspaper in its community.

A substantial amount of local advertising is placed by dealers in nationally advertised products in order to obtain the benefit of the lower rate, using ads prepared by the manufacturer or agency. All or part of such advertising may be paid for in the form of a co-operative allowance; the usual arrangement is on a 50-50 basis.

In recent years a new type of publication, the "Shopping News," has challenged newspapers in various cities. Several of these weekly free-distribution sheets were reportedly started by, or with the blessing of, retail merchants with the idea of forcing down newspaper rates. They have seldom had that effect. However, some of them have successfully established themselves as recognized media. The Chicago Downtown Shopping News, for example, has a circulation of 625,000, all home-delivered. In addition to retail advertisers, some 40 national advertisers were using this publication in the spring of 1947. Originally, like other shopping papers, Downtown Shopping News was devoted exclusively to advertising. At present a number of editorial features can be found in each issue, including columns on fashions, food, homemaking and shoppers' information. The publication also sponsors a monthly "Women's Forum" in the Civic Opera House, with speakers on current events, cooking and other subjects, evidencing its stability.

\section{The Study of Newspaper Reading}

Since 1939 the Advertising Research Foundation, sponsored by the Association of National Advertisers and the American Association of 
Advertising Agencies, has conducted "The Continuing Study of Newspaper Readership."

This unusual research project has produced a wealth of information about the way people read a newspaper, what subjects interest them most, which ads attract their attention, what types of headlines, pictures and articles lead in eye-appeal.

In this study, a weekday edition of a selected newspaper is taken by trained interviewers to approximately 500 typical adult readers, divided equally between men and women and balanced as to occupation or economic status. Calls are made the day after the paper is published. The interviewer places before the respondent a fresh, unmarked copy of the newspaper and asks him to go through it page by page, pointing out those items, features and departments which he has seen or read, including the advertisements. The totals are then tabulated and miniature facsimiles of each page of the selected paper are reproduced for analysis. Survey costs have been largely borne by the Bureau of Advertising, American Newspaper Publishers Association, and the local paper.

To date, well over 100 such studies have been made, starting with the Akron Beacon-Journal for July 27, 1939. Cities as large as Los Angeles and as small as Lockport, N. Y. $(24,379)$ have been included. Nearly all have been single-issue surveys, although the Troy, New York, Times-Record was made the subject of a six-day study from March 19 through March 24, 1945, to determine the rise and fall of readership throughout the week, and the Indianapolis News was studied on May 7 and May 9 to get a comparison between the announcement of V-E Day and a later issue to check the impact of great national news on readership. The V-E edition was devoid of local and classified ads, running only 16 pages, while the issue two days later ran 36 pages with a full quota of ads. Several Sunday newspapers have been included among the more recent surveys.

Here are some of the highlights of the summary of the first 100 studies:

Local advertising, and specifically department store advertising, leads all newspaper features in women's readership, averaging better than 94 percent.* Next in order come editorial-page items, society

* This figure represents the over-all picture. The summary showed that in "Reading by Types of Content" $100 \%$ of the women and $97 \%$ of the men read advertising-a higher percentage than read any other feature. 
news or pictures, comics, national advertising, and radio programs. Among men, editorial-page items lead with 82 percent, followed by advertising and comics, tied at 79 percent, with sports news and radio programs following. National advertising gets a higher readership among men than department store ads.

The popularity of humor panels, comics and human interest pictures was clearly demonstrated early in the study. As a result, many advertisers switched to these techniques in their newspaper ads and often obtained a high readership.

Among women, human interest, crime and society pictures lead in appeal, with movie and radio celebrities far down the list. Among men, photos of war or national defense, human interest and crime come first; beauty queens and glamour girls are tenth, behind national politics.

The best-read single advertisement was a full page of Kaufman's Department Store in the Pittsburgh Post-Gazette for June 4, 1945seen by 87 percent of the women.

An ad sponsored by the Milwaukee Journal, in the Cincinnati TimesStar for December 2, 1943, stressing the need for a veteran's rehabilitation program, led all national ads-seen by 73 percent of the men, 68 percent of the women. Other high-readership ads sponsored waste fats and red cross. Leader among straight product ads was a Chesterfield Cigarette display in the Daily Oklahoman November 16, 1939, seen by 66 percent of the women.

Convincing proof of the power of cartoon and comic-style ads in newspapers was shown in the summary of the ten leading food ads based on reading per line per 100,000 readers. The list included seven Wheaties ads, one Armour \& Company, one Hostess Cup Cakes and one Land o' Lakes, all small eye-catchers of this type.

Many of the highest-rated ads were modest in size, relying on attractive illustrations rather than screaming headlines. The surveys have clearly proved that the average newspaper reader goes through his paper page by page, "shopping" for items that appeal to him, and often ignoring big, heavily played features, news stories and ads.*

\section{Newspapers and Community Service}

Since this is a book on advertising as a business, evaluation of the newspaper as a social force is hardly within its scope. Nevertheless, ad

* "100-Study Summary, The Continuing Study of Newspaper Reading," Advertising Research Foundation, Inc., copyrighted 1946. 
men must consider the attitude of customers and prospects toward the media in which they place their appeals. In this respect, newspapers, viewed en masse, have earned the highest vote of confidence from the public. Circulations are greater than ever in history and this despite the fact that people must pay from 50 to 100 percent more per copy than before the war. Readership, as shown by the study just quoted, is both extensive and intensive. Their influence is perhaps less than in the days of the great personal journalists, but they have lost none of their crusading fervor.

An appraisal of newspapers, made nearly 60 years ago in the first issue of Printers' Ink, still seems adequately to cover the average ad man's view:

Newspapers are private undertakings, founded and supported by private means for the purpose of lawful gain to those whose capital or labor is invested in them. No pious millionaire endows them in behalf of morality, no rich philanthropist in the cause of education. So far as they fit the public need, as the public feels its need, they succeed; so far as they do not fit that need as it is felt, they fail and all their good intentions with them. Journalists think it hardly fair to exact from them, as a whole, proofs of a higher intelligence and conscience than their day and generation possess at large. 


\section{Chapter XV \\ "WE'RE ON THE AIR!"}

"D RIBLETS of advertising, most of it indirect so far, to be sure, but still unmistakable, are floating through the ether every day. Concerts are seasoned here with a dash of advertising paprika. You can't miss it: every little classic number has a slogan all its own."*

This preview of things to come appeared in Radio Broadcast Magazine for November 1922. Two years later Herbert Hoover, then Secretary of Commerce, at a conference of set manufacturers and station owners, declared unequivocally: "I believe the quickest way to kill broadcasting would be to use it for direct advertising."***

Today the driblets have grown into a never-ceasing river. Expenditures for radio advertising in 1946, it was estimated by Printers' Ink, reached $\$ 489,000,000$. Some 50,000 sponsors were spending at the rate of a million and a quarter a day for broadcast time, talent and promotional effort in the medium for which Mr. Hoover had predicted an early death.

The five leading users of radio, Procter \& Gamble, Sterling Drugs, General Foods, General Mills and American Home Products, had time charges on the four major networks alone in excess of $\$ 48,000$, 000 . The CIO Steelworkers, with an outlay of $\$ 100,124$, had to be content with 180th place among the sponsors of network programs. In between were such assorted clients of the NBC, CBS, ABC and MBS as the Curtis Publishing Company $(\$ 971,833)$, Equitable Life Assurance Society $(\$ 699,380)$, Coca-Cola $(\$ 2,011,405)$, Voice of Prophecy, Inc. $(\$ 239,762)$, Florida Citrus Commission $(\$ 320,892)+$ Gum Laboratories $(\$ 122,024)$, Household Finance Company (\$328,659), Kellogg Co. $(\$ 2,791,967)$ and America's Future, Inc. (\$157,045)***

* Robert J. Landry, This Fascinating Radio Business (The Bobbs-Merrill Company, 1946), p. 44. By permission of the publisher.

** Ibid., p. 49.

*** "Leading Radio Advertisers, 1946" (Advertising Age, April 28, 1947), pp. 50-51. (Based on records of Publishers Information Bureau, Inc.). By permission of Advertising Age. 
All this has happened since the "powerful" Westinghouse 100-watt station, KDKA, Pittsburgh, broadcast the election returns in Harding's victory over Cox the night of November 2, 1920. Some 2,000 receivers in the homes of wireless amateurs or "hams" represented the probable audience. Twenty-six years later the number of radio homes had reached 37,000,000 with 48,000,000 radio sets in homes, 9,000,000 automobile radios, and an additional $3,000,000$ in public placesa total of $60,000,000$ sets.

In radio's infancy, many suggestions were offered for financing programs, the most common being that philanthropists should endow radio stations just as they did colleges and universities; a few such gifts were made. Other stations called upon their listeners for contributions. Performers usually worked free. Radio manufacturers, realizing the need of plenty of air-borne entertainment to sell their sets, underwrote some of the cost. Government licensing in the British fashion was never tried in America, possibly because of our traditional individualism.

Very soon the need for regular and substantial revenues became obvious. Musicians and singers who at first had been content to take their pay in publicity began to demand cash. ASCAP, the American Society of Composers, Authors and Publishers, controlling the copyrights on virtually all popular music, informed the stations that payment must be made for airing ASCAP melodies or infringement suits would result; minimum damages, $\$ 250$ per violation. Meanwhile American Telephone and Telegraph, over whose lines network programs are still transmitted, began selling advertising over its own station, WEAF in New York, in 1922 and continued until 1926 when it withdrew from direct participation in broadcasting. But in the intervening years AT\&T solicitors had done much to popularize radio as an advertising medium.

With the establishment of the National Broadcasting Company in 1926 and Columbia Broadcasting System in 1927, national campaigns were made possible. More and better theatrical and musical talent was attracted to radio. As the quality of programs went up, so did the number of listeners. It would not be fair to say that network programs alone have built radio to its present high place as an advertising medium, for local shows, home-town news and public events have had an important part; nevertheless, the lure of big names and entertainment on a par with what Broadway and Hollywood had to offer has 
been a chief audience-builder. And audiences are essential to advertising.

Radio, advertisers soon discovered, could deliver a particularly responsive type of audience. Had it not been for this fact, commercial broadcasting would have remained a minor ad medium, for it was utterly unlike accepted forms of advertising. When a firm invests in a magazine or newspaper or outdoor campaign, the evidence of the purchase is visible and permanent. Salesmen can and do take proofs of ads on dealer calls, or such proofs can be mailed. The man who pays the bills can pick up a publication or drive past a poster location and see his advertising. The actual package can be illustrated, in full color if desired, along with scenes showing the product in use. On the other hand, once a radio program is over, nothing remains except a memory.

Early radio advertisers found one requirement hard to swallow: the very wise insistence of station managers and later of network officials that commercial time be rigidly limited. Nowadays this is accepted as a matter of course. But pioneer sponsors often balked at the idea of paying for half an hour on the air and being allowed to use only three minutes of that time for advertising!

Agencies and clients alike were skeptical of the new vehicle. They bought it with their fingers crossed and demanded proof that people were really listening. Radio delivered that proof in abundance. Any sort of an offer or a request for mail would literally swamp the advertiser. A program promising a gift in response to a phone call might tie up the switchboards of an entire city. Even a simple invitation to send in one's favorite musical selection, no reward or prize involved, would pull thousands of postcards and letters.

It is a debatable question whether or not "mail pull" is a fair criterion of any advertising medium. But at least to those newcomers in radio it gave tangible returns showing that something was happening. Inquiries could be produced at low cost, sometimes incredibly low cost, as compared with other media. In 1933 Procter \& Gamble made identical product offers in three media. The cost per inquiry was $\$ 1.27$ in magazines, $\$ .361$ in newspapers, and $\$ .097$ in radio. Bab-O reported a similar test in 1940 . Cost per inquiry: in magazines, $\$ 1.44$, newspapers $\$ .36$, radio $\$ .08$.*

Particularly in packaged items-soap, cigarettes, canned goods, cos-

* "Radio Today," a prospectus of Columbia Broadcasting System, August 1946. 
metics, beverages, and the like-universally used articles that are bought again and again-does radio seem effective. A case in point is that of Pet Milk. In 1933 the company spent $\$ 26,418$ out of a $\$ 350,000$ budget in radio; sales that year were $\$ 15,600,000$. Use of radio was increased rapidly. In 1936 it received nearly 60 percent of a $\$ 521,000$ budget and sales amounted to $\$ 25,100,000$. The following year Pet Milk went exclusively radio, spending $\$ 537,094$, and sales were $\$ 29,700,000$. Concentration on radio continued with an expanding budget and rapidly climbing sales. For 1945 the company's network radio appropriation was $\$ 831,883$; its sales were $\$ 114,700,000$, a 631.8 percent increase over 1933.*

Other cases could be cited to show remarkable results from consistent and aggressive use of radio with other products such as watches, electrical appliances, gasoline and oil, fountain pens, silverware and floor wax. In some instances radio has been the sole consumer medium. In others it has divided honors with magazines, newspapers, outdoor advertising. This does not mean that radio is necessarily the best medium for all products or services. There are many manufacturers and retailers who use radio only as a secondary medium; some not at all. Nevertheless, there can be no denying that within a very few years radio has taken its place in the national advertising picture alongside older, well intrenched media, and has in numerous cases given a spectacular account of itself.

\section{Reasons for Radio's Effectiveness}

The power of radio advertising stems from a number of causes. Foremost, perhaps, is the fact that this is the one medium (aside from commercial films) that utilizes spoken salesmanship-the impact and persuasiveness of the human voice. Selling messages seem to be addressed directly to the individual listener. In reading, the average person may skip an ad, but even though a person may close his mind to the commercials on a radio program, a certain amount registers.

Radio also permits a dramatization of sales features, with action, humor, music and sound effects carrying on the mood of the program. The star himself may participate in the actual sales "pitch," as Red Skelton does occasionally on the Raleigh cigarette program, Bob Hope on the Pepsodent show, Jack Benny on the Lucky Strike program.

*Ibid. 
Testimonials by celebrities or ordinary folks may be delivered by the endorser in person. From a structural angle, radio advertising has the advantage of being free from competition by the particular medium itself; if the listener wishes to hear the remainder of the program he must stay tuned in while the entertainment stops and wait until it resumes. Moreover, the advertiser can more or less determine the editorial "frame" for his message by his choice of program instead of leaving this to the discretion of the editor or make-up man.

Much has been written about listeners' gratitude leading them to purchase a particular brand because they enjoy its radio program. Early-day broadcasts often contained a request for the radio audience to show its appreciation at the store. This naïve approach has largely given way to more subtle suggestions such as: "If you like our show, you'll like Yum-Yum Candy Bars, too." Fred Allen has a way of winding up with, "Don't forget the two products which make this program possible-Shefford Cheese and Tender Leaf Tea." In general, listeners buy not to thank the sponsor but because in hearing their favorite program week after week, or day after day in the case of a daytime serial, they have been exposed to so much direct, persuasive selling that the sponsoring product just naturally comes to mind first.

Aside from its human appeals there is one very simple additional reason for the growth of radio as a national medium, the cycle. While it is possible for an advertiser to order a single announcement or a 15-minute program on a one-time basis, virtually all network time is sold in cycles of 13 weeks, with increasing discounts being earned for each succeeding period. By thus stressing consistency of effort the radio people have converted many firms from spasmodic, blow-hotblow-cold users of advertising. In 13 weeks of constant repetition results may begin to appear. If the firm will stay put for another 13 weeks a great deal more may be accomplished. At the end of a year, given a good product, a good show and the proper amount of merchandising support, the former "grasshopper" has often settled down for keeps! The same thing is true, of course, of anv other form of advertising.

\section{How Radio Shows are "Merchandised"}

On April 16, 1935, at 8:00 P.M. Eastern Standard Time, S. C. Johnson \& Son, Incorporated, presented the first in a new series of comedy programs featuring Jim and Marian Jordan, the popular Chicago sing- 
ing and joke-telling couple. The Jordans had been tried out with a local test campaign and made a hit in their new characters of "Fibber McGee and Molly." It was decided to launch them nationally over the NBC network.

A week before the show broke, a letter was sent to 40,000 hardware, auto accessory and auto dealer outlets announcing the event. It was accompanied by a comic strip enclosure one side of which showed "Fibber" and his jolly wife exchanging witticisms while he polished his car with Johnson's Wax. The other side carried a semicatalogue style listing of all the company's products.

During the first year millions of these comic strip "throw-aways" were supplied to dealers to be used on counters, as envelope stuffers or package inserts. Special catalogue sheets were sent to jobber's salesmen for use in telling retailers about the new show, in addition to a jumbo presentation going into greater detail.

Counter and window displays with Fibber McGee and Molly as the center of interest were put up all over the country. Two tops, one featuring Fibber and the other Molly, were offered free to children who sent in a tracing of the word "Johnson's" from a bottle of the Liquid Wax.

Everybody knows what happened. "Fibber McGee and Molly" became one of the leading radio shows of the country, being rated No. 1 in 1945. Sales of Johnson's Wax have grown astoundingly. Without taking any credit away from the Jordans, from Don Quinn, the show's brilliant creator, or its talented production staff, not a little of its success must be assigned to the background of merchandising work that preceded and has steadily accompanied the show.

Merchandising of radio programs takes many forms. A few were given above. Others include posters, car cards, house organs, blotters, calendars. When Kraft launched Bing Crosby in the "Kraft Music Hall," Bing's picture appeared on the top of every jar of Miracle Whip and every Swankyswig glass, while Kraft salesmen wore a giant lapel button with the same illustration. Each salesman was expected to secure the signatures of 50 of his dealers pledged to listen to the show on January 23, 1936, which was dedicated to the grocers themselves.

Radio stations do a great deal of merchandising work in their communities, with a double purpose: to increase listenership, and to make the station more productive for advertisers. As a rule, when a national program is launched, the network will send to each station a portfolio containing such items as: 
Facts about the product and the sponsoring company

Suggested letter to the local dealers and wholesalers in that field

Ready-to-run newspaper ads featuring the program

Suggested announcements to be used gratis in promoting the program

Photographs and publicity releases about the show and its stars

Window streamers or counter cards which will be sent to the station in quantities on request for distribution to the trade

Ideas for special stunts or events to be staged by the station for attracting listeners

No one station will use all of these materials on any one program, but it is customary to give some promotional and merchandising support to every national program. The bellwether shows receive extra attention in the form of pre-announcements- "Be sure to listen tonight at 8:30 for "Can You Top This?" "-and in "spotlight" newspaper ads featuring coming attractions.

A popular method of building up interest in a network program is to send the cast around the country, putting on the show in various cities. Special invitations are issued to dealers in the region of the current broadcast, thus giving them a proprietary interest in the show. Window and store displays of the sponsor's products are much easier to secure during the week of the broadcast; results in increased sales may be noted for some time afterward.

\section{Measuring Radio Audiences}

One problem that continually confronts users of radio advertising is that of coverage or circulation. Magazines and newspapers have an accurate check on their circulation in the number of copies sold. Radio stations have no such resource. As a substitute several methods have been tried.

The "contour" method was one of the first. Engineers equipped with test instruments would cruise around the station to determine the outermost limits at which its "signal" could be heard with a 2 millivolt intensity, and still farther out, at a .5 millivolt strength. Tests were made for both daytime and evening, and the results plotted on maps showing "primary" and "secondary" listening areas. The 
objection to this method is that it tells where a station can be heard, but not necessarily who listens to it.

Another method is to plot the density of mail received by the station. Records are kept by counties and a map prepared rating the counties surrounding the station as excellent, intense, good, or fair. The "audience mail count" method has been criticized because it covers only that type of person who writes letters to radio stations. If a station is serving a territory in which letter writers are commoner than in the area served by another station there is no sound standard of comparison as to the relative coverage of the two.

A combination of audience mail and signal strength has also been tried, but again the same variables among stations still exist.

To develop a satisfactory solution to this problem, the ANA and the AAAA, in collaboration with the National Association of Broadcasters, representing 667 stations, organized the Broadcast Measurement Bureau in 1945. The method adopted for determining station circulation was to circularize the radio listeners themselves with a mail questionnaire or "station ballot." On it the listener was asked to check the radio stations heard (1) any time, (2) at night, (3) daytime. Under (2) and (3) were spaces to check 3 or more times a week, I or 2 a week, less than 1 a week and never. Space was provided for listing a dozen or more stations by call letters. Below, questions were asked as to number in family, number of radios in working order, how long the family had lived in that neighborhood, ownership of an auto and telephone.

The first BMB study, in 1946, covered half a million radio famiiles and took in 25,000 cities and 3,100 farming areas, representing all income and cultural levels. Returns of as high as 75 and 80 percent were obtained on the "ballot" and no United States county was tabulated until 50 percent of the sample in each type of community was in. All ballots were coded on some 10,000,000 Hollerith cards which could be run through IBM machines to give complete information on size of family, car and telephone ownership and other data in relation to station listening.

At this writing plans were being made for Study No. 2 either in 1948 or 1949. The majority of agency time buyers feel that when the "station ballot" method is fully refined it may provide a service somewhat comparable to that rendered by the Audit Bureau of Circulations in the publication field. 


\section{Program Ratings}

Of great interest to the advertiser, but not necessarily the only factor determining the sales power of a radio program, is the "rating" of his show. With several stations competing for attention, which gets the highest proportion of listeners? What type of program will attract the largest audience? What time of the day or evening is best? How does listening vary among the different days of the week, and according to the season? If a different program is put on over a competing network, how will that affect the popularity of the advertiser's show?

These and other questions asked by agencies and advertisers led in 1929 to the establishment of the Cooperative Analysis of Broadcasting under the direction of Archibald Crossley. Telephone calls were made after the listening period and the listener asked to recall what programs he had heard, calls being made in early morning for the previous evening, at noon for the morning period and at twilight for the afternoon. During the 1930's a program's "Crossley" was often considered an infallible index of its success or failure.

Then a private research firm, C. E. Hooper, Inc., started making "coincidental" checkups on audiences. Interviewers would call at different times during the day or evening and ask, "Is your radio turned on? If so, to what station or program are you listening? Can you identify the sponsor?" Those homes not answering were included in the report to figure the percentage of sets not in use. "Hooperatings" are obtained by taking the percentage naming a particular show and projecting it against the total number of homes called. This is the figure commonly publicized. A few top shows will have a Hoop. erating of 25 to 35 percent. An evening rating of 10 to 15 percent fos a less expensive show is considered satisfactory, while daytime adver tisers are happy to settle for a rating often as low as 2,3 or 4 percent

Both the co-incidental and the recall method of rating depend on relatively small samples from a limited number of localities and do not necessarily reflect universal listening habits, for example, in the rural areas. Some programs which have made a dismal showing in the $\mathrm{CAB}$ or Hooper reports continue to produce excellent results year after year, while others with a high Hooperating may fold.

Hence seasoned radio advertisers, while aware of their ratings, take them with reservations, though recognizing their value in analyzing program appeal. 

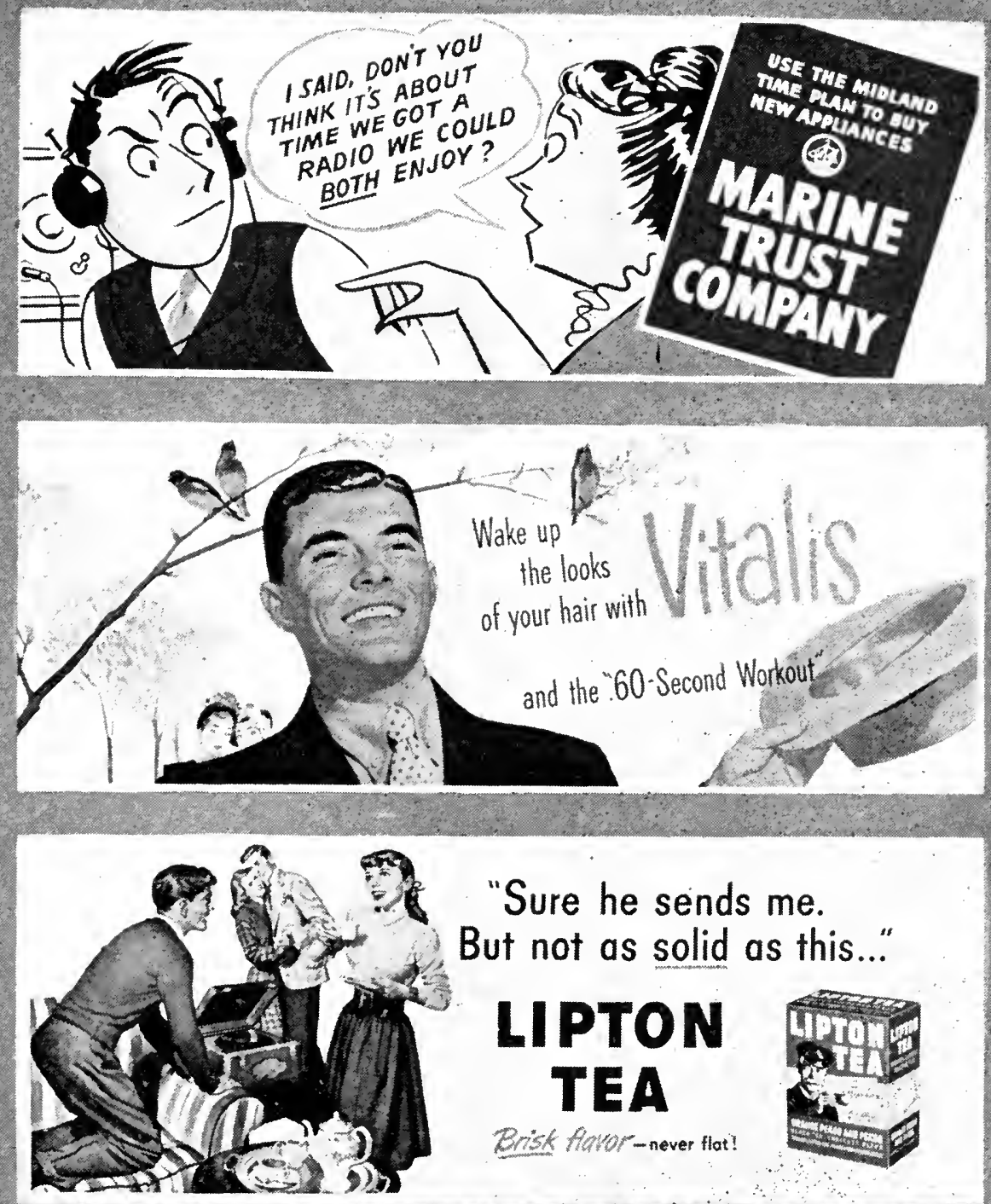

"Sure he sends me. But not as solid as this..."

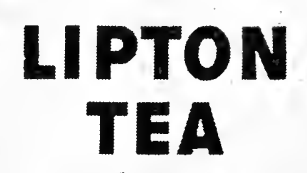

Brisk faror-never flat!

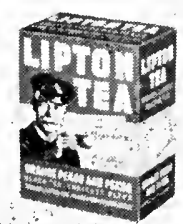

Courtesy National Transitads CAR CARD COPY CAN BE LONGER THAN OUTDOOR POSTERS, BUT MUST TELL A SIMPLE, DIRECT STORY 


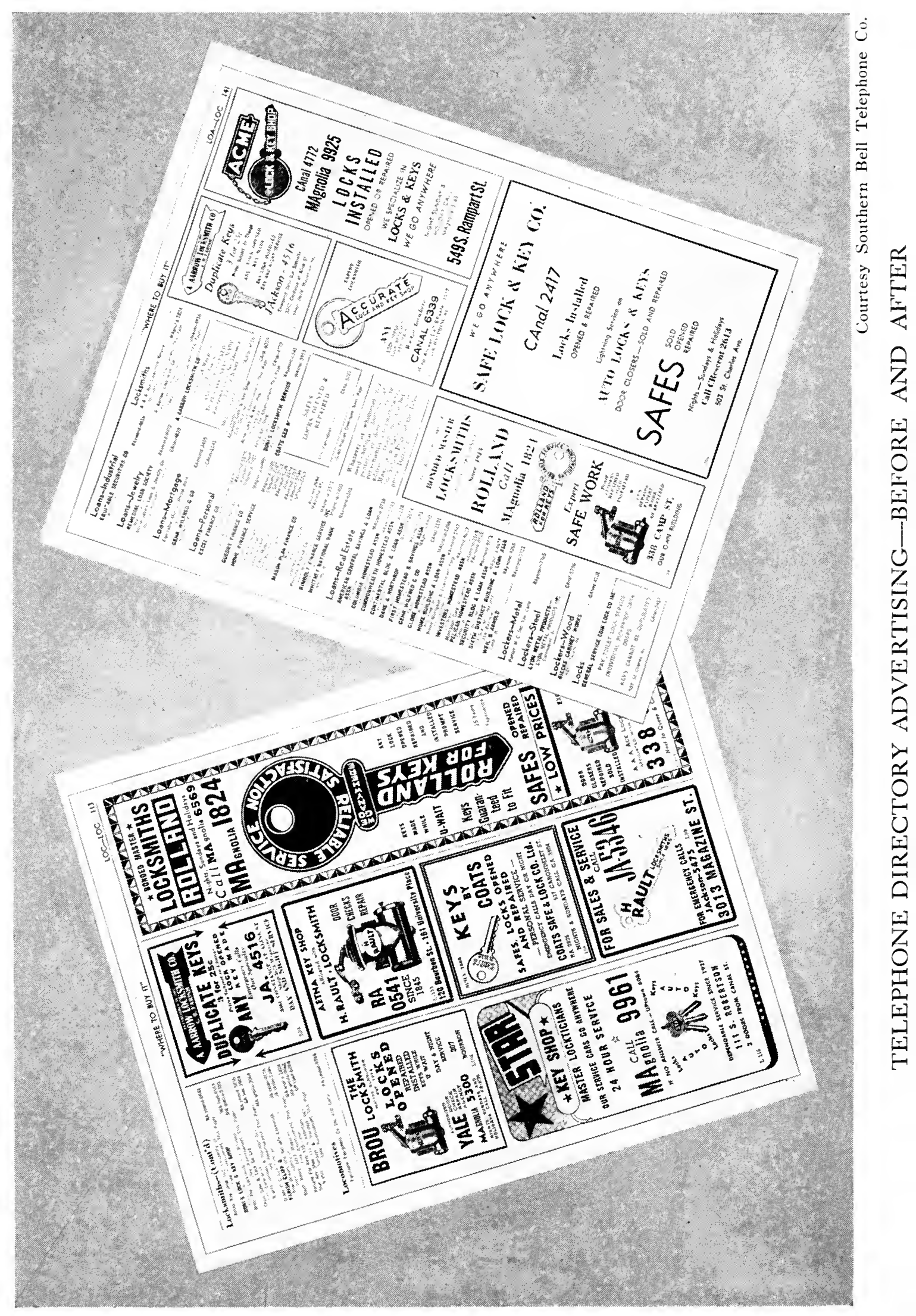


Other methods of studying listener habits include the "audimeter," originated by the research firm of A. C. Nielsen Company, in which a recording device is attached to radio sets in homes to show which stations are tuned in and for what periods; the "listener diary" plan, in which families are paid to keep a log of their program choices; and a number of electrical and electronic devices to show how typical individuals react to radio programs. These last named are used in pretesting proposed radio shows and commercials.

Ratings have a direct bearing on one widely followed radio practice which is unpopular with listeners and stations alike-the so-called "summer replacement." Hooper's studies have shown a marked drop in number of sets in use during the summer months as well as a decline in the rating of big shows. Consequently many leading network advertisers give their expensive stars an enforced vacation, substituting less costly productions. Whether or not this drop would occur to such an extent if the name programs were continued is a debatable point. At least the summer hiatus gives many unknown and lesser known performers a chance to demonstrate their ability.

"Adjacencies" and "opposites" have marked effects on program ratings. The former refers to the program immediately preceding and the one immediately following. A series of shows more or less similar will hold an audience, where a sharp change in style may cause a falling off. This may explain why NBC has a solid four hours of "soap operas" after lunch every day and why Mutual has three half-hour mysteries in a row on Sunday afternoon. "Opposites," programs simultaneously broadcast on other networks, may be strong or weak. Hooper indicates a sharp decline in other network listening Sundays from 9:00 to 9:15 P.M. EST, when Walter Winchell is on ABC. Yet here again it is possible to put too much faith in ratings. The nearpanic created back in 1938 by Orson Welles' overly realistic "War of the Worlds" broadcast occurred during the half hour when "everybody" was supposedly listening to Charley McCarthy!

Audience "turnover" is another factor that advertisers weigh against a program rating. A five-day-a-week serial, for example, may have a 5.0 rating, yet be found to have attracted some listeners every day, some only one or two days during the week. Consequently the advertiser might actually reach as much as 12.5 percent of the radio families. This type of information can be brought out by the Nielsen Radio Index (the audimeter technique), the "listener diary" method or direct surveys by trained investigators. 


\section{Daytime Radio Serials}

Shortly after the formation of the first national networks a new form of radio entertainment started to attract the attenion of adverisers, the daily serial story. Since most of these programs were sponsored by Procter \& Gamble they acquired the tag of "soap operas" which has clung ever since, although General Mills, Sterling Drug, General Foods, Whitehall Pharmacal and others outside the soap field have long used the format.

Some serial programs are aired before noon, notably the veteran "David Harum" for Bab-O. The majority, however, come between the hours of 2:00 and 6:00 P.M., EST, and during that four-hour stretch NBC's basic network and most supplementary stations are booked solid. From two to three o'clock General Mills, as of January, 1947, was presenting Mondays through Fridays successive installments of "Today's Children," "Woman in White," "Masquerade" (with a fiveminute' Betty Crocker interlude), and "Light of the World." Then Procter \& Gamble took over with four quarter-hour serials, followed by Sterling Drug with four more. By that time some of the children's serials were coming in over other networks but NBC continued with its woman appeal; from 5:00 to 5:15, "When a Girl Marries," opposite "Terry and the Pirates," and 5:15 to 5:30, "Portia Faces Life." (Portia also faced "Superman" over Mutual and more than held her own with a 7.8 Hooper against 3.9 for the all-powerful bird man!) Both these "soap operas" were sponsored by General Foods. Two more serials with adult appeal, "Just Plain Bill" and "Front Page Farrell," followed for American Home Products, giving a total of sixteen quarter-hour programs consecutively.

Who listens to these shows, and why? Obviously a lot of people must like them or big manufacturers wouldn't continue to foot the bills. The audiences, of course, are predominantly women in homes, women with families for which they buy groceries, cleaners, tooth paste and headache remedies. Hooper reports show that consistently during this four-hour period they rate from 28 to over 40 percent of the sets in use.

A survey made in New England by Dr. S. J. Wump, director of the National Institute of Human Relations, showed that 51.2 percent of the women polled listen to "soap operas." When they were asked why, these reasons were given: 
Women with more trouble than I.................... $32.7 \%$

How women wiggle out of trouble................. $25.5 \%$

Husbands meaner than mine....................... $17.9 \%$

They do the crying, so I needn't.................... $6.3 \%$

Makes conversation with neighbors................. $6.1 \%$

Kills time ................................. $6.0 \%$

Drowns out baby's squawking. ................... $5.6 \%$

No opinion $\ldots \ldots \ldots \ldots \ldots \ldots \ldots \ldots \ldots \ldots \ldots \ldots \ldots \ldots, \quad .2 \%$

Those who said that they do not listen gave the following reasons:

Working girl, not home.........................62.7\%

High blood pressure, too exciting................... 18.3\%

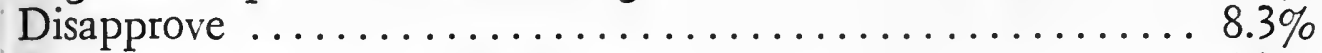

Prefer to do my own weeping..................... $4.8 \%$

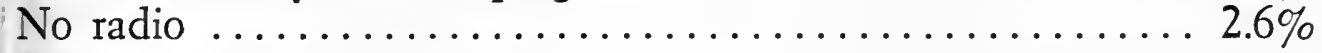

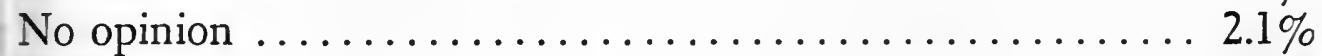

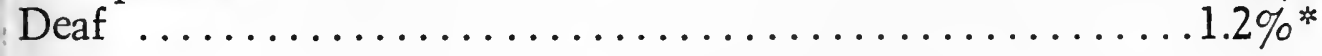

Physicians, sociologists and women's club leaders have condemned these daytime serials as overdrawn, unreal, tending to develop neurotic tendencies in listeners; yet the top programs seem to go on year after year attracting large audiences just the same. Although many types of programs have been tried out for the daytime hours, "soap operas" continue to lead. Only "Kate Smith Speaks," "Aunt Jenny" (a recipe program for Spry shortening), "Breakfast in Hollywood" and "Breakfast Club" were able to crack the first twenty Mondaythrough-Friday daytime shows in the December 1946 ratings, all the others being serials.

The cost of staging a "soap opera" even on a five-day-a-week basis is well below that of most musical and variety programs. Robert Landry estimates that talent will run from $\$ 1,400$ to $\$ 2,000$ per week and script $\$ 150$ to $\$ 350$, although top actors and writers command much more." Network time charges are difficult to estimate because of the wide variation in number of stations used as well as discounts. Daytime rates are usually 50 percent of evening rates and most of the big serial advertisers obtain further reductions by buying time on an hourly basis rather than in quarter hours. There are other forms of discounts, too. For example, NBC has an over-all discount of $22 \mathrm{r} / 2$

* Printers' Ink, June 13, 1947, p. 76. By permission of Printers' Ink.

** Landry, op. cit., p. 284. 
percent on advertisers using $\$ 1,500,000$ or more in gross space during a year. It seems probable that considering everything, the minimum outlay for producing a soap opera over a 52-week stretch is around $\$ 150,000$; the leading shows operate on a much higher budget.

An answer to critics of daytime serials was seen in a move by CBS in mid-1947. A family counselor feature was added to "The Second Mrs. Burton," with guest speakers every Wednesday. Typical consultant was Dr. Valerie Hopkins Parker, discussing ways a young couple could live with in-laws during the housing crisis. Other shows have interpolated recipes, child-care suggestions and news commentaries to combat the charge that all soap operas are pure escapism.

Children's serials generally follow a standard pattern. Many of them stem directly from comic strips: "Dick Tracy," "Tom Mix," "Terry and the Pirates." One of the most successful, "The Lone Ranger," became so popular with kids that it attracted an adult audience as well. Recently it has been broadcast evenings for General Mills.

Virtually all programs beamed at the juvenile market embody some sort of offer: either a gift included with the package, or a premium requiring a label or box top and enough cash to absorb the advertiser's cost. Other attractions, designed to make Young America put the heat on mother to buy the product, include membership pins, badges, secret codes and other paraphernalia in special clubs; prize contests, requiring a part of the package "or a reasonably accurate facsimile of the same"; and give-away booklets available only at dealers' stores. An example of this latter type of proposal was used on an NBC program by Smilin' Ed McConnell. A Buster Brown comic book was offered on two successive Saturdays if children would come to a Buster Brown shoestore accompanied by a parent, and the entire edition of 1,000 ,000 was promptly exhausted. Comic book two, announced a bit later, had a 750,000 run, which was also cleaned out quickly. Radio advertisers who strike a successful child appeal expect returns in the hundreds of thousands and are not too surprised when an offer passes the million mark.

\section{Radio Advertising for Retailers}

Less than 27 percent of the total amount spent on radio advertising in 1946 came from retailers, according to the Printers' Ink estimate. Yet 

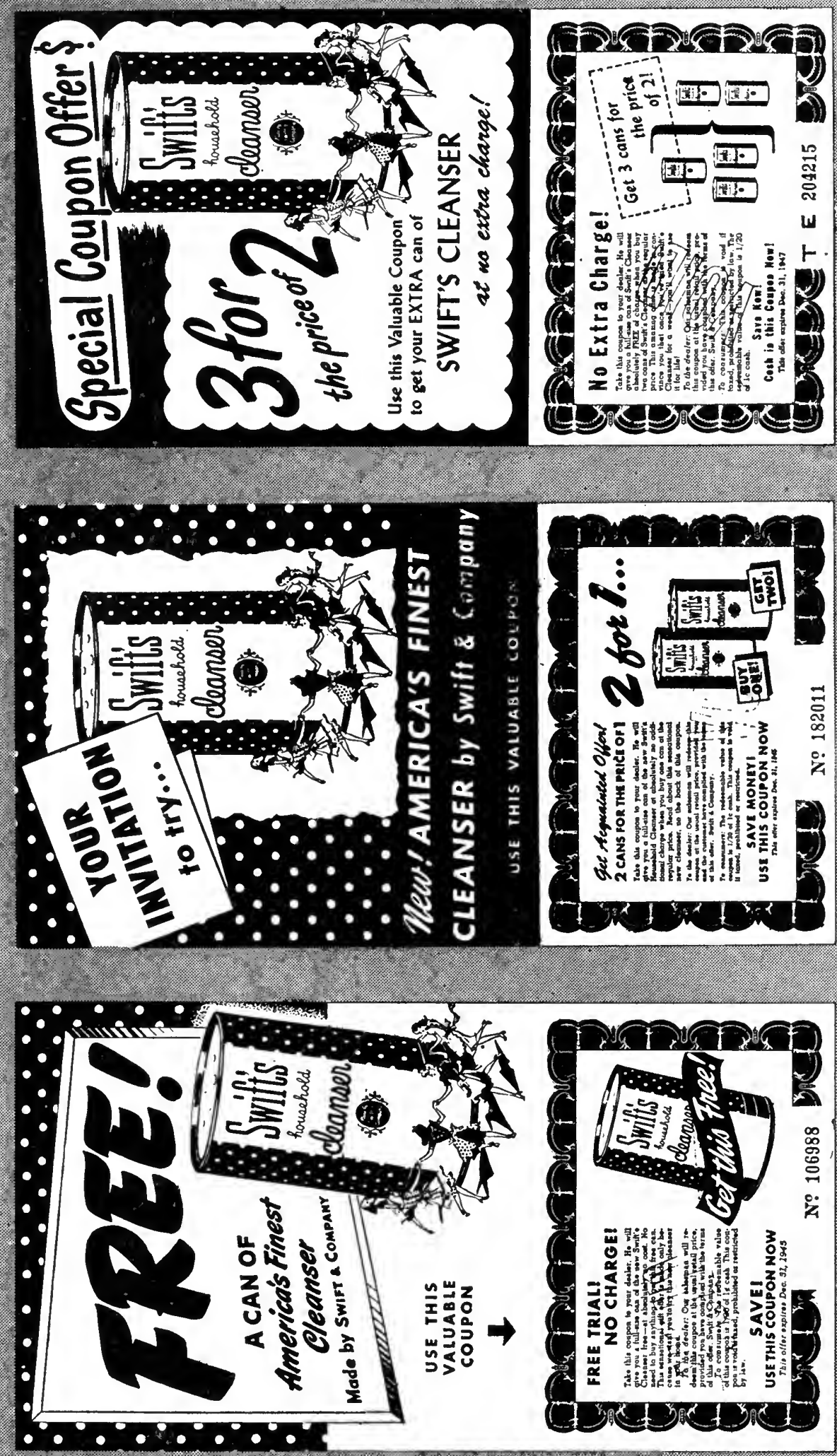
this added up to over $\$ 130,000,000$. This money was spent by many types of stores and local service firms on a wide variety of programs.

Some of the larger department stores participate in network shows, buying the local outlet and having an announcer in the local station read their commercials while the network broadcast is silent or is playing "fill-in" music. Newscasts are popular with retail sponsors. The morning "musical clock" type of program has been used by numerous stores.

An outstanding example of intensive use of radio by a retailer is Joske's, San Antonio department store. Under the vice-president in charge of sales promotion, a separate radio advertising department has been set up with a director, copy writers and clerical help independent of those employees handling newspaper, magazine or direct-mail advertising. Three types of appeals are used: long term promotions, stressing the general advantages of certain store divisions; short term promotions, featuring certain departments, brands or kinds of merchandise for a week at a time; and immediate promotions, designed for one or two days of concentrated selling on special events or items.

In a one-year test, Joske's of Texas made itself a guinea pig for the retailers and radio stations of the county, using five stations, 54 programs weekly and 109 spot announcements weekly. The "beamed program" technique was employed, the promotion of a specific type of merchandise or service directed toward a pre-determined audience, by the careful selection of suitable programs, times and stations.

Before the test was started on January 1, 1945, a series of surveys was made of the store, its competition, trading area, customers and prospective customers. It was learned, for example, that, while the store had a good high-fashion reputation and had particularly fine acceptance in better ready-to-wear, cosmetics, jewelry, books and appliances, it was not particularly strong in some popular-priced fields, such as furniture and basement merchandising. In part this was due to the lesser acceptance of the store by San Antonio's Mexican-born element, comprising 90,000 or 100,000 of the city's 350,000 population. To reach this particular market a number of programs went to $\mathrm{KONO}$, a local station with a wide following in the lower and middle income groups. Other programs were "beamed" at other markets in similar fashion.

In 1945 Joske's devoted a total of 1,359 commercials to Upstairs Fashions; 1,020 to Men's and Boys' Departments; 903 to the Base- 
ment Store; 865 to Cosmetics; and 865 to Furniture. A sample schedule included the following features:

\begin{tabular}{|c|c|c|c|c|}
\hline Program & Station & Time & How Often & Mdse. or Depts. \\
\hline Old Ranch Hand & -KABC & $7: 15 \mathrm{AM}$ & M-W-F & $\begin{array}{l}\text { Basement, Notions, } \\
\text { Stationery }\end{array}$ \\
\hline Good Morning Show & KTSA & $\begin{array}{l}7: 45 \mathrm{AM} \\
8: 30 \mathrm{AM}\end{array}$ & M thru Sat & Many depts. \\
\hline at Nine & KONO & 9:00 AM & $\mathrm{Mt}$ & epts. \\
\hline s Onl & KONO & 11:00 & & depts. \\
\hline & & $11: 15 \mathrm{~A}$ & & \\
\hline Members Only & KONO & $11: 45 \mathrm{AM}$ & M thru Sat & Budget House (furniture) \\
\hline & KMAC & & & e, other depts. \\
\hline & & & & \\
\hline & WOAI & 11:00 PM & M thr & Men's Store, other depts. \\
\hline & & 10:00 A & & Teens and Boys' \\
\hline & & & & Basen \\
\hline & & $10: 0$ & & Institutional \\
\hline
\end{tabular}

Besides these regularly scheduled programs, Joske's also used 68 spot announcements during the week and 24 on Sunday. Some of these were on co-operating programs containing brief messages by a number of sponsors; some were at station breaks; some followed network programs which advertised national brands carried by Joske's. (The Berkshire Hosiery program was followed by a Joske's hosiery tie-in.)

A slogan identified each program and spot announcement: “... brought to you by Joske's of Texas, by the Alamo in San Antonio, the largest store in the largest state."

Results of this saturation use of radio were not always easy to isolate, but there were many instances of dramatic sales increases. For example, after the store's five lines of cosmetics were featured on "Beauty and a Song," they showed gains of 50, 43, 31, 25 and 22 percent respectively.

At the end of the study year of 1945 Joske's further co-operated with the National Association of Broadcasters by setting up certain "test" departments which received radio advertising and "control" departments which received normal advertising in other media but no radio. These conclusions were reached after a study during the last six months of 1946:

1. Radio contributed directly to an average sales increase of 61.96 percent in the three test departments, over the preceding six-week period of normal promotion. 
2. Radio contributed directly to an average increase of 46.89 percent in the test departments during the first six weeks and 76.99 percent during the second six weeks, indicating its cumulative effect.

3. Radio proved its "carry-over" value. Although sales decreased when radio advertising was stopped, the average decline in test departments was not so great as in control departments.

Other stores have used radio almost as intensively as Joske's. Heinemann's, at Jonesboro, Arkansas, concentrates 13 quarter hours, one half hour, and 30 spot announcements per week on Station KBTM. The station manager says his most frequent call from the sponsor is to "take off that copy-you've sold us out."

Rich's Department Store of Atlanta developed a unique program, "Rich's Radio School," a recorded daily program for youngsters from kindergarten to sixth-grade age. Broadcast over six Georgia stations it is designed for in-school listening. Teachers receive prebroadcast pamphlets including a bibliography and teaching aids on each subject covered; occasionally give-aways such as bird prints or maps are sent out. The programs contain no commercials, merely the store name in the title, but are designed to identify Rich's as a Georgia institution. McCurdy and Company of Rochester, New York, have a "Hi News" program Mondays through Fridays over WHEC to win good will for the store among teen-agers. At last reports it had a 5.4 rating in competition with network serials and was popular with teachers as well as students.

The Morris B. Sachs Amateur Hour, sponsored each Sunday by a Chicago clothier whose store is ten miles from the loop, is one of the oldest retail programs in continuous performance. It started in 1934 and has never missed a week, now being broadcast from 12:30 to $1: 30$ P.M. over two stations, WENR and WIND, simultaneously. In June 1946, its rating was 7.9 which was considered unusually high for a local program at this time on Sunday. The show is produced in the $\mathrm{ABC}$ studios in Chicago except on special occasions such as anniversaries and Christmas, or when it is staged at one of the veterans' hospitals. Former amateurs who have appeared as unknowns include movie star June Haver, stage stars Pamela Britton and Maureen Cannon and singer Skip Farrell. Commercials stress particular types of merchandise, quality assortments, price range and the store's location. The appeal of the show has been demonstrated by the fact that Sachs, 
though far from centrally located, draws trade from every part of Chicago and the outlying towns.

"Telephone quizzes" are favorites with retail radio advertisers. A catch question is given over the air, the announcer picks a number at random from the local directory and quizzes whoever responds. If that person fails to give the correct answer the award goes up, usually $\$ 5.00$ for each failure. The loser, who may have missed out on a prize of several hundred dollars, is compensated with a merchandise certificate. This may be varied by playing a "mystery tune," or by asking the selected listener to identify a "mystery voice."

Another inexpensive and popular type of local show is the "man in the street" broadcast, patterned after the network show, "Vox Pop," in which bystanders are asked to give their opinions on topics of broad human interest. This may be varied by having the interviews in the store, as is the case with the "Meet Your Neighbor" program of Vogel's Super Market, Pekin, Illinois, heard daily over WSIV. An instance of the drawing power of this particular program occurred during the postwar meat shortage; the announcer casually mentioned that one of the participants had steak in her shopping basket, and within 20 minutes there was a line a block long waiting to buy meat at Vogel's!*

\section{Electrical Transcriptions}

For advertisers whose appropriations do not permit a costly "live" show, recorded programs offer a wide variety of choices.

National Broadcasting Company was one of the first in the field, setting up its "NBC Thesaurus," a musical library sold to the affiliated stations on a subscription basis. In 1935, when it was introduced, 50 stations subscribed; by 1947, some 400 stations had the service. The subscriber receives an initial 4,000 varied selections on 16-inch discs, a script service, and 60 to 70 new selections a month. Among the name artists are Sammy Kaye, Xavier Cugat, Vincent Lopez and the Deep River Boys.

Since 1937 NBC has also offered syndicated 5-minute, quarter-hour and half-hour shows including dramatic, quiz, comedy, sports, adventure, mystery, musical and news programs. Some 900 stations use this

* Data for this section supplied by Frank E. Pellegrin, National Association of Broadcasters. 
service. Costs are based on the size of the station and its market potential. The other networks also provide recorded programs of many appeals: hillbilly, sophisticated, artistic and all stages between.

Independent producers figure prominently in the "E. T." business, which was expected to gross over ten million dollars in 1947. Among them are such firms as World Broadcasting Company, Frederic W. Ziv Company, and Louis G. Cowan, Inc. (Cowan was the originator of the world-famous "Quiz-Kids" program.)

Among the shows offered by Ziv are Easy Aces, a comedy serial; "Favorite Story," a half-hour dramatic show with Ronald Colman as narrator; and such musical attractions as Barry Wood, Wayne King and Kenny Baker. The Colman show is budgeted at $\$ 9,000$ a week. Ziv shows are used not only by local and regional advertisers but also by such national advertisers as Borden, Vick, Wildroot and Grove Laboratories.

Interest in transcribed shows received impetus when Bing Crosby, after more than ten years as star of the Kraft Music Hall, signed with Philco in 1946 with the understanding that he could record his programs in advance. Despite some loss in rating, Bing's new "platters" proved sufficiently popular to presage a trend toward more programs of this type by established performers.

The "disc jockey" type of program was also on the upswing in 1947. For years radio stations had been playing phonograph records interspersed with commercials as fill-ins for "live" programs. Bob Hawk, later to achieve celebrity with "Take It or Leave It" and "Thanks to the Yanks," for Eversharp and Camel respectively, got his start in Chicago with a program of jive records known as "Red Hot and Low Down." Barry Gray of WOR won a wide following by his disparaging remarks aimed at those who phoned in requests. Most of these programs were of the "Midnight Watch" or "Matinee" variety. It remained for Martin Block of WNEW, New York, to put the record rodeos in the realm of big business. His "Make-Believe Ballroom" burgeoned during the 1940's into one of the best-rated local programs, with its own theme song and a waiting list of sponsors.

Currently such radio veterans as Ted Husing, Paul Whiteman and Tommy Dorsey have invaded the field, all operating on a percentage basis. By making available to the advertiser with $\$ 5,000$ to $\$ 100,000$ a year to spend in radio the same type of performance as the $\$ 1,000,000$ sponsor, electrical transcriptions raise the standards of radio pro- 
grams in general and challenge the networks to produce better and better shows if they are to retain their hold on the listening public.

\section{Spot Broadcasting}

Network programs may be compared with saturation barrages or bombardments; spot radio is "pinpoint" bombing of specific objectives.

Spot broadcasting, as officially defined by the National Association of Broadcasters, is "radio advertising of any type on stations individually selected. Regardless of the number of stations selected, each schedule is separately arranged, giving the advertiser free choice of markets and of stations in each market, free choice of programs or announcements, either live or transcribed." Spot announcements may be either local or national in origin.

The one-minute recorded announcement is a favorite unit for spot radio. It permits the use of orchestras, singers, sound effects. Local announcers, with the best intentions, may fluff a commercial. The "pitch on a pancake" can be rehearsed and re-rehearsed until it is letter-perfect.

In 1941 the Pepsi-Cola Company decided to use one-minute dramatized commercials on a large number of stations. To open and close these quickies, a singing jingle was developed. But the little tune proved so catchy, so complete in itself, that the advertising agency, Newell-Emmett Company, recommended its adoption as a station break. Its briefness, slightly under 15 seconds, permitted many more repetitions than a 60-second spot. Surveys showed that it also removed the "annoyance factor" which sometimes came up in longer announcements. The original jingle was:

Pepsi-Cola hits the spot,

12 full ounces that's a lot!

Twice as much for a nickel too-

Pepsi-Cola is the drink for you.

Nickel, nickel, etc.

The jingles were recorded by such well-known performers as the Radio Rogues, the Tune Twisters and other combinations. More than fifty variants of the standard jingle were recorded. It began to bob up 
everywhere, between network programs, in the midst of local "participating" shows, at many different times of day and night.

Inspired by numerous mail requests, Pepsi-Cola prepared complete orchestrations of the tune, hired a name band and had recordings made which eventually resulted in orders for over 100,000 discs for juke boxes all over the country. The agency won the 1941 Advertising 6 Selling award for excellence in commercial announcements.

Another jingle to hit the jack-pot was the lilting "Chiquita Banana," devised by Batten, Barton, Durstine \& Osborn in 1944 for United Fruit Company. Tested in various markets, by November of the following year the one-minute commercial was being heard over 138 stations in 55 United States markets as well as 24 Canadian stations, including a French version for the bilingual provinces. Its object was not to promote the sale of bananas at that time, as the supply was limited, but to educate the public about bananas and clear up misinformation, so that when the supply became ample bananas would "resume their rightful place in the diet of the American people."

Main points stressed were: (1) bananas should not be kept in the refrigerator; (2) should not be eaten until "golden and flecked with brown." The song caught on. Gene Krupa, Vincent Lopez, Fred Allen, Carmen Miranda all gave it free plugs on the air. A survey of 513 typical housewives, shortly after the spot broadcasts began, had 100 percent correct answers to the question: "Where should bananas never be kept?"

Among the largest and most consistent users of spots has been Bulova Watch, with its familiar time signals. Except for an occasional magazine ad virtually all of the Bulova budget for many years has been devoted to this type of broadcast. A gigantic spot campaign, perhaps the largest ever run in so short a time, was the six-week drive on Lucky Strike Cigarettes starting in April 1947 over 920 stations. On April 14, twenty-four college stations were added for a five-week schedule, bringing the total to 944 . Number of transcribed spots varied from 15 per week on stations in smaller cities to 100 per week on major stations, the total estimated cost being in the neighborhood of $\$ 3,000,000$.

\section{How Much Commercial?}

The "pet peeve" of millions of radio listeners is the repetitious, long-drawn-out, overly frank commercial. John Crosby, radio column- 
ist for the New York Herald Tribune, has devoted a number of his columns to the subject. On November 25, 1946, he excerpted a few of hundreds of letters, among them the following juicy morsels:

I'm so sick of B-O boomed at me from every angle that I'd cheerfully send every cake of Lifebuoy overseas in the hope that the advertising would be switched in that direction.

My insides are my own business. I'll thank the pill people to stop telling me how to put them in shape.

Won't you do something about the awful advertising in rhyme of the Alka-Seltzer people? Those awful rhymes! That inane dialogue!

"Containing not one but several ingredients" doesn't mean a thing. It's almost impossible to make a medicine containing only one ingredient.

The girl who goes for a man in an Adam Hat would go for anything. Any man in an Adam Hat would get thrown out of my house-that's what I think of their singing commercials!

Crosby also tells of one man who wrote in that he had broken his ankle in a mad dash across the room to turn off an announcer chanting "LS/MFT ... LS/MFT." Several have announced that they were starting crusades to boycott certain products because of the "horrible, disgusting, revolting commercials."

Correspondents of Ulmer Turner, Chicago Sun commentator, protest violently against the program interrupted at a dramatic moment with "But first, a word from our sponsor!" which usually turns out to be 150 words. To keep listeners dangling on the verge of a mystery solution while the virtues of a laxative or a beer or a cigarette are extolled is enough to make many vow never to buy that product, he is often told.

As against these hand-picked objections to radio commercials could be cited a mass of evidence to prove that the average listener does not resent the advertising portion of broadcasting. This was established in a nation-wide survey by the National Opinion Research Center as reported in "The People Look at Radio," edited by Lazarsfeld and Field and published in 1946 by the University of North Carolina Press. 
A few courageous advertisers have deliberately minimized their commercial time. Goodyear, in sponsoring a weekly drama based upon the teachings of Christ taken from the New Testament, over some $200 \mathrm{ABC}$ stations in the first half of 1947, carefully avoided any selling. Produced under the guidance of Fulton Oursler, the series was intended to illuminate the original meaning of familiar Bible stories, with a board of clergymen of various faiths passing on each script. Only the required sponsor identification precedes and follows the show: "The Greatest Story Ever Told, presented by the Goodyear Tire \& Rubber Co." The Texas Company, in presenting the Metropolitan Opera, used the intermission periods for discussion about opera and its people, answers to questions about opera and talks on democracy by prominent Americans. Allis-Chalmers also kept well in the background in presenting the Boston Symphony Orchestra. The Ford Sunday Evening Hour, heard for many years over a coast-to-coast network, had a minimum of sales talk. All of these and similar programs received much favorable comment. Evidence is lacking as to their sales effectiveness, however, and the average advertiser will no doubt continue to pack as much "hard-hitting sales wallop" into his program as possible.

There are restrictions, of course, on the amount of commercial time permitted on network programs. The NBC Program Policies Manual gives the following limits:

\section{Maximum Length of Commercials}

Length of Program (Minutes)

5
10
15
25
30

News Programs

(Day and Night)

$1: 20$
$1: 45$
$2: 15$
$\ldots$.
$\ldots$.

All Other Programs

Day Night

2:00 $\quad 1: 45$

$2: 30$

$3: 15$

2:00

2:30

$4: 15$

$4: 30$

These limitations do not apply to programs largely devoted to discussing products, such as those of Galen Drake in New York and Paul Gibson in Chicago; to recipe and homemaker programs like Beulah Karney's popular feature; nor to local programs on many stations.

Commercials must be submitted to the network at least 48 hours in advance of the broadcast. They are subject to approval by the net- 
work, which reserves the right to reject any material contrary to its policies and to demand proof of any statements or claims. Requirements are particularly strict with regard to medical accounts. The words "safe" and "harmless" are banned; certain proprietary remedies must carry the warning: "Use only as directed"; no claims that a product will effect a cure are acceptable.

Among types of accounts considered "unacceptable" by NBC were: professions in which it is deemed unethical to advertise (physicians, lawyers, dentists, etc.); stocks and bonds; cathartics, deodorants, reducing agents, hair restoratives; fortunetelling, astrology and "other forms of occultism"; wines and liquors (beer is acceptable, subject to local and federal laws); firearms and fireworks; matrimonial agencies; horse-racing organizations and publications; cemeteries, morticians, casket manufacturers and other products or services associated with burial. No NBC announcer was permitted to give a personal testimonial on the air, personally endorse the advertiser's product, or ask listeners to purchase it as a favor to himself.*

The NAB has adopted standards of practice which are adhered to by the majority of independent stations as well as the network affiliates. This means that local programs, with few exceptions, reflect the same rigid standards of control as network shows.

\section{Things to Come}

Twelve hundred and seven broadcasting stations were listed in the June 1947 issue of Standard Rate G Data Service aside from FM and television stations. Of these, all but 30 had time for sale. The exceptions were some 20 owned by universities and colleges; a few by religious organizations such as the Pillar of Fire, operating KPOF in Denver and WAWZ in Zarephath, New Jersey; Echo Park Evangelical Association, with KFSG, Los Angeles, and First Presbyterian Church of Seattle with KTW; and most notable, WNYC, owned and operated by the City of New York.

Clearly, commercially sponsored broadcasting predominated in America, with 97.5 percent of all standard stations selling time. The majority of the new FM stations also were on a time-selling basis.

\footnotetext{
* NBC Program Policies and Working Manual, Copyrighted 1945 by National Broadcasting Co.
} 
There seemed little doubt that when television went past its pioneering stage it too would be developed largely by advertising revenue.

The end of World War II saw a tremendous increase in the number of radio stations, and an even greater clamor from people who wanted to get into the field. In April 1947 the Federal Communications Commission reported that it had authorized over $700 \mathrm{FM}$ and 64 television stations, although Standard Rate G Data Service listed only 55 . The majority were building or still in the blueprint stage. What disturbed the FCC most was the terrific number of applicants for new stations: 1,114 still pending, even though more new stations had been licensed in 1946 than in the entire 11 preceding years.

Radio networks were growing, too. Mutual, largest in numbers, announced early in 1947 that it had 411 affiliated stations, with some 30 more under consideration. Many of its stations were not exclusive but also received programs from other nets. There was no doubt, however, about the fact that the fledgling network of 1934 which challenged National and Columbia with little more than WOR, Newark, and WGN, Chicago, was a full-sized institution. American Broadcasting Company, the former NBC "Blue" headed by Edward J. Noble of "Life-Savers" fame, since its separation in 1944 had also assumed new magnitude with 258 basic or affiliated stations. National with 165 and Columbia with 163 stations maintained their leadership on the basis of prestige, station power and coverage.

Only a small proportion of all stations, less than 20, are networkowned. Columbia owns WCBS (formerly WABC) in New York, WBBM in Chicago, KNX in Los Angeles, for example; but like the other networks it must depend upon the good will of its local outlets. Consequently the position of "Station Relations Manager" is an important one. Executives of independent stations have a voice in formulating the policies of the networks and are not slow to voice their "gripes" when they don't like the way things are being run.

While the affiliated stations need their network to supply the audience-winning programs that make their local time more salable and also to fill in the unsold time with attractive sustaining material, the networks need the stations too. Realization of this fact has done much to preserve the "grass-roots" character of chain broadcasting whenever it showed a tendency to become too far removed from the ideas and customs of the hinterland.

Besides the four coast-to-coast networks, a number of regional net- 
works or groups have been established, chiefly for economy and unity in selling time rather than for developing programs-although they may offer creative facilities, too. The Don Lee Network on the Pa: cific coast has 18 stations in California, ten in Oregon, nine in Washington, two in Idaho and one in Nevada, all MBS affliates. The Intermountain Network is a similar group with 15 stations. The Keystone Broadcasting System has some 260 smaller-city stations in what it calls the "Beyond-Metropolitan" area-from Anchorage, Alaska's KFQD, to Florida's WDLP at Panama City. Coverage is given by electrical transcriptions instead of wire connections. The Yankee Network in New England has some 23 stations and has developed a number of effective co-operating programs. State networks also vie for the advertiser's attention, among them the Tall Corn Network with ten stations offered "as a package-or split 'em to fit your need." The national networks also have regional groups which can be bought without going country-wide.

As with newspapers and magazines, radio has its "reps," independent selling organizations that handle the advertising contacts of a number of stations. Some, such as the Branham Company, represent other media, but the majority specialize on radio alone. These include such well-known firms as John Blair and Company, Free and Peters, William G. Rambeau, Paul Raymer, Edward Petry and Company and Walker. Solicitors for these firms call on manufacturers and advertising agencies but do not concen themselves with local advertisers. The make-up of a network list is flexible and certain markets are optional with the sponsor; it is the representative's job to get the maximum number of stations handled by his firm, on the maximum number of schedules. He is also concerned with obtaining spot radio orders for stations which he represents.

"How much does it cost to broadcast a program?" is a question frequently asked. Rates vary tremendously, depending on the station's range, the number of listeners covered and other factors. All rates have probably increased in recent years due to growing costs of operating a radio station and the incidental services that have been added to augment the effectiveness of radio advertising. For instance, Professor Hotchkiss gave time charges for Station WOR, Newark, in May 1931, as $\$ 750$ an hour, $\$ 450$ for a half hour and $\$ 300$ for a quarter hour of evening time, with the daytime charges being one-third those of evening. The 1947 base rate for that station was $\$ 1,200$ for 
one hour, $\$ 720$ for a half hour and $\$ 480$ for a quarter hour. These are one-time prices, subject to discounts for frequency. It is noteworthy, however, that the cost of broadcasts has gone up considerably over this period.

These are, of course, among the highest rates in the industry. At the other end of the scale, smaller stations sell time for as little as $\$ 10$ for a quarter hour. As with other media, there are expensive ones and inexpensive ones. The advertiser takes his choice.

Today most stations divide their hours on the air into several periods. On WOR Class A time is from 6:30 to 10:30 P.M. Some network stations extend this period, which is known as the "ice cream hours," from 6:00 to 11:00 P.M. Class B time on WOR, which has a 25 percent markdown, is from 6:00 to 6:30 P.M. and 10:30 to 11:00 P.M. weekdays, and 12 noon to 6:00 P.M. Sundays (after which it becomes Class A). Class C, 50 percent off in rates, extends from 8:00 A.M. to 6:00 P.M. and 11:00 to 11:30 P.M. daily, 8:00 A.M. to noon Sundays. Class D, one-third the top rates, is from 11:30 P.M. to 8:00 A.M., Station WOR being operated 24 hours a day.

There are variations in this rate structure, some stations having only three classes, others as many as five or six. But the fundamental principle is uniform: the highest price is during the evening hours between supper and bedtime when both husband and wife are apt to be listening, when more sets are in use and when there is greatest competition for time on the air. Next come the periods immediately before and after these choice spots, then the long daytime stretches when women's programs abound, and finally the "dog watch" hours.

Frequency modulation or FM has been hailed as the radio of tomorrow because of its ability to eliminate outside noises (static) which sometimes spoil perfect reception under the present amplitude modulation (AM) technique. Thus far no major station has gone FM. The cost of converting all broadcasting facilities to the new type of equipment is colossal and undoubtedly will be deferred until a majority of home radios are able to receive FM broadcasts.

Television has been "in the air" for 20 years. Its enthusiasts have cried "Wolf!" so often that most people are skeptical about its imminence. Technical difficulties have been overcome to a large extent through the change from mechanical "scanning" to all-electronic equipment. The industry struck a snag immediately after the war when there was a movement toward the use of color in television. The 
FCC denied an application of Columbia Broadcasting for television in color in March 1947, and this was hailed as a go-ahead signal for those who felt that the immediate future of the new medium lay in the black-and-white image.

Du Mont, Radio Corporation of America and other manufacturers of television sets freely predicted a boom. Du Mont planned to double its production; RCA announced plans to build 160,000 sets in 1947. A number of agencies with television departments scheduled full-scale campaigns on the existing facilities. Thus far television was limited in range, and plans for network programs waited on the construction of "coaxial" cables connecting the cities, since television, unlike radio, cannot be transmitted over regular telephone wires.

The advertising fraternity awaits the advent of television with mixed feelings. Undoubtedly new complexities will be added to an already complex profession. More than ever, advertisers will find themselves in "show business," since the spasmodic experiments already reported indicate that television commercials to be effective must embody drama and action.

One short-cut to producing satisfactory commercials for the new medium seems to be the use of films rather than live action. Just as electrical transcriptions permit the radio advertiser to rehearse announcer, sound effects and music until all flaws have been eliminated, so will movies avoid the embarrassment of television actors "blowing up" on the commercials. On the other hand, it is argued that the cost of filming a commercial, estimated by John Allen of Marschalk and Pratt, New York agency, at between $\$ 750$ and $\$ 3,000$, makes their use impractical for the average advertiser. Firms using theater film advertising or industrial movies will be able to take advantage of television in this respect more readily than those that must start from scratch. Possibly "stock films" may be developed for local advertisers leaving only the individual name, address and telephone number to be dubbed in by an announcer.

Trail blazers in advertising by television have already discovered that the medium has a powerful impact on its observers. While one may take with some reservations the statement of Leonard Cramer, executive vice-president of Du Mont, that "a brief but well integrated visual commercial will sell a thousand times as well as the aural one,"* it is evident that opportunities are presented which combine

*Advertising Age, October 28, 1946. By permission of Advertising Age. 
the strongest advantages of radio and printed advertising. These include showing the product in home settings, actual demonstrations of how to use it and the results, action testimonials by celebrities and ordinary folk, and dramatized incidents in the design and manufacturing processes.

Companies with a trade character can bring it to life. For example, Atlantic Refining Company has been sponsoring football telecasts for more than six years over WPTZ, Philadelphia, through N. W. Ayer \& Son. Don McClure, Ayer's television director, developed commercials featuring "Sparky," the trade character of Atlantic Gasoline, which have been very effective. In another instance, Chef Boy-Ar-Dee Quality Foods, Inc., staged a television broadcast over WRGB, Schenectady, in which Chef Hector Boiardi himself participated, demonstrating how easy it is to prepare his famous packaged spaghetti dinner. LeRoy Kling, vice-president of the Gordon Best Company, the Chef Boy-Ar-Dee agency, declared afterward that the Chef was a "natural" for television.

The possibilities of television for department store advertising have been vouched for by David Arons of Gimbel's in Philadelphia. At first he tried dramatized skits but discarded these in favor of "real people in real situations doing real things, with merchandise the first consideration." Fashions, furniture and kitchenware, he found, "fall flat on television." But hair-dos, garden shrubs, kitchen gadgets (showing new and old ways of doing kitchen chores), dress patterns and men's shirts were successful. On one program Gimbel's had a letter-writing contest and received 52 letters, which he estimated was a 7.1 percent return on all television sets in Philadelphia at that time.*

Television in early 1947 was still a small factor to the advertiser thinking in millions. Chicago had an estimated 2,500 receivers, New York perhaps 7,000. But the possibilities were unlimited. Just as radio had opened up an entirely new vista to the manufacturer and retailer of the 1920's, television-or video, to use the abbreviated term-seemed likely to cause another revolution in advertising strategy. As usual, there were doubters. That didn't deter the youngminded, the adventurous. They looked ahead to new techniques, new strategies in influencing people to buy, and they visualized what television might mean. It was a heady dream. But the improbable has a way of coming true in advertising.

* Ibid. 


\section{Chapter XVI \\ SIGNS OF THE TIMES}

"T $\mathrm{HAT}$ he who runs may read" has been the basic principle of an important part of the advertising field from the earliest

1 days. Undoubtedly signs and posters were the first form of advertising, long before handbills and newspapers and magazines were known. Throughout the growth and development of these other media, posters maintained their place. And today, despite all the competition from radio, periodicals and other methods of selling the public, these brief, colorful displays still rank as a major advertising technique.

Several distinctive forms are included under this general heading. First and largest from the standpoint of cash outlay is the 24-sheet poster or "billboard"- to use a term which is anathema in the industry. Next perhaps comes the painted bulletin or handmade electric "spectacular," a particular sign for a particular spot. Also included in this category are miniature posters in streetcars, subway trains, busses and other common carriers; posters on and around subway, bus and ferry depots; posters on the sides of retail stores; highway signs, whether in rhyme or in straight copy; and innumerable variations.

The field of outdoor advertising, according to various estimates, accounts for somewhere between $\$ 50,000,000$ and $\$ 100,000,000$ a year. The Printers' Ink figures gave $\$ 71,700,000$ in $1945, \$ 85,900,000$ in 1946.* Subway, streetcar and bus advertising services do not announce their annual figures, but these and similar forms probably received $\$ 25,000,000$ or more. Electric signs, highway bulletins and other permanent or semipermanent displays undoubtedly ran into many millions more.

- A common denominator of all these advertising media is their extreme brevity of copy. The most successful 24-sheet posters seldom contain more than eight or ten words including the name of the product, whereas an average magazine or newspaper ad may have

* Poster Advertising Coverage, Outdoor Advertising Association of America, 1941. 240 
150 to 300 words. Thus the three prize-winning posters for 1945 had only the following text:

1st Award: "Remember this wrapper! Wrigley's Spearmint Chewing Gum" (7 words)

2nd Award: "Refreshing-Coca-Cola" ( 3 words)

3rd Award: "Red Magic! Heinz Ketchup" (4 words)

Reproductions of the package are frequently used in outdoor advertising. But almost invariably the label is simplified by eliminating all wording except for the product's name. A common device is to show the package so large that it alone identifies the advertiser without the necessity of repeating the name elsewhere on the sign or poster. Illustrations are likewise kept very simple. Rarely does a poster have more than one or two figures; these usually appear as close-ups. Anything which might distract the attention or prevent instant recognition of the poster's meaning must be blanked out. Electric signs, painted wall displays and highway signs rarely attempt to do more than give the name of the product and a brief slogan or selling message. A notable exception is the Burma-Shave technique: a humorous rhyme split up into a series of small, regularly spaced signs along the road.

Most outdoor and sign advertising is used to remind consumers of products with which they are already familiar. Even though they may not know the particular brand they will understand the type of product advertised. Because of the necessity for quick reading, this medium does not lend itself easily to a pioneering or educational advertising job, unless the theme can be expressed in a few words. But for such universally used items as chewing gum, soft drinks, bread, gasoline, automobiles, bathing suits, beer and candy bars, outdoor advertising has demonstrated its power both as a basic and as a supplementary medium.

\section{The 24-Sheet Poster}

The most efficient and highly organized factor in the field of outdoor advertising is the group of companies handling the displaying of 24-sheet posters.

Today this service has become standardized. It is possible to order a "showing" in more than 17,000 cities and towns in the United 


\section{2}

THIS FASCINATING ADVERTISING BUSINESS

States with the assurance that the "paper" will be carefully mounted on well located "poster panels" on or about the date specified, and will remain in view for a minimum of 30 days. Figures are available as to the number of pedestrians, motorists and users of mass transportation who will be exposed to these posters. Different intensities of coverage are offered to the advertiser according to the limitations of his budget. All this sounds simple but cumulatively it represents the lifelong efforts of many men. Perhaps no medium of advertising presented more obstacles to unification. The outdoor advertising field as it functions now is a monument to the work of men like Thomas Cusack, O. J. Gude, Kerwin Fulton, Burr Robbins, Barney Link and other foresighted leaders.

Englishmen call outdoor posters "hoardings," from the old AngloSaxon hurd, meaning a fence or barrier. The earliest paper posters were hung on those temporary walls erected around buildings under construction. The American designation of " 24 sheet" had a more practical origin. In the middle of the nineteenth century, the largest sheet of paper that could be printed by lithography measured 28 by 42 inches. This was commonly used by theatrical promoters like P. T. Barnum. Combinations of several such impressions became known as "two-sheets," "three-sheets" and so on. A group four sheets high and six sheets wide, 24 in all, became accepted as a standard for giant displays featuring circuses and other gala events, and frames were built to accommodate them. Nowadays, though far larger sheets can be accommodated on the presses, and the average poster may consist of as few as eight separate pieces, they are still called "24-sheets." The printed surface measures 106 by 236 inches, which allows for an overlap where the sheets come together.

Outdoor advertising in America may be said to have had its real origin 75 years ago, when the International Bill Posters' Association of North America was organized. In that year, 1872, the firm of Kissam \& Allen began to erect and lease their own poster panels instead of painting or papering over competitors' signs. In 1891 the Associated Bill Posters' Association, the first national effort to stabilize the industry, tackled the problem of working out a uniform practice. At that time posters might be anything from one to 48 sheets and even though the advertiser specified a 24-sheet poster there was often a variation of several inches in size. Not until 1912 was the present uniform size adopted generally. 
Meanwhile the number of posting companies had grown from a scattered few to over 3,100 "official" billposters (recognized by the Association) in 1910. The real development of the medium came, however, with formation of the National Outdoor Advertising Bureau in 1915. This organization of advertising agencies became interested in correlating posters with publication advertising so that their clients could receive a nation-wide service in the outdoor field comparable with that in newspapers and magazines. The Bureau still functions as the nonprofit buying and field service representative for member agencies and their clients.

The Associated Bill Posters gave way to the Poster Advertising Association; finally, in 1925, to the Outdoor Advertising Association of America, which has since been the official voice of the poster industry, under such leaders as Harry O'Mealia, Clarence Philley, George Kleiser, and Rex Bell (of Terre Haute, not Hollywood). This very alert and aggressive association of poster-plant owners is not to be confused with Outdoor Advertising, Inc., an organization which confines its activities to selling poster space for outdoor plants wherever located, filling much the same role as do the special reps for magazines, newspapers and radio stations.

Prior to 1910 advertising agencies were not granted a commission on poster advertising. The various outdoor companies sold their space direct to advertisers. Gradually this situation changed until by the early 1920's most plant operators were giving the accepted 15 percent commission to recognized agencies. A 1947 estimate by Printers' Ink indicated that 70 percent of all poster revenue was derived from national advertisers.

The familiar green lattice panel, now standard for the industry, also contributed much to outdoor advertising progress. In April, 1946, the OAAA also approved as an alternative standard a modernistic gray, gold and white moulding 19 inches wide, constructed of steel and finished in porcelain or baked enamel. Designed by Raymond Loewy Associates, this new "frontice" is appearing in increasing numbers throughout the country.

\section{Outdoor Advertising Technique}

Two attributes give outdoor advertising its strong appeal to advertisers: size and repetition. 
With the standard 24-sheet, any manufacturer or retailer has at his disposal an area some 223 times the size of a magazine page and 71 times as large as a full newspaper ad. The board under proper conditions can be seen from several hundred feet away and although the observer may be traveling rapidly in an automobile or common carrier there is a period of several seconds when the massive display will be exposed to his conscious or unconscious observation.

From sheer size and impact alone, the poster has had its opportunity to record a significant impression on the mind of the observer. The average observation time of a poster is said to be only five seconds, but during that brief span much can be accomplished. The appearance of a package, the name and slogan of a product, the advantage of a service can all be recorded for future reference when purchases are being made.

Posters are democratic. The smallest concern occupies the same space as the behemoth. An advertiser with a limited appropriation can appear just as impressive on his particular poster as the big corporation. Moreover, he can tell his story without worrying about competition; accepted poster practice does not permit the placing of boards for similar products in adjacent panels.

Repetition is the keystone of advertising. Posters, strategically placed to catch the eye of the maximum number of passers-by, whether on foot, in autos or riding the elevated, streetcar or bus, are on view for a minimum of 30 days. Even a small showing in any except the tiniest hamlet will include several posters, while in New York, as of 1941, a showing for Brooklyn, Flushing, Bronx and Manhattan might run to 170 regular and 132 illuminated posters at a cost of $\$ 8,670$ per month. Obviously there is no exact method of determining how many people will be exposed to an advertiser's boards during that period, but the chances of multiple impression in the course of a month are plentiful.

Poster-plant owners increase these opportunities for observation by placing their frames along well-traveled arteries, carefully spotted so as to secure the utmost attention from car, bus and trolley riders. At busy intersections, posters are "angled" to be visible from two or more thoroughfares. Where ground-level locations are not obtainable, the displays may be erected on roofs of buildings, but never at a height greater than the normal range of vision. Preferred poster spots are at places where traffic tends to slow down or halt, thus affording greater opportunity for observation. 


\section{Poster "Circulation"}

Realizing the need for some standard of measurement as to the number of people who might see a given poster or series of posters, in 1931 the ANA asked the Outdoor Advertising Association of America, in connection with the $4 \mathrm{~A}$ 's, to sponsor a study that might lead to developing such a yardstick. This survey, conducted by Harvard University, took 18 months and covered 150 cities. As a result, the Traffic Audit Bureau was established, consisting of directors from each of the sponsoring associations, with Dr. Miller McClintock, who directed the basic researches, in charge.

The TAB evolved a method of determining the average amount of traffic that would pass given locations during the course of a day, a week, a month. While this method is too complex to explain in a few words, it can be said that it depends on obtaining the gross traffic figures for the poster location and then discounting them on the ratio of 50 percent of pedestrian traffic, 50 percent of automobile passenger traffic and 25 percent of mass transportation (trolleys, busses, etc.). The total of these reduced figures is then considered "effective circulation."

By thus leaning backward in the amount of net coverage of a given area, the $T A B$ has earned the respect of national advertisers and agencies. It is recognized that the figures are ultraconservative. Even so, these statistics rapidly assume amazing totals. According to OAAA estimates, a "Number 100 " showing in cities covered by their poster plants would result in a minimum of $100,000,000 \mathrm{im}$ pressions per day, the equivalent of one poster impression for every United States resident over 15 years of age.

Modern outdoor advertising representatives do not deal, however, in national figures. They are concerned with specific markets, certain cities and the surrounding areas, which they represent. It is their contention that the medium covers not once but a number of times during the course of a 30-day display, every possible consumer in their territory.

Two time-periods are used: 6:00 A.M. to 6:00 P.M. for unilluminated structures and 6:00 A.M to 12:00 P.M. for illuminated posters. In virtually every outdoor campaign except in the smaller towns, some illuminated posters are included with a showing, the proportion increasing with the population. Larger cities, having more night traf- 
fic, customarily have an average of one-third to one-half of their boards illuminated. The ratio gives an interesting clue to the customs of a city. For example, Davenport, Iowa, lights up 28 percent of the boards in a showing; Los Angeles, 52 percent.*

Three basic factors govern the value of a poster, aside from the amount of traffic that passes it. There are:

1. The unobstructed distance through which approaching traffic may see a panel. The ideals are: over 350 feet for fast travel, 250 feet for slow travel. This is known as a "long approach" and rates 100 percent of the effective circulation. The "medium approach" is 200-350 feet for fast travel, 150-250 for slow, rating 80 percent. The "short approach", 100-200 feet and 75-100 feet respectively, rates 60 percent, and the "flash approach," below these distances, may rate from 0 to 40 percent.

2. The speed of approaching traffic.

3. The angle of the panel to the traffic, and the relative position of the panel in relation to other panels. A single panel, or the one in a group nearest the line of travel, receives the highest rating. All others in a group are discounted 10 percent. A poster parallel with the line of traffic, being less visible from a distance, is discounted another 10 percent.

The most valuable poster is one located at an angle at an intersection where it can be seen by two or more converging lines of traffic. If it is a junction or two or more streetcar or bus lines, with many people getting on and off, so much the better. Generally such corners are built up, however, and the only available poster sites are on top of buildings. Should the panel be only one story above the street, it will receive a good rating, but higher signs are discounted.

Poster-plant owners furnish a statement of each poster panel to the Traffic Audit Bureau annually. These statements are analyzed by the $\mathrm{TAB}$, and later sample checks are taken by field auditors. The panels are studied not only for effective circulation, but also to make certain that they cover all essential parts of a market, with displays distributed along all principal routes of travel.**

\footnotetext{
* Poster Advertising Coverage, Outdoor Advertising Association of America, 1941.

** By permission from Outdoor Advertising, by Hugh E. Agnew. Copyrighted 1938, by McGraw-Hill Book Co., Inc.
} 


\section{Different Types of "Showings"}

Advertisers wishing to use posters in a certain market may purchase varying quantities, depending on the size of the budget and the intensity of coverage desired. These different quantities, known as "showings," are distributed throughout the area, some being on the busier routes, others in outlying spots, so that no one advertiser will enjoy all the choice locations.

The names by which various sizes of showings are identified have undergone many changes. At one time the industry generally offered three types: the so-called "full," "half" and "quarter" showings. Later these became the "intensive," "representative" and "minimum." None of these was satisfactory because in many cities more than three assortments were available. In 1940 the OAAA adopted a numeral system. The No. 100 showing of today corresponds roughly to the former representative or half showing; however, due to relocation of panels and general increase in traffic, its effectiveness is considerably greater. The No. 50 showing, replacing the former minimum, likewise represents a circulation increase. The No. 150 and No. 200 showings provide more intensive coverage of a market.

Poster-plant owners offer showings of many kinds. In Sacramento, California, for instance, a Number 100 showing comprised eight regular and eight illuminated panels. It was possible to buy, in 1941, anything from a No. 10 showing (one regular, one illuminated) to a No. 150 ( 12 of each) with the quantity of posters increasing by one of each type and the rate $\$ 52.50$ per month per number. In New Orleans, only No. $25,50,75,100,125$ and 150 showings were offered. In smaller cities, a lesser number of showing was available.*

Rates are based on amount of circulation, type of market, and other factors. The medium is flexible, in that it is possible to order showings by the month to take advantage of seasonal variations in the demand for a product. In recent years the popularity of poster advertising has made it necessary for advertisers to place reservations well in advance and many orders have been refused for lack of space.

The method of determining the quantity of posters in a No. 100 showing is a combination of statistics and common sense. The number of principal streets and routes of traffic, the density of population,

* Poster Advertising Coverage, Outdoor Advertising Association of America, 1941. 
purchasing power of the community and other factors are taken into account. In Chicago, for example, there are some 480 miles of principal streets-those on which the daily volume of traffic makes it economically sound for posting-and a No. 100 showing includes 100 regular and 60 illuminated boards, or approximately one poster for each three miles of main arteries. According to Professor Agnew, the market area should be zoned to give an average of three or four miles of principal routes per zone; a desirable condition would be two poster panels in each zone for a representative showing. *

\section{Painted Displays}

By contrast with 24-sheet posters, which are standard in size, painted displays can vary widely. The chief kinds offered by poster companies are:

1. Streamliners-These are large, impressive structures measuring 50 feet or more in length, sometimes with neon lettering, built-up portions, possibly embodying a clock or thermometer. They are located on boulevards or main thoroughfares with a great deal of traffic, and are used for prestige purposes by such institutions as banks, hotels, insurance companies and the like.

2. City and suburban bulletins-Placed along important streets, these displays are standardized at $121 / 2$ feet high by 47 feet long, and are attractively designed. Painted bulletins have a white frame and latticework, whereas the poster panels are usually finished in green.

3. Store bulletins-Located on the sides of stores and other buildings. The height is a standard 9 feet 10\%/4 inches, but the length varies according to angle of visibility and length of wall available. This type may be used where the product is sold through exclusive dealers, to give "point-of-sale" impression.

4. Highway and railroad bulletins-12x/2 $\times 42$ feet, standard white structure, on principal highways and along main railroad lines.

5. Metropolitan bulletins-18 feet high by 72 feet long, facing citybound traffic on heavily traveled highways and main-line or suburban railways.

6. Painted walls-These may be any size or shape, depending on the space available.

* Ibid. 
Painted displays are usually changed three or four times a year. Most users of this medium prefer to employ simple designs, since the reproduction must be done by painters who are craftsmen rather than artists. Colors for painted bulletins have been standardized to 26 hues, and paint manufacturers and advertisers supplied with samples to assure uniformity.*

\section{Electric Spectaculars}

As their name implies, these big signs are designed to create a dramatic impression on the spectators. They do their heavy selling after dark. New York City's "Great White Way" derived its nickname from the battery of electric signs around Times Square, although nowadays there are more lights in color than in white. Chicago's Michigan Avenue, Cleveland's Euclid, Los Angeles' "Sunset Strip" are all begemmed with mammoth, colorful, flashing spectaculars.

The more modest versions of this type of outdoor advertising have a conventional painted bulletin, with additional neon and incandescent lighting, thus giving them a day and night value. The more lavish contain animated sections such as moving ribbons of changing letters to give commercial messages, news and time signals, dramatic sequences, and kaleidoscopic fantasies. Douglas Leigh has won a national reputation by his Broadway spectaculars.

Most famous prewar display was that of Wrigley's Spearmint Gum, located on the east side of 7th Avenue between 44th and 45th Streets. Seventy-five feet high and 200 feet long, it was composed of 29,508 electric bulbs and 1,084 feet of neon tubing. Against green waves giant multicolored fish seemed to glide about. Dominating the scene was the Wrigley "spearman" and a monster replica of the package. At various times the spearman would point to selling slogans which would flash on and off-"Aids Digestion"-"The Flavor Lasts"- "After Every Meal."

Spectaculars are contracted for on a long-term basis, often three or more years. The cost of construction is absorbed by the advertiser through monthly charges which may amount to several thousand dollars. Naturally, the more desirable locations command high rentals from property owners, while heavy additional expense is in-

* Agnew, op. cit. 
curred by the necessity of having maintenance electricians on hand to assure proper functioning of the signs and to replace burned-out bulbs and tubes.

\section{Three-Sheet Posters}

A highly specialized type of outdoor display is the "three-sheet" poster affixed to the wall of a grocery or drug store at a busy neighborhood shopping center, advertising a specific product. Chief advocate of this medium is Criterion Service, which under its long-time president, Frank Birch, has developed a coast-to-coast coverage of community markets with over 70,000 panels.

Birch, a native of Mark Twain's birthplace, Hannibal, Missouri, got his start in advertising by designing the original Bull Durham tobacco sign which was once a feature in baseball parks. Having established an outdoor plant in Boston, in 1917 he became interested in a three-sheet poster service that was leasing the sides of buildings housing tobacco shops, then selling displays to cigarette companies. He saw its possibilities for food and drug manufacturers. The business has grown steadily since he took it over and now grosses over $\$ 3,000$,000 a year. General Foods, Heinz, Ward Baking, Lever Bros. and Ralston have been among its largest customers.

Criterion in 1947 had a flat charge of $\$ 3.60$ per month for its frames on a three-year contract. The advertiser, providing panels were available, could buy as many as he wished on this basis. Because people of like races tend to cluster together in cities, Criterion posters could be spotted to appeal to racial audiences (Jewish, Italian, Negro, Polish, etc.) if desired. A recent OAAA development is the six-sheet or "junior poster panel." This panel has the same ratio to height as has the 24-sheet. Like the three-sheet size, it is designed chiefly for wall use in retail shopping centers.

General Outdoor Advertising Company has also sold three-sheets and in addition has developed a nine-sheet poster service in the New York area. United Advertising Corporation has a "neighborhood panel" slightly smaller than the 24-sheet. Other companies also offer space for small posters. To date, however, Criterion is the only company providing this service on a national basis.*

* Tide, February 28, 1947, pp. 15-17. By permission of Tide. 


\section{Transportation Advertising}

Car cards, like posters, depend upon brief copy. Pictures are used liberally. However, since transit riders have a longer opportunity to read the message than the auto passenger, car cards sometimes contain much greater wordage than posters. It is estimated that some 39 million people see these "transitads" every day.

The standard card in streetcars is $11 \times 21$ inches. A smaller size, $11 \times 14$, is now offered, as well as a double size, $11 \times 28$, and a triple size, $11 \times 42$. For many years, Wrigley's Gum had a card in every strêetcar in the country. Manufacturers of foods, drugs and cosmetics are among the most constant users of this medium.

The car card was a primitive advertising vehicle as far back as 1860 , when B. T. Babbitt used the Third Avenue horsecar line in New York to promote soap sales. In the 90's Artemas Ward contracted with transportation companies in ten cities to post cards in their trolleys. His successor was Barron G. Collier, who by 1905, at the age of 33 , controlled the advertising in over 11,000 streetcars in nearly 350 cities. For many years, car cards were sold direct to advertisers, paying no commission to advertising agencies. Like the outdoor industry, transportation advertising eventually recognized the agency as an integral factor in sales promotion and granted the customary 15 percent commission to legitimate agencies.

As the medium accepted the agency, so have agencies accepted the medium. In recent years an increasing proportion of transit advertising has been agency-created. Starting in 1944, the 4 A's and the ANA directed its joint venture, the Advertising Research Foundation, to conduct a continuing study of transportation advertising, under Otis Kenyon of Kenyon and Eckhardt, Inc. Between October 1944 and May 1946, ARF completed seven surveys: Newark, New Haven, Detroit, Cleveland, Milwaukee, St. Louis and Chicago. Objects were to delineate the general nature of the audience, to measure the actual number of people who receive impressions from specific transportation ads and to get general information about the habits of riders of mass transportation vehicles.

Alfred Politz, noted research consultant, devised the formula for testing car card effectiveness, the "controlled-recognition method." In this method, those interviewed are shown a portfolio of cards that 
have appeared for at least 30 days in the cars and busses. Included are cards which have not appeared. A certain proportion of respondents will say that they have seen the unpublished cards. Their answers are weighted in computing the accuracy of the total number of interviews. Homes are selected at random, but by a procedure beyond the control of the interviewer, to avoid prejudice. In the Chicago survey, two samples totaling 2,139 calls on car or bus riders over 15 years of age constituted the basis.

Of the 12 cards measured, the one which received the most recognitions was one for PM Whisky, which 64 percent of the riders reported seeing in post-examination. However, in a pre-examination 53 percent said they had seen the card; by the Politz formula this yielded a net of 24 percent of actual audience. On the other hand, a card for Marchand's Hair Rinse was recognized by only 52 percent of the riders, but just 25 percent said in the pre-examination that they had seen it; hence this card came up with a net of 36 percent. On the basis of the "corrected real audience," the Marchand display corralled 840,000 actual witnesses while PM had but 570,000.

Among details of transportation habits brought out by the Chicago survey were the following:

$77 \%$ of all men, $82 \%$ of all women, used mass transportation (streetcars, elevated, busses, suburban rail lines).

$85 \%$ of the population $15-29$ are riders; $82 \%$ of those $30-44$, and $73 \%$ of those 45 and over.

The number was slightly smaller for top rental bracket, but insignifcant as to variation among lower three-quarters.

The average length of ride was 32 minutes.

$39 \%$ made five or more round trips a week, $23 \%$ two to four, $17 \%$ one or less, $21 \%$ were classed as nonriders.

$53 \%$ changed cars one or more times.

$46 \%$ sat most of the time, $29 \%$ stood most of the time, $25 \%$ stood and sat equally.*

The rates charged for car cards range from 50 cents to several dollars per car per month. Kleppner estimated the average cost at 90 cents per card,** while Hotchkiss reported in 1931 that a "full run" in all the

* Continuing Study of Transportation Advertising, Study No.7, Advertising Research Foundation, Inc., Copyright 1946.

** Kleppner, Advertising Procedure, p. 385. 
cars in the United States would cost $\$ 40,000$ per month for some 70,000 cards.* Higher prices are charged for the larger cards, particularly those located at the ends of the cars in positions of greater visibility.

\section{Other Transportation Media}

Single-sheet as well as two and three-sheet posters have been used in railroad, ferry and bus terminals and on subway and elevated platforms. The New York Subways Advertising Company, for instance, offers poster space in over 500 subway stations, stating that "9 out of 10 New York City adults are subway riders."

Most terminal and station platform posters are adaptations of outdoor boards or conventional displays. A series for Savarin Coffee prepared by Roy S. Durstine agency, however, demonstrated real ingenuity. As everyone who has ridden the New York subways knows, the walls of the underground stations are covered with square white tiles. These posters reproduced the same tiles actual size, with the Savarin Coffee can and a selling message apparently emerging from the wall. The effect was startlingly realistic-so much so that with one particular poster, which gave the Savarin can a particularly strong third-dimension effect, many subwayites unconsciously stepped away from the wall to avoid bumping into the supposed projection!

Posters on the sides of Railway Express trucks are no novelty. This space has been sold to advertisers for years. More recently, U. S. Traveling Ads announced a similar service on interstate trailer trucks. Post-office trucks have carried side panels with such messages as "Mail early for Christmas" and "Be sure to include Zone Number on Address" since before World War II.

In some cities the exteriors of streetcars and busses carry advertising posters, though not to the extent of the English trams, which are virtually moving billboards. Bus advertising is as a rule confined to the interior, utilizing the same units as streetcars; the same general statement may be applied to suburban trains and ferryboats. Taxi$\mathrm{cab}$ advertising, both inside and outside-the latter in place of the former spare-tire cover in the rear-has had a limited acceptance, as has sky-writing by airplanes and sky-banners trailed by planes or

\footnotetext{
* Hotchkiss, Outline of Advertising, p. 393.
} 
dirigibles. These media have a certain virtue of novelty but by that very fact the observer's attention is focused on the method rather than the message.

\section{Mechanics and Cost of Outdoor Advertising}

With almost all forms of outdoor or poster advertising, including car cards, the advertiser is expected to furnish complete cards of "paper" ready to use. The production of the material thus becomes a factor to be figured in the total cost of the medium, just as the magazine or newspaper advertiser must consider his art and plate expense.

Able poster artists come high. Such acknowledged masters as Howard Scott, Otis. Shepard, Haddon Sundblom and Andrew Loomis were accustomed to receive from $\$ 1,000$ to $\$ 2,500$ per poster. Advertisers using several media sought to hold down this expense by sometimes using art work prepared for publications, but this was not always successful. The different treatment required for magazines and posters called for separate art work.

Lithographing costs in the postwar era ran high. One poster with which the author had first-hand acquaintance cost over $\$ 3,000$ for the paper required to cover less than 300 panels, an average of nearly $\$ 12$ apiece, while the actual space cost amounted to less than $\$ 30$ per board. Local advertisers sometimes attempt to cut down this heavy expense by using "syndicated" posters, that is, stock designs which require only a small strip across the bottom or in one corner to individualize, the main poster being a universally applicable situation. The silk-screen process is another method of reducing cost's on short runs.

In World War II the outdoor industry co-operated wholeheartedly with the Advertising Council to promote home-front victory projects. Millions of dollars in free space were given to war bonds and other Council campaigns. Many users of poster advertising donated their space to win-the-war themes. The Outdoor Advertising Association of America and its member plants have been keenly aware of the antagonism to "billboards" by garden clubs and other civic organizations, and have sought to overcome this opposition by locating posters where they would give the least offense and by joining in movements for safe driving and community betterment. 


\section{Chapter XVII}

\section{IT'S IN THE MAILBAG}

NLY a comparative few of the hundreds of thousands of businesses run ads in the national magazines or in newspapers outside their own locality, or sponsor a network radio show. Nearly every firm uses direct-mail advertising.

The name describes this most universally used medium. Any message sent directly through the mails from the advertiser to the individual or company with whom he wishes to do business, or whose good will he is anxious to maintain, may be classified as "direct mail." This includes any piece from a penny post card to the bulkiest catalogue; circulars, folders enclosed with monthly bills, house organs, blotters, form letters.

By general consent, individually written letters are not considered direct mail unless produced on a mass basis. And the giant merchandising books of such concerns as Sears Roebuck, Montgomery Ward and Alden's (Chicago Mail Order Company) are classified as "mail-order advertising"-a highly specialized field. Printed matter similar in form to that sent through the mails but distributed by other means is usually called "direct advertising"; this term covers folders and booklets handed out by salesmen, demonstrators, house-to-house delivery services and attendants at expositions.

The direct-mail advertiser is free from many of the restrictions involved in using other media. He can make his piece any size, shape, or number of colors; select any kind of paper to print it on, within the limits of availability; he can send his mailing to as many or as few names as he chooses, timing its arrival for a certain day of the week. And he can follow this mailing with others according to the number and frequency he thinks best.

Campaigns have been conducted in this medium with an outlay of only a few dollars. The majority of direct-mail efforts involve mere "pin money" compared with the cost of a single page in a national magazine. Yet because these small outlays may comprise an important part of the user's annual advertising budget, the returns from individual mailings as a rule are more carefully checked than is 
the case with general media. It is, of course, much easier to trace the amount of new business obtained by sending a letter and circular to a list of 1,000 car owners-if you happen to be running an auto-supply store or a filling station-than to isolate the exact degree of dealer and consumer reaction from a full-color page in Life, when the latter is one of a series of similar ads in a long list of national magazines.

Advocates of direct mail sometimes compare it to a rifle, shooting a single bullet straight at the target, in contrast to the "shotgun" or "scatter-shot" blast of general media. This simile would be correct if every mailing list were 100 percent accurate and every mailing piece perfectly planned, produced and timed for its purpose. These ideal conditions seldom exist. Every home, store, office, factory and service institution will receive in the course of a month many examples of poorly aimed direct mail, the result of out-of-date or improperly selected mailing lists. Even when the bullet reaches the right target, it may still prove a dud if it lacks the right copy appeal, is so cheaply prepared as to evoke distrust rather than confidence or if it arrives at the wrong time.

To guard against such waste, direct-mail experts keep a continuous check on mailing lists, insist that each piece be sufficiently attractive and impressive to do its job when delivered and, wherever possible, try out a mailing on a small part of the list before shooting the works.

\section{The Care and Feeding of Mailing Lists}

Perhaps the most satisfactory list is that of a firm's present customers. For example, an electric utility wishing to sell home appliances has a complete record of every possible purchaser in a community, except for residents in apartments or hotels where electric service is provided as part of the rent. The retail store has an excellent list in its file of active charge-account customers, although this may exclude some of its best prospects, the people who come into the store and pay cash for their purchases.

Most firms using direct mail on other than a local basis buy mailing lists from one of the several reliable houses specializing in this work. These concerns offer lists of individuals and businesses under every conceivable heading, at a cost usually below that required for compiling a special list. They are able to do this because their compilation costs are spread out over a large number of users. 


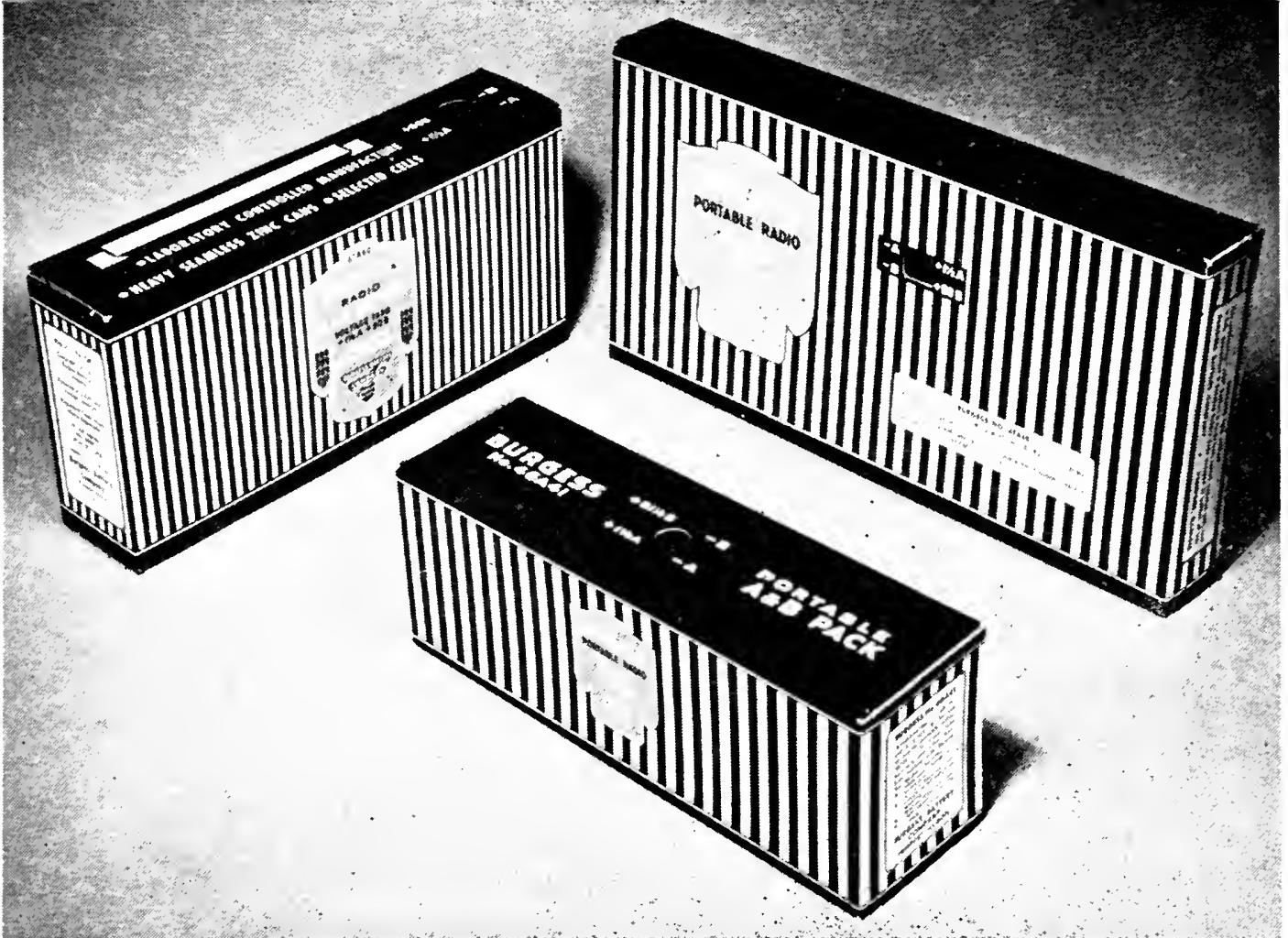

(Above) Burgess Battery Company had established the vertical black and white stripes as package identification but there was no uniformity in width of stripes.

(Below) Same batteries, redesigned. Note how brand name is spotlighted from any position, line given greater character while retaining family identity.

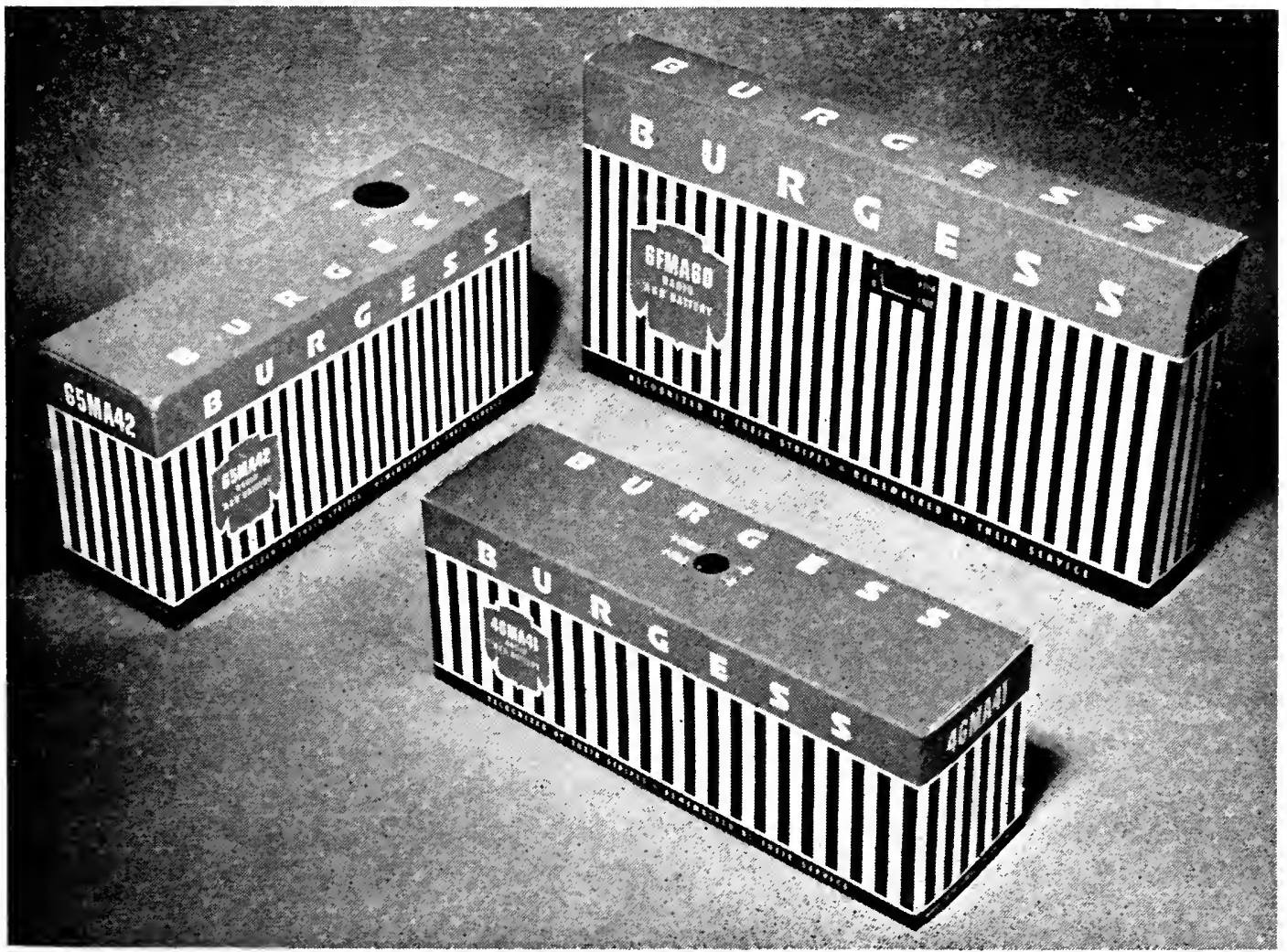

Photos courtesy Robert Sidney Dickens \& Associates

BEFORE AND AFTER IN PACKAGE REDESIGNING 

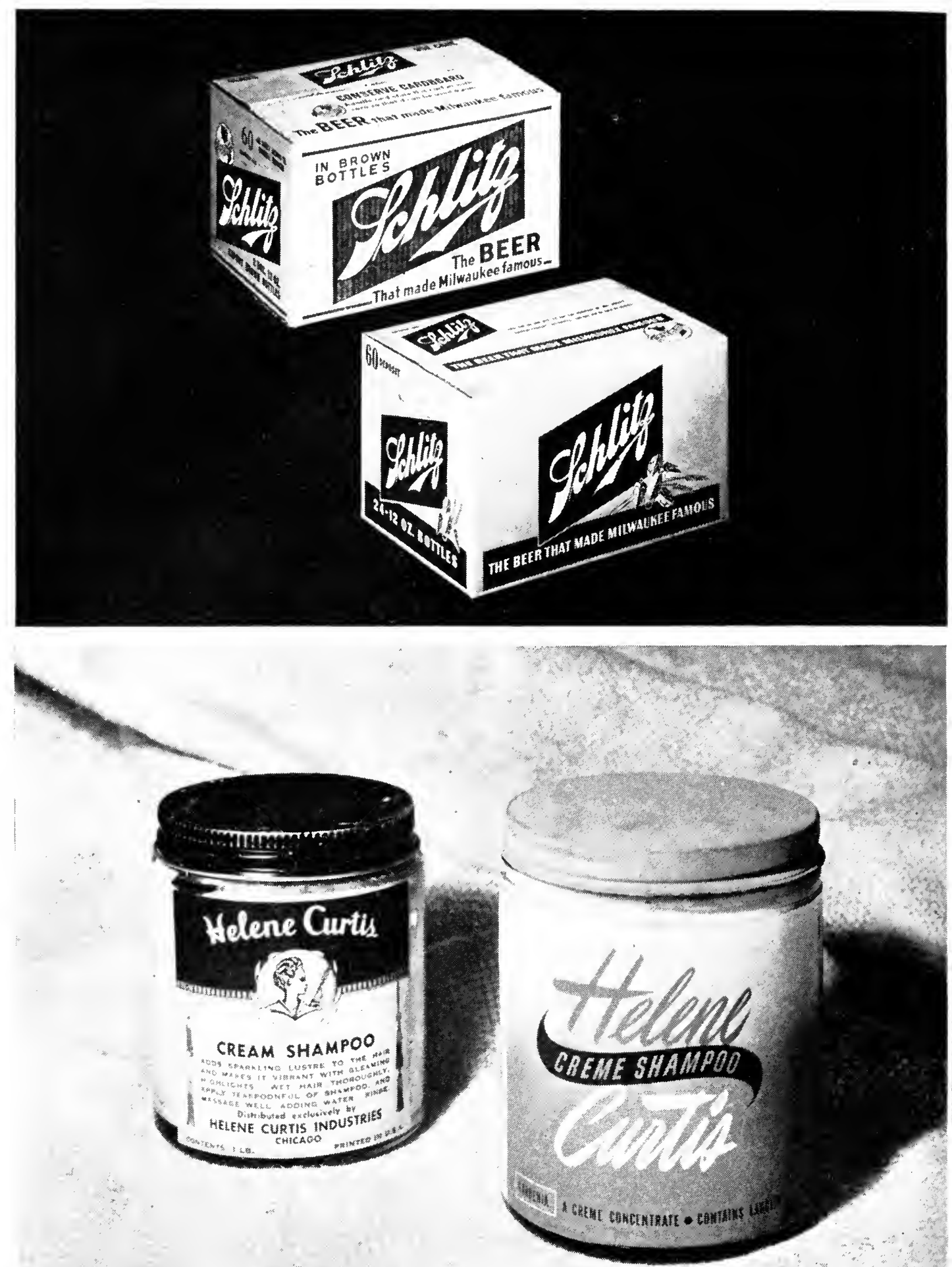

Photos courtesy Robert Sidney Dickens \& Associates

SOLVING VARIOUS PACKAGING PROBLEMS

Schlitz Becr carton gets a face lifting. Obscrve how new layout makes case look larger, more inviting.

Helene Curtis Shampoo İabel, before and after. New jar has definite quality appcal. 
List houses go to far greater lengths in keeping their records up to date than does the occasional direct-mail user. In fact, despite the many changes in addresses constantly occurring everywhere, these purchased lists carry a "postage guarantee" by which the advertiser is reimbursed for postage on all undelivered mail beyond a fixed minimum. Buckley-Dement of Chicago, for example, give a 98 percent postage guarantee on most of their lists. On a few business lists where changes are above average, they guarantee only 95 percent. For the gigantic list of automobile owners-the latest United States count, compiled by Reuben H. Donnelley Corporation, was 25,301,345-the guarantee drops to 90 percent, while for clergymen (apparently the most migratory of all groups!) the figure is down to 85 percent.

Dun and Bradstreet is authority for the statement that nearly 6,000 changes occur every business day: firms going out of business, firms starting up, changes of ownership and of address. This amounts to more than 50 percent in changes on commercial mailing lists every year and underscores the vital necessity of continuous vigilance to avoid waste. A mailing piece sent to a wrong address not only means loss in postage, cost of printed matter and mailing-room labor but also a missed opportunity to make a sale at the right address.

Mailing-list catalogues afford a fascinating glimpse of the number and variety of trades and industries in America. Browsing through the new Buckley-Dement booklet one finds such unusual lists as these:

76 manufacturers of canes and walking sticks

77 manufacturers of high chairs

166 dealers in Indian curios

34 manufacturers of teeth (artificial)

8 manufacturers of toboggans

141,770 doctors

2,200 landscape gardeners and architects (available by states, but none listed for Nevada or Wyoming!)

5 dice manufacturers

60 silk hat manufacturers

90 skin and hide brokers

151 society editors of large daily newspapers

100,000 high-salaried school officials

8 licorice manufacturers

6,930 millionaires 
Besides supplying names, some mailing-list firms render a complete direct-mail service including planning, writing, laying out, illustrating, printing, addressing and putting the finished pieces in the mail.

Some 2,500 letter shops throughout the country render economical service to advertisers who do not have their own form-letter equipment.

Postal regulations must receive thorough attention. Many mailings require more postage than would be necessary if the contents had been trimmed slightly to avoid taking a higher rate; this is particularly important when first-class mail is used since even a tiny fraction over the ounce weight sends the postage up an additional three cents, or $\$ 30$ per thousand.

Sources of mailing lists include official records for automobile and other licenses, such as marriage, hunting, fishing and dog; building permits; birth certificates; credit reports; city and telephone directories; rosters of clubs and fraternal orders; and answers to advertisements. This last named source is often one of the most productive. Experience has shown that people who buy a certain kind of article once will frequently repeat in that field. A book publisher may obtain names of buyers of technical books, for instance, by advertising his own volumes in magazines like Science o Mechanics. After he has made several mailings to this list, offering other books along related lines, he may sell the use of his list to other publishers, to trade schools, manufacturers of home workshops and so on. Or he may arrange to trade an even number of names with another advertiser, thus securing a fresh list of prospects. In bygone days one method of building lists was to run a small ad in rural papers with the heading, "Get lots of mail!" Needless to say, this produced a very poor quality of direct-mail prospects.

Uncle Sam co-operates in keeping mailing lists accurate. No doubt you have received mailings with this wording in small print on the envelope: "POSTMASTER - If this mail is undeliverable for any reason notify sender on Form 3547. Postage for notice guaranteed." If this notice does not appear on third-class matter, the advertiser may continue sending mail to places where the addressee has died, moved away or changed jobs; even where the building may have been torn down!

First-class mail is forwarded if a new address is known to the postman, but this does not correct the mailing list for future mailings. It 
does, however, eliminate the deadwood when letters are returned to the sender stamped "Moved-left no address."

\section{Forms of Direct Advertising}

To have his campaign chosen as one of the "Fifty Direct Mail Leaders of 19-" is the life ambition of many an advertising manager. And seeing this absorbing exhibit which annually makes the rounds of leading cities is a liberal education in planning and creating direct mail. Nothing else demonstrates quite so dramatically the endless versatility of this medium.

One may know that the main forms of direct advertising are letters, folders, broadsides, booklets, mailing cards, catalogues, enclosures, blotters and brochures. But each of these divisions has innumerable subdivisions.

Take for instance, Letters. A letter may be individually typed on an automatic typewriter with personalized salutation, fill-ins at various points mentioning the recipient by name, and a pen signature; produced on 100 percent rag bond, engraved stationery; sent firstclass or air mail. Or, it may be multigraphed, mimeographed, printed through a ribbon to imitate typewriting or from a line cut to imitate handwriting. It may be one page or several pages in length. The letterhead may be printed in one or more colors, on white or a tinted stock. It may be what the trade calls an "illustrated letter" with the personalized message on page 1 of a four-page folder, the two inside pages containing pictures and/or descriptive matter. It may be a miniature letter two or three inches wide; or a "jumbo letter" with enlarged printing on a sheet as big as a newspaper. It may be die-cut in some shape having to do with the product, or contain a "window" allowing the reader to look through at some special wording or illustration. Its reverse side may serve as a small poster for a dealer to mount on his window or door. It may have a built-in folder or return card. Then there are "novelty" letters with tucked in units that pop up when the fold is opened. And letters that can be refolded to serve as return envelopes.

Broadsides are the big, "flashy" mailing pieces favored by advertisers to attract attention for some particularly important sales effort. Here again there are virtually no restrictions as to size, shape, color 
or treatment, although a broadside that is overly large may defeat its own purpose by being too hard to read and handle, and if not protected by an envelope may get "beat up" in the mails.

Brochures are the elite citizens of direct advertising. Literally speaking, any printed booklet or pamphlet may be called a brochure, but in the trade the term is applied only to de luxe presentations, often with a cloth, leatherette or plastic binding. The brochure may tell a prestige-building story of the institution and its products or services but generally does not bid for immediate sales. Its purpose might be to commemorate an anniversary, to introduce a new model with a great deal of flourish or to mark the "grand opening" of a new store, factory, hotel or streamlined train. Some annual reports of corporations are so elaborate as to rate in the brochure class.

Mailing Cards have a vast assortment of uses. They can herald the impending arrival of a catalogue or brochure, or of a salesman. They may direct the recipient's attention to the company's sensational announcement on page 89 of the March 15 issue of Collier's. They may bridge the time intervals between more pretentious selling pieces. One popular use of such cards before the war was for reminding motorists that their cars needed a greasing or oil change. The major oil companies would supply attractively printed government post cards to their service-station operators leaving a space to be filled in with the mileage of the last oil or grease job. The operator was supposed to keep a record of such jobs, and if the customer did not repeat in 30 days one of the cards was to be mailed to him.

House Magazines take many forms. They may be purely intracompany, like the excellent ones issued by the different companies of the Bell System, containing personal items and photos. They may be masterpieces of conservative salesmanship, such as the famous What's New, published by Abbott Laboratories for the medical profession and a consistent award winner. Still another kind consists of a number of pages devoted to subjects of general interest, the advertiser using only the covers and perhaps a center spread for his message. William Feather of Cleveland has been supplying his own rare brand of philosophic comment for such house organs for the past 25 years; sold to one advertiser in a city (usually a printer) it has a circulation of 200,000 copies per month distributed among the clients.

Unique among house organs is Direct Advertising, a beautifully produced bimonthly published by the Paper Makers' Advertising 
Club. Each mill represented in the group supplies a two or fourpage insert demonstrating one of its own paper stocks; each issue contains a complete set of return post cards which the reader may use to obtain further information and other samples of the papers in which he is interested.

Folders and booklets are the work horses of direct mail. Their flexibility of size enables the advertiser to give all the necessary information about what he has to sell. Due to its light weight, a small folder can be inserted with a letter, invoice or other type of mailing without increasing the postage. Often it is advisable, in answering an inquiry, to make the letter brief and enclose a folder to cover the details. A company offering a number of items or services may distribute a folder describing the entire line with each sale, the idea being that if a customer likes his first purchase he may be induced to make additional purchases from the same company.

Educational institutions-for example, private schools, military academies, business colleges, trade schools and correspondence schools-rely heavily upon attractively prepared booklets to obtain enrollments. By a curious twist of terminology, booklets about general schools, colleges or professional institutes are called "catalogues" or "bulletins," while those on home-study or residential trade courses are almost invariably called "books."

Where booklets are meant to be kept for reference use, as by a purchasing agent, the tendency is to standardize on $8 \mathrm{r} / 2 \times 11$-inch size, which fits conveniently into any filing cabinet. Booklets smaller than this are apt to slip down in a file and be overlooked; larger booklets are apt to be discarded because there is no convenient place to keep them. On the other hand, consumer booklets, such as owner instruction manuals, are more acceptable when they slip into a coat pocket.

\section{Is Direct Mail Profitable?}

It's easy to drive a dyed-in-the-wool user of direct mail berserk. All you do is to imply that "nobody ever reads those circulars-they just go straight to the wastebasket." He knows nothing could be farther from the truth. Yet this is a commonly held belief.

With some media an advertiser may continue for years, not knowing the precise effect of his campaign. With direct mail, when a 
series of pieces is planned to produce inquiries, or orders, or contributions, the results can be definitely determined. The return post cards or envelopes are merely given a "key," usually a department number which is changed for each mailing, each change of list or any other variation the sender may wish to check. He can tell from past experience what percentage of his total response should be in at the end of the first week, the second week and so on. Before a month has passed he can predict approximately how much that particular mailing will cost, per inquiry or per sale.

In deciding whether a mailing is profitable, all costs must be taken into consideration-paper, printing, art work and plates, labor of addressing, enclosing and sealing, postage, a share of the overhead for record keeping and administration. If a purchased list is used, its cost is prorated for each mailing. When the responses are received, their total is divided into the over-all cost to get the cost per individual inquiry or order.

Let's assume that we have a $\$ 10$ item on which we can make a profit if our selling cost is 25 percent or less. We have a large list of prospects but before plunging we make a test on 5,000 names. Our total cost might be $\$ 40$ per thousand, or $\$ 200$. Operating on a $\$ 2.50$ margin, we need 80 orders to break even, a 1.6 percent return. Anything over this is velvet. If our test yields 100 orders, we have a safe cushion and undoubtedly will send the mailing to the entire list, confident that it will pay out.

A generous margin of extra orders above the minimum invariably suggests to the direct-mail veteran that the list can be worked again with the same offer probably, although not necessarily, with a different letter and folder. This process can be continued until returns fall below the minimum, at which point the list is said to be "worn out" on that particular proposition.

Where inquiries must first be obtained by mail and then converted into sales, also by mail, cost figuring is a bit more complex. The expense of the inquiry-producing mailing is divided by the return, to obtain cost per inquiry. Then the further expense of servicing all inquiries must be added to their total cost, and divided by the number of orders for the actual cost per order.

Generally this double process of first qualifying or "screening" the list by obtaining bona fide inquiries before going after the order is used where costly literature is needed to close the sale. A correspond- 
ence course selling for $\$ 100$ requires an attractive "book" of many pages to secure enrollments because of the keen competition in this field. The school cannot afford to send out this book with a mailing cost of 15 to 30 cents per name to cold prospects. Hence an inexpensive mailing is used to get a certain percentage of the list to request the book, and from this smaller list come the enrollments. The same strategy applies whether the product is an intangible, like technical training, or merchandise.

Once having secured the inquiry, either through advertising in other media or by direct mail and having sent the expensive booklet, that name should be cultivated by systematically timed "follow-ups" until the sale is made or a mailing fails to bring enough response to pay its way. With certain products, the first mailing including the booklet may close say 5 percent of the inquiries; before the followup is finished six months or a year later, an additional five or more may have been sold. So failing to follow inquiries thoroughly would have resulted in missing half of the potential business.

What percentage of response can be expected from direct mail? For some purposes a return of one or two percent might be profitable. In other instances, 25 percent might be disappointing. Here are a few case histories from The Reporter of Direct Mail Advertising to indicate what sometimes happens:

The Shelby Cycle Company, Shelby, Ohio, mailed one letter to 1,200 retail merchants selling bicycles. Two hundred and sixty-four dealers $(22 \%)$ replied, purchased 1,005 bicycles for a total of $\$ 19,044.65$.

A New York department store mailed 5,000 letters to inactive accounts. Two hundred and seventy-five $(5.05 \%)$ reopened and produced $\$ 28,097$ sales.

Saw Bill Lodge, Tofte, Minn., sent a series of sixteen printed government post cards to 1,200 old guests and selected names. Received $844(70.3 \%)$ directly traceable inquiries.

Central Manufacturers' Mutual Insurance Co., Van Wert, Ohio, mailed a series of four letters to 55,074 fire insurance prospects and received a total of $11,750(21.3 \%)$ inquiries which were turned over to local agents. One letter in the series produced $9.87 \%$.

Levitt-Ferguson Co. sent 8,000 post-card folders to druggists, advertising a $\$ 22$ pharmaceutical dispensing scale. Results: 320 (4\%) orders totaling 7,040 . 
An Air Express questionnaire (8 pages) with a personalized sales letter to 3,742 executives in heavy industries brought 1,494 (40\%) replies.

These returns prove that direct mail can and does pay under proper conditions. It has its share of waste. So does every other form of human activity, from running a government to raising a family. But its standards have been steadily raised over the years, through the leadership of such men as Homer Buckley, first president of the DMAA, Charles R. Wiers, Leonard Raymond, Ed Mayer, Frank Egner, the late John Howie Wright, Henry Hoke, Jules Paglin and J. C. Aspley. It has helped many types of business in many ways. Let those who would legislate against direct mail realize that it is one of the chief hopes of the small businessman in his competition with "big business."

Advertising men who cut their eyeteeth in the field of direct advertising are apt to be very realistic about all media. They recognize the limitations in applying mail-selling tactics to other forms of advertising; but they know that the insistence of direct-mail users on verifying results wherever possible, on pretesting, on keeping the human approach, on knowing who their customers are and maintaining contact with them has had a wholesome influence throughout the whole advertising business. 


\section{Chapter XVIII}

\section{OTHER MEDIA-LARGE AND SMALL}

TEWSPAPERS, consumer magazines, radio, outdoor and direct mail are sometimes considered the "major" media of advertis1 ing. But they are by no means the only ones. Over the years,
innumerable other vehicles have been tried out, and those that demonstrated their efficiency, their ability to accomplish specific selling or educational tasks, have thrived. In this chapter some of the many advertising media not previously discussed will be examined briefly.

\section{Farm Papers}

Agricultural magazines were among the earliest forms of periodicals. Through the years they have retained their hold on farm readers. The June 1947 Standard Rate G Data Service listed 65 national, 59 sectional and 92 state farm papers.

Largest in point of circulation were Farm Journal, with 2,626,228, Country Gentleman with 2,176,418, Capper's Farmer with 1,353,411, Successful Farming with 1,205,912, the Midwest Farm Paper Unit with 1,204,723, Nation's Agriculture (published by the American Farm Bureau Federation) with 1,075,417, and Progressive Farmer with $1,002,366$ copies per issue.

Among the national magazines, Farm Journal (and Farmer's Wife) led in circulation and in line rate $(\$ 14$ per line or $\$ 196$ per column inch). It surpassed all others in number of pages of advertising carried in a single issue in June, 1947, with 84.6 pages, for which it grossed over $\$ 510,000$. The upsurge of the farm field is shown by the fact that this was nearly twice the total advertising revenue for the magazine for the year 1935 .

Founded in 1877, Farm Journal had an initial circulation of 25,000. While not the oldest, it has outlasted many other national publications to reach its present eminence. It has an "all-family" editorial policy and does not confine itself to purely farm material, as is shown by this study of its features: 
National Affairs

General Interest $\ldots \ldots \ldots \ldots \ldots \ldots \ldots \ldots \ldots \ldots \ldots \ldots . \ldots \ldots \ldots \ldots$

Fiction $\ldots \ldots \ldots \ldots \ldots \ldots \ldots \ldots \ldots, \ldots .3$

Farm Management........................ 7.0

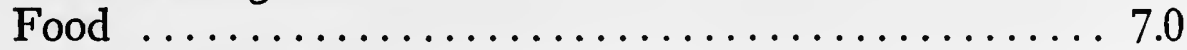

Livestock and Poultry...................... 6.3

Crops, Gardening, General Farming............... 6.0

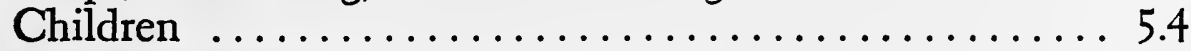

Wearing Apparel $\ldots \ldots \ldots \ldots \ldots \ldots \ldots \ldots \ldots \ldots \ldots . .4 .1$

Home Furnishings $\ldots \ldots \ldots \ldots \ldots \ldots \ldots \ldots \ldots . . .6$

Business and Industry....................... 3.7

Cultural Interests $\ldots \ldots \ldots \ldots \ldots \ldots \ldots \ldots \ldots \ldots \ldots . \ldots . . .6$

Farm Equipment $\ldots \ldots \ldots \ldots \ldots \ldots \ldots \ldots \ldots \ldots . \ldots .6 . \ldots$

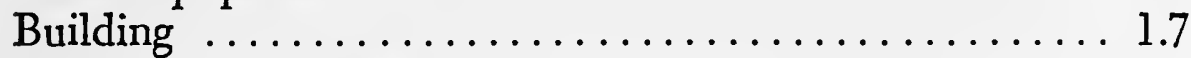

Travel and Transportation..................... 1.6

Amusements and Sports...................... 1.3

Beauty $\ldots \ldots \ldots \ldots \ldots \ldots \ldots \ldots \ldots \ldots \ldots \ldots \ldots \ldots \ldots . .3$

Health $\ldots \ldots \ldots \ldots \ldots \ldots \ldots \ldots \ldots \ldots \ldots \ldots, 1.3$

Miscellaneous ............................... 5.4

The timeliness of editorial features was stressed by its announced "four day writer-to-reader service." Over 88 percent of its circulation was to R.F.D. addresses or post offices in towns under 2,500. Responsiveness of readers was shown by the receipt of over 500,000 letters per year from subscribers exdressing opinions or asking for information.

Country Gentleman, published by Curtis Publishing Company, is a weekly magazine of Saturday Evening Post page size and general format. It has the highest page rate of any farm magazine, $\$ 6,500$, and carries the advertising of many makers of general consumer products as well as farm equipment and supplies. Like other farm papers, "Country Gent" includes several pages of classified ads on livestock, poultry, rabbits, dogs and other subjects. This type of advertising is offered at $\$ 6.50$ per line with a minimum of five lines (payable in advance) whereas the general rate is $\$ 10.25$ per line.

Ads in farm papers by national advertisers are often "slanted" to appeal to that market. Thus General Electric in a 1947 display to farm readers headlined its copy, "Look at the places GE Lamps can help make farming more profitable," with illustrations showing a GE reflector lamp installed in a haymow, a projector lamp in a barn- 
yard, a fluorescent lamp in a kitchen, a germicidal lamp in a hen house and a 100-watt bulb in a feed room. Each caption not only described the particular lamp but also gave its list price. Ads for Ford, Dodge, Willys, Chevrolet and other trucks showed the machines in actual farm use. A typical Kelvinator ad featured the 9-cubic-foot refrigerator, "Built for Farm Living." Studebaker showed a passenger car against a background of the Pride Brothers' farm in Winnebago County, Wisconsin, with a secondary picture of the two men, both Studebaker owners since 1925.

Some farm papers, while national in that they have circulation in every part of the country, tend to concentrate in certain areas. Thus Capper's Farmer, with 1,300,000, has 570,000 in the west North Central Region and 492,000 in the east North Central-the area from Ohio and Michigan to Kansas and the Dakotas. Successful Farming, a Meredith publication out of Des Moines, Iowa, likewise spots nearly 80 percent of its $1,200,000$ in this region. The Progressive Farmer of Birmingham, Alabama, is frankly regional, with all but 8,000 of its $1,000,000$ circulation spread through the South from Virginia to Texas. This last-named magazine is published in five editions with separate editorial offices to maintain intimate contact in each region.

Farmers represent a market of increasing interest to national advertisers. It is generally assumed that because they raise so much produce farmers buy little food in stores. A survey by Midwest Farm Paper Unit (Nebraska Farmer, Prairie Farmer, The Farmer, Wallace's Farmer $\sigma$ Iowa Homestead and Wisconsin Agriculturist $\sigma$ Farmer) selecting typical farm and city families showed that while in 1945 the average city family spent more all told for food, in packaged goods the farm family ran nearly 50 percent ahead of the city sample. And expenditures for electrical equipment, plumbing, heating and other durable goods are increasing more rapidly than in urban areas. In a 1946 survey of over 3,000 ranch homes, Western Livestock Journal reported that 97 percent owned sinks, 91 percent refrigerators, 100 percent radios, 87 percent bathtubs, 64 percent pianos and 12 percent movie projectors. Of the ranch wives, 43 percent said they had their hair done in a beauty parlor and 64 percent used nail polish; all but 3 percent shopped in retail stores.

The preference of the farmer for buying "in town" is stressed by Country Gentleman, whose market analysts state that 87 percent of 
all U. S. farms are within a 25 -mile radius of one or more towns of 2,500 and over. Because farmers spend less for housing, taxes and perishable goods than their city cousins while earning a nearly comparable income, it is safe to assume that they have more available funds for advertised merchandise. The farm papers, edited to appeal to this vast rural market of over $7,000,000$ agricultural families, offer the logical medium for advertisers. In a study by the Association of National Advertisers as to which source gave farmers the most practical help, farm papers and farm magazines ran first, radio second, state and government bulletins third, newspapers fourth and manufacturers' literature fifth.

The 1946 Printers' Ink estimate of farm-paper advertising expenditures was $\$ 35,800,000$, up 11 percent over the previous year.

\section{Export Advertising}

The advertiser wishing to sell in other countries has several types of media at his command.

First comes the "export magazine," produced in the United States and edited for businessmen in other countries wishing to deal in American goods. Some 26 firms in this country publish 54 such magazines with a combined circulation of 458,000 , according to Business Publishers International Corporation. Annually they carry about 25,000 pages of advertising. A checkup by BPIC showed that in 1947 one or more of these magazines went to 267 cities in Mexico, 395 cities in Argentina, 257 in South Africa, 425 in Brazil and over 200 in Sweden. There were even copies penetrating "behind the iron curtain."

Some of these industrial magazines are published in foreign languages, such as El Automovil Americano, printed entirely in Spanish. Established in 1917, this automobile trade publication has some 15,000 circulation in Latin America. An annual Overseas Buyers' Guide for Automotive Distributors is also issued in Spanish. Advertisers may supply copy in English to be translated into Spanish for use in the magazine. McGraw-Hill, the publishers, also have a translation service charging 45 cents per 100 words for rendering foreign commercial correspondence into English, and 50 cents per 100 words to translate English correspondence into Spanish, Portuguese or French.

In addition to business papers, American-made consumer maga- 
zines are active in invading foreign countries. True Story launched its international editions in 1946; one year later it had 10 editions going, with 1,000,000 copies per issue, a revival of its prewar activity in this field which reached a peak of 75,000,000 magazines per year. The International True Story Group, including True Romance and Photoplay, is written in the language of the country, edited to refer to the people of that country and backed by a prominent local publisher.

Cine-Mundial, a movie-fan magazine printed in Spanish, one of the oldest export consumer magazines, was established in 1916. Selling for $\$ 2.00$ per year, it features photos and stories about movie stars much after the fashion of American periodicals of this same type.

Aimed at what it calls "the agro-industrial market in every Spanish and Portuguese-speaking country of the world," La Hacienda Company of New York publishes twin monthlies-La Hacienda (Spanish) and A Fazenda (Portuguese) with a total circulation of 25,000. The Spanish edition was established in 1905 and has maintained uninterrupted publication ever since. It reaches dealers in machinery, electrical equipment, automobiles, trucks, aircraft and luxury consumer goods. The publishers announce that they perform "valuable liaison work" between readers and American manufacturers.

Veteran among business publications reaching the foreign market is American Exporter, issued since 1877. Some 31,000 free circulation is about equally divided between the English and Spanish editions. An appraisal of postwar export markets by this publication indicated an average annual business in foreign trade of from $\$ 7,000$,000,000 to $\$ 8,000,000,000$ - a field well worth cultivating.

Circulation leader of U. S. magazines going to foreign markets is Reader's Digest, which distributed some 2,000,000 copies of the pocket-sized periodical each month. Selecciones del Reader's Digest, the Spanish edition, launched in 1940, in 1947 had approximately half of the total. A black-and-white page cost $\$ 2,100$ in 1947, a fourcolor page, $\$ 3,150$. Early advertisers included such familiar names as Eastman Kodak, United Fruit, Pan American-Grace, Gillette, Ipana, Philco. Other editions of the magazine, all carrying advertising, were issued in Arabic, Danish, Finnish, Norwegian, Portuguese, French (separate editions for Canada and for Belgium, France, Switzerland and the French colonies), Swedish and Japanese. A separate edition is also published in Australia. 
Time in 1941 invaded the overseas market with an edition printed on lightweight paper and delivered by air express, to all 20 nations south of the Rio Grande. A Canadian edition was started in 1943, followed by the Atlantic Overseas and Pacific Overseas editions after the war, all in English. Life International was another postwar venture of this publisher.

This country's largest export market, Canada, is well covered by all media. Many U. S. magazines circulate widely north of the border. The Saturday Evening Post, for example, showed a Canadian circulation of 156,085 in its December 1946 ABC statement; Life reported 187,669. Among women's service magazines, Ladies' Home Journal had over 233,000-including 73 in Yukon and 32 in the Northwest Territories.

Canada has over thirty general magazines of its own. Leaders are National Home Monthly with 308,460, published at Winnipeg; Maclean's, a semimonthly, which had 316,139 net paid for its December 15,1946 , issue; Chatelaine, a woman's magazine, with 286,874; and Canadian Home Journal, 281,656. There are approximately 100 Canadian daily newspapers, including a number printed in French of which La Presse of Montreal is perhaps the best known. Canada has over 150 business papers; the French-speaking population is represented here also with such publications as La Revue Municipale and L'Epicier. In addition, there are more than 115 Canadian radio stations and some 17 Canadian farm papers. All of these media carry advertising from U. S. manufacturers.

Before World War II several leading British newspapers had advertising solicitors in this country, as did the Times of India, the Tokyo Advertiser, and other foreign media. Most space in overseas publications, however, was placed either through American advertising agencies with branches abroad, or through agencies specializing in foreign markets. Among the latter were Irwin Vladimir \& Company of New York, handling overseas campaigns for such firms as McKesson \& Robbins, Pabst, Mennen, Waterman, Seagram and Simoniz; Robert Otto \& Associates-Campbell, General Motors, DuPont, Old Gold, Alka-Seltzer, U. S. Rubber Export Co. and others; Export Advertising Agency of Chicago headed by R. C. Lebret with many a "blue-chip" account, and J. Roland Kay, Inc., of the same city.

Advertising alone will not, of course, build American export trade on a stable basis. Factors of politics, international agreements, tariff 
walls, racial antagonism, all play a part. Nevertheless innumerable evidences exist that the peoples of other countries are influenced by ads of American-made products. They may not always be able to buy, but the desire has been created. That is a long stride in the direction of international co-operation.

\section{Foreign Language Markets}

Mention has already been made of French newspapers and magazines in Canada, where bilingualism is officially recognized in several provinces. The extent of the foreign-speaking market in the United States, little recognized by the average citizen, is a matter of interest to the admen.

In New York City alone there are newspapers published in Yiddish, German, Polish, Norwegian, Spanish and Italian. Chicago has its German, Swedish, Polish and Jewish papers. Scranton has a Slovak semiweekly; Los Angeles and San Antonio, Spanish dailies. Largest in circulation, the Jewish Daily Forward, with 113,194 Sunday ABC (1946), has local editions in Philadelphia, Newark, Boston and Chicago, besides the New York edition. Rotogravure as well as run-of-paper advertising is available. La Prensa is the name of the Spanish-language dailies in New York, Los Angeles and San Antonio, all ranging between 10,000 and 20,000 copies per issue.

The New York Jewish newspapers are represented by Joseph Jacobs Organization. Mr. Jacobs found that the Jewish population of 2,500,000 in Greater New York accounted for one-third of all retail purchases, operated 78 percent of the groceries and 70 percent of the drug outlets. By advertising directed at this group, a national advertiser could "crack" the desirable Manhattan territory if his product and appeal were right. Jacobs' counsel and advertising in his papers have aided a number of manufacturers to obtain a foothold in Hebrew areas.

\section{"Playbill" Advertising}

People who go to the theater represent a choice market for luxury products. What better way to reach them than with the programs they read while waiting for the curtain to go up? That is the basis upon which modern theater-program advertising has been promoted. 
A Daniel Starch survey revealed that over half of the theater audience was seated and engrossed in program reading 15 minutes before curtain time, and 87 percent of those interviewed confessed to reading the advertisements. Moreover, 55 percent read the program during first intermission, 37 percent during second intermission, and 66 percent took their programs home to read later. In view of this longevity, the New York theater page rate of $\$ 30$ per house per week, based on an average attendance of 7,000 , with discounts ranging up to 15 percent for 1,200 "theater weeks," did not seem excessive.

\section{Commercial Films}

Advertising by means of films is as old as the movies, and this medium received a tremendous impetus during the war. The armed services used films extensively, not only for training, but in propaganda and "documentary" pictures aimed at inspiring war workers to greater productivity. Business saw what such films could do and many companies decided to try similar ventures. Moreover, production of film and projectors was greatly expanded by war needs. Although film was still scarce in mid-1947, producers were already pushing commercial applications. Tide estimated that 5,000 firms would use commercial films in 1947 in some form, where only 600 did so in 1941.*

"Minute Movies" have become a national medium under the guidance of General Screen Advertising Company and other selling and producing organizations. About 12,000 out of the nation's 18,000 movie houses will accept these vignettes, which run from 45 to 90 seconds and cost the national advertiser from $\$ 3$ to $\$ 5$ per 1,000 circulation per week. Screenings are often arranged on a basis of every third week, the advertiser supplying four separate films which are rotated among the theaters in the selected territory for a threemonth campaign, corresponding roughly to a 13-week radio "cycle."

Production quality of "Minute Movies" is necessarily good, since the little films must compete with the Hollywood offerings on the same bill. Many are in Cinecolor. Recall tests show that most people remember many details of the shorts for a considerable length of time. Products which can be demonstrated in use-such as foods,

* "Commercial Films-1947 Status," Tide, January 3, 1947, p. 17. By permission of Tide. 
cleansers, paints-can use them effectively. Cereals, soft drinks, appliances and automobiles are other types of merchandise using the medium. Some of the big first-run houses and chains do not accept Minute Movies, but schedules can be arranged to deliver a high proportion of any market. The films are popular with dealers and salesmen.

One-reel sponsored shorts are accepted by some 8,000-9,000 U. S. theaters. Such films must have a high percentage of noncommercial entertainment and cannot do the direct selling job of the Minute Movie.

Movies are being used for selling nontheatrical audiences too. A group of selected prospects will be brought together to see a film, with a sales solicitation following. Examples: farmers (equipment and farm material); executives and managers (industrial equipment); home owners (insulation, appliances). Training films-for instance, showing retailers common errors in their methods, leading to a solicitation for store equipment-are coming into greater use.*

The educational or institutional film, circulated to clubs, schools, colleges, farm groups, YMCA's and the like, has already been mentioned. Among recent films of this type were:

"Men of Gloucester," completed in December 1946 for Ford by Transfilm, Inc., first in a series of color films promoting travel in the United States. The series was to contain no direct selling for Ford cars.

"Prospecting for Petroleum," animated cartoon for Shell produced by George Pal of Hollywood (Puppetoons), also first of a series, this one to tell the whole story of oil.

"More Power to America," a series by General Electric, designed to help the company's dealers promote their products.

A widely viewed institutional film is "Unfinished Rainbows," a four-reel Technicolor production by Wilding, sponsored by Aluminum Company of America and starring Alan Ladd of the movies. It is estimated that some 17,000,000 people have seen either the full-length version or a one-reel short for theatrical distribution. It is shown to

* New Horizons for Business Films (Association of National Advertisers, 1946), pp. 3-4. By permission of the Association of National Advertisers. 
new employees as an indoctrination film. Although made several years ago, "Unfinished Rainbows" is still in demand for school and club showings. *

\section{Premiums and Novelties}

"Something for nothing" has a universal appeal. Starting with that premise, the purveyors of advertising premiums and novelties have built a business estimated at well over $\$ 100,000,000$ annually.

The theory of the advertising novelty is simple: give an article which has some utility or amusement value, making it the vehicle for carrying an advertising message. Commonest and most popular give-away is, of course, the match book, used by many thousands of advertisers both local and national.

Two of the largest producers of match-cover ads, Match Corporation of America and the Diamond Match Company, have developed this item into an important medium. This has been done by stepping up the quality of design and printing and by carefully controlling distribution. Nowadays an advertiser can buy match-cover circulation in the precise markets he selects and even, to a limited extent, the quality of that circulation. If he wishes to reach "free-and-easy spenders" his matches might be dispensed among night club and tavern patrons; should his market be the wage earner, the allotments could be placed through stores and restaurants favored by this class.

A 1946 presentation by Diamond Match gives its rates to advertisers. The base price at that time was $\$ 1.10$ per thousand covers on a minimum of two million. From there the cost came down to a low of 40 cents per thousand for 100 million. The advertiser or his agency merely supplied the match-cover art work-and Diamond maintained its own art staff in case the client wanted assistance on a design. All plate-making, printing and distribution was taken care of by the match company.

Most match books are printed only on the outside. Some advertisers, however, have used the inside surface in various ways, such as a coupon offering a free sample, a helpful booklet, or a premium. Finance companies sometimes print a table of loans and monthly repayments there. Book publishers, especially in the trade or technical field, have sought direct orders on a "pay postman, money back

* "Commercial Films-1947 Status" (Tide, January 3, 1947). 
if not satisfied" offer. A variant of the conventional match block of 20 slender matches is the block of 10 double-width matches containing a design or message; sometimes these super-matches are bottle shaped to simulate a product that comes in such a container.

"Billboard" match books, twice the usual width, give an area permitting a bold advertising display. They are favorites with owners of radio stations and other media, being sent by the box to agency space buyers and advertisers in no inconsiderable numbers.

Another popular form of reminder advertising is the calendar. Costing from a few pennies to several dollars each, the calendar appeals to many advertisers because it may remain on display for a full year, serving as a constant vehicle for the company's name and sales message. Some calendars are elaborate affairs with a full-color reproduction or a painting by some well-known artist for every month of the year. Others may have only one illustration or merely a bold type display.

Most national advertisers use exclusive calendar art. The local coal dealer or laundry owner, who can't afford such an expense, may buy a few hundred or thousand syndicated calendars from one of the big houses like Gerlach-Barklow or Brown \& Bigelow, making his selection from the array offered in the salesman's portfolio: pictures of babies, dogs, undraped beauties, landscapes, sports, humorous situations, and other "sure-fire" appeals. Calendar salesmen start the day after Christmas to take orders for the line a full year in advance.

Brown \& Bigelow of St. Paul features calendars by Norman Rockwell, Maxfield Parrish, Rolf Armstrong, Gil Elvgren and other famous artists, as well as cartoon and photographic calendars. This company, founded in 1896, did $\$ 12,000$ in business the first year; in 1946 , its volume reached $\$ 30,000,000$. Besides calendars it offers many other types of what it calls "Remembrance Advertising" (a trade-marked name): desk sets, memorandum pads, playing cards, key cases, blotters, pens, pencils, many more. It sells 30,000,000 calendars alone, has a sales force of 800 men. It is one of the world's largest playing-card manufacturers, although selling no cards at retail.

The Advertising Specialty National Association with 206 members reported some $\$ 72,000,000$ in novelties for 1946. Many of the items appeal to children. These include balloons, games, tricks, puzzles, noisemakers, poster stamps, "beanie" hats, and innumerable sizes of buttons. 
The distinction between advertising novelties and premiums is not clearly drawn; usually the former term refers to an item given away for advertising purposes and carrying the advertiser's name or slogan, while the latter denotes an article either given by the advertiser as a bonus with a purchase or in return for some effort, or sold at a reduced price to users of a product. The premium does not, as a rule, carry any advertising.

One of the largest users of premiums is General Foods. W. Parlin Lillard, staff division manager, in an address before the Premium Advertising Association of America in May 1947, described the General Foods strategy as "Push-Pull Merchandising-pushing merchandise into trade channels and onto the shelves, and pulling consumers into the stores." He mentioned these ways his company employs premiums:

1. As incentives for jobbers' salesmen. At certain times, points are given for orders on specified products. When the salesman has acquired a sufficient number of points, he can have his choice of many premiums shown in a prize book.

2. Coupons given to buyers for restaurants, drugstores, hospitals, colleges, even jails, with selection of premiums as shown in an "Institution Premium Book."

3. Coupons to consumers who buy products of the Jersey Cereal Company, a G-F subsidiary. These are redeemable by mail or through premium stores maintained by Colgate-Palmolive-Peet, who have a similar coupon plan on Octagon and Kirkman Soaps.

4. Paper cutouts with G-F packages, such as circus animals, supplied one with each box of Post's cereals. Additional toys would be sent to youngsters mailing in box tops, eventually giving them a full "circus." This particular offer was featured in national magazines and on the radio.

5. Consumer contests with merchandise prizes, arranged by salesmen to be run by grocers in their territory.

6. "Self-liquidating" premium promotions. One deal offered a silverplated knife and fork for a Grape-Nuts Wheat Meal box top and 75 cents. The consumer can get a complete set by purchasing additional boxes and sending in 75 cents for each pair. This offer might run several months or more, being featured in ads, radio shows, dealer cards, and on packages. In this case it would be known as a "continuing" promotion, to differentiate it from a "one-shot" or limited time offer. 
7. Point-of-purchase premiums. The gift could be in the product package, banded to it with tape, or displayed alongside. One such G-F offer in 1947 was on Maxwell House Tea-an iced tea glass free with each one-fourth pound of tea. The glasses were shipped to the dealer in the same carton with the packages of tea, the carton opening up to form a display stand for the deal.*

Premiums which require a consumer to buy a product and mail in proof of purchase (box top, label, sales slip or coupon) in order to obtain the article are sometimes called "mail-aways." Some of the popular items in this category as shown by public response to innumerable offers of this kind, are: novelty jewelry, birthstone rings, compacts, garden seeds, kitchen shears, paring knives, recipe books, greeting cards, cereal bowls, snapshot enlargements. Premiums appealing strongly to youngsters are: trick rings of various kinds, club memberships, books of magic and magic tricks, lead pencils imprinted with youngster's name, model airplanes or cutouts (particularly during the war). Articles which have the recipient's name or initials in gold are also likely to be productive.

According to F. Harvey Morse of Reuben H. Donnelley Corporation, which handles mailing of many premiums for advertisers, "A popular premium is one which satisfies a want which cannot otherwise be satisfied or which does so at a genuine bargain price. When either of these conditions exists, women will send for the premium by the hundreds of thousands."* Mr. Morse also declares that for a promotion to be successful, the advertiser must sell the premium just as hard as the product. That is why in many ads and radio shows where the manufacturer is offering a premium, he will devote the lion's share of his message to describing the desirability and big value of the premium and tell about his own product only secondarily.

\section{Sampling and Couponing}

Closely associated with premium offers as a "hard-hitting" marketing device is the use of samples and coupon distribution. This technique was virtually abandoned during World War II because merchandise shortages enabled any manufacturer to sell all he could make. As goods became plentiful and competitive selling returned, so did various sampling methods.

* Premium. Practice, June 1947, pp. 20-21. By permission of Premium Practice.

** Ibid.,.p. 22. 
It may surprise the layman to learn that more sampling is done by products with which the public is already familiar than with brandnew products. Among products using sampling campaigns in 1946 were Bab-O, Baker's Cocoa, Calox Tooth Powder, Cheerio, as well as various items made by Colgate-Palmolive, Seeman Brothers and Standard Brands. Prewar, Procter \& Gamble, Lever Bros. and Kellogg were perhaps the largest of all samplers. They employed the device not only to introduce new products-for instance, Lever's Swan Soap, P \& G's Duz, Teel, Dreft-but also to revive interest in a universally known item whose sales might have declined in a given market because of aggressive competition.

Sampling is done in several ways, the commonest being by means of a coupon which, when presented at a store, will be good for 5 cents, 10 cents or more toward the purchase of a product, or will entitle the holder to a second package free upon buying the first package. Sometimes full-sized units are distributed, at other times miniature packages. Wrigley, a steady user of samples before the war, had one card containing single sticks of three different Wrigley Gums.

The nomenclature of sampling is picturesque. The surest method is the "ring, wait and hand-in." The carrier goes from door to door with a supply of samples or coupons, rings each bell, waits for a reply, and presents the material, with or without a sales phrase as desired. This service is most effective when performed by companies specializing in the field, like Advertising Distributors of America and Reuben H. Donnelley Corporation. It is proof against pilferage which sometimes occurs with other methods, particularly if a gang of youngsters discovers what is going on and starts following the carrier. The other methods are "straight leave," in which the material is wedged into the door-jamb or, if possible, slid under the door; "leave and ring," and "hand-to-hand," the last generally performed by girls on downtown streets or around factories. Western Union before the war was an important factor in "bulk distribution," handling circulars, coupons and actual samples, and was expected to return to the field in 1947. There are also many local concerns in the field. The matter of reliability is important to the advertiser. Reputable distribution firms train the carriers and work them under experienced supervisors. Many of the carriers are uniformed, and in some cities are unionized.*

*Advertising Age, October 26, 1946, pp. 18-20. 


\section{Trade and Dealer Publications}

In the chapter on "The Industrial Advertiser," business papers were discussed at length, particularly those of a technical nature. There is another class of business paper very important to national advertisers-the periodical edited for retail dealers in the grocery, drug, hardware, dry goods, home furnishings and syndicate store field. These are the real "trade papers" because the bulk of their circulation comes from the retail trade.

In the primitive days of advertising, national advertisers operated on the basis of developing "consumer demand" which would compel dealers to handle certain popular lines or lose business. Then it became apparent that the retailer exercised more power than he'd been given credit for, and could, if he wished, switch the purchaser who asked for an advertised brand over to "something just as good." From this came the present doctrine of "consumer acceptance"-meaning that a buyer would accept a nationally advertised brand without sales talk if the local retailer chose to offer it. Net result was an immediate and persistent wooing of the local grocer, druggist or hardware store proprietor as the man who held the fate of advertised brands in his hands.

Advertising men began to study the dealer publications-to learn which he read, and why. Special campaigns were planned for dealers. In recent years it has become accepted practice to announce any consumer program first to the retail trade, and to follow through with advertising to retailers that would tell them how to "cash in" on the consumer campaign. Manufacturers of equipment and supplies use retail publications to advertise their products, but they are outnumbered by the consumer goods firms.

Largest group of trade papers is in the grocery field, which in 1947 had some 25 national and 45 regional or local publications. Many of the latter were official organs of state, sectional or city associations of retail grocers. The National Association of Retail Grocers (NARGUS) publishes National Grocers Bulletin, with over 50,000 membership subscriptions. Chain Store Age, which issues a number of editions for various fields, has some 30,000 circulation with its Grocery Executives and Grocery Managers combination. This is net paid. In the controlled (free) distribution group, Progressive Grocer 
averaged 78,112 copies monthly in the last six months of 1946, and Food Topics, a new tabloid-newspaper-style biweekly, reported a 92,500 average.

Supermarkets are the object of much attention by trade publications. Although numerically less than 3 percent of the total food outlets, according to Super Market Merchandising, these giant stores did over 40 percent of the nation's retail food business. To get into this classification, a grocery must gross a minimum of $\$ 250,000$ yearly. But the volume need not necessarily be confined to the food field; supermarkets sell something like 7 percent of the country's drugs and 15 percent of the wines. Pioneer in the field, Super Market Merchandising, was started in 1936, now has over 10,000 net paid. Self-Service Grocer had about the same circulation in 1947.

Newspaper-type periodicals are popular for regional coverage. Grocer-Graphic in New York, Food Mart News in Chicago and Food Trade News in Philadelphia reach over 12,000 grocers apiece every other week.

To illustrate the importance of trade papers to national advertisers, an analysis of the June 1947 National Grocers Bulletin showed 68 food manufacturers and processors advertising in the issue as compared to 23 makers of grocery equipment or supplies. Of the 68 food companies, 40 featured or mentioned their consumer advertising. In addition, seven associations like Florida Citrus Commission, American Meat Institute, Ice Cream Manufacturers, and Ice Industries, as well as two consumer magazines, Life and Saturday Evening Post, were in the ad columns. Swift \& Company used a four-page full-color insert built around the theme, "The Swift Name Helps YOU Sell." One of the most interesting ads was a spread for Lever Brothers featuring a $9 \times 12$ booklet, "Grocery Stores around the World," and a check list of subjects on which the retailer could obtain information and help from the company's Special Service Plan Department. This check list was printed on blanks carried by each Lever Brothers salesman and included: store plans and layouts, selling displays, signs and price tickets, clerk training, stock control, produce merchandising and other phases of store operation.

In fields related to groceries, trade papers also abound. The new and fast-growing frozen foods industry had no less than 11, mostly postwar; first in the field, Quick Frozen Foods, was established in 1938. 
Trade-paper advertising rates are low in comparison with consumer magazines. In 1947, National Grocers Bulletin charged $\$ 400$ per page, $\$ 350$ on a 12-time basis. Chain Store Age asked $\$ 485$ for a single page, $\$ 420$ each for 12 pages a year. Food Topics with a $10 \times 14$ page size, had the highest rate, $\$ 980$ for one page, scaling down to $\$ 747.25$ each for 52 pages. Progressive Grocer was priced at $\$ 430$ per page on a one-time basis, down to $\$ 345$ apiece for 48 pages; its pocket size (4r/4 $\times 7 \mathrm{r} / 4$ inches) made it the most costly per square inch of all national food papers. To obtain greater impact, many advertisers in Progressive Grocer took two or more pages.' The June 1947 issue containeci no less than 27 double spreads.

\section{Telephone Directory Advertising}

"An inch or two of space in the telephone classified directory will cost little and will serve to keep your business name before the public. Many persons pay little attention to the names of stores and shops and must refer to the classified directory for phone numbers and addresses." This comment is not, as one might suspect, taken from a Bell System advertisement, but from a U. S. Department of Commerce bulletin, "Establishing and Operating a Beauty Shop."

Directory advertising, virtually ignored by most writers of books and magazine articles, has swelled to tremendous proportions in recent years. The 1947 total for Bell System directories alone was over $\$ 80,000,000$. The June 1947 Chicago Red Book grossed more than $\$ 7,000,000$, according to J. W. Fisher, Jr., directory superintendent of the Illinois Bell Telephone Company. It was a volume of 1,752 pages with 250,000 reference items under 3,000 separate headings and had a total circulation of $1,350,000$ copies which cost an estimated $\$ 2.75$ apiece.

Only New York, Chicago, Philadelphia, Detroit and Los Angelès have separate classified directories, but in every other city or town where there are more than a handful of retailers the local phone book contains "yellow pages" serving the same purpose. These pages are used in several ways:

1. "Name and number service." A phone subscriber wants to look up a firm whose name he has forgotten but will recognize if he sees it. He consults the appropriate section of the classified, runs down the listings until he runs across the firm he is after. 
2. "Trade-mark service." A subscriber wants to buy or get repairs on some nationally advertised article. He turns to the directory, locates the manufacturer's name, and under it finds the names of dealers, wholesalers and repair shops.

3. A subscriber has no particular firm in mind but wishes to obtain some product or service. He looks under the desired heading and makes his selection.

The "directory habit" has been encouraged by national advertising in Life, Ladies' Home Journal, The Saturday Evening Post and other consumer media. In the Chicago area, the local Red Book was promoted in 1947 in newspapers, book matches, car cards, business publications, and blotters enclosed with telephone bills: a total of 845,000,000 impressions of the message, "Look in the Red Book."

Advertisers in classified directories include not only national firms but also-and predominantly-local retailers, wholesalers and service institutions. Small manufacturers found this medium particularly effective during the war when many business firms were cut off from their regular sources of supply or went into new fields and had to establish new buying connections.

Rates are on a monthly basis, even though the directory may be issued only every six or nine months. The largest space sold in the Chicago Red Book is a quarter-page, which costs $\$ 128$ per month. Each business or professional telephone subscriber is allowed one free listing. Additional listings are $\$ 1.50$ per month, extra copy under a listing 75 cents per line, and names in boldface $\$ 3.00$ per month.

Success stories in plenty attest to the pulling power of directory advertising. A small plant in Chicago, Delta Company, had been cutting foil for use in electronic tubes during the war. The owner wished to expand his market and inserted a half-inch ad in the Red Book. Within two months he reported over 100 sales from Red Book calls and had a backlog of orders which enabled the company to move into its own building. Another type of business, ABC Diaper Service, averaged 20 calls a day from a quarter-page. Results were traceable because a special phone number not listed in the "alphabetical" directory was given in the ad.

Bell System's national "trade-mark service" was inaugurated in 1927. At present over 3,000 companies use it, some of them in every classified directory in the country. The manufacturer pays for a small 
reproduction of his trade-mark and a few lines of copy. He gets a heading in bold-faced type. Under his space are listed the local sales and service firms. With an "open listing" any dealer or repair shop can buy space under this heading; with a "closed listing" only those named by the manufacturer are eligible.

Growth of directory advertising is shown by the fact that between 1937 and 1947 the number of advertisers in the Chicago Red Book increased from 25,449 to 55,791. The annual expenditure to promote Red Book usage was stepped up from less than $\$ 25,000$ to $\$ 100,000$.

The appearance of directory pages has been steadily improved of late. Maximum space has been reduced to a quarter-page and unsightly black "reverse" headings eliminated. Layout and art service is supplied to advertisers without charge and this has been an important factor in upgrading the quality of classified displays.

\section{The Circus Goes to Town}

Innumerable other media could be considered in this chapter. Negro magazines like Ebony reach a market of many millions. Decalcomanias (paint transfers applied to glass) and other methods of dealer identification constitute an important vehicle for national advertisers. Cooking schools, homemaker forums, store demonstrations, traveling displays are dramatic forms of product promotion. But perhaps as good a place as any to stop is at the circus.

Ringling Bros.-Barnum \& Bailey Circus has been carrying ads in its program since the 1880's. The present Circus Magazine is a colorful affair of 72 pages with an annual circulation of over a million. The current rate card gave $\$ 2,000$ as the page rate, $\$ 3,500$ for the back cover. Besides circulation, advertisers also enjoyed the privilege of having their products sold to the audience and used in the circus dining room, as well as free testimonials, photographs and personal appearances of circus artists, and photographs of all the animalsincluding Gargantua! 


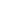




\section{BOOK IV}

\section{THE "WHAT" OF ADVERTISING}





\section{Chapter XIX}

\section{GOOD PRODUCTS AND GOOD PACKAGES}

TT has been said repeatedly that no product which could not succeed without advertising can succeed with advertising. One of the ${ }_{\text {first steps taken by any experienced advertising man or agency in }}$ planning a campaign is to analyze the sales appeal of the article or service to be promoted.

This may involve innumerable factors. First of all, how about quality, style, value, in comparison with competitive offerings? No use attempting to develop a demand for something that is hopelessly outclassed from the start! If a food or ingredient of foods, the matter of flavor must be considered; a slight variation in taste may make a big difference. Local and regional eating habits vary and often are too deep-rooted for one advertiser-particularly a newcomer-to try to change. If an article of apparel, to what age group will it appeal? Can a slight modification of design broaden the base from say the 15-20-year-olds to the 15-35-year market? If a multiunit item, such as pills, bobby pins or meat balls, is the present number of units the best, or might a larger or smaller quantity sell better? How about the package? Is glass the most effective container, or tin? Paper, foil or cellophane? A utility package or one that has a second use after the product has been exhausted?

Asking-and answering-questions like these may seem far removed from advertising. Yet they have a direct bearing on the outcome of many advertising programs. Sometimes a very simple change in the size, shape or exterior appearance of a product or its package will have far greater effect in stimulating sales than all the fancy copy imaginable. It is taking nothing away from advertising to admit that it works best when every condition is most favorable.

Fortunate is the advertising man who starts with a new product. He can study competitors' packages, see what mistakes to avoid, incorporate in his new box or label only those words that will contribute directly to getting the product sold and used correctly. But where an item has been on the market for some time and has done well in its present dress, any alteration is apt to encounter resistance from 
the top management. They argue that a restyling of the package will cause sales to fall off because old customers will not accept or recognize the new design. This despite numerous case histories of companies that have made radical changes in package design without antagonizing established trade, but with marked stimulation of new business.

C. B. Larrabee tells about a cosmetic house that set about changing a package made samiliar by years of advertising and use. The package had become seriously outmoded. But in bringing the package up-to-date the company wished to avoid any loss of good will; the modernizing was done in seven easy stages, so that consumers would not be conscious of it. Later the advertising manager said, "If we had the job to do over again we would make the change in one jump. Not only did we lose the news value of the change, but also we were submitted to a lot of extra trouble and expense."*

Contrast this with the manufacturer who boldly announces, "We couldn't improve the product so we improved the package," or "Now even finer than ever-look for the new label!" Company salesmen, jobbers and dealers get a shot in the arm as the new design is introduced with a fanfare. The "new" product rates extra displays in stores. And customers who for one reason or another had a prejudice against the old product may try the repackaged job and decide they like it.

\section{Modern Packaging Materials}

As with many other industrial activities, packaging was affected by developments of World War II. Foods and other perishables or semiperishable products that were shipped to the tropics and to the far north had to withstand conditions of extreme heat, cold, humidity or dryness. Many of the new materials and methods that were perfected for military use have since been adapted to civilian requirements. The annual Packaging Exposition of the American Management Association for the postwar years has featured a variety of such innovations.

Cellophane, pliofilm, lumarith, sylphwrap and other transparent wraps were becoming increasingly prevalent in the food field with

\footnotetext{
* C. B. Larrabee, How to Package for Profit (Harper \& Bros., 1935), p. 19. Quoted by permission of the publishers.
} 

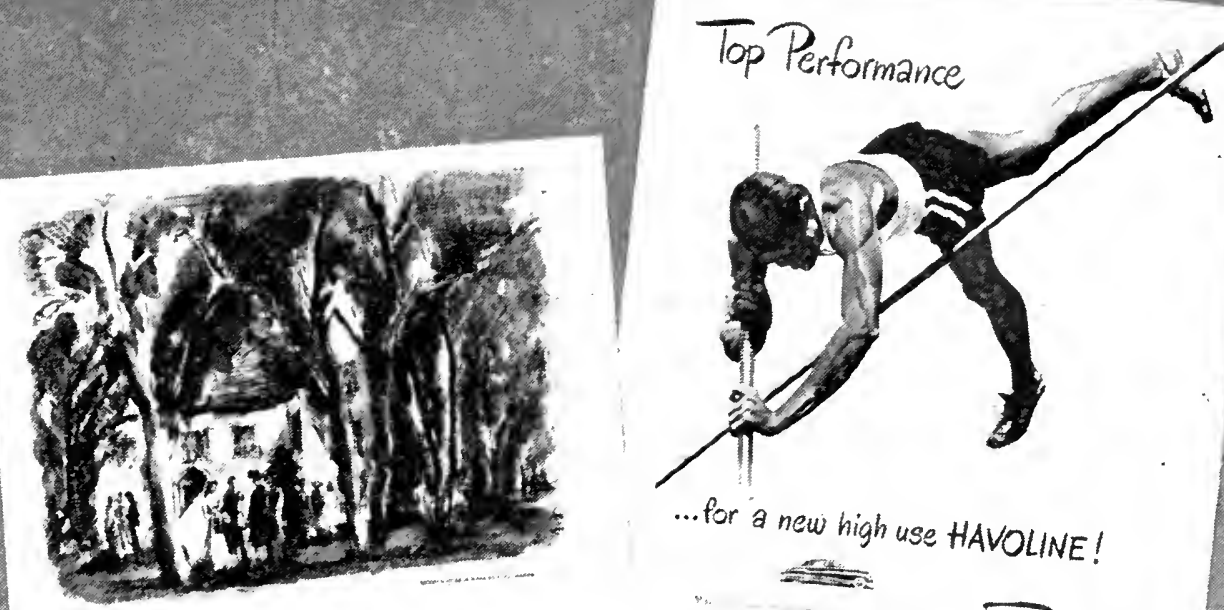

...for a new high use HAVOLINE!
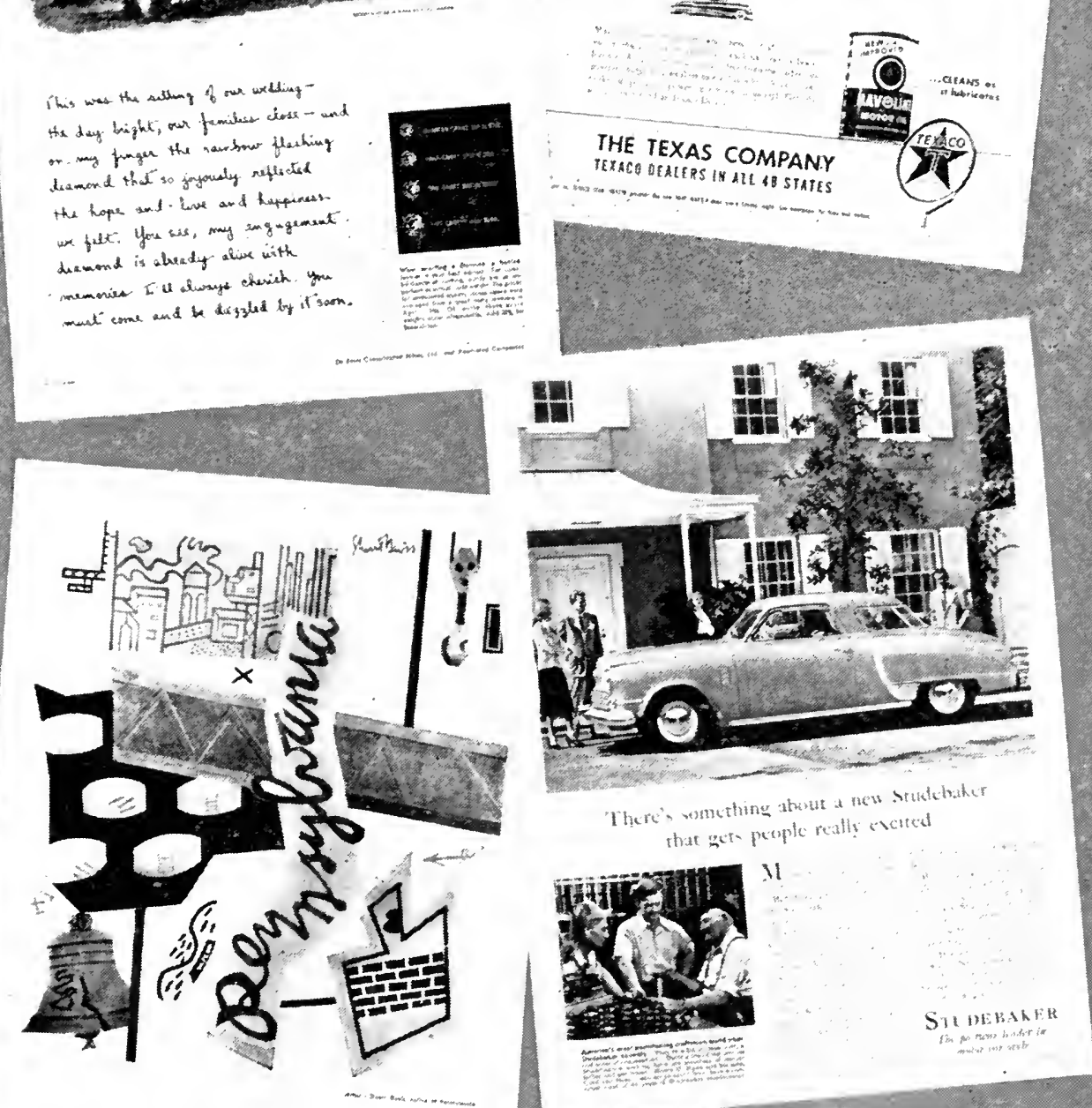

FOUR VARIED IIIUUS'IRATIVE 'IECIINIOUHS IN IODDFRN ADVFR'I'ISING

DeBeers Diamonds use a recherché painting by Paul Darrow; Havoline, a "postery" tempera painting: Containcr Corporation, a Stuart Daris original. 


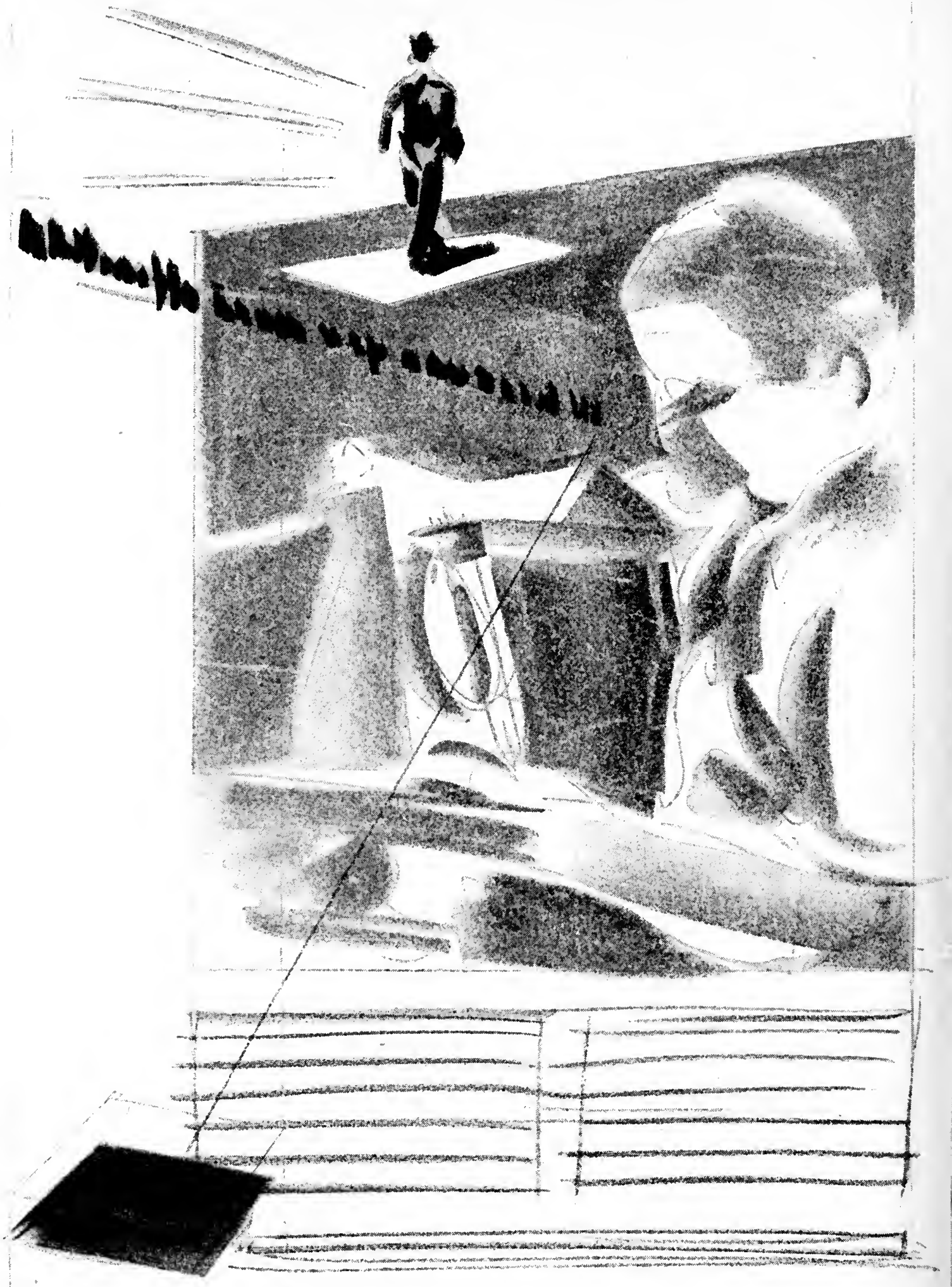

Courtesy Don May: “101 Roug

THE FIRST STAGE IN AD-MAKING: THE "ROUGH"

Here the layout man has blocked in the main elements of the advertisement. An experienced adman can visualize the appearance of the finished job from this preliminary sketch. 


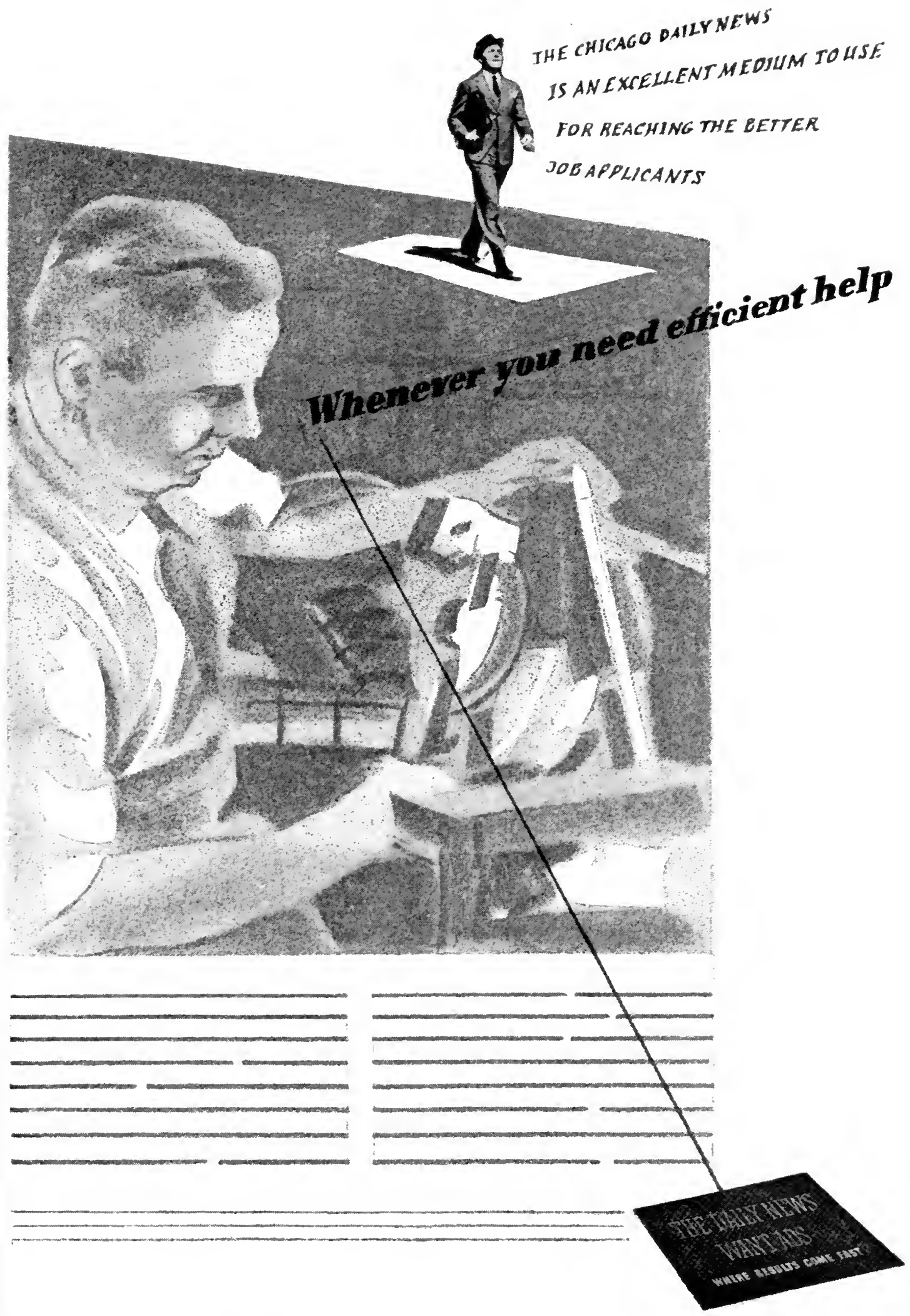

THE SECOND STAGE: THE "SEMI-COMP"

Headlines have been lettered in, illustration indicated in some detail. Note that picture has been "flopped" (turned over) to improve readability of ad. A third stage, the "full comp" would show the actual photo to be used, perhaps with the text matter set in type. 


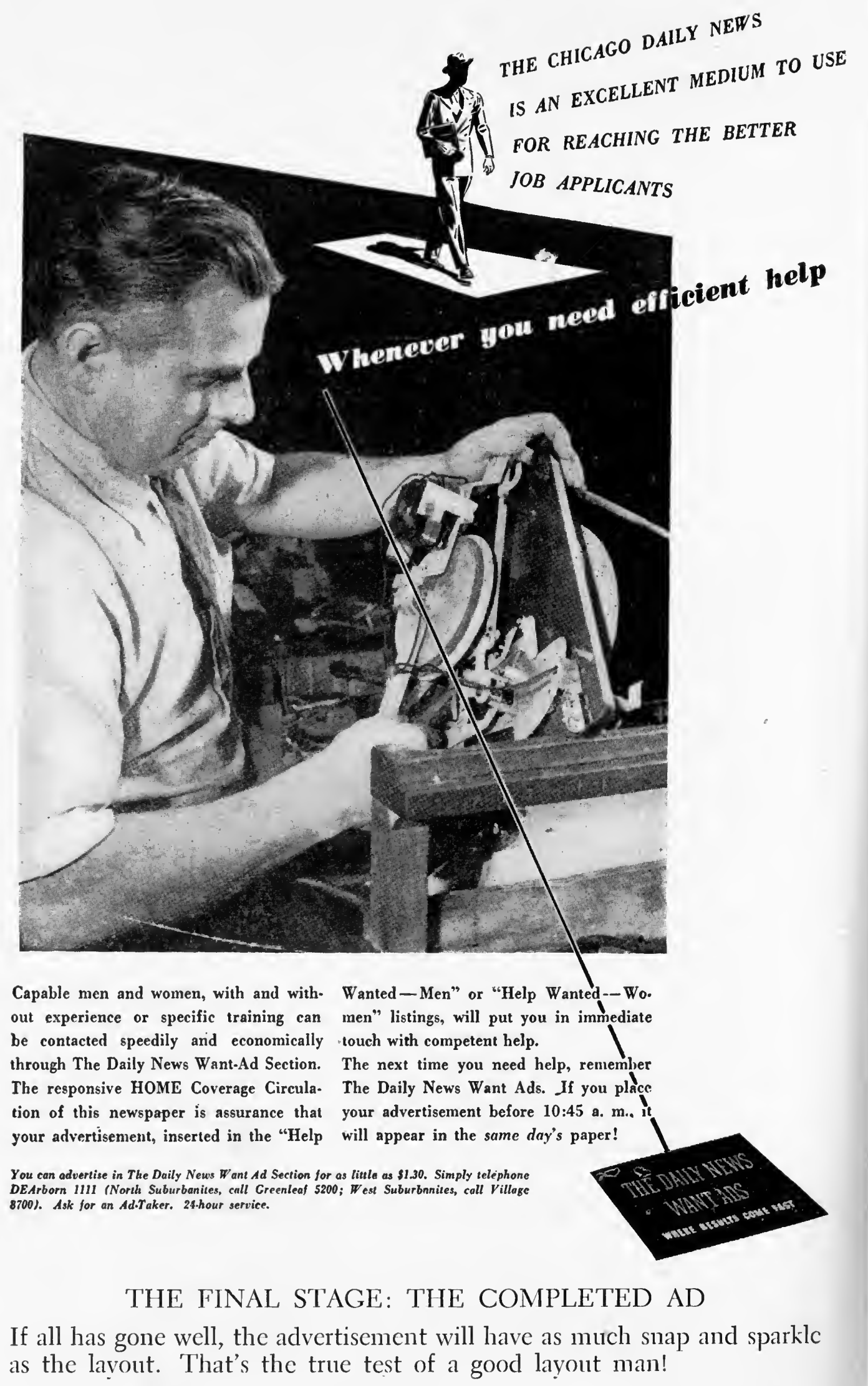


the continuing swing toward self-service. The prepackaging of fresh fruits, vegetables and meats which is necessary if food stores are to become completely self-service requires coverings that repel exterior moisture and keep the contents from drying out. These materials, synthetic in origin, had also to be adapted to receive printing in one or more colors, to permit producers to brand their wares. More and more produce was being shipped by air, posing new packaging problems. Many items can be shipped in dry ice, for example, but the carbon dioxide will kill lobsters; hence for air-expressage of live lobsters a special carton has been devised. It is a paperboard box fitted with waterproofed envelopes containing regular ice at either end. The lobsters are placed in the main part of the box in seaweed.

Aluminum foil was developed as a food wrapper and proved successful in tests by Beatrice Creamery Company on Blue Valley Butter. The foil, laminated to parchment, was said to show far less weight loss in a household refrigerator, and at the same time had a distinctly greater eye appeal. This was a Reynolds Metals Company project.

Another new type of packaging material consisted of a layer of kraft paper, a wall of duplex asphalt and a vegetable parchment inner liner. This was being used for such products as ready-peeled potatoes delivered to lunchrooms. Cellophane was also being laminated to paper to give a glossy outer surface or a smooth, nonsticking inner surface.

The majority of packages seen in stores, however, continued to be made of cardboard, either coated to receive the printed matter or covered with a separate paper label which was "tight-wrapped" to appear like part of the box. All cans and the majority of bottles were identified by paper labels glued to their surface, although a few soft-drink bottlers were using a paint-process label applied directly to the bottle.

Package designers. were giving more and more thought to the "stacking" quality of a container. In erecting mass displays of an item it is essential to have a flat surface above and below. A protruding pour-spout or other irregularity makes pyramid displays diffcult if not impossible. The trend toward multiple use of packages has also led to another exciting consideration-the possibility of designing the different sides of a package so that they will form a larger picture or pattern when placed with different faces adjoining. Several manufacturers of cake flour, for example, have sponsored packages on which a portion of a cake is visible from the front; when 
the side and back of other packages are placed alongside, a complete cake appears.

\section{Package Copy}

How much text should appear on a package and what should it say? For certain kinds of merchandise there are indispensables, such as brand name, company name, net weight or number of units. In addition, if the product is a food, the package or label logically should include directions for use and perhaps typical recipes. If it happens to be, for instance, a wallpaper cleaner, directions are certainly desirable. On the other hand, a can of beans or tomatoes, or a bar of soap, has little need for instructions on the label.

Manufacturers often utilize the package for copy suggesting new product applications. Thus a steel-wool scouring pad (such as Brillo, Glo or SOS) is accepted as being an efficient means of cleaning and polishing aluminum kitchenware. But how many women know that it is also useful for restoring linoleum, removing fingerprints from woodwork, shining up tools, golf clubs and even auto fixtures? Obviously if the makers of these pads could induce more people to use them in these ways, the consumption would greatly increase. The sides and back of the package are logical places to push these additional uses.

Premiums of various kinds sometimes are featured on packages. Any offer must naturally be arranged on a long-time setup, since several months may elapse between the printing of the package and its arrival in the home. Ralston and General Mills are two concerns that have used package copy to push premiums.

The package itself may be a prize. Post Toasties, Wheaties and others have run cut-outs with child appeal on their boxes. The back is generally used for this purpose. Or in the case of a cheese jar, the package may be suitable for use as a jelly glass or drinking glass. In the South, flour sacks are frequently laundered and adapted as shirts, sunsuits or aprons. The manufacturer takes pains to use washable inks on his label to enhance their utility, figuring that the good will should more than offset the dubious advertising value of having his trade-mark appear on a garment. Carey Salt designs its pickle-salt bags with an attractive border of vegetables, to make a decorative dish towel. Some cosmetics packages become jewel cases or ash trays 
after the contents are gone; in such instances the necessary product information may be printed on a detachable outer wrapper, with the permanent cover carrying only the brand name or crest.

Soap wrappers which serve as merchandise coupons; cards, holding small-unit articles, which are made larger than necessary in order to serve also as counter displays for the product; side or back panels of packages which promote the sale of other items in the manufacturer's line-all these are examples of package copy that performs a double duty.

Yale \& Towne Manufacturing Co., in repackaging their hardware line recently, made good use of the sides and tops of boxes to encourage related sales. Thus on the box containing a cylinder front-door set, one large panel displayed the copy: "How Many Keys Do You Carry? Ask the Yale Dealer about Masterkey System for Home, School, Office, Factory." Other boxes holding more than one of an item, where the main package would remain in the store, were supplied with product information to help the clerk make the sale. The repackaging program was also planned to reduce the amount of returned goods by inspiring confidence in the quality of the product, by helping the customer make the correct choice of merchandise and by supplying simplified direction folders in which lengthy explanations were replaced by illustrations and short copy. The buyer was resold on his purchase with such phrases as: "You bought a fine lock. Please use it this way:" followed by simple instructions.

Commenting on this program, Meade Johnson, marketing manager of the Yale hardware line, said: "In its journey from factory to user, a box is handled or seen by many customers. Packages, therefore, are a powerful advertising medium."*

\section{Growth of Packaging Industry}

Packaging of foods received its first real impetus in the 1880's and 1890's with the rise of prepared cereals. Originally the designs were crude and purely utilitarian, but before long illustrations began to appear. It was found that the use of color would make a package stand out on a shelf and thereby increase its sale. By the turn of the century the grocer's and druggist's shelves were blazing with gaudy

* Carroll J. Swan, "What a Good Package Should Do," Printers" Ink, June 21, 1946. By permission of Printers' Ink. 
boxes and labels. Since then the trend has been gradually in the other direction. Today's packages are colorful, eye-catching but on the whole in far better taste than those of 20 or 30 years ago.

Much of the credit for this must go to the comparatively new profession of package designing.

The competent package designer must be not only an artist, with a flair for color, form, lettering, but also something of an engineer, familiar with materials, machinery and processes, and moreover, a student of human nature and buying psychology. His designs must be practical, so that they look as attractive in the store as they did on the drawing board. Certain box materials, for example, do not take kindly to different colors printed one on top of another; some require a sizing or underprinting to serve as a base. Various types of packaging machines must be taken into account. The needs of the consumer will of course get thorough consideration; the container must be easy to open and use; if the entire contents are not emptied at once it should be equally easy to close. The package or bottle should stand firmly, not tip or spill. Directions on the package should be legible even in poor light. The container should fit into its surroundings-kitchen, boudoir, workshop, business office. These are just a few of the details to be watched when a new label or package is in preparation.

One factor of great importance is the way the package will look in the company's advertisements. Usually the reproduction of the package is quite small. A complex design or one in which the product name has been played down will definitely lack visibility and sales wallop under such circumstances. On the other hand, an overly bold or "studhorse" package will seem out of place if the advertising is high style.

Despite all the "Do's and Don'ts" the professional package designer almost invariably comes through with a solution that meets every requirement and is at the same time a marked improvement over the former container-especially if he is working against designs 15 or 20 years old. So much progress has been made in this field during the past decade that any one of a hundred recognized package men is certain to add sales power to any redesigning job he undertakes.

Rates for package designing depend upon the amount of research, trial sketches, testing and finished art work that the assignment will 
entail, as well as upon the standing of the designer. Under certain circumstances a fee of $\$ 250$ might cover a simple problem; for a complicated project, embracing the restyling of an entire "family" of products, the bill might run all the way from $\$ 10,000$ to $\$ 50,000$. But when the future of a multimillion-dollar business is at stake, the question of initial cost is not nearly as vital as the results. Frequently the designer can make suggestions as to processing which will give a finer label or package at less cost than the supposedly economical one. Here is an instance:

Before it was changed, a well-known proprietary remedy had a package that was a typical overstuffed mid-Victorian eyesore. Everything about it was cheap and unhandy. The cheap newsprint carton was omitted, the number of labels reduced to one, and the closure was changed. Finer glass was used in the new bottle, better quality labels and a plastic closure. The net result was that the new package, costing more than the old, reduced packaging costs. It reduced the number of and simplified packaging operations.*

Modern packaging takes cognizance of all expenses incurred in sending a product from the manufacturer to the consumer. In the old days virtually all merchandise was packed by hand, but that was when $\$ 1.00$ a day was considered good pay. Our present economic structure makes it unlikely that such a situation will return. Hence automatic machinery is indispensable if the manufacturer wishes to stay in business. The more short cuts that can be devised in preparing a product for market, the greater will be his chances of retaining his present volume and adding to it.

Precisely at this point, the package designer-or perhaps more correctly he should be called the packaging engineer-enters the picture. $\mathrm{He}$ analyzes every aspect of the company's procedure. The present box may be printed in three colors; would two be equally effective? A bottle may have an outer wrap of glassine paper; is this necessary? The company uses several dozen different sizes and shapes of corrugated boxes to ship its products; could the number be reduced to permit ordering in larger quantities at a lower price? It is amazing to discover how many supposedly efficient firms have profit-leaks in packaging and shipping.

* Larrabee, op. cit. 
Primarily, of course, the package designer is concerned with appearance. His suggestions as to mechanics and methods are by-products. $\mathrm{He}$ is basically an artist. And in that area he can accomplish miracles. Advertising history teems with case histories of products that have had a rebirth of public favor after new packages have been adopted.

It is difficult to signal out any specific designers for mention here. But among those who have achieved recognition might be listed, such names as Georges Wilmet, Raymond Loewy, Egmont Arens, Ben Nash, DeForest Sackett, E. Willis Jones, Robert Sidney Dickens, Harry Farrell, Ed Sullivan (of Chen-Yu fame) and Otis Shepard, the versatile art director for Wi-gley. Raymond Loewy, one of the better known designers, has in recent years concentrated on products rather than packaging. Most of the newer designing jobs have been directed by advertising agencies, working with the designers.

Package design can take odd twists. As part of his duties in connection with Wrigley's Gum, for instance, Otis Shepard has had to function as design consultant on a variety of matters connected with the Chicago Cubs, in which Mr. Wrigley has an interest. Not only has Shepard helped to restyle the Cubs' advertising; he has been called in to offer suggestions as to the general arrangement of the field, the stands and the concessions. But this is not unusual. Other designers have had their advice solicited in such matters as the color of elevator operators' uniforms, the pattern to be painted on the factory smokestack, the dresses to be worn by demonstrators. Individually such details are trivial. But they add up to the cumulative effect of an institution on its public. And in a very pragmatic sense, they are "packaging" problems. 


\section{Chapter XX \\ THEY CALL IT "COPY"}

$\mathrm{H}$

EADLINE and text in a printed advertisement, words and phrases in a radio commercial, art work to be used for making engravings-all come under the general heading of "copy."

Actually the word is grossly misleading. Advertising copy is anything but a copy. Originality is the sine qua non of selling diction. This does not mean that the appeal must be new. But in its presentation there should be a fresh treatment, a different approach to the product. The successful copy writer does not consciously strive for unused terms; he studies his proposition, figures out why and how it is different and better than the others and aims his ads accordingly. For some articles the proper approach may seem to be simple expository treatment-for others, the light touch, possibly with cartoons or amusing sketches-for still others, the romantic or glamorous angle. In any event, he is more engrossed with presenting and developing his message than he is with an exact choice of words. As he delves into his subject, explores it, evolves its one best copy slant, headlines and text flow naturally.

It is not the purpose of this book to teach advertising, and most certainly not the most esoteric branch of the subject, copy writing. Those who wish instruction are referred to the following mediums, the reading of which will well repay any aspirant to a word-wielding job in the advertising business:

How Advertising is Written-and Why, by Aesop Glim (McGrawHill).

Advertising Copy, by George Burton Hotchkiss (Harper).

How to Write Advertising That Sells, by Clyde Bedell (McGrawHill).

Psyching the Ads, by Carroll Rheinstrom (Covici-Friede).

How to Write Advertising, by K. M. Goode (Longmans-Green)

Advertising to the Mass Market, by James D. Woolf (Ronald).

This is by no means a complete bibliography on advertising copy. But it is a fair start, and may explain why the author, after 25 years 295 
as an advertising writer, will not attempt, in a single chapter, to compete with the already bulky literature dealing with the subject. So the matter of copy will be dealt with lightly. Not because,copy is unimportant; no phase of advertising is more significant, has a more profound effect on the productivity of an individual ad, radio program, poster, mailing piece or complete campaign. Copy is the lifeblood of advertising. Strong, convincing, idea-full copy can succeed with the poorest treatment, but the most elaborate campaign can miss the mark if the copy isn't right.

Yet oddly enough, nobody has been able to pin down copy to a pattern. Many years ago John Powers wrote copy for Wanamaker that swamped the store with customers-but Powers'. stuff would fall flat on many types of products. Claude Hopkins was considered a master of copy; he had countless successes to prove it. But today the Hopkins approach sounds stilted, lumbering, in the light of our fast-moving times. Among modern writers, Walter Weir, Amedee Cole, John Rosebrook, Joe Katz, Lou Thomas, Jim Martindale, Ken Ward, George Drake, Margaret Fishback and a few dozen others have caught the tempo of the age as did the "old masters" of 25 or 50 years ago. Your true copy star can't be pigeonholed. He has no rigid pattern for any and all products. Each new problem calls for a virginal approach. And it is this very fluidity, this refusal to be typed, that keeps advertising copy so fresh and stimulating.

\section{The Headline}

The best read part of any advertisement is the headlint. Starch readership tests have shown the power of the headline outweighs that of the text by ratios of as high as 25 to l; even a well-rated ad may run four or five to one in favor of the heading as against the text. Hence the copy writer concentrates his heaviest artillery on the headline.

Clyde Bedell, foremost teacher and writer on creative advertising, has this to say:

It should be remembered that your headline is probably the most important part of your ad. It should never be left until after the copy is prepared and then dashed off in slapstick fashion. It is good practice to work and work hard on your headline first. Get a good one, if you can, before you proceed with the copy.*

* By permission from How to Write Advertising That Sells, by Clyde Bedell. Copyrighted 1940, by McGraw-Hill Book Co., Inc. 
After the body copy has been written, Mr. Bedell states, it may seem advisable to go back and refine or strengthen the headline. But the writing of the text will be easier and more coherent if based on a strong, brief, convincing heading.

Choice of headlines will depend to a certain extent on the product being advertised and what has been developed regarding it. A brandnew article or a new feature created for a familiar product is, in the author's opinion, the most desirable basis for a headline. It has the advantage of being news, of telling the reader something he didn't know before. This same principle holds true in radio commercials. When the element of news can be injected, audiences prick up their ears.

Next in attention value seems to be the "how" appeal. This may take many forms. In the women's magazines, recipes generally have the highest reader interest-they tell "how" to prepare certain foods. In general publications, in newspapers, on the air, folks are interested in how to do things that will bring them greater enjoyment, satisfaction, comfort. A headline that promises information aimed at the reader's own needs and problems will command attention.

Curiosity is probably third in line. The "teaser" type of caption will stop a large number of readers. However, the copy must quickly follow through, justifying the headline and pulling the reader on into the sales talk. Tricky headings that do not lead logically and directly to the copy may boomerang in ill will.

Last in order is the bossy type of headline, commanding the reader to take a certain action. This style is more apt to be encountered in newspapers or spot radio announcements than in general magazines or network programs. One seldom sees it in posters. Generally the news-style or how-to-do-it headline may be adapted to almost any product or service and is far more effective than a direct command.

Next time you listen to your radio or leaf through a magazine, notice how many advertisers use either the news or how approach, how few resort to direct commands.

One further type of headline should be mentioned, that which predominantly talks about the product. Broad claims are made as to quality, efficiency, economy-all from the angle of the manufacturer rather than the consumer. Unless this sort of heading can be given a news or a how-to-do-it appeal, it is more apt than not to prove a dud.

Endless arguments have been waged over the matter of long vs. 
short headlines. A headline containing only a few words unquestionably presents fewer problems to the layout man, and may result in a more attractive ad. As against this is the virtually unanswerable argument: if from three to twenty times as many people read the headline as go on through the complete ad, isn't it common sense to pack as much sell into the headline as possible?

Compromises have sometimes been reached by using a short headline, followed by a fairly lengthy, explanatory suichead which "wraps up" the selling message and gives even the hit-and-run reader a digest of the sales story.

The "logotype" or product name as displayed at the base of the ad can also be considered a part of the heading. Here are a few examples:

MORE ROOF VALUE FOR YOUR MONEY (main headline) Greater Protection Plus Greater Beauty (subhead)

RUBEROID Dubl-coverage TIte-on Shingles

(Signature)

Now You Can Have LOVELIER FLOORS WITH LESS CARE (main heading)

Self-Polishing SIMONIZ for Floors (signature)

Meet the Best Pot Roast Everl (main heading)

Pot Roast à la New Orleans (subhead, followed by recipe)

WESSON OIL for Salads \& Cooking (signature),

Skin that makes men lovers is

'SKIN THAT STIRS THE SENSES' (main headline)

This luxurious PHILLIPS' 'BEAUTY FACIAL' is

designed to give you such lovely skin! (subhead)

New PHILLIPS' CLEANSING CREAM (signature)

In each of these advertisements, taken from June 1947 Better Homes and Gardens, we can see an appeal to the reader's self-interest, a "how" angle, and a close tie-in with the product by way of conclusion. The direct progress from headline to signoff would be much more obvious if the whole advertisement, including pictures and body text, could be reproduced in each case.

Mail-order copy has a headline technique of its own. Long head- 
lines are the rule. One inexplicable feature is the pulling power of certain words. "Amazing" heads the list. Nobody has been able to explain why an "amazing offer" or an "amazing discovery" should attract more inquiries than a surprising, startling or exciting one, but there it is. Other sure-fire words are "free", "new" and "now." A variant of the "now" approach is the phrase "at last." Mail-order writers have learned that comparatives like "greater", "better", "lovelier", far outpull the superlative forms such as "greatest", "best", "loveliest".

\section{"Text Goes Here"}

Ad writers are often irked by the offhand way in which artists regard the body copy of an advertisement. On rough layouts the space to be occupied by text is merely indicated by a series of parallel lines-the fewer lines the better, in the artist's opinion! And many times the artist is proved right, when readership reports show a 40 or 50 percent observation of his illustration as against a 1 or 2 percent "read most" for the copy. On the other hand, this is not always the fault of the writer. Layouts may be so "artistic" as actually to discourage readers from going into the text.

Book publishers who sell by mail always pack their ads with copyand copy arranged in such a manner as to invite reading. The large amount of text will not appeal to the person merely scanning through a magazine or newspaper, but when one pauses at all, one usually gives the ad thorough attention. For example, a page in Life for September 30, 1946, by Wilfred Funk, Inc., offering a $\$ 2.00$ book, "30 Days to a More Powerful Vocabulary," contained nearly 2,000 words of text. A readership study showed this ad was noted by 15 percent of the men and 15 percent of the women interviewed-not a strong showing, considering that some ads in the same issue rated 50 percent or higher. Yet of the main text, 7 percent of both men and women said they had read most. A display panel listing 30 things the book would do was read by 11 percent of the men, 9 percent of the womenalthough it was set in extremely small type and ran to nearly 500 words. In this case, more than half of those who saw the ad stayed with it long enough to receive an intensive sales talk about the product. And since the advertiser had to depend on this message for his results, the longer he could hold the reader the more likelihood there would be of his getting an order.

One device that has been used more and more frequently of late is 
the picture-caption treatment for text matter. Adapted from the comic strip and the photo-story type of magazine, this method suggests an interesting sequence of events. The reader looks at each picture in turn, then reads the accompanying copy to learn what is happening. The selling features of the product are woven into the dialogue or running commentary. Such ads often have as high-or nearly as high - a readership for the concluding paragraph as for the opening. And that is the optimum for copy.

A variant of this is the semicatalogue treatment, with small pictures of different models or product features, each with explanatory text. Again the eye travels from the illustration to the caption to assure reading.

In contrast to these ruses for obtaining attention, a straightforward, logically ordered, persuasively written piece of copy can sometimes do a better job. This is true where the product is new or has distinctive features that must be understood to be appreciated. Brief, "clever" copy will not achieve the objective. Aesop Glim gives this dictum to ad writers:

Unless you know, beyond all doubt, that you can sell your wares in fourteen words or less, stick to the formulas of writing educational copy. Construct each advertisement with the detcrmination to get it read from start to finish.*

\section{Short Words-Short Sentences}

Advertisers who aim at the mass market have always known that simple words and short sentences will reach more people than polysyllables and ponderosity. In recent years this generalization has been given a scientific basis-the Flesch Readability Scale.

Dr. Rudolf Flesch, a former Viennese lawyer and now a psychologist, who came to America shortly before the war, created the system. He worked out a formula which was first used in federal government offices, where involved, wordy, almost unintelligible writing was rampant. Typical example, from the Office of Price Administration:

Ultimate consumer means a person or group of persons, generally constituting a domestic household, who purchase eggs generally at

\footnotetext{
* By permission from How Advertising is Written-and Why, by Aesop Glim. Copyrighted 1945, by McGraw-Hill Book Co., Inc.
} 
the individual stores of retailers or purchase and receive deliveries of eggs at the place of abode of the individual or domestic household from producers or retail route sellers and who use such eggs for their consumption as food.

As revised by Dr. Flesch: "Ultimate consumers are people who buy eggs to eat them."

For the government, he prepared a booklet, "How Does Your Writing Read?" which had an immediate effect. Previously for his Ph.D. at Columbia University he had written Marks of Readable Style, working under Lyman Bryson, then head of the Readability Laboratory at Teachers College. In 1946 he presented his views to the public in The Art of Plain Talk.

Meanwhile he had been asked by Macfadden Women's Group to analyze their magazines from the readability angle, in comparison with other periodicals. Using his "Flesch Scale," he rated the general weeklies, general monthlies, women's service magazines, and masstype (screen-and-romance) magazines such as Macfadden's. With this scale, the easier a piece is to read-as interpreted by Dr. Fleschthe lower its score. Three factors are considered:

1. Average sentence length. Sentences of about 11 words each are considered an "easy" reading level for 75 percent of adult Americans.

2. Number of affixes (prefixes and suffixes). About 26 per 100 words are regarded as "easy" for this group.

3. Personal references (personal pronouns, names of people, words that refer to human beings or human relationships). About 14 of these per 100 words are the norm.

Each of these elements is reduced and combined into a single figure ranging from 0 to 6 or more. His ratings for the different types of publications were: weeklies, 2.90; women's service magazines, 2.77; general monthlies, 2.75; mass-type advertising, 1.98. The same formula was then applied to various advertisements, and three of the best read, according to their Starch ratings, had Flesch scores of 0.68 , 1.22 and 1.46. The lowest in score-hence easiest to read under the Flesch system-was a half-page for Cream of Wheat consisting of a "Li'l Abner" comic strip by Al Capp. It averaged six words per sentence, 22 affixes and 12 personal references per 100 words. This, according to Dr. Flesch, was lower than necessary to fall within 
range of the $75,000,000$ adult Americans who form the great bulk of domestic buying power. A 2.0 rating or below will reach this entire group, he says, while a 3.0 rating will appeal to only $40,000,000$ adults and a 4.0 average to only $24,000,000$. The contention is that an advertiser whose copy has a score of 4 or higher is appealing only to 24 percent of the total market. By using shorter sent-nces, words with fewer affixes and more personal references to reduce his score to 3 , he will add 16 percent to the total, and by dropping the level down to 2 , another 35 percent.*

William Feather, Cleveland commentator and house-organ editor, wrote this remarkable plea for simplicity some years ago:

If you wish what you write to be read, you should use plain words. Use of such words makes you think hard. If you use short words, you dare not be vague, since the worst old fool would then know your brain was soft.

If your thought is clear, you can give it form and strength by wit and skill in the choice of short words. When you start your theme with long words, stop at once and make sure that you know what is in your mind and that you have thought it cleai through. If you are in doubt, put your pen down and think some more.

When you use short words you don't have to write much. All that you have to say will be heard. Words can shout, cry, wink, laugh, and coax. As a change from some stale game, write in not more than a page of words what vou think should be done for the peace of the world.

The amazing thing about this tours de force is that it is written entirely in words of one syllable. And if my mathematics is correct, it has a Flesch score of 0.072 , probably the lowest rating ever recorded for a passage of this length!

\section{Copy Testing-Before and After}

Every time an ad is inserted in a periodical or a radio commercial prepared, the questions arise, Will it be read? or Will it be listened to? and the all-important clincher, Will it make 'em buy? Copy testing has been a comparatively new development in advertising, yet already it has made great strides.

* Data supplied by Macfadden Women's Group. 
The first comprehensive study of copy testing was conducted in 1935 and 1936 by the Psychological Corporation for the Association of National Advertisers. In 1939 the Advertising Research Foundation, jointly maintained by the ANA and 4 A's, issued Copy Testing, a book published by the Ronald Press. Since then developments have come thick and fast. One of the most popular new methods is the "consumer panel" which is employed to obtain many kinds of information, including reactions to copy. The authoritative book, How to Conduct Consumer and Opinion Research, edited by Dr. Albert B. Blankenship and published by Harpers, devotes two chapters to copy: "Consumer Research in the Development of Advertising Copy," by Alfred C. Welch, marketing director of Knox Reeves Advertising, Inc., which describes methods used to predetermine the effectiveness of basic appeals and copy treatments; and "Copy Testing," by Albert D. Frieberg of the Psychological Corporation.

Methods currently favored for checking the effectiveness of newspaper and magazine advertising can be classified as follows:

1. Recognition and identification tests. Results are reported as the number of people who noticed an advertisement, the headline or illustration, and the number who read some or all of an advertisement.

2. Recall tests. Here the scores are the number of people who remember having seen the advertising of a particular product, who remember a slogan, etc.

3. Controlled opinion tests. Here the score is in terms of the advertisement "most interesting," "liked best," etc.

4. Inquiry and coupon tests. The criterion is the number of inquiries, the cost per inquiry, or both.

5. Sales tests. The criterion is usually the cost per sale, the rate of sales, etc.*

The "recognition method" has been used by the Daniel Starch organization since 1932 and is sold on a subscription basis. Trained interviewers in cities and communities of different sizes in some 65 sections of the United States conduct issue-by-issue tests on more than 20 national magazines and the major Sunday supplements. In each of these, all advertisements of one-half page or more are checked

* Dr. Albert B. Blankenship, ed., How to Conduct Consumer and Opinion Research (Harper \& Bros., 1946), p. 119. Quoted by permission of the publisher. 
to determine the percentage of readers who noted each ad; all who associated it with the name of the product or advertiser, those who read a little of the text and those who read most. Questions are asked about each part of an ad-headline, illustration, main text, secondary text, logotype, etc. Costs per 100 readers are determined under each heading (Noted, Seen-Associated, Read Most) by dividing the cost of the ad among readers for that heading, and the ads are ranked according to this cost ratio.

With the "identification method" the brand name and other identifying features of an ad are blanked out and readers asked to name the advertiser. Percentages are obtained on those who correctly identified the product or firm, and those who named the wrong product or firm. Errors in recognition, represented by those who "recognize" ads they have never seen before, can be corrected to a certain extent by discounting replies according to the formula described in the section on transportation advertising.*

"Recall tests" are of two kinds, aided and snaided. In the unaided method, the person is shown a magazine which he has read, and asked which ads he remembers seeing. There is no assurance that the ad was not seen in another publication, or that the interviewee did not confuse it with some similar ad. The "aided recall" test is not used for specific ads, but to determine the impact of advertising in general. Questions are asked such as: "What brand of tooth paste have you seen or heard advertised recently?" After the brand name is given, the next question might be: "What did it say?" The replies determine to what extent the advertising theme has registered. The "triple associates" is a special form of recall test developed by Dr. H. C. Link, and is illustrated by this question: "What company advertises 'Better Things for Better Living through Chemistry?' " Frieberg describes one such test in which the advertiser had been using as a theme in local advertising, "The Deeper Suds Test." It was found that after an eight-week campaign, 16 percent of the women identified the theme with Super Suds, which was incorrect, to only 2 percent for the advertiser. Obviously, the campaign was doing an excellent advertising job for its competitor. This would not have been apparent without research of this kind.* *

"Controlled opinion" or "consumer jury" tests are conducted by showing two or more ads to a person and asking: "Which advertise-

* Chapter XVI, p. 252.

** Blankenship, op. cit. 
ment interests you most? Which headline appeals most to you? Which illustration do you like best? What story does the ad tell?" and so on. This type of test can be conducted with rough layouts before an ad appears, saving considerable money if a theme or copy slant lacks popular appeal. Consumer jury tests must be discounted somewhat because respondents may make unnatural answers to the questions rather than give their spontaneous. feelings. On certain themes, such as "halitosis," few people will admit that they are concerned about the subject, even though they might be keenly interested when reading the ad in private.

Coupon and inquiry tests have been employed for decades. The ad has a coupon or "buried offer" (a sample, booklet or premium not prominently displayed) and returns are checked according to a key number-a "department," "box" or special address-to decide which of several ads is most effective. Care must be taken that the inquiries are from bona fide prospects, not habitual coupon clippers or children, which explains why the "hidden offer" may be more dependable than the coupon method even though it does not produce as many responses.

Many factors must be considered in judging ads from inquiries: the position of the ad, the medium used, seasonal influences, competition. Most of these variables can be offset by using a "split run"that is, dividing the periodical's circulation so that half of the readers see one ad and half another. A number of magazines and newspapers offer this service at a slight extra cost. Among them are the New York Mirror and Woman's Day.

Concerns selling by mail often learn surprising facts by checking their coupon returns. In his book of case histories, Psyching the Ads, Carroll Rheinstrom tells of a book on hair culture which had been advertised to women for several years. The book sold fairly well. Then it was suggested that an appeal to men be tried. Sales, which had been averaging 66 per ad in a certain publication, immediately soared to 312 for the first ad addressed to men in the same magazine. In another instance, sales cost on a $\$ 5.00$ memory course dropped from $\$ 2.25$ to $\$ 1.00$ by the addition of a small picture to the ad. In still another, inquiry cost was reduced from $\$ 1.34$ each to 18 cents by a new copy slant.*

Sales tests are generally handled by selecting two or more "test

* Carroll Rheinstrom, Psyching the Ads (Covici-Friede, 1929), pp. 215, 231, 241. Quoted by permission of the author. 
markets" and conducting separate campaigns in each, with results carefully checked. Sometimes an additional city, where no advertising or else the regular campaign is run, will be used as a "control" to compare sales figures in the test period. Cities of comparable size, average income, newspaper or radio coverage, and other factors affecting sales are used for such tests. After the campaign, sales to jobbers, dealers and consumers, rate of reorder, and other effects of the advertising are analyzed to decide which of the two or more test programs should be adopted on a broader scale.

Various electrical and mechanical devices have also been developed to test advertising. One of these is the Purdue Eye-Camera, which photographs the reader's eyes as he looks through a magazine or newspaper and shows the order in which he looks at each part of an ad and how much time he spends there. A postwar machine designed to measure ad reactions in a unique way is the "Psycho-Graph"-a supersensitive galvanometer which charts the sweat gland activity in the palm of the observer's hand in terms of increased or decreased electric current. When the subject is "aroused" perspiration is stimulated and the line goes up. With no reaction, it remains static. If the subject is very bored, the line may go down. Tests are made by showing the subject various ads, or by having him listen to a radio program. The sponsors of the Psycho-Graph, Gilliland-RanseenWesley \& Ragan, Inc., claim a statistically reliable "sample" with as few as 15 or 20 typical subjects.

\section{Copy Check-Lists}

Innumerable sets of check-lists have been devised to aid the copy writer in producing effective advertising. Points are given on a chart. The writer is supposed to go over his ad to make sure that all, or as many as practicable, are covered.

Clyde Bedell, former advertising manager of Marshall Field \& Company and a widely popular copy instructor, lists " 31 proved selling stratagems" as a guide to effective ad writing. These are divided into four main headings:

Get Attention-Make Your Headline Work-Be Brief

Arouse Interest and Create Desire

Create Conviction

Try for Action

These are to be consulted before and during the actual writing. He 
also suggests 16 "touchstones" to be used after the ad has been prepared. A few of the touchstones: "Does it start interestingly-with a bang if possible?" "Does it use visual words and lively verbs?" "Is it broken up for easy reading?" "Does it sell for competitors or for you alone?" "Does it end interestingly?" "Does it present a bold summary?"*

Another and considerably simpler pre-evaluation program is that offered by Richard Manville, consultant on advertising and research. He calls it "34 Magic Words" and suggests its use in estimating the potential pulling power of two different ads:

Which of these (two) advertisements offers

(1) to the correct customer-market (not too limited)

(2) satisfaction most clearly (wants vs. don't wants)

(3) with the least possible distraction (relevancy)

(4) in the most specific terms (specificness)

(5) with the greatest assurance to the readers (believable-ness)

(6) and at the least expenditure of effort (easy to act)

(7) or money?

This yardstick, Mr. Manville explains, is not intended to replace and accurate pretesting by split runs or other methods, but merely to narrow down the number of ads to get the two or four strongest ones. If pretesting is not used, Mr. Manville believes that careful application of his 34-word key will nevertheless enable the advertiser to turn out better ads than before.**

No amount of research, pre-testing or post-testing of ads will take the place of copy skill and imagination. It can supply information and data on which to base advertising, can determine which of two or more given ads is likely to pull best. But this is no assurance that some totally different idea-some brand-new, untried, radically different piece of copy may not outproduce anything that has been previously tried. In this fact is found the greatest challenge to people in advertising and those who want to get into the creative end of the profession. There is potential dynamite in every radio program, every publication ad. The statistician, the analyst can place the charge, but it is up to the copy writer to light the fuse.

* By permission from How to Write Advertising That Sells, by Clyde Bedell. Copyrighted 1940. McGraw-Hill Book Co., Inc.

** Richard Manville, "How to Pre-value an Ad Before It Appears in Print," Printers' Ink, November 29, 1946, p. 41. Quoted by permission of Printers' Ink. 


\section{Chapter XXI \\ THE IDEA TAKES SHAPE}

TL visual advertising requires some form of "art." Even an allAype ad, booklet or display card can benefit from good design. 1 The great majority of ads and printed selling pieces use either drawings-including everything from an oil painting to a cartoon or thumbnail sketch-or photographs to reinforce the copy. In fact, the art work often is the ad.

As previous chapters have revealed, art in advertising had its timid beginnings during the late Victorian period. But not until the days of Teddy Roosevelt did many ad men begin to think boldly on the subject. In 1908 Earnest Elmo Calkins and Fred Lamb assembled the first exhibition of advertising art in New York City, and similar shows were staged the following two years. Some of the names represented are still remembered: Maxfield Parrish, N. C. Wyeth, the Leyendeckers, James Montgomery Flagg, C. B. Falls, F. G. Cooper, Will Bradley, Adolph Treidler. Writings in Arts and Decoration about the 1910 show, Franklin Warren declared: "Ten years ago, the art world would have scoffed at the idea of an exhibition of advertising art. The fact that it was taken seriously by art loving people, that it was held at an art club (The National Arts), is noteworthy. Art has undoubtedly taken a strong hold in the field of advertising."

Ten years more were to pass before the organization of the Art Directors Club in 1920 when, to quote its first president, Heyworth Campbell, "a pilgrim band of wistful adventurers made official, professional, and endurable the title of Art Director."*

The first Art Directors Annual appeared in 1921. Each year since then this exciting book has pictured the progress of advertising art. Those in the profession long ago stopped apologizing for "going commercial." There is no gainsaying the fact that today much of the finest talent in art and photography goes into the illustrating of advertisements. The 25th Anniversary Issue of the Art Directors Annual displays some magnificent work by painters like Doris Lee, Ben Stahl,

* 25th Annual Art Directors Anmual (Art Directors Club of New York, 1946). By permission of the Art Directors Club. 
Stevan Dohanos, Haddon Sundblom, Rockwell Kent, Carolyn Edmundson, Robert Riggs, Douglas Crockwell; photography by such masters as Valentino Sarra, Anton Bruehl, Ruzzie Green, Victor Keppler, Yousef Karsh, Gjon Mili. Nor is fine quality art and photography confined to New York City. Throughout the country the standards have been steadily raised.

Pictures, whether made with a pen, brush or lens, are, in fact, chiefly responsible for the aura that surrounds modern advertising. Hard-boiled sales copy may be just the thing for some products but it is the illustration that catches the eye, stops the page-skimmer, rivets his attention to the ad so that the text will have a chance to register. Competition for reader interest is keener than ever, with magazines of 100,200 or more pages laden with colorful ads and equally colorful editorial features; with newspapers carrying heavy linage and also vying for the reader's eye with comics, roto and color-gravure, wirephotos, Manhattan and Washington and Hollywood columnists and countless other attractions to make the advertiser's job tougher. Outdoor advertising and direct mail have likewise reflected the trend toward finer art work. Many of the most notable pieces in the Art Directors' exhibit each year originate in these media.

Good art costs good money - and it isn't getting any cheaper. One thousand dollars is no longer an exceptional price for a painting, and the topnotchers have long waiting lists of prospective purchasers at rates two and three times that figure. In color photography $\$ 500$ is the minimum for many studios with the leaders starting above that mark. Even black-and-white photos, staged by the "name" cameraman, may run to several hundred dollars for a single shot, particularly where models and properties are required.

Are such charges exorbitant? Not when results are considered. The advertiser pays the same rate for a medium-newspaper, magazine, poster, etc.-regardless of how he uses it. If his space outlay is, for example, $\$ 15,000$ to reach a potential market of 5,000,000 customers, and interest in his advertisement can be increased 10 percent by a better piece of art; he is clearly justified in spending an additional $\$ 1,500$. And there is ample evidence to show that readership may be enhanced as much as 50 to 100 percent or more under circumstances. The same arithmetic applies where an advertiser is investing only $\$ 100$ and is weighing the advisability of spending an additional $\$ 5.00$ or $\$ 10.00$ on art-except that his illustration cost will generally be much 
higher in proportion than the user of a national consumer medium.

This does not mean that the mere buying of high-priced art can take the place of creative planning and originality of ideas. Nor should it be taken to imply that effective art work cannot be produced by artists without a national reputation. The exact opposite is true; some of the most attractive and successful advertising art is the work of unknowns while some dismal failures have been recorded by campaigns in which only the most successful art talent was employed. Rarely, however, does the brilliant newcomer remain long in obscurity. If he "has the stuff" he will soon adjust his prices in line with the market. The advertiser who buys only bargain-counter art, like most bargain hunters, generally gets no more than he pays for.

\section{The Layout or "Visual"}

As was explained in discussing the duties of the agency art director, the design of any advertisement usually goes through a number of stages before art work or photography is ordered.* After the copy has been written, or perhaps prior to completion of the text when only the headline and basic theme of the ad are "set," a layout is made. The layout is to a finished ad what a blueprint is to a completed building. It shows the various units that will be included, their relative size and importance, the approximate nature of the illustration. First worked out in rough form, it can be carried nearer and nearer to the polish of the final ad according to the ability of the client to visualize the successive stages. A veteran advertising manager can tell from the crudest of sketches whether or not he will like the end result. The less imaginative president or general manager, on the other hand, may require a more comprehensive treatment.

Creating an effective layout demands a variety of skills. The layout man must have a sound knowledge of design, of balance, of art techniques; very often he has had a well-rounded art-school training with several years in an art studio or art department doing finished work. An understanding of type faces and hand-lettering styles is essential. But these are mechanical assets that can be acquired through study. The two semi-intuitive qualifications are far more vital and more difficult to obtain. They are: (1) a flair for the new, the untried, the daring, in advertising design-the sort of light-

* See Chapter VIII. 
ning-stroke hunch that is always presented with an apologetic, "This may seem like a crazy idea, but let's try it!" and (2) an appreciation of the merchandising aspects of an ad-a realization of the fact that, after all, the advertisement is supposed to sell goods as well as look pretty. Most of the individuals who combine these rare qualities are art directors of agencies, department stores or advertising service organizations; a few are free lances, and a few more are found in art studios. Some have gone on to head advertising agencies or, like Fred Ludekens, have switched to illustrating or other forms of finished art.

A really great layout man was Bob Evans of Chicago and New York, who died in 1941 at the age of 38. Following a brief art school training he went to work for the advertising service department of a Chicago newspaper, where his job was to whip up ads for local merchants who wished to use his paper but had neither an agency nor an art staff to handle the creative work. In this "boiler factory" he acquired both speed and a realistic viewpoint toward advertising art. Following this apprenticeship he went to the Stevens Sundblom \& Stults studios, at first merely to do layouts, then as art director. $\mathrm{He}$ had continued his art-school studies under Frank Young, Harry Timmins and other instructors at the American Academy of Art, but it was with the idea of being able to do better layouts rather than to paint masterpieces. In 1933 with Larry Stults he started one of the first studios to specialize in layouts (it has since become Bracken \& Tyler, Chuck Bracken having been Evans' protégé and chief assistant). The firm was amazingly successful. At its height both of the principals were kept constantly busy making layouts for agencies, advertisers, mail-order firms and publications. Out-of-town trips were charged on the basis of $\$ 150$ a day plus expenses. In 1937 Evans moved to New York to open an office there, later becoming art director of C. L. Miller \& Co., the agency handling Corn Products' advertising.

It was a joy to watch Bob Evans at work. The author would "feed" him headlines, general copy themes, possible illustrative treatments. He would wrinkle his forehead, pull out a big pad of tissue, a box of pastels, a dozen smudgy pencils, a T-square, and start in. One by one the layouts would be roughed in, torn from the pad, laid aside for later consideration. In the course of an hour or two he would have a stack of tissues. Some would be dynamic, packed with conflict and excitement, others dignified and sedate. But all would have a 


\section{THIS FASCINATING ADVERTISING BUSINESS}

spark; would have the quality of attracting attention without impeding readability; would be sound from the merchandising angle. The really expert layout men never let a desire to be an artistic show-off outweigh their sales sense.

How does a layout get made? Not by rule, says Don May, former Chicago designer, who was the first art editor of Holiday, in his book 101 Roughs. Rather it is a combination of "a large amount of labor, some muddling, a bit of imagination, a pinch of intuition, and a lot of luck." He continues:

A good advertisement actually lays itself out on paper. The material of the advertising problem is active; the designer is passive. He acts as a coil thru which the enthusiasm of the idea is conducted and registered on paper.*

Many factors influence a layout. Size and shape are usually fixed in advance. But even here the layout man can take liberties. By judicious use of white space he can often appropriate a share of the publication's margin as part of his ad. The headlines and copy must go into the fixed area, with illustrations, captions, a display of the advertiser's name or brand (the logotype) and other miscellany. The designer will work to "organize these elements"-that is, group them so that several scattered items emerge as a unit. He must consider the amount of emphasis to be given each portion of the message; the possible competition from other ads on the same or facing page; the nature of the product, which will dictate whether the layout is to be masculine or feminine in treatment, aristocratic or blue-shirt. If color is available, this simplifies the problem of attracting attention but adds other considerations. How much color should be used, and where? The amateur always wants to employ color lavishly, to get his money's worth from the additional cost; the old hand knows the value of restraint and may hold the color to a single vivid spot. Where the occasion demands, however, the veteran designer will splash his colors with all the abandon of a circus parade.

The "pattern" of a layout offers endless possibilities for variety. It may take the shape of a letter-an $S$, a $T$, a $Z$. It may have formal balance, with all elements in perfect symmetry. More often it has informal balance, with some parts deliberately off-center, large illustra-

* Don May, 101 Roughs (Frederick J. Drake \& Co., 1942), p. 11. By permission of the publisher. 
tion areas opposed by white space, a small spot of color by a bigger mass of gray.

There are fads and trends in layouts. The pendulum may swing from a very loose, airy technique to one that is compact, presumably "hard-hitting." During prosperous years the tendency in general seems to be toward a more carefree style of advertising but as conditions get less rosy the advertiser often demands ads with more "sell" and "wallop." The layout man must be able to supply this additional punch without sacrificing too much of the spontaneity and charm and good taste which he has had such an influential part in bringing to the ad pages of America's periodicals.

\section{Finished Art}

The ad designer seldom makes the final drawings or paintings which he indicates in his layout. The general practice is to turn this work over to artists who specialize in a particular type of art. Sometimes where an agency or advertiser has a large volume of such work it will have full-time artists on the pay roll, but as a rule the jobs are handled in studios or by free lances.

In the larger cities, art studios may employ dozens of artists-one or more to do illustrations, others who are adept at drawing still lifes (furniture or foods or replicas of the package, for example), others for hand-lettering, photo-retouching, and other semimechanical forms of art, and a few beginners or apprentices to handle odd jobs such as pasting up, trimming and shipping. Salaries vary according to ability and demand. At this writing (1947) good journeymen artists are making from $\$ 50$ to $\$ 150$ a week. Above that figure many studios work on a percentage basis, sometimes dividing 50-50 with the artist after guaranteeing him a fixed minimum. Free-lance artists often reduce their overhead expenses by sharing studio space co-operatively; they may go farther and retain a representative to get in touch with agencies, advertisers and other users of art, paying him a commission which may run from 10 to 25 percent of the gross price.

The principal kinds of advertising art are pen-and-ink, dry brush, wash, pencil, crayon, pastel, tempera, water-color and oil-or a combination of two or more of these media. Pen-and-ink, dry-brush (done with India ink and a brush which is kept almost but not quite dry, to give loosely shaded effects) and wash drawings (done with a brush 
using gray tones similar in effect to photography) are the most frequently seen newspaper art forms. Pen-and-ink drawings are often given body by the use of Ben Day, a mechanical shading process. Crayon or grease pencil work on scratchboard, producing mottled surfaces where desired, will also reproduce satisfactorily on newsprint.

Tempera (show-card colors) and water color are most often seen in magazine and direct advertising color work, as well as for posters and window displays, although oil paintings are not uncommon.

\section{Advertising Photography}

Photography has enjoyed an increasing vogue among advertisers over the past 20 years. Formerly photographs were used chiefly for realistic subjects, such as catalogue illustrations, portraits of testimonial givers, landscapes, on-the-job shots for industrial publications. Then led by Edward Steichen, Lejaren Hiller, John Paul Pennebaker and a few more, photographers began to make advertising pictures that told dramatic stories. The "candid" or unposed type of picture became more popular. Color photography was vastly improved and it is now possible to get good color pictures of people doing things instead of merely sitting like ventriloquist's dummies. Cooked foods could be photographed quickly in color before they had a chance to congeal into unappetizing messes. Interesting new angles were tried out-bird's-eye and worm's-eye views. Motion-picture techniques were applied to still photography. The quality and intelligence of photographic models showed a marked upward trend, chiefly through the influence of model agents like Powers, Thurston and Conover in New York and the Seamans in Chicago.

Equally important with any of the above developments in popularizing photos for advertising was the fact that art directors and layout men learned new ways to use them. Traditionally, for example, it was considered almost criminal to cut off the top of a person's head in reproducing a photograph. But an advertiser of tooth paste had no particular interest in giving prominence to a coiffure; why, then, give valuable space to a full-face picture in which the teeth would be only one small detail? The answer was logical: crop (cut off) the unessentials, thereby spotlighting the one part of the photo that mat- 
tered. Knowing where and what to crop from a photo is an art.

It might be asked why, if photography has reached such a peak of perfection, drawings or paintings should ever be used. There are many reasons. For newspaper use, line drawings have been found to give the most "foolproof" results. Many newspapers print halftones of photographs with great clarity, but for clean-cut impressions penand-ink, scratchboard, woodcut style or contrasty wash drawings are safer. Then too, the artist can take liberties, emphasize certain features, glamorize a product sometimes more effectively than the photographer. Witness the typical fashion drawing, often nine or ten heads in height!

Many advertising men feel that it is a great deal easier for an ad reader to "identify" himself with a drawing of an individual than with a photograph. The drawing might be you; the photograph can't be, since it is obviously someone else. This may be a significant factor in the continuing popularity of drawings for certain types of products. And of course the fact that so many photos are used makes hand-done art appeal to the advertiser who wants to be different.

Setting up a scene for an advertising photograph may involve almost as much work as preparing for a movie. For a table setting, as an example, linens, dishes, silverware, flowers and other properties must be obtained. A home economist is often engaged to cook the food and arrange it tastefully. Color schemes must be painstakingly studied so that the tone of the product is not overpowered by the dishes and napery. Similar care must be taken with other subjects.

More and more commercial photos are being taken "on location." Alden's Chicago Mail Order House sent a group of models to Arizona to make color shots of fashions for its catalogue. "Miss Rheingold" goes to Florida and California for photos to be used in advertising Rheingold Beer. New models of cars are sent to exotic locations to be photographed.

Retouching is seldom used with color photography or candid-camera shots. Its main uses are to cover defects, to accent important features of a product and to improve reproduction qualities. The retoucher usually works with an "airbrush" which projects a mist of the desired tint onto the photo. Parts not being treated are covered with a "frisket" paper cut out in the proper shape. Expert retouchers can match virtually any photographic tone. 


\section{Hand Lettering and Typography}

The words of an advertisement can be reproduced in one of two ways: type, or specially drawn letters. Except in rare cases, the body copy is always set in type. But the headline and other display portions of an ad are frequently hand-drawn in order to obtain exactly the gradation of emphasis, the quality and tone sought by the advertiser.

Type comes in a variety of designs or "faces" as will be apparent on studying the letter formations on any newspaper or magazine page. Art directors and layout men must be familiar with the different faces in order to select those suited to each message. Some types are dainty, gracious, feminine; others brisk and vigorous; others rugged; others, normal and matter-of-fact. The same words set in different type styles will not only look different but actually have a different impact on the reader.

Families of type are variations in the same basic letter style according to thickness of strokes and other minor changes. Thus Caslon, a type family similar to the style in which this book is set, has such members as Caslon Old Style, Caslon Bold, American Caslon (a medium weight), Caslon Condensed and Caslon Shaded (an outline letter). Caslon Old Style has a variety of offshoots usually identified by numbers, the most popular being 471 (long "descenders," i.e., parts extending below the line like the tail on a " $y$ " or " $\mathrm{p}$ ") and 540 , with shorter descenders. Each style has a "roman" or upright version, and an "italic" or slanting form. It comes in many sizes, distinguished according to the "points" in depth which each occupies. A point is 1/72 of an inch; hence six lines of 12-point would fill an inch if the type were set solidly, one line below another. Normally in advertising, type is "leaded" or spaced between the lines for easier reading.

Besides the letter shape, type faces vary according to their "serifs"the small projections at the tops and bottoms of letters. Caslon serifs, for example, are thickest near the main stroke and taper outward. This is a characteristic feature of "old style" type. Other type families in this same feeling are Baskerville, Garamond, Goudy and Cooper. The so-called "modern" faces have a straight serif with no taper. Bodoni and Century are the best examples. A type face which has no serifs-the kind usually seen in newspaper headlines, for ex- 
ample, is known as a "block letter," "Gothic" or "sans serif." The original Gothics were crude and too cheap-looking to satisfy any except bargain-basement advertisers. In recent years a number of beautiful sans-serif faces have been designed, including Futura and Spartan (in which all strokes are uniform width) and Lydian (thick vertical, thin horizontal strokes). A fourth general style is the "square serif" letter, in which the serifs are the same thickness throughout as the main body strokes. Examples of this style are Stymie and Girder.

With the growing use of hand lettering, especially "script" which simulates handwriting, a number of type faces have been introduced to approximate these hand-letter effects. Most favored by advertisers are Kaufman Script, Trafton Script and Brush. The letters are so designed that when set into words they seem to flow together as though drawn in a unit.

Besides these the ad designer has at his command an enormous range of novelty faces. There is Stencil, a bold type with breaks in the letters just like those seen in stenciled wording on shipping containers; Balloon, a face resembling the typical comic-strip lettering; Typewriter, whose name is self-explanatory; Beton Open and other faces with shading along one side for a "third dimension" effect; Legend, resembling the calligraphy on an old manuscript; and a number of faces revived in recent years from the gaudy theatrical poster types of the 1870's-one of which is appropriately called Barnum, another Playbill.

When to use hand lettering and when to stay with type headings is largely left to the discrimination of the ad designer, though budget limitations may sometimes make type headings imperative. Hand lettering is prevalent in national advertising. Its greater flexibility permits words to be "packed" without appearing crowded when space is at a premium. It gives the informality of personal penmanship far more effectively than even the best of the script types. It imparts greater individuality to an ad. Most important, it makes possible an evenness of "color" throughout the heading whereas type tends to appear spotty when set in display.

Good typography has come to be considered an indispensable part of good advertising. While most publications will set an ad in type on request, virtually all national advertisers and a great many local ones now use the services of an advertising compositor or a printer 
A "FAMILY" OF TYPE FACES

BODONI BOOK.... a light faced text type BODONI BOOK ITALIC...for emphasis BODONI (REgULAR)... a favorite for ads BODONI ITALIC ... brisk and legible BODONI BOLD..one weight heavier BODONI BOLD ITALIC. . to match ULTRA BODONI..blacker ULTRA BODONI ITALIC ULTRA BODONI EXTRA CONDENSED .. a CORVINUS MEDIUM .. akin to Bodoni CORVINUS SKYLINE . . . similar but condensed ONYX... Tall and slim, another Bodoni cousin 
Other POPUlar ad type Styles

CASLON Oldstyle No. $471 \ldots$ and Italic

CASLON No. $540 \ldots$ and 540 Italic

GARAMOND..Italic..BOLD..Bold Italic

BASKERVILLE..Bookman.. Century

FUTURA Light..Medium..Demibold..Bold

STYMIE Light. . Medium.. Bold \&cc

Kaufmann Script. . Bold. . Brush (a script)

BALLOON BOLD.. BALLOON EXTRABOLD

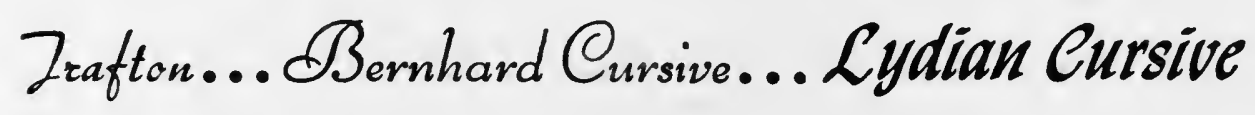

\section{STINCIL.. ORPLID..P.T. BARNUM}

\section{Franklin Gothic Condensed - Extra Cond.}

NOTE: All type specimens on these pages are 18-point size (approximately $1 / 4$ height). Variation in apparent height is due to length of descenders. Some faces, such as Stencil, come in capitals only, hence have no descenders.

-Typography courtesy of J. M. Bundscho, Inc., Chicago 
specializing in this field. The larger cities have ad shops which do nothing except set ads. These shops offer not only the widest selection of type faces in maximum assortments of sizes and weights, but also skilled typographers to arrange the text matter to best advantage. Many of these firms are members of the Advertising Typographers of America, of which Arthur S. Overbay of Typographic Service, Indianapolis, is president. Edwin H. Stuart of Pittsburgh E. M. Diamant of New York, Bertsch \& Cooper and J. M. Bundscho, Inc., of Chicago, have made notable contributions to the ad-setting art. So big has the field become that some shops specialize in parts of it. Harry Baird Corporation of Chicago, for instance, has made a reputation in the composition of mail-order and coupon ads.

Many printing plants pride themselves on producing fine typography. Norman T. A. Munder of Baltimore and William Edwin Rudge of New York were pioneers in creating beautifully designed brochures for advertisers. Lakeside Press and Runkle-ThompsonKovats of Chicago, Wetzel Brothers in Milwaukee, Harold Cornay in New Orleans and James Green, New York, are modern exponents of the creed that direct advertising can be just as well done typographically as any ad in the big magazines. In type design the industry owes much to the steady flow of beautiful and utilitarian new faces from American Type Founders, Linotype, Ludlow and other suppliers.

Art, photography and typography, the interpretative vehicles of advertising, have all shared in the renaissance which followed the "dark ages" of the post-Civil War era. All are continuing to develop, adding fresh ideas and techniques to help keep advertising fascinating. 

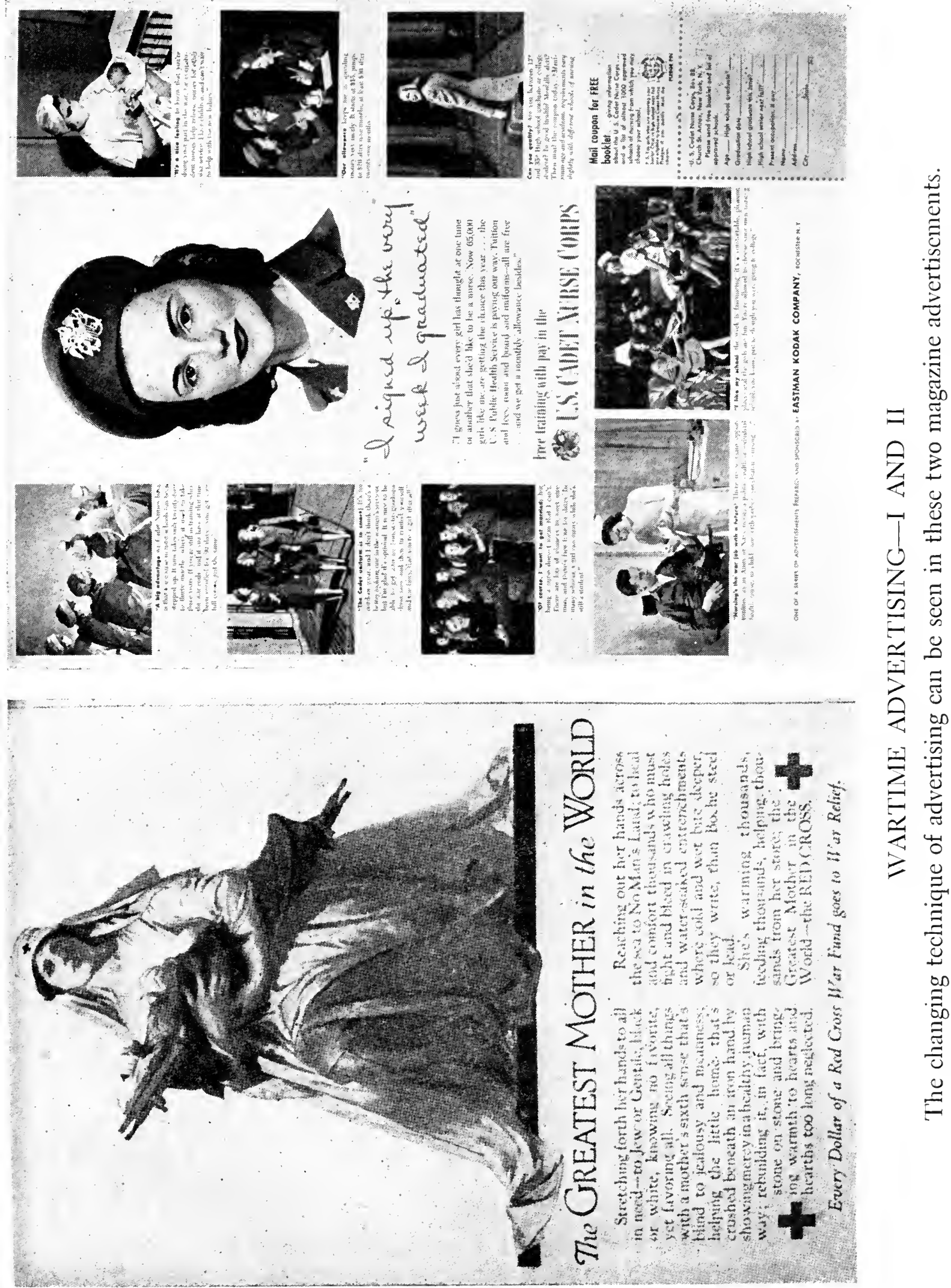


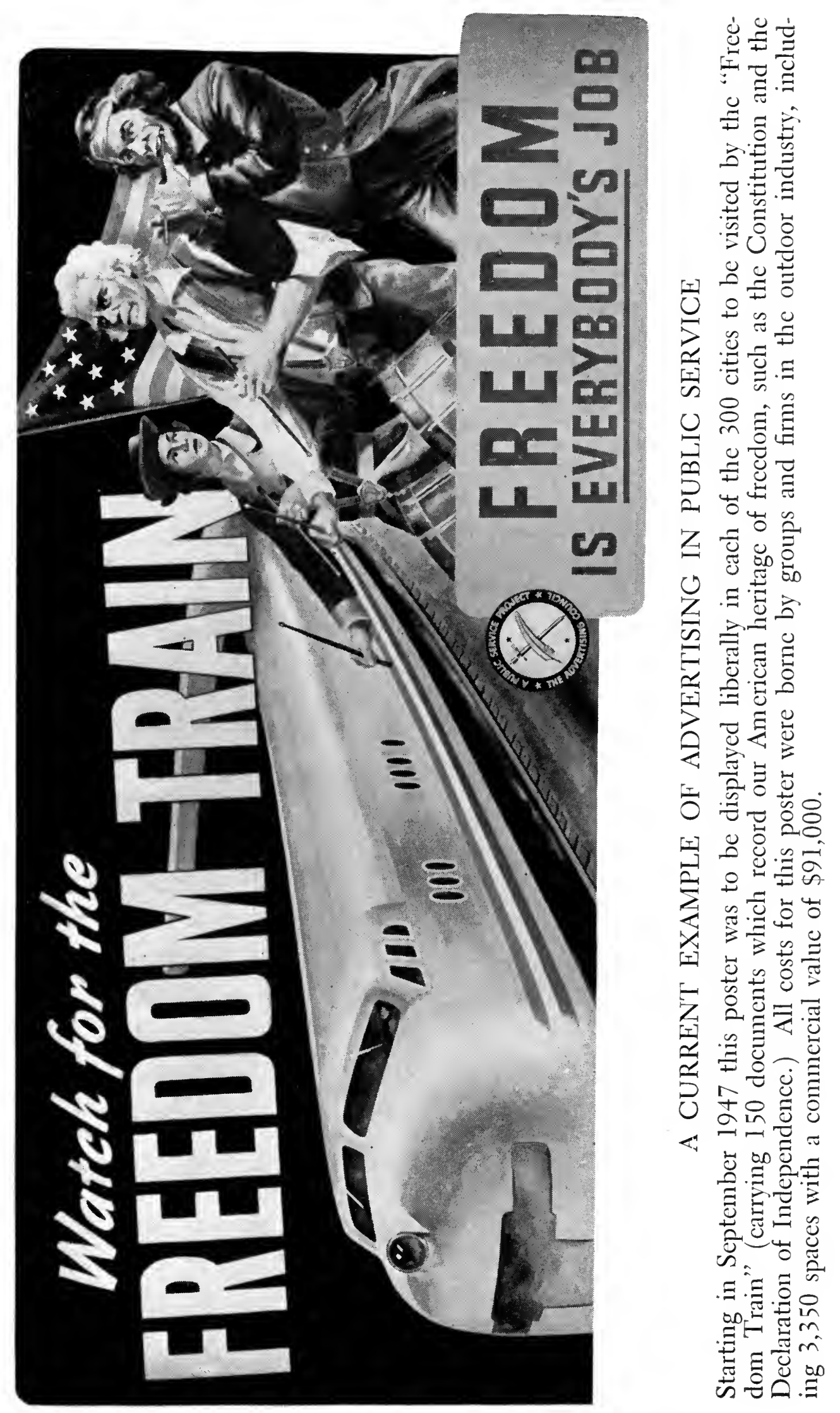




\section{ChAPTER XXII}

\section{PRODUCING AND REPRODUCING THE ADS}

$\prod$ HE advertisement has been written, approved, set in type; illustrations have been drawn, photographs taken. Now comes the

1 process of conveying these words and pictures to the publicthe complex series of operations known as advertising production.

What happens next depends upon the method by which the ad will be reproduced in its final form in newspapers, magazines, direct mail or posters. If the medium to be used is printed by letterpress, then engravings (commonly called "cuts" or "plates") and duplicate plates of various kinds will be required. If lithography or intaglio printing is used, the different elements of the ad will be assembled and either pasted into their exact position for reproduction or the printer furnished with detailed instructions so that the elements can be "stripped" into place when the reproduction negatives are made.

Since letterpress is the method used in printing nearly all newspapers (except the rotogravure sections) as well as most magazines and books, the logical order of procedure is to explain how letterpress plates are made.

\section{Photoengraving}

Printing by letterpress requires plates with raised surfaces that will receive the ink. In between the raised surfaces will be depressionsthe parts that do not print. To obtain the necessary variations a photographic negative is made of the "copy" (which might be anything from a proof of type matter to an oil painting), this being the exact size desired for the finished plate. This negative is placed against a sensitized sheet of metal and exposed to a strong light. The parts not shielded by the dark parts of the negative will harden. These areas are built up with a protective coating and the plate is "etched" in a series of acid baths to eat away the unwanted portions. This is a slow and complicated operation, for it is here that the printing quality of the plate is determined. After the plate has been etched it is 
trimmed, the excess or "dead" metal routed out by high-speed machines, and the finished job either mounted on a block of wood or delivered unmounted. The final step is the pulling of proofs, which the engraver studies to correct any defects hitherto unnoticed.

There are two basic types of photoengravings, line etchings and halftones. Line etchings (sometimes called "zincs" because that is the metal generally used) have only a single tone. With a zinc everything is either black or white. True, the black areas may be made to look gray, as with a scratchboard or pen-and-ink drawing containing many fine lines, but the actual printing surface will be black.

Halftones, on the other hand, can show any gradation between solid black and pure white. This effect is achieved by photographing the "copy" through a ground glass crossed with innumerable fine lines, breaking up the image into dots of varying sizes. It is the differences in these dots that determine the tone. The ruled glass used in halftone negative-making is called a "screen" and a number of lines per inch identifies the cut. Fifty-five to 65-screen halftones are commonly used for newspapers; they are termed "coarse-screen halftones," and the patterns made by the dots are easily visible. On medium grades of book paper $85,100,110$ or 120 -screen halftones may be specified. One hundred thirty-three and 150-screen halftones are suitable only for fine enamel stock. Copper is universally used for halftones although some coarse-screen newspaper cuts may be etched on zinc.

Hand-finishers scan each halftone after etching, to tool out excess dots. Where part of a halftone is too dark by comparison with the original "copy" it can be etched down; if too light, it may be "burnished" in that section, making the dots larger and thus giving a stronger tone.

Type or hand-lettering photographed through a halftone screen will be broken up into dots and appear gray, not black. If unscreened type is desired on the same plate with a halftone, this is done by superimposing a line negative of the type over the screened negative, resulting in what is known as a "combination" plate. There are other types of halftones, such as "high-light" or "drop-out" in which some areas may appear white rather than with a light screen. This treatment is occasionally used in reproducing pencil sketches. A "vignette", halftone is one in which the edge of the picture seems to 
fade away. An "outline" or "silhouette" halftone has portions of the background cut away, giving greater prominence to the subject.

Line etchings or zincs may be given simulated halftone effects by means of the Ben Day process. Certain areas of a pen-and-ink drawing are marked with a light-blue wash and the style of Ben Day indicated. There are some 200 available designs, some black dots on white, some white dots on black, others stripes, checks, herringbones, etc., to resemble fabrics. Ben Day may be applied either to the negative or to the zinc before it is etched. Patterned effects may also be obtained by applying "shading sheets" to drawings.

\section{Color Plates}

Color plates may be all zincs, a combination of zinc and halftone plates, or all halftones-the latter being known to the trade as "process" plates (pronounced with a long "o" as in "proceed"). A separate plate is required for each color.

The simplest form of color work is done with line etchings. A penand-ink drawing is made in black and white, and the breakup of colors indicated on a tissue flap. The engraver makes two, three or four line plates of the subject according to the number of colors desired, and paints out from each plate, before etching, those parts that are not to show in that color. Ben Day tones or solids may be used to give variety. This is the type of engraving work seen in the Sunday comics. It is not applicable to photographs or wash drawings.

Inexpensive halftone color results can be obtained by combining a black-and-white halftone with a zinc "tint plate" in a second color.

Color process plates are the most expensive and most attractive. They may be made from a natural-color kodachrome or color print, a hand-colored photograph, a color drawing in water color or tempera or an oil painting. Four-color process is the most common, although surprisingly realistic effects may be obtained in two colors by using an orange-red and a blue-green ink. For many years The Saturday Evening Post and Collier's covers were printed in "duotones" of this kind.

In preparing process plates the "copy" is photographed not only through a halftone screen, but through a color filter as well. For the plate to be printed in yellow ink, a purple filter is used, nullifying the red and blue tones; for the red plate, a green filter; for the blue plate, 
an orange filter. A fourth plate is made in black, to enhance the colors and "key" the whole illustration. Process plates are etched with extreme care, chiefly by hand, the color etcher working with the original art before him to bring out the precise tone values. Frequent proofs are pulled, both of the individual plates and the series printed one over the other, and further etching done as necessary. Then final proofs are made of each plate separately, of the yellow and red plates together, of the yellow, red and blue plates, and all four combined. This group of proofs is known as "a set of progs" (progressives) and is the printer's guide for reproduction of the job. It is thoroughly dissected by the art director and production manager of the agency, and by the advertiser, before receiving the final okay. A set of fourcolor process plates may cost from $\$ 500$ to $\$ 1,000$ or more.

A very essential feature of color plates is that they must "register," that is, fit exactly, one color upon the other. When plates are out of register images will appear blurred and lines of solid color may appear along the edges. Present-day magazines are miracles of precision in color printing. Since changes in humidity will cause paper to shrink or expand, pressrooms are air-conditioned. Sensitive electronic controls keep the sheets feeding exactly true, and make certain that no plate gets out of line. Fidelity of color reproduction is further assured by the use of standard colors. Publications furnish supplies of their magazine paper to engravers so that plates can be proved on the same stock as in the book. This is important, because process plates to be printed on a very white paper will be etched differently from those on a grayer or yellower stock.

\section{Duplicate Plates}

An advertisement to appear in several newspapers or magazines calls for a separate plate for each. Copies of the original plate, known as "electrotypes," are suitable for newspapers and all except the largest magazines. An electro is made by taking a wax or lead mold of the original plate and immersing it in a solution of copper sulphate, sulphuric acid and water. (The wax mold must be graphite-coated to make it an electrical conductor.) The mold is attached to a negative wire of an electric circuit and a bar of copper or nickel attached to the positive wire and also immersed. The current produces a reaction in the tank, causing metal particles to be deposited on the 
mold until a thick shell has been built up. This is then backed with alloy metal to form the plate.

Where a large number of electros is needed, an extra-strength "pattern plate" is made and the other electros made from this to avoid damaging the original engraving. The most durable type of electro is the lead-mold nickeltype, which is always specified for colorprocess work.

Less expensive than the electro is the matrix or mat, a papier-mache mold from an engraving or electro. Mats are not only cheap but can be mailed much more easily than electros. From a mat the newspaper publisher makes a stereotype, a cut which gives less satisfactory results than the electro. Plastic mats, made with a plastic material, then coated and baked under pressure, are becoming more popular because they produce sharper, clearer stereos than the paper mat, yet cost less than electros. Mats and stereos are suitable only for newspaper or handbill advertising.

Publishers of leading magazines insist on original plates, since they must make many electros of each ad for their huge press runs, and electros made from electros do not print as well as electros from originals. For an advertiser using the same ad in several publications this means almost as heavy a plate cost for the duplicate sets as for the first plates. Recently, however, a new method has been developed for reproducing plates with all the fidelity of the originals but at considerable saving. These plates are known as Reillytypes, Royaltypes, Atlantictypes, etc., according to their source. They are accepted by publications just as original engravings are.

\section{Lithography and Offset}

Unlike letterpress, in which impressions come from raised surfaces or relief, lithographic printing is done with a smooth surface. Originally it was done on porous stone, hence the name (from the Greek word lithos, a stone). Now zinc sheets may be used, treated so that the ink adheres only to that part of the surface on which a drawing or photograph has been printed. With direct lithography the paper comes directly against this surface. With offset, a rubber roller picks up the impression from the inked cylinder and this prints on the paper.

Lithography is used for outdoor posters where the design may re- 
quire as many as six, eight or ten colors to reproduce the original art. Many window and store displays, booklets and other direct advertising pieces, boxes, labels and signs are printed in offset. On long runs or jobs requiring unusually large plates offset is an economical and popular printing method.

Planographing, an inexpensive form of offset printing adapted to smaller-sized jobs and short runs, is a comparatively new development but is proving satisfactory for such work as company bulletins, sales portfolios and reproductions of typewriting. This saves money by eliminating the cost of typesetting.

For offset printing, no plates are required. The type matter and illustrations are sometimes mounted in place, as has been mentioned, or a detailed layout given to the printer. From this "copy" the necessary negatives or "transfers" are made, all combining of text and pictures being done on the negatives. A feature of offset printing is that large areas of color can be obtained merely by indicating on the drawing or layout where these are desired; the operator will then "paint them in" on his negatives.

An advantage of offset is that smooth-surface paper need not be used for the reproduction of halftones, as is the case with letterpress. "Antique" (rough-surface) paper, stocks with fancy finishes and even cover paper will give acceptable halftone impressions.

\section{Intaglio Printing}

Still a third class of printing is that done by the intaglio method (pronounced "intal'-yo" in the dictionary but just like it's spelled by everybody else) in which the subject to be reproduced is etched into the metal instead of standing out above the surface as in letterpress. This results in a series of tiny pockets which catch the ink as the inktrough meets the cylinder. The surface ink is then wiped off by steel knives known as ductor (or "doctor") blades after which the paper passes over the cylinder and by suction draws the ink out of the etched pockets.

The intaglio process is the basis of all rotogravure and color-gravure printing. Perhaps no branch of the graphic arts has made such startling progress during the past few years. Today Sunday newspapers all over the country are delivering full-color reproductions of famous paintings, actual color photographs of local scenes and celeb- 
rities, and beautifully illustrated feature stories in their gravure supplements where not so long ago the first color-roto efforts were blotchy, out of register and anything but pleasing to advertisers.

Several national magazines, including the Crowell publications, Collier's, American Magazine and Woman's Home Companion, are printed wholly or in part in gravure.

The rotogravure press is an incredible machine. It takes a roll of paper, prints one side in monotone (one-color) gravure, then in rapid succession prints yellow, red, blue and black impressions on the other side, passing the web of paper over a heated drum between each two contacts to dry the ink and prevent smearing, then shoots the paper to the assembler and cutter, from which it emerges in the form of completely gathered, folded and trimmed color-gravure sections-at the rate of 10,000 or more copies per hour.

Rotogravure is printed from etched copper cylinders each with as many as 12 full-sized newspaper pages. The etching is done after the cylinder has been covered with a carbon tissue containing the images, which deposits an acid-resisting gelatin coating on the copper. Halftone and line work are etched separately. Afterward, the cylinder is cleaned and dried. The etched impressions can scarcely be felt, but they are deep enough to hold the "soupy" rotogravure ink during the half-cylinder revolution from the ink trough up past the ductor blade to the paper.

The screen in gravure is the reverse of photoengraving. Instead of black lines the gravure screen has transparent lines with black dots between, since the dots must be etched into the printing surface. Gravure screens are usually finer than in letterpress, a 150-line screen being customary.

One thing about both offset and gravure which makes advertising men very unhappy is that once the art and copy have been arranged, there are no proofs to correct-the ad must run "as is." And to the account executive or client who is a fast man with a blue pencil, that's very bad news indeed. 


\section{CHAPTER XXIII \\ TO MARKET! TO MARKET!}

W

HEN a new product is about to be launched, when sales wane in a hitherto productive territory, when results from a campaign are unusually good or unusually bad, the experienced advertising man has two comments.

1. "Let's get the facts about that market!"

2. "Let's ask some questions-find out what people are thinking."

Getting facts and asking questions both come into that phase of advertising known as research (not to be confused with technical or industrial research, which deals with materials and machines.) There is a wide gap between market research and analysis on the one hand, and consumer or dealer opinion investigations, but they are alike in one respect. All fact-finding efforts represent a desire to eliminate guesswork from the advertising program.

M. C. Otto tells about a very lively dispute that occurred in a monastery in the year 1432 A.D., having to do with the number of teeth in the mouth of a horse. Books and documents going back to the earliest times were brought forth to support this or that position. The monks argued brilliantly for 13 days but the problem remained insoluble. Finally a youthful friar asked permission to speak. "To the wonderment of the disputants," the monastery's chronicle reports, "he beseeched them to unbend in a manner unheard of, and to look into the open mouth of a horse for an answer to their questionings. At this, their dignity being grievously hurt, they waxed exceedingly wroth; and joining in a mighty uproar, they flew upon him and smote him hip and thigh, and cast him out forthwith. Surely, "the chronicler concluded, "Satan hath tempted this bold neophyte to declare unholy and unheard-of ways of finding truth contrary to the teachings of the fathers."*

Present-day advertisers do not hesitate to "look into the open mouth of a horse" for the information they seek. The agency without a research director is as rare as one without an art director. Many

* From Otto, M. C., The Human Enterprise, published by F. S. Crofts \& Co., 1941. 328 
manufacturers have their own full-time market analysts and some have large departments. Department stores and chains make extensive use of research, as do virtually all advertising media and trade associations. In previous chapters of this book various types of research have been discussed.

Unquestionably advertising research has done much to provide constructive data and help the campaign planners to avoid serious mistakes. At the same time, such research is far from being an exact science. The results of a hastily prepared survey may lead a business astray if taken too literally. Sam Gill, research director of Sherman \& Marquette, Inc., New York agency, proved this in reporting the results of two "opinion polls." In one case a group of people was asked: "Which of the following statements most closely coincide with your opinion of the Metallic Metals Act?"

It would be a good move on the part of the U. S. (21.4 percent). It would be a good thing but should be left to individual states ( 58.6 percent).

It is all right for foreign countries but should not be required here (15.7 percent).

It is of no value at all ( 4.3 percent).

The percentages represent the answers of 70 percent of the total; 30 percent had no opinion. The National Metallic Metals Act existed only in the mind of the individual who planned the poll. In another test consumers were asked several questions, including: "Are you in favor of or opposed to compulsory education? Are you in favor of or opposed to workmen's compensation laws? Are you in favor of or opposed to incest? Are you in favor of or opposed to lowering corporation taxes?" The answers to three of the questions are unimportant; on the other, after eliminating 40 percent who had no opinion, results showed 33.5 percent in favor of incest.*

Discounting the proved fact that many people will answer questions on subjects of which they are sublimely ignorant, modern consumer research has been built on the equally well established basis that the average person in America, if asked about his personal dislikes and likes, will give a frank response. Much depends upon the

\footnotetext{
"How Do You Stand on Sin?" Tide, March 14, 1947, p. 72. Quoted by permission of Tide.
} 
wording of the questionnaire, the care with which the "sample" or cross-section to be interviewed is selected, and the skill of the investigator. These are all areas in which marked progress has been made in recent years.

\section{Market Analysis}

The old wheeze about trying to sell iceboxes to Eskimos and fur coats at the equator is no more far-fetched than was the thinking behind too many ad campaigns before market analysis became prevalent. Innumerable advertisements have been run on the same strategy as that expressed by Longfellow: "I shot an arrow into the air; it fell to earth, I know not where." Often-such is the dynamic power of advertising - the arrow found its mark. But with narrowing profit margins, rapidly rising costs for labor and materials and increasing competition for sales, old hit-or-miss methods had to go. Today the business that does not study its markets scientifically and continuously is operating on a gambling basis. It is not only jeopardizing the investment of its stockholders and bondholders but also the future of its wage-earning employees and, indirectly at least, the whole economic system upon which our present standard of living is based.

The first recorded instance of market analysis in the advertising field happened in 1879. Henry McKinney of N. W. Ayer \& Son had been soliciting the account of Nichols-Shepard of Battle Creek, Michigan, manufacturers of threshing machines. He asked for a list of papers in which ads were to be run. "Make up your own list," was the reply. "We want to advertise wherever we can sell our product." "Where do you sell them?" "That's for you to find out," was the challenging reply. And find out McKinney did. At that time the U. S. Department of Agriculture had not been created; so he sent telegrams to every state and to agricultural publishers likely to have information. The Ayer staff worked day and night to compile data on production of wheat, oats, rye and other threshable grains by states and counties, weighing these facts against all available figures on farmpaper circulation and rates. The manager of the company was amazed when he saw the Ayer report, said he'd been trying to get such information for years, and asked the price. "It is not for sale," Mr. McKinney replied. "We are not in the book business, we are in the advertising business. If you are our customer, it is yours for the 
asking." There was no resisting this appeal, and the firm's order, amounting to $\$ 18,000$, was telegraphed to Philadelphia.*

Spasmodic attempts at market analysis were made by manufacturers, agencies and media as advertising grew in importance. But the real birth of the science-if such it can be called-happened in 1911 when Charles C. Parlin launched his first market surveys for the Curtis Publishing Company, which had recently acquired Country Gentleman. He set out to find where farm implements were sold, by whom and to whom. The object, of course, was to sell more space in the magazine to more advertisers. It worked very well. Since then many magazines, newspapers, radio and other media have made market investigations, some of which have already been touched on. Advertising agencies have studied statistics supplied by the Departments of Commerce, Labor, Agriculture, Treasury, other federal and state bureaus, local chambers of commerce and whatever other source material was obtainable. National and regional magazines have analyzed their subscription lists, occasionally felt the pulse of their readers with questionnaires. Newspapers have made "pantry surveys." Business papers have applied the microscope. The net result has been a much more accurate knowledge of who buys what-where, when and why.

So many different products and services use advertising that each company becomes a separate problem. To illustrate: the modern automobile is a specific and easily defined article of commerce. Yet how does one set about determining the market for, say, a Chevrolet, as against that for a Lincoln? A study of Lincoln registrations (based on license applications) might show a high percentage in low-income areas; it would take further analysis to reveal that these are used Lincolns bought either because the purchaser wished to impress his neighbors or because he intended to use the machine as a taxicab. Similarly, many people with upper-strata incomes buy Fords or Chevrolets or Plymouths either because no other car is obtainable at the moment or to serve as understudies or replacements for their higher-priced machines.

In recent years dozens of firms have sprung up to meet the advertiser's demand for facts about his investments for marketing pur-

* Reprinted by permission of the publishers from Ralph M. Hower, The History of an Advertising Agency: N. W. Ayer \& Son at Work, 1869-1939, Cambridge, Mass.: Harvard University Press, 1939. 
poses. The majority of these are research organizations employing investigators in various cities and offering opinion surveys-similar to the Gallup poll on political matters-with regard to buying habits. The advertiser prepares a questionnaire covering the main points in his sales and advertising plan, and this is made the basis of a market analysis, regarding the salability of a certain product. The number of persons interviewed is relatively small compared to the total population of a particular area or of the entire country. However, it has been scientifically demonstrated that if a representative cross-section of any given market is chosen for a survey, at a certain point the responses will "level out" and thereafter only a slight variation will be observed. Research men gauge the size of their sample from experience. After having studied a few hundred or a few thousand responses they are able to project the average for the entire section.

A survey of national buying habits might cover say 2,000 homesout of $39,000,000$ in this country. But with the proper selection of "average" families the survey figures might stand up even though every home in the United States were covered. This is the basic principle of consumer research.

Market analysts, however, seldom resort to consumer investigations. They focus on such statistics as number of dealers in a town, total and average retail sales, fixed buying habits, known brand preferences, economic status and other factors. They obtain an accurate "picture" of the market by combining figures with opinion studies. In the past two decades, thanks to governmental activity, media research, and a myriad other sources, advertisers are able to base their expenditures on a relatively sound scientific background.

\section{Consumer and Dealer Studies}

Market analysis is primarily concerned with deciding which sections of the country or which types of individuals are the most logical prospects for a sales and advertising push. Consumer and dealer research devolves around the matter of ideas: ways and means of selling a product or service. The matter of where to sell is not germane; the problem is solely a question of how and what. A local retailer, for example, does not need to be briefed as to the scope of his market. It includes all those within easy riding distance. Nor does this fret the manufacturer with national distribution. His market is the whole 
nation. But in each instance, the advertiser needs to learn the type of appeal, the price range and other factors that will make sales easy or difficult. Consumer research can give a clue to the mystery.

To be reliable, consumer or dealer surveys must be impartial, free from any influence either by the wording of the questionnaire or the bias of the interviewer. When the respondent is asked to express a choice, it must be between things of comparable value or benefit. The information desired must be sought with a minimum of annoyance and delay, lest the persons interviewed become bored and answer thoughtlessly or end the interview before all facts have been ascertained. And obviously, the subjects interviewed must be bona fide users or prospects-otherwise their opinions have no value.

Surveys are conducted in three ways: by mail, personal call, or telephone. The mail method, while generally evoking a smaller percentage of replies, can be done more quickly than either of the others. The respondent, moreover, is not influenced by the personality of the interviewer or his own activities. If he is busy, he will either put the questionnaire aside for a leisure moment or not answer at all. Many business and industrial surveys are handled by mail for this reason. The Dartnell Corporation, publisher of sales and executive material, relies almost solely on mail investigations, and has since it was founded in 1916 by J. C. Aspley. Many of the widely quoted surveys by Fortune are based on mail queries. Companies with large numbers of salesmen or distributors may find out what the organization thinks about a proposed campaign or product in the same way.

Consumer polls may be used to determine the extent to which an advertising idea has registered. In 1945 Stuart Peabody, in charge of Borden advertising, wanted to learn whether people knew the origin of his company's trade character, Elsie the Cow. A survey showed that 58 percent of the people did-as against 48 percent who knew the correct identity for Einstein and 43 percent for Van Johnson. In 1947 another survey showed a 63.5 percent recognition for Elsie, compared with 40.2 percent for Chief Justice Fred Vinson and 20.1 percent for Alfred P. Sloan.

The case for continuing consumer research was stated by A. C. Nielsen, head of his own survey company since 1923. In a recent speech he stated that his organization kept a "box score of executive judgments" which showed the average businessman to be right only 
58 percent of the time. To increase accuracy, he said, there is no substitute for research at the consumer level and for charting the flow of goods from retailer to consumer.

Marketing specialists are concerned over the fact that the average business invests a relatively trifling amount in research. A study among members of the National Association of Manufacturers in early 1947, supervised by the American Marketing Association, revealed that few companies had consistent research programs in the marketing field, and that these spent an average of less than 0.3 percent of net sales for this essential activity. There was evidence, however, that "top management"-presidents and chairmen of boards of directors-was realizing the value of this work and that more companies were planning to expand it.

Many advertising people have found research a practical means of getting into the field. There is always a need for interviewers. Housewives earn extra spending money by making calls occasionally to fill in questionnaires door-to-door. Elderly people and high-school youngsters take naturally to this work, generally on special assignments from companies specializing in market research.

Informal investigations are frequently staged by agency employees. In work on a campaign, questions may arise as to dealer or consumer attitudes, whereupon various staff members may leave their desks and head for the stores or the residential areas to "ask some questions." While such impromptu studies lack the validity of carefully chosen "samples" they undeniably help to keep ad planners and writers in touch with the masses. Interrogating salesmen just in from direct contacts with jobbers, dealers and consumers is also recommended as a means of retaining the common touch. Reports from various advertising media and articles in business papers also help the advertising man to keep posted on market developments.

\section{Point of Purchase}

The "last three feet" which separate the prospect from the product may be the most vital of all. Advertising has not done its job if the intended purchaser does not go through with his purchase.

With many products, this crucial moment occurs in a retail store. National advertising has aroused interest. Newspaper or radio locally may have intensified this predilection. But unless and until the pur- 
chase is made, all this preparatory work may be futile. No wonder makers of advertised products are so keenly alive to the need for "point of sale" displays!

Window streamers, colorful window displays, eye-catching signs and banners and posters inside the retail establishment, all come under this heading. Large sums of money are invested annually by advertisers to make sure that the customer will remember a specific brand when the buying is done. This job is normally entrusted to two channels-window and interior pieces.

Posters or banners pasted on the windows are as a rule simple in design. Price is often featured prominently. Material prepared for drug and cigar store windows may be quite elaborate. Large easelback cards of pretty girls may be used by the cigarette companies. Most grocery windows, if used at all, contain mountains of fresh produce, canned and bottled goods. The food-store advertiser generally confines his efforts to the interior. Many stores have overhead wires from front to rear, over which are draped gaily colored paper signs known as "wire hangers," supplied gratis by food manufacturers. Above the shelves may be wall posters. Along the narrow shelf ledges may be strips of cardboard, colorfully advertising special products. If the manufacturer is so fortunate as to obtain a "mass display" (a large stack of cans or packages in the aisle) this may be adorned by a card or poster. Close to the cash register-to catch the "impulse" buyerwill be counter cards and a small display of the favored merchandise. In the drug or hardware store this is apt to take the form of a showing in a specially built rack or case. It can be guaranteed that these choice spots are the result of special pleading by the manufacturer's or jobber's salesman.

All of these devices are aimed to create sales. The Point of Purchase Advertising Institute has made a special study of this field and has information on window displays, counter, shelf and "back bar" pieces. Most of this material has brief copy-a slogan, the brand name and possibly a picture of the package. Its purpose is to remind the purchaser of a name already familiar through advertising and thereby bridge the inevitable gap between producer and consumer. 


\section{Chapter XXIV}

\section{GETTING IN AND GETTING ON}

"DVERTISING seems to be one of the professions with the greatest appeal to returning service men," wrote Robert T. 1 Kesner, American Home Foods' director of Advertising, in May 1946. "While I was in the Navy perhaps the question most frequently asked me was, "How do I get into advertising when I get the hell out of here?" "

From the author's own observation, extending over 25 years, there is only one thing wrong with Mr. Kesner's comment: it shouldn't be limited to ex-GI's. Nonveterans, stenographers, schoolteachers, salesmen, farmers, retail clerks, printers, housewives, elevator operatorsthese are only a few of the types who have besought his help to crash the gates of the advertising arena. Some it has been possible to aid. Others, seeking some mystic password or skeleton key, have shaken their heads and gone away muttering about "the brush-off."

Charles F. Kettering told a story at an advertising convention many years ago that illustrates the advice of many veteran ad men on being asked how to get into their field. It seems he was driving through the Kentucky mountains and lost his way; finally he stopped to ask an old native how to get back to Cincinnati. The hillbilly scratched his head, mentioned various routes and rejected each one. "Well, stranger," he said at last, "if I was a-goin' t' Cincinnati-I wouldn't start from here!" By the same token, the road to success taken by probably the majority of leading advertising men and women did not start with advertising.

Creating merchandising plans that produce sales, layouts and copy that win attention and action, calls for more than superficial skill. Ability to put words together is desirable but by no means essential. A knack for making attractive designs or coining catch phrases will help, but again this is not indispensable. The fundamental requirement of a good advertising man, in the opinion of many of its topdrawer practitioners, is a deep-rooted knowledge of why and how people buy.

"Advertising is the business of selling with words and ideas," Mr. 336 
Kesner told the ex-GI'S. "Its sole purpose is to move goods to people, making people buy. It is vitally concerned with profits, with breaking consumer habits, with bettering standards of living ... a at a price, of course. If you want a job in advertising, the best background in the world is that of selling the products or the services you hope to represent. If you want to write copy for foods, or manage advertising for foods, or do research or merchandising or publicity for foods, you had best know what foods are all about and why people buy them and what the prices are and where these foods are sold. Go out and sell the foods. You may make only thirty or forty fast bucks a week, Colonel, but a year from now you'll have the edge on everyone else who wants to get into food advertising but doesn't know the first thing of what is behind successful manufacture, distribution and movement of foods from producer to the little woman who winds up buying them. Education and personality and character all help, but knowing the fundamentals is the great shining treasure you can possess that all your cousins will lack."*

Note that Mr. Kesner does not say the only way to break into advertising is via the sample case and the order book. He merely gives it as his opinion that the best background is selling the products or services for which the aspirant wishes to do the advertising. There are sound reasons for this advice, in addition to that of acquiring firsthand knowledge as to what that particular type of product or service "is all about." Selling, whether store-to-store, door-to-door, or over the counter, gives the observant individual endless opportunities to study human nature. Theories about psychological reactions are all very well, but the successful salesman —and ad man-must be an applied psychologist.

Raymond Rubicam, one of the greatest of contemporary advertising men, put it this way in writing to a young man just out of college who had held a selling job briefly but wanted to leave it for advertising work:

... I repeat that I think you would never be quite so good an advertising man if you left selling now and went into advertising as you would be if you gave yourself a couple of years of selling experience.

Your advertising judgment would be entirely too personal and

* From The Palm of Alpha Tau Omega, June 1946, pp. 9-10. 
"artistic" and theoretical, and not nearly practical or hard-headed or commercial enough.

There are two types of people in this business who are only halfgood. One is the hard-headed individual with "practical" merchandising experience and knowledge, but with no imagination or intellectual talents. The other half-good man is overweighted on the opposite side. To him advertising is (whether he admits it or not) principally a means of personal expression of an intellectual or artistic sort. He approaches it subjectively, not objectively; his standard is likely to be to please and satisfy himself-not to reach and satisfy the masses of people.

Many of the most talented youngsters who want to go into advertising are at the outset in this latter class. Nearly all the dull ones are in the former. The great ones are the ones who, starting with talent, are hard-headed enough, patient enough, tough enough and objective enough in their outlook to learn about people by mixing with them and to find out about selling by engaging in it.*

In addition to these vital benefits of a sales background to the would-be advertising man, there are others. For one, advertising in recent years has become so closely integrated with sales that a knowledge of sales-department functioning is virtually a must. And from a personal angle, any worker in the advertising field who expects to go beyond mediocrity should be able, when the occasion demands, to sell himself and/or his ideas. The glib extrovert does this intuitively. The introvert-a type far more often met in the creative end of advertising - had best learn to do it early in life, or forever after suffer frustration and obscurity.

Next to selling, newspaper reporting seems the most favored pathway to advertising. The reporter encounters humanity in all aspects and under all conditions. He acquires another valuable asset of a good adman, the capacity to ferret out facts and to sense the most appealing features of a story. He gets training in working under pressure, in meeting deadlines, in subordinating his personal views for the sake of the assignment. A big part of a reporter's job consists in asking questions-and so it is in advertising!

Closely akin to personal salesmanship is selling by mail. A large group of advertising top-notchers first tried their wings on form letters, circulars, and catalogue copy for mail-order firms like Montgomery

* Walter A. Lowen and Lillian Eichler Watson, How to Get a Job and Win Success in Advertising (Prentice-Hall, Inc., 1941), p. 362. By permission of the publisher. 
Ward, Sears Roebuck, Spiegel's. Others were correspondents for book publishers, home-study schools, firms selling through agents. No apprenticeship is quite so exacting as that of writing copy whose returns are directly traceable. Mail-order executives are severe critics, and the writer who can survive under their pay-as-you-go standards has learned a valuable lesson in making words count.

Notwithstanding the above, plenty of important advertising people started right out with an agency or an advertising department. But they are the exceptions; and they have had to acquire their background of selling knowledge as they went along. Just as there are occasional Bobby Fellers and Christy Mathewsons who jump to the major leagues with no minor league experience, so some folks have started their advertising careers in posts which the majority reach only after years of seasoning. This sort of thing, however, is steadily becoming less frequent as the profession grows more complex, more professional. The beginner today would be well advised to acquire a basic understanding of human nature, of selling strategy, of business procedure, in one of the ways suggested above before attempting to storm the inner fortress.

\section{Getting Started-Some Examples}

In Chapter XII allusions were made to the methods by which some advertising people gained a toehold in the profession. It might be of interest to check up on a few more.

Homer McKee, who for many years headed his own advertising agency in Indianapolis and Chicago and is at this writing a vicepresident of Roche, Williams and Cleary, began life-like John Barrymore and Gary Cooper-as a newspaper cartoonist, filling that role for seven years with the Indianapolis Star before becoming advertising manager of the Cole, and later of the Marmon Motor Car Company. His start was in marked contrast to that of Otis A. Kenyon, chairman of Kenyon \& Eckhardt agency in New York, who was chief engineer of the Arc Welding Machine Co. before entering the advertising field via the technical press. Another who took the technical route is Edgar Kobak, president of the Mutual Broadcasting System and former vice-president and general sales manager of McGraw-Hill Publishing Company. He had previously been an engineer in the department of tests and repairs for Georgia Power Company. 
Ted Patrick, a copy supervisor for Young \& Rubicam before the war, later with OWI, then head of creative work for Compton Advertising, now editor of Holiday, began as a newspaper man. Following this he took a fling at professional baseball before entering the agency field. Henry T. Ewald, who in 1947 held among other distinctions that of heading the oldest agency in the United States founded and still directed by the same individual, in 1904 went to work as a ticket taker for the Detroit \& Cleveland Navigation Company, later becoming its advertising manager. He launched Campbell-Ewald Company in 1911 with D \& C as one of his first accounts (others now include Chevrolet, U. S. Rubber, Burroughs Adding Machines, Delco, Norge, Foulds Macaroni).

Jackson McQuiston, for more than 30 years advertising manager of Westinghouse Electric, started as a clerk with the Pennsylvania Railroad. E. H.Calhoun, advertising manager for American-Marietta Company, was a clerk for Tennessee-Eastman Corporation before deciding that merchandising was what he most wanted to do. Lyman Weld, treasurer and account executive of Mitchell-Faust Advertising Company, reported news for the Rock Island Argus in his early days. Joseph Epstein, vice-president of Fitzgerald Advertising Agency, was a feature writer for the New Orleans Item. Helen Wing, who occupied an office adjoining the author's at Needham, Louis \& Brorby some eight or nine years ago, was a writer of children's stories before going into the agency field.

For women, department stores and secretarial work seem to offer the best entrees. There are numerous instances of talented young ladies who, determined to land in advertising by hook or crook, got their start by-pothooks. Taking dictation from agency or advertising executives, they kept their eyes open and, when emergencies arose, they were ready with copy ideas that clicked. Others gained a knowledge of merchandising behind the counter and used it to open the door to an advertising career. Sara Pennoyer, advertising manager of Bonwit Teller, said her three months "on the floor" at McCreery's were worth more to her than a semester at college. During that time she not only absorbed merchandising knowledge, but used her lunch hours and after-hours time to browse in the store's advertising scrap book, get acquainted with the people in that department, and finally get an opportunity to take a hand when regular writers were rushed.

Cooking skill has helped other women find their way in. A lot of 
food manufacturers have home economics staffs, to test their products, to devise new recipes, to build publicity releases, to give demonstrations. A few advertising agencies have a similar operation. Magazines, newspapers, radio stations have their food consultants. Any of these jobs is good background for a woman who wants to write food advertising.

\section{Making the Presentation}

Walter Lowen of New York, who has specialized in advertising placement for 25 years and has seen thousands of applicants land jobs in this field, recommends that the prospective ad man prepare a portfolio about himself to be shown to employers. Into it, he suggests, can go selected samples of writing-whether ads, radio scripts, articles or other wordage, published or unpublished; layouts, reports on surveys; letters of recommendation by people whose opinion will carry weight; a brief resumé covering age, education, high-school or college activities related to the kind of job being sought and a photograph. The candidate will be judged by the appearance of the portfolio and by what he selects as the "best" examples of his work. So it is important to be neat and to be discriminating.

Originality of the application counts heavily, he says. He tells of one young man who had hundreds of book matches printed up with his name, phone number and job record; another who made a recording of his experience and sent it to an agency executive with a portable phonograph. Still another prepared 81 identical letters describing his background and stating that he was stranded in a small city for lack of opportunity. Each letter was enclosed in a bottle and "cast adrift on the swiftly flowing tide of U. S. Mail," just as castaways used to send out messages for help. His 81 bottle mailings brought half a dozen offers. A young lady had her qualifications printed on a blotter. One ingenious job-seeker attached his letter of application to a cage containing a homing pigeon. The employer was asked to fasten his reply to the pigeon's leg and release the bird. A good job resulted.*

A prominent New York copy star had trouble getting agency heads to "see" his talents as a beginner. So he had a brief message printed

* Walter A. Lowen and Lillian Eichler Watson, How to Get a Job and Win Success in Advertising (Prentice-Hall, Inc., 1941), pp. 212-215. By permission of the publisher. 
in type so small it had to be read through a magnifying glass-and then sent along a magnifying glass for the employer to use! This stunt worked.

But, Mr. Lowen points out, the device can be too clever. He mentions one ambitious girl seeking a copy job, who sent the copy chief of the agency she had chosen as her objective a long-stemmed American Beauty rose every day for 12 days. The copy chief received so much kidding from his fellow workers that when the girl finally came to see him about a job he refused to interview her, not caring to risk further joshing.

The young hopeful with no experience sometimes tries to make up this lack by selecting products from magazines and producing sample ads to show what he can do. All too often these test flights merely reveal their creator's complete ignorance of basic layout and copy principles, besides having no sound underlying idea. It is better to show a well-written school theme or news story than an attempt to be clever in an unfamiliar field.

Letters of application-whether in answer to want ads or sent "cold turkey"-seldom have the spark that should be exhibited by anyone who wants to write persuasive copy. To quote Don Rivers' delightful new book, Your Career in Advertising, "a large percentage are obviously dashed off in the same casual vein as you might write to dear old Aunt Sophie about that week-end trip to the country":

You want to become an advertising man or woman; very well-be one when you start drafting a letter of self-introduction. You are advertising a product. ... That product is you. Prepare your letter of application with as much thought and care and imagination as you would if you were writing an ad for automobiles or sterling silver.

Remember that a good advertisement always appeals to the selfinterest of the reader. It tells what the product will do for him. Likewise, your letter must be built around the idea: what do you have to offer that the executive reading your letter may want in an employee?*

Tackling any new product, a skilled copy writer first asks how it is different from other products in the same field, for selling copy depends on making the reader want that particular brand because it gives something special. One is reminded of the ancient wheeze

* Don Rivers, Your Career in Advertising (E. P. Dutton \& Co., Inc., New York, 1947), pp. 188-189. By permission of the publisher. 
about the Englishman who delivered a long address to prove that man and woman are fundamentally identical, concluding with the remark that in reality there was only a slight difference between the two sexes-whereupon a Frenchman in the audience cried, "Vive la différence!" Advertising has been shouting "Vive la différence!" since the Stone Age. And it is up to the job applicant to point out the difference between himself and the hundreds of others seeking to break in.

Any sort of hobby or special interest may be turned to account in this process of self-differentiation. A few years ago, who'd have dreamed that John Kieran's fondness for studying birds and reading Shakespeare in his spare time would make him the star of "Information Please"? Down in North Carolina, a young girl reporter started writing chatty items about things she saw in the local stores (what woman doesn't love to shop?) and Nancy Sasser's "Buy-Lines" became a nationwide institution. In Chicago a young chap got irritated because most of the advertising aimed at teen-agers seemed to miss the mark. "Why don't advertisers find out what high-school students really like?" asked Gene Gilbert, and today he has a coast-to-coast research service doing exactly that for manufacturers, retailers and publications, with a staff none of whom (in 1947) has yet been eligible to vote!

So far, about the only avocations that have not been capitalized to any great extent in advertising are stamp collecting and chess. Each is said to have millions of devotees. Perhaps some wide-awake advertising hopeful has a suggestion? Who knows? It may lead him to a real job!

Despite the many ways in which advertising people get started, one fact predominates: somewhere along the line, each of them demonstrated ingenuity and resourcefulness by devising a means to attract the attention of the higher-ups, and thus breached the wall. What particular stunt might prove successful in the reader's case is impossible to foretell. It can only be said that if he has the instincts and makings of a real adman, the inspiration will come!

\section{Jobs in Advertising}

Those who have read thus far will have ample ideas as to the types of work open to qualified people in advertising. For review purposes, it might be well to summarize them: 
1. Department and other retail stores.

2. Mail-order houses.

3. Manufacturers.

4. Trade associations.

5. Publications.

6. Advertising service companies.

7. Advertising agencies.

The different kinds of jobs include writing of advertising copy, direct-mail and catalogue text, radio commercials, sales presentations, publicity; art, such as layouts, lettering, finished drawings, package designs; research, mechanical production, space buying, merchandising and administrative work. This does not encompass the innumerable routine jobs which develop in advertising as in any other business enterprise, like stenography, shipping, messenger service and clerical work. Positions of this nature may be taken by people qualified for far more responsible duties, with the idea of securing any sort of a job in the advertising business.

It should be borne in mind, however, that merely working for an agency or an advertising department does not give the ambitious novice any great advantage. The important posts will still go to those qualified by experience and ability. So, from a long-range viewpoint, the candidate is better off to remain outside the portals until he has something tangible to offer in the way of a background. There are many thousands of men and women on the pay rolls of agencies and advertising departments who are not, strictly speaking, in the advertising business, nor do they share to any marked extent in the personal or financial satisfactions that come to those who have arrived.

This does not mean that a job in the creative or administrative end of advertising is the peak of all human desires. Many have reached that goal only to start planning for something else. Some, like Marguerite Lyon of And So to Bedlam, have gone on to the rural life. Others, like Samuel Raphaelson, Sherwood Anderson, Carl Sandburg, Guy Gilpatric and Frederic Wakeman, have become playwrights or poets or novelists. Some, like Albert Sloan and Tex Roden and George Washington Hill, have become corporation presidents. Some, like William Benton, Raymond Rubicam and Chester Bowles, have gone into public service. Many have utilized their schooling in antici- 
pating and guiding popular tastes, to go into business for themselves, running specialty shops, resort hotels, printing plants, research services.

However they may wind up, it is certain that all will look back on their years in advertising with nostalgia. Hectic and nerve-racking though it may be, the field has its allure. Things are always happening in advertising. Perhaps that, as much as its overpublicized Bohemianism and high salaries, is the real reason why so large a proportion of young people want to get into it. 


\section{Chapter XXV}

\section{WHEN AD FELLOWS GET TOGETHER}

DVERTISING men are great joiners. Organizations by the hunA dreds represent specialized branches of the craft; innumerable 1 local advertising clubs hold luncheon meetings, hear speakers, conduct training courses. Some of the national associations have sponsored and are continuing to sponsor aggressive programs of research, promotion and other activities designed to benefit either the advertising field or society as a whole.

References have been made in different chapters of this book to the work of various associations. While it is impossible to list all of the organizations, a brief review of several major groups will demonstrate the tremendous amount of co-operation that exists within the advertising business.

\section{Advertising Federation of America}

The AFA is composed of many elements: local advertising clubs, national associations in the advertising field, and sustaining memberships held by manufacturers, publications, agencies, graphic arts and other firms. Affiliated clubs as of 1947 had an aggregate membership of 13,000 and nearly 1,000 companies were listed as sustaining members. Founded in 1905 as the American Federation of Advertising Clubs, it launched the "Truth in Advertising" movement in 1911 with Vigilance Committees to foster honest copy and to police violators of the model statute. In 1914 the name was changed to Associated Advertising Clubs of the World and clubs in other countries were admitted. Between then and 1929 the international angle was stressed, occasional annual conventions being held abroad. In that year foreign affiliations were transferred to the International Advertising Council and the present name adopted.

Headquarters are at New York, where the research and educational work centers under President Elon G. Borton with Earle Pearson, long-time general manager, as director of special services and Alfred T. Falk heading the Bureau of Research and Education. AFA con346 
stantly labors for a better public understanding of advertising, providing material for schools, colleges, clubs, periodicals, radio and vocational groups. It co-operates with the Advertising Research Foundation and Better Business Bureaus. Leading figures in agency, manufacturing and media organizations serve on its board of directors.

The following Statement of Principles promulgated by the AFA in January 1946 sums up its goals:

1. Good advertising aims to inform the consumer and help him to buy more intelligently.

2. Good advertising tells the truth, avoiding misstatements of facts as well as possible deception through implication of omission. It makes no claims which cannot be met in full and without further qualification. It uses only testimonials of competent witnesses.

3. Good advertising conforms to the generally accepted standards of good taste. It seeks public acceptance on the basis of the merits of the product or service advertised rather than by the disparagement of competing goods. It tries to avoid practices that are offensive or annoying.

4. Good advertising recognizes both its economic responsibility to help reduce distribution costs and its social responsibility in serving the public interest.

\section{Association of National Advertisers}

Established in 1901 as the Association of National Advertising Managers, the ANA in October 1946 had 437 members with an annual advertising appropriation averaging $\$ 900,000$ each. Among its members are 80 women advertising executives. Paul B. West became its president in 1932 and ten years later was awarded the Advertising of Selling gold medal as the individual who had contributed most to advertising that year. Albert E. Haase, former associate editor of Printers' Ink, is managing director.

Of the many ANA services, members like the news bulletins and semiannual meetings best; they get valuable help from ANA studies on all phases of advertising. ANA participates in many joint enterprises such as the Advertising Research Foundation, Traffic Audit Bureau, Broadcast Measurement Bureau, the Advertising Council and others. It was one of the influential factors in setting up the Audit Bureau of Circulations in 1914. 
While a majority of ANA members are concerned with consumer advertising, many direct their campaigns at industrial or technical markets. It is currently sponsoring a study on business-paper readership (with the AAAA, the NIAA and the Associated Business Papers) and another on farm publications with the Agricultural Publishers Association, both through the Advertising Research Foundation.

ANA members were among the earliest and most stalwart supporters of the War Advertising Council. Paul B. West served as a vicechairman and Stuart Peabody, Harold B. Thomas, Lee Bristol and other ANA leaders were among the top officials. At this writing Charles G. Mortimer, Jr., of General Foods Corporation is the Council chairman.

\section{American Association of Advertising Agencies}

The " $4 \mathrm{~A}$ 's" is the national organization of the advertising agency business. It was organized in 1917 in response to the request of media for a responsible spokesman for the country's advertising agencies. Membership is open to any advertising agency, regardless of its size, so long as it meets the standards of sound and ethical business practices established by the association.

Today its 200 member agencies handle over two-thirds of the national advertising volume. Their 373 offices and branch offices are located in every major city in the United States and in 16 foreign countries. The association has five regional councils and eight chapters and maintains its executive headquarters at 420 Lexington Avenue, New York.

From the start it has consistently labored for higher standards of agency practice; opposed false and misleading advertising, rebating of commissions, unfair competitive tactics and the use of speculative materials in soliciting accounts. While many of its members have large billings-some as high as $\$ 50,000,000$ a year or more-the size of an agency is not a factor in qualifying for membership, nor is geographical location. But applicants must be adequately equipped financially, in experience and in ability, to conform to $4 \mathrm{~A}$ standards.

The joint enterprises sponsored by the ANA are also actively supported by the 4 A's. Frederic R. Gamble was secretary-treasurer of the Council throughout the war and James W. Young, William Reydel, Thomas D'Arcy Brophy, Don Belding, Louis N. Brockway and other agency executives had important posts. The Advertising Re- 
search Foundation is an important 4 A-ANA undertaking, of which more later. In certain fields the AAAA also conducts individual research-including analyses of agency costs, newspaper reader surveys in major markets and data collected by its Export Information Bureau on foreign media and markets.

As part of an effort "to reduce still further the small amount of bad taste that tends to lessen the usefulness of all advertising," the 4 A's conducts a Monthly Interchange of Opinions on advertising which, in the opinion of any of the members, is in bad taste. Advertisements regarded as offensive are called to the attention of the originating agency. The association also maintains an expanding public relations program in behalf of the association and the agency business, and works with other groups to promote better understanding of advertising, distribution and our national economy. Prominent among these activities has been the Joint ANA-AAAA Committee on Improvement of Public Understanding of Our Economic System.

In 1946 the association launched an examination plan to be carried out by local councils and chapters to measure the special aptitude of applicants for agency positions with the object of attracting young men and women of superior talent to the agency field. Questions covered the agency structure, and the applicant's choice of tests in such branches as copy, research, media, merchandising, production, radio, layout and art. Five hundred forty-one candidates took the first examination. Each received a comprehensive report showing his particular aptitudes as well as his score on the knowledge tests, as a guide to his chance of success in agency work and for use with prospective employers.

\section{Advertising Research Foundation}

The oldest and most comprehensive project of the ARF has already been described-the Continuing Study of Newspaper Readership, started in 1937. Mention has also been made of similar studies in transportation advertising, business-paper and farm-paper readership.* Another project has to do with weekly newspapers in smaller communities.

In the nine years between 1937 and 1946, ARF spent about \$650,000 on its varied activities. The ANA and 4 A's each contributed financially but the largest share of this outlay was provided by the

* See Chapters XV, XVI, XVIII. 
different media being studied. However, both the parent organizations gave something even.more important than money-unlimited amounts of time and effort, counsel and direction. The ARF officers and board are composed of agency men and national advertisers of long experience, giving freely of their knowledge for the benefit of all advertising. Heading the full-time staff are A. W. Lehman, managing director, and D. B. Lucas, technical director. The Foundation's headquarters are in New York City.

\section{Audit Bureau of Circulations}

From pioneer days, buyers of advertising sought some means of knowing how much circulation their dollars would purchase. Honest publishers were penalized because their true statements were overshadowed by the unscrupulous. All sorts of premiums and cut rates were used to bolster subscription lists; sometimes readers would continue to receive copies long after their subscriptions had expired. But with the rapid growth of advertising and the application to it of scientific principles, such a situation could not continue.

The founding of the Audit Bureau of Circulations in 1914 marked the real beginning of modern fact-based advertising. Advertisers, advertising agencies and publishers collaborated to set up an independent, wholly unbiased organization to establish standards and to verify the circulation claims of member publications according to those standards. Starting with 499 charter members, A. B. C. now has over 3,000, of which some 2,500 are media owners, and the remainder agencies or advertisers. A staff of field auditors is kept busy checking the regular semiannual statements of publishers under the supervision of headquarters in Chicago. Audit reports are issued once a year. These reports enable a space buyer to determine accurately if a medium reaches the desired field, in what parts of the country it circulates, whether city or rural or small-town coverage and the exact quantity of net paid circulation. (No attempt is made to study the quality.) A. B. C. reports also give an index of reader interest through such items as renewal rate of subscriptions; inducements such as premiums or discounts to subscribers; rise or fall in number of copies per issue.

A leading figure in launching the A. B. C. was Stanley Clague, who had his own advertising agency. He was managing director from 
1917 to 1927, and was followed by Orlando C. Harn, former advertising manager of the National Lead Company. On Harn's retirement in 1939 he was succeeded by James N. Shryock, former assistant general manager of the Indianapolis News. President since 1927 has been Philip L. Thomson, for many years in charge of advertising for Western Electric Company. Thus all three phases of the businessmedia, agency, client-have been represented in A. B. C. management, and also on the board of directors. In matters affecting the continuing welfare of the Bureau, however, these men are rigidly impartial. They realize the importance of maintaining the integrity of this unique institution, which has been called

... the one great example of the ability of business to regulate itself. It [the A. B. C.] has proved that competitors, no matter how divergent their interests, can, if they will it earnestly enough, make fair rules and stick to them. It stands the envy of those who long for the correction of evils in other phases of business."*

\section{National Association of Broadcasters}

The NAB was founded in 1922 and is the trade association of the radio stations. Headquarters are in Washington, D. C., where a large staff operates under Judge Justin Miller, president; A. B. Willard, Jr., executive vice-president; and C. E. Arney, secretary-treasurer. The director of broadcast advertising, Frank E. Pellegrin, initiates and supervises activities to encourage the increased use of broadcast advertising, working with the ANA, 4 A's, individual agencies and advertisers. Case histories such as the one of Joske's Department Store described in Chapter XV are issued from time to time, as well as material for station sales managers and special studies for small market stations. The NAB aided in starting the Broadcast Measurement Bureau, works with the ANA Radio Council and has been actively affliated with the Advertising Council since its inception.

\section{Special Organizations}

Among the advertising groups devoting their attention to limited fields might be mentioned the Financial Advertisers Association,

* Scientific Space Selection, Audit Bureau of Circulations, 1937. 
Export Advertising Association, Life Insurance Advertisers Association, Public Utilities Advertising Association, American Community Advertising Association, Point of Purchase Advertising Institute and the Premium Advertising Association of America.

Closely identified with the industry are the American Newspaper Publishers Association and its Bureau of Advertising directed by Alfred Stanford, former agency copy director; the Brand Names Foundation, Inc., headed by Henry E. Abt; the Associated Business Papers and the National Business Papers Association; National Association of Transportation Advertising; Agricultural Publishers Association; United Typothetae of America (printers); Lithographers National Association; Advertising Typographers Association; Periodical Publishers Association and the Magazine Advertising Bureau; Negro Newspaper Publishers Association; National Council on Business Mail; National Roadside Council; American Highway Sign Association and National Council of Industrial Editors (company magazines).

Mention has already been made of the National Industrial Advertisers Association, the Direct. Mail Advertising Association and the organizations in the poster field.

If this list seems unduly long, it should be remembered that the advertising field is enormously complex. Each association was started to meet a definite need; those that did not fill any sound purpose soon withered. Those that have endured do so because they serve constructively. In total they represent an amazing phenomenonthe spectacle of competing businessmen, all bent on getting more business at the expense if necessary of their rivals, sitting down together to exchange ideas on ways to operate more efficiently. It has been truly said that the trade association is democracy in action. Nowhere is this more forcefully proved than in advertising.

\section{Advertising Publications}

Printers' Ink, the oldest existing magazine in the field, was founded in 1888 by George P. Rowell. It has been the bible and the inspiration of thousands of advertising neophytes, a crusading force for honest advertising - as witness the "Printers' Ink Model Statute"and a stimulus to more exact, pretested, carefully planned campaigns. For many years it was a pocket-size weekly. During the 1920's a 
large-size monthly was also issued. These were combined ten years ago into the present $7 \times 10$ page-size weekly. A. B. C. circulation as of December 31, 1946, was over 20,000 per issue.

Advertising $\sigma$ Selling, established in 1923 by Frederick C. Kendall as Advertising Fortnightly, is a monthly publication, printed on "slick paper" and featuring articles by established authorities in the advertising field. Since 1935 it has sponsored the Annual Advertising Awards which were instituted in 1924 by Edward W. Bok, late editor of the Ladies' Home Journal, and carried on under a fund provided by him until 1930, when they lapsed with Bok's death. During those years they were known as the Harvard Advertising Awards. Perhaps the most significant award was the annual Gold Medal for distinguished service to advertising - won in various years by a number of individuals mentioned in this book: Earnest Elmo Calkins, Orlando C. Harn, James H. McGraw (president of McGraw-Hill), Rene Clark of Calkins \& Holden, Cyrus H. K. Curtis, Raymond Rubicam, Philip L. Thomson (ABC), Henry T. Ewald, John Benson (president of 4 A's), Paul West (ANA), Chester LaRoche and James W. Young (War Advertising Council). In 1930 this medal was won by Mr. Kendall.

Advertising Age, a tabloid-size weekly, was started in 1930 by George Crain of Chicago, publisher of Industrial Marketing. It features the news of advertising, with other editorial features including a personality sketch of some prominent advertising figure, case studies of advertisers and statistical reports. Its $1947 \mathrm{ABC}$ circulation was over 17,000 .

Tide, launched in 1927 as a house organ for Time Magazine-the "time and tide" combination was too pat to be ignored!-became an independent publication soon after. It has over $11,000 \mathrm{~A}$. B. C. circulation among advertisers and agencies. Reginald Clough is the editor. It has spot-news items and a range of articles on advertising subjects departmentalized much after the fashion of its parent, although not attempting Timese phraseology.

Other publications in the field include The Advertiser, edited by pencil-sketcher Manuel Rosenberg; Editor \& Publisher (newspapers); The Reporter (direct mail); Sales Management; Tell (free distribution); Premium Practice; Modern Packaging and a number of regional and local ad magazines of which Western Advertising and the Adcrafter (Detroit Advertising Club) are among the oldest. 


\section{Advertising Service Books}

Indispensable to the agency space buyer, account executive and client is Standard Rate \& Data Service, published monthly in five massive sections: (1) newspapers; (2) magazines, farm papers and transportation advertising; (3) business papers; (4) radio; and (5) newspaper map section. The cost of the complete service is $\$ 50$ per year; of a single section, $\$ 25$. It contains not only the complete rate schedule for each medium, but also sizes of ads, mechanical requirements, names of officers, circulation and representatives. It is probably the busiest book in any agency media department.

Two publishers give a parallel service in listing national advertisers and agencies: Standard Advertising Register and McKittrick's Directory. In each case, separate volumes are issued for the advertisers and the agencies. Under the former appear the names of all national advertising accounts, officials, present agency, types of advertising being done, and in some cases the amount of the appropriation. In the agency book are given all recognized agencies, their offices, key personnel and list of accounts.

Leading National Advertisers was started in 1945 to give a record of advertising used in apparel, food and beverage, drug and toiletry, transportation and agriculture, home and general fields.

Several publications issue annual summaries of value to advertisers-such as the Market Data Book of Industrial Marketing and the Survey of Buying Power by Sales Management. The U. S. Department of Commerce published-and still does unless a Congressional economy drive has intervened-a number of periodic reports.

This list is by no means complete. It does suggest, however, that the advertising man who wants to keep up-to-date in his profession has plenty of reading matter to cover and consult! 


\section{Chapter XXVI}

\section{ADVERTISING IN THE ATOMIC AGE}

W ARS have a way of speeding up technical processes. World War I saw the rapid development of radio, aviation and many other new fields. Out of World War II have come such varied wonders as radar, jet-propelled planes, vest-pocket hearing aids and applications of atomic energy.

Advertising, too, had its war-stimulated innovation: the tremendous increase in what has been called "advertising with a social conscience."

Whether this aspect of the art of mass persuasion will continue to grow in significance or lapse into disuse remains to be seen. Certainly it gained great momentum while America was fighting, and many of the industry's leaders have resolved that this momentum shall not be lost.

Twenty years ago Stuart Chase and F. J. Schlink wrote a book called Your Money's Worth. In it, advertising was taken sharply to task for many selfish and deceptive practices, some widespread, some limited. Ad men everywhere denounced the book, overlooking the fact that it was not an attack on their profession, but on its abuses. The authors had a vision of a use to which advertising might be puta vision which they frankly felt was impossible of fulfillment. Yet this very conception, utopian as it seemed then, has become an actuality. This is what Chase and Schlink wrote in 1927:

The technique of advertising is a magnificent technique. Sanely applied it could remake the world. Think of what might be done with applied psychology in a great publicity drive for public health, for better housing, for cleaning up the slums, for honest and timely information about goods, for genuine education in a hundred fields! Many advertisers see this: a few of them try to practice it, but their hands are tied. Between the interest of the whole community in more abundant life, and of the individual in his profit and loss account, there yawns a chasm which no optimism, no sophistries about "service," no pretty little talks ... may cross."

* Stuart Chase and F. J. Schlink, Your Money's Worth (The Macmillan Co., 1927). Quoted by permission of the publisher. 
It took the greatest war in history to cross that chasm, but the bridge has been built. Today powerful forces in advertising are definitely committed to widening and strengthening that bridge. Their job has been made immeasurably easier by what advertising did in the war. It has been given urgency by the belated discovery of business in general that the American free enterprise system is by no means the indestructible, perpetual way of life it once seemed to be. German industrialists of the 1930's, threatened by the destructive forces of communism, backed Hitler. Farsighted American industrialists of the 1940's are coming more and more to realize that their lone chance of survival lies in backing a healthy, prosperous, enlightened democracy.

\section{Advertising Goes to War}

To understand this newest, most significant trend in advertising it is necessary to know what happened between Pearl Harbor and Hiroshima.

As the colorful, dynamic spokesman of American business, advertising had led the nation to ever higher standards of material comfort. Off to a slow start in the nineteenth century, it had gathered strength steadily before World War I and reached its zenith in 1929 when nearly $\$ 3,000,000,000$ were invested in various advertising media.

Advertising had helped to put telephones and bathtubs and electric refrigerators into millions of homes; sold a new automobile every six seconds and a new radio every three seconds; made the small-town girl as style and glamour-conscious as her big-city cousin; created countless new wants, new yearnings, new habits.

None of this had anything to do with war-or did it? Some advertising men, looking ahead in the fall of 1941, thought they saw an immediate and vital relationship. They were right.

For just as the manufacturer of bobby pins was able to convert his technological skill to the making of shell fuses, so the advertising profession adapted its experience in mass marketing to an unprecedented achievement in telling the American people what needed to be done to win the war.

Here, briefly, is what happened, as stated in a bulletin issued shortly after V-J Day by the War Advertising Council: 
Advertising helped America fight its greatest war, yet remain a democracy.

In a war for survival, all bets are off. Action-swift, decisive action-is all that counts. A warring nation must remedy its shortages. It must get the scrap, the fats, the paper, the money, the factory manpower it needs-or its army and navy have little to fight with.

It must man its merchant ships, change the people's habits, increase its food supply-or lose the war.

Government cannot do these things. Only the people can. And the people must either be compelled or persuaded-there is no other way.

During the entire war, for the most part, they [the American people] were persuaded. There were no compulsory savings. No national service act, no labor draft. There was not even a draft of sorely needed wartime skills, such as miners, tool-makers, farm help, railroad workers or nurses.

The Country, the people, did the job the democratic way, and just one thing made it possible: this nation used every known channel to carry to the people the news of what needed to be done-to explain, persuade and inspire. The people did the rest.

Thus our great wartime information mechanism enabled this nation to fight through our first global war-with a minimum of compulsion. In a period when the [world] trend toward centralized controls might well have become an irresistible force, this was a service of lasting significance to every business and every citizen.

The job of "explaining, persuading and inspiring" America's home front was not done by advertising alone. Every newspaper gave unstintingly of its news, editorial and feature columns; its cartoonists and even its comic strip artists were enrolled for the program. National magazines and trade papers donated space for government bulletins and ads, in addition to assigning their finest writers to prepare articles on essential war projects. Radio stations were notably liberal with free time for announcements, talks and special broadcastsoften canceling commercial broadcasts at a considerable loss in revenue. Retail stores, banks, public utilities, life insurance companies and innumerable other enterprises co-operated by having employees solicit war bond orders, USO donations, Red Cross membershipson company time.

All of this vast publicity and sales activity was important.

But, just as in a private business venture, free publicity and per- 
sonal salesmanship cannot market a product nationally without advertising, so in our victory drive advertising supplied the spark to start the machine and the horsepower to keep it going.

Newspapers and magazines, the radio and the movies must offer their customers a varied bill of fare. To repeat the same message over and over again would be fatal.

Only advertising, one of whose cardinal principles is repetition, repetition and more repetition, can accomplish the universal masspenetration results that are necessary for nationwide co-operation.

Moreover, advertising does not merely din away at a theme or a slogan -it asks for the order. And keeps on asking!

It costs money to change people's habits and ideas. Billions of dollars had been spent, before the war, to make this a nation of automobile owners, of orange-juice drinkers, of washing-machine and vacuum-cleaner users. Human nature resists change. One magazine ad or one poster won't turn the trick.

To carry through its part of the wartime information program, American business staged what was far and away the greatest advertising campaign of all time. It was so enormous, so all-inclusive, that. the total cost can never be accurately computed.

An estimated $\$ 1,000,000,000$ was spent by private business for advertising space and time alone. As much or more went for production costs, contributions of printing, plates, illustrations, and salaries of advertising people working full or part time on war projects.

In the fall of 1941 at a joint meeting of the Association of National Advertisers and the American Association of Advertising Agencies, the first steps were taken to mobilize advertising resources in the event of war. Immediately after its outbreak, Donald M. Nelson, wartime production chief, declared:

We are up against the toughest situation in our history. Time is running against us, and every minute counts. We must use every constructive organization, and gear these organizations to all-out war production. In my opinion, the organized machinery of advertising will be absolutely essential in getting the job done. In heaven's name, get yourself organized quickly.

With this challenge, heads of leading advertising associations promptly pooled their resources to form the War Advertising Coun- 
cil. The Office of War Information became the liaison between the government departments and bureaus that wanted special campaigns, and the Council, which co-ordinated the media, advertisers and advertising agencies.

The Council directed more than 100 separate campaigns, each representing a crisis in the war effort. The needs were determined by those in command of the fighting forces, consulting with top federal officials. The methods were worked out by advertising "task forces" assigned by the Council, all serving voluntarily and a large part of the work being done after hours. The bills were paid by private industry and business.

\section{A Typical Campaign}

In 1944, for example, campaigns were conducted for three war bond drives, the National War Fund, the Red Cross, victory gardens, V-mail, tin-can conservation, reduction of absenteeism, WAVE, WAC and Merchant Marine recruitment and many more. Twenty-seven government agencies were "clients" of the Council. It would require volumes to tell the whole story. But the method can be grasped by studying one campaign. For this purpose, the Cadet Nurse Recruitment program has been chosen.

Always in past wars, lives that might have been saved were lost through lack of proper nursing. In the spring of 1943, the men who were planning the coming offensives knew that thousands upon thousands of additional trained hospital attendants must be ready if this tragedy were not to be repeated.

Training a nurse takes time; hence the raw material had to be obtained at the earliest possible date. The easy way would have been to drain these nurses from civilian hospitals, and to a certain extent that had already been done. In 1940, the Army had but 955 nurses; the Navy, 200. Under the national defense program, this figure rose rapidly. In December 1941, there were 7,500 Army nurses; a year later, 20,000. But these volunteers represented the younger, more adventurous nurses fired by patriotism and eager to serve dangerously. Their going left critical gaps at home which had to be filled, besides the many more who would be desperately needed for the armed services a year or two hence.

Throughout the land, a number of independent nursing organiza- 
tions had been struggling with the situation. They came together to form the National Nursing Council for War Service. Congresswoman Frances Payne Bolton of Ohio had become a crusader for more nurses. She introduced a measure into Congress to create a student nurse reserve. Transformed into law, the Bolton Act authorized the training at government expense of 60,000 student nurses for the year 1943-44, and thereafter as the needs dictated.

So far, so good. But how and where were those 60,000 to be obtained? The largest number of new student nurses in any one year had been 39,000 in 1938, and the average per year somewhere between 28,000 and 30,000 . Now the aggressive campaigns of the WAVE, WAC and SPAR recruitment officials were attracting a considerable portion of the eligibles, and war plants were offering alluring wages to able-bodied young women who wanted to do their part.

It was a situation made to order for advertising.

Given an excellent product, a known market and the means with which to operate, any ad man worthy of his hire can get results. What if there was competition? Advertising men thrive on it!

By this time the War Advertising Council had been functioning for over a year, and it moved smoothly to meet the emergency. A "task force" was created with William S. Brown, advertising manager of Canada Dry Ginger Ale, Inc., as campaign manager; Miss Jean Flinner of the Council as staff manager; and the J. Walter Thompson Company as the agency to handle the "account," with VicePresident Anson C. Lowitz as account executive.

Veterans of the U.S. Public Health Service and the nursing profession had key assignments. Among them, Miss Jean Henderson, chief of USPHS wartime Information Division, working directly under the Surgeon General, Dr. Thomas Parran, had complete charge of all informational activities and field work. Co-operating wholeheartedly in the campaign was Miss Lucille Petry, who held the top post in the Nursing Corps, comparable with that of Mrs. Oveta Hobby in the WAC; and Mrs. Elmira Wickenden, head of the National Nursing Council.

The field staff of the U. S. Public Health Service and the state and regional nursing groups were invaluable in arranging local tie-ins and publicity for the program. In a measure they corresponded to the salesmen or local dealers of a manufacturer in helping to complete 
the chain from original idea to actual enrollment of the individual Cadet Nurses.

\section{The "Product" and the "Package"}

Starting from scratch, this advertising team decided first of all that their "product"-student nursing-would have to be glamorized in order to compete with the other alluring wartime careers then bidding for their "market." Obviously there was nothing to stir the imagination of a young girl in the phrase "student nurse"; it suggested nothing but study and hard work. So they came up with the new name, "U. S. Cadet Nurse Corps." That word "cadet," borrowed from West Point, implied training and discipline but it had romance and showmanship too!

That wasn't enough. For any product to win against competition, the package must be right. Student nurses had always worn garments that were crisp, efficient, and-unglamorous! The recruitment task force decided that "Cadet Nurses" should have costumes as dashing as those worn by the WAVES. They announced a contest among leading designers to create a Cadet Nurses's wardrobe that would attract young women. The designers caught the fever.

On August 18, 1943, there gathered at the Waldorf perhaps the most distinguished group of judges ever to pick a style-show winner. It embraced the woman's page editors of dozens of leading newspapers, the style authorities of all the big magazines, the fashion arbiters from Hollywood studios. After lunch, models wearing the different suggested Cadet Nurse costumes paraded before this critical audience. Ballots were passed, and the judges made their selection.

What happened can now be told for the first time. The 55 judges at the showing agreed unanimously! Perhaps never before in history have so many experts concurred on a question of fashion. The fact remains that one and all picked the same design. Needless to say, this became the official uniform of the U. S. Cadet Nurse Corps.

As a result of this re-styling of the "package," the Cadet Nurse's uniform became important fashion news. It was featured in all daily papers. It appeared on the front cover of such influential magazines as Vogue, Harper's Bazaar, and Ladies' Home Journal.

Meanwhile, the agency task force had not been idle. Classes were to start in September. The uniform had not been yet selected when 
a flood of radio appeals hit the country-all arranged by the War Advertising Council. A campaign guide was prepared for release to national advertisers, agencies and heavy retail advertisers, containing suggested copy themes and radio commercials.

Very shortly, national magazine advertising began to appear. A number of important concerns gave virtually their entire space to the Cadet Nurse appeal, running only a single line in small type at the bottom of the advertisement to identify the advertiser.

One of the most notable campaigns on behalf of student-nurse recruitment was that of Eastman Kodak. Although known to the public primarily as manufacturers of cameras, this firm has long been identified with public health through its position as a leading supplier of X-ray film. For four months in 1943, the Eastman people devoted almost their entire advertising budget to the Cadet Nurse Corps. This particular series, carrying a direct appeal, accounted for over 40 percent of all inquiries, and nine months after the last ad appeared, coupons were still being received.

Other national advertisers who used space at their own expense to back the Cadet Nurse drive were the Maytag Company, Wheatena Corporation, General Foods (Sanka Coffee), Prudential Insurance Company and many more. This barrage of magazine messages had its local counterpart in the numerous full-page newspaper ads sponsored by the businessmen of a community.

Radio, magazines, newspapers-the heavy artillery of the program - created an immediate rush of inquiries. Direct mail was used to "complete the sale." Attractive booklets and folders were ready to be sent. Printed material was prepared also by the task force for the training school recruiting officials. And finally, since this was to be a continuing campaign, portfolios of advertising plans were distributed to local and national sponsors, giving suggested radio commercials and ad copy, publicity ideas and community activities to tie in with the advertising.

\section{Overcoming Objections}

The successful adman or woman knows how to analyze a product and turn apparent disadvantages into talking points. Thus, the unglamorous "student nurse" uniform was restyled and dramatized through smart showmanship. A further allure was imparted through 
announcing that wearing of the uniform outside the training school was optional, not compulsory. One bit of ad copy phrased it this way-speaking in the girls' own words:

The Cadet uniform is so smart! It's for outdoor wear, and I don't think there's a better looking one in the women's services; but I'm glad it's optional. It is nice to be able to get into an honest-to-goodness dress now and then to remind yourself, and the boys, that you're a girl after all.

The extremely low pay offered to these nursing-school students was another objection, and a very serious one. But it had to be met fairly and squarely. There was no use in drawing inquiries from girls who expected war-plant wages while in training. So the copy stressed the free features-tuition, fees, room, board, uniforms-and took the sting out of the microscopic pay check by calling it a "monthly allowance." One piece showed a group of Cadet Nurses sipping sodas and looking very chipper, with a girl saying:

Our allowance keeps me in spending money very nicely. It starts at $\$ 15$, jumps to $\$ 20$ after nine months, at least $\$ 30$ after 21 months.

The girl who held back from inquiring about the corps because of the long period of training involved found her objection minimized by copy like this:

A big advantage we Cadet Nurses have is that the course in most schools has been stepped up. It now takes only 24 to 30 months, where it used to take three years. If you're still in training when the war ends-and if you have at that time been enrolled for 90 daysyou get your full course just the same.

For the young girl who had a boy friend, or was socially minded, one ad picture showed a dance with several happy maidens in party dresses; their escorts were young soldiers, sailors and civilians. The explanatory text said:

Of course, I want to get married; but being a nurse doesn't mean that I can't. There are lots of chances to meet nice men, and there's free time for dates. In many schools, a girl can marry while she's still a student.

Whether by accident or intent, the shoulder patch of the Cadet 
Nurses had the same contours as the emblem of a widely publicized college fraternity. Capital was made of this fact by creating a "Cadet Nurse Pledge Pin" to be worn by high-school senior girls who had qualified for the Corps. Thus not only the immediate but also the future needs of the project were given the glamour treatment.

These innovations were not adopted without some serious qualms on the part of the supervisory organizations involved. But the professional nurses and the medical authorities, with whom the "task force" consulted in creating the plans and writing the ads, knew that a desperate situation justified drastic methods. The American Journal of Nursing covered this contretemps in most charming phraseology in an article on the Nurse Recruitment Campaigns. After praising the magnificent work of the War Advertising Council, the Office of War Information, and the vast advertising contributions of business and industry, this highly ethical publication said:

The spirit of volunteer service has been unquestioned. If an occasional departure from nursing tradition or preference has occurred, it has been on that margin of judgment where any volunteer effort may escape professional guidance or control.*

There was a tense period during that first year. The quota had been raised to 65,000 but the standards of admission also had been raised. The girls had to be in the top one-third of their class in high school, in addition to passing a rigid physical test. Moreover, all nursing schools had to be checked by the Surgeon General's staff before being allowed grants for tuition, board and allowances. This meant "better nurses in fewer schools."

At one point near the close of the year, enrollments stood at 54,000 $-11,000$ short of the objective. The Cadet Nurse task force redoubled its efforts. But instead of bewailing the fact that enlistments were 11,000 short of the target, they told the nation that there were only 11,000 opportunities left.

By July 1, 1944, the deadline of the first year's drive, the Council was able to report that 65,921 student nurses had been accepted.

For 1944-45, the goal was set at 60,000 more Cadet Nurses. With the previous year's experience as a guide, the team hit that mark well

* The American Journal of Nursing, July 1945, p. 543. Quoted by permission of The American Journal of Nursing. 
ahead of schedule. In fact, some enrollments had to be declined for lack of allotments.

Again for 1945-46, the figure was 60,000. Japan surrendered before the campaign had scarcely started, yet by October an additional 33,000 girls had enrolled, making a total in little over two years of some 160,000 Cadet Nurses. At this point the program ended, but the results in available nurses and in future applications for nurse training by girls whose interest in the profession was first aroused by the campaign will be felt for many years.

The U. S. Public Health Service wrote finis to this typical wartime project, financed, developed and carried to success by advertising men and women, with a terse yet all-embracing comment: "Quota Filled."

\section{Other Wartime Advertising}

Similar teamwork produced results all along the line. More than $800,000,000$ war bonds were sold. Eighty-five million Americans bought small-denomination bonds, and at the end of the war \$45,$000,000,000$ were outstanding. Advertisers and media contributed an estimated $\$ 350,000,000$ in space and time to war bond promotion.

Some $\$ 100,000,000$ in advertising "sold" the country on Victory Gardens. Fifty million plots of ground were planted and in 1945 accounted for 40 percent of all fresh vegetables consumed by civilians. Home canning received a tremendous impetus, with 25,000,000 households putting up 3,500,000,000 quarts of fruits and vegetables that year. Four million workers were recruited for farms and food plants.

In conservation and salvage, $\$ 65,000,000$ worth of advertising stimulated Americans to reclaim $538,000,000$ pounds of waste fats, $800,000,000$ pounds of tin and 23,000,000 tons of waste paper. Merchant Marine recruiting was stepped up, WAC hospital technicians enlisted, blood donors enrolled, all with the help of advertising paid for by business.

Contributions of space and radio time were not left to chance. As in all well-planned advertising campaigns, the creative staffs of Council projects worked closely with the "sales force"-a network of sponsorship committees throughout the country whose object it was to bring to the attention of advertisers the urgent campaigns on the docket, and sign them up for specific commitments. 
Users of radio advertising were organized under several allocation plans, administered by the Domestic Radio Bureau of the Office of War Information. Commercial time was regularly devoted to whatever project the government might designate: war bonds, absenteeism, scrap and paper collections, special recruiting, V-mail and security of war information, to mention only a few. On many a network show the star himself delivered the message. Three topics were allocated each week for discussion on regular commercial broadcasts, and were kept on the schedules as long as conditions demanded.

The Graphic Arts Victory Committee contributed plates, typesetting and presswork for many war projects.

Trade associations not directly connected with advertising took an active part. For instance the National Retail Dry Goods Association, in co-operation with the American Red Cross, sponsored campaigns to bring graduate nurses who had retired to civilian life, back into service, and also to recruit more hospital technicians, nurse's aides, Cadet Nurses and Red Cross home-nursing workers. On one NRDGA drive 893 booths were set up and 3,200 department and drygoods stores actively participated, with a total of over 12,000 separate ads.

Outdoor advertising companies provided 24-sheet posters on war themes for local sponsors, and further aided by "sniping" the blank white borders around posters with special wartime messages.

These were but a few of the many ways in which businessmen used the power of advertising co-operatively, often working side by side with their most serious competitors.

\section{From War to Peace}

Even before war's end, leaders of the Council were considering what action should be taken when peace came. As early as November 1944 it issued a booklet, The Council Looks Ahead, voicing the opinion of the Board that some sort of public service program should be continued.

In September 1945, shortly after Japan's surrender, the Council declared that from a purely selfish point of view alone, business should continue to support advertising in the public interest. Said the Council:

Almost unnoticed, a revolution in business public relations thinking has taken place. Business, which formerly told the public, "What 
helps business, helps you," is now, in effect, demonstrating to the people that what is good for the public welfare is good for business. Perhaps this should have been obvious all along. But it remained for a war to demonstrate it. *

There were protests from some advertisers who had gone along with the Council during the war but now wanted to get back at their main job of selling goods. There was sound logic in the argument that advertising could render its greatest service by helping to maintain full employment after the pent-up wartime demand had been met. As Raymond Rubicam, retired head of Young \& Rubicam agency, put it in his chapter on advertising in the symposium, While You Were Gone:

In the war, the men and women of advertising had their first major chance to devote the content of advertising to themes of noncommercial public service. One result was a strong sentiment in the Advertising Council for the continuance of such work not only through the reconversion period, but into peace.... But in the final test the great contribution of advertising has been and must be the selling of goods and services-new and old-into use and consumption. It carries its real Sunday punch in its everyday job. And now it must be getting down to business. * *

On the other hand, James W. Young, then chairman of the Advertising Council, declared in a speech on December 11, 1945:

We [the Council directors] have no delusions about the principal job of the advertiser and his agency being the sale of goods. ... But we do believe that where you have a good will, an institutional, a character building job to do, we have a technique to offer you that is more effective than the old techniques. It is embodied in our slogan, "the best public relations advertising is public service advertising."

We believe that many advertisers and agencies already see this, and that more will do so.

Evidencing the support of business for this new venture in public

* From War to Peace-the New Challenge to Business and Advertising, War Advertising Council. Used by permission of the War Advertising Council.

** From Raymond Rubicam's chapter on Advertising in While You Were Gone, edited by Jack Goodman. Copyright, 1946, by Simon and Schuster, Inc. 
relations, the Council announced that 117 national radio advertisers, representing 85 percent of the network circulation, had agreed to carry allocations on one out of every six evening shows or one out of every 15 daytime shows. This was a cutback from wartime contributions, but still substantial. Magazines and newspapers continued to make free space available for ads prepared by the Council. The car-card industry set aside 75,000 car spaces per month, and the outdoor industry, 3,200 poster panels, while the window-display industry provided facilities for 70,000 one-sheet posters in selected store locations each month. Transportation advertising interests also made available a pool of 4,000 three-sheet poster spaces.

Replacing the Office of War Information, which represented the government in deciding which campaigns should be featured, a special advisory committee of prominent figures was named to pass on all proposed projects. Evans Clark, executive director, Twentieth Century Fund, was made chairman and others on the committee were Mrs. Olive Clapper, Kermit Eby of the CIO, Dr. Reinhold Niebuhr of Union Theological Seminary, Boris Shishkin of the AFL, Dr. George Gallup and various doctors, businessmen and educators. With this distinguished committee choosing the projects to be backed, it seemed improbable that the Council would ever become an instrument for political or ideological propaganda.

Postwar campaigns created by the Council include veterans' housing, prevention of forest fires, salvage of waste fats, reduction of accidents on highways and in homes, hospital personnel recruitment, U. S. savings bonds, Girl Scouts, National Brotherhood Week, famine emergency, used clothing for war victims and many more.

Theodore S. Repplier, executive director since 1943, became president of the Council in 1946. This former advertising agency copy star had a staff of veteran advertising, radio and public relations employees to assure campaigns as efficiently conducted as any in the commercial field. Offices were established in New York, Washington. Chicago and Hollywood to assist co-operating advertisers.

\section{GI Insurance-a Case History}

After World War I, the government had almost $\$ 49,000,000,000$ in life insurance on $4,500,000$ service men; today this figure has dwindled to $\$ 2,400,000,000$. 
To prevent such a debacle with the $\$ 142,000,000,000$ in World War II service life insurance, the Advertising Council began in 1946 to work with the many private companies and associations interested in keeping these policies in force.

The task was-and still is-a tough one. Many veterans promptly dropped their government insurance when discharged. By midyear of 1946 only $\$ 23,500,000,000$ was in force. According to the advertising magazine Tide, chief reasons for so many lapses were: "highpressure methods in selling the coverage" by the Army and Navy, which "soured many a man on the idea of hanging on to it"; objection to the stringent limitations on whom they could pick as beneficiaries, to the fact that death benefits were not payable in lump sums, and to the limited forms to which the term policies could be converted; and the fact that most veterans were young and not much worried about providing for dependents. *

Changes in G.I. insurance policies were made in August 1946, permitting men to name any beneficiary they wish and to convert to endowment insurance in addition to straight life or 20 or 30-payment life. Sickness and accident benefits were added. Death settlements could be paid in lump sums if desired.

With these new features, an aggressive drive was started by the Veterans Administration, private life insurance companies and the Advertising Council to convince veterans of the wisdom of converting their term insurance to permanent policies. In four months the amount in force had increased 50 percent to $\$ 38,000,000,000$, and there was hope that the figures might reach $\$ 50,000,000,000$ or more.

The Advertising Council's part in the 1946 campaign was two-fold. Eight hundred and fifty radio stations carrying veterans' programs each week plugged service life insurance. Various advertising campaigns were prepared, including a series of car cards, among them one showing George Baker's famous cartoon character, "Sad Sack," with the copy:

Don't Be the Sad Sack Who Dropped His Service Life Insurance! Even if you've missed payments

... you can reinstate easily.

See Your Nearest Veterans Administration Office Today

* "GI Insurance," Tide, Nov. 29, 1946, pp. 45-6. Quoted by permission of Tide. 


\section{THIS FASCINATING ADVERTISING BUSINESS}

Campaign manager for the task force was Holgar J. Johnson of the Institute of Life Insurance, and co-ordinator for all veterans' problems campaigns Philip J. Kelly of Carstairs Distillers, both serving, of course, without pay.

This particular program is cited as an example of a public service program in which private business carried the bulk of the load, with the Advertising Council helping where needed.

\section{The Freedom Train}

In the spring of 1947 , advertising was preparing to undertake what might well prove its most ambitious and far-reaching project-mass education in the ideals and practices of American democracy. One hundred and fifty leaders in business, the professions, labor, the amusement world, and in racial, fraternal and patriotic organizations met at the White House on May 22, 1947, to establish the American Heritage Foundation. The campaign started with a $\$ 300,000$ fund raised by subscriptions from industries and other interested groups.

Outstanding feature of the campaign was to be a "Freedom Train" to tour the country for a year, exhibiting the original Declaration of Independence, the Constitution of the United States, the Bill of Rights, the Emancipation Proclamation, and 100 other documents forming the foundation of American democracy. The train, furnished by the Association of American Railroads, was to leave Philadelphia September 17, 1947, the 160th anniversary of the adoption of the Constitution. In each city along the route it was planned to stage a "community rededication week" with public exercises dramatizing "America's traditions of the past and promise of the future."

Named as chairman of the foundation was Winthrop W. Aldrich, president of the Chase National Bank, and as president, Thomas D'Arcy Brophy of Kenyon \& Eckhardt, nationally known advertising executive. Mr. Brophy, in outlining the aims of the campaign, said, "We must work at democracy to make democracy work."

The Advertising Council prepared a vast program of advertising to appear in all types of media. As with every Council project, space and time costs were to be borne by industry and business, with the probability that this investment would run many times larger than the original $\$ 300,000$ operating fund.

The "American Heritage" program is only one phase of a concerted 
over-all effort to strengthen public understanding and appreciation of the free enterprise system. By mid-1947 a campaign developed jointly by the Association of National Advertisers and the American Association of Advertising Agencies was well under way. As outlined by Evans Clark, chairman of the Public Advisory Committee of the Advertising Council, it had these objectives:

1. To show the reasons why, in spite of its shortcomings, the American system has given us the highest standard of living and the greatest freedom in the world.

2. To rally all groups in the nation for a common effort to improve our system through constantly increasing productivity and a wider distribution of its benefits.

In this statement of aims can be seen the twofold strategy always advocated by experienced advertising men for commercial campaigns. Step one is to promote the product-in this case the American economic system - on the basis of its present advantages over competing products (i.e., Communist or Fascist ideologies). Step two, which must go hand-in-hand with the first, is to make the product steadily better and thus keep ahead of competition.

It is apparent that business leaders realize the necessity of "improving the product" while selling the free economy system to the public. This fact received frank consideration at the 1946 meeting of the Association of National Advertisers, at which President Paul B. West declared, "A. N. A. members are looking to advertising as an important tool to be used in the broad task of presenting the facts about industry to the American people so that they will understand, preserve and support the competitive enterprise system." A principal speaker was Paul Hoffman, chairman of the Committee for Economic Development and president of Studebaker Corporation. Business must do everything possible to reduce the intensity of fluctuations in the economic cycle if the campaign for the American system is to succeed, he said, adding:

With all due respect to advertising-in which I have great confidence-it is idle to think that we can advertise a system into permanence if the system doesn't work to the satisfaction of the rank and

\footnotetext{
*.Advertising Age, April 28, 1947, p. 26.
} 
file of our people, and the rank and file of our people don't like a system that produces major depressions.*

Unquestionably advertising cannot gloss over the defects in the free enterprise system. On the other hand, advertising men are accustomed to studying commercial products and through research and creative imagination devising means of improving those products. It is not too much to assume that the same skills can contribute thinking which will make this system more "salable" to the public.

One contribution advertising can and will make is to aid in the promotion of continuing and expanding peak national prosperity. If it is successful in this, the task of "merchandising" American business will be vastly simplified.

During World War II, advertising men declared that their techniques could win nationwide co-operation for essential civilian activities-and proved it. Can they, through this new type of public service advertising, fill a similar role in preserving America's democratic traditions?

Industry has often been criticized for concentrating all its attention on selling its output and none on "selling" the economic system which makes the output possible. Now that the campaign is actually under way, it will be watched with the most intense interest by every group and individual with a stake in the American way of life. It is at once the gravest responsibility and the most magnificent opportunity in the colorful history of this fascinating advertising business.

* The Challenge and Opportunity for Advertising Management, Association of National Advertisers, 1946. 


\section{THE ADMAN'S LANGUAGE}

THE author acknowledges his indebtedness to previously published advertising dictionaries, including Radio Alphabet, by Columbia Broadcasting System, and that in Advertising Procedure, by Otto Kleppner.

A.A.A.A.-(The 4 A's) -American Association of Advertising Agencies, $\mathrm{ABC}$-American Broadcasting Company.

A.B.C.-Audit Bureau of Circulations. An organization which sets up circulation standards and gathers accurate circulation statements. Sponsored jointly by publications, advertisers and agencies.

ACCOUnT EXECUTrve-the liaison man between an advertising agency and its clients. He is employed by the agency and has the responsibility of directing the advertising of one or more clients. Also known as Contact Man.

ACROSS THE BOARD-radio program appearing at the same time five or more consecutive days per week.

ADVERTISING AgENCY-an organization with media recognition, serving three or more clients in the planning, preparation and placing of advertising campaigns.

A.F.A.-Advertising Federation of America. Its membership includes such organizations as the 4 A's, the A.N.A., and local ad clubs.

AFRA-American Federation of Radio Artists.

AGate LiNE-Standard unit of measurement in computing depth of a printed page. One agate line is one column wide and 1/14 of an inch deep.

AIR-White space within a layout. In radio, verb meaning "to broadcast."

A.N.A.-Association of National Advertisers. (Sometimes written ANA. The periods are optional in many of these abbreviations.)

ANNouncement-(1) the "brief word from our sponsor," from 20 words to 150 words in length. (2) An ad or folder introducing a new product or campaign.

A.N.P.A.-American Newspaper Publishers' Association.

A.S.C.A.P.-American Society of Composers, Authors and Publishers. An organization to which member composers, authors and publishers assign their copyrights, collecting royalties in return.

Audience TuRnOVER-the total number of different listeners to a given program over a specific number of consecutive broadcasts; or, the rate at which a program increases its audience of different listeners over a given span of performances.

Auditron-a try-out of artists or musicians or programs under broadcasting conditions.

BALLOONS-the method of indicating speech commonly used in comic strips. Now frequently seen in advertising. Also called BLuRB.

BEARD - an error in performance; more often words misread by an actor.

373 
BEN DAY - from the name of its inventor, Benjamin Day. A mechanical process by which an engraver can give shades and tones to a line plate.

BLACK AND WHITE-an advertisement without color. Also, used by radio people to describe all printed advertising, whether one color or not.

BLANKING-white sheets around border of a 24-sheet poster.

BLEED-any page on which the printed matter or illustration runs out to the edge of the sheet. Produced by printing an oversize plate and then trimming down to page size.

BLow-UP-an enlargement. Usually refers to an oversize reproduction of an advertisement used for display purposes.

BLURB - a statement handed out for publicity.

BMB-Broadcast Measurement Bureau.

BoILER Plate - the syndicated stereotype pages used by country weeklies.

Book-a magazine. "Front of book" or "back of book" refer to ad locations in the magazine. Also a mail-order catalogue or trade-school brochure.

BREAK - a scheduled or unscheduled interruption of a radio program, or a recess in rehearsal schedule.

BRIDGE - a musical or sound-effect cue linking two scenes in radio.

BuCKEYE-a blatant display or commonplace ad treatment. Not to be confused with Buckeye Cover, a popular heavy-duty stock for catalogue and booklet covers.

BuG - a trade-mark, approval seal or other small unit inserted inconspicuously in an ad. Also the union label (a must on political ads or posters). "Bugs"defects in product or plan; should be eliminated before general use.

BUILD-UP-technique used to increase the popularity of a program, a personality or a product.

BULLDOG-the predate edition of a morning newspaper. Printed in the early evening of the day prior to date of issue.

Cali Letters-initials assigned by the Federal Communications Commission to identify a broadcasting station.

CAPTION-a heading. Also, descriptive lines under an illustration.

CAST - the performers in a radio program; to select the performers for a radio program.

CBS-Columbia Broadcasting System.

ChAIN BREAK-brief commercial inserted during 30-second pause for station identification between network programs.

ChANNEL - $a$ band of frequencies in the spectrum assigned to a given radio station or stations.

CharaCter-(1) A casting term referring to an individual dramatic role. Also currently, an eccentric person. (2) In computing type, any single unit such as a letter, punctuation mark or word space. (3) The "personality" of a store.

CHEESECAKE-photo or artwork featuring attractive feminine legs.

Circulation-In periodicals, the number of copies of a single issue distributed. In radio, the number of radio families who listen to a station or network during some definite span of time (usually one or more times a week).

Clambake-a shapeless program filled with uncertainties; rehearsals marked 
by errors, changes and failures, likely to result in a bad performance. Sometimes called Clamaroo.

Closing Date-the final date on which a publisher will accept copy or plates of an advertisement scheduled to appear in a given issue.

CleAR a NUMBER-to obtain legal permission from responsible sources to use a certain musical selection in radio.

Cliff HANGER-a serial dramatic program played at a high pitch of excitement on a strong note of suspense.

COARSE SCREeN-A halftone illustration prepared to run on low-grade paper.

COAXIAL CABLE - a special cable for high-fidelity transmission of electrical impulses. Essential for the overland transmission of television images.

CoINCIDENTAL - a method of measurement of the size of a program's audience by telephone calls during the progress of an actual broadcast to determine the proportion of listeners and nonlisteners, i.e., coincidentally.

Combrnation RATE-a special rate granted to advertisers who contract to use two or more papers which offer special rate concessions. Usually used in connection with a morning and evening newspaper in the same town and owned by the same publisher. A forced combination is the rate for two or more papers which cannot be bought separately.

CoMp (short for "comprehensive") - a carefully executed layout. Also a typesetter (compositor).

Consumer Advertising-advertising directed to the ultimate user of a product.

ContaCt (verb) - to see or communicate with client, customer or prospect; (noun)-any such meeting or communication. In agency-client relations, the continuous liaison involved in handling an account.

ConTINUITY - the written form of a radio program: a radio script.

Co-operative Program - a network program sponsored in each station area by a local advertiser who usually pays for the time at local rates and shares the cost of talent pro rata.

Copy-matter prepared for publication. Hence, the manuscript for an advertisement; the text for a printer; the finished art or photographs for an engraver.

COPY WrITER-a man or woman who prepares the headline and text of an advertisement.

COVERAGE - the area in which a station or network of stations can be heard according to engineering standards. Also, the market reached by any medium.

Cow-CATCHER - an isolated commercial announcement at the beginning of a program, which advertises a "secondary" product of the sponsor not mentioned in the program itself.

CROPPING-trimming off portions of an illustration in preparation for publication.

Cuffo-an adverb or adjective applied to speculative or donated work without pay, or on the cuff.

CuT-(1) shortening of the word woodcut. Now generally applied to all photoengravings. (2) In radio, to stop transmission of a program. (3) To 
delete copy in order that it may be short enough to fit prescribed limitations.

Cut a Record, Disc or Platter-to make a recording.

Dawn Patrol-the engineers, announcers and others who open the studio and put on the early morning programs.

DeAd Metal-also called bearers. Excess metal which is left on an engraved plate to give extra strength and protection during the electrotyping process.

DELAYED BROADCAST - postponed airing of a program by means of an instaintaneous recording made from the network lines during the original broadcast.

DisC JockEy-the master of ceremonies of a program of transcribed music (records). He turns them over.

Double-page Spread (Double Truck) -a single advertisement printed on two facing pages of a publication.

DRESS-the final complete radio program rehearsal.

DUMMY - (1) A "mock-up" of a proposed printing job using blank sheets of paper of the size, shape and weight desired in the final folder or booklet, as guide to printer. (2) An empty carton or box used for display purposes.

Есно Chamber-a reverberant space through which sound and voices are channeled to give them an echolike, faraway quality.

Electrical Transcription-a form of high-fidelity recording made especially for broadcasting and allied purposes.

ELECTROTYPE-a metal plate made by the electrotype process. When several identical plates are needed, one original is made. Then a wax or lead mold is taken from the original and, by the electrotype process, as many facsimile copies of the original as are needed are made from the mold.

EXTENSION-allowance, made by publisher, of extra time beyond announced due date for ad copy or plates.

FACE-in type, the printing surface. Hence, also the printing surface of a plate.

FACILITIEs-a general term describing the technical equipment of a radio station or network. Also, the stations of a network.

FACSIMILE BROADCASTING-a process of transmitting and receiving, by radio, graphic material such as pictures and printed matter.

FCC-Federal Communications Commission.

FrlL-IN-(1) Blurring of a halftone in printing. (2) Hand-typed name and address of sender on a form letter. (3) Details of a proposed campaign, to be worked out after broad policies have been decided.

FIRM ORDER - a positive contract for space or time.

FIsH BowL-the clients' observation booth overlooking the broadcasting studio.

FLACK - a publicity writer or his output.

FLAT RATE-a single uniform charge for space in a medium. As differentiated from "time discounts" or "quantity discounts" when special rates are given based on the amount of space used or the frequency of insertion.

FLOP-OVER (or FLIP-FLOP) -a series of large sheets containing text on charts mounted in an easel binder and turned one by one as a talk is made. 
FLUSH-method of trimming plate so that type matter can be set close, without need of allowing space for "shoulder".

FOREIGN ADVERTISING (also, "National Advertising")—advertising sponsored by a national manufacturer, as differentiated from "Local advertising" paid for by local retailers.

FREE GOODS-extra merchandise given retailer as bonus for stocking an item.

FREE LANCE - an independent artist or copy writer, employed by various accounts to do specific jobs.

FREQUENCY - (1) In radio, the wave length of a radio station measured in kilocycles. (2) In printed advertising, the number of insertions over a given period of time.

FREQUENCY Modulation-a method of broadcasting to provide reception comparatively free of interference or static. Usually called FM.

FroM HUNGER - epithet applied to a poorly written or badly acted program or scene, equivalent to: "It is a trite, makeshift device," or "It doesn't look strong."

FTC-Federal Trade Commission.

GIMMICK-also "hook," "gadget" or "peg." Device such as premium offer, prize contest, or recipe booklet, intended to make advertising more productive. (Hard g.)

Good House-Good Housekeeping Magazine.

Go 'RounD - series of calls on trade prior to or during a campaign.

GUTTER-division between left and right facing pages.

HALFTONE-a photoengraving plate, or a picture made from such a plate, which reproduces the tones in a photograph by means of a system of dots. In printing, these dots are usually invisible. Made by photographing the subject through a glass screen varying from 45 to 300 lines to the inch.

HAND LETTERING-lettering, as in a headline, which has been drawn by hand for a specific ad as differentiated from standard type which may be used in many ads.

HEARTBREAKER-a commercial audition made on speculation.

HITCHHIKER-separate commercial at the end of a program on another of the sponsor's products. A "cow-catcher" is a similar device at the beginning of a program.

Hog Calling Contest-a strenuous commercial audition for announcers possessed of pear-shaped tones of voice.

Hook - a device used to attract tangible response from the radio or magazine audience, e.g., an offer, a contest, etc.

HoOPERATING - a program's audience-rating as determined by the C. E. Hooper, Inc., research service.

HouR-any radio program.

House ORGAN - a periodical published by a firm for regular distribution to its own employees, stockholders, jobbers or customers.

Hypo (short for "hypodermic")-intensified effort applied to specific product or territory to stimulate sales. Verb or noun. Also described as "needling." INTAGLIO-printing from a depressed plate as distinguished from "Letter- 
press" and "Lithographic" printing. Examples: engraved calling cards; rotogravure.

IsLAND-(1) In newspapers or magazines, the location of an advertisement so that it is entirely surrounded by editorial matter. (2) In stores, a display of merchandise in the center of an aisle.

KEYING AN ADVERTISEMENT-a method of tracing the source of an inquiry from a given advertisement. Example: coupons appearing in several publications bearing separate "department numbers," one for each periodical.

LAYOUT-a sketch of an advertisement designed to show how it will look in print.

LETTERPRESS-printing from a raised surface as distinguished from "Intaglio" and "Lithographic" printing. Newspapers and books are usually printed by letterpress, as are many magazines.

LINAGE - in periodicals, the total number of lines occupied by advertisements in a publication.

LiNe-see Agate LiNe.

LINE DRAWING - a drawing made with solid lines and no variation of tone.

LITHOGRAPH-printing from a flat surface as distinguished from "Intaglio" and "Letterpress" printing. Example: large quantity of color work such as labels.

LrvE-a program actually being performed by people at the time of broadcasting in contrast to a recording of a previous live performance.

LOCAL-a program originating in a local station as contrasted with a network program.

LoCAL AdVertising-in newspapers, advertising placed by a local retailer, generally without agency commission.

LoGo (short for "logotype") - specially designed arrangement of firm or product name, usually appearing at base of advertisement.

LOWER CASE-also "l.c." The small letters of the alphabet as contrasted to UPPER CASE LETTERS.

MARKETING-the business activities, such as advertising and salesmanship which are designed to get the finished goods from the factory into the hands of the consumer.

MATRIX-also "mat." The paper or plastic mold made by pressing with an engraving plate or type form. The stereotype is made from this matrix by pouring molten lead into it, thus giving a duplicate of the original plate. In linotype printing, the brass molds from which the linotype slugs are cast. MBS-Mutual Broadcasting System.

Medrum-plural, "Media." Any newspaper, radio station, magazine, poster or other vehicle which carries an advertisement. Also, in art, the method used by the artist as wash, crayon, pen and ink, etc. (see definitions at beginning of book.)

Milline RATE-a standardized unit for measuring advertising costs in periodicals. Shows the cost in a given periodical of printing one agate line for a million readers.

MoBILE UNIT-a truck or trailer equipped with transmitting apparatus used to relay programs from remote points to the studio. 
MooD Music-background music to establish or intensify the mood of a dramatic scene.

NAB-National Association of Broadcasters.

Nameplate Polishing-advertising which seeks to glorify the advertiser rather than make sales.

NBC-National Broadcasting Company.

NETWORK-multiple radio stations linked by land (wire) lines. (1) CoAstTO-COAST NETWORK - a group of stations covering the whole or greater part of the United States. (2) Regronal Network-One covering a definite segment of the country. (3) SPLIT NETwORK-Selected stations of a network used to meet specific distribution problems.

NIELSEN RADIO INDEX-a reporting service for broadcasters and advertisers based on the use of the Audimeter. Operated by the A. C. Nielsen Co., this service regularly reports program ratings, trends, and the amount and distribution of radio listening by periods of the day.

N.O.A.B.-National Outdoor Advertising Bureau, the central outdoor service department for member advertising agencies.

O.A.A.A.-Outdoor Advertising Association of America, made up of poster plant owners.

O.A.I.-Outdoor Advertising, Incorporated, the national sales representative of the plant owners.

OFFSET-(1) A lithographic printing process by which the impression is transferred to a rubber blanket before being imprinted on the paper. (2) The smudging of a freshly printed page on an accompanying page.

Old Style-in printing, as differentiated from modern type. Modern has sharp contrasts in its strokes, horizontal or vertical serifs. Old style has shaded differences in its strokes and generally has oblique serifs. Also, a common name for the lighter member of a family of types.

ONE SHOT-a single ad or program which is not one of a series.

ON THE BOARD-artwork which already has been started.

ON THE NOSE- a program that ends exactly on the planned second.

OPEN COLD - to open a radio program without theme, or musical introduction or background, or even without rehearsal.

ORIGINATE-to broadcast from a specific location.

Outlet-(1) A dealer. (2) A radio station which puts the program on the air. P.A.- "Public address," an intramural loudspeaker wire system, used in studios, halls, battleships, parks, airports, and industrial plants.

PACKAGE-a special program or series of programs bought by an advertiser (usually for a lump sum), which includes all components, all ready-to-broadcast.

Painted Bulletin-an outdoor structure on which an advertisement is reproduced in paint. The standard size is 42 feet long by $14 \mathrm{I} / 2$ feet high.

PATTERN-typical advertisement serving as model for future ads in a campaign. Also a printing plate from which duplicates can be made.

PENCIL-artist's outline for a drawing, sometimes submitted to an advertiser to permit changes before finishing.

PICA-printing measurement: approximately 6 picas equal one inch. 
PlanT-the structures for carrying outdoor advertising in a given market.

PLAYBACK - the playing of a recording for audition or reference purposes after it is made.

PoINT; pt.-in printing, the standard unit of type measurement. A point is $1 / 72$ of an inch in depth. In paper, a unit for measurement of paper thickness. Here a point is $1 / 1000$ of an inch.

Poster Showing-the unit of sale established by the local poster plant, varying in number of panels from city to city. An advertiser may contract for a "full showing," a "half showing," etc.

P.P.A.-Periodical Publishers' Association.

Presentation (pronounced pree-sentation)-a portfolio, mailing-piece, film or speech intended to sell an advertising proposal. Also known as "the pitch."

PRIVATE LABEL - a product labeled and sold under the trade-mark of a wholesaler or retailer as differentiated from a nationally advertised brand carrying the trade-mark of the manufacturer.

Process Plates (pronounced proh-cess)-in photoengraving, plates used in color printing, each of which is used to print a separate color. The impressions from 2,3 , or 4 plates are superimposed on each other to produce the final effect desired.

PROCESS PRINTING-letterpress color printing in which one color is printed over the other by means of a set of process plates.

PRODUCER-the individual, or impresario, or sponsor, or broadcaster, originating and presenting a program.

PRoDuction Department-(1) The department of an advertising agency responsible for the mechanical production of an advertisement, dealing with printers and engravers. In some agencies it includes the copy and art departments. (2) The department responsible for the proper broadcasting of a radio program.

RECALL - a test of advertising effectiveness in which subject is asked to remember an advertiser from an ad headline, campaign theme, or radio program title.

RECOGNIZEd AgenCY-an advertising agency which has been accepted by various media or their associations as eligible to receive standard commission on the space it buys for advertisers.

RED CARPET-overly dignified radio show or magazine campaign without much mass appeal.

RELEASE-a publicity item; so called because it generally bears the date on which it may be "released" (published). Also-a legal form signed by a model authorizing the advertiser to use signer's picture in ads.

REP-short for representative; a space or time solicitor. "General rep"solicitor handling several noncompeting newspapers or stations.

REPEAT-the second presentation of a regular studio program for those stations not served by the original broadcast, usually due to time differences.

RETOUCHING-the correction and improvement of photographs, usually by airbrush. 
Reverse Plate-in engraving, a line plate by which the background is printed, leaving lettering or design in the original color of the paper. Usually appearing as white type or letters on a dark background.

RIDE THE SHOWING-in outdoor advertising, to visit various poster locations to check visibility, proper mounting and other factors.

ROTOGRAVURE, or ROTO-the method of intaglio printing in which the part to be printed is chemically etched out of a copper roller.

RoUGH RoUGH-preliminary sketches in planning an advertising layout. (See "comp.")

R.P.M.-revolutions per minute, the speed at which a recorded program is played: for transcriptions, 3.31 3 R.P.M.; for phonograph records, 78 R.P.M.

Sales Promotion - any activity (except personal selling) designed to increase a firm's volume of business. In some firms the sales promotion department is separated from media advertising and handles only market studies, inquiry follow-ups and sales department literature.

SAMPLE-(1) a segment of the market, the opinion, habits and tastes of which are taken as representative of all; (2) to distribute free packages of a manufacturer's product.

SCHEDULE-an advertiser's list showing details of media to be used in a campaign.

SCRIPT-see ContinutTy.

SEGUE-pronounced seg-way. The transition from one musical theme to another without a break or announcements.

SELF-MAILER-a direct-mail piece that requires no envelope but includes space for address and stamp on the piece itself.

SHARE-OF-AudienCE- the percent of listeners tuned to a given station (or program) based on the total of sets-in-use.

SHELF-WARMER-slow-moving item; also known as a "sleeper." A number of such items may be called "cats and dogs."

SHOWING-the group of posters used to provide coverage in a market.

SigNAL-when you hear a given station, you're hearing its signal. When you can see a station's television picture, you're seeing its signal.

SIGNATURE- the name of the advertiser, usually printed at the bottom of an advertisement. In radio, the identifying sound of music which introduces a particular program.

Sing-to flow smoothly, inspiringly; applied to headlines and text as a supercompliment.

SLUG-a single line of type; also a standard element in an ad, such as the trade-mark or copyright line.

SNEAK-IN-to bring music in softly, behind the dialogue.

SOAP OPERA - a patronizing term loosely applied to popular daytime dramatic serial programs because the early sponsors of these programs were soap manufacturers.

SPECIAL REPRESENTATIVE-also, foreign representative. An organization which represents a number of noncompetitive media in selling space outside their cities of publication or broadcasting. 
SPECTACULAR-a large illuminated outdoor display often with some movement, as a clock, flashing light, etc.

SPLIT NETwORK-in radio, two or more sections of a single national network each of which carries a different program.

SPLIT RUN-division of a newspaper or magazine printing into two or more press runs, enabling advertiser to test different copy appeals in same issue.

SPONSOR-one of the 50,000 or more advertisers in America who use radio to sell their products and services.

SPOT BROADCASTING-programs or announcements broadcast independently by individual radio stations. Spots-the time locations selected for spot broadcasting.

STAND BY-a substitute program ready "in the wings" to go on the air in any emergency. Or, a command to performers to get ready to take the air.

STAT (short for "photostat")-inexpensive method of reproducing art or type matter, often used in layouts.

Station AnNouncement - the signature announcement which identifies the call letters, city and slogan of the station which is being listened to.

Station DIRECTOR-the executive in charge of a broadcasting station.

STEREo (stereotype)-in printing, a duplicate metal plate made from a matrix. Newspapers are printed from stereotypes.

STET-in proofreading, "Let it stand." Generally used when a change has been indicated in a proof and it is decided to disregard the change.

Stock Cuts-plates of illustrations used by several advertisers on a nonexclusive basis to picture standard situations.

STOPPER-a striking headline or illustration, considered by its proud parent to be irresistible even to the casual reader.

STRETCH-to slow up the playing of musical numbers or the reading of script so that a show will finish exactly on time.

STRIP-group of illustrations in sequence, as in newspaper comics. Also, in reproduction, process of combining two or more units into finished ad.

STUDIo-in radio, a room for presenting broadcasts. Also, an organization producing commercial art and/or photography.

SURVEY - investigation made to learn facts in advance of, or popular reaction after, a campaign. Also called "study."

T.A.B.-(Traffic Audit Bureau.) Organization representing A.N.A., A.A.A.A., and O.A.A.A. furnishing market data on outdoor advertising coverage.

TAG-in radio, a few bars of music at end of commercial, to supply transition to next part of program. Also the sign-off announcement.

Tear SheEt-page torn from publication and sent to client as proof that ad has appeared.

THROW IT AWAY - to fade out or underplay radio dialogue.

TIE-IN-local ad or display appearing simultaneously with national campaign. Also, special sale offering two products at price below their combined price.

Tigri-closely set text; also a closely timed radio show.

TIIL-ForBID; RUN T.F. - an ad run by a publisher until he receives orders to stop. 
TIME BUYER-agency employee responsible for making the proper selection of radio coverage to meet the requirements of the advertiser.

TOPPER-advertising offer or product feature superior to competition.

TRADE ADVERTISING-product advertising to jobbers or retailers as differentiated from advertisements directed to consumers.

TRAFFIC-(1) Number of people who pass a given poster location. (2) The expediting department in an agency. (3) The number of customers who enter a store.

TRANSOM-unsolicited business is said to come in "over the transom."

$T_{R}$.- - proofreader's abbreviation: to transpose.

Twenty-Four SHeEt-the standard outdoor poster panel, of which the printed area is $19 \mathrm{ft} .8 \mathrm{in}$. long and $8 \mathrm{ft} .10 \mathrm{in}$. high. THREe ShEET-a small poster panel, usually on the side of a store, printed area, $3 \mathrm{ft} .5 \mathrm{in}$. wide by $6 \mathrm{ft} .10 \mathrm{in}$. high.

VIDEO-electric currents or equipment associated with transmitting television pictures. Loosely used to refer to television.

VISUAL - quick layout made to indicate essential ad elements. Also a radio show presented before an audience.

WARM UP-the 3 or 5 minute period immediately preceding a broadcasting in which the announcer or star puts the studio audience in a receptive mood by amiably introducing the cast of the program, or discussing its problems. WASH-a drawing made with diluted ink or tempera with varying shades of gray.

WIDow-short line at end of paragraph. A "widow" at the top of a column (sometimes called an "orphan") is considered particularly bad makeup.

WRAP-UP-completion of details of a campaign.

YESTERDAY - the date when most advertising copy, art work and plates are due. "Day before yesterday"-indicating even greater rush. (See "extension.")

ZILCH-the standard name used to describe anyone who walks into a radio studio and whose name is not known.

ZrNc-in photoengraving, a line plate made on zinc. 
IN DEX 


\section{INDEX}

AAAA, see American Association of Advertising Agencies

A \& P Stores, 138

ABC Diaper Service, 282

Abt, Henry E., 352

Adams, James R., 174, 175

Adams, Samuel Hopkins, 67

Adcrafter, 353

Adman's Language, 373-383

Advertiser, The, 353

Advertising, defined, 17 ; creative aspects, 19 ; in radio, 21 ; negative side, 23 ; war bonds in World War II, 37; "trail blazer," 51 ; truthful, 65 ; consumer, 73 ; appropriation, 95 ; agency, 103 ; department store, 129 ; promotion, 132, 142 ; chain-store, 137; industrial, 72, 144; intangibles, 153; postwar, 156; women in, 176-178; newspaper, 197; color, 206; direct-mail, 255; media, 265-283; products of, 287-294; how written, 295-307; art in, 308-314; photography, 314-315; hand lettering, 316-320; duplicate plates, 324 ; jobs in, 343-345; organizations of, 346-352; during World War II, 355-365; reconversion, 366-372

Advertising, Goode, $39 n$

Advertising Age, 108, 119, 120, 134, $140 \mathrm{n}$, $149 n, 166,175 n, 190 n, 212 n, 238 n, 278$, $353,371 n$

Advertising Agency, The, Keeler and Haase, $117 n, 121$

"Advertising Agency Functions and Compensation," Advertising Age, 108

Advertising \& Selling, 166n, 168n, 231, 347,353

Advertising Campaigns, Barton and Lichtenberg, $89 n$

Advertising Copy, 295

Advertising Council, 346, 347, 351, 371

Advertising Distributors of America, 278

Advertising Federation of America, 42, $65,66,346-347,373$

Advertising Fortnightly, 59, 353

Advertising in Our Economy, 69 n

"Advertising Placed by Agencies in Business Papers," 148n, $149 n$
Advertising Procedure, Kleppner, 110n, $183 n, 253 n, 373$

Advertising Research Foundation, 42, 208, 251, 303, 347, 348, 349, 350

Advertising Research Foundation, Inc., $210 n, 252 n$

Advertising Specialty National Assn., The, 275

Advertising to the Mass Market, 295

Advertising Typographers of America, 320,352

Aerocar, 59

"Afro-American" group (newspapers), 203

Agnew, Prof. Hugh E., 246n, 248, 249n

Agricultural Publishers Assn., 105, 348, 352

Ahrens Publications, 151

Air Express Co., 264

Akron Beacon-Journal, 209

Albert Frank-Guenther Law, 149

Alden's (Chicago Mail Order Company), 255,315

Aldrich, Winthrop W., 370

Alexander Hamilton Institute, $89 n$

Alka-Seltzer, 270

All American Comics, 191

Allen, E. C., 47, 48

Allen, Fred, 216, 231

Allen, John, 238

All Flash Comics, 191

Allis-Chalmers, 145, 167, 233

"Aloha from the Islands," 226

Altman's, 134

Aluminum Company of America, 146, 149,273

AM, 237

American Academy of Art, 311

American Agriculturist, 65

American Airlines, 85

American Association of Advertising, 109, 208

American Association of Advertising Agencies; 42, 119, 123, 124, 126, 219, $245,303,348,349,351,352,353,358$, 371,373

American Bankers Assn., 154 
American Broadcasting Co. (ABC), 373 American Exporter, 269

American Farm Bureau Federation, 265

American Federation of Advertising Clubs, 346

American Federation of Radio Artists (AFRA), 373

"American Heritage," 370

American Heritage Foundation, 370

American Highway Sign Assn., 352

American Home, The, 159, 190

American Home Foods, 336

American Home Products, 85, 212, 222

American Institute of Laundering, The, 155

American Institute of Laundering Seal of Approval, The, 155

American Journal of Nursing, The, 364

American Legion Magazine, 193

American Locomotive, 145

American Machinist, 151

American Magazine, 170, 172, 185, 327

American Management Assn., 288

American-Marietta Co., 340

American Marketing Assn., 334

American Meat Institute, 156, 280

American Museum, New York City, 33

American National Bank and Trust Company of Chicago, 154

American Newspaper Advertising Network, 205, 206

American Newspaper Directory, 40

American Newspaper Publishers' Assn., $105,197,352,373$

American Newspaper Publishers' Association Bureau of Advertising, 197, 209, 352

American Press Assn., 198, 204

American Red Cross, 366

American Society of Composers, Authors and Publishers, 213, 373

American Telephone and Telegraph Co., 85,213

American Tobacco Co., 76, 86, 164, 165, 166

American Trade Association Executives, 157

American Type Founders, 320

American Way of Life, The, Sokolsky, $56 n, 64 n$

American Weekly, 189, 194, 205

American Wheelman, 58

America's Future, Inc., 212

Amplitude modulation, see AM

ANA, see Association of National Advertisers

Anderson, Sherwood, 344
And Hearing Not: the Annals of an Adman, Calkins, 170

And So to Bedlam, Lyon, 344

"Ann Page," 138

Annual Advertising Awards, 162, 353

Anthony, Edward, 186

Appel, Joseph H., 67

Arc Welding Machine Co., 339

Architectural Concrete, 159

Arens, Egmont, 294

ARF, see Advertising Research Foundation

Armbruster's Orchestra, Robert, 158

Armour \& Co., 210

Armstrong, Rolf, 275

Armstrong Cork Co., 146

Arney, C. E., 351

Arons, David, 239

Art Directors Annual, 308

Art Directors Club, 308

Art Institute, 178

Art \& Decoration, Warren, 308

Art of Plain Talk, The, Flesch, 301

Aspley, J. C., 264, 333

Associated Advertising Clubs of the World, see Advertising Federation of America, 66, 346

Associated Bill Posters, 243

Associated Business Papers, 42, 105, 149, $150,348,352$

Associated Publishers, Inc., 203

Association of American Railroads, 156, 160,370

Association of National Advertisers, 42, $91,169,208,217,245,251,268,273 n$, $303,348,349,351,353,358,371,372 n$, 373,382

Association of National Advertisers, Inc. $94 n$

Association of National Advertisers Radio Council, 351

Astor, J. Jacob, 31

Atlanta, Ga., 205

Atlanta Journal, 200

Atlantic, 170, 185

Atlantic Gasoline, 239

Atlantic Monthly Press, 170 n

Atlantic Overseas (Time), 270

Atlantic Refining Co., 239

Auburn automobile, 59

Audimeter, 221

Audit Bureau of Circulations, 150, 182, $219,270,271,347,350,351,353,373$

Augusta, Me., 47, 48

"Aunt Jenny," 223

Aurora Dawn, Wouk, 22

Automovil Americano, $E l, 151$

"Auto Shows," 59 
Awakening of Cupid, The, Perrault, 43

Ayer, F. Wayland, 45, 46, 171, 173

Ayer \& Son, N. W., 37, 45, 61, 177, 239, 330

Ayres \& Co., L. S., 134

Babbitt, B. T., 251

Bab-O, 214, 278

Baird Corp., Harry, 320

Bakelite, 146

Baker, George, 369

Baker, Kenny, 229

Baker's Cocoa, 278

Ball, Max W., 24n, 58n

Balmer, Thomas, 171

Barclay, McClelland, 60

Barkers, 25

Barnes \& Noble, $68 n$

Barnum, C. P., 67

Barnum, Phineas T., 32, 33, 36, 45, 123, 242, 319

Barton, Bruce, 89

Basford Co., G. M., 149

Bates, Charles Austin, 38, 45, 170, 171

Bates, John, 114

"Bat Man," 191

Batten, Barton, Durstine \& Osborne, Inc., 92, 114, 149, 167, 231

Battle Creek, Mich., 55

Battle Creek Sanitarium, 55

Bayer Aspirin, 174

Beatrice Creamery Co., 289

"Beauty and a Song," 226

Beautyrest Mattress, 78, 79

Beech-Nut chewing gum, 170

Bedell, Clyde, 295, 296, 297, 306, $307 n$

Belding, Don, 348

Bell, Alexander Graham, 51

Bell, Rex, 243

Bell System, The, 155, 260, 281, 282

Bendix Aviation, 175

Bendix Radio, 175

Benny, Jack, 215

Benson, John, 353

Benton, William, 173, 344

Bergdorf-Goodman, 134

Berkowitz, Mortimer, 189 •

Bertsch \& Cooper, 320

Better Business Bureau, 23, 67n, 347

Better Homes and Gardens, 159, 182, 189, 190, 298

Betty Crocker Soups, 92

Billingsley, Allen L., 148

Bill of Rights, 370

Birch, Frank, 250

Birnie, William, 186

Bisquick, 92

Black Mask, 191
Blair and Co., John, 236

Blankenship, Dr. Albert B., 303, 304n

Blatz Beer, 203

Block, Martin, 229

Blue Valley Butter, 289

Bob Hope show, 49

Boiardi, Chef Hector, 239

"Boiler plate," 48

Bok, Edward W., 186, 353

Bolton, Frances Payne, 360

Bolton Act, 360

Bond Clothing, 139

Bonner, Robert, 34

Bonwit Teller, 340

Boone, F. E., 165

Boot and Shoe Recorder, 151

Borden, Prof. Neil, 68, 69

Borden Co., 86, 229, 333

Borton, Elon G., 346

Boston, Mass., 205, 250

Boston and Maine Railroad, 162

Boston Globe, 205

Boston Herald-Traveler, 205

Bostonian shoes, 139

Boston Neros Letter, The, 29

Boston Store (Milwaukee), 207

Boston Symphony Orchestra, 233

Bowles, Chester, 173, 344

Boy Commandos, 191

Boyd, William, 171

BPIC, 268

Bracken, Chuck, 311

Bracken \& Tyler, 311

Bradley, Will, 308

Brady's Photographic Gallery, 35

Brand names, 73, 75, 78, 80, 138, 224, 232

Brand Names Foundation, Inc., 75, 81, 352

Branham Co., 236

"Breakfast Club," 223

"Breakfast in Hollywood," 223

Brenlin Window Shades, 174

Briardale Food Stores, 141

Brillo, 290

Bristol, Lee, 348

Bristol-Myers, 86

Britton, Pamela, 227

Broadcast Measurement Bureau, 219, 347,374

Broadsides, 259

Brochures, defined, 260

Brockway, Louis N., 348

Bronx, N. Y., The, 244

Brooklyn, N. Y., 244

Brophy, Thomas D'Arcy, 348

Brotherton, Nort, 174

Brown, William S., 360

Bruehl, Anton, 309 
Bryson, Lyman, 301

Buchan Co., 149

Buckley, Homer, 264

Buckley-Dement, 58, 257

Bull Durham Tobacco, 250

Bullis, Harry A., 92

Bulova Watch, 231

Bundscho, Inc., J. M., 320

Bureau of Research \& Education, 346

Bureau of Standards, 158

Burn, Walter P., 129n

Burnett Co., Inc., Leo, 94, 156

Burroughs Adding Machines, 340

Business of Advertising, The, 170

Business Publishers International Corp., 151

Business the Civilizer, 170

Business Week, 151, 159

Butler Brothers, 47

Butterick Co., $142 n$

"Buy-Lines by Nancy Sasser," 28

Byron, Lord George, 4

Cadillac automobile, 60, 175

Calhoun, E. H., 340

Calkins, Earnest Elmo, 170, 171, 308, 353

Calkins \& Holden, 38, 116, 170, 353

Calling All Kids, 191

Camel Cigarettes, 71, 117, 164, 229

Campbell-Ewald Co., 170, 270, 340

Campbell Soup Co., 49, 86

Canada Dry Ginger Ale, Inc., 114, 360

Canaday, Ward, 174

Canadian Home Journal, 270

Cannon, Maureen, 227

"Can You Top This?" 218

Capp, Al, 301

Capper Publications, 186

Capper's Farmer, 265, 267

Carey's Salt, 28, 290

Carlton \& Smith, 45

Carstairs Distillers, 370

Castoria, 49

Caterpillar Tractor, 145

Caxton, William, 26, 27

Census of Manufacturers (1939), 181

Central Manufacturers' Mutual Inance Co., 263

Century, The, 41

Chain Store Age, 279, 281

Challenge and Opportunity for Advertising Management, The, $372 n$

Champion Spark Plug, 175

Chandler automobile, 59

Chapman Store (Milwaukee), 134

Chappelow agency, 174

Charles, Prince, 27
Charles II; 27

Chase, Stuart, 355

Chase National Bank, 370

Chatelaine, 270

Cheerioats, see Cheerios

Cheerios, 56, 92, 278

Chef Boy-Ar-Dee Quality Foods, Inc., 239

Chen-Yu, 294

Chesapeake \& Ohio Railroad, 91, 161

Chesterfield Cigarettes, 71, 164

Chevrolet automobile, 61, 175, 267, 331, 340

Chicago, Ill., 205, 228, 239, 248, 249, 251 , $252,350,368$

Chicago Blade and Ledger, 48

Chicago Cubs, 294

Chicago Daily News, 189, 200

Chicago Federated Adv. Club Nezws, $168 n$

Chicago Sun, 232

Chicago Times, 200, 202

Chicago Tribune, 33, 189, 198, 199, 200, 205, 207

Chicago Women's Advertising Club, 176

Chilton Co., 151

"Chiquita Banana," 231

Christian Herald, 192

Christian Science Monitor, 192

Chrysler, Walter P., 60

Chrysler automobile, 60

Cincinnati, Ohio, 205

Cincinnati Times-Star, 210

Cine-Mundial, 269

CIO Steelworkers, 212, 368

Circus Magazine, 283

Civic Opera House, 208

Clague, Stanley, 350

Clapper, Olive, 368

Clark, Evans, 368, 371

Clark, Rene, 116, 353

Cleary, J. M., 174

Cleveland Press, 42, 202

Clough, Reginald, 353

Coca-Cola, 203, 212, 241

Cocks, Dorothy, 176

Cole, Amedee; 296

Cole Motor Car Co., 339

Colgate-Palmolive-Peet Co., 70, 85, 276, 278

Collection for the Improvement of Husbandry and Trade, $A, 27$

College Comic Magazine Group, 204

Collegiate Digest, 204

Collier, Barron G., 251

Collier's, 183, 185, 194, 260, 323, 327

Collyer, Barbara, 176

Colman, Ronald, 229 
"Color Advertising in Newspapers," 207x

Color plates, in advertising, 323-324

Colton Co., Wendell P., 161

Columbia Broadcasting Co., 51, 213, $214 n, 235,238,373,374$

Columbus, Ohio, 204

Comfort, 48

Comic books, 191, 224

Comic Cavalcade, 191

"Commercial Films-1947 Status," 272n, $274 n$

Committee for Economic Development, 371

Committee on Improvement of Public Understanding of Our Economic System, 349

Compton Advertising, 340

Concrete Builder, The, 159

Concrete for Railways, 159

Coney Island, N. Y., 25

Congratulations, 192

Conover (model agency), 314

Constitution of U.S., 370

Continuing Study of Transportation Advertising, Study No. 7, 252n

Controlled Circulation Audit, 150

Cooper, F. G., 308

Cooperative Analysis of Broadcasting, 220

Copy Testing, 303

Corn Products' advertising, 311

Cornay, Harold, 320

Coronet, 185

Cosmopolitan Magazine, 44, 185

Council Looks Ahead, The, 366

Country Gentleman, 160, 265, 266, 267, 331

Covici-Friede, 295, 305n

Cowan, Inc., Louis G., 229

Cowles, John, 195

Cox, James M., 213

Craig-Martin tooth paste, 69,70

Crain, George, 353

Cramer, Leonard, 238

Crane Co., 146

Crawford, Nelson Antrim, 186

Cream of Wheat, 28, 301

Critchfield \& Co., 175

Criterion Service, 250

Crockwell, Douglas, 309

Crofts \& Co., F. S., $328 n$

Crosby, Bing, 217, 229

Crosby, John, 231, 232

Crossley, Archibald, 220

Crowell-Collier publications, 42, 172, 327

Cugat, Xavier, 228

Curtis, Cyrus H. K., 65, 353
Curtis Publishing Co., 42, 117, 141n, 164, $212,266,331$

Cusack, Thomas, 242

Daily Oklahoman, 210

Dancer-Fitzgerald-Sample, Inc., 92

Dartnell Corp., The, 333

Davega, 139

Davenport, Iowa, 246

"David Harum," 222

Day, Ben, 31, 314, 323, 373

Day, William L., 166

Dayton Rubber Co., 149

Deb, 136

Declaration of Independence, 370

Deep River Boys, 228

DeForest, Lee, 51

Delco, 340

Dell Modern Group, 187

DeLong Hook \& Eye, 49

Delta Co. (of Chicago), 282

Denver, Col., 204

Department Store Economist, 151

Des Moines Register, 195, 205

Des Moines Tribune, 195, 205

DeSoto Division of Chrysler, 67

Detective Comics, 191

Detroit, Mich., 205, 251

Detroit Advertising Club, 353

Detroit \& Cleveland Navigation Co., 340

Deutsch \& Shea, 202

Dever, Edward J., Jr., $89 n$

Diamant, E. M., 320

Diamond Match Co., 274

Dickens, Robert Sidney, 294

"Dick Tracy," 57, 224

Direct Advertising, 260

Direct Mail Advertising Assn., 264, 352

Distillers' Corp. (Seagram), 86

DMAA, see Direct Mail Advertising Assn.

Dobbs, Samuel C., 66

Dobbs Hats, 170

278

Dodge Brothers, 60

Dodge Truck, 267

Dohanos, Stevan, 309

Domestic Radio Bureau, 366

Don Lee Network, 236

Donnelley Corp., Reuben H., 257, 277,

Dorothy Gray, Ltd., 176

Dorsey, Tommy, 229

Douglas, W. L., 139

Dow Chemical Co., 175

Downtown Shopping News, Chicago, 208

Drake, Alexander, 41

Drake, Galen, 233 
Drake, George, 296

Drake \& Co., Frederic J., $312 n$

Dreft, 90, 278

DuMont, 238

Dun and Bradstreet, 257

DuPont, 146, 270

Durant automobile, 59

Durante, Jimmy, 18, 176

Durstine Agency, Roy S., 253

Dutton \& Co., E. P., $342 n$

Duz, 90, 278

Eagles, 193

Eastman Kodak, 49, 269, 362

Easy Aces, 229

Ebony, 283

Eby, Kermit, 368

Echo Park Evangelical Assn., 234

Economic Effects of Advertising, The, 69

Eddy, Nelson, 158

Edison, Thomas A., 42, 46, 51

Editor \& Publisher, 353

Edmundson, Carolyn, 309

Edwards, C. M., 131n

Egan, Margaret, 176

Egner, Frank, 264

Electrical Equipment, 150

Electrical Industries Advertising Program, 157

Electrical Merchandising, 151

"Electric Hour, The," 158

"Elijah's Manna," 55. See also Post Toasties

Elks Lodge, 193

El Paso, Tex., 204

Elvgren, Gil, 275

Emancipation Proclamation, 370

Encyclopadia Britannica, $34 n$

"Engineer Analyzes Industrial Advertising, An," 144n

Engineering News-Record, 151

Epstein, Joseph, 340

Equitable Life Assurance Society, 212

Esquire, 185, 195

Esty \& Co., William, 114, 117

Ethridge, George, 171

"Evaluating Research Activities," Olsen, $152 n$

Evans, Bob, 311

Evans, Evan Llewellyn, 166

Evans Associates, 149

Evansville, Ind., 204

Eversharp, Inc., 86, 128, 229

Everywoman's, 186

Ewald, Henry, 173, 174, 340, 353

Export Advertising Agency, 270
Export Advertising Assn., 352

Export Information Bureau, 349

Extension, 192

Factory Management and Maintenance, 151

"Facts in Food and Grocery Distribution," $142 n$

Falk, Alfred T., 346

Falls, C. B., 308

Family Circle, 186

Farmer, The, 267

Farmer's Wife, 265

Farm Journal, 65, 265

Farrar \& Rinehart, 56n, 64n

Farrell, Harry, 294

Farrell, Skip, 227

"Father Standfield," 22

"Favorite Story," 229

Fawcett, Walter, 171, 185

Fawcett Women's Group, 187

Fazenda, A, 269

Feasley, Milton, 100

Feather, William, 260, 302

Federal Communications Commission, $42,235,238,374,376$

Federal Trade Commission, 42, 68, 165, 377

Federal War Loan advertising (Civil War), 37

Fellers, Bobby, 339

Fenton, Fleur, 176

Ferro Enamel, 149

FHA Title I, 154

Fibber McGee and Molly, 75, 163, 217

Field and Stream, 192

"Fifty Direct Mail Leaders of 19__," 259

Fight for Truth in Advertising, The, Kenner, $67 n$

Financial Advertisers Assn., 153, 154, 155, 351

First Presbyterian Church of Seattle, 234

"First Three Markets Group," 205

Fishback, Margaret, 296

Fisher, J. W., Jr., 281

Fisher Body, 60, 61

Fisher Building (Detroit), 175

Fitch, Clyde, 170

Fitzgerald Advertising Agency, 340

Fitzgibbon, Bernice, 176

Flagg, James Montgomery, 308

Flesch, Dr. Rudolph, 300, 301 ; readabil. ity scale, 300,301 ; score, 302

Flinner, Jean, 360

Florida Citrus Commission, 212, 280

Florsheim shoes, 139

Flushing, N. Y., 244 
FM, 235, 237

Food Mart News, 280

Food Topics, 184n, 280, 281

Food Trade News, 280

Foote, Cone \& Belding, 137

Force Breakfast Food, 171

Ford, Henry, 51, 61

Ford, Henry, II, 124

Ford Motor Co., 60, 61, 86, 124, 175, 267, 273,331

Ford Sunday Evening Hour, 233

Foreman \& Clark, 139

Forhan's Tooth Paste, 70

"For Members Only," 226

Fort Lauderdale, Fla., 205

Fortune Magazine, 333

Fort Worth, Texas, 204

45th Street (New York, N. Y.), 249

44th Street (New York, N. Y.), 249

42nd Street (New York, N. Y.), 25

Forty Years an Advertising Agent, Rowell, 37, 40n, 47n

Foulds Macaroni, 340

Fourdrinier paper-making machine, 31

Fowler, Nathaniel C., 45

Fox, — 39

Franklin, Benjamin, 30

Franklin, James, 30

Franklin automobile, 59

Frazer, J. K., 49, 124

Frazer's "Spotless Town" jingles, 49

Free and Peters, 236

"Freedom Train," 370

Frequency modulation, 237. See also FM

Fresno Bee, 200

Frieberg, Albert D., 303, 304

Frigidaire, 28, 172

From War to Peace-the New Challenge to Business. \& Advertising, $367 n$

"Front Page Farrell," 222

Frozen Foods Institute, 124

Fruit, Garden and Home, 190

Fuller \& Smith \& Ross, Inc., 148, 149

Fulton, Kerwin, 242

Fulton, Robert, 31, 51

Funny Stuff, 191

Gair's, Redlands, Cal., 73

Gale, S. C., 92, 93

Gallup, Dr. George, 368

Gamble, Frederick R., 348

Gardner Advertising Co., 176, 195

General Electric Co., 51, 86, 145, 172, 266, 273

General Foods, 56, 85, 212, 222, 250, 276, 348,362
General Mills, Inc., 28, 56, 76, 85, 92, 93, $212,222,224,290$

General Motors, 60, 61, 85, 175, 270

General Outdoor Advertising Co., 250

General Screen Advertising Co., 272

George Ethridge Co., The, 38

"George Washington Hill as I Knew Him," $166 n$

Georgia Power Co., 339

Gerlach-Barklow, 275

Getchell, J. Sterling, 60, 167, 168, 195

Geyer, Cornell \& Newell, 174

Geyer, Newell \& Ganger, 117, 176

Gibson, Paul, 233

"GI Insurance," $369 n$

Gilbert, Gene, 343

Gill, Sam, 329

Gillam, Manly, 170

"Gillam-Wanamaker style, the," 170

Gillette, King C., 52

Gillette Blue Blades, 53

Gillette razor, 52, 269

Gilliland-Ranseen-Wesley \& Ragan, Inc., 306

Gilpatric, Guy, 344

Gimbel's Dept. Store, 176, 239

Girl Scouts, 368

Glim, Aesop, 295, 300

Glo, 290

Godey's Lady's Book, 43, 193

Gold medal award, 353

Gold Medal Flour, 92

Golenpaul, Dan, 114

Goode, Kenneth M., 38, 39n, 295

Good Housekeeping Institute, 186

Good Housekeeping Magazine, 28, 65, $118,182,186,194,377$

"Good Housekeeping Seal of Approval," 65,186

Goodman, Jack, $367 n$

"Good Morning Show," 226

Goodrich, B. F., Co., 146

Goodyear India Rubber Co., 169

Goodyear Tire \& Rubber Co., 33, 146, 233

Gordon, Lewis F., 153

Gordon Best Co., 176, 239

Goshorn, Clarence, $173 n$

Gould, Beatrice, 186

Gould, Bruce, 186

Graduate School of Banking, 154

Graduate School of Business Administration (Harvard), 68

Grady, May Laing, 155

Graf's (Milwaukee), 203

Grant Co., W. T., 139

Grape-Nuts, 55

Grape-Nuts Wheat Meal, 276 


\section{THIS FASCINATING ADVERTISING BUSINESS}

Graphic Arts Victory Committee, 366

Gray, Barry, 229

"Greatest Name in Rubber," 33

"Greatest Show on Earth, The," 33

Greatest Story Ever Told, The, 233

"Great White Way," 94, 249

Green, James, 320

Green, Ruzzie, 309

Green Hornet, 191

Grey Advertising Agency, 176

Griswold-Eshleman, 149

Grit, 48

Grocer-Graphic, 280

Grocers' Wholesale Cooperative, Inc., 141

Grocery Executives and Grocery Managers Combination, 279

Grove Laboratories, 229

Gruen Watches, 174

Gude, O. J., 242

Gum Laboratories, 212

Gutenberg, Johannes, 26

Haase, Albert E., 117n, 347

Haire Publishing Co., 151

Hall, Pres. Joseph B., 184

Handbook of Advertising, Weiss, Kendall and Larrabee, $\mathbf{1 5 2 n}$

Hannibal, Mo., 250

Harding, Pres. Warren G., 213

Harn, Orlando C., 67, 351, 353

Harper \& Brothers, 112n, 117n, 288n, 295, $303 n$

Harper's Bazaar, 43, 136, 185, 193, 303, 361

Harvard Award, 170, 176, 353

Harvard University, 29

Harvard University Press, 38n, 46n, 331n

Harvey Comics, 191

Haver, June, 227

Hawk, Bob, 229

Haynes automobile, 59

Hearst Advertising Service, 205

Hearst newspapers, 189, 204, 205, 206

Heinemann's, Jonesboro, Ark., 227

Heinz Co., H. J., 28, 114, 170, 241, 250

Henderson, Jean, 360

Henrietta Maria, Princess, 27

Henry, Robert Selph, 24n

Hercules Powder, 149

Herpicide, 49

Heth, Joice, 32

Highways, 159

Hill, George Washington, 90, 164, 165, 166,344

Hill, Percival S., 164

Hiller, Lejaren, 314

Hillman Women's Group, 187
History and Development of Advertising, Presbrey, 30n, 46n

History of an Advertising Agency: $N$. W. Ayer \& Son at Work, 1809-1939, The, Hower, $38 n, 46 n, 331 n$

"Hit the Road," 150

Hobby, Oveta, 360

Hobler, Atherton W., $173 n$

Hoffman, Paul, 371

Hoke, Henry, 264

Holden, Ralph, 170

Holiday, 117, 312, 340

Hollywood, Cal., 368

Holmes (store), New Orleans, La., 134

Honolulu Advertiser, 201

Hooper, C. E., Inc., 220, 221, 222, 377

Hooper, John L., 36

"Hooperating," 220, 374

Hoover, Herbert, 212

Hoover Co., 94

Hope, Bob, 75, 163, 215

Hopkins, Claude, 45, 87, 112, 296

Hormel, 28

Horn, Stanley F., $24 n$

Hostess Cup Cakes, 210

Hotchkiss, Prof. G. B., 49n, 97, 129n, 236, $252,295,353 n$

Houghton, John, 27

House \& Garden, 190

House Beautiful, 190

Household, 186

Household Finance Co., 212

Houston, Herbert S., 67

Houston, Texas, 204

How Advertising is Written-and Why, $295,300 n$

Howard, W. H., $131 n$

"How Do You Stand on Sin?" 329n

Hower, Ralph M., 37, 38n, 46n, 331n

"How Hill Lifted Lucky Sales," Hughes, $166 n$

"How Some Advertisers Guide Agency Solicitations," Dever, $89 n$

How to Become an Advertising Man, Lewis, 174

How to Conduct Consumer and Opinion Research, 303

How to Determine the Advertising Appropriation, $98 n$

How to Get a Job and Win Success in Advertising, Lowen and Watson, 338n, $341 n$

How to Package for Profit, Larrabee, $288 n$

"How to Pre-value an Ad Before It Appears in Print," $307 n$

How to Write Advertising That Sells, Bedell, 295, 296n, 307n 
Hubbard, Elbert, $68 n$

Hucksters, The, Wakeman, 166

Hudson, Store, J. L., 134

Hughes, Lawrence, 166

Human Enterprise, The, Otto, 328n

Hunter Screenland Unit, 187

Hunting and Fishing, 192

Hupmobile, 59

Husing, Ted, 229

Ice Cream Manufacturers, 280

Ice Industries, 280

Idaho, 236

Ideal Women's Group, 187

Illinois Bell Telephone Co., 281

Illinois Central Railroad, 162

Illinois Department of Highways, 15t

Independent Grocer, Report No. 2, The, $141 n$

Indianapolis, Ind., 204

Indianapolis News, 209, 351

Indianapolis Star, 70, 339

Indianapolis Times, 206, 207

Indiana University, 175

"Industrial Advertising Budgets for 1946," 145n

Industrial Equipment News, 150

Industrial Marketing, 144n, 148n, 149n, $152 n, 353$

"Information Please," 114

Ingersoll, William H., 67

Ingersoll Watch, 170

Institute of Life Insurance, 370

Institution Premium Book, 276

Intaglio Printing, 326

Intermountain Network, 236

International Advertising Council, 346

International Bill Posters' Association of North America, 242

International Correspondence Schools, 173

International Harvester Co., 94

International True Story Group, 269

Interstate Commerce Commission, 42

Interstate United Newspapers, Inc., 203

Intertype, 43

Iodent, 70

Iowa State Automobile Dealer Assn., 151

Ipana, 70, 269

Iron Age, 151

Ivory Flakes, 90

Ivory Soap, 43, 49

"Jack Armstrong," 56

Jacobs Launderall, 175

James, Clifford L., $68 n$

Jefferson, Pres. Thomas, 32

Jersey Cereal Co., 276
Jewish Daily Forward, 271

Joe Palooka, 191

John, W. A. P., "Wap," 174, 175

John \& Adams, 149

Johns-Manville, 146

Johnson, George H., 155

Johnson, Holgar J., 370

Johnson, Meade, 291

Johnson, Dr. Samuel, 29, 63

Johnson \& Son., Inc., S. C., 216

Johnson's Wax, 163, 217

Jones, E. Willis, 294

Jonesboro, Ark., 227

Jordan, Edward S., 59

Jordan, Marian and Jim, 163, 216, 217

Jordan Motor Car, 59, 60

Jordan Playboy, 60

Joseph, John J., 155, 156

Joseph Jacobs Organization, 271

Joske's Department Store, 225, 226, 227, 351

Journal Général d'Affiches, Le, 26

Judd, Orange, 65

Junior Bazaar, 193

Just Like a Woman! Kidd, 177

"Just Plain Bill," 222

Kaiser and Frazer, 61, 124

Kansas City Journal, 43

Karney, Beulah, 233

Karsh, Yousef, 309

"Kate Smith Speaks," 223

Katz, Joe, 296

Katz Agency, 201

Kaufman's Department Store, 210

Kay, Inc., J. Roland, 270

Kaye, Sammy, 228

Kaylin, Edward, 135n

KDKA, Pittsburgh, 213

Keeler, Floyd Y., $117 n$

Kellogg, Dr. J. H., 55, 57

Kellogg, W. K., 55

Kellogg Co., 86, 212, 278

Kellogg Group of Railroad Employee Publications, 193

Kelly, Philip, 370

Kelly-Springfield Tires, 167

Kelvinator, 267

Kendall, Frederick C., $152 n, 353$

Kenner, H. J., $67 n$

Kent, Rockwell, 309

Kenyon, Otis, 251, 339

Kenyon \& Eckhardt, Inc., 114, 251, 339, 370

Keppler, Victor, 309

Kesner, Robert T., 336, 337

Kettering, Charles F., 336

Keystone Broadcasting System, 236 


\section{THIS FASCINATING ADVERTISING BUSINESS}

KFQD, Anchorage, Alaska, 236

KFSG, Los Angeles, 234

Kidd, Mrs. Elizabeth, "Bj," 177, 178

Kidd, Harry, 178

Kildow, Fred, 204

King, Wayne, 229

Kissam \& Allen, 242

$\mathrm{Kix}, 56,92$

Kleiser, George, 243

Kleppner, Otto, $110 n, 183 n, 252,373$

Kling, LeRoy, 239

Knox College, 170

Knox Reeves Advertising, Inc., 92, 303

Knoxville, Tenn., 204

Kobak, Edgar, 339

Koch's List of Railroad Magazines, 193

Kolynos Tooth Paste, 69, 70

KONO, San Antonio, 225

KPOF, Denver, 234

Kraft, 217

"Kraft Music Hall," 217, 229

Kresge Co., S. S., 139

Kroger Co., 128, 184

Krupa, Gene, 231

KTW, Seattle, 234

Kudner, Arthur, 156

Lackawanna Railroad, 49

Ladies' Home Journal, 44, 65, 111, 177, $182,186,194,270,282,353,361$

La Hacienda, 269

La Hacienda Co., 269

Laird, Dr. Donald E., 108

Lakeside Press, 320

Lamb, Fred, 308

Land o' Lakes, 210

Landry, Robert J., 24n, 212n, 223n

Lane Bryant, 139

La Prensa, 271

La Presse, 270

La Revue Municipale, 270

LaRoche, Chester, 353

Larrabee, C. B., $152 n, 288 n, 293 n$

Larrowe Feeds, 92

Latzke, Paul, 56

Laundryowners National Assn., 156

Lazarsfeld and Field, 232

Leading National Advertisers, 194, 354

"Leading Radio Advertisers, 1946," 212n

Leatherneck, The, 193

Lebret, R. C., 270

Lee, Doris, 308

Leigh, Douglas, 249

Lennen \& Mitchell, 167

Lennen, Phil, 200

L'Epicier, 270

Lever Brothers Co., 85, 163, 250, 270, 278

Levitt-Ferguson Co., 263
Lewis \& Gilman, 177

Lewis, Fulton, Jr., 226

Lewis, Norman, 173, 174

Lewis, Thomas H. A., 114

Leyindechers, the, 308

Libbey-Owens-Ford, 149

Liberty Magazine, 56, 64, 183, 184, 185

Lichtenberg, Bernard, $89 n$

Life, 128, 137, 146, 158, 182, 183, 184, $193,194,195,256,270,280,282,299$

Life Insurance Advertisers Assn., 352

Life International, 270

Liggett \& Myers, 77, 86

"Light of the World," 222

Lill Abner, 191, 301

Lillard, W. Parlin, 276

Lillibridge, Ray, 100

Lincoln automobile, 175, 331

Lind, Jenny, 33

Linder, Ralph F., 142n

Lindquist, Robert, 154

Link, Barney, 242

Link, Dr. H. C., 304

Linotype machine, 43

Lionel Corp., 184

Listerine, 70, 100

Lithographers National Assn., 352

Lithography, 325-326

"Little Announcements," see Petites Affiches, Les

"Little Dramas in the Life of a Great Newspaper System," 200

"Little Orphan Annie," 198

Locomobile, 59

Loewy, Raymond, 294

Logotype, 76, 135

Loh, Lester, 117

London Gazette, 27

London Times, 31

"Lone Ranger, The," 224

Look Magazine, 183, 195

Loomis, Andrew, 254

Lopez, Vincent, 228, 231

Lord \& Taylor, 40, 176

Lord \& Thomas, 167, 174

Los Angeles, Cal., 205, 246, 249

Los Angeles Times, 189, 205

Louder Pleasel 170

Louis, Jack, 163

Lowen, Walter, 338n, 341, 342

Lowitz, Anson C., 360

Loyal Order of Moose, 193

Lucas, D. B., 350

Luckenbill, Tom, 114

Luckman, Charles, 163

Lucky Strike Cigarettes, 71, 90, 114, 164, 165,231

Lucky Strike Show, 215 
Ludekins, Fred, 311

Ludlow machine, 43

Lyon, Margaret, 344

Macbeth lamp chimneys, 45

McCall Corp., 42

McCall's, 170, 186, 194

McCann-Erickson, Inc., 117, 129, 149

McCarthy, Charley, 221

McClatchy Newspapers, 200

McClintock, Dr. Miller, 245

McClure, Don, 239

McConnell, Smilin' Ed, 224

McCreery's, 340

McCurdy \& Co., 227

McDevitt Co., George A., 202

Macfadden, Bernarr, 187

Macfadden Women's Group, 42, 182, $188,301,302 n$

McGivena, Leo, 201

McGraw, James H., 353

McGraw-Hill Book Co., Inc., 151, 268, 353

McKee, Homer, 174, 339

McKesson \& Robbins, 270

McKinney, Henry, 330

McKinsey \& Co., $91,94 n$

McKittrick's Directory of Advertisers, 88,354

Maclean's Magazine, 270

MacManus, John \& Adams, 174, 175

MacManus, Theodore F., 60, 149, 174, 175

McQuiston, Jackson, 340

Macy Department Store, R. H., 40, 128, 134

Mademoiselle, 136, 193

Magazine Advertising Bureau, 352

Mailing cards, 260

"Make Believe Ballroom," 229

Mandel Brothers, 74

Manhattan, N. Y., 244

Mann, Harvey, 174

Manville, Richard, 307

Marchand's Hair Rinse, 252

"March of Time," 194

Marconi, Guglielmo, 51

Market Data Book of Industrial Marketing, 354

Mark of Readable Style, 301

Marmon Motor Car Co., 339

Marschalk and Pratt, 238

Marshall Field \& Co., 128, 134, 137, 176, 306

Martin, Mac, 67

Martindale, Jim, 296

"Masquerade," 222

Massachusetts, 67
Mathes, Inc., J. M., 114, 117

Mathewson, Christy, 339

Mathews Special Agency, Julius, 202

Maxwell Arcade Bldg., 205

Maxwell-Chalmers companies, 60

May, Don, 312

Mayer, Ed, 264

Mayflower, the, 29

Maytag Co., 362

Mechanix Illustrated, 192

"Meet Your Neighbor," 228

Mellon Institute, 78

Memphis, Tenn., 204

Mennen, 270

"Men of Gloucester," 273

Merchant Marine, 359, 365

Mercury Magazine, 27

Mergenthaler, Ottmer, 43

Metal Finishing, 150

Metro-Goldwyn-Mayer, 85

Metro Group Comics, 189

Metropolitan Group Gravure, 189

Metropolitan Opera, 233

Mexico, 29

Michigan Ave. (Chicago), 249

Midwest Farm Paper Unit, 265, 267

Miles Laboratories, 86

Mili, Gjon, 309

Miller, Judge Justin, 351

Miller Beer, 203

Miller \& Co., C. L., 311

Millis, Fred, 156

Milwaukee, Wis., 48, 203, 251

Milwaukee Evening Wisconsin, 48

Milwaukee Journal, 42, 70, 202, 203, 207, 210

Minneapolis, Minn., 48

Minnesota State Automobile Dealer Assn., 151

"Minute Movies," 272

Miracle Whip, 217

Miranda, Carmen, 231

Mitchell-Faust Advertising Co., 340

Modern Packaging, 353

Modern Romances, 187

Modern Screen, 187

Modesto Bee, 200

Moloney, Regan \& Schmitt, 202

Monotype machine, 43

Montana State Automobile Dealer Assn., 151

Monsanto Chemical, 146

Montgomery Ward \& Co., 47, 140, 338

More Power to Advertising, Adams, 175

"More Power to America," 273

Morse, F. Harvey, 277

Morse, Samuel, 51

Mortimer, Charles G., Jr., 348 
Motion Picture, 187

Motley, Arthur H., "Red," 171, 172, 173

Movie Story, 187

Motor Age, 151

"Mrs. Warren," 48

Munder, Norman T. A., 320

Munro, Leslie, 176

Murphy, John Allen, 151, 152

"Musical Clock" program, 136

"Musical Headliners," 226

Mutt and Jeff, 191

Mutual Broadcasting System, 221, 222, 235, 236, 339, 378

My Life in Advertising, Hopkins, $112 n$

NAB, see National Association of Broadcasters

Nash, Ben, 294

National Advertising Managers, 347. See also Association of National Advertisers

National Association of Broadcasters, $105,219,226,228 n, 230,234,351,379$

National Association of Manufacturers, 334

National Association of Retail Grocers, $140,141,279$

National Association of Transportation Advertising, 352

National Baptist, 45

National Better Business Bureaus, 66, 68

National Biscuit Co., 56, 57, 76

National Broadcasting Co., 213, 221, 222, $223,228,234 n, 235,379$

National Brotherhood Week, 368

National Business Papers Assn., 149, 150, 352

National Comics Group, 190

National Confectioners Assn., 165

National Council of Industrial Editors, 352

National Council on Business Mail, 352

National Dairy Products Co., 86

National Geographic, 185.

National Geographic Society, 185

National Grocers Bulletin, 279, 280, 281

National Home Monthly, 270

National Industrial Advertisers Assn., $145 n, 147,149,348,352$

National Institute of Human Relations, 222

National Lead Co., 351

National Macaroni Manufacturers Assn., 156

National Metallic Metals Act, The, 329

National Nursing Council for War Service, 360
National Opinion Research Center, 232

National Outdoor Advertising Bureau, $106,243,379$

National Retail Dry Goods Assn., 135n, $141 n, 366$

National Retail Furniture Assn., 156

National Roadside Council, 352

National Scholastic Press Assn., 204

National War Fund, 359

Nation's Agriculture, 265

NBC Program Policies and Working Manual, 233, 234n

"NBC Thesaurus," 228

Nebraska Farmer, 267

Needham, Louis \& Brorby, 163, 340

Negro Newspaper Publishers Assn., 35?

Neiman-Marcus, 134

Nelson, Donald M., 358

Nevada, 236, 257

Newark, N. J., 251

Newell-Emmett Co., 230

New England, 222

New England Courant, 30

New Haven, 161, 251

New Horizons for Business Films, 273n

New Idea Book for Food Merchants, Linder, ed., $142 n$

New Orleans, La., 247

New Orleans Item, 340

"News at Nine," 226

"Newscast," 226

Newspaper Advertising Executives Assn., 207

Newsreel, 194

Newsweek, 159, 183, 185

New York, 67, 244

New York Advertiser, 31

New York Central, 161

New York City, 239

New Yorker, The, 183, 185

New York Herald Tribune, 35, 189, 232

New York Journal-American, 207

New York Ledger, 34, 35

New York Mirror, 205, 305

New York, New Haven \& Hartford Railroad, 161

New York News, 189, 201, 204, 205

New York Subways Advertising Co., 352

New York Sun, 31

New York Times, 205

New York Tribune, 35, 36 .

New York World, 43

New York World-Telegram, 42

Nichols-Shepard, 330

Nickel Plate R. R., 161

Niebuhr, Dr. Reinhold, 368

Nielsen Co., A. C., 221, 333, 379

Nielsen Radio Index, 221, 379 
"1946 Advertising Volume Greatest in U. S. History," Zeisel, 129n

"1912 Quiz Kids, The," Lewis, 174n

"94 Billions in Retail Sales in 1946," Burn, 129n

Noble, Edward J., 235

Norge, 340

North Dakota State Automobile Dealer Assn., 151

Northern Automotive Journal, 151

Northwest Automotive Wholesalers Association, 151

Notre Dame University, 175

NRDGA, see National Retail Dry Goods Assn.

Nunn-Bush shoes, 139

N. W. Automotive Electrical Assn., 151

Octagon and Kirkman Soap, 276

Office of Price Administration, 300

Office of War Information, 359, 364, 366, 368

Ohio Bell Telephone Co., 155

Oklahoma City Oklahoman and Times, 202

Oldfield, Barney, 59

Old Gold cigarettes, 270

"Old Ranch Hand," 226

Olds automobile, 59

Oldsmobile, 175

Olsen, Fred, 152

Omaha World-Herald, 70, 202

O'Mara \& Ormsbee, 202

O'Mealia, Harry, 243

101 Roughs, 312

"100-Study Summary, The Continuing Study of Newspaper Reading," $210 n$ Oregon, 236

Organization of the Advertising Function, 91

Osborn, Scolaro \& Meeker, 202

Otto, M. C., 328

Otto \& Associates, Robert, 270

Our Army, 193

Our Navy, 193

Oursler, Fulton, 64, 233

Outdoor Advertising, Agnew, 246n, 247

Outdoor Advertising Association of America, 106, 240n, 243, 245, 246n, $247 n, 250,254,379,382$

Outdoor Life, 192

Outdoors, 192

Outdoorsmen, 192

Outline of Advertising, An, Hotchkiss, $49 n, 253 n$

Outlines of the Principles of Economics, $68 n$

Overbay, Arthur S., 320
Overseas Buyers' Guide for Automotive Distributors, 268

OWI, 340

Oyster Bay, I. I., 30

Pabst Beer, 203, 270

Pacific Overseas (Time), 270

Packaging Exposition, 288

Paglin, Jules, 264

Pal, George, 273

Pall Mall Cigarettes, 164

Palmer, Volney B., 36

Palm of Alpha Tau Omega, The, 337n

Pan American-Grace, 269

Paper Makers' Advertising Club, 260

Parade, 172, 189

Pardee, Harvey S., $144 n$

Parents' Magazine, 159, 182, 191

Parker, Dr. Valerie Hopkins, 224

Parker Pen, 114

Parlin, Charles C., 331

Parran, Dr. Thomas, 360

Parrish, Maxfield, 275, 308

Pathinder, 183

Patrick, Ted, 340

Peabody, Stuart, 333, 348

Pearl Harbor, H. I., 21

Pearson, Earle, 346

Pear's Soap, 49

Peaslee \& Co., 37

Pekin, Ill., 228

Pellegrin, Frank E., 228n, 351

Pennebaker, John Paul, 314

Penney Co., J. C., 128, 139

Pennoyer, Sara, 340

Pennsylvania Packet and Daily Advertiser, 30

Pennsylvania Railroad, 85, 161, 340

Pennzoil, 100

Penton Publishing Co., 151

"People Look at Radio, The, 232

Pepsi-Cola Co., 18, 203, 230, 231

Pepsodent Tooth Paste, 49, 70

Pepsodent Tooth Paste, program, 163, 215

Periodical Publishers' Assn, 105, 352, 380

Perkey, Henry D., 56

Persons, H. C., 159

Peru, S. A., 29

Petites Affiches, Les, 26

Pet Milk, 176, 215

Petry, Lucille, 360

Petry and Co., Edward, 236

Pettingill \& Co., S. M., 36

Philadelphia, Pa., 205, 239

Philadelphia Bulletin, 200, 205

Philadelphia Centennial (1876), 46 
Philadelphia Inquirer, The, 172, 189, 205

Philco, 184, 229, 269

Philley, Clarence, 243

Phillip Morris \& Co., 86

Phillips' Cleansing Cream, 298

Phillips 66, 18, 70

"Phoebe Snow," 49

Photoengraving, 321-323

Photographers Association of America, 156

Photoplay, 187, 269

Pickwick Papers, Dickens, 48

Pictorial Review, 189, 205

Picture, 195

"Picture Magazines: 10 Years," 195n

Pierce-Arrow automobile, 59

Pillar of Fire, 234

Pittsburgh, Pa., 204

Pittsburgh Post-Gazette, 210

"Planning and Budgeting a Bank's Advertising Program," 154n

Plymouth, Mass., 29

Plymouth automobile, 331

Plymouth Division of Chrysler, 167

PM Whisky, 252

Point of Purchase Advertising Institute, 335,352

Politz, Alfred, 251, 252

Polly Pigtails, 191

Pontiac automobile, 175

Pope automobile, 59

Popular Mechanics, 182, 192

Popular Science, 192

"Portia Faces Life," 222

Portland Cement Assn, 158, 159, 160

Post, Charles W., 55, 57

Poster Advertising Assn., 243

Poster Advertising Coverage, 240n, 246n, $247 n$

Post Toasties, 55, 290

Postum, 55

Power, 151

Powers, John E., 44-45, 299, 314

Prairie Farmer, 267

Premium Advertising Association of America, 276, 352

Premium Practice, 277n, 353

Prentice-Hall, Inc., 110n, 131n, 338n, $341 n$

Presbrey, Frank, 30m, 35, 42, 46n, 49n

Presbrey, Mrs. Frank, 30n, 46n

Pride Brothers, 267

Principles of Advertising, Starch, $44 \bar{i}$

Printed Salesmanship, 176

Printers' Ink , 23, 36, 40n, 43n, 57, 66, $77 n, 88,89 n, 98,99,112,129,174 n$, $196 n, 197 n, 211,212,223 n, 224,240$, $243,268,291 n, 307 n, 347,352$
Printers' Ink Model Statute, 352

Procter \& Gamble, 43, 85, 90, 212, 214, 222,278

Proetz, Mrs. Erma Perham, 176

Progressive Farmer, 265, 267

Progressive Grocer, 140, 142, 150, 279, 281

"Prospecting for Petroleum," 273

Prudential Insurance Co., 85, 362

Pryor, Arthur, Jr., 114

Psyching the Ads, 295, 305

Psycho-Graph, 306

Psychological Corporation of the Association of National Advertisers, 303

Public Advisory Committee, 371

Public crier, 25, 26

Publick Occurrences both Foreign and Domestick, 29

Public Utilities Advertising Assn., 352

Publishers' Information Bureau, 94, 212n

Puck, 189, 205

Puppetoons, 273

Purdue Eye-Camera, 306

Pure Food and Drugs Act, 65

Pyes of Salisbury, The, 26

Quaker Puffed Rice, 56

Quaker Puffed Wheat, 56

Quick Frozen Foods, 280

Quinn, Don, 217

Radio advertising, serials, 222, 224 ; mentioned, 226, 229. For radio programs, see individual listings

Radio Alphabet, 373

Radio Broadcast Magazine, 212

Radio Corporation of America, 238

Radio Mirror, 187

Radio Rogues, 230

"Radio Today," 214n, 215

Railway Express, 253

Raleigh Cigarette program, 215

Ralston, 250, 290

Rambeau, William G., 236

Raphaelson, Samuel, 344

Raymer, Paul, 236

Raymond, Leonard, 264

Reader's Digest , 21, 64, 196, 269

"Reading by Types of Content," 209n

"Real Concept of Advertising, A," Young, $168 n$

Redbook, 185, 281, 282, 283

Red Cross, 357, 359

Red Cross shoes, 174

"Red Hot and Low Down," 229

Redlands Daily Facts, 73

Reed, Hazel, 176

Rehearsal, 194 
Reinforced Concrete, 159

Religious Press Assn., 46

Remington Rand, 53

Reporter, The, 353

Reporter of Direct Mail Advertising, The, 263

Report of 30th Annual Convention, 154n

Repplier, Theodore S., 368

Resor, Stanley, 173

Retail Advertising and Sales Promotion, Edwards and Howard, 130, 131n

Retailing Home Furnishings, 79

Revere Copper \& Brass, 146

Reydel, William, 348

Reynolds, Franklin, 199

Reynolds Metals Co., 289

Reynolds Rocket, 199

Reynolds Tobacco Co., R. J., 86

Rheingold Beer, 315

Rheinstrom, Carroll, 295, 305

Richman Brothers, 139

Richmond Advertising Service of Brooklyn, 204

Rich's Department Store, Atlanta, 227

"Rich's Radio School," 227

Ridgway Co., 174

Riggs, L. A. (Speed), 165

Riggs, Robert, 309

Ringling Bros.-Barnum \& Bailey Circus, 283

Rivers, Don, 342

"Road of Anthracite, the," 49

Robbins, Burr, 242

Robbins, Harry, 67

Robbins Publishing Company, 151

Roche, Williams and Cleary, 159, 339

Rocket pen, 199

Rock Island Argus, 340

Rockwell, Norman, 275

Roden, Tex., 344

Romer, John Irving, 66

Ronald Press, 295, 303

Roosevelt, Pres. Franklin D., 199

Rosebrook, John, 296

Rosenberg, Manuel, 353

Ross, Albert, 174

Rotarian, The, 193

Rowell, George P., 36, 37, 39, 40, 47, 66, 352

Ruberoid, 298

Rubicam, Raymond, 337, 344, 353, 367

Rudge, Edwin William, 320

Rutgers University, 154

Sachs Amateur Hour, Morris B., 227

Sackett, DeForest, 294

Sacramento, California, 247

Sacrameto Bee, 200
"Sad Sack," 369

S. A. E. Journal, 151

Safety Magazine, 159

St. Louis, Mo., 48, 251

St. Louis Globe-Democrat, 201

Sales Management, 353

Samples, Demonstrations and Packaging, Lewis, 174

Sandburg, Carl, 344

San Francisco, Calif., 205

Santa Fe Railroad, 161

Sapolio, 49

Sarra, Valentino, 309

Sasser, Nancy, 343

Saturday Evening Post, The, 30, 53, 56n, $117,141,146,170,182,183,184,193$, $266,270,280,282,323$

Saturday Home Magazine, 205

Savarin Coffee, 253

Saw Bill Lodge, Tofte, Minn., 263

Schenley Distillers, 86, 207

Schipper \& Black, 170

Schlink, F. J., 53, 355

Schlitz Beer, 28, 100, 203

Scholastic Roto, 204

Science and Mechanics, 192, 257

Science Illustrated, 151

Scientific American, 58

Scientific Space Selection, $351 n$

Scott, Howard, 254

Screen Guide, 187

Screen Romances, 187

Scribner's Monthly, 41

Scripps-Howard Newspapers, 200, 204, 205, 206

Seagram Distillers, 270

Seamans (model agency), 314

Sears, Richard W., 47

Sears, Roebuck \& Co., 47, 139, 140, 255, 339

Seattle, Wash., 205

"Second Mrs. Burton, The," 224

Seeman Brothers, 278

Selecciones del Reader's Digest, 269

Self-Service Grocer, 280

"Seneka Rattlesnake Root," 30

Service Life Insurance, 369

"Services Advertisers Expect from Agencies," Dever, $112 n$

Seventeen, 193

7th Avenue, New York, N. Y., 249

Shaver, Dorothy, 176

Sheets, Frank T., 158

Shefford Cheese, 216

Shelby Cycle Co., 263

Shell Oil Co., Inc., 146, 273

Shepard, Otis, 254, 294

Sherman \& Marquette, Inc., 329 
Shinn, Cobb, 30

Shishkin, Boris, 368

"Shopping News," 208

Shredded Ralston, 56

Shredded Wheat, 56

Shryock, James N., 351

Siamese Twins, 33

Sidener, Merle, 67

Simmons, Grant, 80

Simmons, Zalmon G., 78, 79

Simmons Bed, 78

Simmons-Boardman, 151

Simmons Co., 78, 80

Simmons Electronic Blanket, 79

Simoniz, 270, 298

Simplified Sales Promotion for Retailers, Kaylin and Wells, 135n

Sioux City, Ia., 48

si quis, 26

Sizer, Lawrence, 176

Skelton, Red, 215

Sloan, Albert, 344

Sloan, Alfred P., 61, 333

Smith, Everett R., 187

Smith, Capt. John, 29

Smith, W. R. C., 151

Smith Brothers, The, 29

Snapp, Josephine, 176

Society of American Florists, 156

Society of Automotive Engineers, Inc., 151

Socony-Vacuum, 167

Softasilk Cake Flour, 92

Soil Cement Neros, 159

Sokolsky, George, $56 n, 64 n$

SOS, 290

South Bend Tribune, 175

South Dakota State Automobile Dealer Assn., 151

SPAR, 360

"Sparky," 239

Spiegel's, 339

Spitalny's All-Girl Orchestra, Phil, 158

Sports A field, 192

Sportsman, The, 193

"Spotless Town" jingles, see Frazer, J. K.

Spur, The, 193

Squibb's Dental Cream, 70

Stahl, Ben, 308

Standard Advertising Register, 88, 92, 354

Standard Brands, 86, 278

Standard Oil Company of Indiana, 94

Standard Rate \& Data Service, 40, 182, $183,189,234,235,265,354$

Stanford, Alfred, 197, 352

Stapleford, Ed, 174
Star Spangled Comics, 191

Starch, Daniel A., 44n, 193, 272, 296

Statler Hotels, 85

Steichen, Edward, 314

Stephenson, George, 51

Sterling Drug Co., 85, 174, 212, 222

Steve Canyon, 191

Stevens Sundblom \& Stults Studios, 311

Stineway Drug Stores, 138

Stoddard, Charles, 171

Straube Piano Co., 175

Street \& Smith, 185, 193

Structure of the Advertising Agency Business, The, 109n, 123n

Stuart, Edwin H., 320

Studebaker automobile, $61,175,184,267$, 371

Study on the Organization of the Advertising Function, McKinsey \& Co., $94 n$

Stults, Larry, 311

Successful Farming, 265, 267

Sullivan, Ed, 294

Sunbeam Electric Shaver, 53

Sundblom, Haddon, 254, 309

"Sunny Jim," 56, 57

"Sunset Strip" (Los Angeles), 249

Superior Underwear, 174

"Superman," 191, 222

Super Market Merchandising, 280

Super Suds, 304

Surin, Arthur, 117

Survey of Buying Power by Sales Management, 354

Sutter's Mill, 34

Swan, Carroll J., $291 n$

Swan Soap, 278

Swift \& Co., 28, 86, 280

"Symphonic Hour," 138

Taft-Hartley Labor Bill, 200

"Take It or Leave It," 229

Tall Corn Network, 236

Tatler, The, 28, 29

Teacher's College, Columbia University, 301

Teel, 278

"Teen Top Tunes," 226

Tell, 353

Tender Leaf Tea, 216

Tennessee-Eastman Corp., 340

Terry and the Pirates, 191

"Terry and the Pirates," 222, 224

Texas Company, The, 233

"Texas Today," 226

Textile World, 151 
"Thanks to the Yanks," 229

Third Avenue (New York, N. Y.), 251

This Fascinating Lumber Business, Horn, $24 n$

This Fascinating Oil Business, Ball, 24n, $58 n$

This Fascinating Radio Business, Landry, $24 n, 212 n$

This Fascinating Railroad Business, Henry, $24 n$

This Week, 189

Thomas, Harold B., 348

Thomas, Lou, 296

Thomas Publishing Co., 151

Thompson, J. Walter, Co., 45, 149, 167, $171,173,360$

Thomson, Philip L., 67, 351, 353

Thorne, George R., 47

Thrilling Fiction Group, 191

Thurston (model agency), 314

Tide, 195n, 207n, 250n, 272n, 274n, 329n, $353,369 n$

Tiffany \& Co., 44

Time, Inc., 194

Time Magazine, 119, 146, 158, 159, 160, $161,182,183,185,194,270,353$

Times of India, 270

Times Square (New York, N. Y.), 249

Timmins, Harry, 311

"Today's Children," 222

Today's Woman, 186

Tokyo Advertiser, 270

"Tom Mix," 224

"Tom Thumb, Gen.," 32

Traffic Audit Bureau, 42, 245, 246, 347, 382

Transfilm, Inc., 273

Treidler, Adolph, 308

Troy Times Record (N. Y.), 209

True, 185

True Comics, 191

True Confessions, 187

True Detective, 191

True Experiences, 187

True Love and Romance, 187.

True Romance, 187, 269

True Story, 187, 269

Tucker automobile, 61

Tune Twisters, 230

Turner, Ulmer, 232

Twentieth Century Fund, 368

Twin City Garage Assn., 151

Type specimens, 316-320

Typographic Service, 320

Uneeda Biscuits, 57,76

"Unfinished Rainbows," 273, 274
Union Theological Seminary, 368

United Advertising Corp., 250

United Cigars, 166

United Fruit Co., 231, 269

United States Newes, 183, 185

United Typothetae of America, 352

Universal Instructor in All the Arts and Sciences and Pennsylvania Gazette, The, 30

University of Chicago, 174, 178

University of Minnesota, 172, 204

University of North Carolina Press, 232

U. S. Bureau of Foreign and Domestic Commerce, 42

U. S. Bureau of Standards, 42

U. S. Cadet Nurse Corps, 360, 361, 362, $363,364,365,366$

U. S. Cadet Nurse Corps. Recruitment program, 359, 364

U.S. Census Bureau, 42

U.S. Department of Agriculture, 42, 65, 330, 331

U. S. Department of Commerce, 42, 181, 281, 331, 354

U.S. Department of Labor, 331

U.S. Department of Treasury, 331

U.S. Gypsum, 146

U.S. Navy, 369

U.S.O., 357

U.S. Patent Office, 42, 76

USPHS Wartime Information Division, 360

U. S. Public Health Service, 360, 365

U.S. Rubber Co., 169, 340

U.S. Rubber Export Co., 270

U.S. Steel Corp., 146

U. S. Traveling Ads, 253

Veterans' Administration, 369

Vickery-Hill list, 48

Vicks Chemical Co., 229

Victor, div. of RCA, 51

Vigilance Committees, 346

Vinson, Chief Justice Fred, 333

Vladimir \& Co., 270

Vogel's Super Market, 228

Vogue Magazine, 43, 136, 193, 195, 361

Voice of Prophecy, 212

"Vox Pop," 228

WAC, $359,360,365$

Wakeman, Frederic, 166, 344

Walgreen Drug Stores, 128, 138

Walker (advertising agency), 236

Wallace's Farmer \& Iowa Homestead, 267 
Wanamaker, John, 44, 67, 170, 296

War Advertising Council, 174, 254, 348, $353,356,358,359,360,362,364,365$, $366,367,368,369,370$

Ward, A. Montgomery, 47, 255

Ward, Artemas, 251

Ward, Ken, 296

Ward Baking Co., 250

"War of the Worlds," 221

Warren, Franklin, 308

Warren's Shoe Blacking jingles, 48

Washburn-Crosby Co., Minneapolis, 56. See also General Mills

Washington, Pres. George, 31, 66

Watch Corporation of America, 274

Waterman Pen Co., 270

Watson, Lillian Eichler, 338n, $341 n$

WAVE, 359, 360

WAWZ, Karephath, N. J., 234

WDLP, Panama City, 236

WEAF, New York, N. Y., 213

Webster, Mass., 158

Weir, Walter, 296

Weise, Otis, 186

Weiss, E. B., $152 n$

Welch, Alfred C., 303

Weld, Lyman, 340

Welles, Orson, 221

Wells, Alan A., 135n

Wells, Sid, 117

WENR, Chicago, 227

Wesson Oil, 298

West, Paul B., 347, 348, 353, 371

Western Advertising, 353

Western Auto Stores, 139

Western Cartridge Co., 152

Western Electric Co., 351

Western Family, 186

Western Livestock Journal, 267

Western Newspaper Union, 48, 204

Western Union, 278

West-Holliday Company, 202

Westinghouse Electric, 51, 145, 149, 340

Wesup, Mrs. Elieda Van, 176

Wetzel Brothers, 320

Weyerhaeuser Lumber, 146

"What a Good Package Should Do," Swan, 291n

What Makes People Buy, Donald E. Laird, 108n

What's New, 260

Wheatena Corp., 362

Wheaties, 56, 92, 290

"When a Girl Marries," 222

While You Were Gone, 367

Whitehall Pharmacal, 222

White House, 370
Whiteman, Paul, 229

Whitney, Eli, 31, 51

Wickenden, Elmira, 360

Wieboldt's (Chicago), 136

Wiers, Charles R., 264

Wilding,, 273

Wildroot, 229

Wiley, Dr. Harvey W., 65

Wilfred Funk, Inc., 299

Willard, A. B., Jr., 351

Williams College, 164

Williamsport, Pa., 48

Willys automobile, 267

Wilmet, Georges, 294

Winchell, Walter, 221

WIND, Chicago, 227

Wing, Helen, 340

Winton, $\longrightarrow, 58,59$

Wisconsin Agriculturist \& Farmer, 267

Wisconsin State Automobile Dealer Assn., 151

WNEW, New York, 229

WNYC, New York City, N. Y., 234

Woman, The, 186

"Woman in White," 222

Woman's Day, 138, 186, 305

Woman's Home Companion, 170, 186, 327

"Women's Forum," 208

"Wonder Woman," 191

Wood, Barry, 229

Woodbury's Soap, 174

Woodward, Inc., John B., 202

Woolf, James Davis, 173, 174, 295

Woolworth Co., F. W., 128, 139

WOR, Newark, 236, 237

World Broadcasting Co., 229

World Petroleum, 150

World Report, 183

"World's Greatest Newspaper, The," 33

Wouk, Herman, 22

WPTZ, Philadelphia, 239

Wright, John Howie, 264

Wrigley's Chewing Gum, 241, 249, 251, 278, 294

WSN, Pekin, Ill., 228

Wump, Dr. S. J., 222

Wyeth, N. C., 308

Wyoming, 257

Yachting, 193

Yale \& Towne Manufacturing Co., 146, 149, 291

Yankee Network, 236

Yates, James, 117

YMCA, 273 
Young, Frank, 311

Young, James Webb, 173, 348, 367

Young, Robert R., 91, 161

Young, Thomas H., 168n, 169

Young, Webb, 174

Young \& Rubicam, 114, 340, 367

Your Career in Advertising, Rivers, 342
Your Money's Worth, Chase and Schlink, 355

Youth's Companion, 43

Zeisel, Dr. Hans, 129, 196, 197

Zimmer-Keller, Inc., 92

Ziv Co., Frederic W., 229 
. 



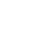


